ORNL/ER--I 55

DE93 006272

भै
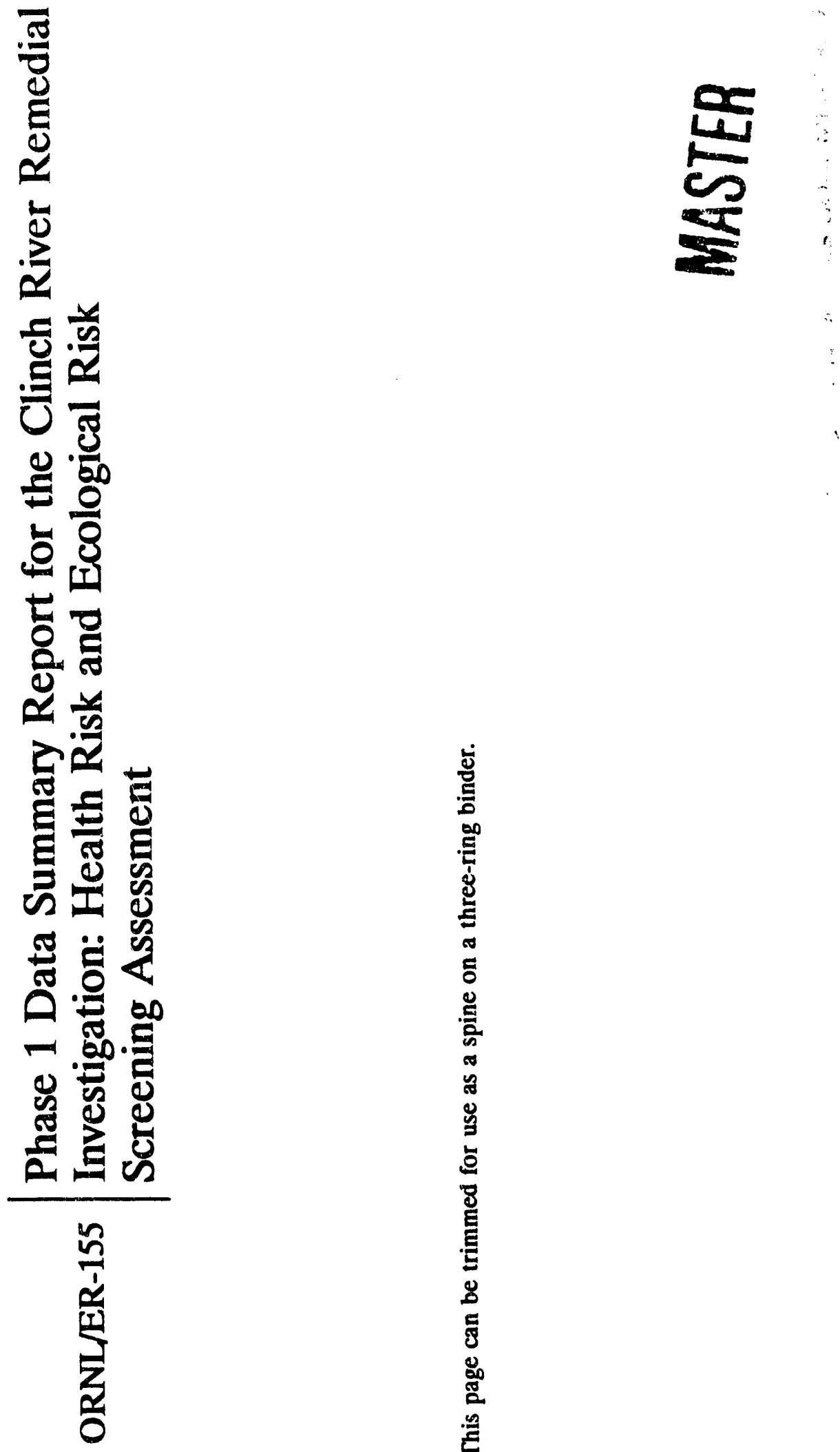
Energy Systems Environmental Restoration Program Clinch River Environmental Restoration Program

\title{
Phase 1 Data Summary Report for the Clinch River Remedial Investigation: Health Risk and Ecological Risk Screening Assessment
}
R. B. Cook
S. M. Adams
S. K. Holladay
J. J. Beauchamp
L. A. Hook
M. S. Bevelhimer
D. A. Levine
B. G. Blaylock
R. C. Longman
C. C. Brandt
C. W. McGinn
C. J. Ford
J. L. Skiles
G. W. Suter
M. L. Frank
L. F. Williams
M. J. Gentry

Date Issued-December 1992

\author{
Prepared by \\ Environmental Sciences Division \\ Oak Ridge National Laboratory \\ ESD Publication 4021
}

Prepared for

U.S. Department of Energy

Office of Environmental Restoration and Waste Management

under budget and reporting code EW 20

OAK RIDGE NATIONAL LABORATORY

Oak Ridge, Tennessee 37831-6285

managed by

MARTIN MARIETTA ENERGY SYSTEMS, INC.

for the

U.S. DEPARTMENT OF ENERGY

under contract DE-ACO5-84OR21400 


\section{Author Affiliations}

R. B. Cook (Program Manager), S. M. Adams, B. G. Blaylock, C. J. Ford, M. L. Frank, S. K. Holladay, L A. Hook, and G. W. Suter are members of the Environmental Sciences Division; J. J. Beauchamp and C. C. Brandt are members of the Engineering Physics and Mathematics Division; and C. W. McGinn and J. L. Skiles are members of the Health and Safety Research Division. All of the aforementioned divisions are part of Oak Ridge National Laboratory, Martin Marietta Energy Systems, Inc. M. S. Bevelhimer and D. A. Levine are with Automated Sciences Group, Inc., in Oak Ridge, Tennessee. M. J. Gentry, R. C. Longman, and L. F. Williams are with The University of Tennessee, Knoxville. 


\section{CONTENTS}

FIGURES $\ldots \ldots \ldots \ldots \ldots \ldots \ldots \ldots \ldots \ldots \ldots \ldots \ldots \ldots \ldots$

TABLES $\ldots \ldots \ldots \ldots \ldots \ldots \ldots \ldots \ldots \ldots \ldots \ldots \ldots \ldots \ldots \ldots \ldots \ldots \ldots \ldots$

ABBREVIATIONS $\ldots \ldots \ldots \ldots \ldots \ldots \ldots \ldots \ldots \ldots \ldots \ldots \ldots \ldots \ldots \ldots \ldots$ xiii

EXECUTTVE SUMMARY $\ldots \ldots \ldots \ldots \ldots \ldots \ldots \ldots \ldots \ldots \ldots \ldots \ldots \ldots \ldots$

1. INTRODUCTION $\ldots \ldots \ldots \ldots \ldots \ldots \ldots \ldots \ldots \ldots \ldots \ldots \ldots \ldots \ldots \ldots$

1.1 OBJECTIVES AND APPROACH OF THE CLINCH RIVER

REMEDIAL INVESTIGATION ..................... 1-3

1.2 SUMMARY OF THE SITE CONCEPTUAL MODEL . . . . . . . . . 1 . 1 .5

1.3 REPORT ORGANIZATION $\ldots \ldots \ldots \ldots \ldots \ldots \ldots \ldots \ldots \ldots \ldots$. $1-6$

2. PHASE 1 SAMPLE COLLECTION AND ANALYSIS $\ldots \ldots \ldots \ldots \ldots \ldots \ldots 2-1$

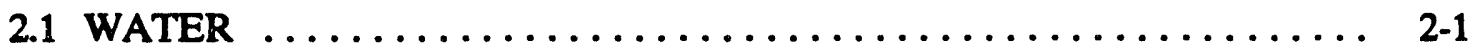

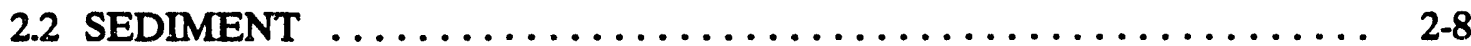

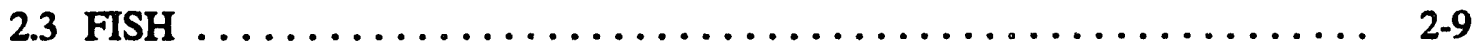

2.4 QANQC PROGRAM FOR THE PHASE 1 DATA COLLECTION . . . . . . 2-12

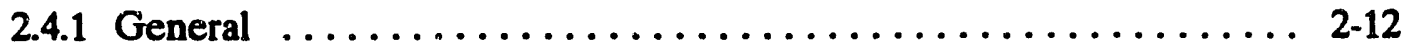

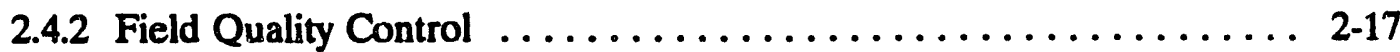

2.4.3 Laboratory Quality Control Program ................. 2-18

2.4.4 Data Validation ........................... 2-18

2.4 .5 Data Assessment ........................ 2-19

3. SITE CHARACTERIZATION $\ldots \ldots \ldots \ldots \ldots \ldots \ldots \ldots \ldots \ldots \ldots \ldots \ldots \ldots \ldots \ldots$ 3-1

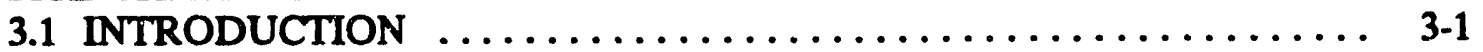

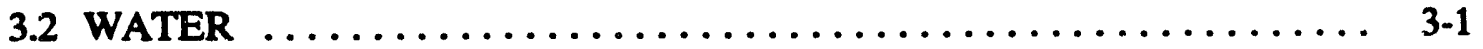

3.2.1 Discussion of Contaminants for the System ............ 3-1

3.2.2 Discussion of Contaminants by Study Reach $\ldots \ldots \ldots \ldots \ldots \ldots . . \ldots \ldots$

3.2.3 Summary ............................... 3-3

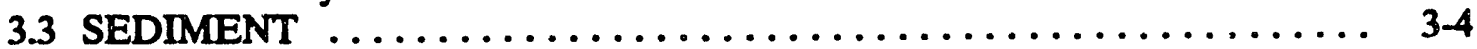

3.3.1 Discussion of Contaminants for the System $\ldots \ldots \ldots \ldots \ldots \ldots \ldots$ 3-5

3.3.2 Discussion of Contaminants by Study Reach ............. $3-6$

3.3.3 Summary .............................. 3-16

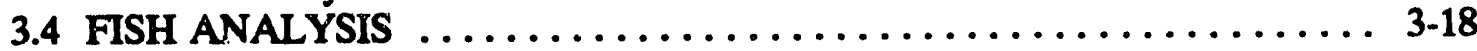

3.4.1 Discussion of Contaminants for the System . . . . . . . . . . . 3-19

3.4.2 Discussion of Contaminants by Study Reach ............. 3-19

3.4.3 Summary ................................ 3-25

4. SCREENING RISK ASSESSMENT $\ldots \ldots \ldots \ldots \ldots \ldots \ldots \ldots \ldots \ldots \ldots$ 4-1

4.1 SCREENING ASSESSMENT FOR HUMAN EXPOSURE ........ 4-1

4.1.1 Approach ........................... 4-1

4.1.2 Exposure Pathways ....................... 4-1

4.1.3 Usage and Exposure Factors .................. 4-2 
4.1.4 Data Bases ........................... 4-2

4.1.5 Screening Criteria ......................... 4-3

4.1.6 Contaminant Screening Results for Primary Exposure Pathways .... 4-5

4.1.7 Dredging Scenario ......................... 4-16

4.1.8 Comparison of the Phase 1 Screening Analysis with a Previous

Screening Analysis of Historical Data . . . . . . . . . . . . . . 4-19

4.1.9 Nondetected Contaminants ... . . . . . . . . . . . . . . . . . 4-20

4.1.10 Contaminants Having No Available Toxicity Values ... . . . . . . . . 4-20

4.1.11 Special Case-Lead ... . . . . . . . . . . . . . . . . . . . 4-21

4.1.12 High Priority Contaminants and Contaminants Requiring

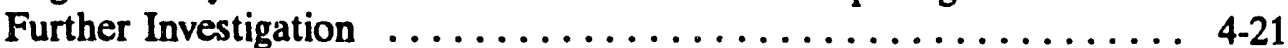

4.1.13 Summary for Screening Risk Assessment . . . . . . . . . . . . . . 4-22

4.2 ECOLOGICAL RISK ... . . . . . . . . . . . . . . . . . . . 4-24

4.2.1 Hazard Definition ........................... 4-25

4.2.2 Exposure Assessment ........................ 4-25

4.2.3 Effects Assessment: Screening Benchmarks . . . . . . . . . . . . . 4-27

4.2.4 Risk Characterization: Contaminant Screening Results ........ . 4 4-28

4.2.5 Comparison to Previous Results .................. 4-33

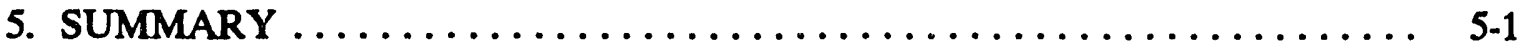

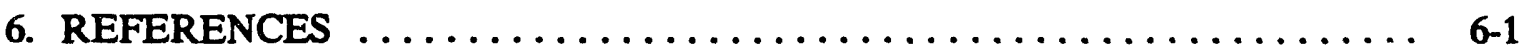

Appendix A. LISTING OF ALL ANALYTES WITH CAS NUMBERS . . . . . . A-1

Appendix B. SUMMARY STATISTICS FOR WATER SAMPLES $\ldots \ldots \ldots \ldots$ B-1

Appendix C. SUMMARY STATISTICS FOR SEDIMENT SAMPLES $\ldots \ldots \ldots$ C-1

Appendix D. STATISTICAL PROCEDURE FOR PAIRWISE COMPARISON

OF FISH TISSUE RESULTS $\ldots \ldots \ldots \ldots \ldots \ldots \ldots \ldots \ldots \ldots$ D-1

Appendix E. HUMAN HEALTH RISK METHODS $\ldots \ldots \ldots \ldots \ldots \ldots \ldots \ldots$ E-1

Appendix F. ECOLOGICAL RISK METHODS $\ldots \ldots \ldots \ldots \ldots \ldots \ldots \ldots$ F-1

Appendix G. BRADEN BRANCH $\ldots \ldots \ldots \ldots \ldots \ldots \ldots \ldots \ldots \ldots \ldots \ldots \ldots \ldots$ 


\section{FIGURES}

1.1 Map showing the location of the Clinch River, Watts Bar Reservoir, and the Department of Energy's Oak Ridge Reservation ........... . 1-2

1.2 The phased approach used in the Clinch River Remedial Investigation .... . 1-4

2.1 Locations of reaches used in Phase 1 sampling, analysis, and

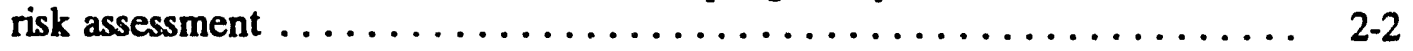

2.2 Location of sample sites for Phase 1 water and sediment core collection in Clinch River/Watts Bar system ............... 2-5

2.3 Location of sites for Phase 1 surface sediment grab sample collection in Clinch River/Watts Bar system ............... 2-10

2.4 Location of sample sites for Phase 1 fish collection in Clinch River/Watts Bar Reservoir system ................ 2-13

3.1 Average ${ }^{137} \mathrm{Cs}$ concentration in surface sediment grabs within each reach ... 3-7

3.2 Average ${ }^{60} \mathrm{Co}$ concentration in surface sediment grabs within each reach ... 3-9

3.3 Average concentrations of arsenic and zinc for cores sampling sites $\ldots \ldots$ 3-10

3.4 Average concentrations of beryllium and cadmium for cores

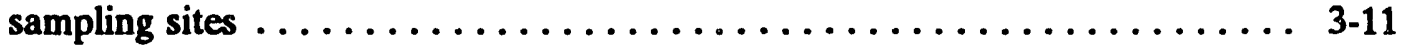

3.5 Average concentrations of chromium, copper, and lead for cores

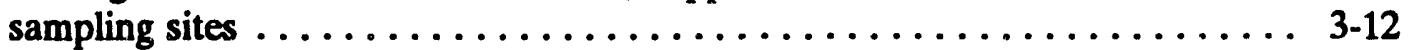

3.6 Average concentrations of mercury for cores sampling sites $\ldots \ldots \ldots \ldots$ 3-13

3.7 Average concentrations of ${ }^{137} \mathrm{Cs}$ for cores sampling sites $\ldots \ldots \ldots \ldots \ldots$ 3-14

3.8 Average concentrations of ${ }^{60} \mathrm{Co}$ for core sampling sites $\ldots \ldots \ldots \ldots \ldots \ldots$

3.9 Arithmetic mean concentrations of total chlordane in Clinch River/Watts Bar fish tissue for all sample sites . . . . . . . . . 3-21

3.10 Arithmetic mean concentrations of total PCBs in Clinch River/Watts Bar fish tissue for each site sampled in Phase $1 \ldots \ldots \ldots \ldots \ldots \ldots \ldots \ldots . \ldots .22$

3.11 Arithmetic $v$ can concentrations of mercury in Clinch River/Watts Bar fish tissue samples from each Phase 1 site $\ldots \ldots \ldots \ldots \ldots \ldots \ldots \ldots . \ldots . . \ldots$ 
3.12 Arithmetic mean concentrations of ${ }^{137} \mathrm{Cs}$ in Clinch River/Watts Bar fish tissue sampled from each Phase 1 site

4.1 Screening criteria for carcinogens $\ldots \ldots \ldots \ldots \ldots \ldots \ldots \ldots \ldots \ldots \ldots$

4.2 Screening criteria for noncarcinogens $\ldots \ldots \ldots \ldots \ldots \ldots \ldots \ldots \ldots \ldots$

E.1 Location of NPDES monitoring sites in Clinch River/Watts Bar System . . . E-5

G.1 Braden Branch near-shore sample sites ................ G-4

G.2 Cobalt -60 concentrations at Braden Branch $\ldots \ldots \ldots \ldots \ldots \ldots \ldots$ G-10

G.3 Cobalt concentrations in Braden Branch core (No. 18700G) ........ G-11 


\section{TABLES}

2.1 Stream and river reaches used in the CRRI

site characterization and screening risk assessment $\ldots \ldots \ldots \ldots . \ldots \ldots$

2.2 Matrices sampled in each reach during Phase 1

of the CRRI (validated and accepted data) .............. $2-4$

2.3 Summary of surface water analysis for the contaminants of concern $\ldots \ldots$ 2-6

2.4 Number of CRRI water samples, by site and type of analysis

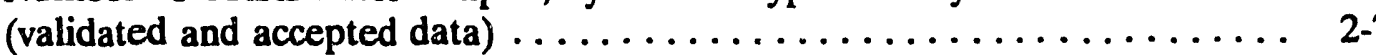

2.5 Number of CR ERP sediment samples by reach and type of analysis

(validated and accepted data)

2.6 Sample sites for Phase 1 fish collection in Clinch River/Watts Bar

Reservoir system

2.7 Number of regular samples (i.e., does not include QC samples)

submitted for analysis for each analytical group by species

and by sampling location (validated and accepted data) $\ldots \ldots \ldots \ldots$ 2-15

Data qualifiers

2.9 Summary of the number of rejected samples as a result of

the validation of laboratory analyses $\ldots \ldots \ldots \ldots \ldots \ldots \ldots \ldots \ldots \ldots . \ldots \ldots$

3.1 Summary of study site-to-reference site comparisons for fish tissue

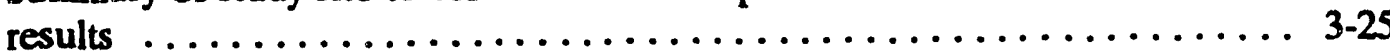

4.1 Summary of adult screening results for carcinogens in the fish

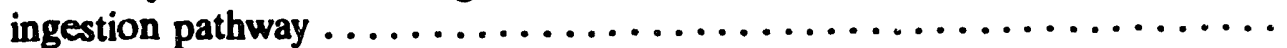

4.2 Summary of screening results for noncarcinogens in the fish ingestion pathways

4.3 Summary of adult screening results for radionuclides in near-shore surface sediment exposure

4.4 Summary of adult screening results for carcinogens in the water

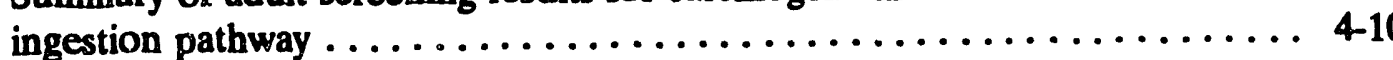

4.5 Summary of screening results for noncarcinogens in the water ingestion pathway 
4.6 Summary by reach of contaminants in the dredging scenario identified by conservative screening as requiring further investigation before taking action or designating as low priority $\ldots \ldots \ldots \ldots \ldots \ldots \ldots$

4.7 Contaminants for which the use of detection limits produced screening indices $>10^{-4}$ for carcinogens or $>1.0$ for noncarcinogens by nonconservative screening .

4.8 Summary of contaminants requiring further investigation before taking action or designating as low priority based on fish ingestion and dredging scenarios

4.9 Contaminants of concern for ecological risk assessment 4-30

A.1 Listing of all analytes with CAS numbers and matrices analyzed for each analyte

B.1 Summary statistics for water data summarized for all reaches sorted by type of analysis and decreasing percentage detected

B.2 Summary statistics for water data detected compounds summarized by reach sorted by type of analysis, analysis, and reach $\ldots \ldots \ldots \ldots \ldots \ldots$

C.1 Summary statistics for sediment core data summarized for all reaches sorted by type of analysis and decreasing percentage detected . . . . . . . .

C.2 Summary statistics for sediment core data detected compounds summarized by reach sorted by type of analysis, analysis, and reach

C.3 Summary statistics for sediment grab data summarized for all reaches sorted by type of analysis and decreasing percentage detected.

C.4 Summary statistics for sediment grab data detected compounds summarized by reach sorted by type of analysis, analysis, and reach

D.1 Summary statistics for fish tissue data summarized for all reaches sorted by type of analysis and decreasing percentage detected...

D.2 Summary statistics for fish tissue data detected compounds summarized by subreach sorted by type of analysis, reach, and subreach

E.1 Receiving reaches for Oak Ridge Reservation source monitoring and surface water environmental monitoring stations

E.2 Usage and exposure factors for conservative and nonconservative screening 
E.3 Reference dose factors and slope (cancer potency) factors for

inorganic compounds $\ldots \ldots \ldots \ldots \ldots \ldots \ldots \ldots \ldots \ldots \ldots \ldots \ldots \ldots$

E.4 Reference dose factors and slope (cancer potency) factors for

organic compounds . . . . . . . . . . . . . . . . . . $\ldots \ldots \ldots$ E-11

E.5 Slope (cancer potency) factors for radionuclides $\ldots \ldots \ldots \ldots \ldots \ldots$ E-15

E.6 Summary of carcinogens in the secondary pathways identified as low priority for further investigation $\ldots \ldots \ldots \ldots \ldots \ldots \ldots \ldots \ldots \ldots \ldots \ldots \ldots \ldots$

E.7 Summary of noncarcinogens in the secondary pathways identified as low priority for further investigation $\ldots \ldots \ldots \ldots \ldots \ldots \ldots \ldots \ldots \ldots \ldots$ E-19

E.8 Results of adult nonconservative screening for carcinogens in fish, surface sediment, and water where at least one measurement in a reach was above detection limits $\ldots \ldots \ldots \ldots \ldots \ldots \ldots \ldots \ldots \ldots$ E-22

E.9 Results of adult nonconservative screening for noncarcinogens in fish, surface sediment, and water where at least one measurement in a reach was above detection limits

E.10 Results of adut conservative screening for carcinogens in fish, surface sedimast, and water where at least one measurement in a reach was above detection limits

E.11 Results of adult conservative screening for noncarcinogens in fish, surface sediment, and water where at least one measurement in a reach was above detection limits

E.12 Results of child conservative screening for noncarcinogens in fish, surface sediment, and water where at least one measurement in a reach was above detection limits

E.13 Results of adult conservative screening for carcinogens in dredged sediments where at least one measurement in a reach was above detection limits

E.14 Results of adult conservative screening for noncarcinogens in dredged sediments where at least one measurement in a reach was above detection limits

E.15 Results of adult nonconservative screening for carcinogens in fish and water where no measurement in a reach was above detection limits. 
E.16 Results of adult nonconservative screening for noncarcinogens in fish and water where no measurement in a reach was above detection limits

E.17 Results of adult nonconservative screening for carcinogens in dredged sediments where no measurements in a reach were above detection limits

E.18 Results of adult nonconservative screening for noncarcinogens in dredged sediments where no measurements in a reach were above detection limits . . . . . . . . . . . . . . . . . . . . . E-120

E.19 Unclassified analytes $\ldots \ldots \ldots \ldots \ldots \ldots \ldots \ldots \ldots \ldots \ldots \ldots \ldots$ E-128

F.1 Mean and upper confidence limit (UCL) concentrations of chemicals detected in the dissolved phase of CRRI water samples $(\mu \mathrm{g} / \mathrm{L})$, toxicological benchmarks $(\mu \mathrm{g} / \mathrm{L})$, and quotients for aquatic life $\ldots \ldots \ldots \ldots$ F-6

F.2 Limit's of detection of chemicals not detected in the dissolved phasis of the CRRI water samples $(\mu \mathrm{g} / \mathrm{L})$, toxicological benchmarks $(\mu \mathrm{g} / \mathrm{L})$, and quotients for aquatic life $\ldots \ldots \ldots \ldots \ldots \ldots \ldots \ldots \ldots \ldots \ldots$

F.3 Mean and upper confidence limit (UCL) concentrations of chemicals detected in NPDES water samples $(\mu \mathrm{g} / \mathrm{L})$, toxicological benchmarks $(\mu \mathrm{g} / \mathrm{L})$, and quotients for aquatic life $\ldots \ldots \ldots \ldots \ldots \ldots \ldots \ldots \ldots$ F-22

F.4 Limits of detection of chemicals not detected in NPDES water samples $(\mu \mathrm{g} / \mathrm{L})$, toxicological benchmarks $(\mu \mathrm{g} / \mathrm{L})$, and quotients for aquatic life

F.5 Mean and upper confidence limit (UCL) concentrations of chemicals detected in fish $(\mu \mathrm{g} / \mathrm{L})$, bioconcentration factors, estimated exposure in water $(\mu \mathrm{g} / \mathrm{L})$, and quotients for exposure to that water concentration

F.6 Limits of detection of chemicals not detected in fish $(\mu \mathrm{g} / \mathrm{L})$, bioconcentration factors, estimated exposure in water $(\mu \mathrm{g} / \mathrm{L})$, and quotients for exposure to that water concentration

F.7 Concentrations of inorganic chemicals detected in sediment $(\mu \mathrm{g} / \mathrm{L})$, toxicological benchmarks $(\mu \mathrm{g} / \mathrm{L})$, and quotients for benthic aquatic life

F.8 Detection limits for inorganic chemicals not detected in sediment $(\mu \mathrm{g} / \mathrm{L})$, toxicological benchmarks $(\mu \mathrm{g} / \mathrm{L})$, and quotients for benthic aquatic life 
F.9 Mean and upper confidence limit (UCL) concentrations of organic chemicals detected in sediment $(\mu \mathrm{g} / \mathrm{L})$, toxicological benchmarks $(\mu \mathrm{g} / \mathrm{L})$, and quotients for benthic aquatic life

F.10 Detection limits for organic chemicals not detected in sediment $(\mu \mathrm{g} / \mathrm{L})$, estimated pore water concentrations $(\mu \mathrm{g} / \mathrm{L})$, toxicological benchmarks ( $\mu \mathrm{g} / \mathrm{L})$, and quotients for benthic aquatic life

F.11 Mean and upper confidence limit (UCL) concentrations of chemicals in fish fillets (mg/kg), toxicological benchmarks for wildlife (mg/kg), and quotients for hazards to piscivorous wildlife

F.12 Minimum and upper confidence limit (UCL) detection limits for chemicals not detected in fish fillets $(\mathrm{mg} / \mathrm{kg})$, toxicological benchmarks for wildlife $(\mathrm{mg} / \mathrm{kg}$ ), and quotients for hazards to piscivorous wildlife

G.1 Data listing for CR-ERP Braden F/runch sediment grab sample radiological analyses

G.2 Summary statistics for Braden Branch sediment core data

G.3 Data listing for CR-ERP Braden Branch sediment core samples radiological analyses

G.4 Summary statistics for Braden Branch sediment grab data

G.5 Results of adult nonconservative screening for carcinogens in surface sediment of Braden Branch where at least one measurement was

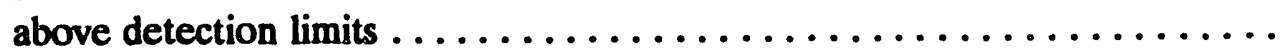

G.6 Results of adult conservative screening for carcinogens in surface sediment of Braden Branch where at least one measurement was above detection limits 


\section{ABBREVIATIONS}

\begin{tabular}{|c|c|}
\hline $\begin{array}{l}\text { AA } \\
\text { BB } \\
\text { BCF } \\
\text { BMAP } \\
\text { CAS } \\
\text { CERCLA } \\
\text { CR } \\
\text { CR-ERP } \\
\text { CRM } \\
\text { CRRFI } \\
\text { CRRI } \\
\text { CR/WR } \\
\text { DDD } \\
\text { DDE } \\
\text { DDT } \\
\text { DL } \\
\text { DOE } \\
\text { EFPC } \\
\text { EPA } \\
\text { ER-L } \\
\text { ER-M } \\
\text { ESD } \\
\text { FDA } \\
\text { FFA } \\
\text { fOC } \\
\text { HDPE } \\
\text { HSWA } \\
\text { ICP } \\
\text { KOC } \\
\text { KP } \\
\text { LCV } \\
\text { LTV } \\
\text { NAWQC } \\
\text { NOAA } \\
\text { NPDES } \\
\text { NPL } \\
\text { NWQC } \\
\text { ORAU } \\
\text { ORNL } \\
\text { ORR } \\
\text { PCB } \\
\text { PCK } \\
\text { QA } \\
\text { QAOC } \\
\text { RCRA }\end{array}$ & 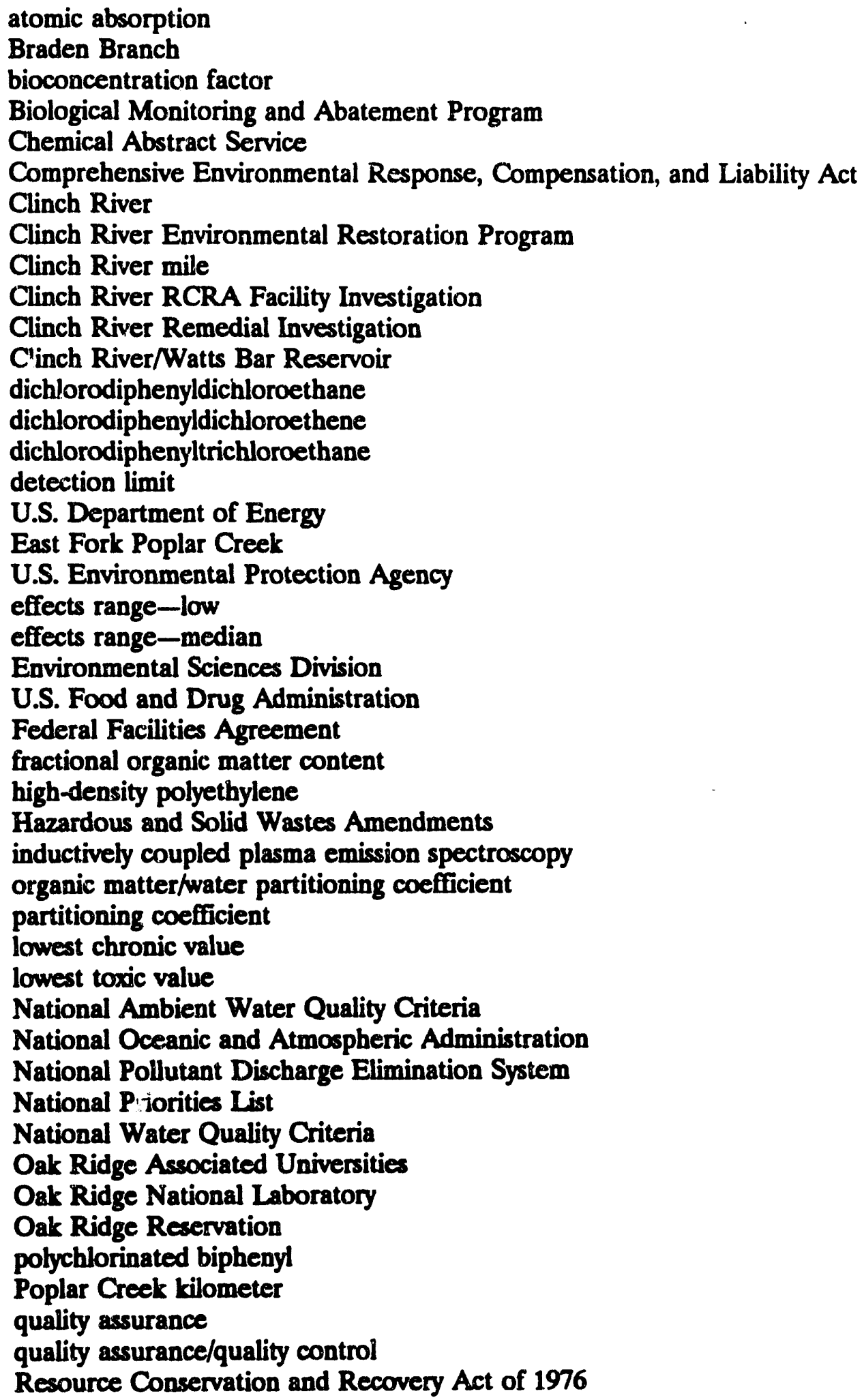 \\
\hline
\end{tabular}


RfD reference dose

RI remedial investigation

SARA Superfund Amendments and Requthorization Act of 1986

SI screening indices

SQL sample quantitation limit

TDEC Tennessee Department of Environment and Conservation

TRM Tennessee River mile

TVA Tennessee Valley Authority

UCL upper confidence limit

WBR Watts Bar Reservoir

WOCE White Oak Creek Embayment 


\section{EXECUTIVE SUMMARY}

The Clinch River Remedial Investigation (CRRI) is designed to address the transport, fate, and distribution of waterborne contaminants released from the U.S. Department of Energy's (DOE's) Oak Ridge Reservation (ORR) and to assess potential risks to human health and the environment associated with these contaminants. The contaminants released since the early 1940s include a variety of radionuclides, metals, and organic compounds. Primary areas of investigation are Melton Hill Reservoir, the Clinch River from Melton Hill Dam to its confluence with the Tennessee River, Poplar Creek, and Watts Bar Reservoir. The receiving river-reservoir system encompasses 140 river miles in length and 44,000 acres in surface area and is used for municipal water supply, sport fishing, navigation, boating, swimming, tourism, and residential development. The contaminants identified in the Clinch River/Watts Bar Reservoir (CR/WBR) downstream of the ORR are those associated with the water, suspended particles, deposited sediments, aquatic organisms, and wildlife feeding on aquatic organisms.

A phased remedial investigation of the CR/WBR system is underway to (1) define the nature and extent of the off-site contamination, (2) evaluate associated environmental and human health risks, and (3) preliminarily identify and evaluate potential remediation alternatives. The purpose of this report is to summarize the results of Phase 1 of the CRRI.

Phase 1 of the CRRI was a preliminary sampling and analysis of fish, sediment, and water in selected areas of the CR/WBR chosen to represent differing levels of media contamination. Specifically, Phase 1 was designed to (1) obtain high-quality data to confirm existing historical data for contaminant levels in fish, sediment, and water from the CR/WBR; (2) determine the range of contaminant concentrations present in the river-reservoir system; (3) identify specific contaminants of concern; and (4) establish the reference (background) concentrations for those contaminants. Previously, scoping studies were conducted to provide an initial determination of contaminant distribution, in the sediments of Watts Bar Reservoir (Olsen et al. 1992) and to preliminarily assess potential human health and ecological risk (Suter 1991; Hoffiman et al. 1991).

For Phase 1 of the CRRI, the CR/WBR system was divided into ten reaches, six of which are potentially affected by releases from the ORR. The other four reaches serve as reference areas. Contaminant concentrations for fish, sediment, and water were summarized for each of the 10 reaches. Analytes detected at least once in a reach were evaluated separately from those never measured above their analytical detection limit (i.e., nondetected).

In water samples collected during Phase 1 , inorganic and organic constituents with the potential to pose a risk to human bealth or the environment were within the ranges reported previously in monitoring reports (e.g., Kornegay et al. 1991). Each inorganic contaminant detected during the Phase 1 investigation is well below the water quality criteria promulgated by the Tennessee Department of Environment and Conservation (rules of the Tennessee Department of Environment and Conservation, Chapter 1200-4-3).

The majority of potential contaminants of concern in Phase 1 water samples were detected between White Oak Creek and Poplar Creek on the Clinch River (reach 2) and in 
the Poplar Creek downstream of the confluence with East Fork Poplar Creek, which receive effluents from several ORR sources for these contaminants. Total copper and zinc were detected in reach 2 surface waters and had values in the range of those previously observed (Kornegay et al. 1991). Dissolved lead, observed in water samples from Poplar Creek upstream of the confluence with East Fork Poplar Creek, may originate from an upstream source.

The Oak Ridge Y-12 Plant, the city of Oak Ridge wastewater treatment facility, and Oak Ridge K-25 Site operations are among the possible sources for mercury, silver, and lead detected in water samples from Poplar Creek downstream of the confluence with East Fork Poplar Creek. Elevated levels of cadmium and lead in water samples from the Clinch River between Poplar Creek and the confluence with the Tennessee River may originate from several sources in and upstream from this reach.

Concentrations of all radiological constituents in Phase 1 water samples were within the ranges of those observed during environmental monitoring (Kornegay et al. 1991) and with previous scoping investigations (Olsen et al. 1992). Dissolved ${ }^{137} \mathrm{Cs}$ and particle-associated ${ }^{137} \mathrm{Cs}$ were detected in the Clinch River arm of Watts Bar Reservoir and Watts Bar Reservoir downstream of the confluence with the Clinch River, with values similar to those reported previously for these reaches. Dissolved ${ }^{137} \mathrm{Cs}$ was detected in Poplar Creek downstream of the confluence with East Fork Poplar Creek, possibly a result of backflow from the Clinch River. Cobalt-60 in Watts Bar Reservoir below the entry of the Clinch was detected at levels comparable with those reported previously. Average ${ }^{90} \mathrm{Sr}$ values for all reaches never exceeded drinking water standards. Each of these radionuclides is currently released in permitted discharges from the ORR to surface waters.

Data resulting from the measurement of inorganic, organic, and radiological contaminants from the Phase 1 water sampling, in combination with historical data, indicate that a focused characterization effort in Phase 2 is warranted for Poplar Creek downstream of the confluence with East Fork Poplar Creek and for the Clinch River arm of Watts Bar Reservoir. Additionally, a more thorough characterization of reference sites is needed to rigorously establish background concentrations in surface water.

Concentrations of ${ }^{137} \mathrm{Cs}$ in surface sediments $(0$ to $10 \mathrm{~cm})$ in near-shore areas of Norris, Melton Hill Reservoirs, and the Tennessee River arm of Watts Bar Reservoir should represent background levels ( $<1.0 \mathrm{pCi} / \mathrm{g}$ ) because they are upstream of ORR and only received fallout from atmospheric testing of nuclear weapons. Concentrations in Poplar Creek and the Emory River average $1 \mathrm{pCi} / \mathrm{g}$, which is consistent with background concentrations. Cesium-137 concentrations in the near-shore surface sediments in the Clinch River arm of Watts Bar Reservoir are between 2 and 3 pCi/g. Concentrations in Watts Bar Reservoir below the confluence of the Tennessee and Clinch rivers are usually less than $1 \mathrm{pCi} / \mathrm{g}$, which are equivalent to background concentrations. Three areas within the Clinch River arm of Watts Bar Reservoir had concentrations between 10 and $34 \mathrm{pCi} / \mathrm{g}$ in surface sediment and will be targeted for sampling and analysis during Phase 2 of the CRRI. Samples collected at these areas will be analyzed for the contaminants identified by the risk screening as requiring further research. 
Patterns of inorganic contaminants in sediment core samples indicate that there are multiple sources for these contaminants. Arsenic, beryllium, cadmium, chromium, copper, and mercury in Poplar Creek and the downstream portion of the Clinch River arm of Watts Bar Reservoir appear to be originating, at least in part, from Poplar Creek. Mercury releases from the Oak Ridge Y-12 Plant into the Poplar Creek system are well documented (Olsen et al. 1992, Turner et al. 1985). The other metals may be derived from disposal of coal fly-ash material and photographic processing chemicals from the Oak Ridge K-25 Site or from the municipal wastewater treatment facility for the city of Oak Ridge. Concentrations of cadmium, lead, and zinc are higher in the sediments in Watts Bar Reservoir below the confluence of the Tennessee River and Clinch River than elsewhere in the system, suggesting that there are sources of these contaminants to the Tennessee River arm of the reservoir or to WBR below the confluence of the two rivers. Phase 2 sampling and analysis will focus on locating any areas where concentrations of these contaminants pose an elevated risk to human health and the environment.

The lack of detectable quantities in sediment samples of most of the 92 organic chemicals for which analyses were conducted allows significant reduction in the list of organic contaminants requiring further study. Flouranthene, phenanthrene, and pyrene were found in Poplar Creek downstream of the confluence with East Fork Poplar Creek and in the Clinch River arm of Watts Bar Reservoir. Aroclor 1254 was found only in sediments at Clinch River Mile 9.5, which is immediately downstream of Poplar Creek. Potentia' sources for these contaminants in sediment are ORNL, the Y-12 Plant, the K-25 Site, and the municipal wastewater treatment facility. Sampling and analysis for these contaminants in Poplar Creek downstream of the confluence with East Fork Poplar Creek and in the Clinch River arm of Watts Bar Reservoir will continue in Phase 2 with the objective of identifying and delineating any areas requiring remediation.

Alpha-emitting radionuclides were detected in every site sampled for sediments. However, concentrations were all at or near background concentrations, except in Poplar Creek downstream of the confluence with East Fork Poplar Creek. Concentrations of ${ }^{24} U$, ${ }^{235} \mathrm{U}$, and ${ }^{238} \mathrm{U}$ in Poplar Creek sediments were above background levels. Poplar Creek downstream of the confluence with East Fork Poplar Creek will be the focus of study for these contaminants during Phase 2 activities.

In order to characterize the nature and extent of contamination in the biota of the CR/WBR system, 126 bluegill sunfish, 119 channel catfish, and 43 largemouth bass were sampled from 15 sites in 8 reaches. These fish species were chosen for sampling by virtue of their positions in the foodweb, their migration/mobility behavior, and relative availability. Of the 77 organic and 13 inorganic analytes, a majority (63 organics and 7 inorganics) were not detected in fish at any site. Of the radionuclides, only ${ }^{137} \mathrm{Cs},{ }^{60} \mathrm{Co}$, and ${ }^{90} \mathrm{Sr}$ were detected in fish. Four analytes were rarely detected, occurring in less than $5 \%$ of the samples. Seventeen analytes were detected in more than $5 \%$ of the samples, with only three of those ${ }^{90} \mathrm{Sr}$, mercury, and zinc) detectable in all samples.

In general, the Phase 1 maxima (individual maximum concentration of an analyte at each site) for fish are lower than those from previous sampling. Exceptions to this generality are mercury, selenium, and Aroclor 1260. Maximum values of mercury in fish collected in Phase 1 were higher than historical values only in lower Watts Bar Reservoir, and at no sites did the 
maximum mercury concentration exceed the Food and Drug Administration's (FDA's) action level of $1.0 \mathrm{mg} / \mathrm{kg}$. Selenium maxima in fish exceeded historical values in Poplar Creek downstream of the confluence with East Fork Poplar Creek and in the Clinch River upstream of noplar Creek and below Melton Hill Reservoir. Aroclor 1260 (a PCB congener) maxima exceeded historical values in Poplar Creek downstream of the confluence with East Fork Poplar Creek and in the Clinch River below Poplar Creek. Average values of Aroclor 1260 in fish did not exceed $1.0 \mathrm{mg} / \mathrm{kg}$ at any site or within any reach, but Aroclor 1260 maxima in fish exceeded the FDA action level of $2.0 \mathrm{mg} / \mathrm{kg}$ at one site in Melton Hill Reservoir, one site in Poplar Creek, and three sites in the Clinch River arm of WBR.

Mean concentiations of some contaminants in fish at some CR/WBR sites were higher than the concentrations at the reference site (Norris Reservoir). Arsenic concentrations were significantly $(P<0.05)$ higher than concentrations at the reference site at only one location (CRM 0.5). In Poplar Creek below the confluence with East Fork Poplar Creek and at the first site downstream of the confluence of Poplar Creek and the Clinch River (Brashear Island), mercury concentrations in fish were predictably higher than those of the reference sites. Selenium concentrations in fish were higher than those in the reference site in main channel sites in the upper part of the system (Upper Melton Hill to Brashear Island). Zinc concentrations in fish at 5 of the 12 sites were higher than those at the reference site, but no obvious spatial distribution was evident. Chlordane concentrations in fish from Upper Melton Hill to the mouth of the Clinch River were higher than reference concentrations. Total PCB concentrations at all CR/WBR sites were higher than those in fish from the reference site (Norris Reservoir). Cesium-137 levels for all fish species were usually higher than the reference, particularly below the confluence of White Oak Creek and the Clinch River. Concentrations of ${ }^{137} \mathrm{Cs}$ and mercury in fish are both elevated at sites downstream of known sources of these contaminants, White Oak Creek and East Fork Poplar Creek, respectively. No such patterns of downstream gradients of chlordane or PCBs in fish are evident.

A screening assessment of ecological effects in the CR/WBR was conducted concurrently with the health screening assessment. The ecological screening assessment considered potential toxic effects on aquatic biota due to exposure to contaminants in water, potential toxic effects to benthic and epibenthic organisms due to contaminants in sediment, and risks to piscivorous wildlife due to ingestion of contaminants in fish flesh. The assessment was performed by comparing chemical concentrations in media to screening benchmarks that are either regulatory criteria or concentrations that are estimated to have minimal effects on the abundance or production of exposed populations. The screening ecological risk assessment for Phase 1 identified 14 contaminants of concern among the chemicals that were analyzed for and detected in water, sediment, or fish fillets. In addition, 19 chemicals that were not detected were identified as potential contaminants of concern because their limits of detection exceed screening benchmarks.

Comparison of media concentrations to toxicological benchmarks produced ambiguous results because of the large number of chemicals that were not detected but had limits of detection higher than potentially toxic concentrations. However, the number of potential contaminants of concern is much lower than in previous screening assessments because of generally lower contaminant concentrations than in the historical data, use of bioavailable (dissolved) concentrations of metals in water rather than total concentrations, and use of better screening benchmarks for metals in sediment. 
A scre ning analysis using human health risk methodology similar to the approach used in Hoffman et al. (1991) to screen historical data was conducted with data collected during Phase 1 of the CRRI. The purpose of this screening exercise, along with the results obtained in Hoffman et al. (1991), is to help guide the development of the Phase 2 sampling plan, which will focus the collection of data on contaminants of concern. A future baseline risk assessment will be completed when data from the Phase 2 sampling are available.

Conservatively biased risk estimates were used to identify contaminants, exposure pathways, and river and reservoir reaches that have a low priority for further investigations. It is highly unlikely that these conservative estimates will underestimate the potential maximum exposure to an individual residing in the vicinity of the Clinch River where it receives releases of effluents from the ORR. Nonconservative estimates of risk were used to identify contaminants, pathways, and reaches that have a high priority for further investigation. These nonconservative estimates are more realistic than the conservatively biased estimates and should not substantially overestimate maximum exposures to local populations or subgroups.

The primary pathways examined were exposure to three media: fish, near-shore surface sediments, and surface water. Currently, there is not a realistic direct exposure pathway to deep sediment, where the highest concentrations of particle-reactive contaminants have been observed (Olsen et al. 1992). However, a dredging scenario was included in the screening analysis to evaluate potential exposure pathways if the sediment should be dredged and placed up on the shore. In addition to the direct exposure pathways from exposed sediment (ingestion and external exposure to radionuclides) included in the dredging scenario, secondary pathways were also considered (ingestion of meat, milk, and vegetables produced on dredged sediments). The dredging scenario depended on mathematical models to determine the concentration of contaminants in the agricultural products. Because the models are designed to increase the conservatism of the results, the dredging scenario was used only to identify contaminants of low priority for further investigation.

Nonconservative screening of data for the fish ingestion pathway identified Aroclor 1260 , a carcinogenic PCB, as a high-priority contaminant requiring immediate consideration for further investiction and potential remedial action for all reaches except reference reach 10 (Norris Reservirs). Z his contaminant was identified previously in Hoffman et al. (1991) as a high-priority contaminant. Other investigations have shown that PCBs contaminate most eastern Tennessee rivers and lakes, and although ORR is a probable source, it is not the only source of PCBs for the Clinch River and Tennessee River system. The Tennessee Department of Environment and Conservation has issued fish consumption advisories for several eastern Tennessee reservoirs (e.g., Fort Loudoun, Watts Bar, Melton Hill) as a result of PCB contamination.

None of the noncarcinogens that were analyzed in fish were identified as high priority contaminants. Conservative screening indicated that radionuclides $\left({ }^{60} \mathrm{Co},{ }^{137} \mathrm{Cs}\right.$, and $\left.{ }^{90} \mathrm{Sr}\right)$ found in fish sampled during Phase 1 could be assigned a low priority for future consideration in all reaches except for ${ }^{137} \mathrm{Cs}$ in the Clinch River arm of Watts Bar Reservoir. Conservative screening identified several carcinogens and noncarcinogens that had been identified previously (Hoffman et al. 1991) as requiring further investigation in fish (i.e., Aroclor 1254, chlordane, arsenic, beryllium, mercury, and selenium). 
Nonconservative screening of the ${ }^{137} \mathrm{Cs}$ and ${ }^{60} \mathrm{Co}$ data from surface-sediment samples from near-shore areas did not identify these radionuclides as high priority contaminants. Conservative screening identified ${ }^{60} \mathrm{Co}$ and ${ }^{137} \mathrm{Cs}$, the only contaminants for which the samples were analyzed, as low priority in all reaches for the ingestion and inhalation pathways. In the external exposure pathway, ${ }^{137} \mathrm{Cs}$ was identified in Poplar Creek downstream of the mouth of East Fork Poplar Creek and in Melton Hill and Watts Bar reservoirs, and ${ }^{60} \mathrm{Co}$ in Poplar Creek and the Clinch River arm of Watts Bar Reservoir as contaminants requiring further investigation. However, Melton Hill Reservoir and the Tennessee River arm of WBR do not receive effluents from the ORR; therefore, the levels of ${ }^{137} \mathrm{Cs}$ found in the surface sediments of these reaches are background levels. A known source of ${ }^{60} \mathrm{Co}$ exists on the Clinch River upstream of the ORR, and it probably influences the screening indices for ${ }^{60} \mathrm{Co}$ in the Clinch River (Appendix G).

The results of the screening analysis for the water ingestion pathway should be viewed with caution because of the limited numbers of samples and because source monitoring data were used as estimates of concentrations in the reservoir. Thorium-228 was tentatively designated as a high priority contaminant in Poplar Creek downstream of the confluence with East Fork Poplar Creek in the water ingestion pathway. However, this designation results from including data from source monitoring sites. The monitoring data should be evaluated further before ${ }^{28} \mathrm{Th}$, which is a daughter of ${ }^{232} \mathrm{U}$ and naturally occurring ${ }^{232} \mathrm{Th}$, is designated a high priority contaminant. Screening of the water ingestion pathway showed that Poplar Creek, which receives effluents from the K-25 Site and from the Y-12 Plant and the city of Oak Ridge west-end sewage treatment plant via East Fork Poplar Creek, has the greatest number of contaminants that require further investigation. In the other reaches, most of the contaminant values were below detection limits or are considered low priority for further investigation.

In the dredging scenario, conservative screening was conducted on two direct pathways - external exposure and ingestion - and three secondary pathways-ingestion of meat, milk, and vegetables. Conservative screening of the secondary pathways identified many organic and inorganic contaminants in all reaches that could be assigned low priority for further investigation. Except for ${ }^{137} \mathrm{Cs}$ and to a lesser extent ${ }^{60} \mathrm{Co}$ and ${ }^{90} \mathrm{Sr}$, most radionuclides for which data were available were assigned low priority for the secondary pathways in all reaches.

Nonconservative screening was conducted for contaminants that had concentrations below analytical detection limits to identify contaminants for which either better analytical methodology is needed or for which source-term data are needed.

Results from Phase 1 of the CRRI indicate that Poplar Creek and the Clinch River arm of Watts Bar Reservoir are the reaches of greatest concern based on the number of contaminants that need further evaluation during Phase 2 of the renedial investigation.

The screening assessment of risk to the environment for $\mathrm{Phase} 1$ indicates that cadmium, mercury and silver in water need to be further investigated to determine the risk to aquatic biota in the CR/WBR system. Arsenic, lead, mercury, and zinc in sediments of the CR/WBR system, which may pose a risk to benthic dwelling organisms, need to be further assessed 
during Phase 2. More detailed sampling, analysis, and assessment are needed during Phase 2 of the CRRI to conduct the baseline assessment for ecological risk.

For assessment of the risk to human health, the Phase 1 fish data are the most complete. The Phase 2 sampling for fish should concentrate on providing statistically valid data for a future baseline assessment of human health risk. Additional samples of water need to be collected and analyzed in surface water areas proximate to the ORR outfalls and sources to provide data for the baseline assessment of human health risk. Organic and inorganic contaminants common to eastern Tennessee and other metropolitan areas should be identified through further analysis of the available data for downstream and reference reaches. Analysis of organic contaminants in water and sediment should concentrate on those contaminants that are routinely released or have been released in the past from the ORR. The Phase 2 sampling and analysis should concentrate on previously identified contaminants in Poplar Creek downstream of the mouth of East Fork Poplar Creek and in the Clinch River arm of Watts Bar Reservoir to provide statistically valid data for a baseline risk assessment.

\section{REFERENCES FOR EXECUTTVE SUMMARY}

Hoffman, F. O., B. G. Blaylock, M. L. Frank, L. A. Hook, E. L. Etnier, and S. S. Talmage. 1991. Preliminary Screening of Contaminants in the Off-Site Surface Water Environment Downstream of the U.S. Department of Energy Oak Ridge Reservation. ORNL/ER-9. Oak Ridge National L aboratory, Oak Ridge, Tennessee.

Kornegay, F. C., D. C. West, R. A. Evans, S. T. Goodpasture, M. F. Tardiff, and A. R. Wilson. 1991. Oak Ridge Reservation Environmental Report for 1990. Volume 2: Data Presentation. ES/ESH-18/V2. Martin Marietta Energy Systems, Inc., Oak Ridge, Tennessee.

Olsen, C. R., I. L. Larsen, P. D. Lowry, C. R. Moriones, C. J. Ford, K. C. Dearstone, R. R. Turner, B. L. Kimmel, and C. C. Brandt. 1992. Transport and Accumulation of Cesium-137 and Mercury in the Clinch River and Watts Bar Reservoir System. ORNL/ER-7. Oak Ridge National Laboratory, Oak Ridge, Tennessee.

Turner, R. R., C. R. Olsen, and W. J. Wilcox, Jr. 1985. Environmental fate of $\mathrm{Hg}$ and ${ }^{137} \mathrm{Cs}$ discharged from Oak Ridge facilities. pp. 329-338. In D. D. Hemphill (ed.), Trace Substances in Environmental Health-XVIII. University of Missouri, Columbia. 


\section{INTRODUCTION}

The purpose of this report is to present and discuss the results of Phase 1 of the Department of Energy's (DOE) remedial investigation (RI) of the Clinch River/Watts Bar Reservoir (CR/WBR) system. A screening risk assessment for human and ecological risk is used to identify contaminants, environmental pathways, and sites in the river and reservoir that require further investigation during Phase 2 of the RI.

The Clinch River RI (CRRI) focuses on the portions of the Clinch and Tennessee rivers that may have been adversely affected by contaminants that were released from DOE's Oak Ridge Reservation (ORR) from the mid-1940s to present. The contaminants released from the ORR to the Clinch and Tennessee rivers originated from research, industrial, and waste disposal activities conducted on the ORR at Oak Ridge National Laboratory (ORNL), the Oak Ridge Gaseous Diffusion Plant (now known as the K-25 Site), and the Y-12 Plant. The contaminants released from these facilities into the Clinch River include a variety of radionuclides, metals, and organic compounds.

Melton Hill Reservoir and the Clinch River, downstream from Melton Hill Dam, form the southern and eastern boundaries of the ORR (Fig. 1.1). All surface water draining the ORR eventually enters the Clinch River system. The Clinch River flows into the Tennessee River system of multiple-purpose impoundments near Kingston, Tennessee, $34 \mathrm{~km}$ downstream from the ORR (Fig. 1.1). Watts Bar Reservoir extends from Watts Bar Dam at Tennessee River Mile (TRM) 529.9 to Fort Loudoun Dam at TRM 602.3, and up the Clinch River to Melton Hill Dam at Clinch River Mile (CRM) 23.1. Chickamauga Reservoir is the next mainstream impoundment downstream of Watts Bar Dam. Watts Bar Reservoir is large, encompassing 140 river miles in length and 44,000 acres in surface area, and is used for municipal water supply, sport fishing, boating, swimming, tourism, and residential development. The CR/WBR system receives effluents from DOE facilities on the ORR, as well as effluents from municipal and industrial water treatment facilities and runoff from agricultural and urban areas.

DOE's ORR was added to the National Priority List (NPL) in December 1989. A Federal Facilities Agreement (FFA) [under Sect. 120 of the Comprehensive Environmental Response, Compensation, and Liability Act (CERCLA), as amended by the Superfund Amendment and Reauthorization Act (SARA) and Sect. 6001 of the Resource Conservation and Recovery Act (RCRA) of 1976] between DOE, the U.S. Environmental Protection Agency (EPA) Region IV, and the Tennessee Department of Environment and Conservation (TDEC) became effective on January 1, 1992. These parties intend to coordinate DOE's CERCLA/RCRA response obligation with corrective measures required and conducted by DOE under its current permit under the Hazardous and Solid Waste Ame: inents (Fidr... to RCRA of 1984. Section 3004(v) of the HSWA of RCRA specifically addresses requirements for corrective actions for releases of hazardous wastes or constituents beyond the boundaries of RCRA-permitted sites. In addition TDEC, DOE, and EPA expect that the response actions under the FFA, together with corrective measures, will achieve comprehensive remediation of releases and potential releases of contaminants from the ORR. The CRRI is being conducted in compliance with the FFA and with Sect. 3004(v) of RCRA. 


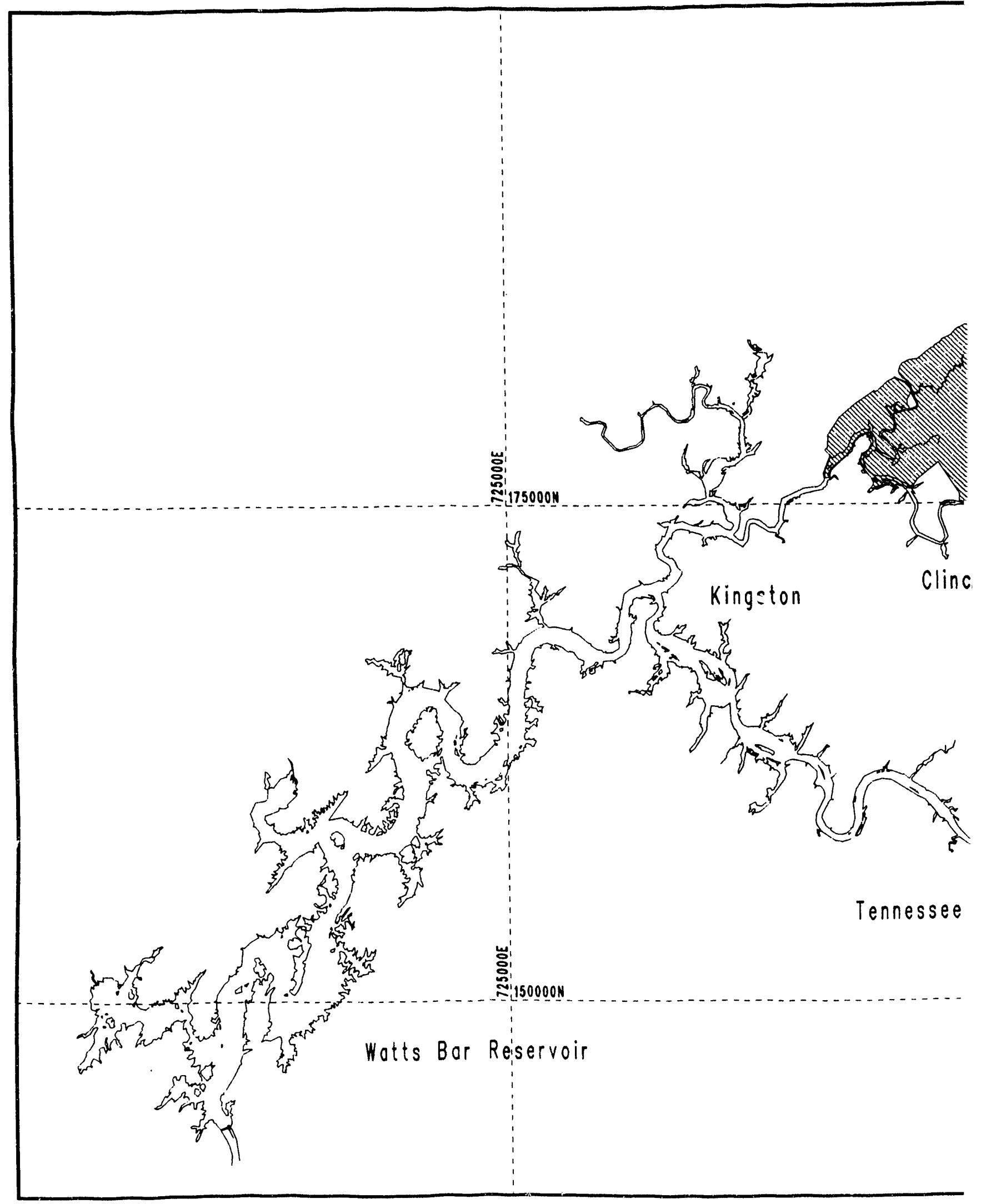

Fig. 1.1. Map showing the location of the Clinch 


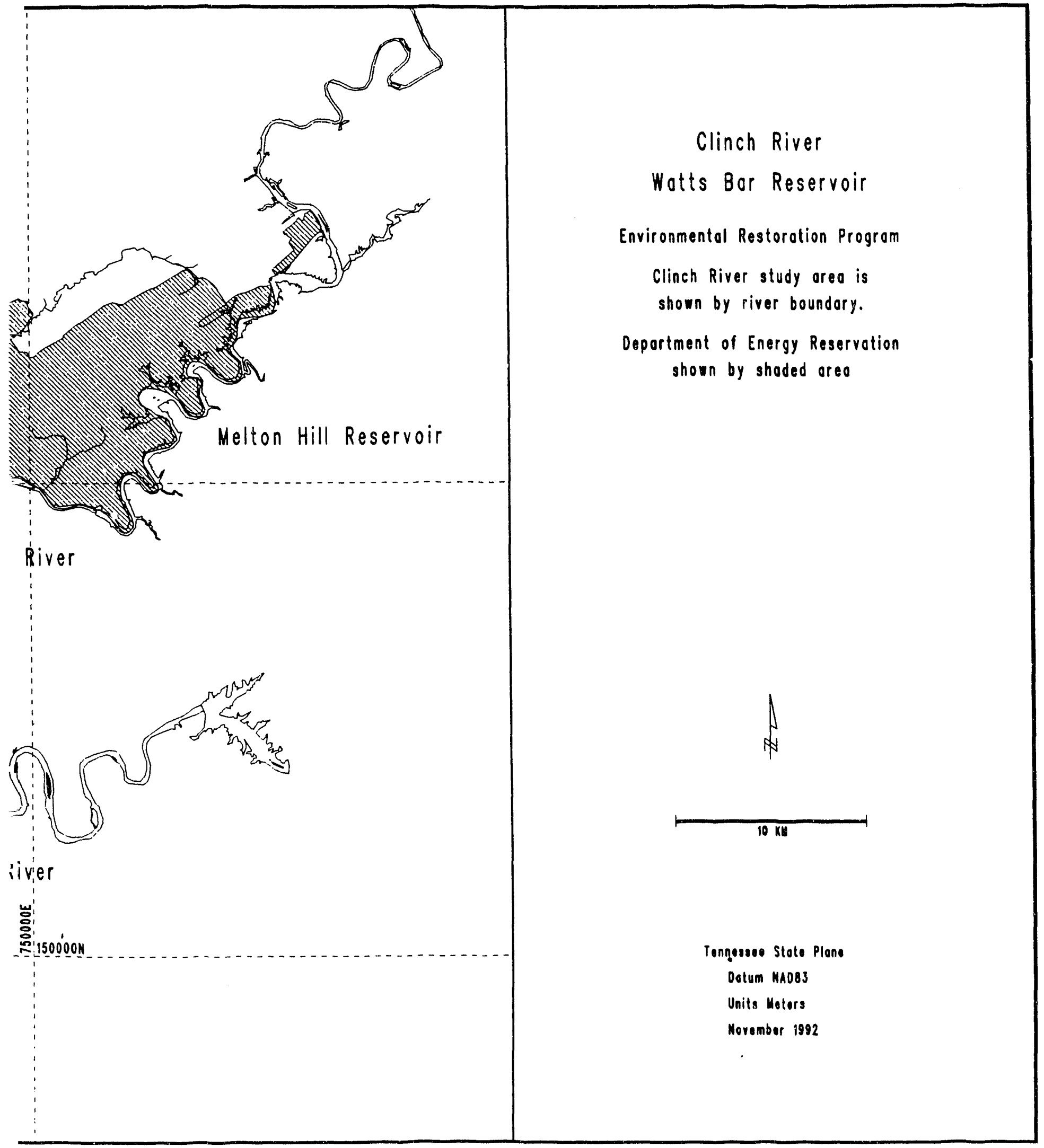

iver, Watts Bar Reservoir, and DOE's Oak Ridge Reservation. 


\subsection{OBJECTIVES AND APPROACH OF THE CLINCH RIVER REMEDIAL INVESTIGATION}

The primary objectives of the CRRI (Martin Marietta Energy Systems 1990) are to

- define the nature and extent of contamination of the off-site surface water and sediment environment downstream from the ORR, which resulted from operations and waste disposal activities at DOE's facilities on the ORR;

- quantify any risk to human health and to the environment resulting from the existing offsite contamination; and

- preliminarily identify and evaluate potential corrective measures and remedial action alternatives.

A phased approach is being employed in the CRRI because a large number of samples potentially may be required to characterize such a large and complex river and reservoir system. The phased approach relies heavily on iterative screening-level risk analysis for estimating human and ecological health and is based on obtaining the data needed for risk analyses and for evaluating remediation alternatives (Fig. 1.2). Primary components of the phased approach include scoping, Phase 1, and Phase 2 studies.

The scoping studies were performed before the work plan for the CRRI was developed and approved. In the scoping studies, extant data were synthesized and used in a screeninglevel risk analysis, which served to (1) preliminarily identify contaminants of concern in the CR/WBR system and (2) identify areas of the river and reservoir in which additional data collection was necessary for site characterization, risk assessment, and evaluation of remediation alternatives. The scoping studies were summarized in Olsen et al. (1992), Suter (1992), and Hoffman et al. (1991).

The Phase 1 study followed the scoping study and consisted of a preliminary sampling and analysis in areas selected to represent differing levels of contamination (including reference sites located upstream from the ORR). The objectives of the Phase 1 study were to (1) obtain high-quality data to confirm and modify preliminary results from the scoping study, (2) determine the range of contaminant concentrations present in the off-site environment, (3) identify the contaminants of concern, and (4) establish the reference concentrations for those contaminants. The Phase 1 study has been completed and is summarized in this report.

The objectives of the Phase 2 study are to (1) perform iterative risk analyses as additional data become available, (2) quantitatively estimate potential risks to human health and the environment, and (3) focus additional sampling efforts. These risk analyses will guide more extensive sampling and analysis and risk assessment, ultimately leading to a baseline risk assessment presented in a final RI report. In addition, the Phase 2 study will include a preliminary evaluation of potential remediation alternatives and identification of effective and acceptable corrective measures. The Phase 2 study is presently in the planning stages.

After the Phase 1 sampling and analysis began, a task was initiated to characterize the near-shore sediment in the CR/WBR. The primary objective of the near-shore sediment task is to provide information on the risks posed to human health from surface sediments (between 0 and $10 \mathrm{~cm}$ depth in the sediments) in shallow waters of the near-shore areas. 
ֻٓ

엉 
These sediments are exposed to the air during the winter season, when the water levels in these reservoirs are lowered as part of the water management activities of the Tennessee Valley Authority (TVA). This task supports the efforts of the TVA and the U.S. Army Corps of Engineers to evaluate permit applications for sediment-disturbing activities (e.g., dredging for private boat access channels, installation of boat docks, shoreline stabilization). An interagency working group composed of the TVA, the Corps of Engineers, DOE, TDEC, EPA, and staff fror the CRRI preliminarily evaluates the levels of contamination prior to TVA and the Corps performing their evaluation. Almost 600 surface sediment samples in near-shore areas of Watts Bar Reservoir and the Clinch River were collected as part of this task and are discussed in Sects. 3 and 4.

\subsection{SUMMARY OF THE SITE CONCEPTUAL MODEL}

A site conceptual model was formulated in Martin Marietta Energy Systems (1990) to identify and summarize the current knowledge and understanding of contaminant sources, the potential environmental pathways of contaminant exposure (inclucing transport media and exposure routes), and the potential receptors for contaminants that may have been released from the ORR to downstream surface waters.

A complicating factor in identifying sources and media for the CRRI site conceptual model is that there also may be non-DOE sources of contaminants to the CR/WBR. The Clinch and Tennessee rivers recrive inputs from municipalities, agricultural activities, and industries that may contribute contaminants to the media, pathways, and endpoints of concern.

Operations and waste disposal activities at the Y-12 Plant, ORNL, and the K-25 Site on the ORR have been sources of a variety of airborne, liquid, and solid contaminants. Some of these contaminants have affected local streams that ultimately drain into the CR/WBR. For the CRRI, the contaminants identified in the CR/WBR were transported by surface water from the point of release on the ORR to the location being investigated. T. zrefore, the media of concern in the CRRI are those associated with the surface water environment downstream from the ORR: the water itself, suspended particles and sediments, deposited sediments, aquatic organisms, and wildlife feeding on aquatic organisms.

The deposited sediments also serve as a secondary source of contaminants. For many contaminants found in deposited sediments (i.e., particle-reactive contaminants), the largest releases occurred 20 to 40 years ago (Martin Marietta Energy Systems 1990). These contaminated sediments were buried by sediments that contain much lower levels of contaminants (Turner et al. 1985; Olsen et al. 1992). Unusual storm events or dredging activities may resuspend these ceeply buried contaminated sediments and reintroduce contaminants into the water column or into the aquatic food chain.

In the CR/WBR system, the highest potential exposure to contaminants released from the ORR occurs at several spatial scales. The highest potential exposure to dissolved conts ninants in off-site surface waters should occur at the ORR boundary, where surface water hisws from the reservation to the public domain. Exposure points with lower predicted chemical concentrations, but larger potentially exposed receptor populations, are locations of municipal water supply intakes. Points of high potential exposure to particle-associated 
contaminants occur at points of sediment deposition and accumulation. A major effort of the planned Phase 2 studiy in the CRRI is to locate areas of high rates of sediment and contaminant accumulation.

The primary exposure routes for the environment (aquatic biota and wildlife feeding on aquatic biota) are uptake and metabolism of dissolved contaminants, direct contact or exposure, absorption, and ingestion of contaminated food organisms or particulate matter. The primary exposure routes of greatest potential risk to human health are ingestion of contaminated water, ingestion of contaminated food (e.g., fish, waterfowl, or vegetables grown on contaminated sediment or soil), direct ingestion of contaminated sediment or soil), and direct exposure to contaminated sediment or soil.

The results of the scoping studies conducted by the CRRI confirm this conceptual site model and further indicate that ingestion of contaminated biota and direct exposure to contaminated sediments are the greatest potential exposure pathways.

\subsection{REPORT ORGANIZATION}

The CRRI Phase 1 Data Summary Report is organized to provide the flow of information from the objectives and phased approach of the CRRI, to the description of Phase 1 data, and to discussion of the screening risk assessment.

In the first volume, Sect. 1 introduces the objectives and approach of the study and provides the regulatory background. Section 2 presents (1) a description of the study area and sampling sites for fish, sediment, and water; (2) methods used for sample collection and analysis; and (3) a brief description of the quality assurance program for Phase 1.

The contaminant concentrations in fish, sediment, and water, based on the Phase 1 data, is summarized in Sect. 3. The risk screening analyses are presented in Sect. 4 for human and ecological health. Section 5 summarizes the Phase 1 results and describes how these results lead to program activities in Phase 2. Supporting information about Phase 1, including summary tables of the analytical data, are collected in Appendixes A through G. 


\section{PHASE 1 SAMPLE COLLECTION AND ANALYSIS}

This section briefly summarizes the rationale and methods for the collection and analysis of water, sediment, and fish samples for Phase 1 of the CRRI. A complete description of the rationale and methods may be found in the Clinch River RCRA Facility Investigation Work Plan (Martin Marietta Energy Systems 1990).

The primary areas of investigation during Phase 1 of the CRRI were the Melton Hill and Watts Bar Reservoirs, with particular emphasis on the Clinch River arm of Watts Bar Reservoir (Melton Hill to the Clinch River-Tennessee River confluence) and Poplar Creek. Phase 1 sampling from these areas occurred from December 1989 to February 1990 for water, October 1989 to April 1990 for fish, and December 1989 to July 1990 for sediment. For the purposes of sampling and analysis, the CR/WBR system was partitioned into reaches (Fig. 2.1, Table 2.1), following those identified by Hoffman et al. (1991). The number of samples collected in each reach for each medium type (water, fish, and sediment) is listed in Table 2.2 and in the section corresponding to that medium. A list of analytes for each medium, with cross-reference to its Chemical Abstract Service (CAS) number, is found in Appendix A.

\section{WATER}

Surface water is the primary transport pathway for contaminants leaving the reservation. It is also the principal exposure medium for the initial introduction of dissolved (non-particleassociated) contaminants into the food web. The complex hydrodynamics and spatial heterogeneity of the CR/WBR system make it difficult to adequately estimate the temporal and spatial extent of surface water contamination, even with a large number of samples (Martin Marietta Energy Systems 1990). The monitoring of NPDES permitted discharges from the ORR for NPDES and DOE Order 5400.1 provides considerable additional information on contaminant concentrations near discharge points.

Phase 1 sampling of water was undertaken to confirm suspected low dissolved concentrations of contaminants that were identified in scoping studies (Suter 1991, Hoffman et al. 1991, Olsen et al. 1992). Accordingly, characterization of the nature and extent of surface water contamination in the CR/WBR system during Phase 1 of the CRRI was limited to a single sampling event for each station (Fig. 2.2). The focus of the first phase of CRRI sample collection was sediment and biota.

Water samples were analyzed for inorganic, radiochemical and organic constituents, as listed in Table 2.3. Field chain-of-custody was established for these samples at the time of collection and maintained throughout processing, handling, transport, and transfer to other analytical laboratories. All sample collection devices were cleaned following appropriate procedures identified in Martin Marietta Energy Systems 1990. Water samples were collected from Norris Reservoir; upper Melton Hill Reservoir; Solway; lower Melton Hill Reservoir; Jones Island; the mouth of Grassy Creek mbayment; Poplar Creek at the Hartland Bridge; four sites within Poplar Creek below the mouth of East Fork; Brashear Island; Kingston City park; and upper, mid and lower Watts Bar Reservoir (Table 2.4). Additional samples for contaminant screening from public water intake structures and beaches in the CR/WBR system were collected by the TVA in 1991 (TVA 1991). Samples were collected using clean 


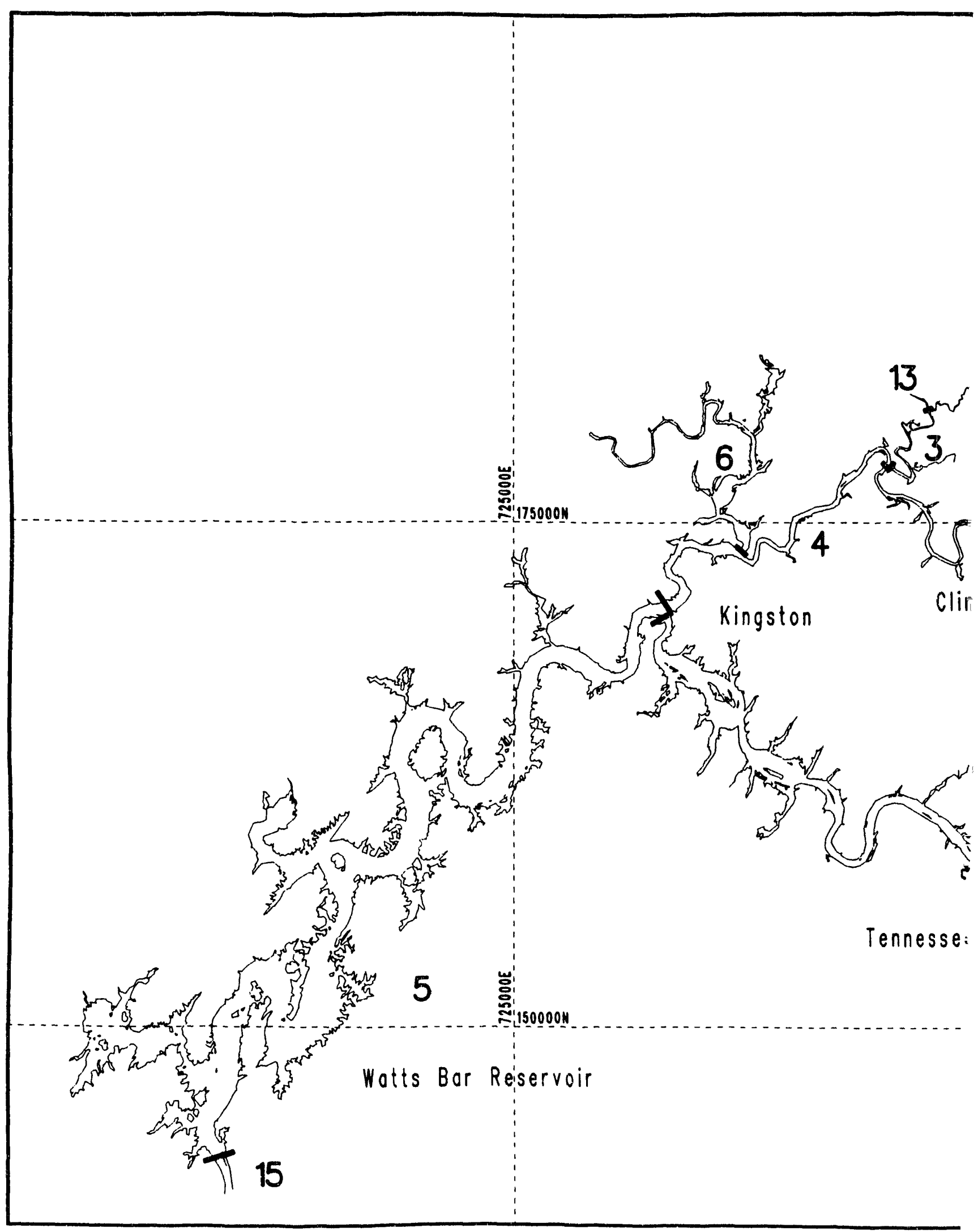

Fig. 21. Locations of reaches used 


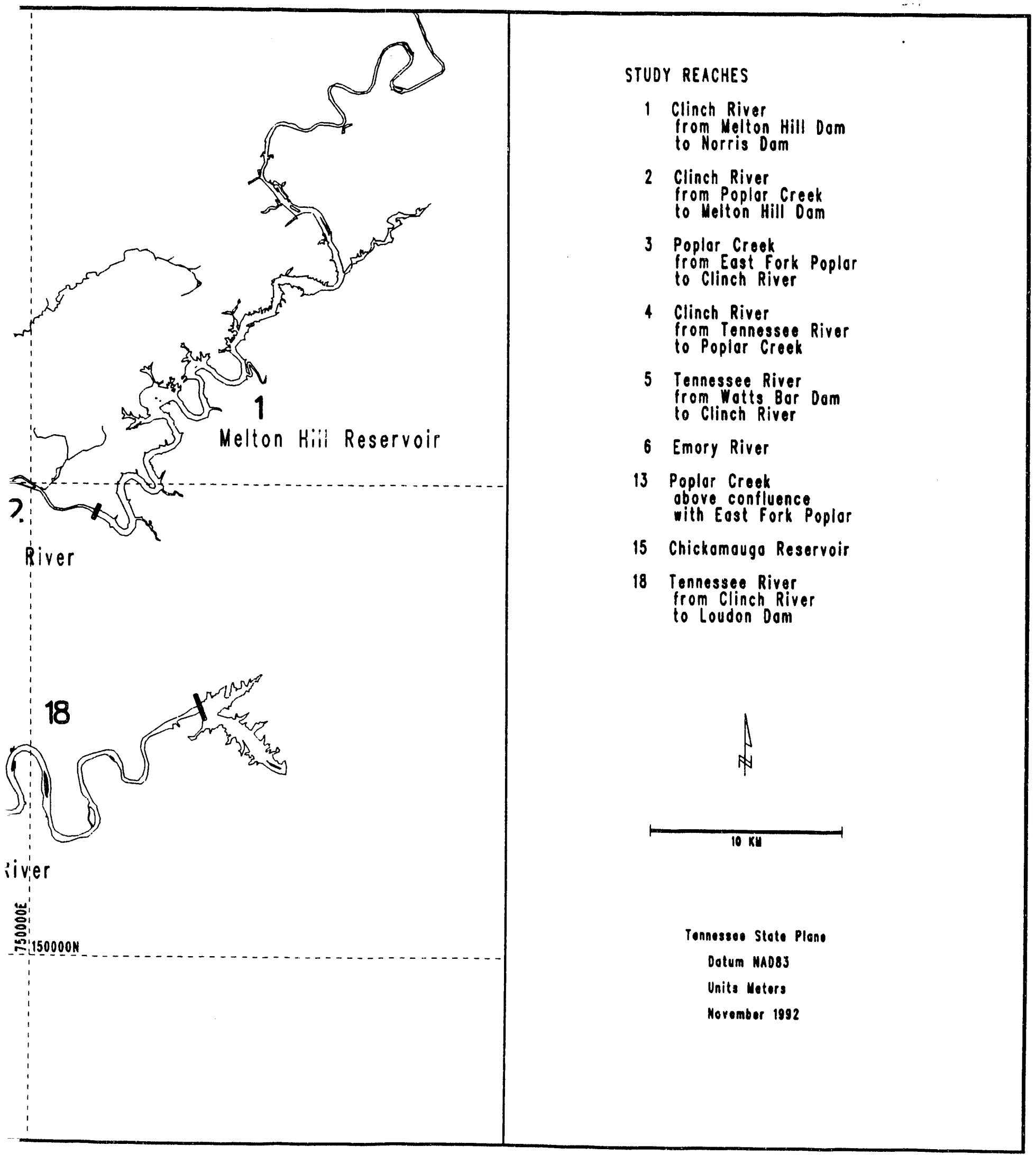

Phase 1 sampling, analysis, and risk assessment. 
Table 21. Stream and river reaches used in the CRRI site characterization and screening risk assessment

\begin{tabular}{|c|c|c|}
\hline $\begin{array}{c}\text { Reach } \\
\text { number }\end{array}$ & Reach name (description) & $\begin{array}{c}\text { River } \\
\text { mile/km }\end{array}$ \\
\hline 1 & $\begin{array}{l}\text { Melton Hill Reservoir (from the Oak Ridge Marina to } \\
\text { Melton Hill Dam) }\end{array}$ & CRM 52.0-23.1 \\
\hline 2 & Clinch (Clinch River from Melton Hill Dam to Poplar Creek) & CRM 23.0-12.1 \\
\hline 3 & $\begin{array}{l}\text { Poplar Creek embayment (Poplar Creek below the confluence } \\
\text { of the East Fork) }\end{array}$ & PCK 8.9-0.0 \\
\hline 4 & $\begin{array}{l}\text { Poplar Creek Clinch (the Clinch River from the mouth of } \\
\text { Poplar Creek to the confluence with the Tennessee River) }\end{array}$ & CRM 12.0-0.0 \\
\hline 5 & $\begin{array}{l}\text { Watts Bar Reservoir (the Tennessee River from the } \\
\text { confluence of the Clinch River to Watts Bar Dam) }\end{array}$ & TRM 567.5-530.0 \\
\hline 6 & Emory River & ERM 14.0-0.0 \\
\hline 10 & $\begin{array}{l}\text { Norris Reservoir (the Clinch and Powell Rivers above Norris } \\
\text { Dam) }\end{array}$ & \\
\hline 13 & $\begin{array}{l}\text { Poplar Creek (Poplar Creek above the confluence of the East } \\
\text { Fork) }\end{array}$ & PCK 11.0-9.0 \\
\hline 15 & Chickamauga Reservoir (below Watts Bar Dam) & TRM 529.9-515.0 \\
\hline 18 & $\begin{array}{l}\text { Tennessee River arm of WBR (from Fort Loudon and Tellico } \\
\text { Dams to the confluence of the Clinch River) }\end{array}$ & TRM 602.0-567.6 \\
\hline
\end{tabular}

${ }^{\circ} \mathrm{CRM}=$ Clinch River mile, PCK = Poplar Creek kilometer, TRM = Tennessee River mile, and ERM = Emory River mile. 
Table 22 Matrices sampled in each reach during Phase 1 of the CRRI (validated and accepted data). Entries with an ' $X$ ' indicate that a particular reach was sampled for that matrix. Blaniss indicate that no sample was collected from the reach for the particular matrix

\begin{tabular}{|c|c|c|c|c|}
\hline \multirow[b]{2}{*}{ Reach } & \multicolumn{4}{|l|}{ Matrix } \\
\hline & Fish & $\begin{array}{l}\text { Sediment } \\
\text { core }\end{array}$ & $\begin{array}{c}\text { Surface } \\
\text { grab } \\
\text { sediment }\end{array}$ & Water \\
\hline 1: Melton Hill Reservoir & $\mathbf{X}$ & $\mathbf{X}$ & $\mathbf{X}$ & $\mathbf{X}$ \\
\hline 2: Clinch R.: Poplar Ck -> Melton Hill Dam & $\mathbf{X}$ & $\mathbf{X}$ & $\mathbf{X}$ & $\mathbf{X}$ \\
\hline 3: Poplar Ck -> East Fork Confluence & $\mathbf{X}$ & $\mathbf{X}$ & $\mathbf{X}$ & $\mathbf{X}$ \\
\hline 4: Clinch R.: Mouth -> Poplar Cx Confluence & $\mathbf{X}$ & $\mathbf{X}$ & $\mathbf{X}$ & $\mathbf{X}$ \\
\hline 5: Watts Bar Reservoir & $\mathbf{X}$ & $\mathbf{X}$ & $\mathbf{X}$ & $\mathbf{X}$ \\
\hline 6: Emory River & & & $\mathbf{X}$ & \\
\hline 10: Norris Reservoir & $\mathbf{X}$ & $\mathbf{x}$ & $\mathbf{X}$ & $\mathbf{X}$ \\
\hline 13: Poplar Creek Above East Fork Confluence & $\mathbf{X}$ & & & $\mathbf{x}$ \\
\hline 15: Chickamauga Reservoir & $\mathbf{X}$ & & & \\
\hline 18: Tennessee R: Clinch R. Confl -> Ft. Loudon & & & $\mathbf{X}$ & \\
\hline Total number of reaches sampled & 8 & 6 & 8 & 7 \\
\hline
\end{tabular}


Table 23. Summary of surface water analysis for the contaminants of concern. Analysis level from ESP-700 Section (Kimbrough et al. 1988).

\begin{tabular}{|c|c|c|c|}
\hline Parameter & $\begin{array}{c}\text { Analytical } \\
\text { level }\end{array}$ & $\begin{array}{l}\text { Containera and processing } \\
\text { specifics }\end{array}$ & Analytical Procedure \\
\hline${ }^{3} \mathrm{H}$ & IV & $\begin{array}{l}4 \mathrm{~L} \text { Cubitainer, chill return } \\
\text { to lab and acidify }\left(\mathrm{HNO}_{3}\right) \\
\mathrm{pH}<2\end{array}$ & Method $906.0^{b}$ \\
\hline${ }^{9} \mathrm{Sr}$ & IV & $\begin{array}{l}4 \mathrm{~L} \text { Cubitainer, chill return } \\
\text { to lab and acidify }\left(\mathrm{HNO}_{3}\right) \\
\text { pH }<2\end{array}$ & Method $905.0^{b}$ \\
\hline \multicolumn{2}{|c|}{ Gamma emitting radionuclides } & \multicolumn{2}{|c|}{21 L Cubitainer, chill to be used for: } \\
\hline Particle-Associated & IV & \multicolumn{2}{|l|}{$\begin{array}{l}\text { filter all of Gamma, collect, air } \\
\text { dry filters }\end{array}$} \\
\hline Dissolved & IV & \multicolumn{2}{|l|}{$\begin{array}{l}\text { filtrate from Gamma, } \\
\text { evaporate to } 90 \mathrm{~mL}\end{array}$} \\
\hline Inorganics & & \multicolumn{2}{|c|}{$4 \mathrm{~L}$ Cubitainer, chill, to be used for: } \\
\hline Total metals & IV & $\begin{array}{l}1 \mathrm{~L} \text { PPE bottle, } \mathrm{HNO}_{3} \\
\text { pH }<2 \text {, chill }\end{array}$ & CLP SOWC \\
\hline Dissolved metals & IV & $\begin{array}{l}\text { Filter into } 1 \mathrm{~L} \text { PPE bottle, } \\
\mathrm{HNO}_{3} \mathrm{PH}<2 \text {, chill }\end{array}$ & CLP SOWc \\
\hline $\begin{array}{l}\text { Organics (as listed in } \\
\text { Table 4.1, Martin } \\
\text { Marietta Energy } \\
\text { Systems 1990) }\end{array}$ & IV & $\begin{array}{l}2.3 \text { L Amber glass bottle, } \\
\text { teflon lined, chill }\end{array}$ & CLP SOW \\
\hline 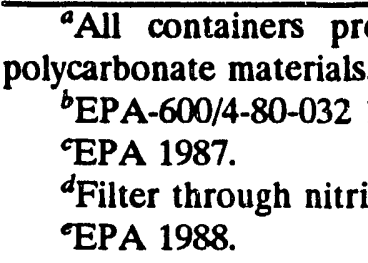 & $\begin{array}{l}\text { ned to } \\
\text { d washed }\end{array}$ & $\begin{array}{l}\text { specifications. Cubitainers } \\
\mu \mathrm{m} \text { diameter effective pore siz }\end{array}$ & manufactured from \\
\hline
\end{tabular}




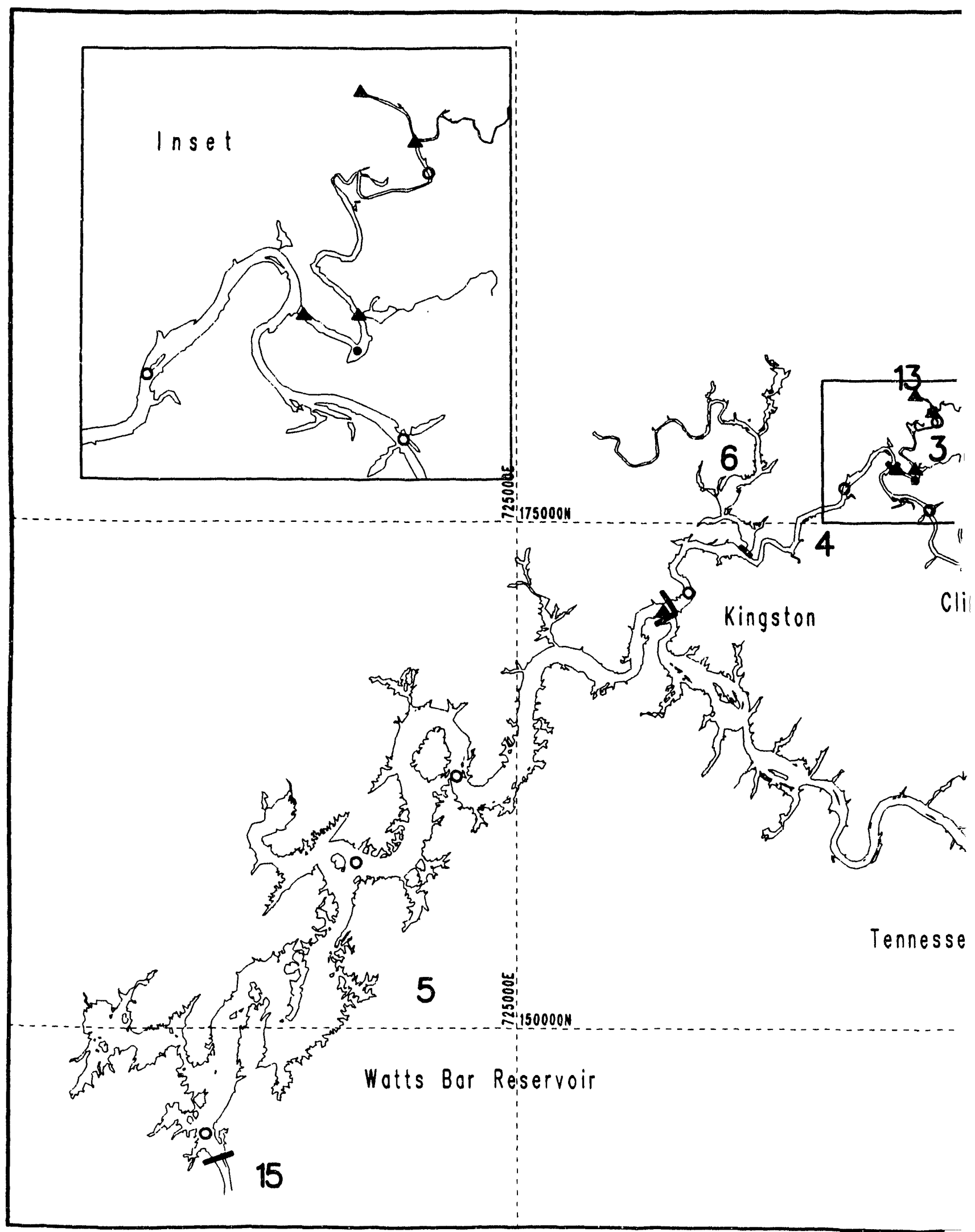

Fig. 2.2 Location of sample sites for Phase 1 w? 


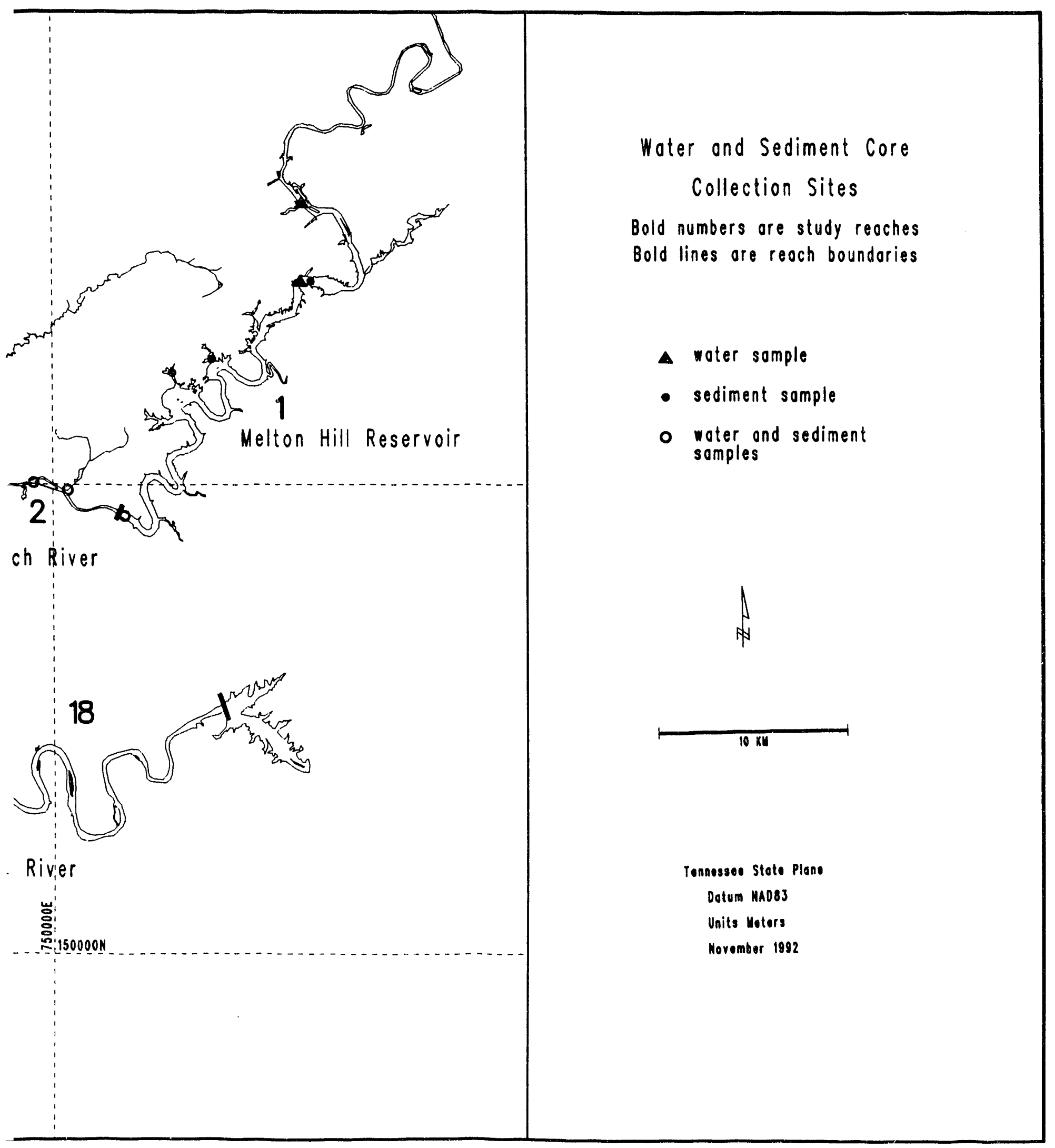

er and sediment core collections in Clinch River/Watts Bar System. 
Table 24. Number of Clinch River RI water samples, by site and type of analysis (validated \& accepted data). Dissolved portion includes both inorganic filtered and gamma spec. evaporate samples. See text for details.

\begin{tabular}{|c|c|c|c|c|c|c|}
\hline \multirow[b]{2}{*}{ Reach } & \multirow[b]{2}{*}{ Site } & \multirow[b]{2}{*}{ Type of Analysis } & \multicolumn{3}{|c|}{ Water Sample Matrix } & \multirow[b]{2}{*}{ Subiotal } \\
\hline & & & Dissolved & Residue & Total & \\
\hline 1 & Upper Melton Hill & $\begin{array}{l}\text { Inorganics } \\
\text { Organics } \\
\text { Radionuclides }\end{array}$ & $\begin{array}{l}1 \\
0 \\
1\end{array}$ & $\begin{array}{l}0 \\
0 \\
1\end{array}$ & $\begin{array}{l}1 \\
1 \\
1\end{array}$ & $\begin{array}{l}2 \\
1 \\
3\end{array}$ \\
\hline 1 & Solway & $\begin{array}{l}\text { Inorganics } \\
\text { Organics } \\
\text { Radionuclides }\end{array}$ & $\begin{array}{l}1 \\
0 \\
1\end{array}$ & $\begin{array}{l}0 \\
0 \\
1\end{array}$ & $\begin{array}{l}1 \\
1 \\
1\end{array}$ & $\begin{array}{l}2 \\
1 \\
3\end{array}$ \\
\hline 1 & Lower Melton Hill & $\begin{array}{l}\text { Inorganics } \\
\text { Organics } \\
\text { Radionuclides }\end{array}$ & $\begin{array}{l}1 \\
0 \\
1\end{array}$ & $\begin{array}{l}0 \\
0 \\
1\end{array}$ & $\begin{array}{l}1 \\
1 \\
1\end{array}$ & $\begin{array}{l}2 \\
1 \\
3\end{array}$ \\
\hline 2 & Jones Island & $\begin{array}{l}\text { Inorganica } \\
\text { Organics } \\
\text { Radionuclides }\end{array}$ & $\begin{array}{l}1 \\
0 \\
1\end{array}$ & $\begin{array}{l}0 \\
0 \\
1\end{array}$ & $\begin{array}{l}1 \\
1 \\
1\end{array}$ & $\begin{array}{l}2 \\
1 \\
3\end{array}$ \\
\hline 2 & Grassy Creek & $\begin{array}{l}\text { Inorganics } \\
\text { Organics } \\
\text { Radionuclides }\end{array}$ & $\begin{array}{l}1 \\
0 \\
1\end{array}$ & $\begin{array}{l}0 \\
0 \\
1\end{array}$ & $\begin{array}{l}1 \\
1 \\
1\end{array}$ & $\begin{array}{l}2 \\
1 \\
3\end{array}$ \\
\hline 3 & PCMouth of East Fork & $\begin{array}{l}\text { Inorganics } \\
\text { Organics } \\
\text { Radionuclides }\end{array}$ & $\begin{array}{l}1 \\
0 \\
1\end{array}$ & $\begin{array}{l}0 \\
0 \\
0\end{array}$ & $\begin{array}{l}1 \\
1 \\
1\end{array}$ & $\begin{array}{l}2 \\
1 \\
2\end{array}$ \\
\hline 3 & K-1007 & $\begin{array}{l}\text { Inorganica } \\
\text { Organics } \\
\text { Radionuclides }\end{array}$ & $\begin{array}{l}1 \\
0 \\
1\end{array}$ & $\begin{array}{l}0 \\
0 \\
1\end{array}$ & $\begin{array}{l}1 \\
1 \\
1\end{array}$ & $\begin{array}{l}2 \\
1 \\
3\end{array}$ \\
\hline 3 & Lower Poplar Creek & $\begin{array}{l}\text { Inorganics } \\
\text { Organics } \\
\text { Radionuclides }\end{array}$ & $\begin{array}{l}1 \\
0 \\
1\end{array}$ & $\begin{array}{l}0 \\
0 \\
1\end{array}$ & $\begin{array}{l}1 \\
1 \\
1\end{array}$ & $\begin{array}{l}2 \\
1 \\
3\end{array}$ \\
\hline 4 & Brashear Island & $\begin{array}{l}\text { Inorganica } \\
\text { Organics } \\
\text { Radionuclides }\end{array}$ & $\begin{array}{l}1 \\
0 \\
1\end{array}$ & $\begin{array}{l}0 \\
0 \\
1\end{array}$ & $\begin{array}{l}1 \\
1 \\
1\end{array}$ & $\begin{array}{l}2 \\
1 \\
3\end{array}$ \\
\hline 4 & Kingston City Park & $\begin{array}{l}\text { Inorganics } \\
\text { Organics } \\
\text { Radionuclides }\end{array}$ & $\begin{array}{l}2 \\
0 \\
1\end{array}$ & $\begin{array}{l}0 \\
0 \\
1\end{array}$ & $\begin{array}{l}2 \\
2 \\
0\end{array}$ & $\begin{array}{l}4 \\
2 \\
2\end{array}$ \\
\hline 5 & Upper Watts Bar & $\begin{array}{l}\text { Inorganics } \\
\text { Organics } \\
\text { Radionuclides }\end{array}$ & $\begin{array}{l}1 \\
0 \\
1\end{array}$ & $\begin{array}{l}0 \\
0 \\
1\end{array}$ & $\begin{array}{l}1 \\
1 \\
0\end{array}$ & $\begin{array}{l}2 \\
1 \\
2\end{array}$ \\
\hline 5 & Mid Watts Bar & $\begin{array}{l}\text { Inorganica } \\
\text { Organics } \\
\text { Radionuclides }\end{array}$ & $\begin{array}{l}2 \\
0 \\
2\end{array}$ & $\begin{array}{l}0 \\
0 \\
1\end{array}$ & $\begin{array}{l}2 \\
2 \\
2\end{array}$ & $\begin{array}{l}4 \\
2 \\
5\end{array}$ \\
\hline 5 & Lower Watts Bar & $\begin{array}{l}\text { Inorganica } \\
\text { Oreanica } \\
\text { Redionuclides }\end{array}$ & $\begin{array}{l}1 \\
0 \\
1\end{array}$ & $\begin{array}{l}0 \\
0 \\
1\end{array}$ & $\begin{array}{l}1 \\
1 \\
1\end{array}$ & $\begin{array}{l}2 \\
1 \\
3\end{array}$ \\
\hline 10 & Norris Recervoir & $\begin{array}{l}\text { Inorganics } \\
\text { Organica } \\
\text { Radionuclides }\end{array}$ & $\begin{array}{l}2 \\
0 \\
2\end{array}$ & $\begin{array}{l}0 \\
0 \\
1\end{array}$ & $\begin{array}{l}2 \\
2 \\
2\end{array}$ & $\begin{array}{l}4 \\
2 \\
5\end{array}$ \\
\hline 13 & Hartland Bridge & $\begin{array}{l}\text { Inorganics } \\
\text { Organics } \\
\text { Radionuclides }\end{array}$ & $\begin{array}{l}1 \\
0 \\
1 \\
\end{array}$ & $\begin{array}{l}0 \\
0 \\
1 \\
\end{array}$ & $\begin{array}{l}1 \\
1 \\
1 \\
\end{array}$ & $\begin{array}{l}2 \\
1 \\
3 \\
\end{array}$ \\
\hline Total & & & 37 & 15 & 54 & 106 \\
\hline
\end{tabular}


sample devices, constructed from stainless steel for organic analytes and PVC plastic for inorganic and radiological analytes. Samples were collected using the following criteria. All samples were collected during winter conditions to ensure nearly uniform physical-chemical parameters (such as temperature, $\mathrm{pH}$, dissolved oxygen, or water flow) throughout the water column. With the exception of Norris Reservoir, a single sample was collected from $1.0 \mathrm{~m}$ below the water's surface for each station. Samples were processed in a manner compatible with the requested analyses (Sect. 9.6.2, Martin Marietta En rrgy Systems 1990). Samples were collected from 1.5 and $16.5 \mathrm{~m}$ deep in Norris Reservoir (reach 10).

Water samples were apportioned for contaminant analysis as follows: (1) gamma-emitting radionuclide samples were filtered, and the filtrate was collected; both filter residue (particle-associated) and dissolved filtrate, evaporated to $90 \mathrm{~mL}$ ) portions were analyzed for gamma spectrometry; (2) inorganic samples were split into two aliquots for total and dissolved trace metals; dissolved were passed through a $0.45 \mu \mathrm{m}$ effective pore size filter, acidified following filtration, and chilled, while total were only acidified and chilled; and (3) organic samples were chilled upon collection (Table 2.3). The complete scheme for apportionment and analysis of samples, including water quality and nutrient analyses, is given in Sect. 9.6.3 and Fig. 9.7 of Martin Marietta Energy Systems (1990). Nineteen individual samples were collected from 16 stations in 7 reaches (Fig. 2.2), with the resulting verification, validation, and acceptance of 106 results. Not all analyses were completed for each individual sample. Additionally, field water-quality parameters were measured at each station using a Hydrolab Surveyor II multiparameter water quality monitoring device. All samples were stored, refrigerated over night, and delivered to the analytical laboratory the following morning.

The water concentration values used in the Phase 1 human health and ecological risk screening (Sect. 4) were supplemented with environmental monitoring samples, including routine NPDES monitoring and grab samples collected by environmental monitoring and compliance personnel at each ORR site. Additionally, these data are the current benchmark against which Phase 1 water data are compared in Sect. 3.2.

\section{SEDMMENT}

Sediments may be the short- and long-term repository for particle-associated contaminants. Contaminated surface sediments are also a direct source of particle-associated contaminants to aquatic biota. Through the continuous process of sediment accumulation, sediments preserve a record of the depositional history for particle-associated contaminants, which may be directly proportional to the contaminant release histories. Vertical profiles of contaminants in the sediments can be used to reconstruct past releases of particle-associated contaminants. Data from contaminant surveys of Watts Bar Reservoir (Turner et al. 1985; Olsen et al. 1992) show higher concentrations of ${ }^{137} \mathrm{Cs}$ and mercury at greater depth in the sediment than at the sediment surface. These higher values were associated with the relatively large releases of these contaminants from the ORR in the mid- to late 1950 s and early 1960 s.

Both surface sediment grab and sediment core samples were collected from all sites, following the criteria established in Sect. 9.5.2 of the CRRFI Plan (Fig. 2.2). Samples were collected from December 1989 through July 1990. Sediment core samples were collected from Norris Reservoir; Solway; lower Melton Hill Reservoir; Jones Island; the mouth of Grassy Creek Embayment; Poplar Creek at the mouth of Mitchell Branch; lower Poplar Creek; 
Brashear Island; Kingston Steam Plant; Kingston City park; and upper, mid, and lower Watts Bar Reservoir. In addition to these sites, surface sediment grab samples were collected from Melton Hill Park, Walker Branch Embayment, Grubb Island, the K-770 area, Campbell Bend, Sugar Grove, the Emory River, and Webster Bluff. Samples were sent to several analytical laboratories for analysis of inorganic and organic chemicals and radionuclides. Surface sediment grab samples were collected using a ponar grab sampler. Sediment cores for contaminant profile determinations were collected using either a free-fall gravity corer (at stations with water depths greater than $5 \mathrm{~m}$ ) or a vibracore device (for shallow water stations), using tubing appropriate to the requested analyses. Sediment cores were sectioned by removing the overlying water, extruding the core vertically, and slicing the core into segments as specified in Sect. 9.5.2 of the CRRFI Plan. All sections were placed in containers appropriate to the requested analyses (glass for organics, glass or plastic for metals, and aluminum cans for radiological analyses). Seventy-one sediment cores, split into 1027 samples (Fig. 2.2), and 487 surface sediment grab samples (Fig. 2.3) were collected from 16 stations in 7 reaches (Table 2.5).

An extensive project of surface sediment grab sample collections from near-shore areas of the CR/WBR system was initiated in July 1990 to assess the extent of surface sediment contamination. This sampling was initiated at the request of an interagency working group on Watts Bar Reservoir contaminated-sediment dredging. This sampling is limited to near-shore sediments in Watts Bar Reservoir, which may be (1) contaminated from past ORR operations or (2) susceptible to sediment disturbing activities. The results of this sampling have been reported regularly to the Watts Bar Interagency Working Group.

Sediment samples were also collected from Braden Branch and the White Oak Creek Embayment (WOCE) areas in conjunction with Phase 1 of the CRRI. Contamination observed in Braden Branch is associated with ? state of Tennessee superfund site, not related to DOE ORR operations. Braden Branch was sampled in order to confirm a source of radiological contamination to Melton Hill, above the ORR. Braden Branch data are summarized in Appendix $G$ for informational purposes only. They are not included in the risk screening for human and ecological health (Sect. 4), but are the focus of a separate risk assessment in Appendix G.

Sediment data from WOCE that were collected as part of Phase 1 sampling are summarized in Blaylock et al. (1992). These Phase 1 data led directly to the accelerated site characterization of this area, with the subsequent decision to construct a coffer cell-sediment retention structure at the mouth of the embayment to prevent erosion and transport from WOCE to the Clinch River. The rationale and the activities undertaken by the WOCE project are summarized in Leslie and Kimmel (1992) and Blaylock et al. (1992).

\subsection{FISH}

The objectives of the Phase 1 fish sampling and analysis were to

1. obtain high quality data to confirm or modify existing data for contaminant levels in fish from the CR/WBR system,

2. determine the range of contaminant concentrations in CR/WBR fish and the spatial distributions of these concentrations in reference to ORR, 


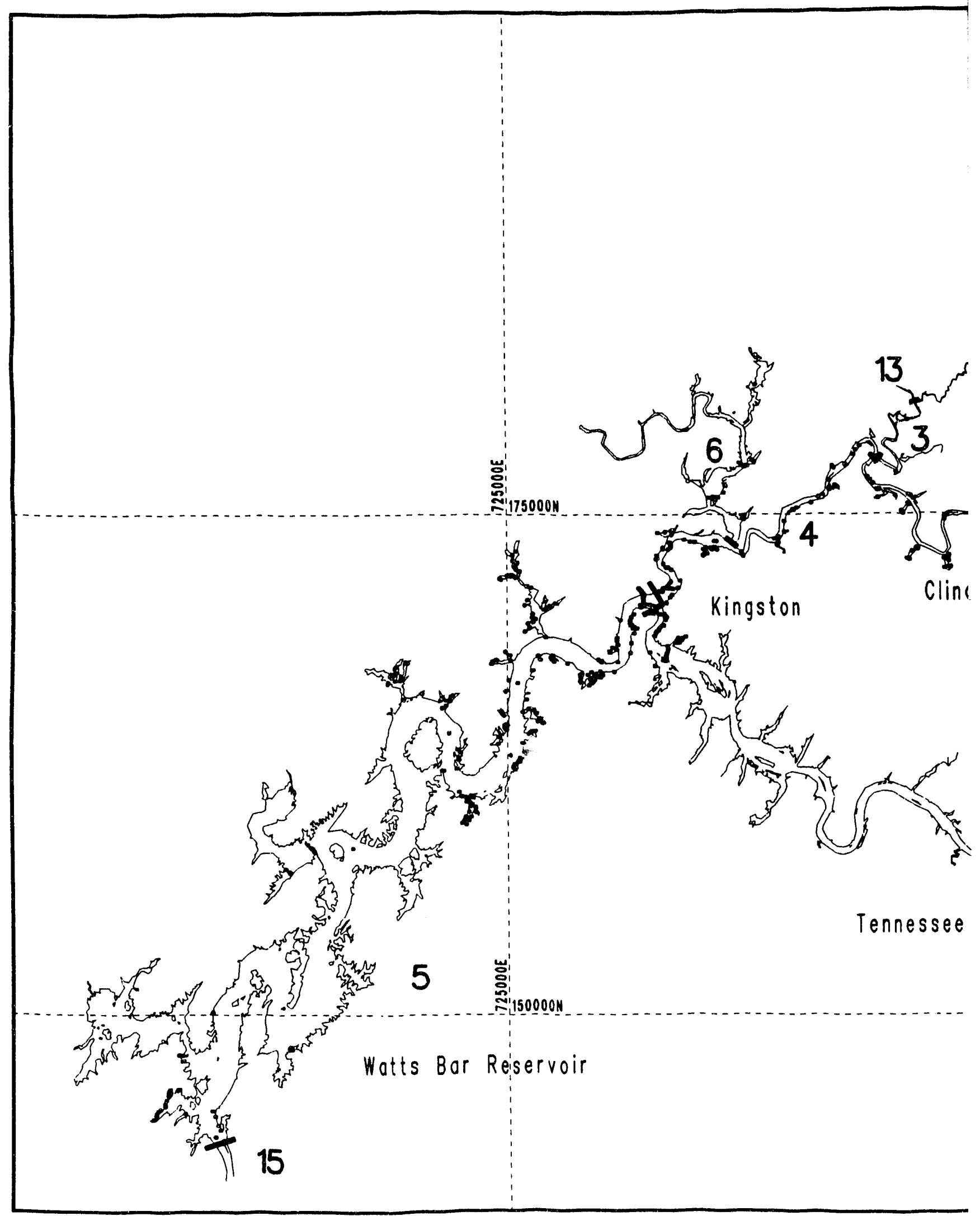

Fig. 2.3. Location of sites for Phase 1 surface sed 


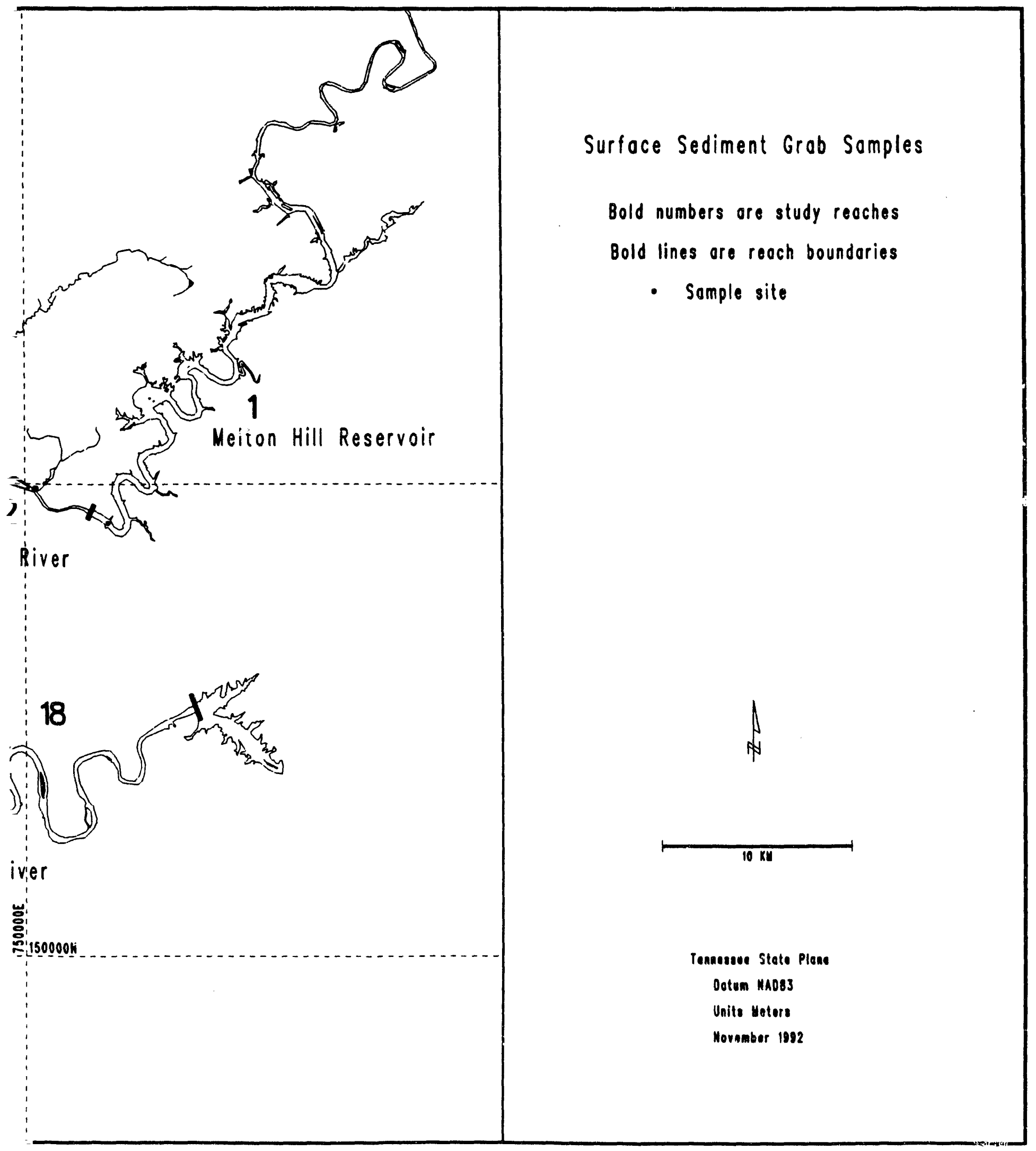

int grab sample collection in Clinch River/Watts Bar system. 
Table 25. Number of Clinch River ERP sediment samples, by reach and type of analysis (validated \& accepted data)

\begin{tabular}{|c|c|c|c|c|c|}
\hline \multirow[b]{2}{*}{ Reach } & \multirow[b]{2}{*}{ Site } & \multirow[b]{2}{*}{$\begin{array}{l}\text { Type of } \\
\text { Analysis }\end{array}$} & \multicolumn{2}{|c|}{ Sample Matrix } & \multirow[b]{2}{*}{ Subtotal } \\
\hline & & & $\begin{array}{c}\text { Core } \\
\text { Section } \\
\end{array}$ & $\begin{array}{c}\text { Surface } \\
\text { Grab }\end{array}$ & \\
\hline 1 & Melton Hill Reservoir & $\begin{array}{l}\text { Inorganics } \\
\text { Organics } \\
\text { Radionuclides }\end{array}$ & $\begin{array}{l}49 \\
25 \\
28\end{array}$ & $\begin{array}{r}0 \\
0 \\
13\end{array}$ & $\begin{array}{l}49 \\
25 \\
41\end{array}$ \\
\hline 2 & $\begin{array}{l}\text { Clinch River: } \\
\text { Melton Hill Dam to Poplar } \\
\text { Creek }\end{array}$ & $\begin{array}{l}\text { Inorganics } \\
\text { Organics } \\
\text { Radionuclides }\end{array}$ & $\begin{array}{l}59 \\
46 \\
58\end{array}$ & $\begin{array}{r}0 \\
0 \\
46\end{array}$ & $\begin{array}{r}59 \\
46 \\
104\end{array}$ \\
\hline 3 & $\begin{array}{l}\text { Poplar Creek: } \\
\text { Ea : Fork Confluence to Poplar } \\
\text { Creek Mouth }\end{array}$ & $\begin{array}{l}\text { Inorganics } \\
\text { Organics } \\
\text { Radionuclides }\end{array}$ & $\begin{array}{l}79 \\
64 \\
80\end{array}$ & $\begin{array}{l}\mathbf{0} \\
\mathbf{0} \\
\mathbf{3}\end{array}$ & $\begin{array}{l}79 \\
64 \\
83\end{array}$ \\
\hline 4 & $\begin{array}{l}\text { Clinch River: } \\
\text { Poplar Creek Confluence to } \\
\text { Clinch River Mouth }\end{array}$ & $\begin{array}{l}\text { Inorganics } \\
\text { Organics } \\
\text { Radionuclides }\end{array}$ & $\begin{array}{r}52 \\
59 \\
110\end{array}$ & $\begin{array}{r}0 \\
0 \\
93\end{array}$ & $\begin{array}{r}52 \\
59 \\
203\end{array}$ \\
\hline 5 & Watts Bar Reservoir & $\begin{array}{l}\text { Inorganics } \\
\text { Organies } \\
\text { Radionuclides }\end{array}$ & $\begin{array}{r}70 \\
63 \\
119\end{array}$ & $\begin{array}{r}0 \\
0 \\
277\end{array}$ & $\begin{array}{r}70 \\
63 \\
396\end{array}$ \\
\hline 6 & Emory River & Radionuclides & $\mathbf{0}$ & 31 & 31 \\
\hline 10 & Norris Reservoir & $\begin{array}{l}\text { Inorganics } \\
\text { Organics } \\
\text { Radionuclides }\end{array}$ & $\begin{array}{l}23 \\
22 \\
21\end{array}$ & $\begin{array}{l}0 \\
0 \\
1\end{array}$ & $\begin{array}{l}23 \\
22 \\
22\end{array}$ \\
\hline 18 & $\begin{array}{l}\text { Tennessee River: } \\
\text { Ft. Loudoun Dam to Clinch } \\
\text { River Consfuence }\end{array}$ & Radionuclides & 0 & 23 & 23 \\
\hline Total & & & 1027 & 487 & 1514 \\
\hline
\end{tabular}


3. provide the necessary data required to perform human health and ecological screening risk assessments to refine the list of contaminants of concern, and

4. establish reference (background) concentrations for contaminants of concern for comparison to those sites impacted by releases from ORR.

Because fish accumulate contaminants from water, sediments, and food, they are integrators of many types of environmental conditions (Adams and McLean 1985). Characterization of the nature and extent of contamination in the aquatic biota in the CR/WBR system included the collection of 288 fish (representing three species) from 15 sites in 8 reaches. To characterize the spatial distribution of contaminants in fish, samples were collected from six sites on the Clinch River, three sites on the Tennessee River downstream of its confluence with the Clinch River, five sites on tributaries of the Clinch River, and one reference site (Norris Reservoir) also in the Clinch River system, but upstream of any influence of ORR (Fig. 2.4, Table 2.6). WOCE was also sampled as part of Phase 1 and these results are presented in Blaylock et al. (1992).

Three species representing different trophic levels were sampled with electrofishing gear and gillnets from August 1989 to April 1990. This sampling effort resulted in the collection of 126 bluegill sunfish (Lepomis macrochirus), 119 channel catfish (Ictalurus punctatus), and 43 largemouth bass (Micropterus salmoides), hereafter referred to as bluegill, catfish, and bass. The target sample size of $\mathbf{8}$ to $\mathbf{1 0}$ of each species at each site was achieved at nearly every site for bluegill and catfish, but rarely for bass because of their unavailability at some sites (Table 2.7). Catfish at four sites (CRM 24.0, CRM 20.6, Poplar Creek Mile (PCK) 7.4, and CRM 9.5) were originally collected as part of the Biological Monitoring and Abatement Plan (BMAP) sampling program on the Clinch River.

Field and laboratory processing of the fish followed procedures described in the CRRFI Plan. Fish fillets were analyzed for a total of 85 chemical constituents (Table A.1) including 13 metals, 2 PCB congeners, 5 pesticides (and derivatives), and 65 semivolatile compounds. Catfish fillets were submitted for analysis of the organic analytes and bass and bluegill for the inorganic analytes. Radionuclide analysis included measuring ${ }^{90} \mathrm{Sr}$ in catfish vertebrae and gamma emitters in the fillets of all three species. The inorganic and organic analyses were performed by two laboratories in the Analytical Chemistry Division of ORNL, and the ${ }^{90} \mathrm{Sr}$ and gamma emitters analyses were performed by Oak Ridge Associated Universities (ORAU) and the Environmental Sciences Division (ESD), respectively. Sample batches consisted of 10 to 20 samples and usually included one duplicate sample, one matrix blank sample, and one matrix spiked sample.

\section{QANC PROGRAM FOR THE PHASE 1 DATA COLLECTION}

\subsection{General}

The quality assurance program for Phase I was designed to comply with both the U.S. Environmental Protection Agency (EPA) QAMS-005/80 and the ANSI/ASME NQA-1 guidelines. The QA objectives for the data follow. 


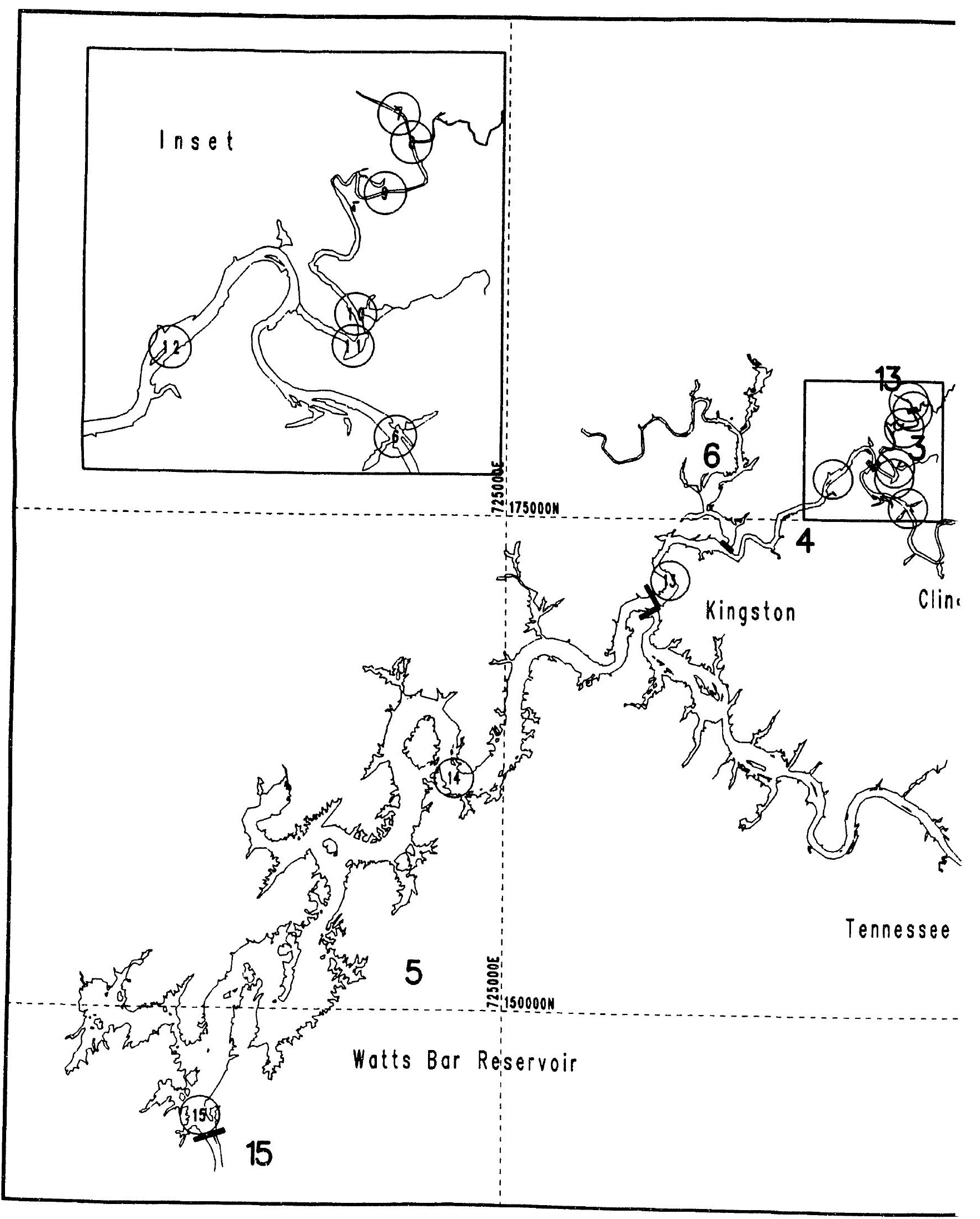

Fig. 24. Location of sample sites for Phase 1 


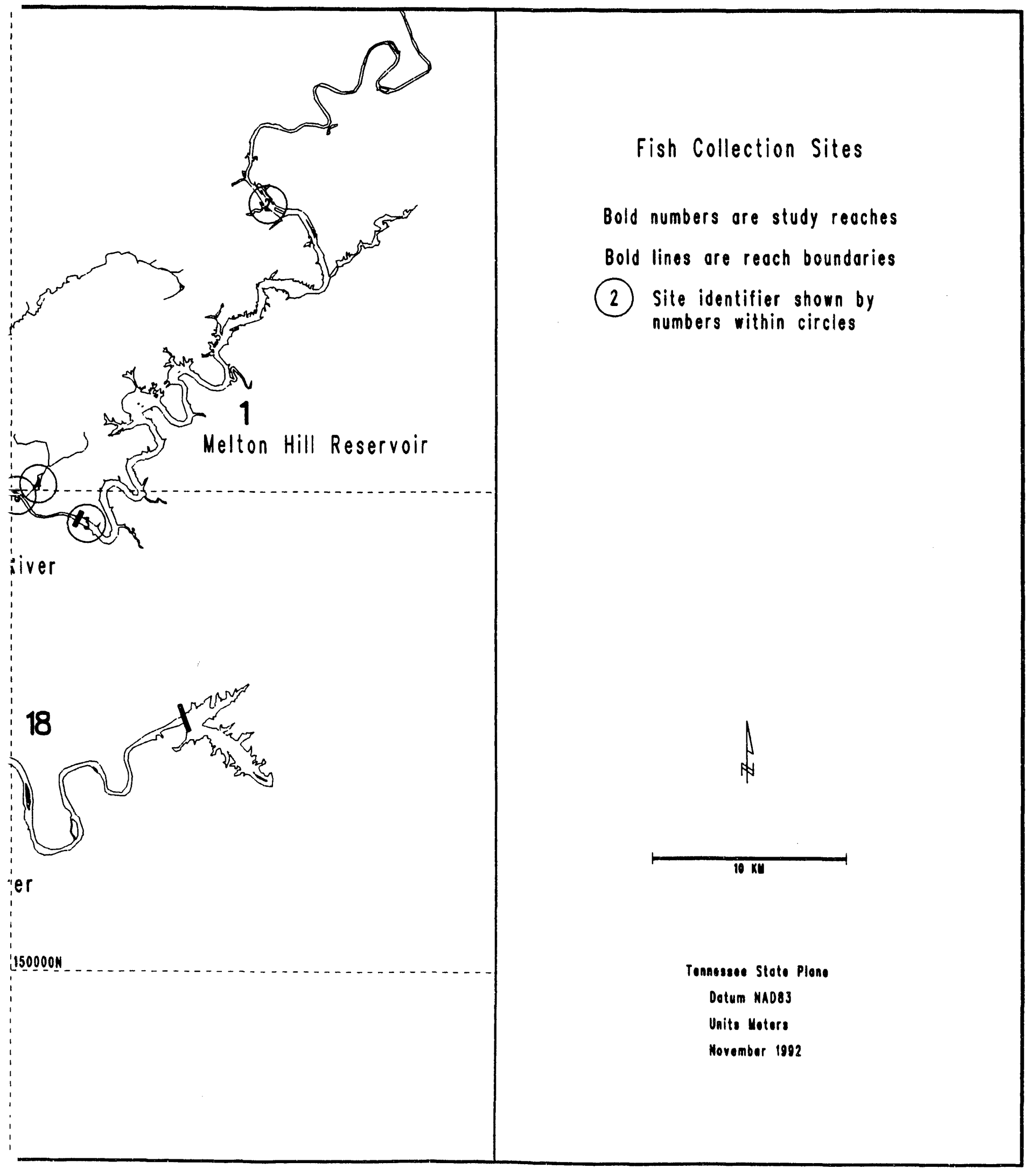

i collection in Clinch River/Watts Bar Reservoir system. 
Table 26. Sample sites for Phase I fish collection in Clinch River/Watts Bar Reservoir system

\begin{tabular}{ccll}
\hline Site No. & $\begin{array}{c}\text { Reach } \\
\text { segment }^{a}\end{array}$ & $\begin{array}{c}\text { River mile } \\
\text { or km }\end{array}$ & \multicolumn{1}{c}{ Name } \\
\hline 1 & 10.1 & CRM 105.0 & Norris Reservoir (reference site) \\
2 & 1.1 & CRM 51.0 & Upper Melton Hill Reservoir \\
3 & 1.5 & CRM 24.0 & Lower Melton Hill Reservoir \\
5 & 2.3 & CRM 20.6 & Jones Island \\
6 & 2.5 & CRM 14.7 & Grassy Creek mouth \\
7 & 13.1 & PCK 9.6 & Poplar Cr. at Hartland Bridge \\
8 & 3.1 & PCK 8.6 & Poplar Cr. at East Fork Poplar Cr. mouth \\
9 & 3.2 & PCK 7.4 & Poplar Cr. at Mitchell Branch mouth \\
10 & 3.3 & PCK 2.2 & Poplar Cr. at K-1007B pond outfall \\
$11^{d}$ & 3.4 & PCK 0.8 & Lower Poplar Cr. embayment \\
12 & 4.2 & CRM 9.5 & Brashear Island \\
13 & 4.5 & CRM 0.5 & Kingston city park \\
14 & 5.2 & TRM 557.0 & Mid Watts Bar Reservoir \\
15 & 5.3 & TRM 530.5 & Lower Watts Bar Reservoir \\
16 & 15.1 & TRM 518.0 & Upper Chickamauga Reservoir \\
\hline
\end{tabular}

${ }^{a}$ Reach segments are divisions of reaches. The number to the left of the decimal is the reach and the number to the right of the decimal indicates the segment.

${ }^{b}$ Channel catfish were collected in the Powell River arm of Norris Reservoir at PRM 30.

'Only channel catfish were collected at the Grassy Creek site.

${ }^{d}$ Fish at sites 10 and 11 were sometimes combined because of small sample sizes. 
Table 27. Number of regular samples (i.e, does not include QC samples) submitted for analysis for each analytical group by species (BLG, bluegill; LMB, largemouth bass; and CHC, channel catfish) and by sampling location

\begin{tabular}{lccccccccc}
\hline & \multicolumn{2}{c}{ Metals } & $\begin{array}{c}\text { Pest/ } \\
\text { PCBs }\end{array}$ & $\begin{array}{c}\text { Semi- } \\
\text { vols. }\end{array}$ & \multicolumn{2}{c}{ Gamma rads } & SR-90 \\
\cline { 2 - 9 } & BLG & LMB & CHC & CHC & CHC & BLG & LMB & CHC \\
\hline Norris Res. & 10 & 5 & 8 & 8 & 8 & 5 & 4 & 8 \\
Upper Melton Hill & 10 & 5 & 8 & 8 & 8 & 2 & 5 & 8 \\
Lower Melton Hill & 10 & 3 & 8 & 8 & 8 & 2 & 3 & \\
Jones Island & 11 & 2 & 8 & 8 & 8 & 11 & 2 & \\
Grassy Cr. & - & - & 6 & 6 & 6 & - & - & 6 \\
PC/Hartland Br. & 10 & - & 4 & 4 & 4 & 2 & - & 4 \\
PC/EFPC mouth & 9 & - & 8 & 7 & 8 & 4 & - & 8 \\
PC/Mitchell Br. & 9 & 4 & 8 & 8 & 8 & 2 & 4 & \\
PC-K-1007 & 2 & 3 & 10 & 10 & 10 & 5 & 3 & 10 \\
PC Embayment & 8 & - & 10 & 9 & 10 & - & - & 10 \\
Brashear Island & 9 & 3 & 8 & 8 & 8 & 9 & 3 & \\
Kingston Park & 10 & 5 & 10 & 10 & 10 & 5 & 5 & 10 \\
Mid Watts Bar & 10 & 2 & 9 & 9 & 9 & 2 & 2 & 9 \\
Lower Watts Bar & 10 & 3 & 10 & 10 & 10 & 2 & 3 & 10 \\
Chickamauga Res. & 8 & 8 & 4 & 4 & 4 & 2 & 8 & 4 \\
\cline { 2 - 10 } Total & 126 & 43 & 119 & 117 & 119 & 53 & 42 & 87 \\
\hline & & & & & & & \\
\hline
\end{tabular}


- Scientific data generated would withstand scientific scrutiny.

- Data would be gathered using appropriate procedures for field sampling, chain-ofcustody, laboratory analyses, and data reporting.

- Data would be of known precision and accuracy.

Audits and surveillances were performed by DOE-OR, MMES Central QA, and others to review and evaluate the adequacy of field and laboratory performance, and to ascertain whether the QAVC Plan was completely and uniformly implemented. Results of these audits and surveillances weredocumented and reported to management. Follow-up action was taken and corrective actions monitored by the Clinch River QAS.

The CRRI samples were analyzed for potential contaminants of concern using established procedures.

Water samples were analyzed for metals, semivolatiles, and pesticide/PCBs by the K-25 ACD. All sediment metals analyses were subcontracted to IT laboratories by the K-25 ACD. The following inorganic elements were reported for sediment: $\mathrm{Sb}, \mathrm{As}, \mathrm{Be}, \mathrm{Cd}, \mathrm{Cr}, \mathrm{Cu}, \mathrm{Pb}, \mathrm{Hg}$, $\mathrm{Ni}, \mathrm{Se}, \mathrm{Ag}, \mathrm{TI}$, and $\mathrm{Zn}$. Inorganic elements that were reported for water were as follows: $\mathrm{Ca}$, $\mathrm{Fe}, \mathrm{Mg}, \mathrm{K}, \mathrm{Na}, \mathrm{Sb}, \mathrm{As}, \mathrm{Be}, \mathrm{Cd}, \mathrm{Cr}, \mathrm{Cu}, \mathrm{Pb}, \mathrm{Hg}, \mathrm{Ni}, \mathrm{Se}, \mathrm{Ag}, \mathrm{Tl}$, and $\mathrm{Zn}$. Organic sediment analyses were performed both by the K-25 ACD and by IT. Metals were analyzed by Contract Laboratory Program (CLP) Statement of Work (SOW) 7/87 or 7/88. Organics were analyzed by CLP SOW 2/88, with the exception that K-25 did not use a second column confirmation for the pesticides/PCBs analyses.

Fish samples were analyzed for semivolatiles and pesticides/PCBs by the Organic Analysis Laboratory (OAL) at ORNL. Semivolatiles were analyzed using a modified GC/MS procedure with no acid surrogates or matrix spike/matrix spike duplicate samples. Laboratory quality control elements that were utilized were method blanks, internal standardization, initial calibration, continuing calibration, and GC/MS tuning. Pesticide/PCB samples were extracted by sonication in hexane with sodium sulfate. Samples were spiked with tetrachloro-m-xylene and decachlorobiphenyl. Extracts were concentrated using Kuderna-Danish concentrators and nitrogen-blowdown. Pesticide extracts were acid washed using concentrated sulfuric acid. Percent lipids were determined on all samples. A method blank (sodium sulfate) was extracted with each group of samples. One sample in each batch was spiked with a matrix spike solution containing $0.5 \mathrm{ppm}$ alpha-chlordane, $0.5 \mathrm{ppm}$ gamma-chlordane and $5 \mathrm{ppm}$ Aroclor 1260 . The extracts were analyzed on a DB-5 capillary column and a DB-1701 megabore column using electron capture detection.

Additional PCB analyses, as well as metals analyses were performed by the ORNL Inorganic Analysis Group (IAG). An internal procedure was used for sample preparation and analysis for PCBs and lipids. An International Atomic Energy Agency (IAEA) fish homogenate was used as a laboratory control sample. Mercury was analyzed by the ORNL $\mathrm{HNO}_{3} / \mathrm{HClO}_{4}$ method (AC-MM10915) for sample preparation and a cold vapor atomic absorption method (AC-MM1214922) for the analysis of $\mathrm{Hg}$. The cold vapor method measures mercury using a standard addition technique. A National Institute of Stanjards and Technology (NIST) standard was used for the standard addition. For analysis of metals, ICP/MS was used to measure As, $\mathrm{Be}, \mathrm{Tl}$, and ICP/OES was used to measure $\mathrm{Sb}, \mathrm{Cd}, \mathrm{Cr}, \mathrm{Cu}$, $\mathrm{Pb}, \mathrm{Ni}, \mathrm{Se}, \mathrm{Ag}$, and $\mathrm{Zn}$. An internal method was used for sample preparation. A VG Plasma Quad P02 was used for the ICP/MS analyses and a JY-48 instrument was used for the 
ICP/OES analyses. The ICP/MS measurements were made using the standard addition technique.

The Oak Ridge Associated University (ORAU) Radiological Laboratory provided radiochemical analytical services for the alpha-beta radionuclide analysis of all samples. QA activities were identifed in Weaver (1988) and standard laboratory procedures were described in Weaver et al. (1988). The Oak Ridge National Laboratory-Environmental Sciences Division (ORNL-ESD) was responsible for analysis of gamma emitting radionuclides (gamma spectroscopy) of biota, sediment, and water.

The QA objectives for precision and accuracy in the laboratory were defined by control limits established for the EPA Contract Laboratory Program. Acceptance criteria for the radiological analyses were generated by each laboratory.

The CRRI program required the independent review and validation of the analytical laboratory data for all Phase I analyses. The review and validation was conducted by a subcontractor following EPA and/or project-specified guidelines to ensure uniformity and comprehensiveness of the review.

\section{Field Quality Control}

Quality Control in field operations, including selection of sampling locations, field data recording and sample collection, were implemented to meeting the Phase 1 project objectives (outlined in Sect. 1.1). Sampling sites for each matrix (fish, sediment or water) and QC sample collection frequencies were specified by the CRRFI Plan, with final determination of each site, and QC sample collection the responsibility of the sample team leader. Methodologies followed for the major categories of field activities, including record keeping, establishment and maintenance of sample custody, instrument calibration, and sample identification were specified in standard operating procedures (SOPs); sample collection procedures followed those of Kimbrough et al. (1990).

All field activities followed standard record keeping, chain-of-custody procedures. These included recording of site specific information in water-proof notebooks, with routine reviews of the notebooks. Sample custody was established by the sampling team upon collection, through the use of standard chain-of-custody forms, and was maintained throughout sample processing, and delivery to analytical services. The goal for submittal of quality control samples was once for every 20 samples, as appropriate. Quality control samples include field duplicates, matrix spikes, equipment cleaning rinse samples and field rinse water blanks. Matrix specific field quality control activities are discussed below.

Fish Site selection was dependent upon the species targeted for collection. Sampling occurred during the fall and spring, when fish were available. Duplicate samples from different halves of the fish were submitted for the requested analysis. Matrix spikes, fish flesh spiked with known quantities of analytes of interest were submitted for organic analysis approximately once every 20 routine samples. Replicate samples were submitted for organic and inorganic analysis approximately once every twenty samples.

Sediment Criteria for selection of sample collection sites included those that were representative of sediment deposition zones, as defined in Martin Marietta Energy 
Systems (1990). Reference material, consisting either of homogenized sediment, stored in a deep freeze, or NBS standard material, was submitted for each sediment core, for inorganic and organic analyses. Approximately one set of duplicate sections for each sediment core was submitted for each requested analysis group.

Water. Samples were collected from mid-channel in the same vicinity as other media. Due to the small number of samples collected, one field duplicate sample, and one equipment cleaning blank was collected per week of sampling. Field blanks and trip blanks were collected approximately once every twenty samples.

\subsection{Laboratory Quality Control Program}

The laboratory quality control program must ensure that all data generated and reported are scientifically valid, consistent with accepted methods, and of known accuracy. An accurate method will produce precise and unbiased results. Results from quality control samples are used to document data quality, verify that the analytical system is functioning for a given matrix/analyte, indicate that an instrument is functioning properly, identify when additional corrections need to be made to the analytical system, and determine the effect of these corrections. The QC data provide an important indication of how well the data quality objectives were met. The types of quality control samples used during Phase I are summarized below.

Radiological check sources were used to determine general performance of the counting system and to ensure that the efficiency of the system had not changed.

\subsubsection{Data Validation}

Analytical results from the laboratories were received by the project database manager in either electronic or hard copy format and merged into a large working database. Analytical results included the concentration of the analyte in the sample if it was present and measurable. When an analyte was not detected in a sample, the sample quantitation limit (SQL) for that particular sample was reported as the result accompanied by a " $U$ " prefix. When spectral data indicated the presence of a compound that met the identification criteria but the result was less than the sample quantitation limit, a "J" tlag was assigned indicating that the result was an estimated value. In data analyses, these " $\mathrm{J"}$ values were treated as normal results.

The primary goal of the Clinch River Environmental Restoration Quality Assurance (QA) Program is to ensure that the analysis of all environmental samples produces data of known quality. According to EPA, "the quality of data is known when all components associated with its derivation are thoroughly documented, with such documentation being verifiable and defensible" (USEPA, 1990). In fulfillment of this goal, a subcontractor, independent of the analytical laboratory that generated the data, was employed by the CR-ERP to validate the analytical results from $\mathrm{Phase} 1$. Organic data packages were assessed by "Laboratory Data Validation Functional Guidelines for Evaluating Organics Analyses" (USEPA), and inorganic data packages were assessed by "Laboratory Data Validation Functional Guidelines for Evaluating Inorganics Analyses" (USEPA), as applicable. Radiological parameters were assessed by SAIC's "Laboratory Data Validation Guidelines for Evaluating Radionuclides Analysis," revision 3. The validation process included an assessment 
of a variety of Quality Assurance/Quality Control (QA/QC) practices, including holding times, matrix spike recovery rates, surrogate recovery rates, calibration standards, and method blanks. Validation flags (or qualifiers) were assigned by the reviewer to each result depending on the quality of the data as determined by the reviewer. A total of 268 data packages, containing approximately 1700 inorganic samples, 1500 organic samples, and 2200 radiological samples were validated. As a result of the external validation some data were rejected as unusable and others were flagged as estimated values. Table 2.8 summarizes the various data qualifier combinations which were attached to each result by the analytical laboratory and/or the validators. Additional data checking was performed as the data were summarized and evaluated for the health nd ecological screening assessment.

\subsection{Data Assessment}

All data deficiencies uncovered in the data validation process were reported to the CR-ERP by the subcontractor's nonconformance process. The CR-ERP reported all nonconformances to laboratory or program personnel for resolution. A nonconformance database was established to track resolution and trends. Two major areas for nonconformances were method use and missing data information. Other areas for nonconformances were illegability, missirig quality control information, matrix spikes missing or recoveries outside limits, and logbooks or worksheets missing or incorrect.

The number of rejected samples is summarized in Table 2.9. All pesticide/PCB and semivolatile analysis of sediment samples that were analyzed by IT were rejected due to missed holding times. Approximately 50\% of the ORNL semivolatile data was rejected because of multiple problems affecting analytical performance, including surrogate recoveries outside of limits, surrogates not added, and inadequate quality control. The QA completeness objective for the project was to obtain valid analytical results for at least $95 \%$ of the samples collected. Overall completeness for all Phase 1 media and analyses combined was $87.8 \%$ valid data. If all the data is considered except for the analysis of semivolatiles in fish (which had the highest refection rate, $48 \%$ ), then the overall completeness is $96 \%$. 
Table 28. Data qualifiers

\begin{tabular}{|c|c|}
\hline Qualifier & Definition \\
\hline $\mathbf{U}$ & $\begin{array}{l}\text { Compound was analyzed for but not detected. Sample quantitation limit was } \\
\text { reporter as the result. }\end{array}$ \\
\hline $\mathbf{J}$ & $\begin{array}{l}\text { Indicates an estimated value either because of laboratory estimation of concentration } \\
\text { or because of validation deficiency. }\end{array}$ \\
\hline $\mathbf{U J}$ & $\begin{array}{l}\text { Compound was analyzed for but not detected, and detection limit was qualified as an } \\
\text { estimate due to validation deficiency. }\end{array}$ \\
\hline $\mathbf{N J}$ & $\begin{array}{l}\text { Tentative compound identification only and estimated concentration. No second } \\
\text { column confirmation of pesticides. }\end{array}$ \\
\hline $\mathbf{x}$ & $\begin{array}{l}\text { Fish tissue which was held frozen while awaiting extraction exceeded allowable } \\
\text { holding time for water samples. However, these criteria are not applicable to } \\
\text { biological samples, and results are considered valid. }\end{array}$ \\
\hline $\mathbf{U X}$ & $\begin{array}{l}\text { Compound was analyzed for but noi detected, and water holding times were } \\
\text { exceeded (see X definition). }\end{array}$ \\
\hline $\mathbf{V} \mathbf{V}$ & Indicates that the result has been verified and is a valid result. \\
\hline
\end{tabular}

Note: Data qualifiers applied to the sample analysis result by the anatytical laboratories and/or independent data validator. In cases where there was no data qualifier required, "VN" has been inserted in the data qualifier field. 
Table 2.9. Summary of the number of rejected samples as a result of the validation of laboratory analyses

\begin{tabular}{|c|c|c|c|c|c|c|}
\hline $\begin{array}{l}\text { Analysis } \\
\text { class }\end{array}$ & $\begin{array}{l}\text { Analysis } \\
\text { type }\end{array}$ & Laboratory & $\begin{array}{c}\text { Total no. } \\
\text { of } \\
\text { analyses }\end{array}$ & $\begin{array}{l}\text { No. of } \\
\text { accepted } \\
\text { analyses }\end{array}$ & $\begin{array}{l}\text { No. of } \\
\text { rejected } \\
\text { analyses }\end{array}$ & $\begin{array}{l}\text { Percent } \\
\text { rejected of } \\
\text { total }\end{array}$ \\
\hline \multirow[t]{4}{*}{ INORGANICS } & METALS & $\mathrm{K} 25$ & 664 & 660 & 4 & $0.6 \%$ \\
\hline & & $\begin{array}{l}\mathrm{K} 25 / \\
\mathrm{IT}\end{array}$ & 4313 & 3818 & 495 & $11.5 \%$ \\
\hline & & $\begin{array}{l}\text { ORNL/ } \\
\text { CPA }\end{array}$ & 2027 & 1933 & 94 & $4.6 \%$ \\
\hline & MERCURY & $\begin{array}{l}\text { ORNL/ } \\
\text { EAL }\end{array}$ & 169 & 169 & $\mathbf{0}$ & $0.0 \%$ \\
\hline \multirow[t]{7}{*}{ ORGANICS } & $\begin{array}{l}\text { PEST/ } \\
\text { PCB }\end{array}$ & $\mathrm{K} 25$ & 7830 & 7205 & 625 & $8.0 \%$ \\
\hline & & $\begin{array}{l}\mathrm{K} 25 / \\
\mathrm{IT}\end{array}$ & 27 & 0 & 27 & $100 \%$ \\
\hline & & $\begin{array}{l}\text { ORNL } \\
\text { CPA }\end{array}$ & 238 & 225 & 13 & $5.5 \%$ \\
\hline & & $\begin{array}{l}\text { ORNL/ } \\
\text { OAL }\end{array}$ & 1160 & 1123 & 37 & $3.2 \%$ \\
\hline & $\begin{array}{l}\text { SEMI- } \\
\text { VOLS }\end{array}$ & K25 & 19306 & 19234 & 72 & $0.4 \%$ \\
\hline & & $\begin{array}{l}\mathrm{K} 25 / \\
\mathrm{IT}\end{array}$ & 65 & 0 & 65 & $100 \%$ \\
\hline & & $\begin{array}{l}\text { ORNL } \\
\text { OAL }\end{array}$ & 7539 & 3930 & 3609 & $47.9 \%$ \\
\hline \multirow{2}{*}{$\begin{array}{l}\text { RADIO- } \\
\text { NUCLIDES }\end{array}$} & & ORAU & 941 & 904 & 37 & $3.9 \%$ \\
\hline & & $\begin{array}{l}\text { ORNL/ } \\
\text { ESD }\end{array}$ & 2339 & 2336 & 3 & $0.1 \%$ \\
\hline \multicolumn{3}{|c|}{ TOTAL NUMBER OF SAMPLES } & 46618 & 41537 & 5081 & $12.2 \%$ \\
\hline
\end{tabular}




\section{SITE CHARACTERIZATION}

\subsection{INTRODUCTION}

The purpose of this section is to discuss contaminant concentrations observed in Phase 1 of the CRRI across the system and in each reach. While data tables referred to in this section include all contaminants for which analyses were performed and accepted through the verification and validation process, discussions are limited to the contaminants identified by the risk screening analysis as high priority contaminants or those contaminants requiring further study. This information is presented in individual sections for each medium type (water, sediment, and fish).

All of the summary tables referred to in this report include data qualifier flags (Table 2.8). It is important to recognize that the derivation of the reported data is dependent on understanding these qualifiers. Contaminants that were not detected at all, or that were detected but not quantifiable, have reported concentrations that are estimates, based upon the detection limits of the instruments used. Assigning the value of the "limit of detection" to compounds that were not detected yields a conservatively high "estimated concentration" for those contaminants.

\subsection{WATER}

Surface water, the primary transport pathway for all contaminants leaving the reservation, is also the principal exposure medium for the initial introduction of dissolved (non-particleassociated) contaminants into the food web. The complex hydrodynamics and spatial heterogeneity of the CR/WBR system make it exceedingly difficult to adequately estimate the temporal and spatial extent of surface water contamination, even with a large number of samples. The NPDES monitoring of permitted discharges provides considerable information on contaminant concentrations near discharge points.

Phase 1 sampling of water was undertaken to (1) obtain high-quality data to confirm or modify suspected low concentrations of contaminants that were identified in scoping studies (Suter 1991, Hoffman et al. 1991, Olsen et al. 1992), (2) determine the range of contaminant concentrations present in the river-reservoir system, (3) provide data for the identification of contaminants of concern, and (4) establish reference concentrations for those contaminants. Accordingly, characterization of the nature and extent of surface water contamination in the CR/WBR system during Phase 1 of the CRRI was limited to a single sampling event for each station. This single water sample from each station was collected during winter conditions of uniform physical-chemical parameters. Samples were analyzed for inorganic, radiochemical, and organic constituents. These data were collected to confirm the results of scoping studies and monitoring reports and they will be supplemented with NPDES monitoring data to evaluate human and ecological risk on a screening level. The intent is to focus sampling and analyses on specific areas and contaminants during Phase 2 of the CRRI.

\subsubsection{Discussion of Contaminants for the System}

The following results reflect the outcome of analyses of total dissolved (filtered) water samples for metals, PCB/pesticides, semivolatile organic compounds, and radionuclides. Few 
contaminants were detected in Phase 1 water samples. Organic, inorganic, and radiological analytes that were observed, verified, and valiciated as acceptable values are included in the data tables, the text, and this discussion. The detected analytes are listed by descending frequency of occurrence in Appendix B.

The most prevalent analytes, observed in both total and dissolved portions of all samples submitted, are the cations calcium, magnesium, potassium, and sodium. Total and dissolved iron were observed less frequently.

Constituents with the potential to pose a risk to human health or the environment rarely met all of the quality criteria for acceptance into the database. Potential contaminants of concern include total and dissolved lead, total copper, dissolved cadmium, total and dissolved zinc, dissolved mercury, and total and dissolved silver (Appendix B). The distribution of these contaminants is discussed in Sect. 3.2.2. Inorganic contaminant values that were averaged over the whole CR/WBR system, with one exception (zinc), were in the ranges expected based on previous monitoring reports (Kornegay et al. 1991). Each inorganic contaminant detected during the Phase 1 investigation is well below the Tennessee Water Quality Criteria for Designated Water Uses (rules of the TDEC, Chapter 1200-4-3). The observed values for zinc ( 1 total and 1 filtered) are greater than the maximum reported for environmental monitoring of the Clinch River. Bis-(2-ethylhexyl)-phthalate was the only organic contaminant observed in any of the samples collected for Phase 1 site characterization (Appendix B).

Radiological constituents observed include ${ }^{90} \mathrm{Sr}$, particle-associated and dissolved (evaporate) ${ }^{137} \mathrm{Cs}$, and dissolved ${ }^{60} \mathrm{Co}$ (Appendix B). Radionuclides that have been observed, verified and validated were more common than organic or most inorganic contaminants. For the dissolved and total water phase radionuclides, observed values were within and below the range of values reported for environmental monitoring data (Kornegay et al. 1991). Analogous values for particle-associated ${ }^{137} \mathrm{Cs}$ are not present in the environmental monitoring report; however, values from Appendix B are within the range of those reported by Olsen et al. (1992).

\subsection{Discussion of Contaminants by Study Reach}

The discussion of patterns in the distribution of organic, inorganic, and radiological analytes is restricted to listing the contaminants found in particular reaches; there are too few observations to adequately address variability of the surface water environment. The data for this section are compiled in Appendix B.

Dissolved zinc was detected only at the Norris Reservoir reference site (reach 10). This observation should be investigated further, since no other values for dissolved zinc were detected in Phase 1 data. Dissolved cadmium and total and dissolved lead were observed in upper Melton Hill Reservoir (reach 1), upstream from all active ORR inputs to the CR/WBR system. The majority of the potential contaminants of concern for which observations have been verified, validated, and accepted were located downstream from ORNL operations (reach 2, between White Oak Creek and Poplar Creek on the Clinch River) and in the vicinity of the K-25 Site (reach 3, Poplar Creek Embayment). Total copper and zinc were detected in reach 2 surface waters, with values in the range previously detected for environmental monitoring (Kornegay et al. 1991). 
Values for dissolved lead, observed in Poplar Creek upstream from the East Fork confluence (reach 13), were comparable to those reported previously (Kornegay et al. 1991); however, dissolved lead was not detected in any Phase 1 sample from reach 3, downstream in Poplar Creek. Dissolved mercury, total and dissolved silver, and total lead were all observed in upper portions of reach 3 (Appendix B). Mercury and lead values are within the range previously reported for this reach, though silver values are greater than previously reported (Kornegay et al. 1991). Dissolved cadmium and dissolved and total lead values in the Clinch River above the confluence of the Clinch and Tennessee rivers (reach 4 ) are greater than those observed for environmental monitoring.

Gamma-emitting radionuclides were not observed in water samples from any of the reference reaches, including Norris Reservoir and Poplar Creek. Additionally, none were detected in Melton Hill Reservoir. Both dissolved and particle-associated ${ }^{137} \mathrm{Cs}$ were detected in reaches 2, 4, and 5 (Appendix B); all values were similar to those reported by Olsen et al. (Table 5 in Olsen et al. 1992) and Kornegay et al. (1991). Only dissolved ${ }^{137} \mathrm{Cs}$ was detected in Poplar Creek (Appendix B). Cobalt-60 was detected in a single filtered sample from reach 5 (Appendix B) at levels comparable with those reported by Olsen et al. (Table 5). Though ${ }^{90} \mathrm{Sr}$ was reported as present in all reaches, the average values for each reach were less than the standard deviation of the measurements (Appendix B). Concentrations of radionuclides in surface waters are comparable with values for both surface sediments and current releases from the ORR (Olsen et al. 1992; Kornegay et al. 1991).

\subsection{Summary}

The cations calcium, magnesium, potassium, and sodium-the most prevalent analytesare constituents of weathered rock and are commonly observed in surface waters. Values for the CR/WBR system are comparable with those observed in routine monitoring near the ORR and in other freshwater ecosystems (Kornegay et al. 1991; Table 10.1, Goldman and Horne 1983). The concentrations of these cations and shifts in their relative abundance within the system affect the geochemistry of the surface water, influencing contaminant availability and the ability of the ecosystem to respond to perturbation.

Inorganic and organic constituents with the potential to pose a risk to human health or the environment were in the ranges expected, based upon previous monitoring reports (eg. Kornegay et al. 1991). The majority of potential contaminants of concern were detected between White Oak Creek and Poplar Creek on the Clinch River (reach 2) and in the Poplar Creek Embayment (reach 3), both of which drain several ORR contaminant sources. Total copper and zinc were detected in reach 2 surface waters, with values in the range previously observed for environmental monitoring (Kornegay et al. 1991). Dissolved lead, observed in samples from the Poplar Creek reference reach (reach 13), may originate from an upstream contamination source.

The Y-12 Plant, the city of Oak Ridge waste water treatment facility, and the K-25 Site operations are among the possible sources for mercury, silver, and lead in detected in reach 3. The elevated levels of cadmium and lead in the Clinch River between Poplar Creek and the Tennessee River confluence may come from several sources in and upstream from this reach.

Phase 1 values for all radiological constituents were comparable with the mean values reported for environmental monitoring (Kornegay et al. 1991) and previous-field 
investigations (Olsen et al. 1992). These values should be used with caution as they may exaggerate the ${ }^{137} \mathrm{Cs}$ concentration observed for surface water systems. The methodology used (Sect 2.2) is sensitive to low concentrations of suspended solids and tends to overrepresent any ${ }^{137} \mathrm{Cs}$ detected on the filters. Concentrations of ${ }^{137} \mathrm{Cs}$ on suspended particles should be compared only generally with those observed for surface sediments, as the latter is a much more accurate measurement.

Dissolved and particle-associated ${ }^{137} \mathrm{Cs}$ were detected in reaches 2,4 , and 5 , with values similar to those reported previously for these reaches. The dissolved ${ }^{137} \mathrm{Cs}$ detected in Poplar Creek, was possibly due to backflow from the Clinch River. Cobalt-60 in reach 5 was detected at levels comparable with those reported previously. Average ${ }^{90} \mathrm{Sr}$ values for all reaches are below levels of concern. Currently, each of these radionuclides is released from the ORR to surface waters. Though comparable with surface sediment values, these surface water radionuclides likely do not result from resuspension of surface sediments in the CR/WBR system.

High quality data confirming the contaminant concentrations observed in the scoping studies, the first objective of the Phase 1 sampling, was achieved for the limited sampling performed. Additionally the range of contaminant concentrations present in the CR/WBR system, the second objective of the Phase 1 sampling was determined, relative to the sampling conducted. The bulk of observations were comparable with those observed previously, and they did demonstrate the range of contaminant concentrations observed within the system. However, more high quality information will be collected as part of Phase 2 of the CRRI in order to determine the spatial-temporal patterns in contaminant concentrations.

Phase 1 water sampling did provide data, augmented with source monitoring data from NPDES and DOE Order 5400.1, for identification of contaminants of concern. In order to more fully support the identification of contaminants of concern, the second sampling phase must characterize the relationship between routine monitoring results and ambient surface water conditions, as well as refining the temporal-spatial concentration range for possible contaminants of concern. Contaminant concentrations from reference stations must also be assessed over time in order to provide relevance to values for contaminants of concern.

The inorganic, organic, and radiological results from these Phase 1 water samples, in combination with historic data, indicate that a greater effort must be made to characterize the Clinch River, Poplar Creek Embayment, and Kingston areas. The sampling and analysis plan for Phase 2 will have a much greater emphasis on the investigation of surface waters.

\subsection{SEDMMENT}

Many of the potential contaminants of concern identified in the screening phase of the CRRI are particle reactive and thus are associated with sediment particles; therefore, the scoping phase of the CRRI focused on identifying sediment deposition areas below the ORR. Because mercury and ${ }^{137} \mathrm{Cs}$ had known release histories and ${ }^{137} \mathrm{Cs}$ is easily analyzed, they were the only constituents analyzed in sediment during the scoping phase. The goal of the scoping phase was to identify areas of contaminated sediment accumulation in the CR/WBR. The results from the scoping phase indicated that sediment with contaminants originating from the ORR were predominantly found in the deep channel sediments of Watts Bar Reservoir. Previous studies (Oakes et al. 1982, Turner et al. 1985) also indicated that contaminated 
sediment accumulated in deep channels of the Clinch River arm of Watts Bar Reservoir. Sediment core samples during Phase 1 were collected from these deep channel areas and other suspected sediment deposition zones and analyzed for potential contaminants of concern. Because sampling occurred in areas of known contamination, the Phase 1 sampling was biased towards "hot spots" and yielded conservatively high estimates of average concentrations for reaches. These data provide the information needed to evaluate human and ecological risk on a screening level. The intent was to further focus sampling and analyses during Phase 2 to specific areas and specific contaminants.

Near-shore surface sediment characterization sampling was initiated during Phase 1 to provide the data necessary to evaluate human health risks from direct exposure to sediment. This was a concern because near-shore sediment in Watts Bar Reservoir is exposed for parts of each year, and most of the sediment disturbing activities (e.g., dredging and dock construction) occur in this zone of the reservoir. Therefore, as part of the permitting process conducted by the U.S. Army Corps of Engineers and TVA for (sediment disturbing activities), samples were collected to evaluate human health risk on a permit-by-permit basis. Near-shore sediment samples were only analyzed for gamma-emitting radionuclides. The rationale for this approach follows that of the phased approach described for the sediment sampling and analysis. If concentrations of ${ }^{137} \mathrm{Cs}$ or ${ }^{60} \mathrm{Co}$ were high enough to indicate a human health risk resulting from deposition of contaminants originating from the ORR, additional analyses would be performed to determine concentrations of the other contaminants.

\subsubsection{Discussion of Contaminants for the System}

\subsubsection{Near-shore sediment samples}

Cesium-137 was present in detectable quantities in $99 \%$ of the 487 samples that were analyzed. Cobalt -60 was present in detectable quantities in $58 \%$ of the 488 samples that were analyzed (Appendix C.3). Of all the analyses performed on these samples, less than $4 \%$ were rejected (Table 2.9). This satisfies the completeness requirement of $95 \%$ defined in the Work Plan. One limitation with this data set is that only one grab sample was collected in Norris Reservoir (reach 10); therefore, a reference concentration average was calculated from the single grab sample and the top layer $(3 \mathrm{~cm})$ of the sediment core taken in reach 10. Data from 23 grab samples from the Tennessee River above the confluence with the Clinch River (reach 18) also provide a reference for surface sediment concentrations of gamma-emitting radionuclides (Appendix C.4).

\subsubsection{Sediment cores}

Sediment cores were collected to provide data for evaluating secondary pathways of human health risk and ecological risk. The exposure pathways resulted from a dredging scenario where deep sediment is dredged and spread on the nearby land. Cores were sectioned in 3- to $6-\mathrm{cm}$ intervals and analyses were performed on each section. The summary tables report core averages and/or reach averages when more than one core was collected in a reach (Appendix C.2).

Detectable concentrations were reported for all 13 inorganic contaminants for which analyses were conducted; however, selenium, antimony, and thallium were detected in less than $30 \%$ of the samples (Appendix C.1). Some maximum values are estimates based on 
detection limits; thus, in some cases, concentrations used in the risk screening analyses may be conservatively high. The number of inorganic samples rejected was less than $12 \%$ (Table 2.9). This does not satisfy the completeness requirement defined in the Work Plan. However 9 of the 13 inorganic contaminants had less than $1 \%$ rejected samples. Antimony, mercury, selenium, and silver all had greater than $10 \%$ but less than $50 \%$ of the samples rejected.

Twenty-two of the 92 organic analytes were detected in at least one sample. Eighteen of these were detected in less than $7 \%$ of the samples. The highest percentage $(36 \%)$ of detected organics in core samples was for bis(2-ethylhexyl)phthalate, which is a plasticizer found in many environmental samples as a common artifact. Twenty percent of the samples analyzed had detectable quantities of Aroclor 1254. Fifteen percent had detectable levels of fluoranthene, $11 \%$ had detectable quantities of pyrene, and less than $7 \%$ had detectable levels of phenanthrene (Appendix C.1). Because of the small percentages of detected organic contaminants reported, minimum, maximum, and average values are almost always estimated values. These are indicated by the " $U$ " or " $U / J$ " codes in the data qualifier fields in the tables. Less than $1.0 \%$ of the semi-volatile organic analyses were rejected during the validation procedure (Table 2.9). This is well within the completeness requirement of $95 \%$ as outlined in the Work Plan. Eight percent of the PCB/pesticide organic analyses were rejected.

Samples were analyzed for alpha-emitting and gamma-emitting radionuclides. Every sample for which analysis for alpha-emitters was performed had detectable, though not always quantifiable, levels. Because of the low values observed, many of the concentrations listed in the tables are estimated from detection limits. Therefore, the risk screening analysis is based on estimated concentrations that are conservatively high. For gamma-emitters, ${ }^{137} \mathrm{Cs}$ was present in detectable quantities in $93 \%$ of the samples analyzed, and ${ }^{60} \mathrm{Co}$ was detected in $36 \%$ of the samples analyzed (Appendix C.1). Only 3\% of the radionuclide analyses were rejected during the validation procedure (Table 2.9). This is within the completeness requirements defined in the Work Plan.

\subsubsection{Discussion of Contaminants by Study Reach}

\subsubsection{Near-shore sediment samples}

Cesium-137 concentrations in the near-shore sediments follow an expected geographic trend (Fig. 3.1). Norris Reservoir (reach 10) and Melton Hill Reservoir (reach 1) show background concentrations ( 0.33 and $0.26 \mathrm{pCi} / \mathrm{g}$, respectively). The Clinch River between the White Oak Creek confluence and Poplar Creek confluence (reach 2) has the highest average concentrations and the highest individual values in the CR/WBR system. The Clinch River below Poplar Creek and above the confluence with the Tennessee River (reach 4) has a slightly lower average ${ }^{137} \mathrm{Cs}$ concentration than reach 2 . Poplar Creek (reach 3) and the Emory River (reach 6), both of which are tributaries to the Clinch River, have concentrations above background but approximately 2.5 times lower than reaches 2 and 4 . Slightly elevated levels of ${ }^{137} \mathrm{Cs}$ in these reaches are not unexpected due to the reversing flows into both Poplar Creek and the Emory River resulting from TVA reservoir operations for peak electrical power. Concentrations of ${ }^{137} \mathrm{Cs}$ in the Tennessee River arm of WBR (reach 18) are at background levels. The near-shore surface sediments in the main body of Watts Bar Reservoir (reach 5) have an average concentration below $1 \mathrm{pCi} / \mathrm{g}$, which approaches background concentration levels (NCRP 1978). 


\section{Reach}

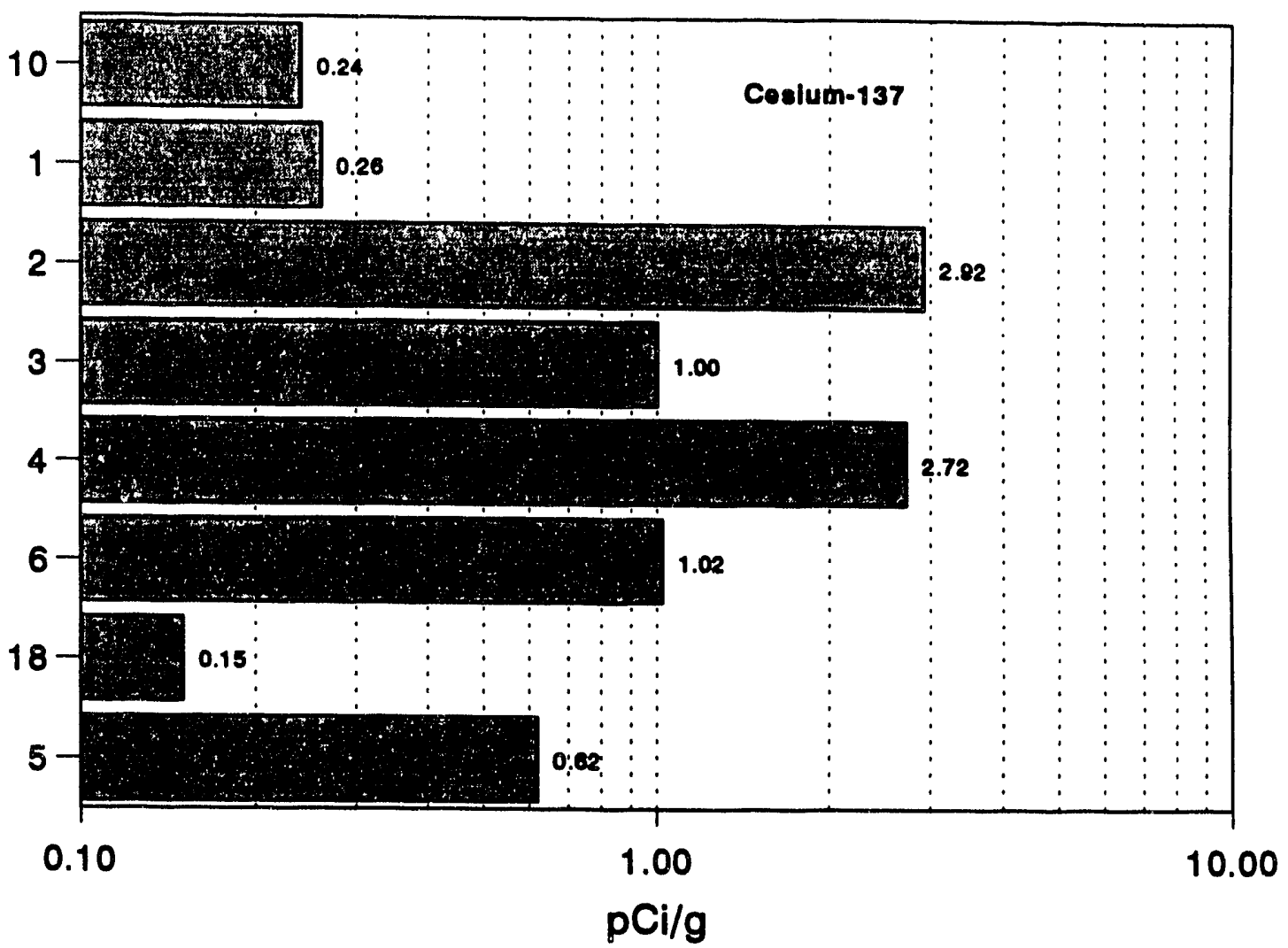

Fig. 3.1. Average ${ }^{137} \mathrm{Cs}$ concentration in surface sediment grabs within each reach. Value for reach 10 is not an average. It is the concentration of the single sample collected in this reach during Phase 1 sampling. Reaches are arranged from upstream on the top to downstream on the bottom. 
The average ${ }^{60} \mathrm{Co}$ concentrations within the study reaches show the same geographic trend as ${ }^{137} \mathrm{Cs}$, with two exceptions (Fig. 3.2). First, ${ }^{60} \mathrm{Co}$ was not detected in Norris Reservoir. Second, the average ${ }^{60} \mathrm{Co}$ concentration in reach 1 is higher than background levels. This can be explained by releases from a closed medical supply facility in Braden Branch that acts as a source within reach 1 but was not part of the ORR operations. This source is discussed in further detail in Appendix G.

\subsubsection{Core sediment samples}

Summary results for sediment cores are presented in Appendix C.2. The arithmetic averages for each reach, reported in Appendix C.2, were calculated using all sections of all cores within a reach and detection limits as actual values when concentrations were below detection limits. For the sake of comparison, if a contaminant was detected in any reach, the average concentration for that contaminant is reported for all reaches even if that contaminant was not detected in all reaches. Again, the data qualifier flags indicate if reported concentrations are estimates. Average concentrations are discussed, rather than minimum and/or maximum concentrations, because in a dredging scenario, exposure would be to well-mixed sediment. The averaging of concentrations across core sections and within reaches mathematically approximates the mixing of sediment as a result of dredging.

\section{Inorganics}

There are several spatial patterns in the distributions of average core concentrations of inorganic contaminants. These patterns are shown in Figs. 3.3 through 3.7, which portray average contaminant concentrations for sediment cores arranged along hydrologic continuum. Presenting the averages by site rather than by reach, but still along a downstream continuum, provides more insight to possible sources of contaminants and will help determine where to focus sampling during Phase 2. Arsenic (Fig. 3.3), beryllium (Fig. 3.4), chromium and copper (Fig. 3.5), and mercury (Fig. 3.6) all show a peak concentration in Poplar Creek (reach 3) or at Brashear Island immediately downstream Poplar Creek (first bar in reach 4), suggesting that Poplar Creek is a source of these contaminants into Watts Bar Reservoir. Concentrations of thallium were detected in Poplar Creek (reach 3) and in McCoy Branch (reach 7), both of which are downstream of a coal ash-pile disposal areas. Average concentrations of arsenic, beryllium, and mercury decrease in downstream sediment core samples, with some concentration averages approaching reference levels in reach 5 . Zinc (Fig. 3.3); cadmium (Fig. 3.4); and chromium, copper, and lead (Fig. 3.5) all have peak average concentrations in reach 5 (Watts Bar Reservoir). The location of these peaks suggests that there is a source of these contaminants downstream of the ORR either on the Tennessee River arm or below the confluence of the Tennessee and Clinch rivers. There are two superfund sites in Rockwood that drain into Caney Creek above the three sampling sites in reach 5. Additionally, historic metal processing operations based in Rockwood may explain the elevated levels of these metals in Watts Bar Reservoir. Industrial activities on the Tennessee River arm of Watts Bar Reservoir could also be responsible for these contaminants. Future sampling will focus on determining the source of these metals. There are no distinctive patterns in the vertical profiles of the inorganic contaminants with the exception of mercury. Concentration peaks of mercury between 40 and $80 \mathrm{~cm}$ deep are apparent in sediment cores from sites in and downstream of Poplar Creek. These peaks coincide with releases of mercury during the midto late 1950s and have been well documented by Olsen et al. (1992) and Turner et al. (1985). 


\section{Reach}

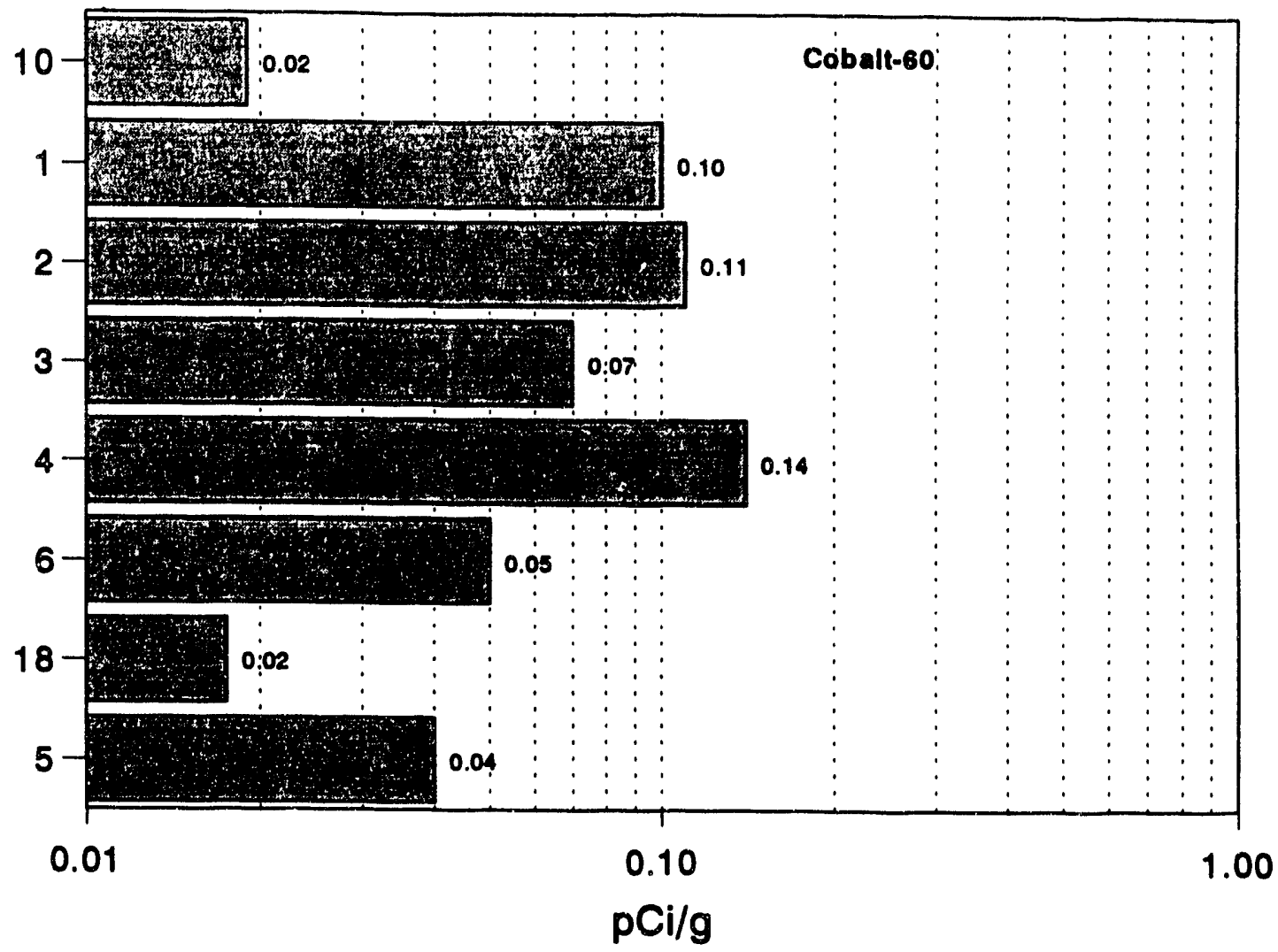

Fig. 3.2 Average ${ }^{60} \mathrm{Co}$ concentration in surface sediment grabs within each reach. Value for reach 10 is not an average. It is the concentration of the single sample collected in this reach during Phase 1 sampling. Reaches are arranged from upstream on the top to downstream on the bottom. 


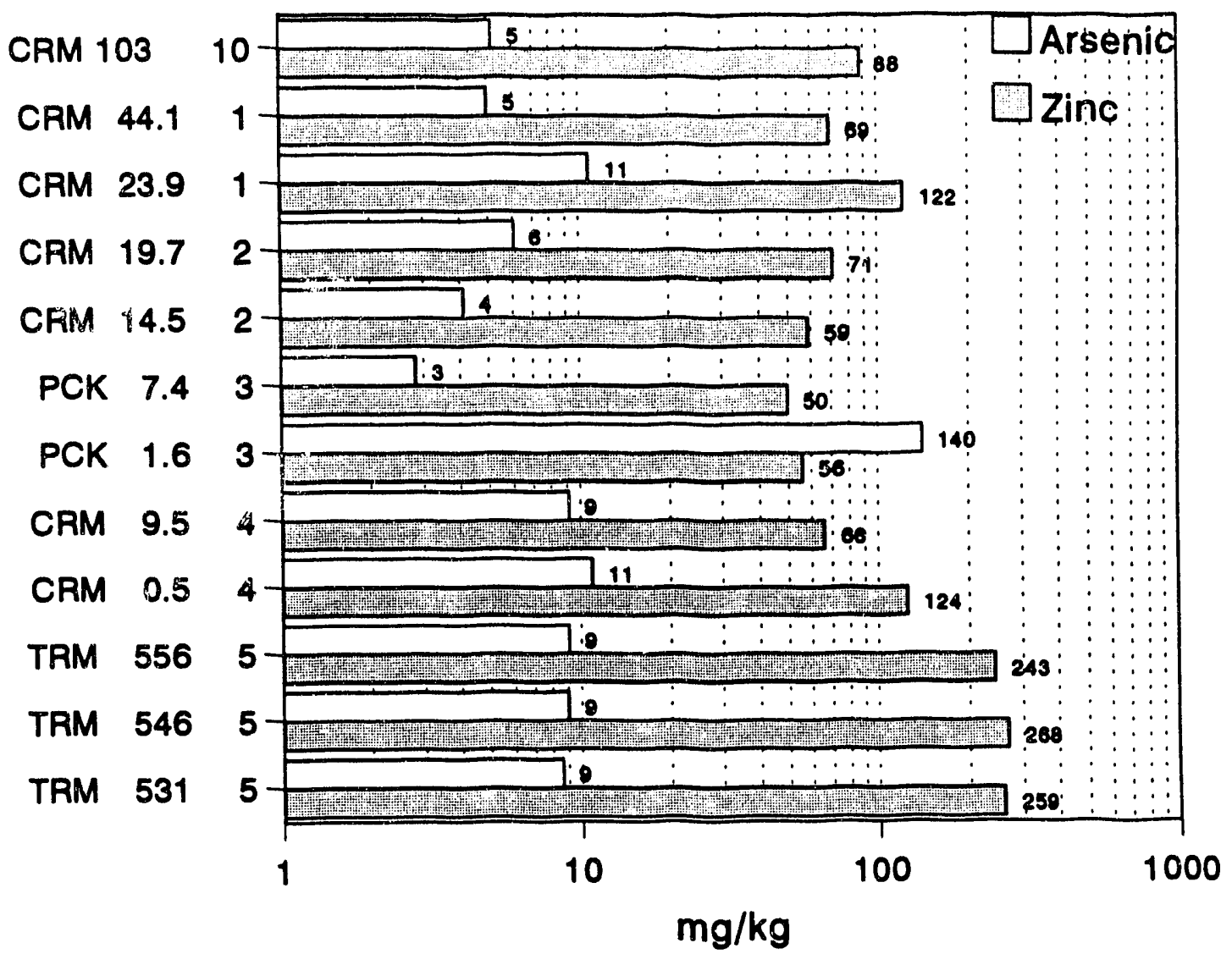

Fig. 3.3. Average concentrations of arsenic and zinc for cores sampling sites. Reaches and cores sampling sites within reaches are arranged from upstream on the top to downstream on the bottom. 


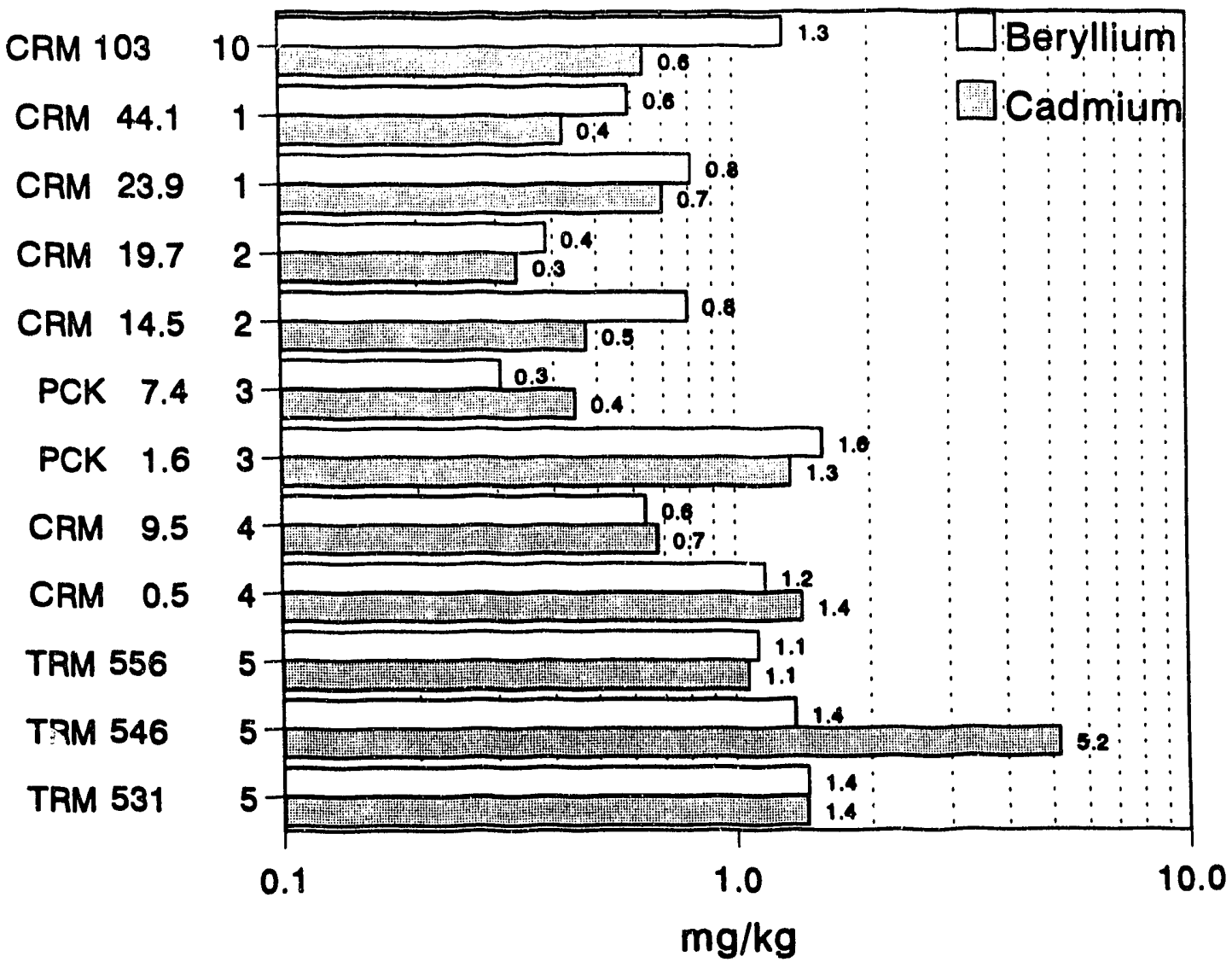

Fig. 3.4. Average concentrations of beryllium and cadmium for cores sampling sites. Reaches and cores within reaches are arranged from upstream on the top to downstream on the bottom. 


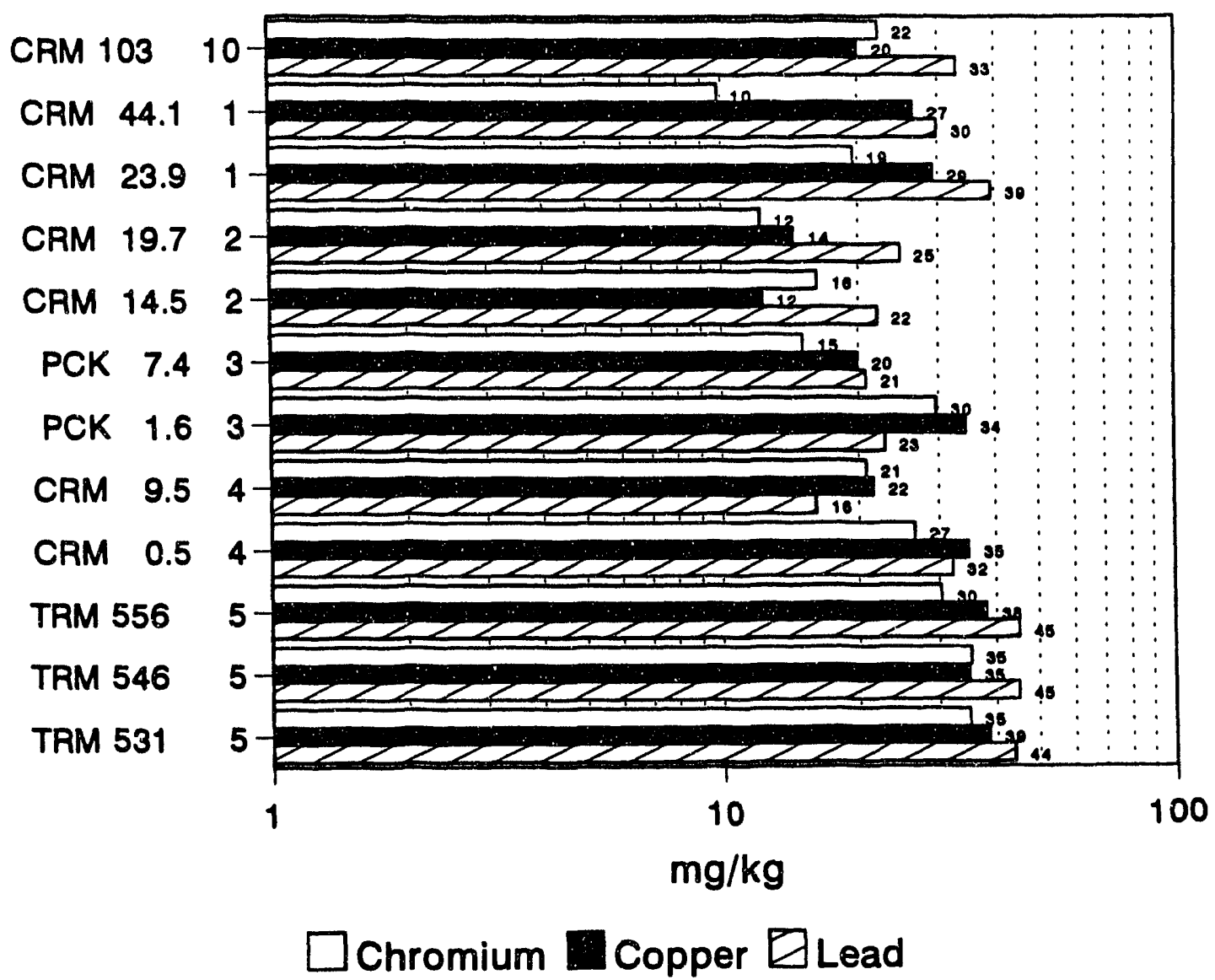

Fig. 3.5. Average concentrations of chromium, copper, and lead for cores sampling sites. Reaches and cores within reaches are arranged from upstream on the top to downstream on the bottom. 


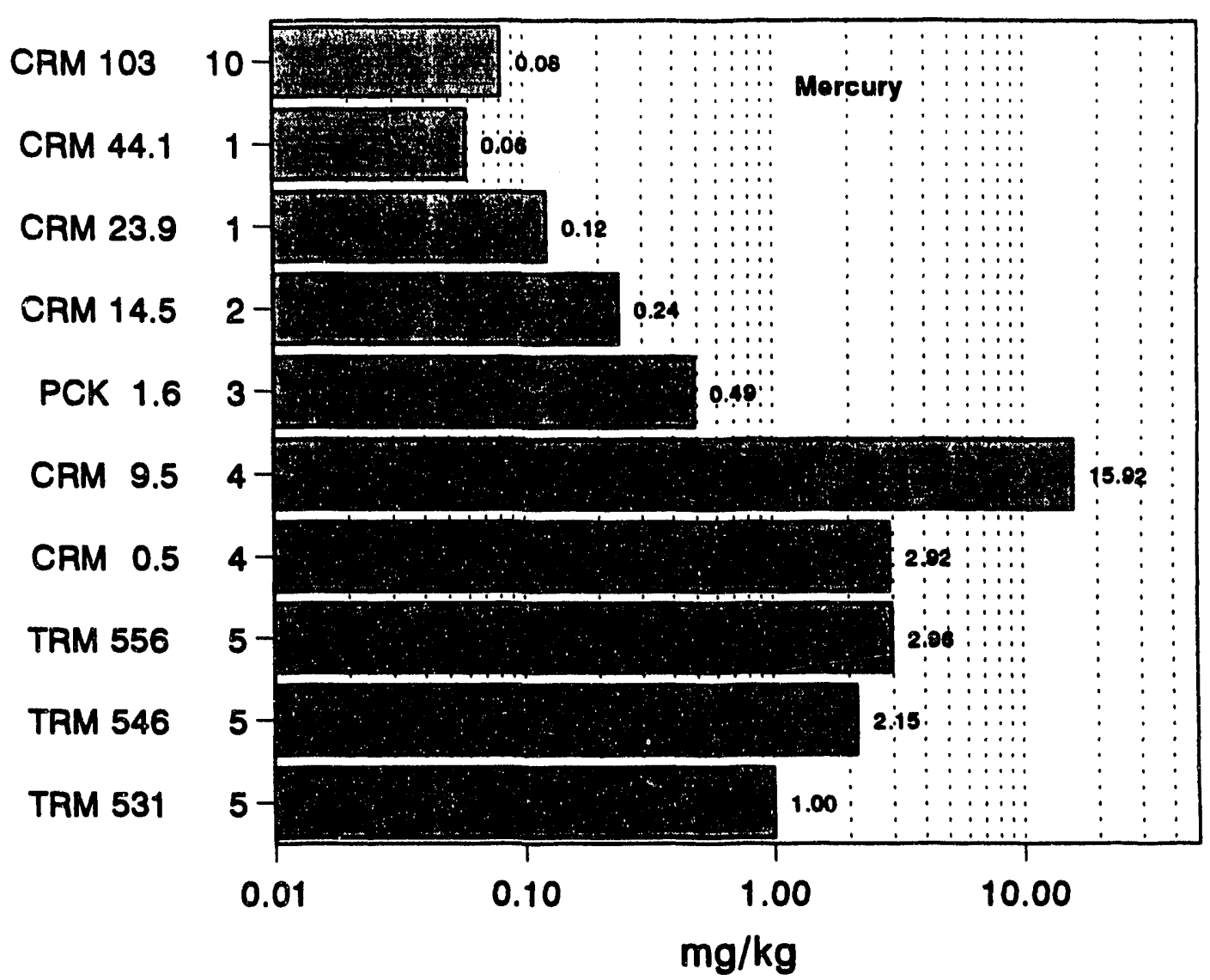

Fig. 3.6. Average concentrations of mercury for cores sampling sites. Reaches and cores within reaches are arranged from upstream on the top to downstream on the bottom. 


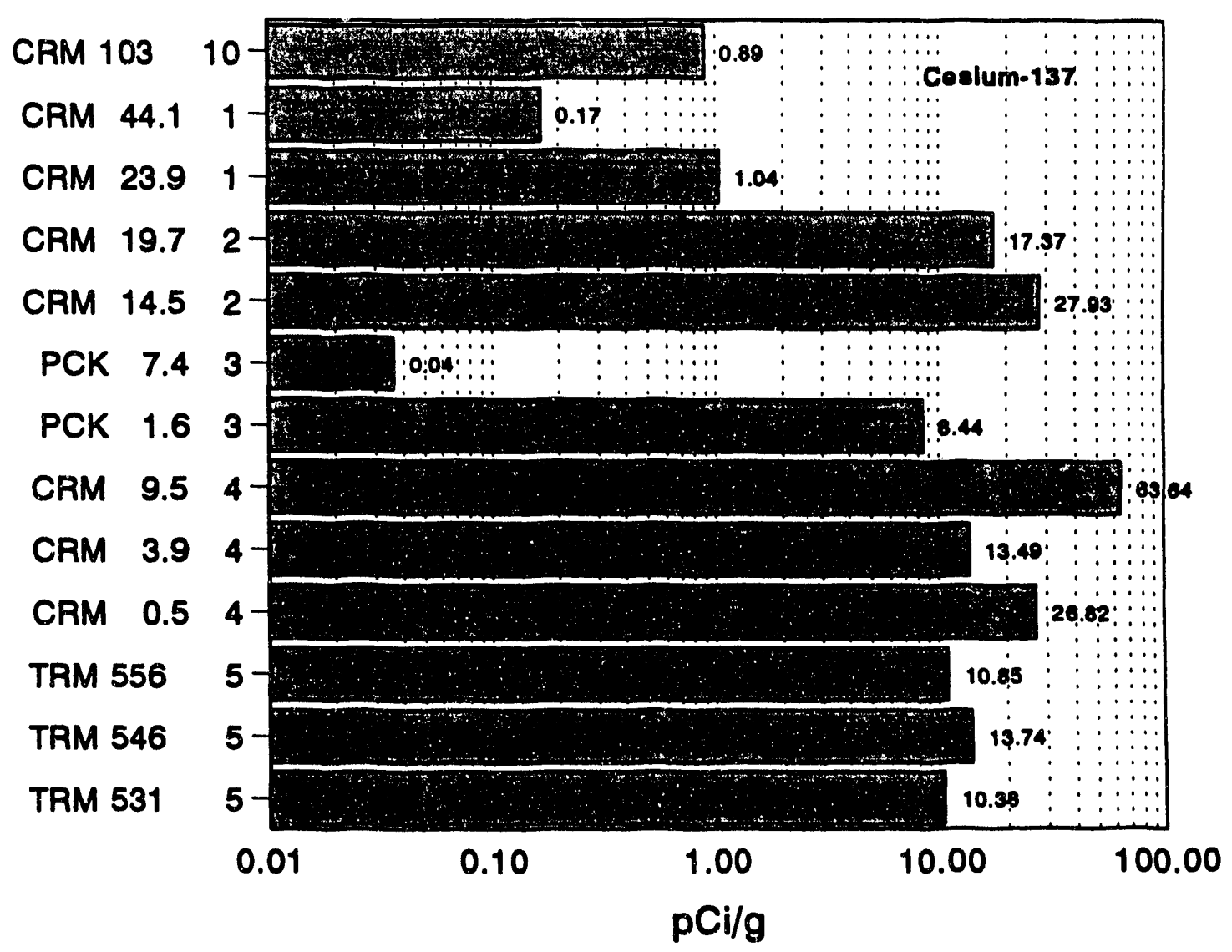

Fig. 3.7. Average concentrations of ${ }^{137} \mathrm{C}$. for cores sampling sites. Reaches and cores within reaches are arranged from upstream on the top to downstream on the bottom. 


\section{Organics}

It is somewhat difficult to interpret the concentrations of organic compounds in the sediment cores because the variability associated with individual estimated averages are often larger than the averages themselves (Appendix C.2). These large variances are a result of ambient concentrations at or below analytical detection limits and indicate generally low concentrations of organics in sediments throughout the system.

Aroclor 1254 was detected only in reaches 2 (once), 3 (twice), and 4 (51 times). Aroclor 1254 was found almost exclusively in reach 4, specifically in the core at CRM 9.5. This suggests an upstream source and could include the ORR from Poplar Creek or the municipal wastewater treatment facilities for the City of Oak Ridge or Oliver Springs. Aroclor 1260 was detected in reach 2 once.

Bis(2-ethylhexyl)phthalate was observed in detectable quantities in reaches $2,3,4,5$, and 10. This compound is a plasticizer and is commonly found in sediments in industrial countries. Flouranthene, phenanthrene, and pyrene in the CR/WBR system were detected in reach 2 and 3 and to a lesser degree in reach 4 . This implies that these compounds originated from the ORR or another upstream source. These polycyclic aromatic hydrocarbons are contaminants commonly found in streams receiving industrial effluent.

\section{Radionuclides}

All of the alpha-emitting radionuclide values for sediment cores were estimates because they were reported as being present but not in high enough concentrations to be quantifiable. Whereas average concentrations of ${ }^{254} U,{ }^{235} U$, and ${ }^{238} U$ are higher in reach 3 , the ratios of ${ }^{235} U{ }^{238} U(0.04)$ and ${ }^{234} U{ }^{238} U(1.10)$ are close to what is expected in undisturbed regions $\left({ }^{235} U{ }^{238} U=0.046\right.$ and $\left.{ }^{234} U /{ }^{23} U=1.0\right)$ (NCRP 1978, Olsen et al. 1989). Average ${ }^{90} \mathrm{Sr}$ concentrations are highest $(0.396 \mathrm{pCi} / \mathrm{g})$ in reach 3 also but are well below soil concentrations expected from fallout (1 pCi/g) (NCRP 1978). Higher concentrations of these radionuclides would be expected in Poplar Creek given the proximity to the Y-12 Plant and the K-25 Site. Sampling and analysis during Phase 2 will focus on these contaminants in Poplar Creek.

The gamma-emitting radionuclides show expected spatial trends in core average concentrations (Fig. 3.7). Background concentrations of ${ }^{137} \mathrm{Cs}$ are found in reaches 10 and 1 which are both upstream of White Oak Creek, the primary source of this contaminant. Immediately downstream of the Clinch River and White Oak Creek confluence, average core concentrations of ${ }^{137} \mathrm{Cs}$ are atove background concentrations. Poplar Creek (reach 3) shows background levels at the site just downstream East Fork Poplar Creek and slightly elevated concentrations at the lower site, which is influenced by backflow from the Clinch River and the K-25 coal-fired power plant which took Clinch River water for cooling and discharged it into Poplar Creek. The highest average concentration and individual concentration are found at the Brashear Island core. This area is the first major depositional zone downstream of White Oak Creek and Poplar Creek. Average ${ }^{137} \mathrm{C}$ s concentrations drop downstream but remain above background levels. It is important to recognize that the concentrations in the surface layers for these samples are relatively low and that the averages are dominated by large peak ${ }^{137} \mathrm{Cs}$ concentrations that are typically 50 to $80 \mathrm{~cm}$ deep in the sediment (Olsen et al. 1992). These peaks are associated with relatively large releases of ${ }^{137} \mathrm{Cs}$ from White Oak Lake in the mid- to late 1950s (DOE 1988). 
Average concentrations of ${ }^{60} \mathrm{Co}$ follow a similar trend as ${ }^{137} \mathrm{Cs}$ concentrations except for slightly higher levels in reach 1 (Fig. 3.8). However, because ${ }^{60} \mathrm{Co}$ was detected in only $36 \%$ of all samples, many of the concentrations reported in Appendix $\mathrm{C}$ are estimates based on detection limits. These higher concentrations probably result from releases from the off-site medical equipment productions facility discussed in Appendix G.

\subsubsection{Summary}

Concentrations of ${ }^{137} \mathrm{Cs}$ in near-shore surface sediments in Norris, Melton Hill reservoirs, and the Tennessee River arm of Watts Bar Reservoir represent background levels $(<1.0)$ because they are upstream of ORR and only received radioactive fallout from atmospheric testing of nuclear weapons. Concentrations in Poplar Creek and the Emory River average 1 $\mathrm{pCi} / \mathrm{g}$, which is consistent with background concentrations. Cesium-137 concentrations in the near-shore surface sediments in the Clinch River arm of Watts Bar reservoir are between 2.7 and $3 \mathrm{pCi} / \mathrm{g}$. Concentrations in Watts Bar Reservoir below the confluence of the Tennessee and Clinch rivers are below $1 \mathrm{pCi} / \mathrm{g}$, again within background concentrations. To date, no sediment disturbance permit that was evaluated by TVA, ACOE, and DOE were rejected on the basis of radiological contamination. Three sites within the Clinch River arm of Watts Bar Reservoir had concentrations between 10 and $34 \mathrm{pCi} / \mathrm{g}$ and will be targeted for sampling and analysis during Phase 2 of the CRRI. Samples collected at these areas will be analyzed for the contaminants identified by the risk screening as requiring further research.

Patterns of inorganic contaminants in sediment core samples indicate that there are multiple sources for these contaminants. Arsenic, beryllium, cadmium, chromium, copper, and mercury in Poplar Creek and the downstream portion of the Clinch River arm of Watts Bar Reservoir appear to be originating, at least in part, from Poplar Creek. Mercury releases from the Y-12 processing plant into Poplar Creek are well documented (Olsen et al. 1992, Turner et al. 1985). Other inorganic contaminants likely result from disposal of coal fly-ash material and photographic processing chemicals from the K-25 Site or the municipal wastewater treatment facilities for the cities of Oak Ridge and Oliver Springs. Concentrations of cadmium, lead, and zinc are higher in the sediments in Watts Bar Reservoir below the confluence of the Tennessee River and Clinch River arms, suggesting that there is a source of these contaminants either within the Tennessee River arm of the reservoir or below the confluence of the two rivers. Phase 2 sampling and analysis will focus on locating areas where concentrations of these contaminants are above acceptable levels.

The lack of detectable quantities of most of the 92 organic chemicals for which analyses were conducted allows significant reduction of the list of organic contaminants to be studied. Flouranthene, phenanthrene, and pyrene were found almost exclusively in the Clinch River arm of Watts Bar Reservoir. Aroclor 1254 was only found at CRM 9.5, which is immediately downstream of Poplar Creek. Likely sources for these contaminants are the Y-12 Plant, the K-25 site, or the municipal wastewater treatment facility. Sampling and analysis for these contaminants in Poplar Creek and the Clinch River arm of Watts Bar Reservoir will continue in Phase 2 with the objective of identifying and delineating any areas requiring remediation.

Quantities of alpha-emitting radionuclides were at or near background concentrations for almost every site sampled. Concentrations of ${ }^{234} U,{ }^{235} U$, and ${ }^{238} U$ in Poplar Creek were above background levels. Poplar Creek will be the focus of study for these contaminants during Phase 2 activities. 


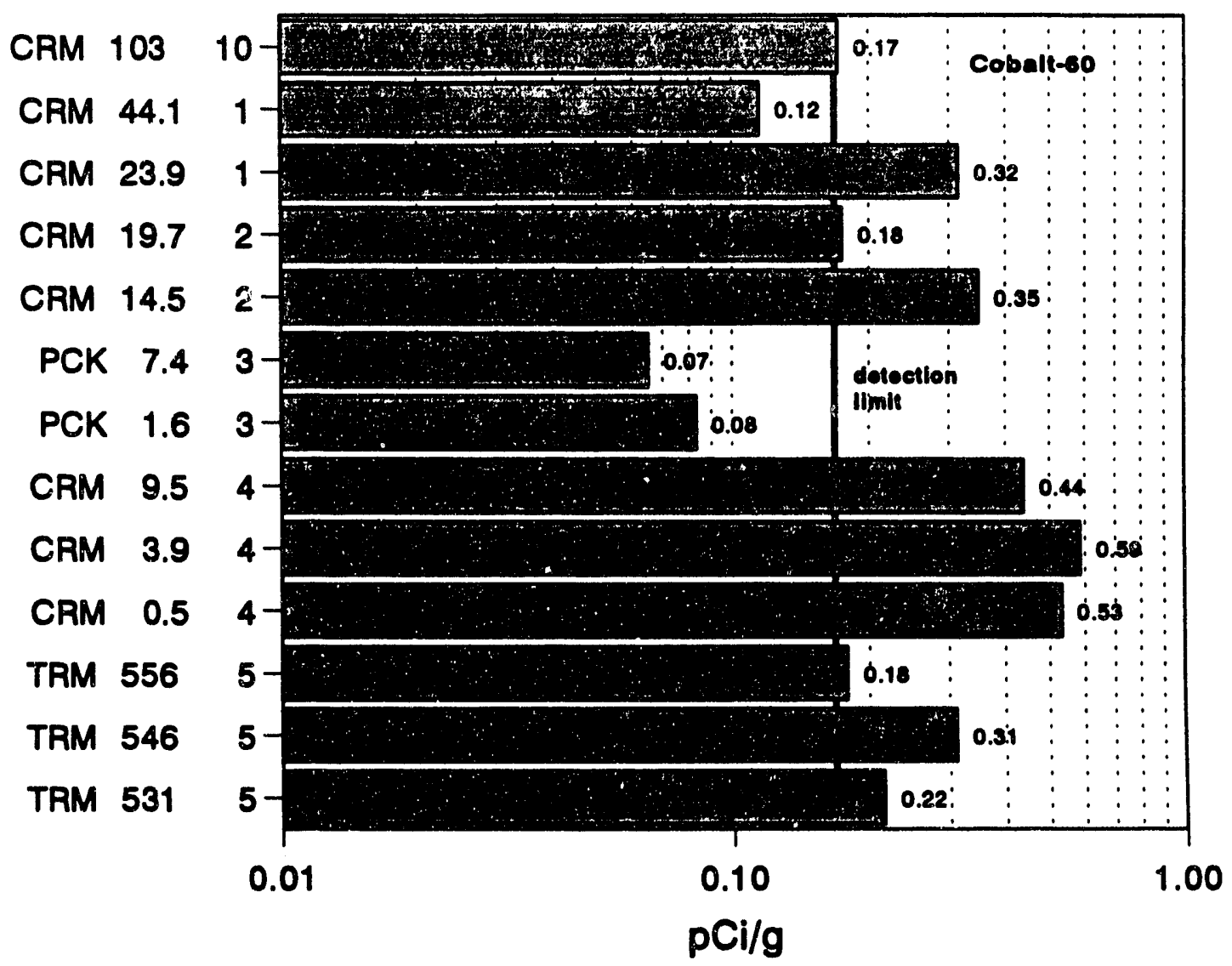

Fig 3.8. Average concentrations of ${ }^{\infty} \mathrm{Co}$ for core sampling sites. Reaches and cores within reaches are arranged from upstream on the top to downstream on the bottom. 
Phase 1 sediment sampling and analysis was conducted to:

- Obtain high quality data to confirm or modify existing data for contaminant levels in sediment.

This goal was met. Results from Phase 1 are consistent with previous studies (Olsen et al. 1992, Ashwood et al. 1986, and Oakes et al. 1982). Patterns of organics and radionuclides concentrations were similar to previous studies. Inorganic concentrations in Poplar Creek were found to be somewhat lower than previous studies indicated (Ashwood et al. 1986).

- Determine the range of contaminant concentrations present in the system.

This goal was met. We now have a working knowledge of concentrations levels of contaminants throughout the system.

- Identify contaminants of concern.

This goal was met. The Risk Analysis sections (Sect. 4.1 and 4.2) discuss this in detail. However, Phase 1 results allowed the list of contaminants of concern to be reduced significantly. Phase 1 data also strengthens level of confidence for establishing low- and highpriority contaminants.

- Establish reference (background) concentrations for contaminants.

This goal was partially met. Whereas Phase 1 sampling and analysis results provide some insight to reference concentrations, statistical comparability is not yet possible for sediment core data. Additional sampling and analysis during Phase 2 to provide the necessary reference data is the highest priority.

\subsection{FISH ANALYSIS}

In order to characterize the nature and extent of contamination in the principal biota of the CR/WBR system, three species of fish representing different trophic levels were sampled during the fall of 1989 and spring of 1990 . Sampling included 126 bluegill sunfish, 119 channel catfish, and 43 largemouth bass. Sampling was conducted at 15 sites throughout the CR/WBR system in order to (1) bracket the entire geographic extent of this system into the sampling design and (2) focus on certain areas of the CR/WBR system such as the upper Clinch River below Melton Hill Dam and Poplar Creek where certain contaminants were known to be elevated. Results of the contaminant analysis in these three species of fish are summarized for all sites combined and individually by site.

The data validation process documented the quality of the data and determined that most of it (>95\% of the metals, PCBs/pesticides, and radionuclides) met the quality standards established by the CR-ERP (see Table 2.9). One exception was the analysis of semivolatiles which was found to be deficient a large portion of the time, resulting in the rejection of nearly $50 \%$ of those results. The proportion of semivolatiles that was judged acceptable included very few detectable results, and is probably not of sufficient quantity to meet the program objectives without additional sampling. 


\subsubsection{Discussion of Contaminants for the System}

Appendix D (Table D.1) summarizes the results of the fish analyses for all sites combined. Of the 77 organic and 13 inorganic analytes, a majority (63 organics and 7 inorganics) were not detected at any site. Of the radionuclides, only ${ }^{137} \mathrm{Cs},{ }^{60} \mathrm{Co}$, and ${ }^{90} \mathrm{Sr}$ were detected. Four analytes were rarely detected, occurring in less than $5 \%$ of the samples. Seventeen analytes were detected in more than 5\% of the samples, with only three of those $\left({ }^{90} \mathrm{Sr}\right.$, mercury, and zinc) detectable in all samples.

If either of the Aroclors was not detected, the detection limit value was included in the sum. Total PCB was calculated by summing the reported values of Aroclor 1254 and Aroclor 1260. Total chlordane was calculated by summing the concentrations of the detectable chlordane congeners. The six congeners measured in this study were $\alpha$-chlordane, $\gamma$ chlordane, $\alpha$-chlordene, $\gamma$-chlordene, chlordene, and oxychlordane. At least one chlordane congener and one Aroclor were detected in every sample submitted for analysis; therefore, total chlordane and total PCB were considered to be detected $100 \%$ of the time. Both total PCB and the individual Aroclors were included in further analysis because of possible point source differences for the two congeners.

Because a preliminary risk assessment was performed on historical contaminant data from the CR/WBR (Hoffman et al. 1991), a comparison of the Phase 1 data with the historical data provides a preliminary indication of any new areas of concern regarding contaminant concentrations and human health risk. Of the 24 detected analytes in Phase 1, four were not reported in the historical database (Hoffman et al. 1991): bis(2-ethylhexyl)phthalate, di-noctylphthalate, aldrin, and 4,4'-DDE. Bis(2-ethylhexyl)phthalate and di-n-octylphthalate were detected in only one sample each. Although bis(2-ethylhexyl)phthalate was not previously detected in tish, it was detected in the sediment in past studies. According to the analytical chemists who performed the analyses, aldrin, 4,4'-DDE, and 4,4'-DDD values are suspect because of the difficulty involved in measuring these compounds when high levels of PCB and chlordane are present (personal communication, L. Wachter, May 31, 1990). Four of the analytes that were reported at detectable levels in the historical data but that were not detected in the Phase 1 sampling are antimony, chromium, silver, and thallium.

\subsection{Discussion of Contaminants by Study Reach}

A summary of the concentrations of those analytes that were detected at least once is found in Appendix D (Table D.2). For the most part, the Phase 1 maxima are lower than those from the historical data which were summarized by reach in Hoffman et al. (1991). Maximum values of mercury in fish collected in Phase 1 were higher than historical values only at reach 5 , and at no sites did the maximum mercury concentration exceed the Food and Drug Administration's (FDA's) action level of $1.0 \mathrm{mg} / \mathrm{kg}$ or EPA's acceptable fish tissue concentration which is also $1.0 \mathrm{mg} / \mathrm{kg}$. Selenium maxima exceeded historical values in reaches 2 and 3; Aroclor 1260 maxima exceeded historical values in reaches 3 and 4 . Aroclor 1260 maxima exceeded the FDA action level of $2.0 \mathrm{mg} / \mathrm{kg}$ at five sites in reaches 2,3 , and 4, but average values did not exceed $1.0 \mathrm{mg} / \mathrm{kg}$ at any site or within any reach. Maximum and average values of both Aroclors 1260 and 1254 exceeded the EPA's $10^{-6}$ cancer risk concentration of $0.0014 \mathrm{mg} / \mathrm{kg}$ at all sites. 
Because fish are mobile organisms (some species more than others), the degree to which their contaminant body burden is representative of the site in which they were collected from may be highly dependent on how long they have been residents of that area and the heterogeneity in contaminant concentrations in the surrounding environment. This along with other factors (e.g., such as size and diet) can contribute to a high degree of variability in a sample of several fish from a single site. A large amount of variation within sites is evident in both the mercury and the Aroclor 1260 results in the Phase 1 data (see standard deviations in Table D.2). The greatest variation in mercury concentrations within a site occurred in Poplar Creek at PCK 9.6 (Hartland Bridge upstream of the influence of ORR) and PCK 8.6 (mouth of EFPC). Because of the short distance between Hartland Bridge and EFPC (the source of mercury to Poplar Creek) the occurrence of a few fish with high mercury concentrations at Hartland Bridge can probably be explained by the movement of fish from the lower contaminated reaches of Poplar Creek into the upstream areas. The Hartland Bridge site was originally chosen as a potential reference site, but given this information, it should not be considered as a reference outside of the influence of releases from ORR.

The spatial distributions of total chlordane, total PCBs, mercury, and ${ }^{137} \mathrm{Cs}$ in fish are illustrated in Figs. 3.9 through 3.12, respectively. Concentrations of ${ }^{137} \mathrm{Cs}$ and mercury in fish are elevated at sites downstream of known sources of these contaminants, White Oak Creek and East Fork Poplar Creek, respectively. No such patterns of downstream gradients of chlordane or PCBs in fish are evident.

There are only a few analytes for which mean concentrations at any of the study sites exceeded those of the reference site (Norris Reservoir) by more than a factor of 2: mean mercury concentrations at two of the Poplar Creek sites and at Brashear Island, and mean copper levels at mid Watts Bar. Elevated levels of mercury at Poplar Creek and Brashear Island are not unexpected since the main source of mercury to the CR/WBR is the Y-12 facility via East Fork Poplar Creek (EFPC). Copper values are somewhat suspect for two reasons. First, elevated copper was detected at only one site in the entire system, and one fish had an abnormal concentration of $170 \mathrm{mg} / \mathrm{kg}$. Second, copper is a well-regulated nutrient element which does not accumulate in muscle tissue even when exposure concentrations are high (Benoit 1975). Total chlordane concentrations were more than twice the reference values at nearly every site, while Aroclor 1254 and Aroclor 1260 concentrations at the affected sites ranged from 3 to 33 times higher than reference concentrations.

Using pairwise statistical tests, we compared the mean concentrations of detected analytes from each CR/WBR site with the reference site. When the data are from censored distributions, the usual analysis-of-variance techniques for comparing equality of the means of $\mathbf{k}$ distributions do not apply. However, if there are some a priori comparisons of particular sites that are of interest (e.g., each affected site with the reference site), a z-test can be used. Because this comparison was made with the means of two lognormal distributions, a statistical procedure was developed especially for this analysis (Appendix D).

The results of these site-to-reference comparisons are summarized in Table 3.1. Arsenic concentrations were significantly $(P<0.05)$ highel han concentrations at the reference site at only one location (Kingston Park). Mercury concentrations were predictably higher than those of the reference sites in Poplar Creek below the confluence with EFPC and at the first site downstream of the confluence of Poplar Creek and the Clinch River (Brashear Island). 
Site Reach

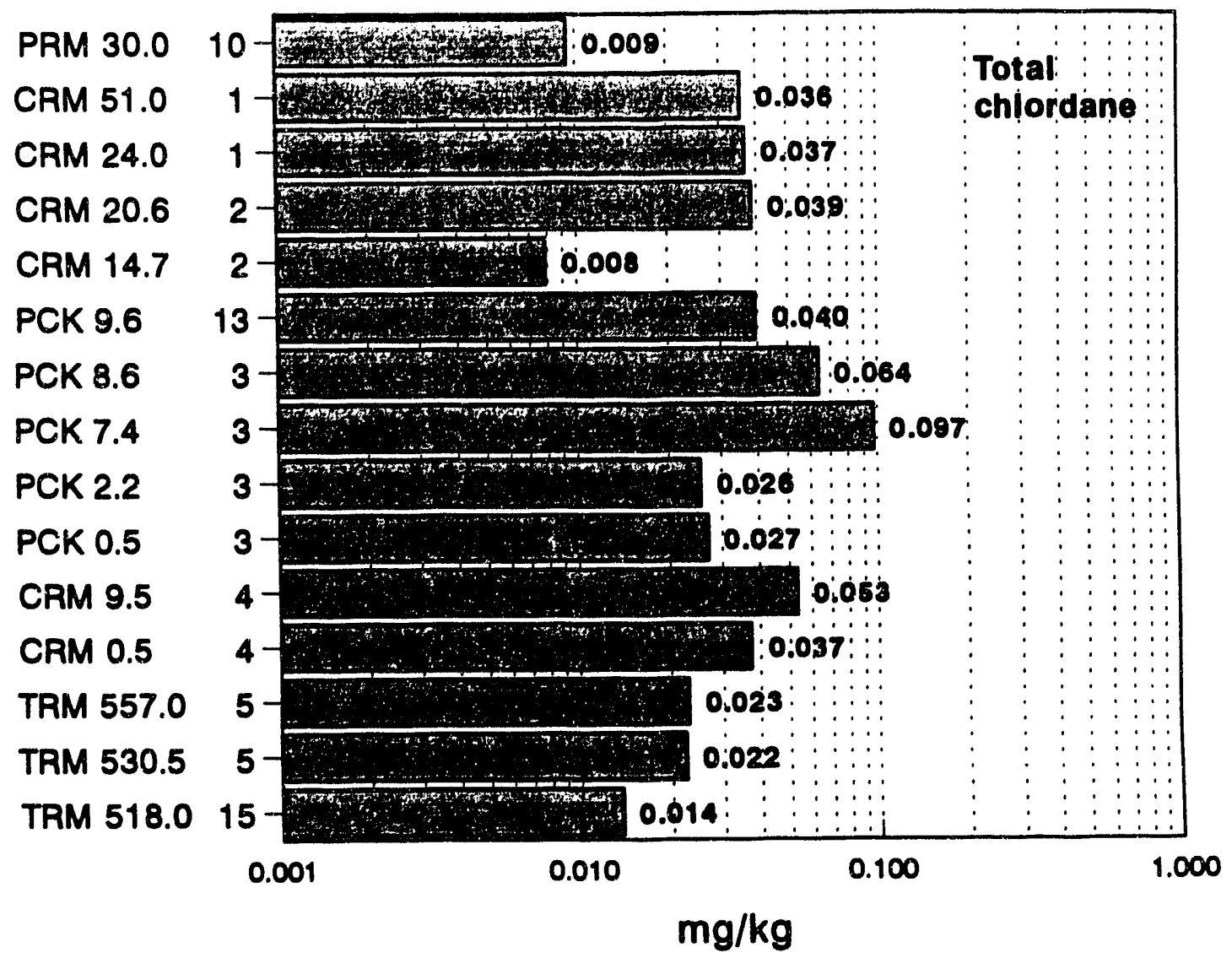

Fig. 3.9. Arithmetic mean concentrations of total chlordane in Clinch River/Watts Bar fish tissue for all sample sites. 


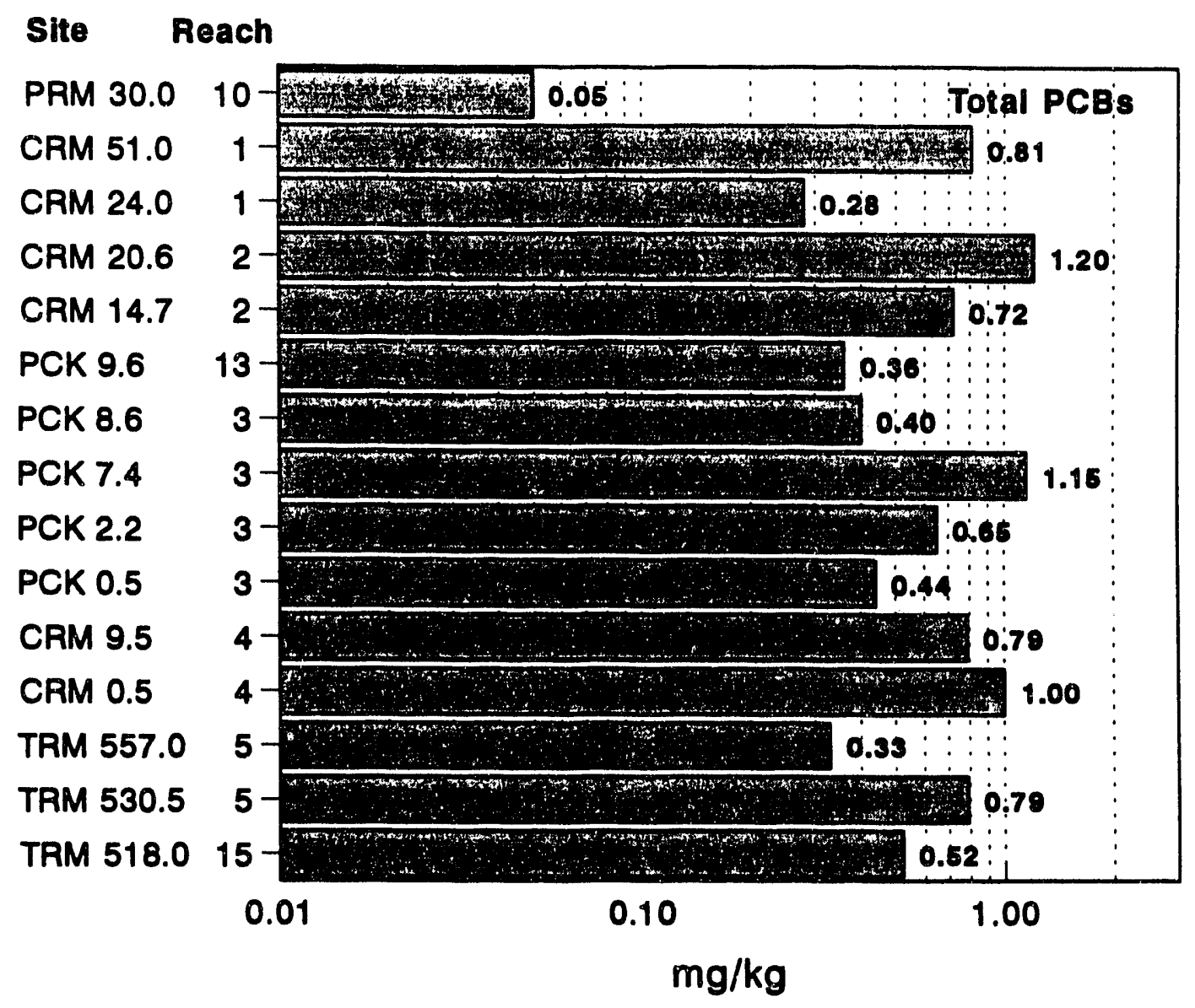

Fig. 3.10. Arithmetic mean concentrations of total PCBs in Clinch River/Watts Bar fish tissue for each site sampled in Phase 1. 


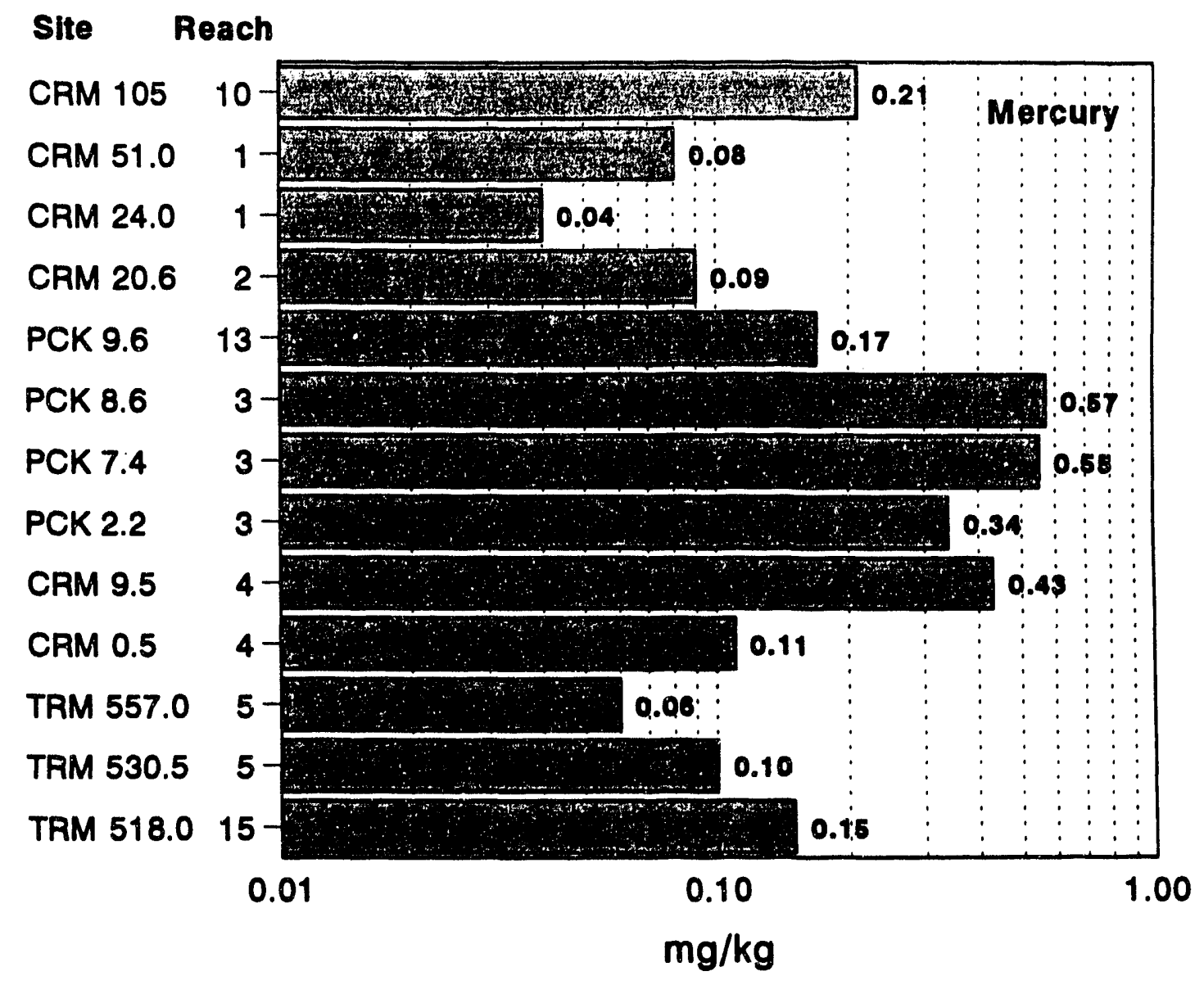

Fig. 3.11. Arithmetic mean concentrations of mercury in Clinch River/Watts Bar fish tissue samples from each Phase 1 site. 


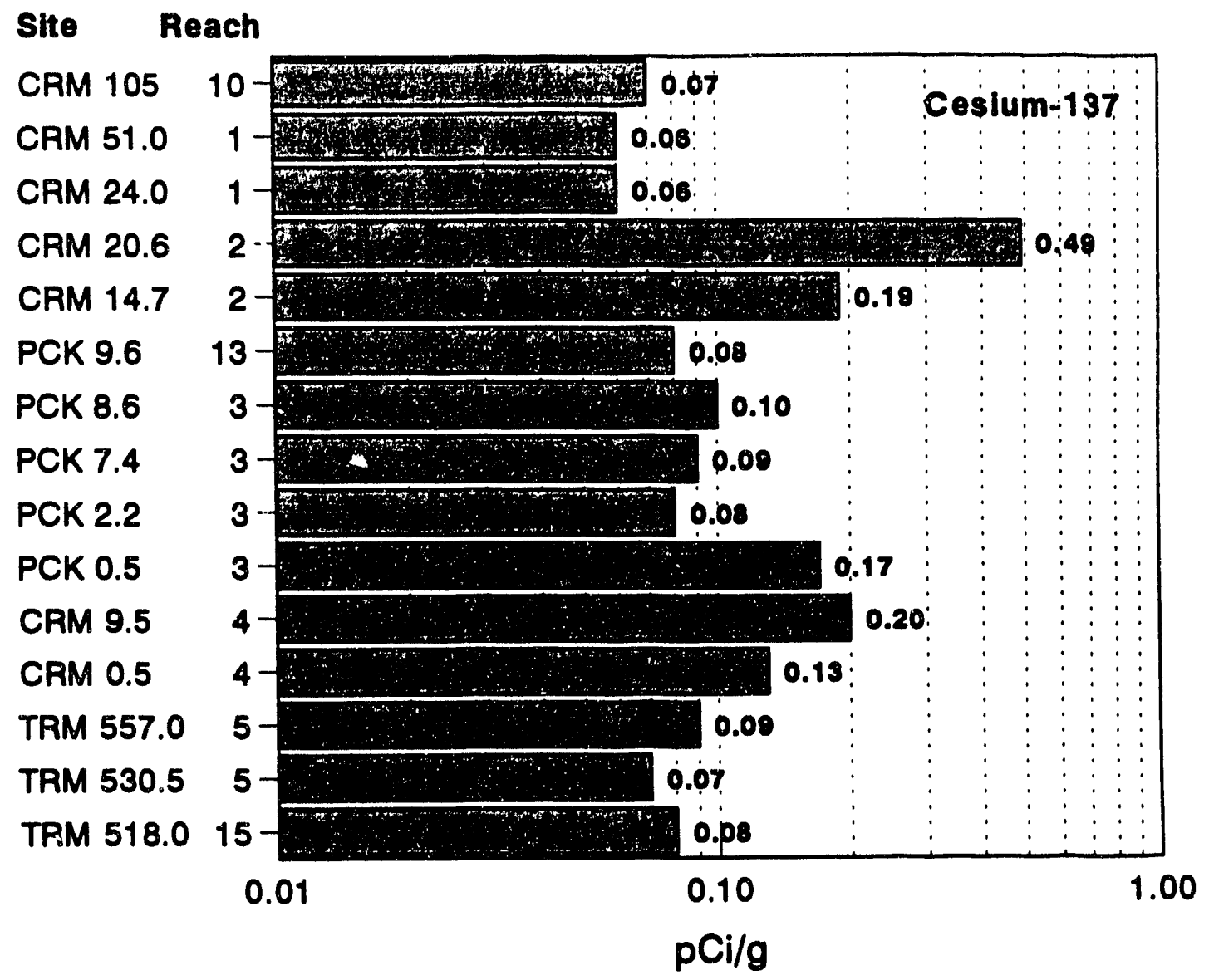

Fig 3.12 Arithmetic mean concentrations of ${ }^{137} \mathrm{Cs}$ in Clinch River/Watts Bar fish tissue sampled from each Phase 1 site. Fish analyzed for ${ }^{137} \mathrm{Cs}$ from reach 10 were collected from the Powell River arm of Norris Reservoir (PRM 30) as well as the Clinch River arm. 
Table 3.1. Summary of study site-to-reference site comparisons for fish tissue results"

\begin{tabular}{|c|c|c|c|c|c|c|c|c|c|}
\hline Affected site & As & $\mathrm{Hg}$ & $\mathrm{Se}$ & $\mathrm{Zn}$ & $\begin{array}{c}\text { Aroclor } \\
1254\end{array}$ & $\begin{array}{c}\text { Aroclor } \\
1260\end{array}$ & $\begin{array}{l}\text { Total } \\
\text { PCB }\end{array}$ & $\begin{array}{c}\text { Total } \\
\text { chlordane }\end{array}$ & $1+2$ \\
\hline 2 Upper Melton Hill & & & $* *$ & $* *$ & & $* *$ & $* *$ & $* *$ & $*$ \\
\hline 3 Lower Melton Hill & & & $* *$ & $* *$ & $* *$ & $* *$ & $* *$ & $* *$ & \\
\hline 5 Jones Island & & & $* *$ & & $* *$ & $* *$ & $* *$ & $* *$ & $* *$ \\
\hline 6 Grassy Creek & - & - & - & - & & ** & $* *$ & & $* *$ \\
\hline $7 \mathrm{PC} /$ Hartland $\mathrm{Br}$. & & & & $* *$ & & $* *$ & $* *$ & & ** \\
\hline 8 PC/EFPC mouth & & $* *$ & & & $* *$ & $* *$ & $* *$ & $* *$ & ** \\
\hline 9 PC/Mitchell Br. & & $* *$ & & & $*$ & $* *$ & $* *$ & $* *$ & $* *$ \\
\hline $10 \mathrm{PC} / \mathrm{K}-1007$ & & $* *$ & & $* *$ & * & $* *$ & $* *$ & $* *$ & *** \\
\hline 11 PC embayment & - & - & - & - & $* *$ & $* *$ & $* *$ & $* *$ & $\mathbf{a}$ \\
\hline 12 Brashear Island & & $* *$ & $* *$ & & & $* *$ & $* *$ & $* *$ & $* *$ \\
\hline 13 Kingston Park & $*$ & & & & $* *$ & ** & $* *$ & $* *$ & $* *$ \\
\hline 14 Mid Watts Bar & & & & & $*$ & $* *$ & $*$ & & $* *$ \\
\hline 15 Lower Watts Bar & & & & $*$ & $* *$ & $* *$ & $* *$ & $*$ & $* *$ \\
\hline 16 Chickamauga Res. & & & & & $* *$ & $* *$ & $* *$ & & \\
\hline
\end{tabular}

aAnalysis type was either z-test or confidence interval (CI) comparison as described in Appendix D (Pairwise Statistical Comparison). Final result was either (") - concentrations from affected site significantly higher than reference site at $0.01<P<0.05,\left({ }^{\circ}\right)$ - concentrations from affected site significantly higher than reference site at $P<0.01$, (a) concentrations from study site apparently higher than reference site based on $\mathrm{Cl}$ comparison, or (no symbol) no apparent difference in concentrations from study site and reference site. A dash $(-)$ means no fish were analyzed for that anatyte at that site. As, $\mathrm{Hg}_{\mathrm{g}} \mathrm{Se}$, and $\mathrm{Zn}$ values were from bluegill and bass onty, Aroclor 1254, Aroclor 1260, total $\mathrm{PCB}$, total chlordane were from catish only; and ${ }^{17} \mathrm{C}$ was from all three species.

Selenium concentrations were higher than the reference site concentrations in main channel sites in the upper part of the CR/WBR (Upper Melton Hill to Brashear Island). Zinc concentrations at 5 of the 12 sites were higher than the those at the reference site, but no obvious spatial distribution was evident. Chlordane concentrations were higher than reference concentrations from Upper Melton Hill to Kingston Park. Total PCB concentrations at all affected sites were ${ }^{1}$ ingher than the reference site concentrations. At nearly all sites, ${ }^{137} \mathrm{Cs}$ levels for all species were higher than the reference site levels and especially below the White Oak Creek confluence with the Clinch River.

\subsubsection{Summary}

The sampling plan for fish in Phase 1 of the CRRI was designed to characterize the extent of contamination in some major fish species in the CR/WBR system. The extent to which Phase 1 objectives as described at the beginning of this section were achieved is summarized below.

1. Data validation/verification exercises indicated that a majority of the data was acceptable for site characterization. At least $95 \%$ of the analyses performed for inorganic, $\mathrm{PCBs} /$ pesticides, and radionuclide analyses were judged acceptable by the validators. Analyses of semivolatiles were less reliable; nearly $50 \%$ were rejected due to validation deficiencies. Based on the acceptable data, a majority of the 90 plus analytes were never or rarely 
detected. Except for aldrin, 4,4'-DDE (which are possible analytical artifacts) and the two organic compounds detected once each, the Phas 21 study did not identify any contaminants in fish tissue that were not already known from previous studies. In addition, of those analytes that were detected during Phase 1 , concentrations were not markedly higher than those reported historically. The Phase 1 data set is markedly more complete and accurate than the historical data, however, and allows a much more comprehensive characterization, particularly on a spatial basis, of biota contamination in the CR/WBR system. Since the semivolatile data set was not complete, more samples should be collected for analysis of those compounds to support the finding that semivolatiles are rarely detected in fish tissue.

2. The data provided preliminary information on the spatial distribution of several contaminants in fish. Some of the contaminants (PCBs and chlordane) are widespread throughout the system and have no apparent spatial relationship to ORR. While others (mercury and ${ }^{137} \mathrm{Cs}$ ) show a distinct relationship between downstream concentrations and distance from known contaminant sources. This information suggests that future sampling should be concentrated in those areas nearest ORR, Poplar Creek and the Clinch River arm of Watts Bar Reservoir.

3. Most of the data resulting from the analysis of fish samples was of sufficient quantity and quality for the screening risk assessment. The quality of the analysis of some pesticides (aldrin, DDT, and DDE) and copper are questionable, and these should be reinvestigated in future sampling. A discussion of the refinement of the contaminants of concern list will be reported in the risk assessment section of this document.

4. Fish samples collected from Norris Reservoir, the primary reference site, provided enough quality data for a preliminary characterization of that area. A pair-wise statistical analysis that compared the Norris Reservoir results to those of the study sites found that mercury, selenium, zinc, total chlordane, PCBs, and ${ }^{137} \mathrm{Cs}$ occur at some of the CR/WBR sites at significantly higher concentrations than at the reference site. Samples were also collected from a site in Reach 13 (Poplar Creek upstream of the influence of ORR, PCK 9.8) for evaluation as an additional reference site. After evaluation of the data, the usefulness of this site as a reference site for fish is questionable. Although the site is upstream of any ORR contamination sources, it is close enough to the mouth of EFPC that fish could move into the upstream site after residing in contaminated areas downstream. Other reference areas should be sampled in Phase 2 to better characterize background concentrations of contaminants of concern. 


\section{SCREENING RISK ASSESSMENT}

\subsection{SCREENING ASSESSMENT FOR HUMAN EXPOSURE}

\subsubsection{Approach}

The objective of the screening assessment, which is based on human health risk methodology, is to utilize data collected in Phase 1 of the CRRI to (1) identify reaches and contaminants that are high priority for further evaluation and (2) identify reaches and contaminants that have a low priority for further investigation.

The screening approaches used in this assessment are similar to those employed in Hoffman et al. (1991), Blaylock et al. (1992a), and Blaylock et al. (1992b) reports. The first approach is the use of conservatively biased calculations to identify contaminants, exposure pathways, and reaches that have a low priority for further investigation. It is unlikely that these conservative calculations will underestimate the potential maximum exposures to an individual residing in the vicinity of the CR/WBR, which receives releases from the ORR. The second approach uses nonconservative calculations and assumptions to identify contaminants, pathways, and reaches that have a high priority for further investigation. These nonconservative risk estimates are more realistic than the conservative estimates and should not substantially overestimate maximum exposures to local population subgroups. Results of this screening assessment do not constitute a baseline risk assessment and are not intended to address issues regarding compliance with regulatory limits. The purpose of this screening exercise, along with the results obtained in Hoffman et al. (1991), is to help guide the development of the Phase 2 sampling plan, which will focus the collection of data on contaminants of concern. A future baseline risk assessment will be completed when data from the Phase 2 field sampling are available.

\subsection{Exposure Pathways}

The screening assessment was conducted on data from five reaches on the Clinch and Tennessee River system, which receives contaminant releases from the ORR (Fig. 2.4) and two reference reaches-Norris Reservoir and Poplar Creek above the confluence with East Fork Poplar Creek. Conservative and nonconservative screening analyses are performed for selected media in both primary and secondary exposure pathways.

Primary exposure pathways are the most realistic and currently the most likely to be encountered by a potential receptor. The primary pathways represent exposure to three media: fish, near-shore surface sediment, and surface water. The primary exposure pathways are: (1) ingestion of fish, (2) external exposure to radionuclides in surface sediment, (3) inadvertent ingestion of surface sediment, (4) inhalation of contaminated air resulting from resuspension of surface sediment, and (5) ingestion of surface water.

Secondary pathways are less likely scenarios and represent potential or future pathways of exposure. The scenario for secondary exposure pathways assumes that sediment from the Clinch and Tennessee River system is dredged and that the dredged material is placed on land where it supports agricultural activities including growing pasture as forage for cows and garden vegetables for human consumption. The pasture-to-cow pathway results in human 
exposure via consumption of milk and meat. Direct analytical measurements of contaminants are not available for the dredging scenario except for the concentrations of contaminants in the dredged sediments. Environmental pathway models that incorporate generic transfer coefficients from sediment are used to predict the concentrations of contaminants in the other exposure media.

Model-predicted concentrations of contaminants have a much higher degree of uncertainty than concentrations based on actual measurements. An irrigation scenario was not considered in this screening analysis because the number of Phase 1 water samples was too limited to reliably extrapolate from water to other media. For the same reason, the consumption of surface water by cows was not included in the cow-meat-milk pathway. Pathways for the dredging scenario include (1) external exposure to dredged sediments, (2) inadvertent ingestion of dredged sediment, (3) inhalation of air contaminated by resuspension of sediments, and (4) ingestion of agricultural products (meat, milk, and vegetables).

\subsubsection{Usage and Exposure Factors}

Usage and exposure factors for conservative and nonconservative screening are listed in Appendix E, Table E.2. These factors are similar to the ones used by Hoffman et al. (1991) and Blaylock et al. (1992a, 1992b); however, various intake rates, exposure times, toxicity values, and other parameters for both carcinogens and noncarcinogens have been modified since the publication of these reports. For example, EPA has reconsidered the maximum exposure duration and now recommends a residential exposure period of $350 \mathrm{~d} /$ year for 30 years instead of the previous recommendation of $365 \mathrm{~d} /$ year for 70 years (OSWER 1991).

\subsubsection{Data Bases}

All data used in this screening analysis were collected in the Phase 1 sampling effort except for the surface water. Because of the limited number of Phase 1 water samples, data from source monitoring sites were also included in the data base (Table E.1). The source monitoring program collects and analyzes water from discharge points, before the effluent readies the surface water body, for NPDES and DOE Order 5400.1 permits. See Appendices $B, C$, and $D$ for summaries of the Phase 1 data.

More than $\mathbf{5 0 0}$ near-shore grab samples of surface-sediment (Sect. 2) were taken to aid several agencies, including the regulators, TVA, and the U.S. Army Corps of Engineers, in evaluating permit applications for activities that would disturb near-shore sediment. The majority of these samples were taken in shallow water where the sediment would be exposed during winter months when the water level in Watts Bar Reservoir is low. These samples were analyzed for gamma-emitting radionuclides only, primarily ${ }^{60} \mathrm{Co}$ and ${ }^{137} \mathrm{Cs}$. Data from these samples were used in this screening analysis for primary sediment exposure pathways (i.e., external exposure, inadvertent ingestion of sediment, and inhalation of resuspended material).

Currently there is not a realistic direct pathway for human exposure to deep sediment where the highest concentrations of contaminants have been observed (Olsen et al. 1992). However, a dredging scenario was included in the screening analysis to consider potential exposure pathways if the sediment should be placed upon shore. This scenario would insure 
that elevated concentrations of contaminants in deep sediments are considered in the screening analysis (Sect. 3.3). Data from the Phase 1 sediment cores that were used in this analysis are summarized in Appendix C.

The data were divided into two categories-detected and nondetected contaminants. Contaminants for which at least one measurement was above the level of detection for a medium and reach were included in the detected data base. Contaminants for which all measurements in a reach and medium were below the detection limit were included in the nondetected data base. For conservative screening, the upper $95 \%$ confidence limit of the arithmetic mean (UCL) for each contaminant in the detectable data set was computed. The UCL was compared with the actual maximum detected value, and the smaller of the two values was used in the risk calculations, as directed in Risk Assessment Guidance for Superfund (RAGS) (EPA 1989). For nonconservative screening, the geometric mean of each contaminant in the detected data set and the lowest detection limit in the nondetected data 3e: were used as the contaminant concentration in the environmental medium.

\subsubsection{Screening Criteria}

\subsubsection{Screening indices}

Screening indices (SIs) for carcinogens and noncarcinogens are calculated for contaminants of potential concern to human health. These indices are based upon EPA-approved or -suggested cancer slope factors and toxicity reference doses (RfDs). The slope factor is based upon an estimate of the lifetime risk of an incremental cancer incidence per unit of exposure. The RfD is an exposure level (threshold) below which no adverse health effects should occur. Tables E.3 and E.5 list the slope factors and RfDs for contaminants evaluated in this report.

The screening index for carcinogens is calculated by multiplying an estimate of exposure to a contaminant via external exposure, ingestion, or inhalation by an EPA slope factor. This index indicates the potential lifetime risk of developing additional cancer (EPA 1992, 1990a) above and beyond the normal incidence of cancer. The screening index for noncarcinogens is the ratio of the estimated daily ingestion or inhalation of a contaminant divided by the contaminant-specific RfD.

To estimate the potential risk from all contaminants in a particular reach, the screening indices are summed for all contaminants in the reach. This summation has been termed a "total reach screening index" throughout this report. Summation is conducted separately for carcinogens and noncarcinogens.

\subsubsection{Screening criteria for carcinogens}

Conservative and nonconservative screening criteria are applied to the EPA action level (Federal Register March 8, 1990) to categorize carcinogenic contaminants as low priority, high priority, or requiring further investigation before designating high or low priority. Low priority indicates that a carcinogen is of little concern for further investigation; high priority requires either immediate consideration for remedial action or further analysis; and contaminants identified as neither low nor high priority must be evaluated further before this determination can be made. Figure 4.1 summarizes the screening criteria for carcinogens used in this report. 


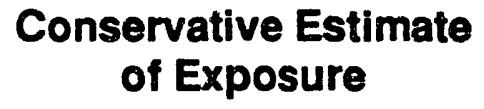

Require further investigation before taking action

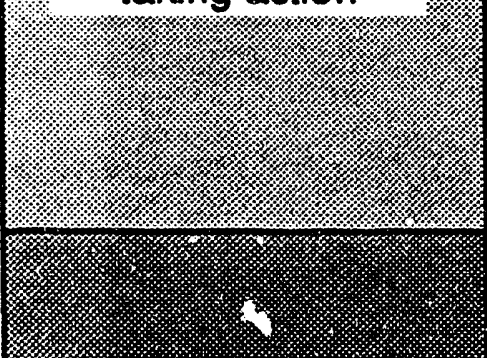

\section{Require further investigation before either taking action or designating low priority}

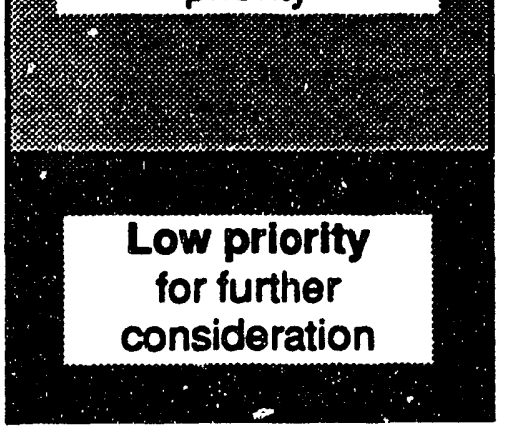

Nonconservative Estimate

of Exposure

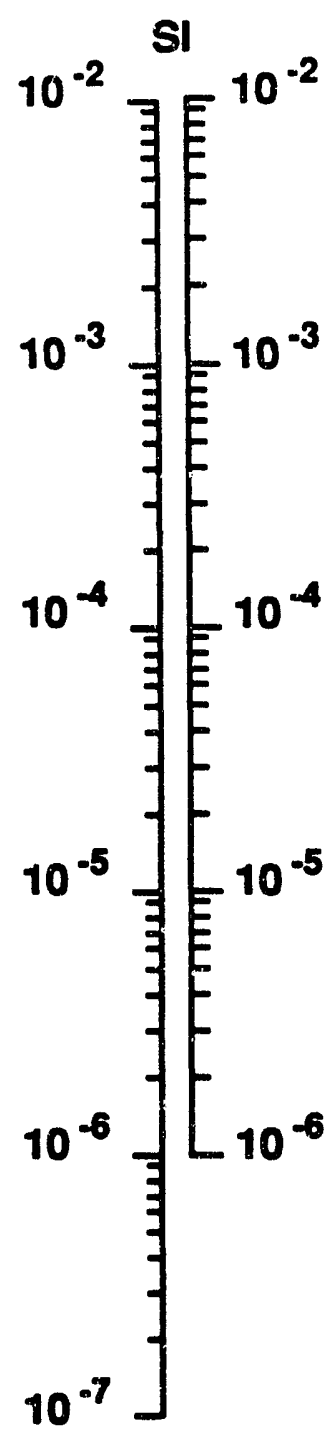

High priorityrequire immediate consideration for remedial action

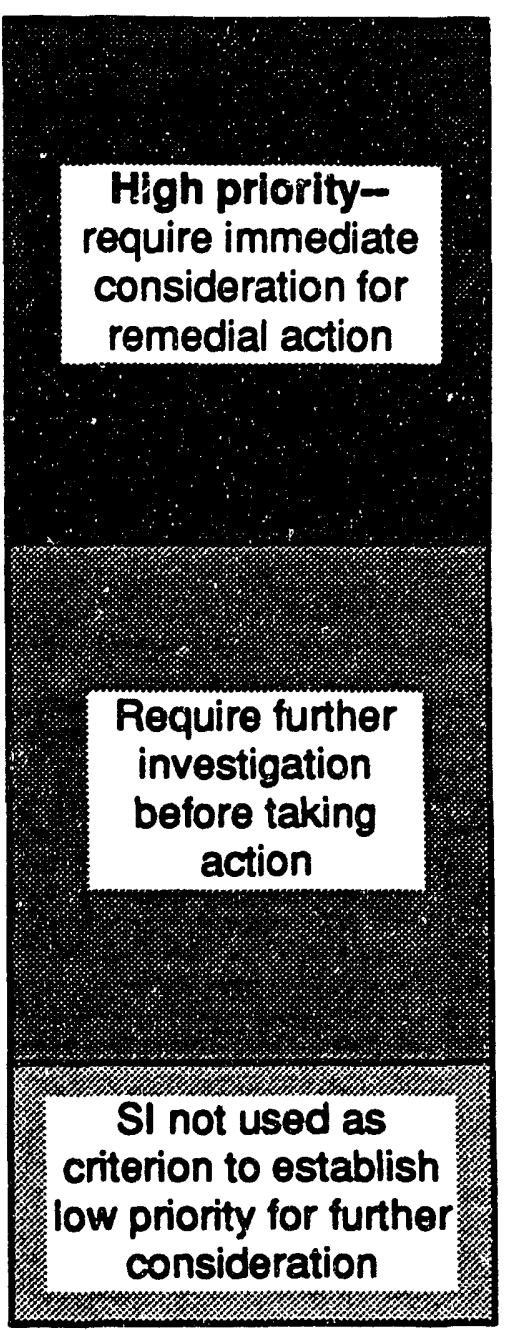

Screening index $(\mathrm{SI})=$ exposure multiplied by a lifetime cancer slope factor

Fig 4.1. Screening criteria for carcinogens. 
For conservative screening, carcinogens having screening indices $<10^{-6}$ are considered low priority contaminants for further consideration. Carcinogens with screening indices between $10^{-6}$ and $10^{-4}$ require further investigation before either taking action or designating these substances as high or low priority. Carcinogens with conservative screening indices $\geq 10^{-4}$ require further investigation before taking action.

For nonconservative screening of carcinogens, substances having screening indices $\geq 10^{-4}$ are high priority carcinogens that require immediate consideration for remedial action. Carcinogens with screening indices between $10^{-4}$ and $10^{-6}$ require further investigation before action is taken (i.e., re-examination of the data base, checking of parameter values, or recalculation of screening indices, etc.). Because nonconservative screening employs parameter values that should not greatly overestimate maximum exposures to a contaminant (and in some cases could underestimate maximum exposure), nonconservative screening is not used to identify contaminants with low priority for further consideration.

\subsubsection{Screening criteria for noncarcinogens}

The screening criteria used for noncarcinogens are summarized in Fig. 4.2. For conservative screening, contaminants with screening indices $<0.1$ are low priority for further consideration, and contaminants with screening indices between 0.1 and 1.0 require further investigation before designating these substances as high or low priority. Noncarcinogens with conservative screening indices $\geq 1.0$ require further investigation before action is taken.

For nonconservative screening of noncarcinogens, contaminants with screening indices Z1.0 are high priority substances requiring immediate consideration for remedial action, and contaminants with screening indices between 1.0 and 0.1 require further investigation before taking action. Nonconservative screening indices $<0.1$ are not used to designate low priority contaminants because nonconservative screening employs parameter values that, under some circumstances, may underestimate maximum exposures to a contaminant.

\subsubsection{Contaminant Screening Results for Primary Exposure Pathways}

Screening results for individual contaminants for each primary exposure pathway and each reach are given in Appendix E, Tables E.8 through E.12. The pathways considered to be primary pathways for this screening exercise are: (1) ingestion of fish, (2) external exposure to gamma-emitting radionuclides present in surface sediment, (3) inadvertent ingestion of surface sediment, (4) inhalation of contaminated air (via either dust resuspension, volatilization, or vapurization of contaminants), and (5) ingestion of surface water. Tables 4.1 through 4.5 summarize the results for carcinogens and noncarcinogens in each exposure pathway for both the conservative and nonconservative screening approaches. These tables identify the high priority contaminants, low priority contaminants, and contaminants requiring further investigation; they also show the reaches where no adverse health effects are expected and those where no data were available.

\subsubsection{Fish ingestion pathwey}

Cancinogens. Listed in Table 4.1 are the results of the conservative and nonconservative screaning analyses for carcinogens in the fish ingestion pathway. Nonconservative screening identified the PCB Aroclor 1260 in all reaches except reach 1 (Melton Hill Reservoir) and 
Conservative Estimate of Exposure

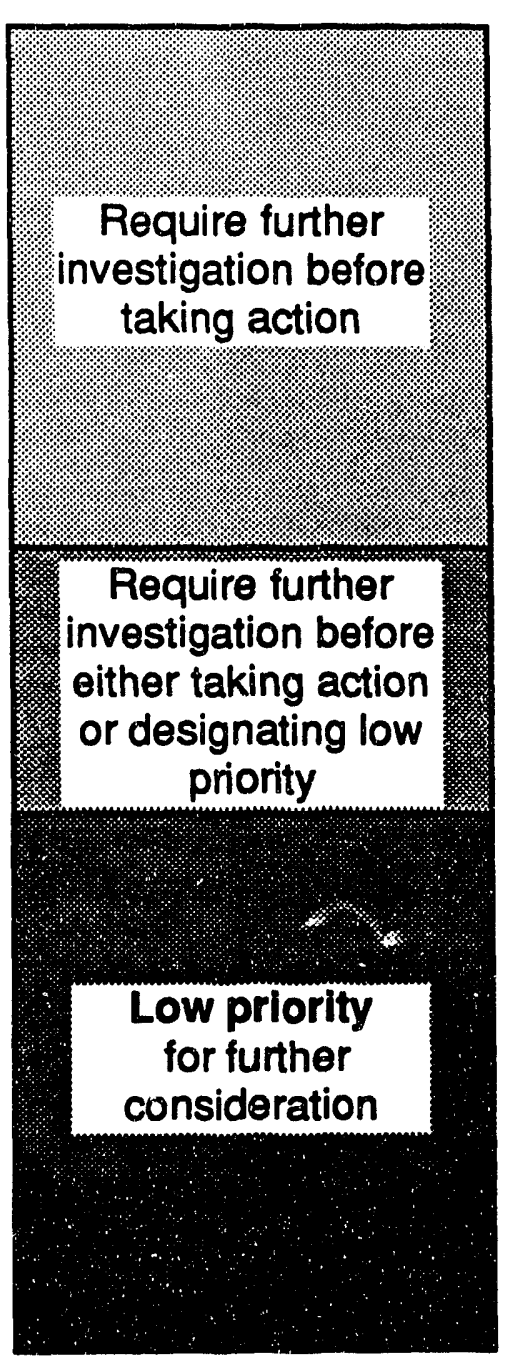

SI

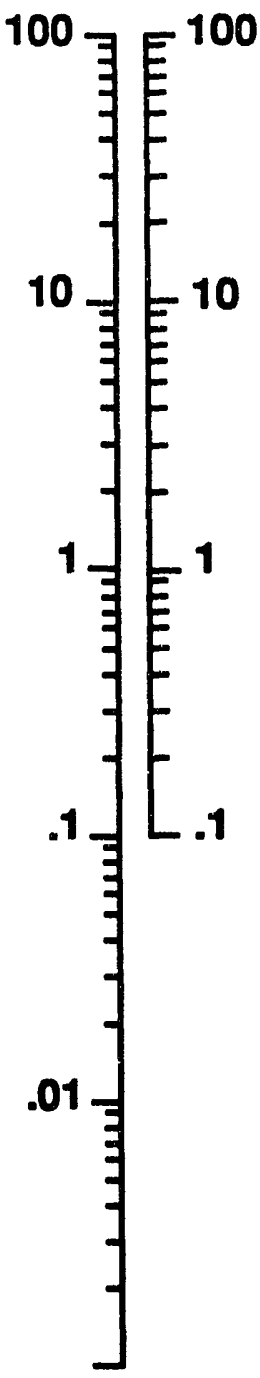

Nonconservative Estimate of Exposure

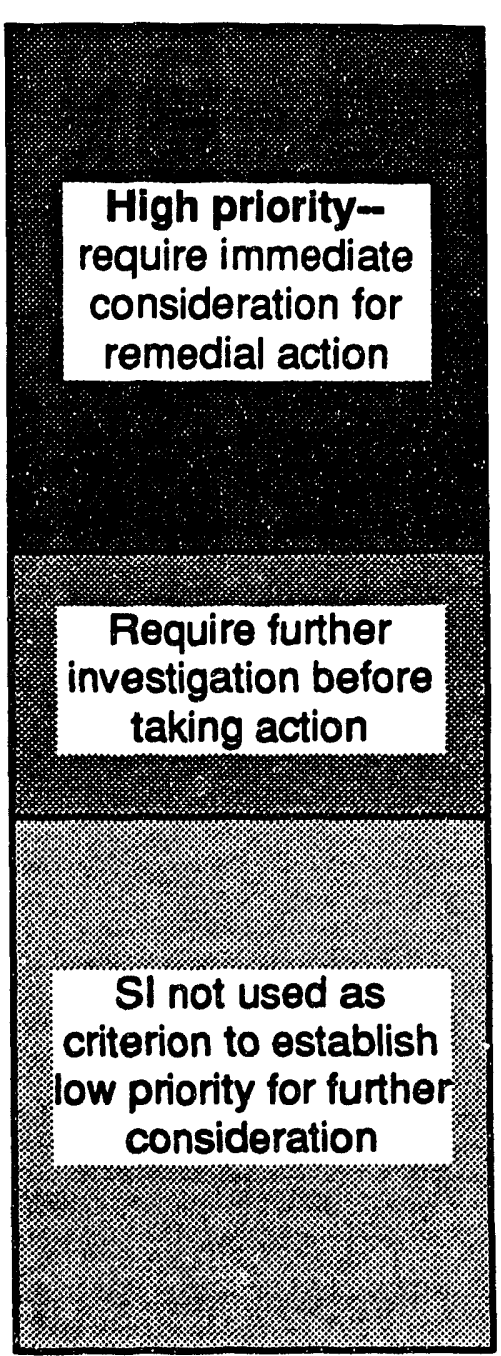

Screening index $(S I)=$ exposure divided by reference dose factor (RfD)

Fig. 42 Screening criteria for noncarcinogens. 
Table 4.1. Summary of adult screening results for carcinogens in the fish ingestion pathway

\begin{tabular}{|c|c|c|c|c|c|c|c|}
\hline \multirow[b]{2}{*}{ Carcinogen } & \multicolumn{7}{|c|}{ Reach } \\
\hline & 1 & 2 & 3 & 4 & 5 & 10 & 13 \\
\hline \multicolumn{8}{|l|}{ Organics } \\
\hline \multicolumn{8}{|l|}{ 4,4'-DDE } \\
\hline 4,4'-DDT & $\mathbf{N}$ & & $\mathbf{N}$ & & & $\mathbf{N}$ & $\mathbf{N}$ \\
\hline Aldrin & $\mathbf{N}$ & & $\mathbf{N}$ & & & $\mathbf{N}$ & \\
\hline Aroclor 1254 & & & & 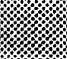 & & $\mathbf{N}$ & \\
\hline Aroclor 1260 & & 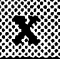 & . & 嬗 & . & & 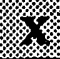 \\
\hline $\begin{array}{l}\text { Bis(2-ethylhexyl) } \\
\text { phthalate }\end{array}$ & $\mathbf{N}$ & $\mathbf{N}$ & 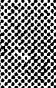 & $\mathbf{N}$ & $\mathbf{s}$ & $\mathbf{S}$ & $\mathbf{s}$ \\
\hline \multicolumn{8}{|l|}{ Chlordane } \\
\hline \multicolumn{8}{|l|}{ Inorganics } \\
\hline \multicolumn{8}{|l|}{ Arsenic } \\
\hline Beryllium & & $\mathbf{N}$ & & $\mathbf{N}$ & & & $\mathbf{N}$ \\
\hline \multicolumn{8}{|l|}{ Radionuclides } \\
\hline${ }^{\infty} \mathrm{Co}$ & & $\mathbf{N}$ & & $\mathbf{N}$ & $\mathbf{N}$ & & \\
\hline${ }^{137} \mathrm{Cs}$ & & & & & & & \\
\hline${ }^{2} \mathrm{Sr}$ & & & & & & & \\
\hline
\end{tabular}

Carcinogens having nonconservative screening indices $>10^{-4}$ that require immediate consideration.

Carcinogens with conservative or nonconservative screening indices between $10^{-6}$ and $10^{-4}$ that further investigation before either taking action or designating as low priority.

Carcinogens baving conservative screening indices $<10^{-6}$ and can be designated as low priority.

N Nondetects - contaminant concentrations were below detection limits.

$S$ No data available. 
Table 4.2. Summary of screening results for noncarcinogens in the fish ingestion pathways

\begin{tabular}{|c|c|c|c|c|c|c|c|}
\hline \multirow[b]{2}{*}{ Contaminant } & \multicolumn{7}{|c|}{ Reach } \\
\hline & 1 & 2 & 3 & 4 & 5 & 10 & 13 \\
\hline \multicolumn{8}{|l|}{ Organics } \\
\hline 4,4'-DDT & $\mathbf{N}$ & & $\mathbf{N}$ & & & $\mathbf{N}$ & $\mathbf{N}$ \\
\hline Aldrin & $\mathbf{N}$ & & $\mathbf{N}$ & & & $\mathbf{N}$ & \\
\hline Bis(2-ethylhexyl phthalate) & $\mathbf{N}$ & $\mathbf{N}$ & & $\mathbf{N}$ & $\mathbf{s}$ & $\mathbf{s}$ & $\mathbf{S}$ \\
\hline \multicolumn{8}{|l|}{ Chlordane } \\
\hline Di-n-octylphthalate & $\mathbf{N}$ & $\mathbf{N}$ & & $\mathbf{N}$ & $\mathbf{s}$ & $\mathbf{s}$ & $\mathbf{s}$ \\
\hline \multicolumn{8}{|l|}{ Irorganics } \\
\hline \multicolumn{8}{|l|}{ Arsenic } \\
\hline Beryllium & & $\mathbf{N}$ & & $\mathbf{N}$ & & & $\mathbf{N}$ \\
\hline Copper & $\mathbf{N}$ & $\mathbf{N}$ & $\mathbf{N}$ & $\mathbf{N}$ & / & $\mathbf{N}$ & $\mathbf{N}$ \\
\hline \multicolumn{8}{|l|}{ Mercury } \\
\hline Selenium & & & & & $\mathbf{N}$ & & $\mathbf{N}$ \\
\hline Zinc & & & & & & & \\
\hline
\end{tabular}

Contaminants with adult nonconservative screening indices $\geq 1.0$ that require immediate consideration.

Contaminants with child conservative sereening indices between 0.1 and 1.0 that require further investigation before either taking action or designating as low priority.

Contaminants having child conservative screening indices $<0.1$ and can be designated as low priority.

Nondetects - contaminant concentrations were below detection limits.

No data available. 
Table 4.3. Summary of adult screening results for radionuclides in near-shore surface sediment exposure

\begin{tabular}{|c|c|c|c|c|c|c|c|c|}
\hline \multirow[b]{2}{*}{ External Bzposure } & \multicolumn{8}{|c|}{ Reach } \\
\hline & 1 & 2 & 3 & 4 & 5 & 10 & 13 & 18 \\
\hline${ }^{\infty} \mathrm{Co}$ & & & & & & $\mathbf{s}$ & $\mathbf{S}$ & \\
\hline${ }^{137} \mathrm{Cs}$ & & & ষ্বি & & & $\mathbf{S}$ & S. & \\
\hline \multicolumn{9}{|l|}{ Ingestion Eposure } \\
\hline${ }^{\infty} \mathrm{Co}$ & & & & & & $\mathbf{s}$ & $\mathbf{s}$ & \\
\hline${ }^{237} \mathrm{Cs}$ & & & & & & $\mathbf{S}$ & $\mathbf{S}$ & \\
\hline \multicolumn{9}{|l|}{ Inhalation Pathway } \\
\hline${ }^{\infty} \mathrm{Co}$ & & & & & & $\mathbf{s}$ & $\mathbf{S}$ & \\
\hline${ }^{137} \mathrm{Cs}$ & & & & & & $\mathbf{s}$ & $\mathbf{S}$ & \\
\hline
\end{tabular}

Carcinogens with nonconservative screening indices $\geq 10^{-4}$ that require immediate consideration. Carcinogens with screening indices between $10^{-6}$ and $10^{-4}$ that require further investigation before designating as low priority.

Carcinogens having conservative screening indices $<10^{-6}$ and can be designated as low priority.

Nondetects - contaminant concentrations were below detection limits.

No data availabie. 
Table 4.4. Summary of adult screening results for carcinogens in the water ingestion pathway

\begin{tabular}{|c|c|c|c|c|c|c|c|}
\hline \multirow[b]{2}{*}{ Contaminant } & \multicolumn{7}{|c|}{ Reach } \\
\hline & 1 & 2 & 3 & 4 & 5 & 10 & 13 \\
\hline \multicolumn{8}{|l|}{ Organics } \\
\hline 1,2-Dichloroethane & $\mathbf{s}$ & $\mathbf{N}$ & & $\mathbf{N}$ & $\mathbf{S}$ & $\mathbf{S}$ & $\mathbf{N}$ \\
\hline 1,2-Dichloropropane & $\mathbf{s}$ & & $\mathbf{N}$ & $\mathbf{N}$ & $\mathbf{S}$ & $\mathbf{s}$ & $\mathbf{N}$ \\
\hline 1,4-Dichlorobenzene & $\mathbf{N}$ & $\mathbf{N}$ & & $\mathbf{N}$ & $\mathbf{N}$ & $\mathbf{N}$ & $\mathbf{N}$ \\
\hline Anthracene & $\mathbf{N}$ & $\mathbf{N}$ & & $\mathbf{N}$ & $\mathbf{N}$ & $\mathbf{N}$ & $\mathbf{N}$ \\
\hline Aroclor 1254 & $\mathbf{N}$ & $\mathbf{N}$ & & $\mathbf{N}$ & $\mathbf{N}$ & $\mathbf{N}$ & $\mathbf{S}$ \\
\hline Benzene & $\mathbf{S}$ & $\mathbf{N}$ & & $\mathbf{N}$ & $\mathbf{S}$ & $\mathbf{S}$ & $\mathbf{N}$ \\
\hline Benzo(a)anthracene & $\mathbf{N}$ & $\mathbf{N}$ & & $\mathbf{N}$ & $\mathbf{N}$ & $\mathbf{N}$ & $\mathbf{N}$ \\
\hline Bis(2-ethylhexyl)phthalate & $\mathbf{N}$ & $\mathbf{N}$ & & $\mathbf{N}$ & $\mathbf{N}$ & & $\mathbf{N}$ \\
\hline Bromoform & $\mathbf{S}$ & $\mathbf{N}$ & & $\mathbf{N}$ & $\mathbf{s}$ & $\mathbf{S}$ & $\mathbf{N}$ \\
\hline Chlorodibromomethane & $\mathbf{S}$ & $\mathbf{N}$ & & $\mathbf{N}$ & $\mathbf{S}$ & $\mathbf{s}$ & $\mathbf{N}$ \\
\hline Chloroform & $\mathbf{S}$ & & & $\mathbf{N}$ & $\mathbf{S}$ & $\mathbf{s}$ & $\mathbf{N}$ \\
\hline Chrysene & $\mathbf{N}$ & $\mathbf{N}$ & & $\mathbf{N}$ & $\mathbf{N}$ & $\mathbf{N}$ & $\mathbf{N}$ \\
\hline Dichlorobromomethane & $\mathbf{s}$ & $\mathbf{N}$ & & $\mathbf{N}$ & $\mathbf{s}$ & $\mathbf{s}$ & $\mathbf{N}$ \\
\hline 1,1-Dichloroethylene & & & & & & & \\
\hline Fluoranthene & $\mathbf{N}$ & $\mathbf{N}$ & & $\mathbf{N}$ & $\mathbf{N}$ & $\mathbf{N}$ & $\mathbf{N}$ \\
\hline Methylene Chloride & $\mathbf{s}$ & & & $\mathbf{N}$ & $\mathbf{S}$ & $\mathbf{S}$ & $\mathbf{N}$ \\
\hline N-nitro-di-n-propylamine & $\mathbf{N}$ & $\mathbf{N}$ & & $\mathbf{N}$ & $\mathbf{N}$ & $\mathbf{N}$ & $\mathbf{N}$ \\
\hline Phenanthrene & $\mathbf{N}$ & $\mathbf{N}$ & & $\mathbf{N}$ & $\mathbf{N}$ & $\mathbf{N}$ & $\mathbb{N}$ \\
\hline Pyrene & $\mathbf{N}$ & $\mathbf{N}$ & & $\mathbf{N}$ & $\mathbf{N}$ & $\mathbf{N}$ & $N$ \\
\hline Tetrachloroethylene & $\mathbf{s}$ & 8 & & $\mathbf{N}$ & $\mathbf{s}$ & $\mathbf{S}$ & $\mathrm{k}$ \\
\hline Trans-1,3-dichloropropene & $\mathbf{s}$ & $\mathbf{N}$ & & $\mathbf{N}$ & $\mathbf{S}$ & $\mathbf{S}$ & $\mathbf{N}$ \\
\hline Trichlorvethylene & $\mathbf{S}$ & $\mathbf{N}$ & & $\mathbf{N}$ & $\mathbf{s}$ & $\mathbf{s}$ & $\mathbf{N}$ \\
\hline Vinyl Chloride & $\mathbf{s}$ & $\mathbf{N}$ & & $\mathbf{N}$ & $\mathbf{s}$ & $\mathbf{S}$ & $\mathbf{N}$ \\
\hline Inorganics & & & & & & & \\
\hline Arsenic & & $\mathbf{N}$ & & $\mathbf{N}$ & $\mathbf{N}$ & ny & $\mathrm{N}$ \\
\hline Beryllium & & $\mathbf{N}$ & & $\mathbf{N}$ & $\mathbf{N}$ & iv & $\mathbf{N}$ \\
\hline
\end{tabular}


Table 4.4 (continued)

\begin{tabular}{|c|c|c|c|c|c|c|c|}
\hline \multirow[b]{2}{*}{ Contaminant } & \multicolumn{7}{|c|}{ Reach } \\
\hline & 1 & 2 & 3 & 4 & 5 & 10 & 13 \\
\hline \multicolumn{8}{|l|}{ Radionuclides } \\
\hline${ }^{\infty} \mathrm{Co}$ & & & $\mathbf{N}$ & & $\mathbf{N}$ & $\mathbf{N}$ & $\mathbf{N}$ \\
\hline${ }^{137} \mathrm{Cs}$ & & & & & & $\mathbf{N}$ & \\
\hline${ }^{3} \mathrm{H}$ & $\mathbf{s}$ & & $\mathbf{S}$ & & $\mathbf{S}$ & $\mathbf{S}$ & $\mathbf{S}$ \\
\hline${ }^{237} \mathrm{~Np}$ & $\mathbf{s}$ & & : & $\mathbf{S}$ & $\mathbf{S}$ & $\mathbf{s}$ & $\mathbf{S}$ \\
\hline${ }^{191} \mathrm{OS}$ & $\mathbf{s}$ & & $\mathbf{S}$ & $\mathbf{S}$ & $\mathbf{S}$ & $\mathbf{S}$ & $\mathbf{S}$ \\
\hline${ }^{204} \mathrm{~Pa}$ & $\mathbf{S}$ & & & & $\mathbf{S}$ & $\mathbf{s}$ & $\mathbf{S}$ \\
\hline${ }^{230} \mathrm{Pu}$ & $\mathbf{s}$ & & & & $\mathbf{s}$ & $\mathbf{s}$ & $\mathbf{S}$ \\
\hline${ }^{209} \mathrm{Pu}$ & & $\mathbf{S}$ & & & $\mathbf{s}$ & $\mathbf{s}$ & $\mathbf{S}$ \\
\hline${ }^{\infty} \mathrm{Sr}$ & 8 & & & & & $\mathbf{s}$ & $\mathbf{S}$ \\
\hline${ }^{\circ} \mathrm{Tc}$ & $\mathbf{s}$ & & & & $\mathbf{s}$ & $\mathbf{S}$ & \\
\hline${ }^{20} \mathrm{Th}$ & $\mathbf{S}$ & 8 & 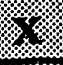 & & $\mathbf{s}$ & $\mathbf{s}$ & \\
\hline${ }^{26} \mathrm{Th}$ & $\mathbf{s}$ & & 桨 & & $\mathbf{s}$ & $\mathbf{s}$ & \\
\hline${ }^{20 N} U$ & & & & & $\mathbf{S}$ & $\mathbf{S}$ & $\mathbf{s}$ \\
\hline${ }^{225} \mathrm{U}$ & & & & & $\mathbf{s}$ & $\mathbf{s}$ & $\mathbf{s}$ \\
\hline 204 & $\mathbf{s}$ & $\mathbf{S}$ & & & $\mathbf{S}$ & $\mathbf{s}$ & $\mathbf{S}$ \\
\hline U2u & & & & & $\mathbf{S}$ & $\mathbf{S}$ & $\mathbf{S}$ \\
\hline
\end{tabular}

Carcinogens having nonconservative screening indices $>10^{-4}$ that require immediate consideration. Carcinogens with conservative or nonconservative screening indices between $10^{-6}$ and $10^{-4}$ that further investigation before designating as low priority.

\begin{tabular}{|l|l|l}
\hline & Carcinogens baving conservative screening indices $<10^{-6}$ and can be designated as low priority. \\
N & Nondetects - contaminant concentrations were below detection limits. \\
S S & No data available.
\end{tabular} 
Table 4.5. Summary of screening results for noncarcinogens in the water ingestion pathway

\begin{tabular}{|c|c|c|c|c|c|c|c|}
\hline \multirow[b]{2}{*}{ Contaminant } & \multicolumn{7}{|c|}{ Reach } \\
\hline & 1 & 2 & 3 & 4 & 5 & 10 & 13 \\
\hline \multicolumn{8}{|l|}{ Organics } \\
\hline 1,1-Dichloroethane & $\mathbf{S}$ & $\mathbf{N}$ & & $\mathbf{N}$ & $\mathbf{S}$ & $\mathbf{S}$ & $\mathbf{N}$ \\
\hline 1,1,1-Trichloroethane & $\mathbf{S}$ & $\mathbf{N}$ & & $\mathbf{N}$ & $\mathbf{S}$ & $\mathbf{S}$ & $\mathbf{N}$ \\
\hline 2,4-Dichlorophenol & $\mathbf{N}$ & $\mathbf{N}$ & & $N^{\prime}$ & $\mathbf{N}$ & $\mathbf{N}$ & $\mathbf{N}$ \\
\hline Acetone & $\mathbf{s}$ & & $\mathbf{N}$ & $\mathbf{S}$ & $\mathbf{S}$ & $\mathbf{S}$ & $\mathbf{S}$ \\
\hline Anthracene & $\mathbf{N}$ & $\mathbf{N}$ & & $\mathbf{N}$ & $\mathrm{N}$ & $\mathbf{N}$ & $\mathbf{N}$ \\
\hline Bis(2-ethylhexyl)phthalate & $\mathbf{N}$ & $\mathbf{N}$ & & $\mathbf{N}$ & $\mathbf{N}$ & & $\mathbf{N}$ \\
\hline Bromoform & $\mathbf{s}$ & $\mathbf{N}$ & & $\mathbf{N}$ & $\mathbf{S}$ & $\mathbf{S}$ & $\mathbf{N}$ \\
\hline Butylbenzylphthalate & $\mathbf{N}$ & $\mathbf{N}$ & & $\mathbf{N}$ & $\mathbf{N}$ & $\mathbf{N}$ & $\mathbf{N}$ \\
\hline Carbon Disulfide & $\mathbf{S}$ & & $\mathbf{S}$ & $\mathbf{S}$ & $\mathbf{S}$ & $\mathbf{S}$ & $\mathbf{S}$ \\
\hline Chlorobenzene & $\mathbf{S}$ & $\mathbf{N}$ & & $\mathbf{N}$ & $\mathbf{S}$ & $\mathbf{S}$ & $\mathbf{N}$ \\
\hline Chlorodibromomethane & $\mathbf{S}$ & $\mathbf{N}$ & & $\mathbf{N}$ & $\mathbf{s}$ & $\mathbf{S}$ & $\mathbf{N}$ \\
\hline Chloroform & $\mathbf{S}$ & & & $\mathbf{N}$ & $\mathbf{s}$ & $\mathbf{S}$ & $\mathbf{N}$ \\
\hline Di-n-butylphthalate & $\mathbf{N}$ & $\mathbf{N}$ & & $\mathbf{N}$ & $\mathbf{N}$ & $\mathbf{N}$ & $\mathbf{N}$ \\
\hline Dichlorobromomethane & $\mathbf{S}$ & $\mathbf{N}$ & & $\mathbf{N}$ & $\mathbf{S}$ & $\mathbf{S}$ & $\mathbf{N}$ \\
\hline Diethylphthalate & $\mathbf{N}$ & $\mathbf{N}$ & & $\mathbf{N}$ & $\mathbf{N}$ & $\mathbf{N}$ & $\mathbf{N}$ \\
\hline Dimethylphthalate & $\mathbf{N}$ & $\mathbf{N}$ & & $\mathbf{N}$ & $\mathbf{N}$ & $\mathbf{N}$ & $\mathbf{N}$ \\
\hline Ethylbenzene & $\mathbf{S}$ & $\mathbf{N}$ & & $\mathbf{N}$ & $\mathbf{S}$ & $\mathbf{s}$ & $\mathbf{N}$ \\
\hline Fluoranthene & $\mathbf{N}$ & $\mathbf{N}$ & & $\mathbf{N}$ & $\mathbf{N}$ & $\mathbf{N}$ & $\mathbf{N}$ \\
\hline Methylene Chloride & $\mathbf{S}$ & & & $\mathbf{N}$ & $\mathbf{s}$ & $\mathbf{S}$ & $\mathbf{N}$ \\
\hline Phenol & $\mathbf{N}$ & & & & $\mathbf{N}$ & $\mathbf{N}$ & $\mathbf{N}$ \\
\hline Pyrene & $\mathbf{N}$ & $\mathbf{N}$ & & $\mathbf{N}$ & $\mathbf{N}$ & $\mathbf{N}$ & $\mathbf{N}$ \\
\hline Tetrachloroethylene & $\mathbf{S}$ & & & $\mathbf{N}$ & $\mathbf{S}$ & $\mathbf{S}$ & $\mathbf{N}$ \\
\hline Toluene & $\mathbf{S}$ & & & $\mathbf{N}$ & $\mathbf{S}$ & $\mathbf{S}$ & $\mathbf{N}$ \\
\hline Trans-1,2-Dichloroethene & $\mathbf{S}$ & $\mathbf{N}$ & & $\mathbf{N}$ & $\mathbf{s}$ & $\mathbf{s}$ & $\mathbf{N}$ \\
\hline Trans-1,3-dichloropropene & $\mathbf{s}$ & $\mathbf{N}$ & & $\mathbf{N}$ & $\mathbf{S}$ & $\mathbf{S}$ & $\mathbf{N}$ \\
\hline Xylene & $\mathbf{s}$ & & $\mathbf{N}$ & $\mathbf{S}$ & $\mathbf{S}$ & $\mathbf{S}$ & $\mathbf{S}$ \\
\hline
\end{tabular}


Table 4.5 (continued)

\begin{tabular}{|c|c|c|c|c|c|c|c|}
\hline \multirow[b]{2}{*}{ Contaminant } & \multicolumn{7}{|c|}{ Reach } \\
\hline & 1 & 2 & 3 & 4 & 5 & 10 & 13 \\
\hline \multicolumn{8}{|l|}{ Inorganics } \\
\hline Antimony & & $\mathbf{N}$ & $\mathbf{N}$ & $\mathbf{N}$ & $\mathbf{N}$ & $\mathbf{N}$ & $\mathbf{N}$ \\
\hline Arsenic & & $\mathbf{N}$ & & $\mathbf{N}$ & $\mathbf{N}$ & $\mathbf{N}$ & $\mathbf{N}$ \\
\hline Barium & & & & & $\mathbf{s}$ & $\mathbf{s}$ & $\mathbf{S}$ \\
\hline Beryllium & & $\mathbf{N}$ & & $\mathbf{N}$ & $\mathbf{N}$ & $\mathbf{N}$ & $\mathbf{N}$ \\
\hline Boron & $\mathbf{N}$ & $\mathbf{N}$ & & & $\mathbf{S}$ & $\mathbf{S}$ & $\mathbf{S}$ \\
\hline Cadmium & & $\mathbf{N}$ & & $\mathbf{N}$ & $\mathbf{N}$ & $\mathbf{N}$ & $\mathbf{N}$ \\
\hline Chromium & & $\mathbf{N}$ & & & $\mathbf{N}$ & $\mathbf{N}$ & \\
\hline Copper & & & & & $\mathbf{N}$ & $\mathbf{N}$ & $\mathbf{N}$ \\
\hline Cyanide & $\mathbf{s}$ & & & & $\mathbf{s}$ & $\mathbf{S}$ & \\
\hline Manganese & & & & & $\mathbf{s}$ & $\mathbf{s}$ & \\
\hline Mercury & & $\mathbf{N}$ & & & $\mathbf{N}$ & $\mathbf{N}$ & $\mathbf{N}$ \\
\hline Molybdenum & $\mathbf{N}$ & $\mathbf{N}$ & & $\mathbf{N}$ & $\mathbf{s}$ & $\mathbf{s}$ & \\
\hline Nickel & : & & & & $\mathbf{N}$ & $\mathbf{N}$ & \\
\hline Selenium & & & & $\mathbf{N}$ & $\mathbf{N}$ & $\mathbf{N}$ & $\mathbf{N}$ \\
\hline Silver & $\mathbf{N}$ & $\mathbf{N}$ & & $\mathbf{N}$ & $\mathbf{N}$ & $\mathbf{N}$ & $\mathbf{N}$ \\
\hline Strontium & & & $\mathbf{S}$ & $\mathbf{s}$ & s & $\mathbf{S}$ & $\mathbf{S}$ \\
\hline Tin & $\mathbf{N}$ & $\mathbf{N}$ & & $\mathbf{N}$ & $\mathbf{s}$ & $\mathbf{s}$ & $\mathbf{s}$ \\
\hline Uranium & $\mathbf{S}$ & & & & $\mathbf{s}$ & $\mathbf{S}$ & $\mathbf{N}$ \\
\hline Vanadium & & $\mathbf{N}$ & $\mathbf{N}$ & $\mathbf{S}$ & $\mathbf{s}$ & $\mathbf{S}$ & $\mathbf{S}$ \\
\hline 7inc & & & & & $\mathbf{N}$ & $\mathbf{N}$ & \\
\hline
\end{tabular}

Noncarcinogens having adult nonconservative screening indices $\geq 1.0$ that require immediate consideration.

Noncarcinogens with child conservative screening indices between 0.1 and 1.0 that require further investigation before either taking action or designating as low priority.

Noncarcinogens having child conservative screening indices $<0.1$ and can be designated as low priority.

N Nondetects - contaminant concentrations were below detection limits.

S No data available. 
reach 10 (Norris Reservoir) as a high priority contaminant requiring immediate consideration for remedial action. In addition, Aroclor 1254 was identified as requiring further study in all reaches except reach 10. In a previous screening analysis of historical data (Hoffman et al. 1991), PCBs were identified as a potentially high priority contaminant (screening index between $10^{-4}$ and $10^{-3}$ ). Other investigations have shown that PCBs are a common pollutant in East Tennessee rivers and reservoirs. Although the ORR is a known source of PCBs, it is not the only one contributing PCBs to the Clinch River/Watts Bar Reservoir system.

Several contaminants were identified as requiring further investigation (screening indices between $10^{-4}$ and $10^{-6}$ ) before action is taken or they are designated as low priority (Table 4.1). Arsenic and chlordane in all reaches, including reference reach 10 (Norris Reservoir), were identified as requiring further investigation. These contaminants were identified in Hoffman et al. (1991) as potentially high priority contaminants. Arsenic is a common pollutant resulting from industrial operations and fossil fuel use in East Tennessee, especially metropolitan areas. A special study is being conducted under the sponsorship of the CRRI to document the concentration of arsenic in water and sediment in areas receiving effluents from the ORR (Byrd 1991). Beryllium was identified in all reaches except 2, 4, and 13, and ${ }^{137} \mathrm{Cs}$ was identified in reaches 2 and 4 as requiring further study.

Several pesticides found in fish (4,4'-DDE, 4,4'-DDT, and Aldrin) were identified as requiring further investigation. These are common agricultural pesticides that were identified in only a few reaches but will require further investigation; however, the occurrence of these contaminants in fish may be the result of analytical procedures.

Noncarcinogens. Exposure parameters for a child were used to identify the low priority noncarcinogens in the fish ingestion pathway because the child scenario is more conservative than the adult and would eliminate fewer contaminants. Results of both conservative (child) and nonconservative (adult) screening analyses for noncarcinogens in the fish ingestion pathway are summarized in Table 4.2. None of the noncarcinogens were identified by nonconservative screening as high priority contaminants that would require immediate consideration for remedial action. Also, none of the sums of the conservative screening indices for the reaches were $<0.1$, including reference reach 10 (Norris Reservoir) (see Tables E.9 and E.12 in Appendix E), thus, no reach could be eliminated from further consideration. Contaminants that were classified as requiring further investigation in most reaches are chlordane, arsenic, mercury, and selenium. These contaminants are ubiquitous in East Tennessee aquatic systems, and, with the exception of mercury, which was released from the Y-12 Plant in large quantities in the past, are common industrial pollutants and not unique to the ORR.

\subsubsection{Near-shore surface sediments}

Results of conservative and nonconservative screening analyses for the near-shore surface sediment for the ingestion, inhalation, and exposure pathways are given in Table 4.3. Nonconservative screening indices were $<10^{-4}$ for all pathways and reaches. Conservative screening indices for the ingestion and inhalation pathways were $<10^{-6}$ for all reaches and can be assigned low priority for consideration for further investigation. Therefore, ${ }^{60} \mathrm{Co}$ and ${ }^{137} \mathrm{Cs}$, the only contaminants for which the near-shore surface sediment samples were analyzed, are assigned low priority for further consideration in ingestion and inhalation pathways for all reaches. 
For the external exposure pathway, ${ }^{60} \mathrm{Co}$ in reaches $1-4$ and ${ }^{137} \mathrm{Cs}$ in reaches $1-5$ and 18 were identified as contaminants with screening indices of $>10^{-6}$. These radionuclides require further investigation before action is taken or they are assigned low priority. In most reaches, the concentrations of ${ }^{60} \mathrm{Co}$ and ${ }^{137} \mathrm{Cs}$ were $<1$ and $4 \mathrm{pCi} / \mathrm{g}$, respectively, in the near-shore surface sediment. Three samples had concentrations $>10 \mathrm{pCi} / \mathrm{g}$ (Section 3.3.1.1); however, these samples came from relatively deep water.

\subsubsection{Water ingestion pathway}

Carcinogens. Because of the limited number of Phase 1 water samples and the use of source monitoring data, which included NPDES data, the screening results for water should be used primarily to guide future sampling and analysis of the surface water. Although source monitoring data are usefu! in identifying contaminants that are released into the surface water, it is unlikely that these data represent the actual contaminant concentrations in the receiving body of water. Results of the screening analysis for the ingestion of carcinogens in surface water are summarized in Table 4.4. This table shows that reach 3 (Poplar Creek), which receives effluents from the K-25 Site, East Fork Poplar Creek, and the City of Oak Ridge west-end sewage treatment plant, has a large number of contaminants that require consideration for further investigation. Thorium-228, a daughter of ${ }^{232} U$ and naturally occuring ${ }^{232} \mathrm{Th}$, was reported in reach 3 at concentrations that produced a screening index $>10^{-3}$. By the current screening criteria, ${ }^{225} \mathrm{Th}$ would be classified as a high priority contaminant requiring immediate consideration for remedial action; however, the ${ }^{20} \mathrm{Th}$ was measured at only surface water monitoring sites, and these measurements are representative of a point source rather than of the downstream surface water. In the other six reaches shown in Table 4.4, either most of the organic and inorganic contaminants in water were below detection limits, or the contaminants were not measured.

In addition to reach 3 , reaches 2 and 4 , which are immediately downstream from ORNL and the K-25 Site, respectively, have concentrations of radionuclides that require further investigation. Many of these radionuclides are isotopes of uranium or their daughter products that occur in nature. In reach $2,{ }^{191} \mathrm{O}$ s was detected once but probably will not be detected again because it is an isotope that is used in nuclear medicine and is not routinely released from ORNL. The tritium $\left({ }^{3} \mathrm{H}\right)$ concentration for reach 2 is from surface water monitoring data taken at White Oak Dam and is not representative of water in the Clinch River. Although ${ }^{99} \mathrm{Tc}$ is identified in reaches 3 and 13 as being a contaminant of concern, the analytical methodology may be questionable when applied to environmental samples. The ${ }^{99} \mathrm{Tc}$ data probably represent gross beta activity rather than the actual activity of ${ }^{99} \mathrm{Tc}$.

Noncarcinogens. Only two organic noncarcinogens in water in reach 3 are identified in Table 4.5 as contaminants that would require further consideration for investigation. However, a relatively large number of inorganic noncarcinogens in reaches 1 and 3 were identified as requiring further investigation. Because the water data are composed of a limited number of Phase 1 samples and are supplemented by NPDES monitoring data that represent point sources of contaminants, results of the screening analyses performed on these imited data are inconclusive. Unless a methodology can be developed to convert the available monitoring data to concentrations representative of the concentrations in the receiving water, additional data for all contaminants in water will be needed for future assessment of the water ingestion pathway. 


\subsubsection{Dredging Scenario}

Conservative screening was used in the dredging scenario to identify contaminants found in buried sediments that require further investigation before designation as high priority contaminants, i.e., carcinogens with screening indices between $10^{-4}$ and $10^{-6}$ and noncarcinogens with a screening indices between 1.0 and 0.1 . Screening indices for the carcinogens are given in Table E.13 and for the noncarcinogens in Table E.14. Screening indices for some inorganics in all pathways were $>10^{-6}$, which indicates that they require further investigation.

Carcinogens and noncarcinogens in the direct and secondary exposure pathways that had screening indices $>10^{-6}$ or $>0.1$, respectively, are summarized in Table 4.6. Reach 3 had the largest number of organic contaminants that require further investigation in both the direct and secondary exposure pathways. Arsenic, beryllium, and chromium in all reaches were identified as requiring further investigation. Mercury and nickel were identified in the screening analysis of the secondary pathways as requiring further investigation in all pathways. Cobalt-60 and ${ }^{137} \mathrm{Cs}$ were identified in the screening analysis of the direct pathways as requiring further investigation in all reaches. Most of the inorganics in the direct and indirect exposure pathways listed in Table 4.6 require further investigation for reach 5 (Watts Bar Reservoir). Further investigation should be conducted to determine the original source of the metals that have relatively high concentrations in reach 5 sediment.

Although no contaminant was identified in the dredging scenario as a high priority contaminant requiring immediate consideration, a relatively large number of organic and inorganic contaminants were identified in most reaches as requiring further investigation. Therefore, dredging should be strictly limited, if tot prohibited, in these reaches.

Conservative screening was used in the dredging scenario to identify low priority contaminants, i.e., carcinogens with a screening index of $<10^{-6}$ and noncarcinogens with a screening index of $<0.1$. Screening results for carcinogens in the secondary pathways are summarized in Table E.6 in Appendix E. Eleven organic and five inorganic carcinogens had screening indices that were $<10^{-6}$ in at least one pathway; but only bis(2-ethylhexyl)phthalate and cadmium can be designated low priority for all reaches. The remaining carcinogens should be considered candidates for future investigation. Ten radionuclides had screening indices that were $<10^{-6}$ in one or more pathways and five of these, ${ }^{211} \mathrm{Am},{ }^{243,244} \mathrm{Cm},{ }^{238} \mathrm{Pu},{ }^{239,240} \mathrm{Pu}$, and ${ }^{235} \mathrm{U}$, can be eliminated from further consideration based on the dredging scenario.

A summary of the noncarcinogens in the dredging scenario that were identified as low priority in one or more pathways is presented in Table E.7 in Appendix E. All nine of the organics had screening indices that were $<0.1$ and can be designated low priority for all pathways and reaches. None of the ten inorganics can be designated low priority because their screening indices for one or more pathways was $>0.1$. Total screening indices for the inhalation pathway for organic and inorganic noncarcinogens were $<0.1$ for all reaches, indicating that this pathway can be assigned low priority; however, only mercury has an inhalation RfD (Table E.14 in Appendix E). Total screening indices for the ingestion of meat, milk, and vegetable pathways were $>0.1$ and cannot be considered low priority. 
Table 4.6. Summary by reach of contaminants in the dredging scenario identified by conservative screening as requiring further investigation

before taking action or designating as low priority

\begin{tabular}{|c|c|c|c|c|c|c|}
\hline \multirow[b]{2}{*}{ Contaminants } & \multicolumn{6}{|c|}{ Reaches } \\
\hline & 1 & 2 & 3 & 4 & 5 & 10 \\
\hline \multicolumn{7}{|c|}{$\begin{array}{l}\text { Sediment exposure vin direct pathways } \\
\text { (Ingestion, inhalation, and external exposure) }\end{array}$} \\
\hline \multicolumn{7}{|l|}{ Organic } \\
\hline Anthracene & & & $\mathbf{X}$ & & & \\
\hline Aroclor-1254 & & $\mathbf{X}$ & $\mathbf{X}$ & & & \\
\hline Arocior-1260 & & $\mathbf{X}$ & & & & \\
\hline Benzo(a)pyrene & & $\mathbf{X}$ & $\mathbf{x}$ & & & \\
\hline Fluoranthene & $\mathbf{X}$ & $\mathbf{X}$ & $\mathbf{X}$ & $\mathbf{X}$ & & $x$ \\
\hline $\mathrm{N}$-Nitro-di-n-propylamine & & & & $\mathbf{x}$ & & \\
\hline Phenanthrene & & $\mathbf{x}$ & $\mathbf{x}$ & $\mathbf{X}$ & & $x$ \\
\hline Pyrene & $\mathbf{x}$ & $\mathbf{X}$ & $\mathbf{x}$ & $\mathbf{x}$ & & $\mathbf{x}$ \\
\hline Toxaphene & & $\mathbf{X}$ & & & & \\
\hline \multicolumn{7}{|l|}{ Inorganic } \\
\hline Arsenic & $\mathbf{x}$ & $\mathbf{x}$ & $\mathbf{X}$ & $\mathbf{x}$ & $\mathbf{x}$ & $\mathbf{x}$ \\
\hline Beryllium & $\mathbf{x}$ & $\mathbf{x}$ & $\mathbf{X}$ & $\mathbf{x}$ & $\mathbf{x}$ & $\mathbf{x}$ \\
\hline Chromium & $\mathbf{X}$ & & $\mathbf{X}$ & $\mathbf{x}$ & $\mathbf{X}$ & $\mathbf{x}$ \\
\hline \multicolumn{7}{|l|}{ Radionuctides } \\
\hline${ }^{\infty} \mathrm{CO}$ & $\mathbf{x}$ & $\mathbf{x}$ & $\mathbf{x}$ & $\mathbf{x}$ & $\mathbf{x}$ & \\
\hline${ }^{137} \mathrm{Cs}$ & $\mathbf{x}$ & $\mathbf{x}$ & $\mathbf{x}$ & $\mathbf{X}$ & $\mathbf{x}$ & $\mathbf{x}$ \\
\hline${ }^{206} \mathrm{U}$ & & & $\mathbf{X}$ & & & \\
\hline \multicolumn{7}{|c|}{$\begin{array}{l}\text { Additional contaminants identified from sediment } \\
\qquad \text { exposure via secondary pathways } \\
\text { (Ingestion of milk, meat, and vegetables produced on sediment) }\end{array}$} \\
\hline \multicolumn{7}{|l|}{ Organic } \\
\hline Aroclor-1254 & & & & $\mathbf{x}$ & & \\
\hline 4,4'-DDD & $\mathbf{X}$ & & & & & \\
\hline 4,4'-DDT & $\mathbf{x}$ & & & & & \\
\hline Benzo(a)anthracene & $\mathbf{x}$ & $\mathbf{x}$ & $\mathrm{x}$ & & & \\
\hline Benzo(b)tlouranthene & & $\mathbf{x}$ & $\mathbf{x}$ & & & \\
\hline
\end{tabular}


Table, 4.6 (continued)

\begin{tabular}{|c|c|c|c|c|c|c|}
\hline \multirow[b]{2}{*}{ Contaminants } & \multicolumn{6}{|c|}{ Reaches } \\
\hline & 1 & 2 & 3 & 4 & 5 & 10 \\
\hline \multicolumn{7}{|l|}{ Organic (continued) } \\
\hline Benzo(k)fluoranthene & $\mathbf{X}$ & & $\mathbf{x}$ & & & \\
\hline Chrysene & & & & & & $\mathbf{X}$ \\
\hline Indeno(1,2,2-cd)pyrene & & $\mathbf{X}$ & & & & \\
\hline \multicolumn{7}{|l|}{ Inorganic } \\
\hline Cadmium & $\mathbf{X}$ & $\mathbf{X}$ & $\mathbf{x}$ & $\mathbf{x}$ & $\mathbf{x}$ & $\mathbf{X}$ \\
\hline Copper & $\mathbf{x}$ & $\mathbf{x}$ & $\mathbf{x}$ & $\mathbf{x}$ & $\mathbf{X}$ & $\mathbf{x}$ \\
\hline Mercury & $\mathbf{X}$ & $\mathbf{X}$ & $\mathbf{X}$ & $\mathbf{x}$ & $\mathbf{x}$ & $\mathbf{x}$ \\
\hline Nickel & $\mathbf{X}$ & $\mathbf{x}$ & $\mathbf{X}$ & $\mathbf{x}$ & $\mathbf{X}$ & $\mathbf{x}$ \\
\hline Selenium & $\mathbf{x}$ & $\mathbf{x}$ & $\mathbf{x}$ & $\mathbf{x}$ & & \\
\hline Silver & & & $\mathbf{x}$ & $\mathbf{x}$ & $\mathbf{X}$ & \\
\hline Thallium & & & $\mathbf{x}$ & & & \\
\hline Uranium & & & $\mathbf{x}$ & & & \\
\hline Zinc & $\mathbf{X}$ & $\mathbf{X}$ & $\mathbf{X}$ & $\mathbf{x}$ & $\mathbf{x}$ & $\mathbf{x}$ \\
\hline \multicolumn{7}{|l|}{ Radionuclides } \\
\hline Sr & & $\mathbf{x}$ & $\mathbf{x}$ & $\mathbf{x}$ & $\mathbf{x}$ & $\mathbf{x}$ \\
\hline${ }^{224} U$ & & & $\mathbf{x}$ & & & \\
\hline
\end{tabular}




\subsubsection{Comparison of the Phase 1 Screening Analysis with a Previous Screening Analysis of Historical Data}

The results of the screening analysis of the historical data base (Hoffnian et al. 1991) were helpful in identifying areas and contaminants that required immediate consideration for remedial action. The screening analysis also helped guide the Phase 1 sampling, which was designed to confirm the areas and contaminants that will require more comprehensive sampling in Phase 2. White Oak Creek Embayment, previously included in reach 2, was identified in Hoffman et al. (1991) as an area requiring immediate attention. Results of intense sampling efforts by the CRRI staff led to the implementation of remedial measures to abate the release of contaminants from the embayment. The White Oak Creek Embayment remediation measures have been completed (Leslie and Kimmel 1992), and this area is no longer considered part of the CRRI. As a result of this remediation, ${ }^{137} \mathrm{Cs}$, which was a high priority contaminant in the previous screening assessment, has been given a lower priority in reach 2 in the current screening assessment.

Generally, the results of the Phase 1 screening analysis are in agreement with results obtained from the earlier human health screening efforts. The screening methodologies used in the two reports are similar; however, modification of several exposure parameters, changes in some EPA-approved risk assessment factors and criteria, and the use of maximum instead of mean concentrations for some media have contributed to the differences in the screening results for the two reports. The identification of ${ }^{20} \mathrm{Th}$ as a high priority contaminant in water from Poplar Creek (reach 3) in the current screening assessments was the most notable difference between the two screening analyses. This result is probably biased and not representative of the entire reach because of the use of source monitoring data to supplement the Phase 1 water data. The source monitoring data should be investigated to document the concentrations of ${ }^{20} \mathrm{Th}$ reported in these data.

PCBs were identified in the fish ingestion pathway as potentially high priority pollutants (screening index between $10^{-4}$ and $10^{-3}$ ) in Hoffman et al. (1991). The PCB Aroclor 1260 was identified in the current screening assessment as a high priority contaminant in fish (screening index $\geq 19^{-4}$ ) requiring immediate consideration for remedial action. A large number of inorganic and organic contaminants were identified as potentially high priority contaminants in the secondary pathways in the dredging scenario in Hoffman et al. (1991). Similar results were obtained for the secondary pathways in the dredging scenario in the current screening assessment, but the number of problem contaminants was smaller. For the dredging scenario, the maximum concentrations for the contaminants found in the sediment cores were used as the sediment concentration in Hoffman et al. (1991) whereas the mean concentration, which is a more realistic value, was used in the current screening assessment. Because of improved analytical procedures, more pesticides and polycyclic aromatic hydrocarbons were detected in the Phase 1 samples than were reported for samples in the historical data base. Several of the contaminants that were not reported in the historical data base are classified in the current screening assessment as requiring further evaluation. However, these contaminants are found in most streams that receive industrial and domestic waste and are not unique to streams that receive effluents from ORR. 


\subsubsection{Nondetected Contaminants}

The nondetected contaminant data base contained several times as many contaminants as the detected contaminant data base. The screening analysis would not be complete without including the nondetected contaminants; however, caution should be exercised in interpreting the resuits because of the uncertainty associated with the reported contaminant concentrations.

Only the nonconservative screening approach was employed for the nondetected contaminants. This approach was used to identify contaminants that have a high priority for action to improve (lower) the detection limits (DLs) or, alternatively, those for which source-term data are needed to determine whether even extremely small quantities of these contaminants have been released from the ORR in the past. Results of the adult nonconservative screening for carcinogens and noncarcinogens in the nondetectable data base are given in Tables E.15-E.18 in Appendix E. Screening indices for individual contaminants are listed according to exposure pathway and reach. Concentrations used in the screening calculations were the minimum DL recorded for a medium across each reach. Screening indices were not summed for contaminant type, pathway, or reach because the uncertainty resulting from using DLs would make the sums overly conservative.

\subsubsection{Carcinogens}

For nondetected carcinogens, a nonconservative screening index $\geq 10^{-4}$ indicated the need to improve the DL of the contaminant for future samples. For organics in fish, the DLs for the same 11 contaminants in reaches 1,2 , and 4 produced screening indices $\geq 10^{-4}$, and four of these contaminants had screening indices of $>10^{-4}$ in reach 3 (Table 4.7). Screening indices for six organic contaminants in water indicated a need for lower detection limits. No radionuclides in water or fish and no carcinogens in the deep core sediments had DLs that produced high priority screening indices (Tables E.15 and E.17 in Appendix E). Near-shore surface sediment grab samples had no problems with DLs.

\subsubsection{Noncarcinogens}

A noncarcinogen in the nondetected data base was assigned a high priority for improvement in analytical methodology if the screening index was $\geq 1.0$. In the fish and water exposure pathways, the detection limit for 4,6-dinitro-2-methylphenol produced screening indices $>1.0$ in most reaches (Table 4.7). None of the DLs for noncarcinogens in sediment produced high priority screening indices (Table E.18 in Appendix E).

\subsubsection{Contaminants Having No Available Toxicity Values}

The number of contaminants that can be quantitatively evaluated in this risk assessment was limited by the availability of chemical-specific, EPA-approved dose/response information. Contaminants for which no slope or reference dose factors are currently available and were therefore not included in the screening assessment are listed in Table E.19 of Appendix E. Of these contaminants, some are essential nutrients that should have little or no toxic effects at the reported concentrations. 
Table 4.7. Contaminants for which we use of detection limits produced screening indices $>10^{-1}$ for carcinogens or $>1.0$ for noncarcinogens by nonconservative screening

\begin{tabular}{lrr}
\hline \multicolumn{1}{c}{ Contaminants } & \multicolumn{2}{c}{ Reaches } \\
\hline Carcinogens & Fish pathway & Water pathway \\
Acenaphthene & $1,2,3,4$ & $1,2,3,4,5,10,13$ \\
Acenaphthylene & $1,2,3,4$ & $1,2,3,4,5,10,13$ \\
Anthracene & $1,2,4$ & \\
Benzo(a)pyrene & $1,2,4$ & $2,3,4,13$ \\
Benzidine & $1,2,4$ & \\
Benzo(g,h,i)perylene & $1,2,3,4$ & $1,2,3,4,5,10,13$ \\
Dibenz(a,h)anthracene & $1,2,4$ & $1,2,3,4,5,10,13$ \\
Fluoranthene & $1,2,3,4$ & $2,3,4,13$ \\
Fluorene & $1,2,4$ & \\
N-Nitroso-di-n-propylamine & $1,2,4$ & \\
N-Nitrosodimethylamine & $1,2,4$ & \\
Phenanthrene & & $1,2,3,4,5,10,13$ \\
Pyrene & $1,2,4,5,13$ & \\
Noncarcinogens & & \\
4,6-Dinitro-2-methylphenol & &
\end{tabular}

\subsubsection{Special Case-Lead}

Although an action level of $0.015 \mathrm{mg} / \mathrm{L}$ for lead has been adopted by EPA (EPA 1991), specific toxicity values are not presently available for risk assessment; instead, an EPA Uptake/Biokinetic Model (Version 0.50) designated for a target population of children (0 to 6 years old) was used to evaluate the risk from lead. The critical value for lead in the blood of young children is $10.0 \mu \mathrm{g} / \mathrm{dL}$. Lead concentrations in the various media for the conservative exposure scenario were input to the model for each reach, and the percentage of the target population estimated to have lead levels greater than the critical value was calculated. EPA Region IV considers an area to be at risk if more than $5 \%$ of the population exceeds the critical value. Only reach 1 (Melton Hill Reservoir), with $6.4 \%$ of the population calculated to exceed the critical value, should be considered of marginal concern for lead exposure. Water concentrations appear to have the most influence on the model results and the model used the direct ingestion of surface water for drinking purposes.

\subsubsection{High Priority Contaminants and Contaminants Requiring Further Imvestigation}

The PCB Aroclor 1260 was identified as a high priority contaminant in the tish ingestion pathway (Section 4.1.6.1). Total PCB concentrations (i.e., Aroclor 1260, Aroclor 1254, and other formulations) should be considered when determining risk to human health; therefore, PCBs in the Clinch River/Watts Bar Reservoir should be considered high priority contaminants. The average concentration for PCBs in fish in the reaches of the Clinch and Tennessee River system used in this screening analysis (Appendix E) is less than the FDA action level of $2.0 \mathrm{ppm}(\mathrm{mg} / \mathrm{kg})$ in fish tissue.

Thorium-228 was identified as a high priority contaminant in the water ingestion pathway in reach 3, Poplar Creek embayment. Because of the limited water data and because the ${ }^{228} \mathrm{Th}$ 
concentrations came from source monitoring data (see Sect. 4.1.6.3), ${ }^{228} \mathrm{Th}$ is not designated as a high priority contaminant in this screening analysis. The concentration of ${ }^{228} \mathrm{Th}$ from the source monitoring data which resulted in a screening index of $>10^{-4}$, for the water ingestion pathway, point out the need for collecting additional water samples and suggest that the source data should be investigated to document the concentrations of ${ }^{228} \mathrm{Th}$ reported in these data.

A listing of the contaminants requiring further investigation is provided in Table 4.8. Results of the water ingestion pathway are not included in this list because of the limited data available for analyses. The contaminants found in the sediments used for the dredging scenario are listed by direct and secondary exposure pathways. The uncertainty associated with results of the screening analysis increases in order from the fish ingestion pathway, to the direct exposure to sediment pathways, to the secondary (modeled) pathways. However, copper is an artifact in the fish ingestion pathway (see Sect. 2.4) and can be designated low priority. In addition, many of the contaminants were detected in less than $5 \%$ of the samples analyzed [i.e., bis(2-ethylhexyl)phthalate in the fish ingestion pathway]. For the organics listed in the secondary pathways, only Aroclor 1260, phenanthrene, and pyrene were detected in more than $5 \%$ of the samples analyzed. Therefore, additional analyses of these data and the methodology used in detecting these contaminants in environmental samples can undoubtedly reduce the number of contaminants listed in Table 4.8 .

\subsubsection{Summary for Screening Risk Assessment}

The human health screening analysis of the Phase 1 data, in general, confirms the results of the previous screening of historical data (Hoffman et al. 1991). Interim remedial action has been completed on the White Oak Creek Embayment, which excludes it from the present study area; therefore, data from the embayment were not included in this report except for NPDES water monitoring data collected at White Oak Dam. The Phase 1 conclusions for the screening analysis for human healtb are listed here.

- Only two contaminants were identified by nonconservative screening as high priority contaminants requiring immediate consideration for remedial action. The PCB Aroclor 1260 was found in fish from the mouth of Poplar Creek to above the confluence with East Fork Poplar Creek, the Clinch River arm of Watts Bar Reservoir, Watts Bar Reservoir below the mouth of the Clinch River, and Chicamauga Reservoir at concentrations that classified it as a high priority contaminant; however, PCBs are found in most Tennessee rivers and lakes. Although the ORR is a probable source of PCBs, it is not the only one for the CR/WBR system.

- Thorium-228 was tentatively identified in Poplar Creek as a high priority contaminant in the water ingestion pathway. Thorium-228 was measured only at source monitoring sites at $\mathrm{K}-25$, and the concentrations probably do not represent concentrations in the main body of water. Additionally, ${ }^{225} \mathrm{Th}$ is a daughter of ${ }^{232} \mathrm{U}$ or naturally occurring ${ }^{232} \mathrm{Th}$, which were not reported in the monitoring data. The absence of either parent radionuclides indicate that the data or analytical methodology used for sample analyses are in need of reevaluation. 
Table 4.8. Summary of contaminants requiring further investigation before taking action or designating as low priority based on fish ingestion and dredging scenarios

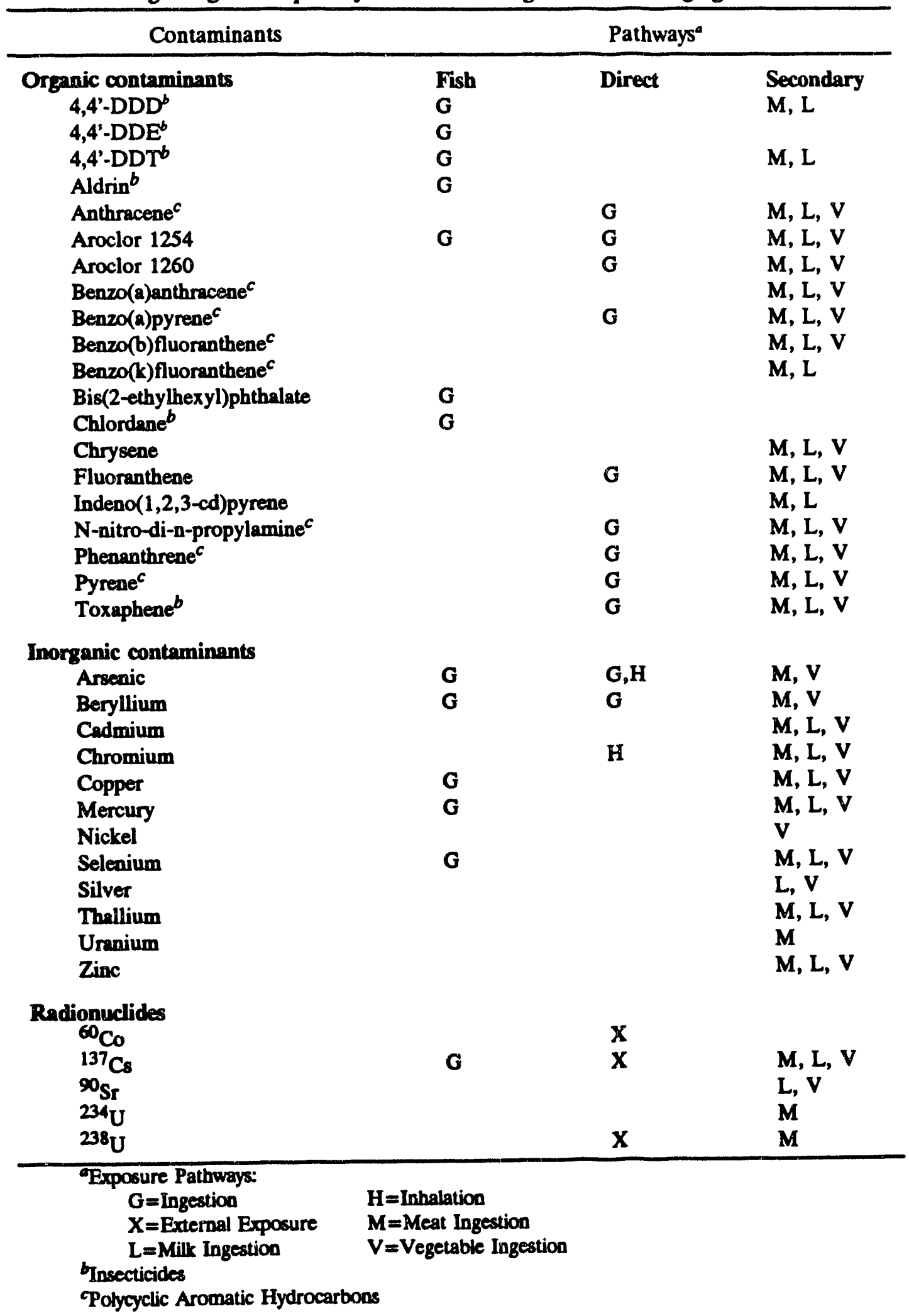


- Results of the screening of the surface water data are inconclusive because of the limited number of Phase 1 samples and the uncertainty associated with using the source monitoring data to predict the concentrations of the contaminants in the different reaches. The water results should be viewed in terms of general patterns rather than results for individual contaminants. The results of the screening analysis indicate that a large number of organic contaminants in Poplar Creek would require further investigation; however, most of these contaminants are common industrial or laboratory chemicals or pesticides that are not unique to the ORR facilities.

- Screening of the contaminants in the fish ingestion pathway identified the PCB Aroclor 1260 as a high priority contaminant. Aroclor 1254, several pesticides (4,4'-DDE, aldrin, and chlordane) that are ubiquitous contaminants in East Tennessee aquatic environments, arsenic, beryllium, mercury, and selenium were identified as contaminants in fish that needed further evaluation. The only radionuclide in the fish ingestion pathway that was identified as needing additional evaluation was ${ }^{137} \mathrm{Cs}$ in the Clinch River arm of Watts Bar Reservoir.

- A conservative screening of near-shore surface-sediment data identified ${ }^{60} \mathrm{Co}$ and ${ }^{137} \mathrm{Cs}$ as low priority contaminants in the ingestion and inhalation pathways. In the external exposure pathway, ${ }^{60} \mathrm{Co}$ and ${ }^{137} \mathrm{Cs}$ were identified as contaminants that would require further investigation. However, because the concentrations at all sites are relatively low and the screening index from all pathways, including external exposure, is $<10^{-4}$, further evaluation of the data will probably classify these contaminants as low priority.

- Screening based on the dredging scenario identified a relatively large number of organic contaminants in Poplar Creek and the Clinch River arm of Watts Bar Reservoir above the mouth of Poplar Creek which would require further investigation. Many of these organic contaminants are common industrial and laboratory chemicals, or by-products of fossil fuel burning, and are not unique to the ORR.

- Conservative screening of Phase 1 sediment data in the dredging scenario eliminated all radionuclides that were identified from all pathways from further consideration except ${ }^{60} \mathrm{Co},{ }^{137} \mathrm{Cs}$, and ${ }^{238} \mathrm{U}$ in the external exposure pathway; ${ }^{90} \mathrm{Sr}$ in the vegetation and milk ingestion pathways; ${ }^{234} \mathrm{U}$ and ${ }^{238} \mathrm{U}$ in the meat ingestion pathways; and ${ }^{137} \mathrm{Cs}$ in the milk, meat, and vegetable ingestion pathways.

\section{ECOLOGICAL RISK}

This preliminary screening ecological risk assessment is structured in terms of the standard paradigm for risk assessment (National Research Council, 1983, Risk Assessment in the Federal Government: Managing the Process, Washington, DC: National Academy Press, Suter 1992, Risk Assessment Forum 1992). It begins with a hazard definition phase (also termed hazard identification or problem formulation) that defines the contaminant sources, the receiving environment, and the assessment endpoints. It follows with an analytical phase consisting of exposure assessment and effects assessment. The results of these analyses are then combined in a risk characterization. Finally, the results of this screening ecological risk assessment are compared to a prior screening ecological risk assessment performed for the off-site RI (Suter 1991). This assessment constitutes initial screening of the Phase 1 data. The 
assessment is intended to provide an interpretive summary of the data with respect to ecological risks and to guide additional sampling and analysis during the initial stages of Phase 2. Additional risk assessments of the Phase 1 data set will be conducted later.

\subsubsection{Hazard Definition}

The purpose of this screening assessment is to determine which of the contaminants detected in the off-site environment occur in forms and concentrations that constitute a hazard to the nonhuman biota of the Clinch River downstream of contaminant releases from the ORR. Those contaminants will be the focus of attention in the Phase 2 sampling and analysis program.

The ultimate sources of the contaminants considered in this assessment are the DOE's operations of the ORR, including waste disposal, spills, and use of chemicals such as pesticides. The intermediate sources are the streams that drain the ORR, all of which are tributaries of the Clinch River. The proximate sources are the contaminated media in the Clinch River: water, sediment, and fish tissues. Other contaminant sources occur on the Clinch and Tennessee rivers and their tributaries, which contribute to ambient concentrations; however, they are not objects of this assessment.

The assessment endpoints for this assessment are

1. a $20 \%$ or greater reduction in the abundance or production of any species of fish, and

2. a $20 \%$ or greater reduction in the abundance or production of any species of aquatic wildlife.

These endpoints are taken from the strategy for ecological risk assessment on the ORR (Suter et al. 1992a). The 20\% level of effect is based on EPA regulatory precedents and practical limitations on the detection of ecological effects. Fish are chosen as the aquatic endpoint species because of their societal importance and because fish integrate direct toxic effects and effects on lower levels in the aquatic food web. All fish are included as potential endpoint species, but special emphasis is placed on the largemouth bass (Micropterus salmoides) because of its recreational importance and because it is a top carnivore (Suter et al. 1992b). The endpoint wildlife species are mink (Mustela vison) and great blue heron (Andea herodias). These species were chosen on the basis of the prior screening ecological risk assessment, which showed the major risk to wildlife to be due to consumption of contaminated fish and showed that mink are particularly sensitive to the most hazardous contaminants and that great blue herons are the most abundant piscivorous bird in the Clinch River near the ORR (Suter 1991).

\section{Exposure Assessment}

Exposure assessment estimates the concentrations of contaminants to which organisms are exposed, taking into consideration (as far as possible) the spatial and temporal distributions of those concentrations. For detected chemicals, mean and upper 95\% confidence limits on concentrations are considered. The mean concentration is assumed to represent typical chronic exposures. Upper $95 \%$ confidence limits may represent local extreme chronic concentrations or acute exposures; the data are not sufficient to determine which. For undetected chemicals, the minimum detection limit and the upper $95 \%$ confidence limits on 
the detection limits are considered. The derivation of these exposure concentrations and the actual values are presented in Appendix F.

\section{Aqueous exposures}

The aquatic biota are assumed to be exposed to the dissolved fraction of the chemicals in water, because that is the bioavailable form (HECD 1992). Dissolved (i.e., $0.45 \mu \mathrm{m}$ filtered) aqueous concentrations are available for inorganic chemicals, but only total concentrations are available for organic chemicals in the CRRI samples. Because only a few CRRI samples are available, NPDES samples are also included and are analyzed and discussed separately. The NPDES analyses are all from total (i.e., unfiltered) samples. In addition, fish tissue concentrations are used to estimate the concentrations of contaminants to which fish have been exposed. This is done by dividing the reported concentrations in fish fillets by the bioconcentration factors (BCFs) provided by the EPA in the water quality criteria support documents.

\subsection{Sediment exposures}

Two different measures of exposure are used for sediments. First, whole sediment concentrations are used for comparison to screening benchmarks expressed as sediment concentrations. Second, for organic chemicals concentrations of chemicals in pore water are estimated by using the equilibrium partitioning approach. Pore-water concentrations of neutral (nonionic) organic chemicals can be calculated by assuming equilibrium partitioning between the pore water and the organic matter fraction of the sediment (OWRS 1989). The partitioning coefficient $\left(\mathrm{K}_{\mathrm{p}}\right)$ is the product of the organic matter/water partitioning coefficient $\left(K_{o c}\right)$ and the fractional organic matter content of the sediment $\left(f_{o c}\right)$. Because sediment-dwelling organisms are approximately as sensitive to chemicals in water as the population of species used to derive the National Water Quality Criteria (NWQC) (OWRS 1989), the same screening criteria can be used as for water but corrected for partitioning. The formula is

or

$$
\mathrm{C}_{\mathrm{s}}=\mathrm{K}_{\mathrm{p}} \mathrm{C}_{\mathrm{w}}
$$

$$
C_{s}=K_{o c} f_{o c} C_{w}
$$

where $C_{8}$ and $C_{w}$ are equivalent concentrations in sediment and water, respectively. $K_{o c}$ is seldom available, but it is quite accurately approximated by the octanol/water partitioning coefficient $\left(\mathrm{K}_{\text {ow }}\right.$ ) (DiToro 1985). This approach is being used by EPA to derive sediment quality criteria (OWRS 1988). This approach does not produce accurate predictions of pore water concentrations for ionic organic chemicals. However, it is used for all organic chemicals in this assessment because it is conservative for ionic chemicals (i.e., it somewhat overestimates pore water concentrations) and because alternative methods are not available for ionic organic chemicals.

\section{Widlife dietary exposures}

Piscivorous wildlife are exposed through consumption of contaminated fish. The fish flesh concentrations reported are for filets rather than the whole fish consumed by a heron or mink. Because many contaminants concentrate in fat or in organs other than muscle, these concentrations are likely to be underestimates of the exposure experienced by piscivorous 
wildlife. The error due to this factor is approximately a factor of 1.5 to 2 for metals and 2 to 3 for organic chemicals (Suter 1991). Therefore, the wildlife screening benchmarks (Sect. 4.2.3) include a factor of 2 for metals and 3 for organic chemicals to conservatively correct for this extrapolation.

\subsection{Effects Assessment: Screening Benchmarks}

In this screening assessment, effects are expressed as toxicological benchmarks: concentrations in media which are indicative of acceptable effects (lower screening benchmarks) or unacceptable effects (upper screening benchmarks). Only lower benchmarks were needed for this assessment, and they are presented in Appendix F.

\subsubsection{Aquatic biota}

The screening benchmarks for aquatic biota are taken from Suter et al. (1992b). Because there are no standard screening benchmarks, sets of alternative benchmarks were calculated. For the upper screening benchmark, they are the acute National Ambient Water Quality Criterion (ANAWQC) or, for chemicals with no criterion value, the lowest reported acute LCSO or ECSO. The alternative chronic benchmarks are the chronic NAWQC (NAWQC ACTUAL); the chronic pesticide screening value, a concentration that is estimated with 95\% confidence not to excreed the unknown chronic NAWQC for those chemicals with no NAWQC (NAWQC ADVISORY); the lowest chronic values for fish (LCV FISH) and daphnids (LCV DAPHNIDS); the lowest EC20 (concentration causing a 20\% reduction in survival, growth, or fesindity) for fish (LTV EC20 FISH) and daphnids (LTV EC20 DAPHNID) from chronic toxicity tests; the estimated EC20 for a sensitive species (SS EC20); and the concentration estimated to cause a $20 \%$ reduction in the recruit abundance of largemouth bass (EC20 POPULATION). The methods of derivation and source data for these benchmarks are provided in Suter et al. (1992b).

\subsubsection{Sediments}

Two types of benchmarks were used with sediment concentrations. First, NOAA's Effects Range-Low (ER-L) and Effects Range-Median (ER-M) concentrations were used for the 43 chemicals for which they are available (Long and Morgan 1991). The ER-L and ER-M are concentrations in whole sediment that appeared to cause toxic effects in no more than $10 \%$ and $50 \%$ of sediments, respectively.

The second type of sediment screening benchmark is based on equilibrium partitioning of organic chemicals between sediments and pore water (Sect. 4.2.2). Because it is assumed that the exposure is due to exposure to the pore water, the aqueous screening benchmarks discussed above are used.

\subsubsection{Wildife}

The screening criteria for wildlife are the same as the prior off-site screening ecological risk assessment (Suter 1991). Because there is not a set of consistent toxicity test data for wildlife as there is for aquatic biota, the screening benchmarks for wildlife are based on expert judgement concerning the best available test endpoint for wildlife found in the literature for each chemical. Wildlife toxicity data were preferred, but data for laboratory rodents and other 
domestic animals were included in the review. Data for ruminants were excluded because of the influence of their unique digestive system on uptake. Data on cancer induction were also excluded because low frequencies of tumors have no effects on population endpoints. Toxicological benchmarks expressed as dietary concentrations are preferred and can be used without conversions. When benchmarks are expressed as acute doses, equivalent dietary concentrations are estimated by assuming that an acute dose is equivalent to one diy's consumption and that the consumption rate is $8 \%$ of body weight per day.

Unlike the screening criteria that are based on NWQC, these criteria do not reflect the diversity of organisms that are exposed by this route. If chronic sublethal effects data are available for either mammals or birds but not both, a correction factor of $\mathbf{1 0}$ for differences in sensitivity is applied. This factor is based on limited studies that indicate that birds and mammals can differ in sensitivity by more than an order of magnitude and either can be more sensitive (Sigal and Suter 1989). If there are data for both birds and mammals, but fewer than five species including at least two avian species, we assume that the variance in sensitivity of the test species approximates the variance in all avian and mammalian species and apply no factor for differences among species. If the most sensitive test end point is death or another severe effect (e./5., reproductive failure), a factor of 5 is applied to estimate the threshold for effects on individuals that could result in population reductions (Tucker and Lietzke 1979). These factors are not applied to the upper criterion, which is intended to be a concentration at which effects are certain. The derivation of wildlife benchmarks for individual chemicals is presented in Suter (1991).

\subsection{Risk Characterization: Contaminant Screening Results}

The quotient method is used to integrate exposure and effects in screening assessments. That is, the environmental concentrations are divided by the screening benchmarks and the decision is based on the magnitude of the quotient. If the quotient is $<1$ for a lower screening benchmark, that indicates a nonhazardous exposure level. If the quotient is $>1$ for an upper screening benchmark, that indicates a clearly hazardous exposure. Chemical concentrations falling between those benchmarks indicate that a hazard worthy of additional investigation exists. All chemicals that have concentrations greater than lower screening benchmarks are potential "contaminants of concern."

Although the use of multiple upper and lower screening benchmarks increases confidence in the results of the screening assessment, it complicates interpretation of results. Because the altirnative screening benchmarks are based on different assumptions, and none of the benchmarks has been shown to consistently estimate thresholds for significant effects, greater confidence in the screening results can be obtained by considering multiple benchmarks. However, interpretation of conflicting results requires expert judgement. The following interpretation rules are applied to the aqueous concentrations, including the estimated pore water concentrations for organics in sediment.

1. If the mean water concentration for a chemical exceeds its chronic NAWQC, then that chemical is a contaminant of concern.

2. If the maximum water concentration for a chemical exceeds its acute NAWQC, then that chemical is a contaminant of concern.

3. If two or more lower screening benchmarks are exceeded by the mean concentration, then that chemical is a contaminant of concern. 
4. If a mean concentration exceeds a single lower screening criterion or a maximum concentration exceeds a single upper screening criterion, then the magnitude of the quotient and the conservatism of the benchmark will be considered in deciding whether to include the chemical as a contaminant of concern. However, a chemical is not a contaminant of concern when only the advisory concentration is exceeded.

5. Because of the uncertainty concerning the applicability of the EPA's bioconcentration factors (BCFs) to the field, aqueous concentrations estimated from fish concentrations are used only as supporting evidence.

Metals in sediment are considered to be contaminants of concern if the mean concentration exceeds the ERL or ERM or if the upper confidence limit concentration exceeds the ERM. Chemicals in fish fillets are considered to be contaminants of concern if their mean concentrations exceed lower screening benchmarks for piscivorous wildlife. The screening calculations and their results are presented in Appendix F. The potential contaminants of concern are discussed below, and the selected contaminants of concern are listed in Table 4.9.

\subsubsection{Potential contaminants of concern in water}

Aluminum Aluminum concentrations in MDRS samples from reaches $1,2,3$, and 4 exceed NAWQC and one or more other ber almost certainly due to particulate forms that are not bioavailable. Aluminum toxicity is not known to occur in circumneutral ambient waters (Baker et al. 1990).

Cadmium. In reaches 1 and 4, dissolved cadmium was detected in one of three samples. The dissolved concentrations in each reach were greater than the lowest chronic value for daphnids and the sensitive species EC20. These benchmarks were also exceeded by the limits of detection in the reaches where it was not detected. Mean cadmium concentrations in NPDES samples (i.e., total rather than bioavailable concentrations) from reach 1 exceeded all seven benchmarks, including the NAWQC, and in reach 3 exceeded all but the population EC20. Cadmium was not detected in fish fillets, but the detection limits were high relative to toxic concentrations.

Copper. Copper concentrations in fish tissues from reach 5 suggest exposure to extremely high aqueous concentrations. The high mean and upper confidence limit values are due to one extremely high value that is likely to be in error (Sect. 3.4.2). Mean copper concentrations in NPDES samples (i.e., total rather than bioavailable concentrations) exceed seven benchmarks in reach 3 (including the NAWQC), five benchmarks in reaches 1 and 2, and three benchmarks in reach 4. Copper was not detected in dissolved fraction analyses but detection limits exceeded four benchmarks in all reaches.

Cyanide Mean cyanide concentrations in NPDES samples (i.e., total rather than bioavailable concentrations) exceed all five benchmarks in reaches $2,3,4$, and 13 (including the NAWCC). Cyanide was not included among the dissolved water or fish analysis results for Phase 1.

Iron. Mean iron concentrations in NPDES samples (i.e., total rather than bioavailable concentrations) exceed two benchmarks in reaches $1,2,3$, and 4 and the NAWQC in reach 3. Iron was detected in dissolved water analyses from reaches 2 , and 5 but not $1,3,4$, or 10 . 
Table 4.9. Contaminants of concern for ecological rist assessment

\begin{tabular}{ll}
\hline Detected & Undetected \\
\hline Arsenic & Acenaphthene \\
Bis(2-ethylhexyl)phthalate & Anthracene \\
Cadmium & Aroclor 1248 \\
Copper & Aroclor 1254 \\
Cyanide & Benzo(a)anthracene \\
DDT & Benzo(a)pyrene \\
Iron & Boron \\
Lead & Chlordane \\
Mercury & Chromium \\
Nickel & Cobalt \\
PCBs (Aroclors) & Vanadium \\
Selenium & 2-methylphenol \\
Silver & Benzoic acid \\
Zinc & Benzyl alcohol \\
& Lindane \\
& Heptachlor \\
& n-Nitrosodiphenylamine \\
& Phenol \\
& $2,4-$ Dinitrophenol \\
& 2-Methylphenol \\
\hline
\end{tabular}


Both the detected concentrations and the detection limits were low. Iron was not measured in fish tissues because it is a macronutrient.

Lead Mean lead concentrations in NPDES samples (i.e., total rather than bioavailable concentrations) exceed five benchmarks in reach 1 and two benchmarks in reaches 2 and 3 including the NAWQC in all three. Lead was detected in dissolved water analyses from reaches 1,4 , and 13 but not $2,3,5$, or 10 . Both the detected concentrations and the detection limits were low. Lead was not detected in fish fillets, and the detection limits were low.

Mercury. Mercury was detected in one dissolved-phase sample from reach 3. The mean concentration exceeded four of six benchmarks. Mean total mercury concentrations in NPDES samples from reaches 1 and 3 also exceed those benchmarks, and in reach 4 it exceeds three benchmarks. Mean aqueous detection limits in reaches $1,2,4,5,10$, and 13 exceed three benchmarks. However, water concentrations estimated from fish fillet concentrations and EPA BCFs suggest aqueous exposure levels much lower than measured values in water. The benchmarks for methyl mercury were used for all of these calculations for conservatism. The relative abundance of organic and inorganic mercury in these sam is unknown.

Nickel Mean nickel concentrations in NPDES samples (i.e., total rather than bioavailable concentrations) exceed five benchmarks in reach 3 and two benchmarks in reaches 1,2 and 4. Nickel was not detected in dissolved water samples at a detection limit that was $12 \%$ of the NAWQC but above two out of seven benchmarks in all reaches. Nickel was not detected in fish tissues, and the detection limit was lower than all benchmarks.

Selenium. Mean selenium concentrations in fish tissues suggest that the fish were exposed to aqueous concentrations that wire higher than two or more benchmarks in all reaches. In reaches $1,2,4,10$, and 15 , the estinated mean aqueous concentration was greater than the NAWQC. However, selenium was not detected in the dissolved phase of water from any reach even though the detection limit was below the NAWQC and all other benchmarks, and total concentrations in NPDES samples were low. This discrepancy is likely to result from use of the EPA's BCF for this metal. There is now considerable evidence that, in the field, selenium is bioaccumulated through diet, which would make an aqueous concentration estimated using a BCF too high (Lemly 1985).

Silver. Dissolved silver was detected in one of four samples from reach 3 . The concentration was greater than all seven lower benchmarks for that metal. In all other reaches silver was undetected, but the limits of detection exceeded all but one of the lower benchmarks. Mean coniderntrations of total silver in NPDES samples from reach 3 were greater than all seven betuthmarks.

\subsection{Potential contaminants of concern in sediment}

Arsenic The upper confidence limit arsenic concentration in sediment exceeds the ERM in reach 3 and the ERL in reaches 1 and 4.

Bis(2-ethylheryl)phthalate. The estimated mean pore water concentration of this phthalate ester exceeds the lowest chronic value and the lowest EC20 for daphnids as well 
as the advisory concentration in reach 5 . The upper confidence limit estimated pore water concentration exceeds those three benchmarks in reaches 2,3 , and 5 .

Lead The mean sediment concentration exceeds the ER-L in reaches 5 and 10 and the upper confidence limit concentration exceeds the ER-M in reach 4 and the ER-L in reaches 1,2 , and 3 .

Mercury. The mean mercury concentration in sediment exceeds the ER-M in reaches 3 and 4 and exceeds the ER-L in reaches 2 and 5 . The upper confidence limit mercury concentration in sediment exceeds the ER-L in reach 1. The ER-L and ER-M values are based on naturally occurring mixtures of organic and inorganic mercury.

Zinc. The mean zinc concentration in sediment exceeds the ER-L in reach 5. The upper confidence limit zinc concentration in sediment exceeds the ER-M in reaches 1 and 4 and the ER-L in reach 3.

\subsubsection{Potential contaminants of concern tor wildlife}

Aroclors. Mean concentrations of Aroclor 1254 in reaches 2, 3, 4, 5, 13, and 15 and of Arochlor 1260 in reaches $1,2,3,4,5,13$, and 15 exceeded the lower piscivore benchmark for PCBs. In addition, upper confidence limit concentrations of Aroclor 1254 in reach 1 and of Aroclor 1260 in reach 10 exceed the lower benchmark. That benchmark is a dietary concentration causing significant reductions in mink reproduction divided by a factor of 5 for an effects threshold and of $\mathbf{3}$ for fillet to whole fish conversion.

Copper. The upper confidence limit copper concentration in reach 5 exceeds the lower wildlife benchmark. However, this value is suspect (see Sect. 3.4).

4,4'-DDT and Metabolites Mean DDE in reach 4 exceeded the lower piscivore benchmark, which is the lowest dietary concentration causing significant reductions in avian reproduction divided by a factor of 5 for an effects threshold and of 3 for fillet to whole fish conversion. Upper confidence limit fish exceeded that benchmark for DDE in reaches 1, 2, 4 , and 5 for DDD in reaches 3 and 15, and for DDT in reach 4 and exceeded concentrations observed to cause reproductive effects in reaches 4 and 15. DDT is not known to be associated with ORR effluents or wastes, but the highest concentrations are found in fish from the Clinch River downstream from Poplar Creek (reach 4).

Mercury. Mean mercury concentrations in fish from all reaches exceeded the lower piscivore benchmark, which is the lowest dietary concentration causing significant reductions in avian reproduction divided by a factor of 2 for fillet to whole fish conversion. Mean fish fillets from reaches $3,4,10,13$, and 15 excec ' $\mathrm{ed}$ the $0.1 \mathrm{mg} / \mathrm{kg}$ concentration observed to cause reduced reproduction in mallard ducks. The highest mean concentrations in fish were found in lower Poplar Creek (reach 3), but the second highest concentrations were found in Norris Reservoir (reach 10).

Selenium. Mean selenium concentrations in fish from reaches $1,2,4,5,10,13$, and 15 barely exceeded the lower piscivore benchmark, which is the lowest dietary concentration causing significant reductions in avian reproduction divided by a factor of 2 for fillet to whole fish conversion. None of the mean or upper confidence limit fish exceeded concentrations 
observed to cause toxic effects in toxicity tests. The highest mean concentrations in fish were found in Melton Hill Reservoir (reach 1), and the second highest concentrations were found immediately below the reservoir but above Poplar Creek in reach 2 .

\subsubsection{Undetected potential contaminants of concern}

Some contaminants were not detected in water, but the detection limits were high enough that they would be contaminants of concern if the actual concentrations were just below the detection limit. In a few cases, such as chlordane and lead, detection limits were above NAWQC.

\subsection{Comparison to Previous Results}

Because of declines in reported concentrations of most chemicals in most media, the number of potential contaminants of concern decreased greatly compared to the screening assessment based on historic data (Suter 1991). Mercury in fish tissues is an exception, having declined only slightly.

Data needs identified in the previous assessment have been met in part (Suter 1991). Concentrations of dissolved metals, which were not available before, were available for this assessment; the data are now consistent across reaches; and monitoring of contaminants in great blue heron eggs and nestlings has begun. However, some data needs identified in the previous assessment are still not filled. These include analyses of whole fish, of sediment pore water, and of certain species for arsenic, mercury, and chromium. In addition, indicators of response to chemical exposures other than body burdens have been monitored in herons but not fish. 


\section{SUMMARY}

This report presents and discusses the results of Phase 1 of DOE's remedial investigation of the CR/WBR system. The approach in this report is to use a screening assessment for human health and ecological risk to identify contaminants, environmental pathways, and sites in the river-reservoir system that will require further investigation during Phase 2 of the CRRI. In addition, the screening assessment will identify contaminants that can be assigned a low priority for further investigation.

The CRRI is designed to address the transport, fate, and distribution of waterborne contaminants released from the ORR and to assess potential risks to human health and the environment associated with these contaminants. The contaminants released since the early 1940 s include a variety of radionuclides, metals, and organic compounds. Primary areas of investigation are Melton Hill Reservoir, the Clinch River from Melton Hill Dam to its confluence with the Tennessee River, Poplar Creek, and Watts Bar Reservoir. The contaminants identified in the CR/WBR downstream of the ORR are those associated with the water, suspended particles, deposited sediments, aquatic organisms, and wildlife feeding on aquatic organisms.

A phased remedial investigation of the CR/WBR system is under way to (1) define the nature and extent of the off-site contamination, (2) evaluate associated environmental and human health risks, and (3) preliminarily identify and evaluate potential remediation alternatives.

Phase 1 of the CRRI was an initial sampling and analysis of fish, sediment, and water in selected areas of the CR/WBR chosen to represent differing levels of media contamination. Specifically, Phase 1 was designed to (1) obtain high-quality data to confirm existing historical data for contaminant levels in fish, sediment, and water from the CR/WBR; (2) determine the range of contaminant concentrations present in the river-reservoir system; (3) identify specific contaminants of concern; and (4) establish the reference (background) concentrations for those contaminants. Previously, scoping studies were conducted to provide an initial determination of contaminant distribution in the sediments of WBR (Olsen et al. 1992) and to preliminarily assess potential human health and ecological risk (Suter 1991; Hoffman et al. 1991) in the CR/WBR system.

For Phase 1 of the CRRI, the CR/WBR system was divided into ten reaches, six of which are potentially affected by releases from the ORR. The other four reaches serve as reference areas. Contaminant concentrations for fish, sediment, and water were summarized for each of the ten reaches. Analytes detected at least once in a reach were evaluated separately from those never measured above their analytical detection limit (i.e., nondetected).

Surface water samples were collected for Phase 1 during winter conditions and analyzed for inorganic, radiochemical, and organic constituents to confirm suspected low concentrations of contaminants in the CR/WBR system. Characterization of the nature and extent of surface water contamination in the CR/WBR system during Phase 1 of the CRRI was limited to a single sampling event for each station. The primary conclusions from the collection and analysis of surface water during Phase 1 are listed here. 
- Inorganic and organic constituents that may pose a risk to human health or the environment had concentrations comparable to those reported previously and were well below the Tennessee Water Quality Criteria.

- Values for all radiological constituents in surface water were comparable with the mean values found in other investigations. Each of these radionuclides has been or is currently being released from the ORR to surface waters.

- The results from Phase 1 water samples, in combination with source monitoring and historical data, indicate that additional work is needed to characterize Poplar Creek below the mouth of East Fork Poplar Creek and the Clinch River arm of Watts Bar Reservoir.

The primary conclusions from the sediments collected and analyzed during Phase 1 and the near-shore sediment task are listed here.

- Concentrations of ${ }^{137} \mathrm{Cs}$ in the near-shore surface sediment of Watts Bar Reservoir below the mouth of the Clinch River are comparable to background levels. However, concentrations within the Clinch River arm of the reservoir are above background and warrant further study.

- Patterns of ${ }^{137} \mathrm{Cs}$ and ${ }^{60} \mathrm{Co}$ in sediment cores confirm previous studies and indicate that these contaminants are deep in the sediment throughout the system with highest concentrations in the Clinch River arm of the reservoir.

- Concentrations of ${ }^{224} \mathrm{U},{ }^{235} \mathrm{U}$, and ${ }^{238} \mathrm{U}$ in sediment cores from Poplar Creek are about 5 times higher than background.

- Concentrations of arsenic, beryllium, cadmium, chromium, copper, and mercury in sediments are above background levels in the Clinch River arm of Watts Bar Reservoir and in Poplar Creek.

- Concentrations of cadmium, lead, and zinc in sediments are higher in the main body of Watts Bar Reservoir, below the mouth of the Clinch River, than in upstream areas.

- Detectable quantities of Aroclor 1254 were only found in sediments at Clinch River Mile 9.5, which is downstream of the confluence of the Clinch River and Poplar Creek.

- Detectable quantities of flouranthene, phenanthrene, and pyrene were found in sediments in Poplar Creek and in the Clinch River between Melton Hill Dam and the mouth of Poplar Creek.

To characterize the nature and extent of contamination in fish in the CR/WBR system, contaminants were analyzed in three species (channel catfish, largemouth bass, and bluegill sunfish) representing three trophic levels. The primary conclusions from the fish sampling and analyses conducted during Phase 1 are listed here. 
- Of the 77 organic and 13 inorganic contaminants that were analyzed in fish, a majority (63 organics and 7 inorganics) were not detected from any CR/WBR site.

- Three of the contaminants ${ }^{90} \mathrm{Sr}$, mercury, and zinc) were detected in all fish samples; 17 analytes were detected in greater than 5\% of all fish samples. PCBs and chlordane were detected in fish at all CR/WBR sites, and ${ }^{137} \mathrm{Cs}$ was detected in $60 \%$ of the sites.

- Mercury and ${ }^{137} \mathrm{Cs}$ in fish were elevated at sites downstream of known sources of contaminant inputs, East Fork Poplar Creek and White Oak Creek, respectively. No pattern of downstream gradients of PCBs or chlordane was evident in fish collected in Phase 1.

- Phase 1 data for fish are not markedly different from previous historical data on contaminant levels in fish from the CR/WBR system.

- Mean mercury concentrations in fish were significantly higher in Poplar Creek below the confluence with East Fork Poplar Creek and at the first site downstream of the confluence of Poplar Creek and the Clinch River than at the reference site (Norris Reservoir). Mean selenium concentrations in Melton Hill Reservoir and the Clinch River arm of Watts Bar Reservoir were higher than those at the reference sites.

- Mean total PCB concentrations in fish at all CR/WBR sites were significantly higher than those at the reference, whereas mean chlordane concentrations were higher than reference concentrations at sites in Melton Hill Reservoir and the Clinch River arm of Watts Bar Reservoir.

The conclusions of the screening assessment for ecological risk for Phase 1 are listed here.

- The assessment of new data confirms the finding of the assessment of historical data that mercury and PCBs in fish constitute a significant risk to piscivorous wildlife.

- Phase 1 anal; jal lata for dissolved (i.e., bioavailable) concentrations of inorganic chemicals in water greatly reduced the number of metals that appear to be hazardous to aquatic life relative to historical data or to source monitoring (e.g., National Pollutant Discharge Elimination System data).

- Cadmium, mercury, and silver appear to be hazardous to aquatic life in water from some reaches, but the number of samples in which they were detected is extremely small. In addition, the assessment of mercury conservatively assumed that all mercury in water was present as methyl mercury.

- Arsenic, lead, mercury, and zinc in sediments from some reaches exceed concentrations that have been found by the U.S. National Oceanic and Atmospheric Administration to cause effects on benthic communities at some sites.

- PCBs and several other organic chemicals that appeared to be hazardous to aquatic life because of their historical concentrations in sediments and water were not detected in those media in the Phase 1 investigation. 
- Because this is a preliminary screening assessment of ecological risks, more detailed analyses will follow.

The human health screening analysis of the Phase 1 data, in general, confirms the results of the previous screening of historical data (Hoffman et al. 1991). The Phase 1 conclusions for the screening analysis for human health are listed here.

- Only two contaminants were identified by nonconservative screening as high priority contaminants requiring further investigation. The PCB Aroclor 1260 was found in fish from the mouth of Poplar Creek to above the confluence with East Fork Poplar Creek, the Clinch River arm of Watts Bar Reservoir, Watts Bar Reservoir below the mouth of the Clinch River, and Chicamauga Reservoir at concentrations that classified it as a high priority contaminant; however, PCBs are found in most Tennessee rivers and lakes. Although the ORR is a probable source of PCBs, it is not the only one for the CR/WBR system.

- Thorium-228 was tentatively identified in Poplar Creek as a high priority contaminant in the water ingestion pathway. Thorium-228 was detected only at source monitoring sites at $\mathrm{K}-25$, and the concentrations probably do not represent concentrations in the main body of water. Additionally, ${ }^{228} \mathrm{Th}$ is a daughter of ${ }^{232} \mathrm{U}$ or naturally occurring ${ }^{232} \mathrm{Th}$, which were not reported in the monitoring data. The absence of either parent radionuclides along with the ${ }^{232} \mathrm{Th}$ indicate that the data or analytical methodology used for sample analyses are in need of reevaluation.

- Results of the screening of the surface water data are inconclusive because of the limited number of Phase 1 samples and the uncertainty associated with using the source monitoring data to predict the concentrations of the contaminants in the river/reservoir system. The water results should be viewed in terms of general patterns rather than results for individual contaminants. The results of the screening analysis indicate that a large number of organic contaminants in Poplar Creek would require further investigation; however, most of these contaminants are common industrial or laboratory chemicals or pesticides that are not unique to the ORR facilities.

- Screening of the contaminants in the fish ingestion pathway identified the PCB Aroclor 1260 as a high priority contaminant. The Tennessee Department of Environment and Conservation has issued fish consumption advisories for several eastern Tennessee reservoirs (e.g., Fort Loudoun, Watts Bar, Melton Hill) as a result of PCB contamination. Aroclor 1254 , several pesticides (4,4'-DDE, aldrin, and chlordane) that are ubiquitous contaminants in eastern Tennessee aquatic environments, arsenic, beryllium, mercury, and selenium were identified as contaminants in fish that needed further evaluation. The only radionuclide in the fish ingestion pathway that was identified as needing additional evaluation was ${ }^{137} \mathrm{Cs}$ in the Clinch River arm of Watts Bar Reservoir.

- A conservative screening of near-shore surface-sediment data identified ${ }^{60} \mathrm{Co}$ and ${ }^{137} \mathrm{Cs}$ as low priority contaminants in the ingestion and inhalation pathways. In the external exposure pathway, ${ }^{60} \mathrm{Co}$ and ${ }^{137} \mathrm{Cs}$ were identified as contaminants that would require further investigation. However, because the concentrations at all sites are relatively low 
and the screening index from all pathways, including external exposure, is $<10^{-4}$, further evaluation of the data will probably classify these contaminants as low priority.

- Screening based on the dredging scenario identified a relatively large number of organic contaminants in Poplar Creek and the Clinch River arm of Watts Bar Reservoir above the mouth of Poplar Creek which would require further investigation. Many of these organic contaminants are common industrial and laboratory chemicals, or by-products of fossil fuel burning, and are not unique to the ORR.

- Conservative screening of Phase 1 sediment data in the dredging scenario eliminated all radionuclides that were identified from all pathways from further consideration except ${ }^{60} \mathrm{Co},{ }^{137} \mathrm{Cs}$, and ${ }^{238} \mathrm{U}$ in the external exposure pathway; ${ }^{90} \mathrm{Sr}$ in the vegetation and milk ingestion pathways; ${ }^{234} \mathrm{U}$ and ${ }^{238} \mathrm{U}$ in the meat ingestion pathways; and ${ }^{137} \mathrm{Cs}$ in the milk, meat, and vegetable ingestion pathways.

Results from Phase 1 of the CRRI provide the following guidance for the collection and analysis of samples during Phase 2:

- Poplar Creek below the mouth of East Fork Poplar Creek and the Clinch River arm of Watts Bar Reservoir are the reaches of greatest concern based of the number of contaminants that need further evaluation.

- Additional data are required on bioavailable inorganic contaminants (i.e., cadmium, copper, cyanide, lead, mercury, nickel, selenium, and silver) in water to determine their risk to aquatic biota.

- Further sampling and analysis is required for bis(2-ethylhexyl)phthalate, arsenic, lead, mercury, and zinc in sediments. These contaminants may pose a risk to benthic dwelling organisms.

- Potential contaminants of concern for wildlife, identified from the Phase 1 data are Aroclor 1254, Aroclor 1260, 4,4'-DDT and its metabolites (4,4'DDD and 4,4'DDE), mercury and selenium.

- Data for the fish ingestion pathway are the most complete. Phase 2 sampling should concentrate on providing statistically valid data for a future baseline risk assessment for human health. Fish tissue analyses should concentrate on the evaluation of contaminants that are routinely released or have been released in the past from the ORR.

- The available data from the Phase 1 water sampling had to be augmented with source monitoring data in order to perforn a screening assessment for human health. Additional water data for contaminants will be required, particularly in surface water areas proximate to ORR outfalls and sources, to provide data for the baseline risk assessment. Data from existing monitoring programs will be evaluated for use in Phase 2 of the CRRI.

- Organic and inorganic contaminants common to eastern Tennessee and other metropolitan areas should be identified through further analysis of the available data for downstream and reference reaches. Analyses of organic contaminants in water and 
sediment should concentrate on those contaminants that are routinely released or have been released in the past from the ORR. In addition, analytical methods providing lower detection limits need to be evaluated and used for the analysis of organic contaminants.

- Phase 2 sediment sampling should concentrate on Poplar Creek below the mouth of East Fork Poplar Creek and on the Clinch River arm of Watts Bar Reservoir to provide statistically valid data for a baseline risk assessment. Analyses of sediment samples should concentrate on the contaminants identified in the screening analysis as needing further evaluation. 


\section{REFERENCES}

Adams, S. M., and R. B. McLean. 1985. Estimation of largemouth bass, Micropterus salmoides Laceoede, growth using the liver somatic index and physiological variables. J. Fish Biol. 26:111-126.

Ashwood, T. L., C. R. Olsen, I. L. Larsen, and P. D. Lowry. 1986. Sediment Contamination in Streams Surrounding the Oak Ridge Gaseous Diffusion Plant. ORNL/TM-9791. Oak Ridge National Laboratory, Oak Ridge, Tennessee.

Baker, J. P., D. P. Bernard, S. W. Christensen, M. J. Sale, J. Freda, K. J. Heltcher, D. R. Marmorek, L. Rowe, P. F. Scanlon, G. W. Suter II, W. J. Warren-Hicks, and P. M. Welbourn. 1990. Biological Effects of Changes in Surface Water Acid-Base Chemistry. NAPAP Report 13. National Acid Precipitation Assessment Program, Washington, D.C.

Benoit, D. A. 1975. Chronic effects of copper on survival, growth, and reproduction of the bluegill (Lepomis macrochinus). Trans. Am. Fish. Soc. 104:353-358.

Blaylock, B. G, M. L. Frank, F. O. Hoffman, L. A. Hook, G. W. Suter, and J. A. Watts. 1992a. Screening of Contaminants in Waste Area Grouping 2 at Oak Ridge National Laboratory, Oak Ridge, Tennessee. ORNL/ER-62/R1. Oak Ridge National Laboratory, Oak Rioge, Tennessee.

Blaylock, B. G., M. L. Frank, L. A. Hook, F. O. Hoffman, and C. J. Ford. 1992b. White Oak Creek Embayment Site Characterization and Contaminant Screening Report. ORNL/ER-81. Oak Ridge National Laboratory, Oak Ridge, Tennessee.

Byrd, J. T. 1991. Work Plan for Continuation of Arsenic Biogeochemistry in the Clinch River and Watts Bar Reservoir II. Submitted to Oak Ridge National Laboratory. Skidaway Institute of Oceanography, Georgia.

DiToro, D. M. 1985. A particle interaction model of reversible organic chemical sorption. Chemosphere 14:1503-1538.

EPA (U.S. Environmental Protection Agency). 1990. Health Effects Assessment Summary Tables. NTIS No. PB90-921104.

EPA (U.S. Environmental Protection Agency). 1992. Health Effects Assessment Summary Tables, Annual Update. OHEA, ECAO-CIN-821.

Goldman, C. R., and A. J. Horne. 1983. Limnology. McGraw-Hill, New York.

HECD (Health and Criteria Division). 1992. Interim Guidance on Interpretation and Implementation of Aquatic Life Criteria for Metals. U.S. Environmental Protection Agency, Washington, D.C.

Hoffman, F. O., B. G. Blaylock, M. L. Frank, L. A. Hook, E. L. Etnier, and S. S. Talmage. 
1991. Preliminary Screening of Contaminants in the Off-Site Surface Water Environment Downstream of the U.S. Department of Energy Oak Ridge Reservation. ORNL/ER-9. Oak Ridge National Laboratory, Oak Ridge, Tennessee.

Martin Marietta Energy Systems. 1990. Clinch River RCRA Facility Investigation Plan. ES/ER-1/D1. Martin Marietta Energy Systems, Inc., Oak Ridge, Tennessee.

Kornegay, F. C., D. C. West, R. A. Evans, S. T. Goodpasture, M. F. Tardiff, and A. R. Wilson. 1991. Oak Ridge Reservation Environmental Report for 1990. Volume 2: Data Presentation. ES/ESH-18/V2. Martin Marietta Energy Systems, Inc., Oak Ridge, Tennessee.

Lemly, A. D. 1985. Toxicology of selenium in a freshwater reservoir: Implications for environmental hazard evaluation and safety. Ecotoxicol. Environ. Safety 10:314-338.

Leslie, M., and B. L. Kimmel. 1992. White Oak Creek Embayment Time-Critical CERCLA Removal Action Regulatory Compliance Study. ORNL/ER/Sub-91-KA931/3. Oak Ridge National Laboratory, Oak Ridge, Tennessee.

Long, E. R., and L. G. Morgan. 1991. The Potential for Biological Effects of Sediment-Sorbed Contaminants Tested in the National Status and Trends Program. NOAA Technical Memo. NOS OMA 52. NOAA, Seattle, Washington.

National Research Council. 1983. Risk Assessment in the Federal Government: Managing the Process. National Academy of Science, Washington, D.C.

NCRP (National Council on Radiation Protection and Measurements). 1978. A Handbook of Radioactivity Measurements Procedures. Report 58. National Council on Radiation Protection and Measurements. Washington, D.C. 506 pp.

NUS Corporation. 1990. Analytical Laboratory Guidebook for Environmental Professionals. NUS Corporation, Pittsburgh, Pennsylvania.

Oakes, T. W., W. F. Ohnesorge, J. S. Eldridge, T. G. Scott, D. W. Parsors, H. M. Hubbard, O. M. Sealand, K. E. Shank, and L. D. Eyman. 1982. Technical Background Information for the Environmental and Safety Report, Vol. 5: The 1977 Clinch River Sediment Survey-Data Presentation. ORNL-5878. Oak Ridge National Laboratory, Oak Ridge, Tennessee.

Olsen, C. R., I. L. Larsen, P. D. Lowry, C. R. Moriones, C. J. Ford, K. C. Dearstone, R. R. Turner, B. L. Kimmel, and C. C. Brandt. 1992. Transport and Accumulation of Cesium-137 and Mercury in the Clinch River and Watts Bar Reservoir System. ORNL/ER-7. Oak Ridge National Laboratory, Oak Ridge, Tennessee.

Olsen, C. R., M. Thein, I. L. Larsen, P. D. Lowry, P. J. Mulholland, N. H. Cutshall, J. T. Byrd, and H. I. Windom. 1989. Plutonium, lead-210, and carbon isotopes in the Savannah Estuary: Riverine versus marine sources. Environ. Sci. Technol. 23(12):1474-1481.

OSWER (Office of Solid Waste and Emergency Response). 1991. OSWER Directive 9285.603, March 25, 1991. Office of Energy and Remedial Response Toxics Integration Branch, U.S. Environmental Protection Agency, Washington, D.C. 
OWRS (Office of Water Regulations and Standards). 1989. Briefing Report to the EPA Science Advisory Board on the Equilibrium Partitioning Approach to Generating Sediment Quality Criteria. EPA 440/5-89-002. Environmental Protection Agency, Washington, D.C.

Risk Assessment Forum. 1992. Framework for Ecological Risk Assessment. EPA/630/R-92/001. U.S. Environmental Protection Agency, Washington, D.C.

Sigal, L. L., and G. W. Suter II. 1989. Potential effects of chemical agents on terrestrial resources. Environ. Prof. 11:376-384.

Suter, G. W., II. 1991. Screening Level Risk Assessmeni for Off-Site Ecological Effects in Surface Waters Downstream from the U.S. Department of Energy Oak Ridge Reservation. ORNL/ER-8. Oak Ridge National Laboratory, Oak Ridge, Tennessee.

Suter, G. W., II (ed.). 1992. Ecological Risk Assessment. Lewis Pub., Chelsea, Michigan.

Suter, G. W., II, A. Refearn, R. K. White, and R. A. Shaw. 1992a. Approach and Strategy for Performing Ecological Risk Assessments for the Department of Energy Oak Ridge Field Office Environmental Restoration Program. ES/ER/TM-33. Oak Ridge National Laboratory, Oak Ridge, Tennessee.

Suter, G. W., II, M. A. Futrell, and J. A Kerchner. 1992b. Taxicological Benchmarks for Screening Potential Contaminants of Concern for Effects on Aquatic Biota on the Oak Ridge Reservation, Oak Ridge, Tennessee. ORNL/ER-139. Oak Ridge National Laboratory, Oak Ridge, Tennessee.

Tucker, R. K, and J. S. Lietzke. 1979. Comparative toxicity of insecticides for vertebrate wildlife and fish. Pharmacol. Ther. 6:167-220.

Turner, R. R., C. R. Olsen, and W. J. Wilcox, Jr. 1985. Environmental fate of $\mathrm{Hg}$ and ${ }^{137} \mathrm{Cs}$ discharged from Oak Ridge facilities. pp. 329-338. In D. D. Hemphill (ed.), Trace Substances in Environmental Health-XVIII. University of Missouri, Columbia.

TVA (Tennessee Valley Authority). 1991. Results of Sediment and Water Sampling for Inorganic, Organic, and Radionuclide Analysis at Recreation Areas and Water Intakes-Norris, Melton Hill, and Watts Bar Lakes. Data Report. TVA Resource Development, River Basin Operations, Water Resources, Water Quality Department, Chattanooga, Tennessee.

USEPA (U.S. Environmental Protection Agency). 1989. Interim Final: Risk Assessment Guidance for Superfund. Vol. I: Human Health Evaluation Manual OSWER Directive 9285.701a. EPA Office of Emergency and Remedial Response, Washington, D.C.

USEPA (U.S. Environmental Protection Agency). 1990. Quality Assurance/Quality Control Guidance for Removal Activities, Sampling QA/QC Plan and Data Validation Procedures. Interim Final. EIPA/540/G-90/004. Environmental Protection Agency, Washington, D.C. 
Appendix A

\section{LISTING OF ALL ANALYTES WITH CAS NUMBERS}




\section{CONTENTS OF APPENDIX A}

Table A.1 Listing of all analytes with CAS numbers and matrices analyzed for

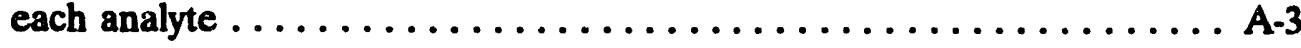


TABLE A.1 LISTING OF AIL ANALYTES WITH CAS NUKBERS AND MATRICIES ANALYZED FOR EACH MNALYTH

TYPE OF ANALYSIS

INORGANICS

ORGANICS
ANAIYTE

ANTIMONY

ARSENIC

BERYLIIUA

CADMIUX

calcius

carosius

COPBER

IRON

ITAND

MARTESIUN

IARCURY

NICKN

potassion

SEIRNIU⿴

SILVER

SODIUNS

TENIIIOX

zIXC

ACENAPEHEENR

ACHNAPHYHYLENT

ATDRIR

NTPEA-BaC

NTPER-CEIORDAM:

NLPEA-CELORDELL

ANTHRacens

AROCLOR-1016

AROCLOR-1221

NROCLOR-1232

NROCLOR-1242

AROCLOR-1248

AROCLOR-1254

AROCLOR-1260

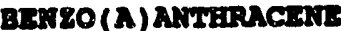

BAH8O (A) PYRERE

BNI8O (B) ITUORNITERAE

BEN20 (G,B, I) PERILAN

BAA2O (x) FLOORATLEANE

BATzOIC ACID

BA1zYL arcosot

BETA-BEC

BIS (2-CEIOROLTHOXY) METENAT:

BI8 (2-CEOROLIEYL) EIALR

BI8 (2-C:IOROI8OPROPYL) ETELA

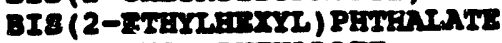

BOLYLBEAEYTPEIENIAT:

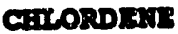

Carrstar

DALAR-BEC

DI-N-BUIYLPEIranLATL

DI-N-OCTrLPEHERTATS

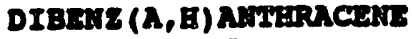

DIBEAzorORA

DItuRI:

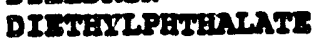

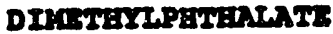

erposurera I

IxDOSULFA II
CHEMICAL ABSTRACT SERVICE NUMBER

ANATX2ED IN (FISH/SEDIMENT/WATER)

83-32-9

208-96-8

309-00-2

319-84-6

5103-71-9

56534-02-2

120-12-7

12674-11-2

11104-28-2

11141-16-5

53469-21-9

12672-29-6

11097-69-1

11096-82-5

56-55-3

50-32-8

205-99-2

$191-24-2$

207-08-9

65-85-0

100-51-6

319-85-7

111-91-1

$111-44-4$

108-60-1

117-81-7

85-68-7

$3734-48-3$

218-01-9

319-86-8

84-74-2

117-84-0

53-70-3

132-64-9

60-57-1

84-66-2

131-11-3

959-98-8

33213-65-9

$E / S / W$

$E / S / W$

$E / S / W$

$8 / 8 / W$

$. / s / w$

is/4

F/s/W

$. / 8 / 1$

$5 / 8 / \mathrm{w}$

$. / 8 / 4$

$5 / 8 / 1$

$5 / 8 / 4$

$. / 8 / 4$

$8 / 8 / 4$

$5 / 8 / W$

$.18 / \mathrm{w}$

$5 / 8 / W$

$E / 8 / W$

$5 / 8 / 4$

$F / 8 / 6$

I/8/W

$. / 8 / 4$

$2 / 8 / 4$

$\mathrm{F} / \mathrm{l}$.

I/S/W

$. / 8 / \mathrm{H}$

$. / 8 / 1$

- $18 / 4$

$. / 8 / \mathrm{N}$

$818 / 1$

$5 / 8 / 10$

$8 / 8 / 4$

$5 / 8 / 1$

$5 / 8 / 6$

F/8/4

$8 / 8 / 1$

$8 / 8 / 1$

$5 / 8 / 1$

$.18 / 4$

I/8/11

$5 / 8 / 1$

I/8/W

$E / 8 / 1$

$\mathrm{F} / 8 / \mathrm{W}$

81.1 .

$8 / 8 / 1$

$. / 8 / 1$

$F / 8 / 1$

$5 / 8 / 11$

$5 / 8 / 14$

$5 / 8 / 4$

$.18 / 1$

F/8/4

$5 / 8 / 4$

$. / 8 / N$

$. / 8 / N$ 
TABLE A.1

LISTING DF ALL ANATYTES WITH CAS NUMERS AND MATRICIES ANALYZED FOR EACH ANALYTE

TYPE OF

MHAYYSIS

ORGANICS
ANAIYTE

ENDOSULEAN SULFATE

ENDRIN

ENDRIN KETONE

FUORANTHENE

FLOORENE

GNYYA-BEC (LINDNNE)

GARM-CERORDANE

GAYYA-CHLORDENE

GEPTACEILOR

LEPIACILOR EPOXIDE

EIXACHOROBENZENR

ERTACIOROAOTROIENE

EEXACHLOROCY CLOPENYADIENE

HEXA CALOROETENNE

INDENO (1, 2, 3-CD) PYRENE

ISOPHORONE

METHOXYCEIOR

N-NITROSO-DI-N-PROPYIANINE

N-NITROSODIPERAYLAYINE

MAPETERTERT

NITROBENEENE

OXYCELORDAM.

PENTRCEIOROPAENOL

PETRANTERELE

PETSOI.

Prtan.

TOXnPtake

1,2-DICEIOROBAYERT:

$1,2,4-$ IRICHOROBENZEHT

1, 3-DICEIOROBEN2ENT

1,4-DICHOROBEN2EH.

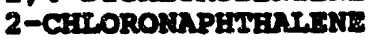

2-Cin OROPtenOT

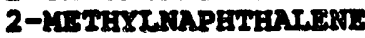

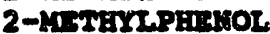

2-MITRONIrIX

2-MITROPLENOT.

2.4-DICHOROPHANOL

2,4-DIMLTH TLPHEHOI

2,4-DIRITROPHTHOI

2.4-DIMITRoror On:

$2,4,5$-IRICATOROPLIAHOL

2,4,6-IRIC:KOROPEINOL

2, 6-DI*ITROTOTU:A

3-NIIRONMIIIN

3,3०-DICHOROBAHEIOIN:

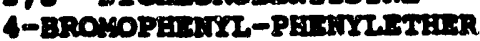

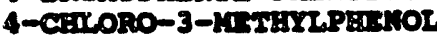

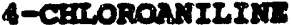

4-CELOROPLAIYL-PHITILFTHER

4-MDTHYTPETHOT

4-aITRONMIIIVT:

4-MITROPHAOL

$4,4 \cdot-D D D$

$4,4^{\circ}-D D E$

$4,40-0 D T$

4,6-DINITRO-2-1LTHYLPEENOL
ChaMcal ABstract SERVICE NUMBER

\begin{tabular}{|c|c|}
\hline $\begin{array}{l}1031-07-8 \\
72-20-8 \\
53494-70-5 \\
206-44-0 \\
86-73-7 \\
58-89-9 \\
5103-74-2 \\
56641-38-4 \\
76-44-8 \\
1024-57-3 \\
118-74-1 \\
87-68-3 \\
77-47-4 \\
67-72-1 \\
193-39-5 \\
78-59-1 \\
72-43-5 \\
621-64-7 \\
86-30-6 \\
91-20-3 \\
98-95-3 \\
27304-13-8 \\
87-86-5 \\
85-01-8 \\
108-95-2 \\
129-00-0 \\
8001-35-2 \\
95-50-1 \\
120-82-1 \\
541-73-1 \\
106-46-7 \\
91-58-7 \\
95-57-8 \\
91-57-6 \\
95-48-7 \\
88-74-4 \\
88-75-5 \\
120-83-2 \\
105-67-9 \\
51-28-5 \\
121-14-2 \\
95-95-4 \\
88-06-2 \\
606-20-2 \\
99-09-2 \\
91-94-1 \\
101-55-3 \\
59-50-7 \\
106-47-8 \\
7005-72-3 \\
106-44-5 \\
100-01-6 \\
100-02-7 \\
72-54-8 \\
72-55-9 \\
50-29-3 \\
534-52-1 \\
\end{array}$ & 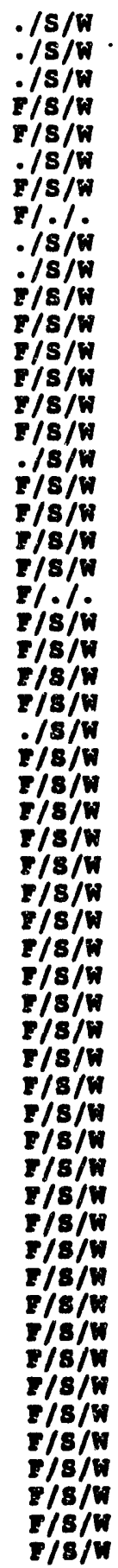 \\
\hline
\end{tabular}

ANALYZED IN (EISH/SEDIKENT/WATER) 
TABLE A.1 LISTING OF AIL ANALYTES WITH CAS NUMBERS AND MATRICIES ANALYZED FOR EACH ANALYTE

TYPE OF ANAIYSIS

RAD
ARALYTE

AM-241

$\mathrm{Cx}-243,244$

Cx $-245,246$

Cy -248

co-60

Cs-137

$\mathrm{B}-3$

PO-238

PJ-239, 240

SR-90

$0-234$

$0-235$

$0-238$
CHDMICAI ABSTRACT SERVICE NUMBER
ANATYYZED IN (FISH/SEDIMENT/WATER)
$. / 5 /$. $. / 5 /$.

$. / 5 /$. $. / \mathrm{s} /$. $\mathrm{F} / \mathrm{s} / \mathrm{H}$ $F / S / W$ .1 .14 $. / s /$. $. / 8 /$. E/s/W

$. / 8 /$. $.18 /$.

.$/ 81$. 
Appendix B

SUMMARY STATISTICS FOR WATER SAMPLES 


\section{CONTENTS OF APPENDIX B}

Table B.1 Summary statistics for water data summarized for all reaches sorted by type of analysis and decreasing percentage detected $\ldots \ldots \ldots$ B-3

Table B.2 Summary statistics for water data detected compounds summarized by reach sorted by type of analysis, analysis, and reach $\ldots \ldots \ldots \ldots$ B-7 


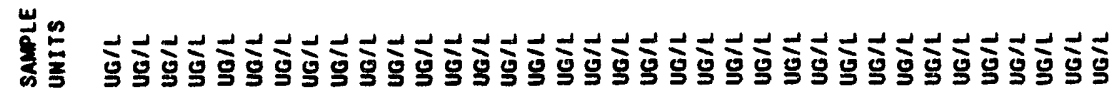

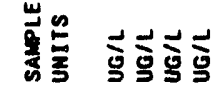
๓

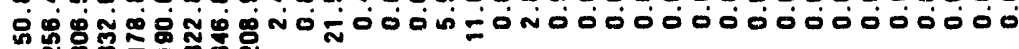

1888 КNㅠㅛ

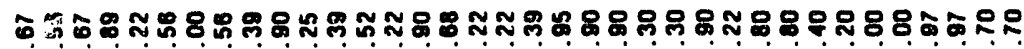

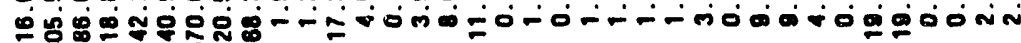

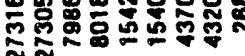

落

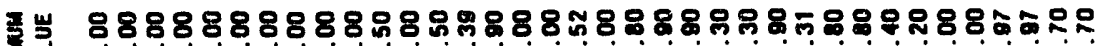

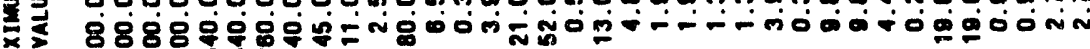

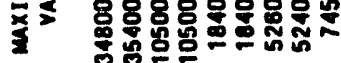

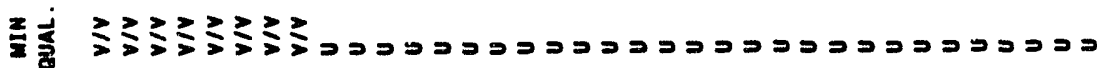

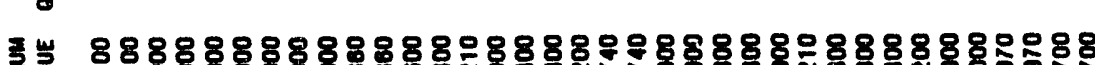

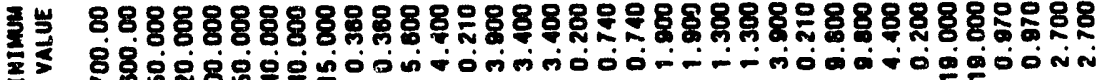

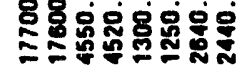

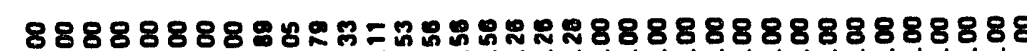

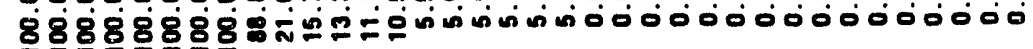

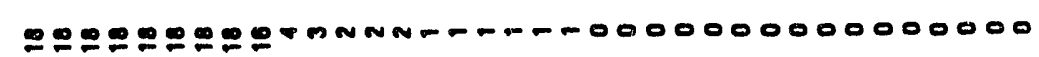
है

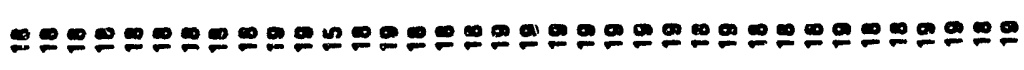

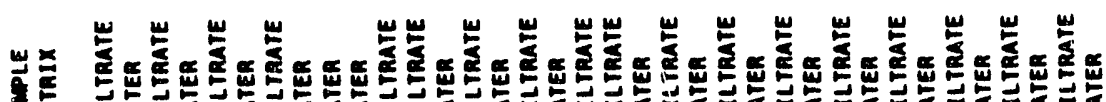

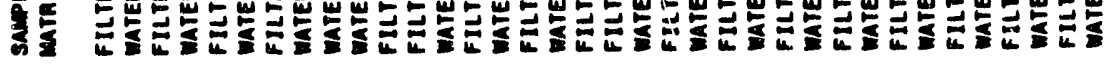

范 333

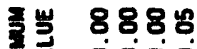

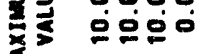

폴령 000

\section{졸 88 웅영 푤 \\ 은 0888 \\ n no \\ 월 -000

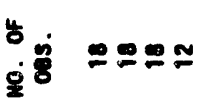

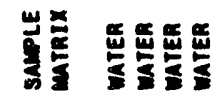

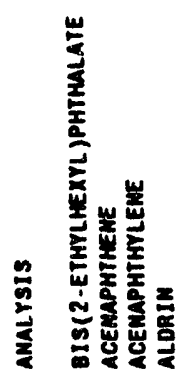




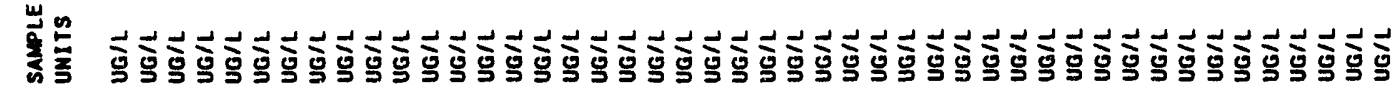
के 8888888888888888888888888888888888888888888888

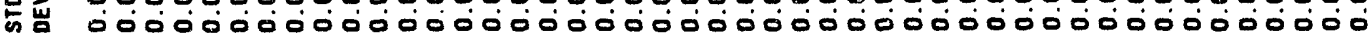

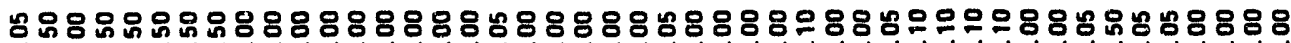

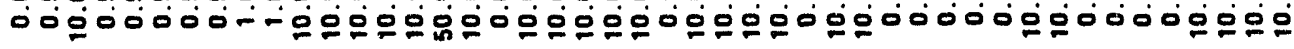

盖

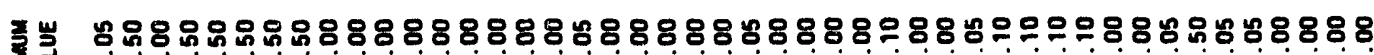
焉

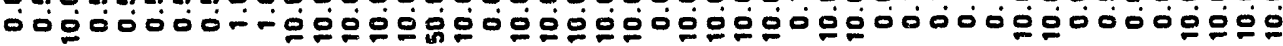

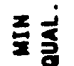
可

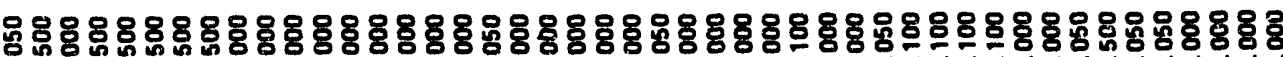

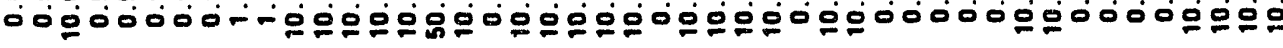
8888888888888888888888888888888888888888888888

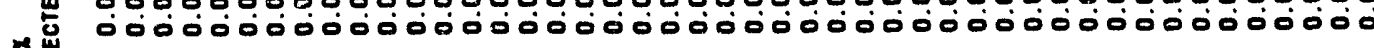

0000000000000000000000000000000000000000000000 ㄴ.

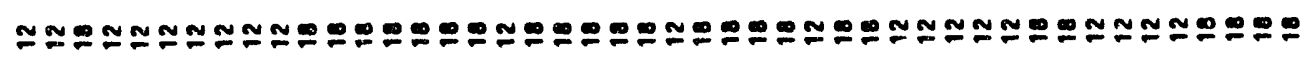

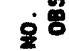

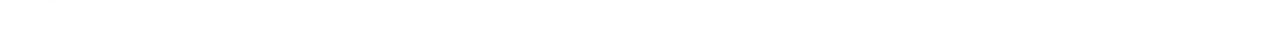

«ะ

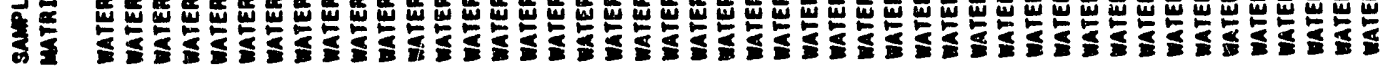

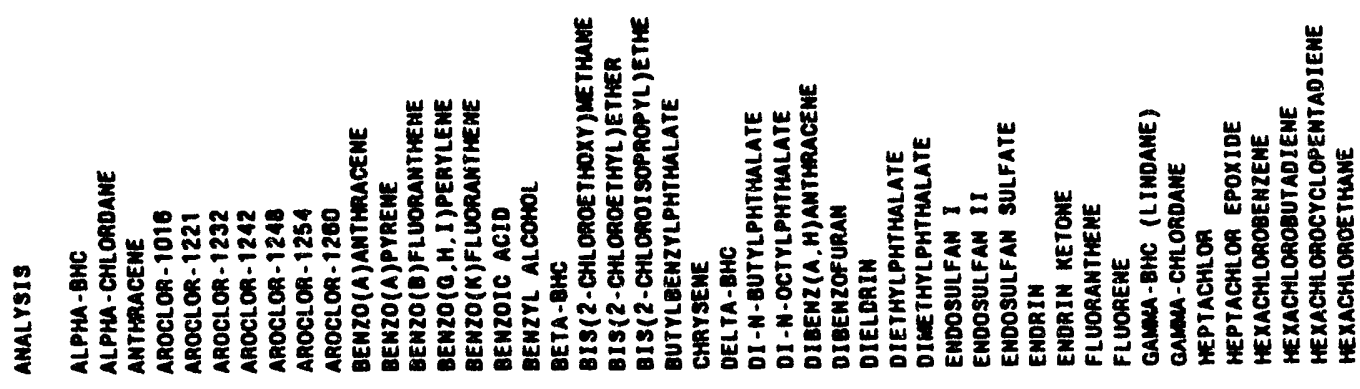




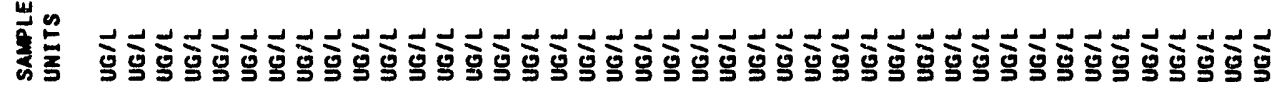
션 888888888888888888888888888888888888888888

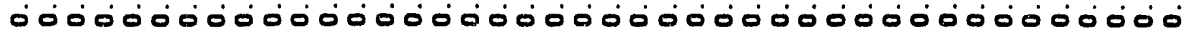

岕 888888888888888888888888888888888888880908 这

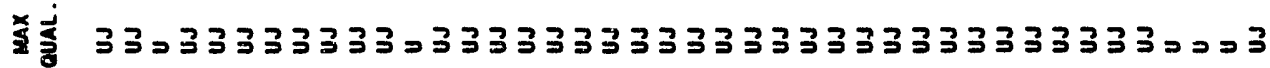
龵 88888888888888888888888888888888888880908

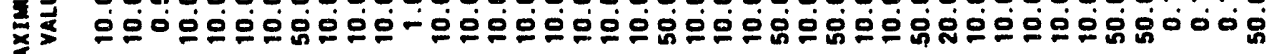

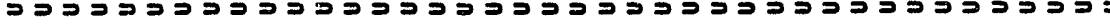

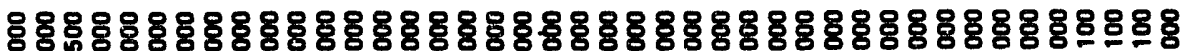

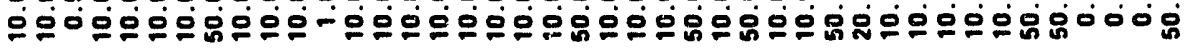
888888888888888888888888888888888888888888

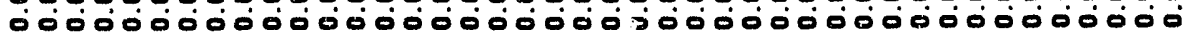

000000000000000000000000000000000000000000 它宽

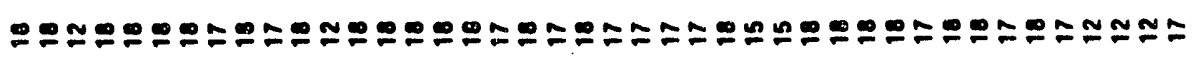

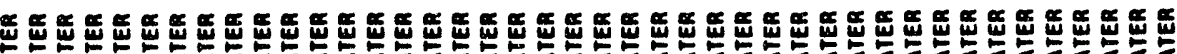

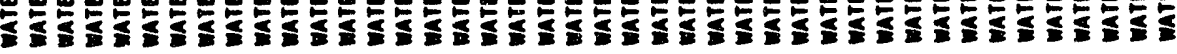

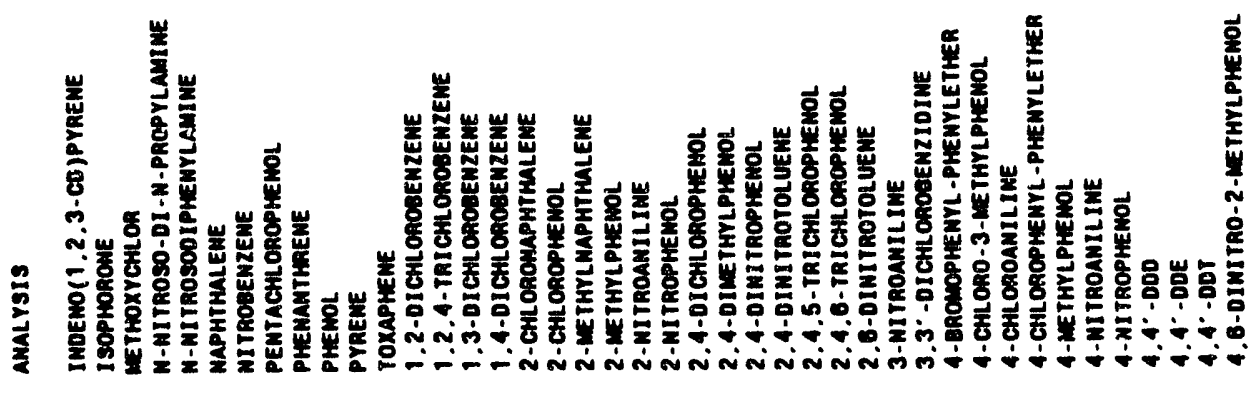




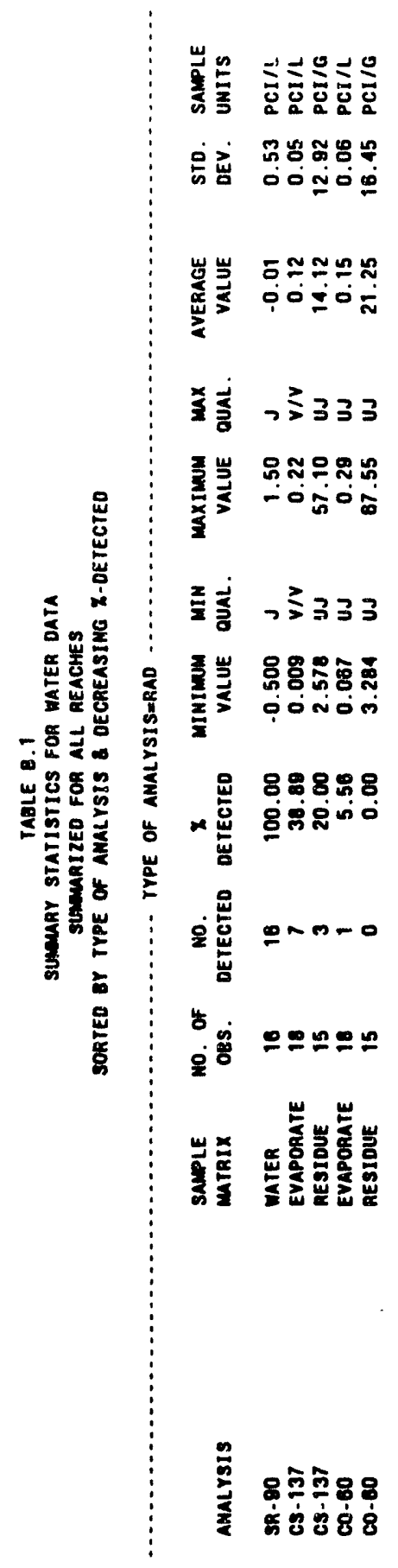


崖突 可

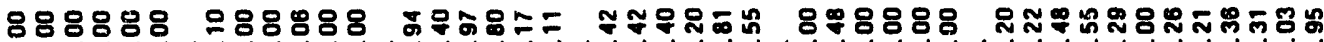

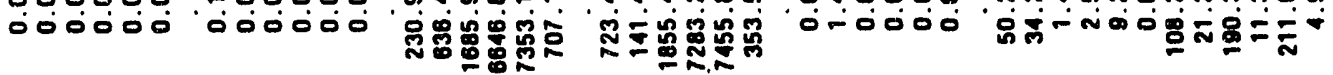

品品品品

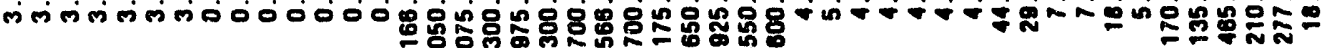

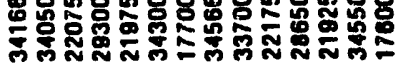

会荷

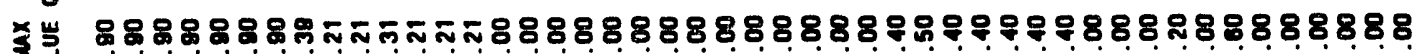

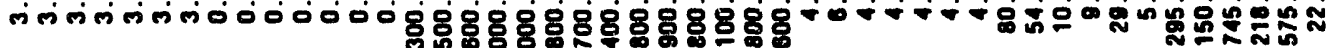

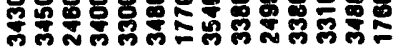

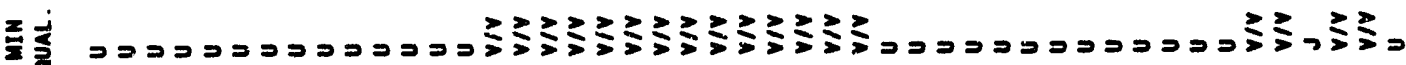

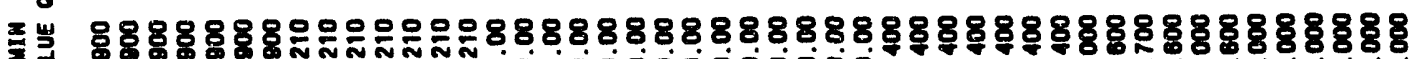

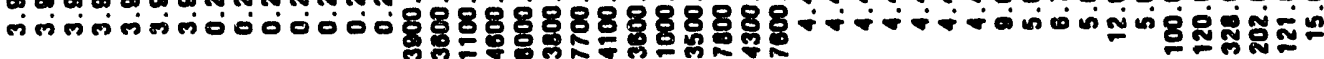

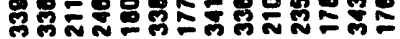

$8888888 \% 88 \% 8888888888888888 \% 8888888888 \% 8888888$

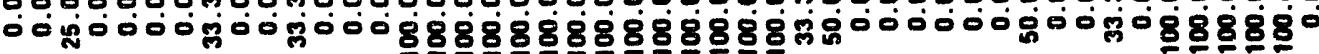

$00-0000-00-0000 n-n+n-m n+n+n-m-000000-00-0 m n t h t 0$

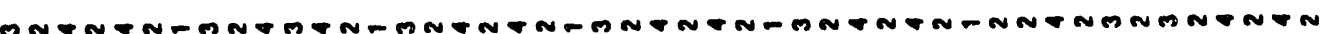

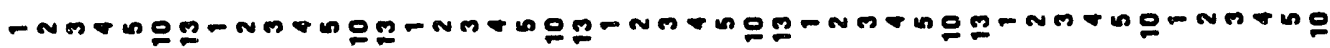
폻

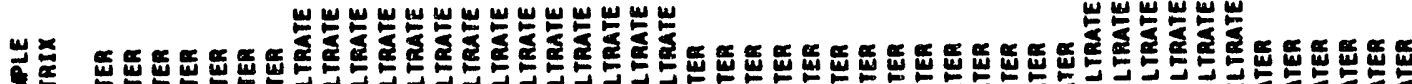

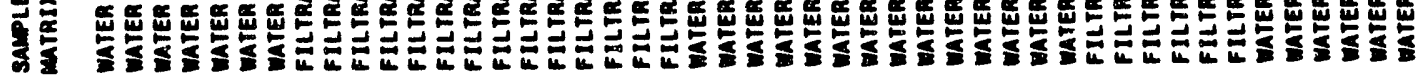

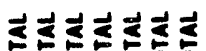

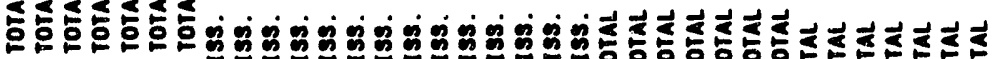

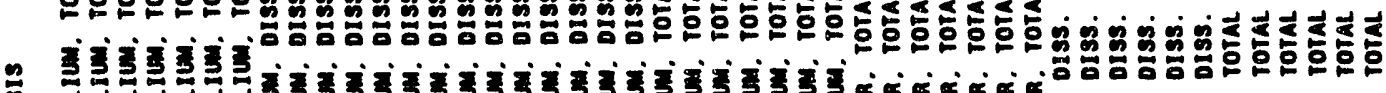

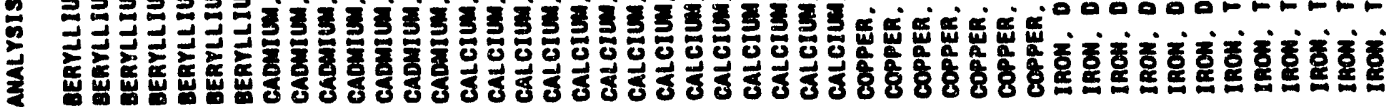




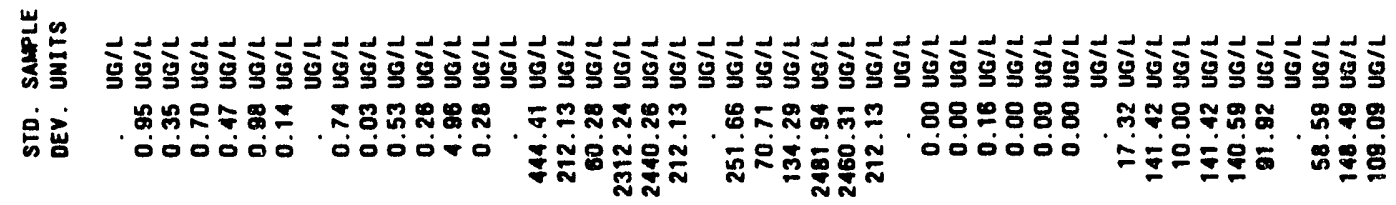

岁岂

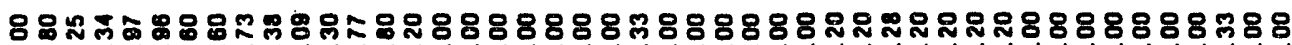

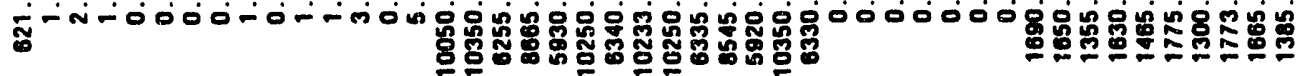

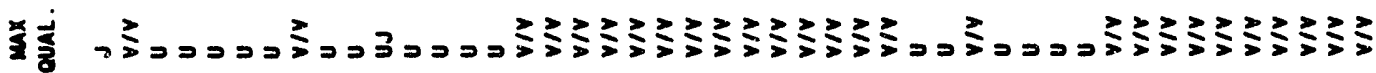

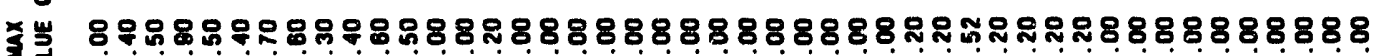

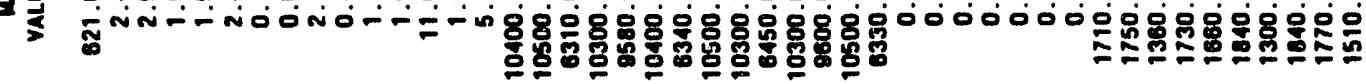

不志

풀

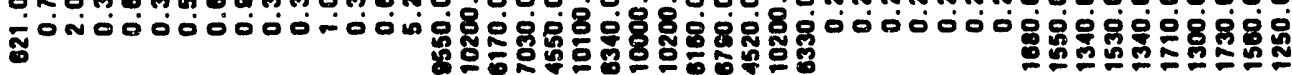

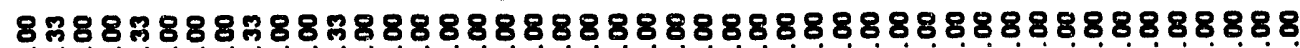

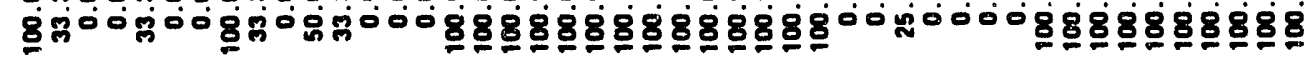

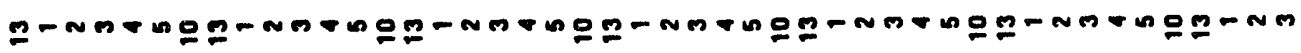

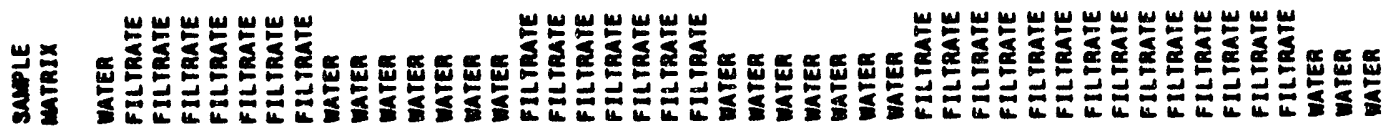

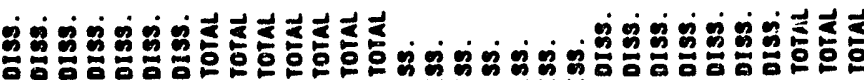

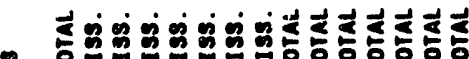


B-9

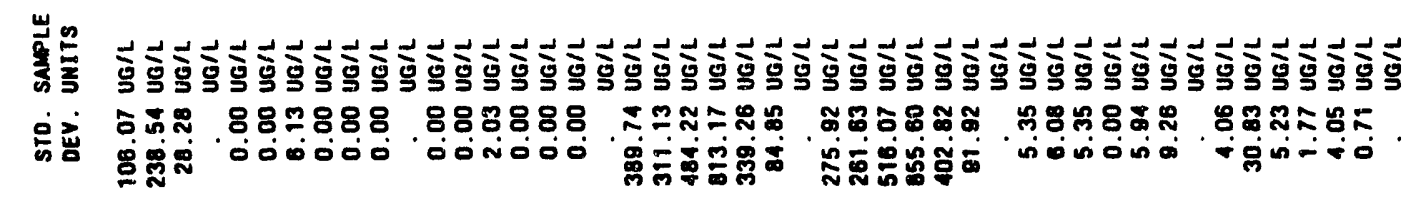

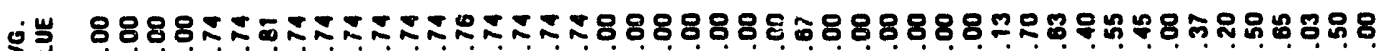

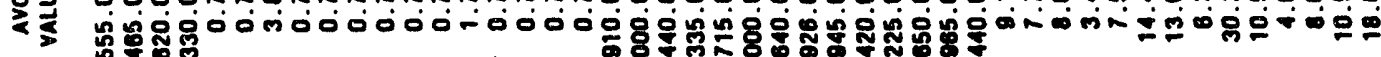

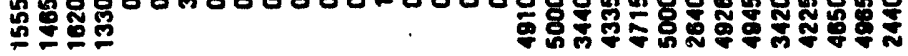

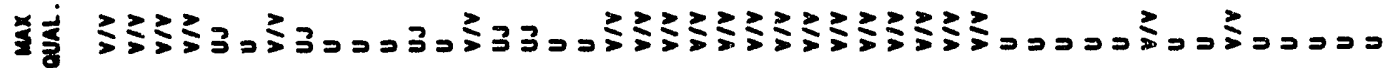

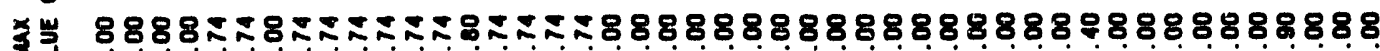

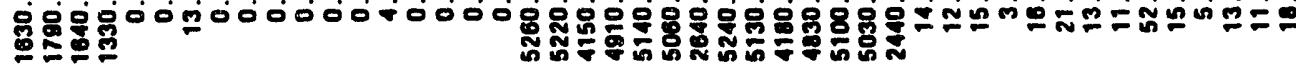

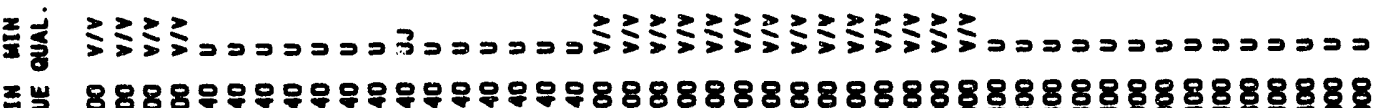

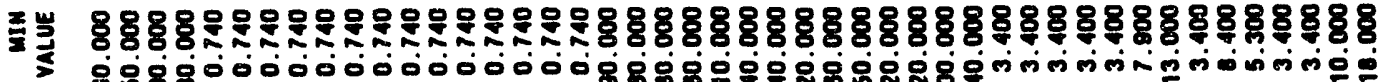

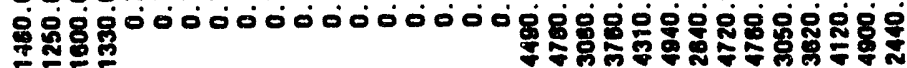

8888888888888888888888888888888888888888888888

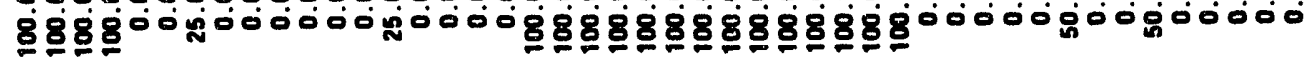

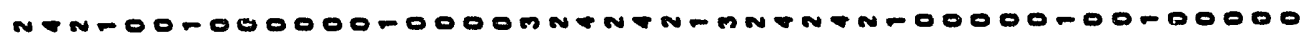

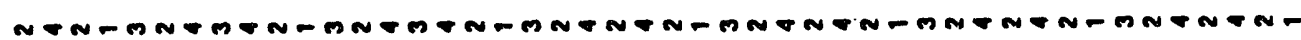

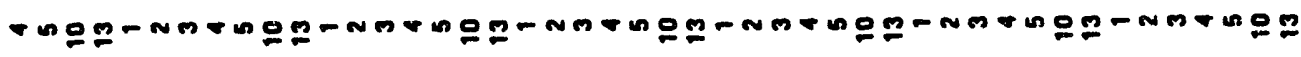

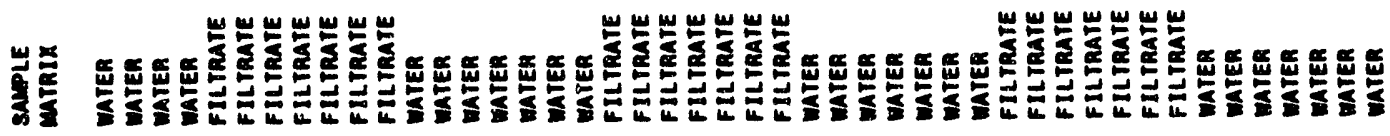

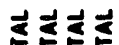

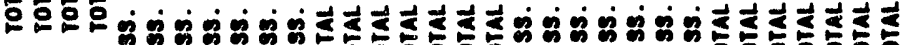

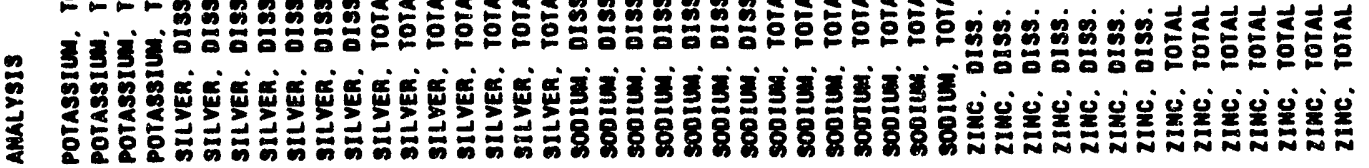


B-10

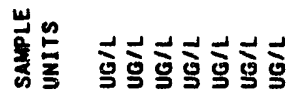

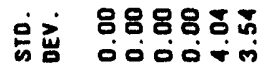 \\ ن 888880

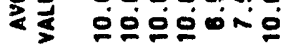

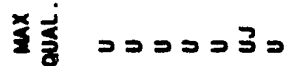

节 8888888

ㅇํㅇํㅇ

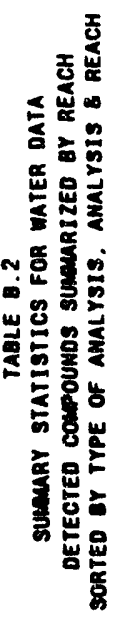

졸 -nomong

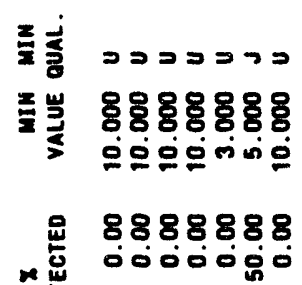

i总 00000-0

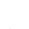

i.

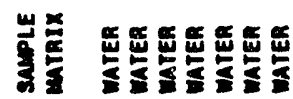

㟧

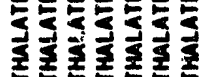

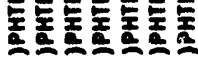

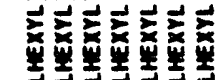

龺

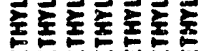

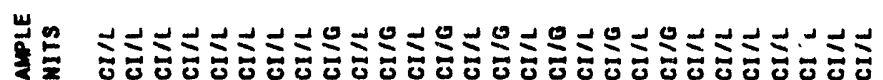

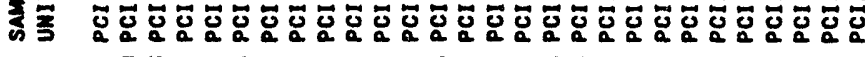

运立

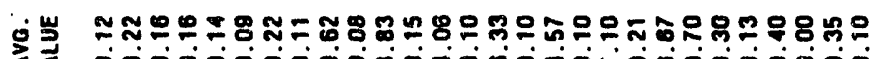

00000000

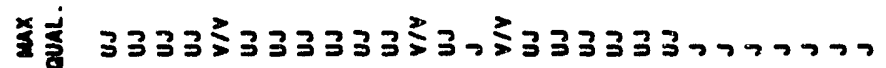

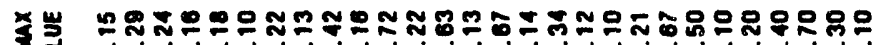
00000000

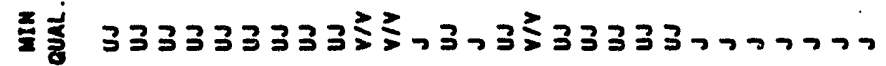

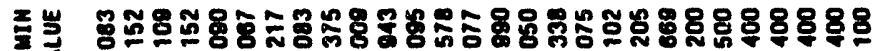
0000000000

8888888888888888988888888888 -000nั000

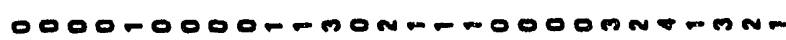

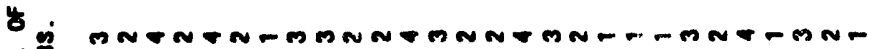
is

T⿱一𫝀口儿⿱

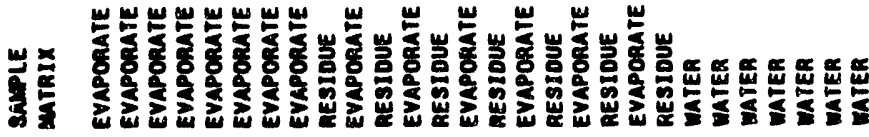

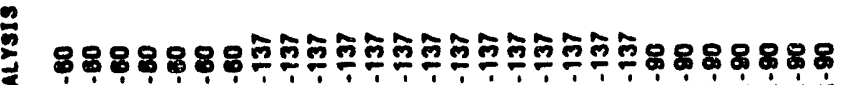

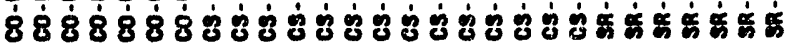


Appendix C

SUMMARY STATISTICS FOR SEDIMI NT SAMPLES 


\section{CONTENTS OF APPENDIX C}

Table C.1 Summary statistics for sediment core data summarized for all reaches sorted by type of analysis and decreasing percentage detected $\ldots \ldots \ldots \ldots \ldots \ldots \ldots \ldots \ldots \ldots \ldots \ldots \ldots \ldots \ldots$ C-3

Table C.2 Summary statistics for sediment core data detected compounds summarized by reach sorted by type of analysis, analysis, and reach ... C-6

Table C.3 Summary statistics for sediment grab data summarized for all reaches sorted by type of analysis and decreasing percentage detected $\ldots \ldots \ldots \ldots \ldots \ldots \ldots \ldots \ldots \ldots \ldots \ldots \ldots \ldots \ldots$ C-13

Table $\quad .4$ Summary statistics for sediment grab data detected compounds summarized by reach sorted by type of analysis, analysis, and reach ... C-14 
C-3

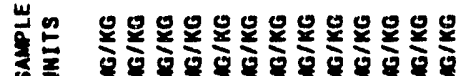

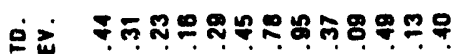

요용

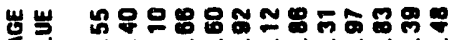

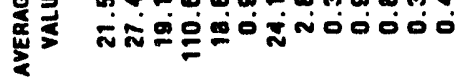

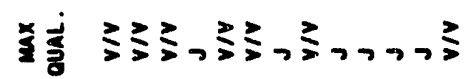

굴

范

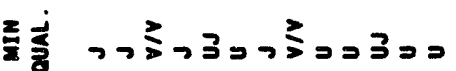

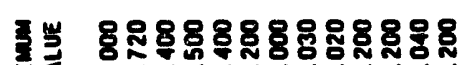

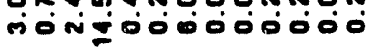

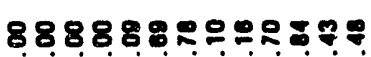

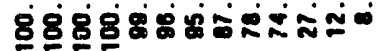

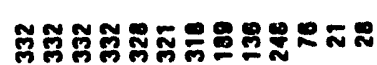
若

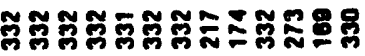
is (1)

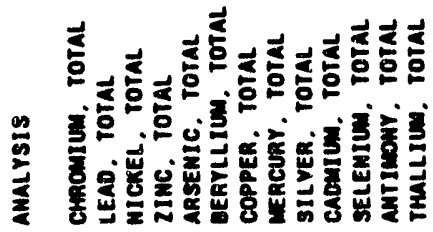

ง้ำ

运

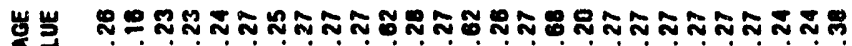
蛋

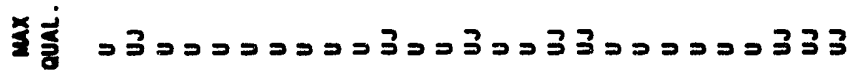

굴 $888888888888808888888888 \% 88$

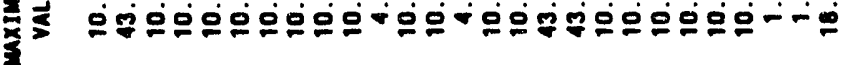

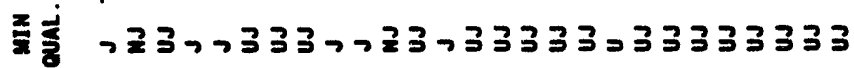

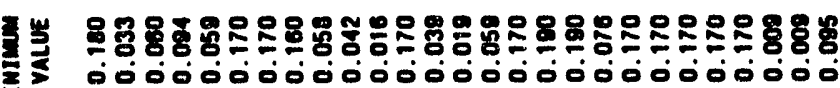

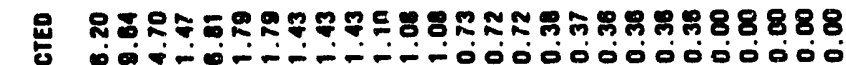
兽

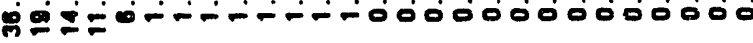

$\dot{8}$

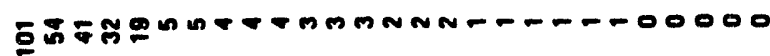

4. i安

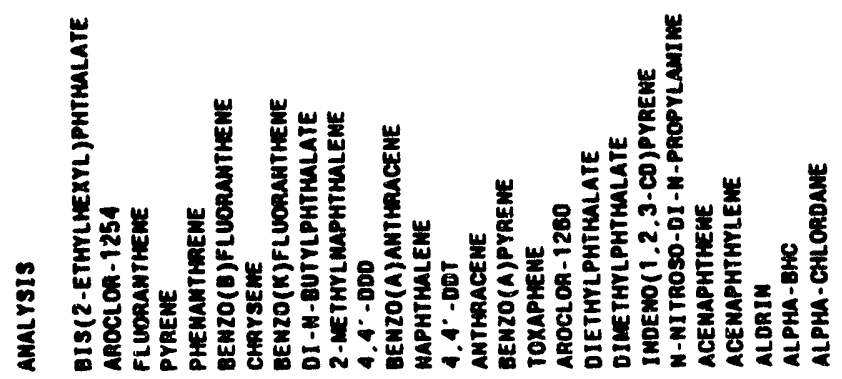




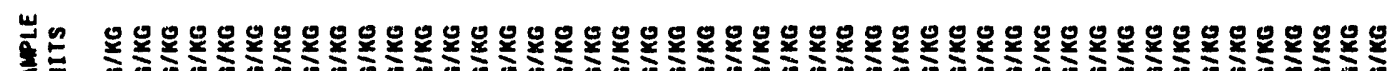

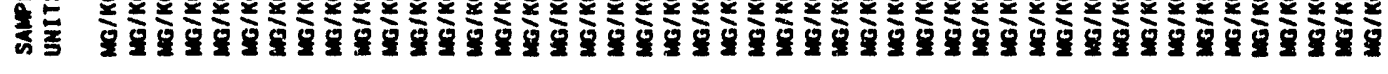

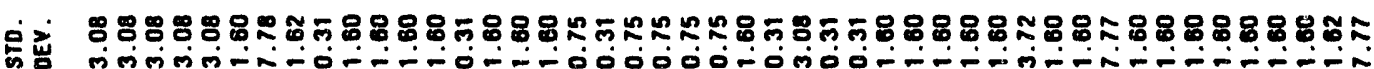

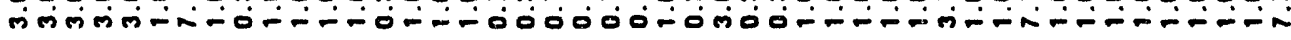

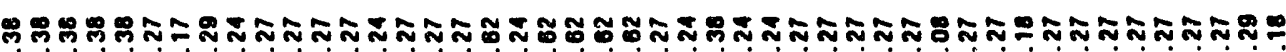

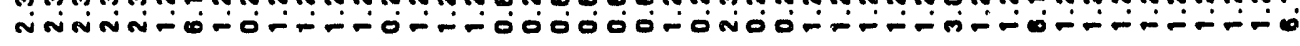

$33333=0030000320=33333303333000003000000000000$

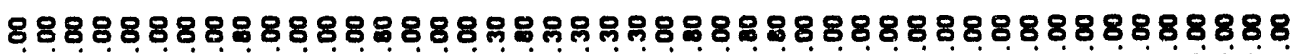

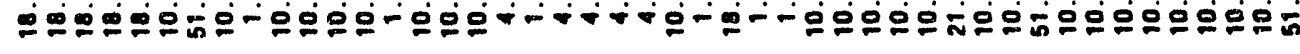

3333333333333333333333333333333333333333333333

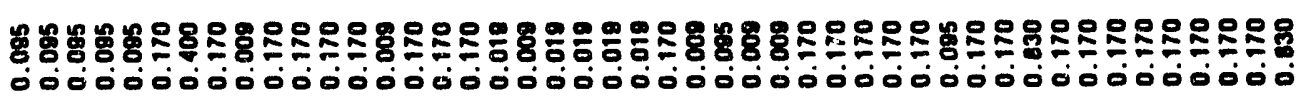

8888888888888888888888888888888888888888888888 总

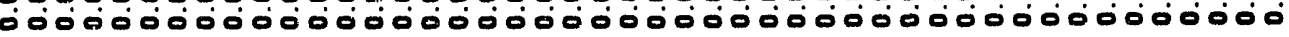
事 0000000000000000000000000000000000000000000000 8

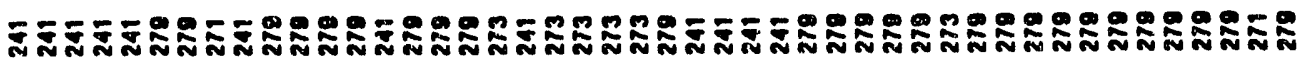

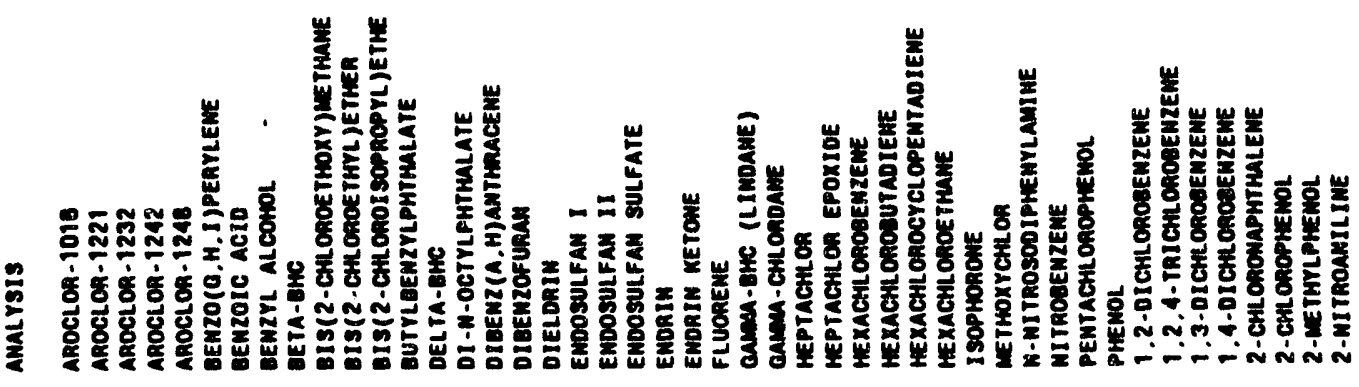




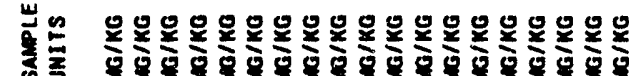

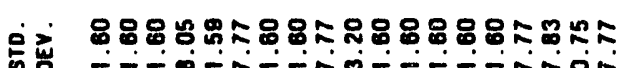

岁 ヘกล์ 蒌

范

象 8888888888888888888

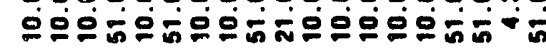

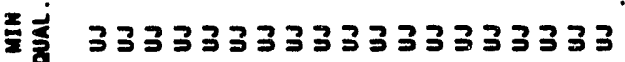

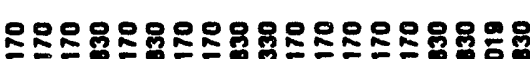

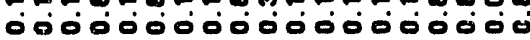

8888888888888888888

0000000000000000000 崖

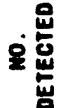

0000000000000000000

y 8 8

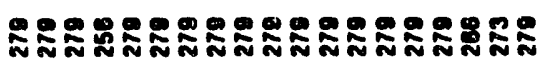

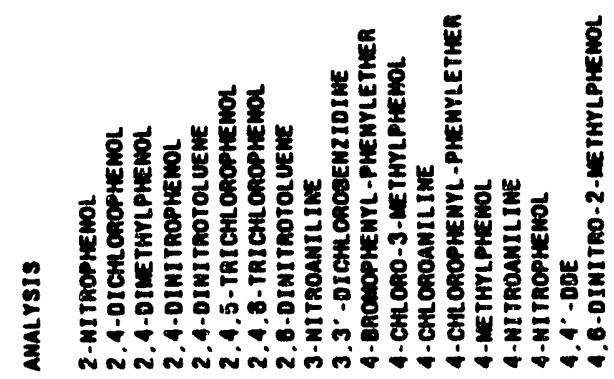

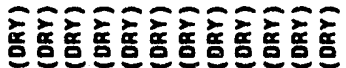

山月

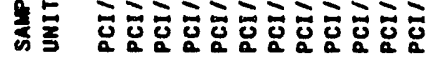

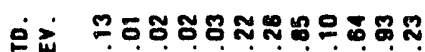

की 000000000 迥

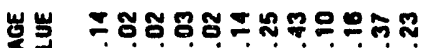

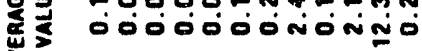

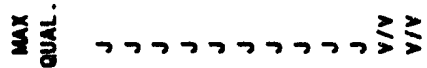

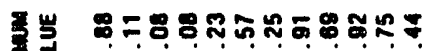

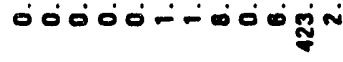

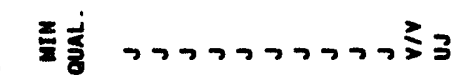

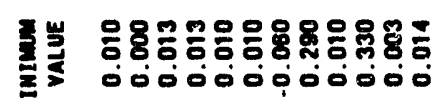

요 $8888888888 \%$

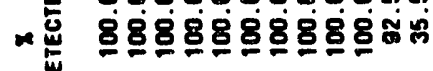

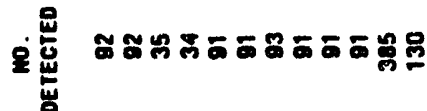

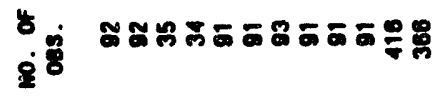

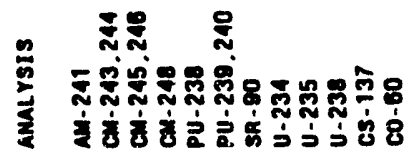


บำ

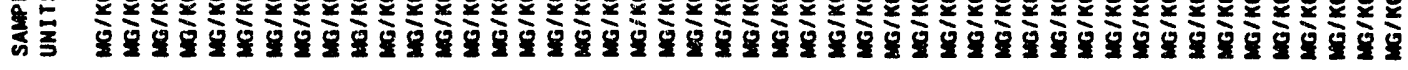

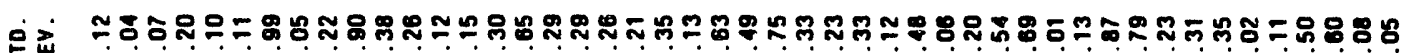

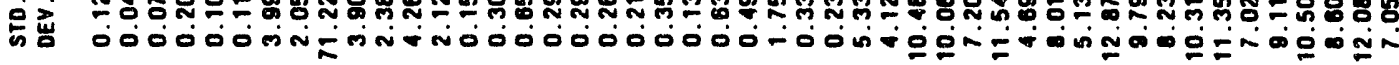

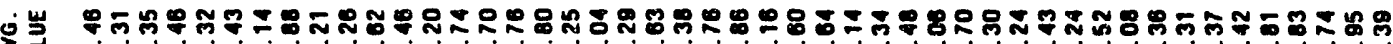

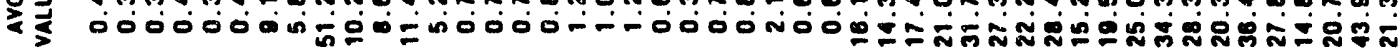

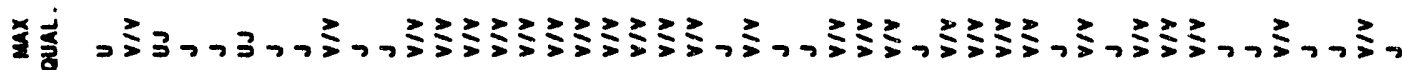

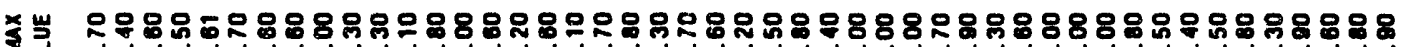

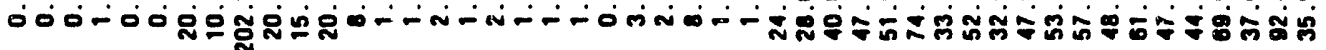

점영

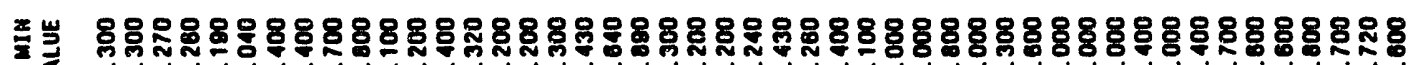

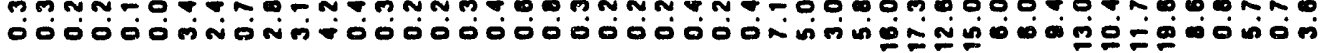

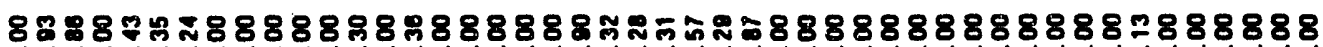
०ल Nं

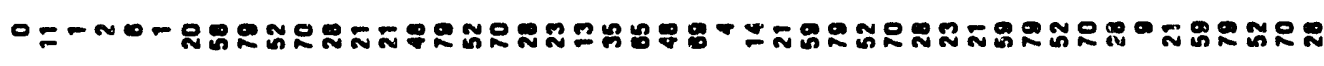

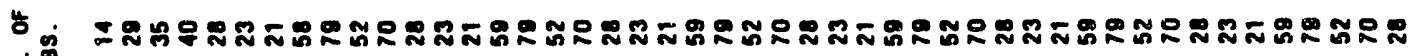
i்

J

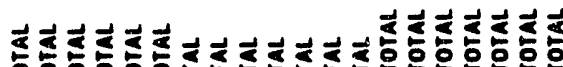

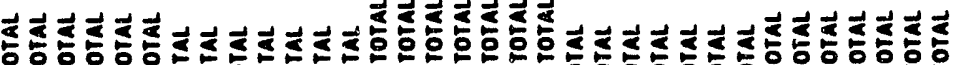

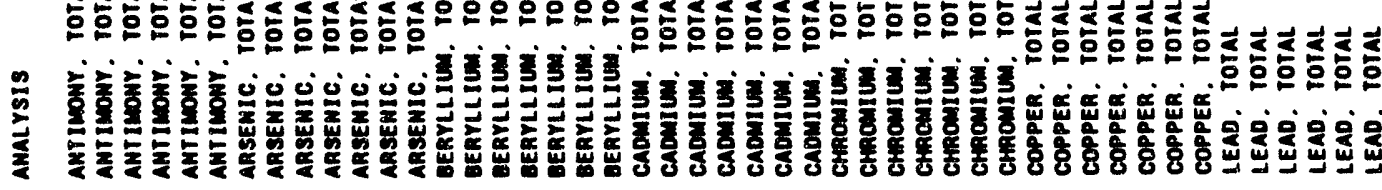


C-7

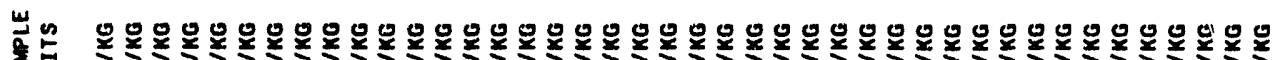

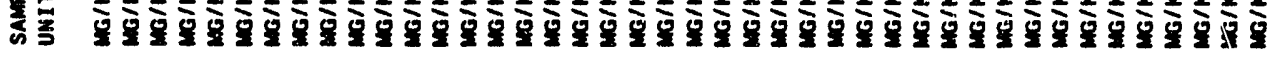

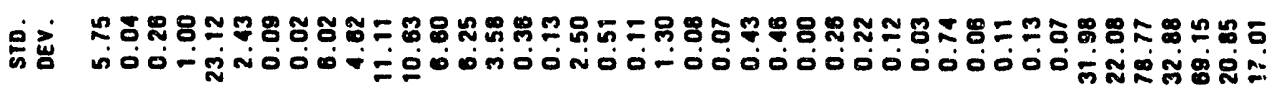

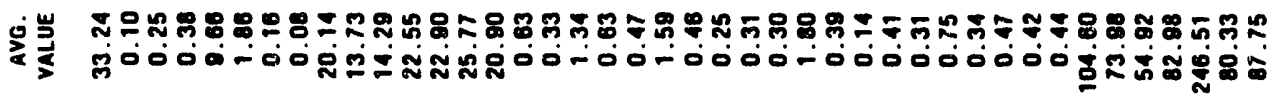

萑

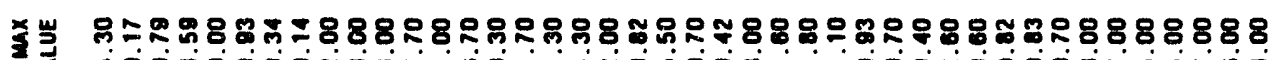

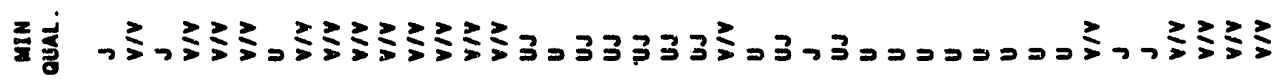

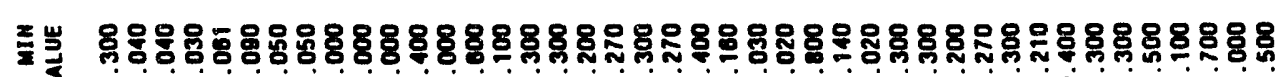

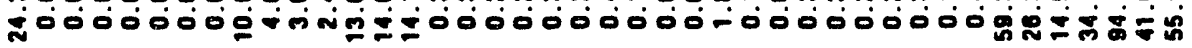

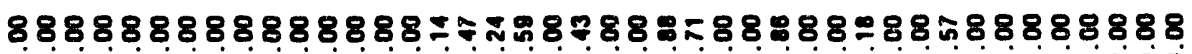

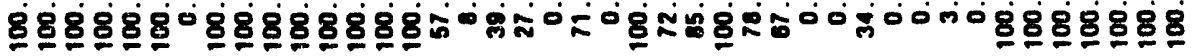

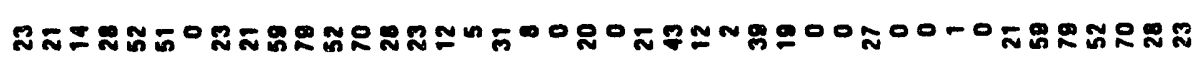
ì

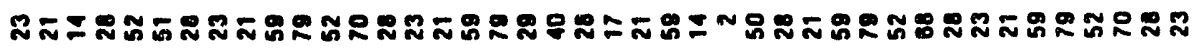
돓

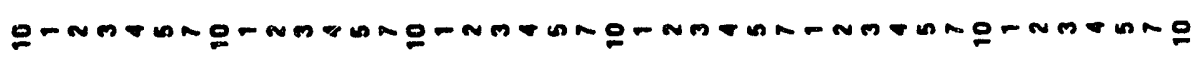

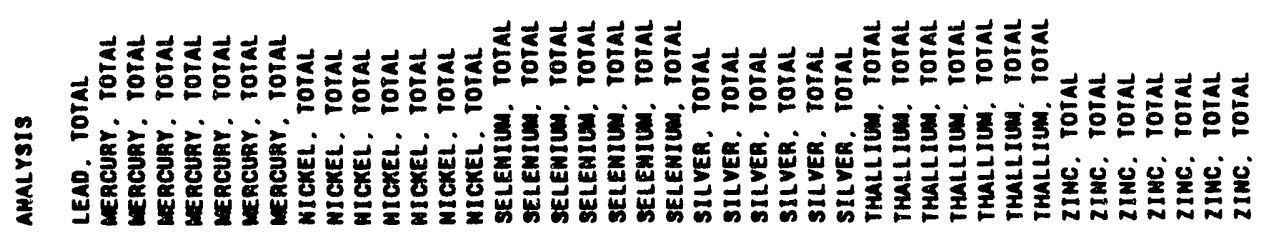


C-8

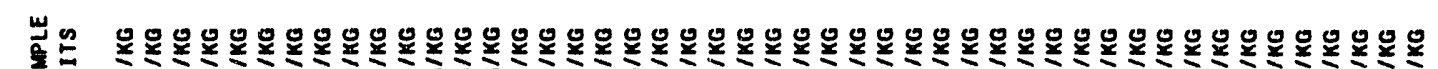

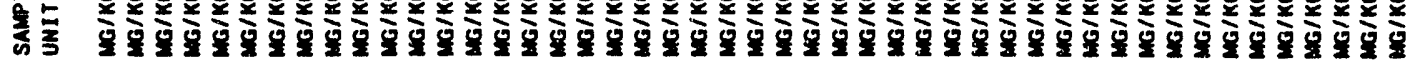

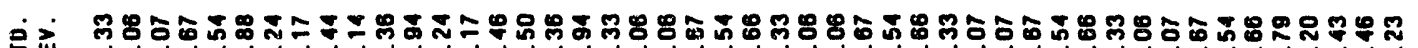

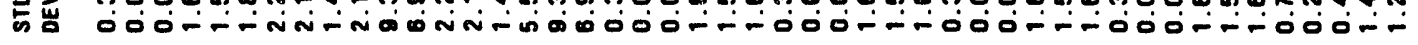

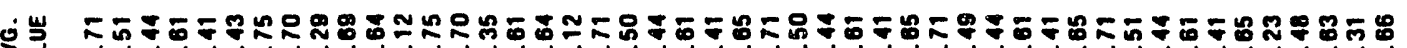

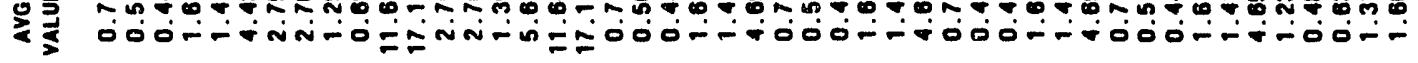

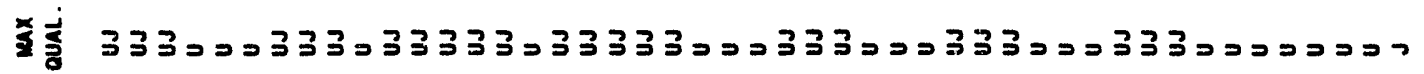

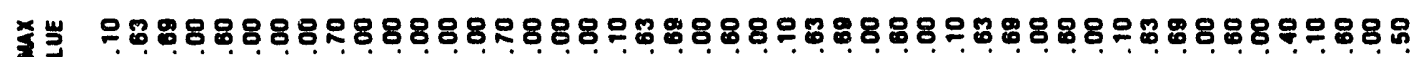

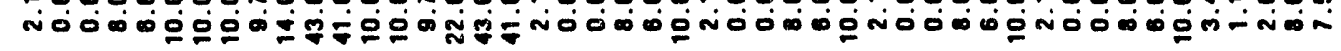

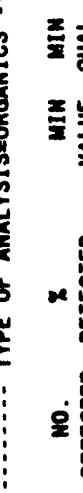

\&. 오웅

J -nmong-nmong-nmeng-nmang-nmong-nmong-nmeng-nmon

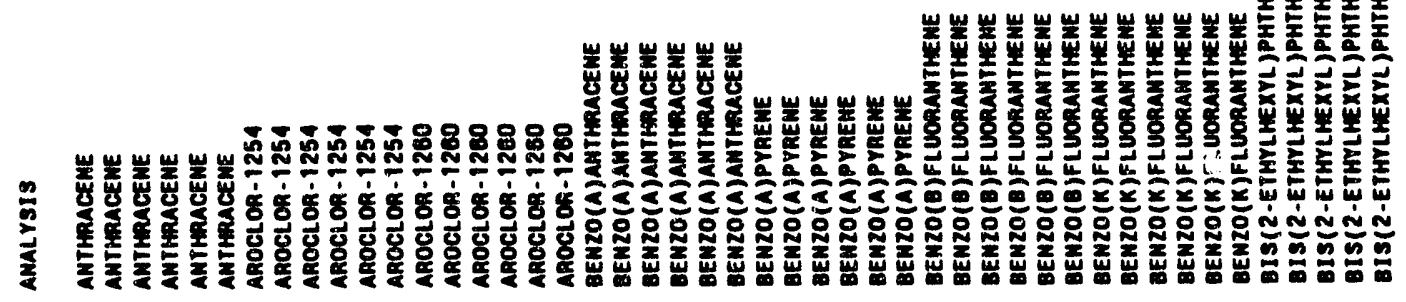


Tั:

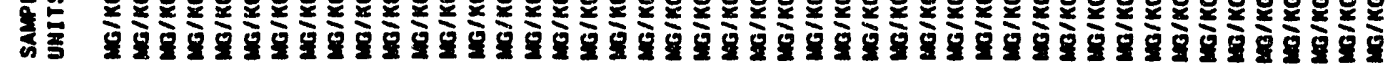

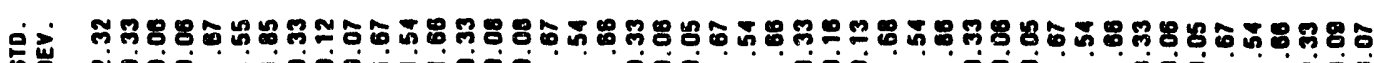

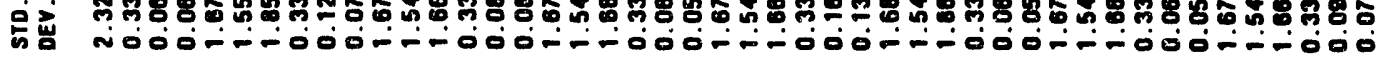

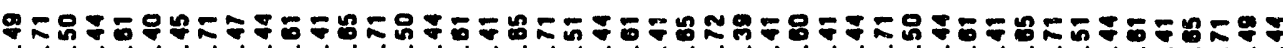
ró0ं-

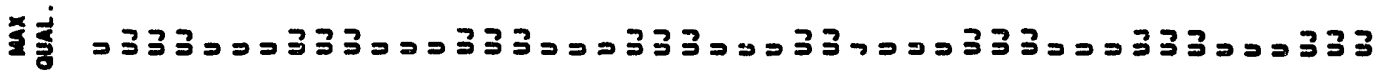

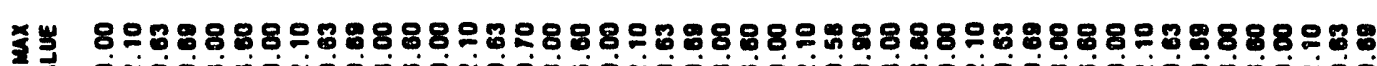

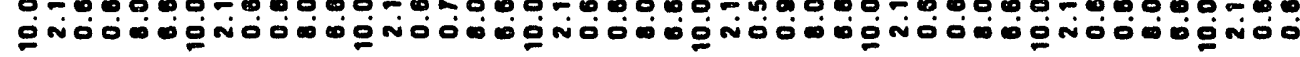

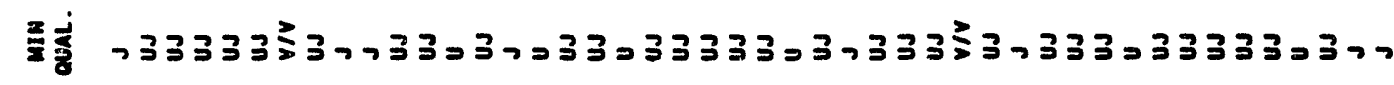

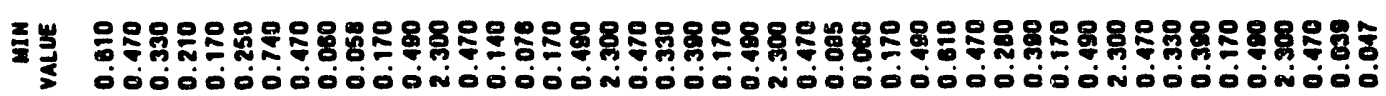

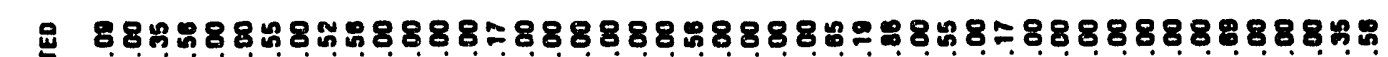

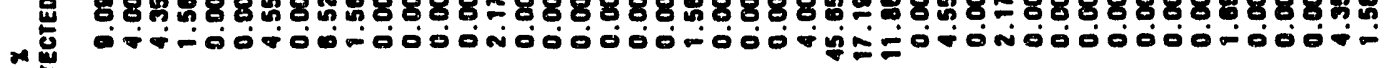

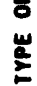
西

월ㄹ⿺ 4. is

ะพจร์ 즘 ญ

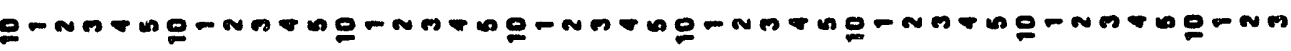

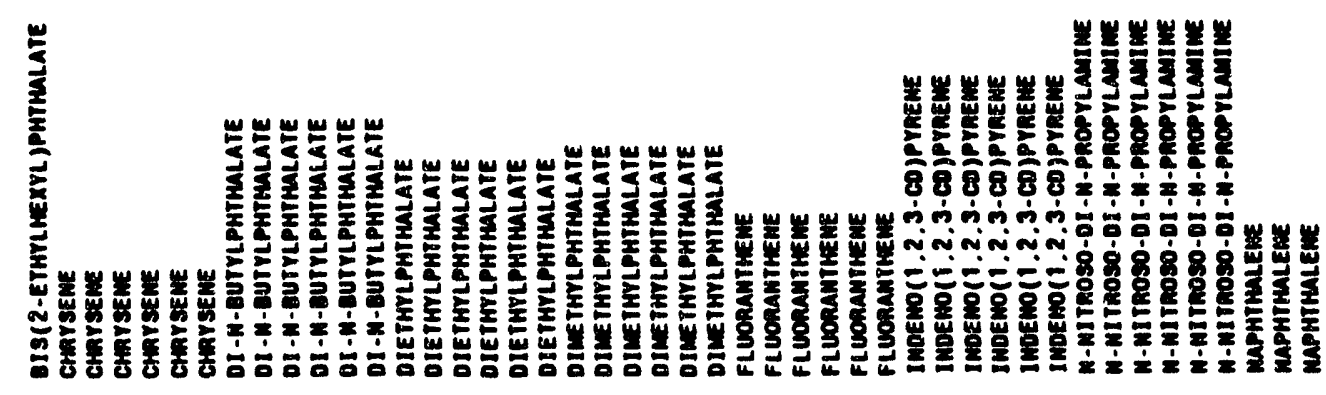


C-10

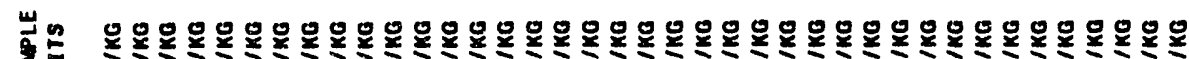

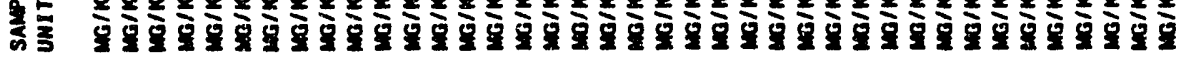

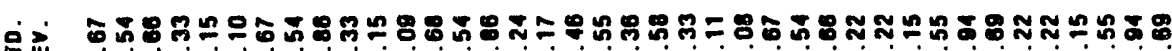
क岁 --

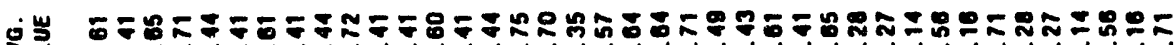

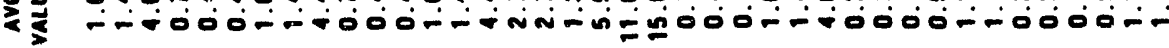

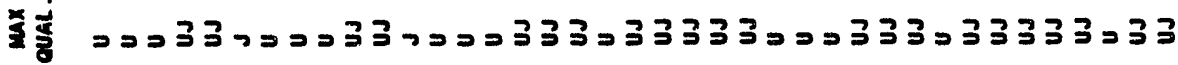

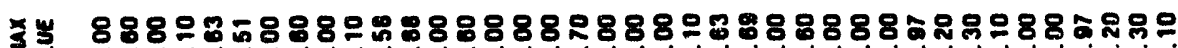

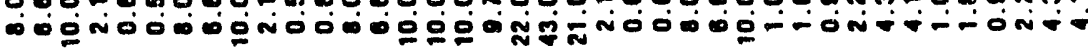

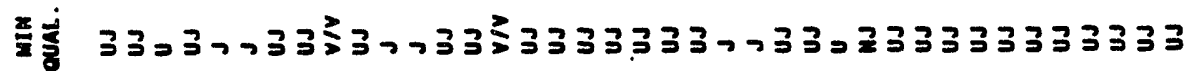

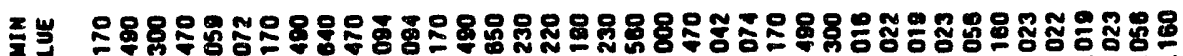

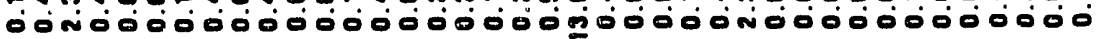

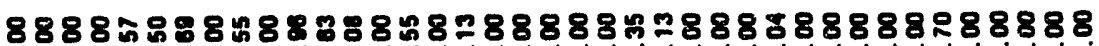

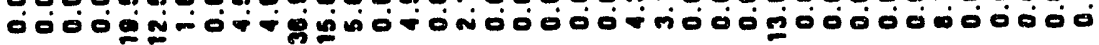

事产

$000000-0-1=000-0-00000 N n 000000000 n 00000$

8 غ8

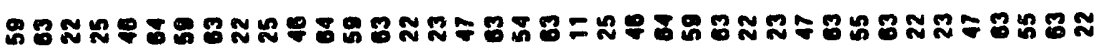

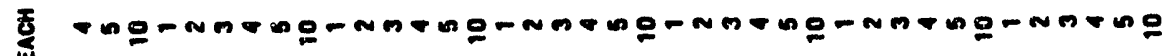

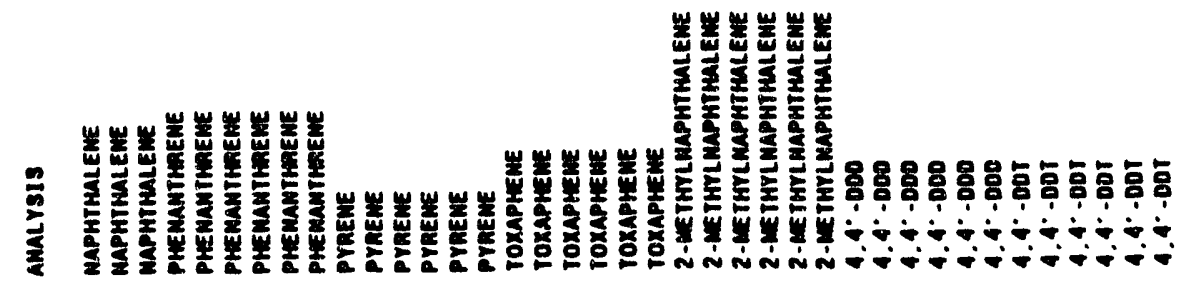


C-11

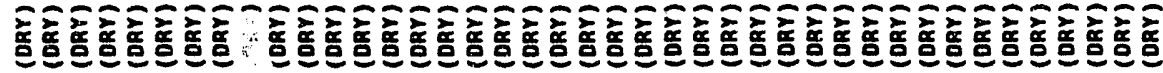

"

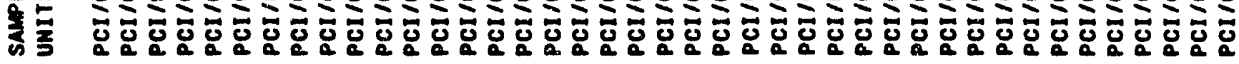

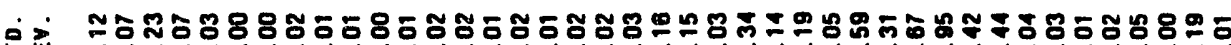

की

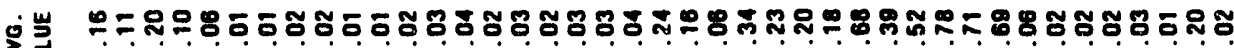

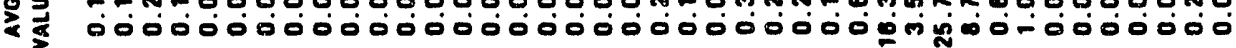

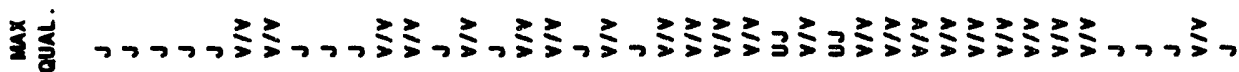

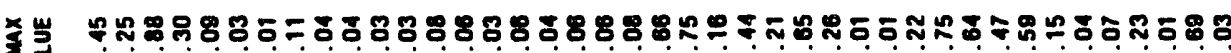

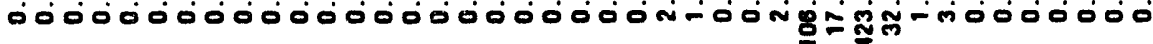

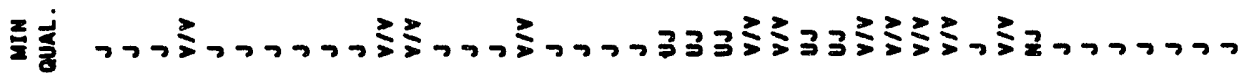

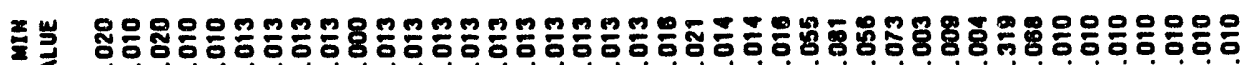

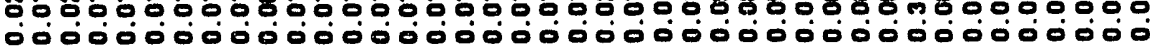

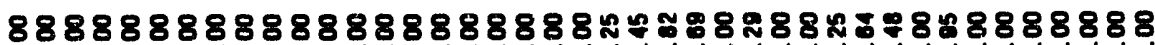

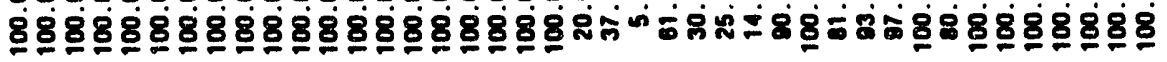

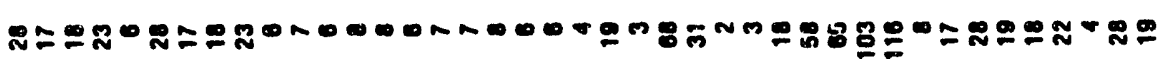
送兽

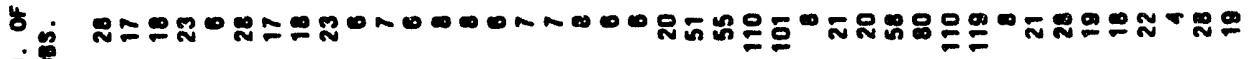
क्ष

J జ

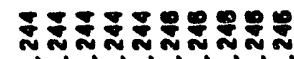

용

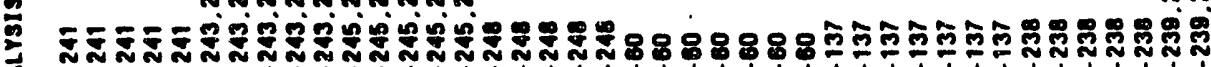

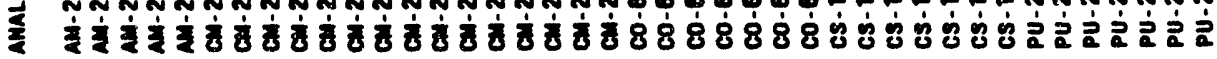



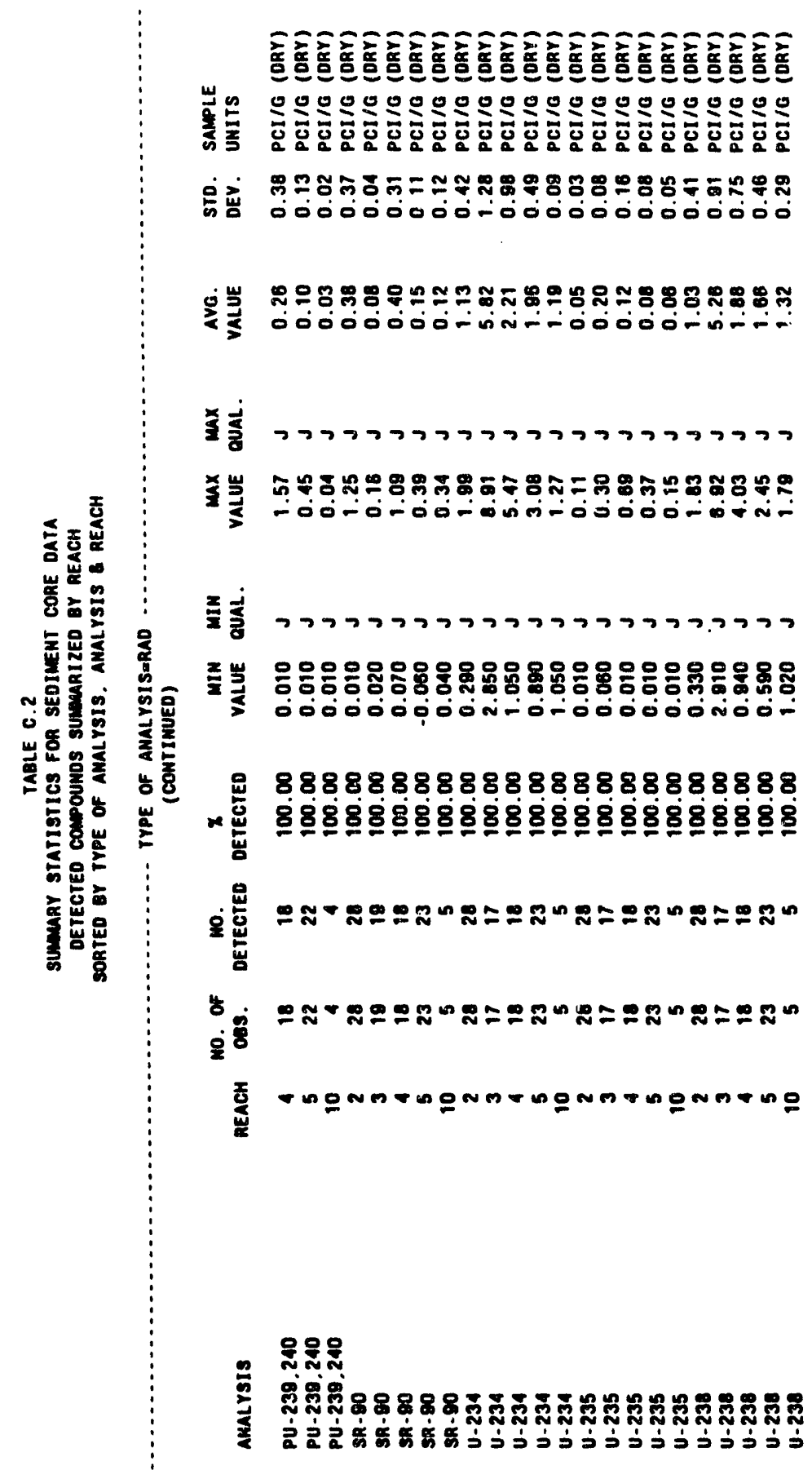
C-13

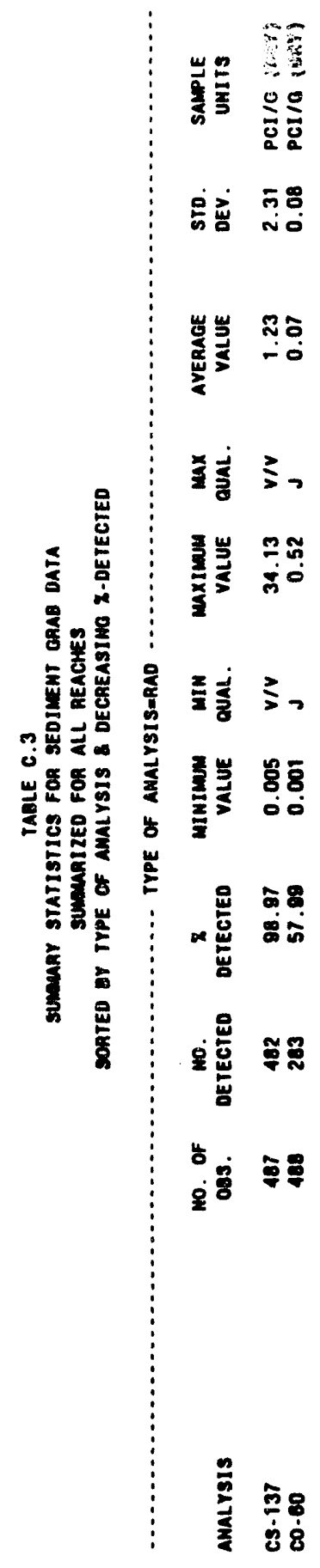


C-14

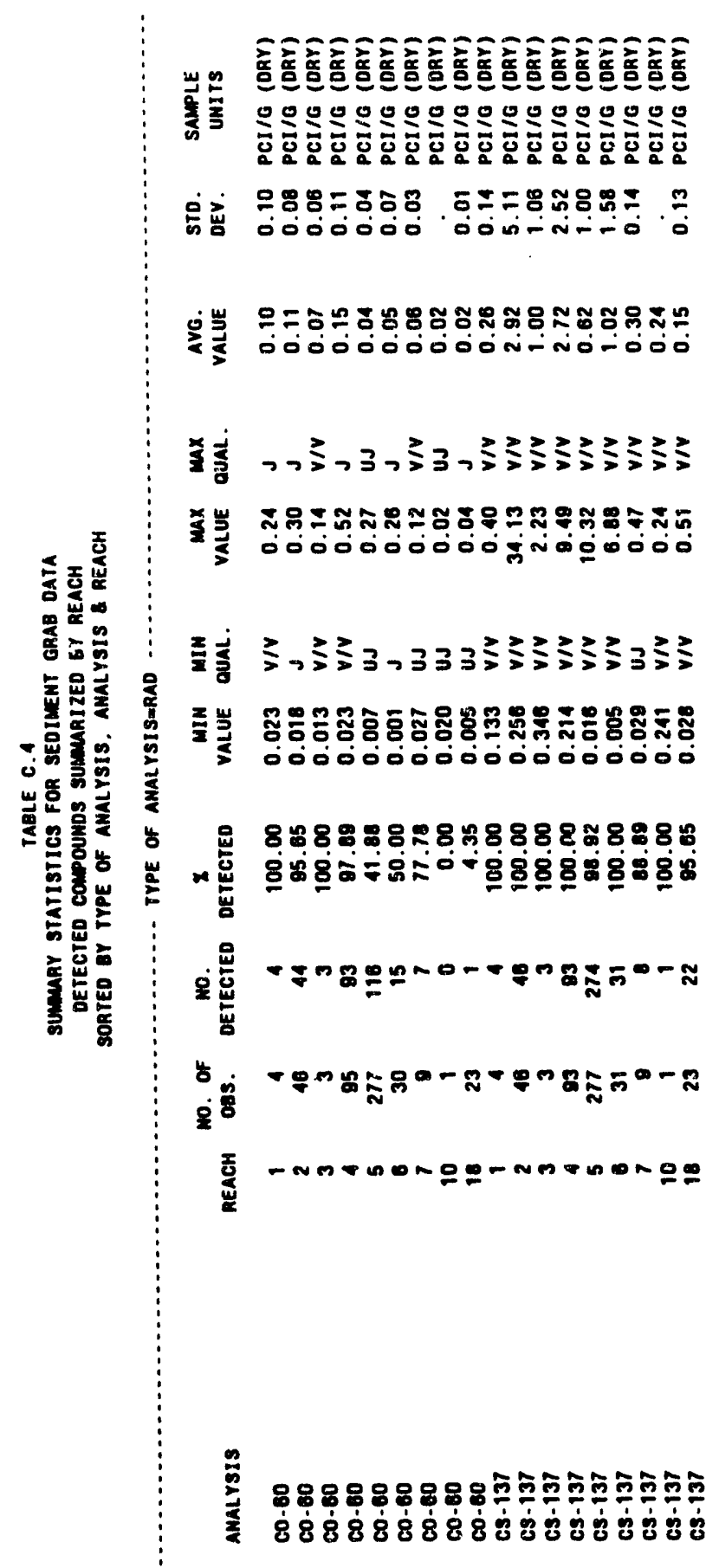


Appendix D

\section{STATISTICAL PROCEDURE FOR PAIRWISE COMPARISON OF FISH TISSUE RESULTS}


CONIENTS OF APPENDIX D

D.1 DATA DISTRIBUTION AND TRANSFORMATION $\ldots \ldots \ldots \ldots \ldots$ D-3

D.2 ESTIMATING MEANS FROM CENSORED DATA SETS $\ldots \ldots \ldots \ldots$ D.3

D.3 PAIR-WISE COMPARISON OF CONTAMINANT CONCENTRATIONS $\ldots \ldots \ldots \ldots \ldots \ldots \ldots \ldots \ldots \ldots \ldots \ldots, D-4$

D.4 REFERENCES FOR APPENDIX D $\ldots \ldots \ldots \ldots \ldots \ldots \ldots \ldots \ldots \ldots \ldots \ldots$

TABLES

Table D.1 Summary statistics for fish tissue data summarized for all reaches sorted by type of analysis and decreasing percentage detected D-6

Table D.2 Summary statistics for fish tissue data detected compounds summarized by subreach sorted by type of analysis, reach, and subreach 


\section{D.1 DATA DISTRIBUTION AND TRANSFORMATION}

Before appropriate analytical methods and statistical tests can be selected and performed on the contaminant concentration data, there should be some basis for assuming a particular form of data distribution (e.g., normal or lognormal). One possible choice for the distribution is the lognormal, because the observations are bounded on the lower side by zero and their distribution tends to be positively skewed with a tail to the right-both properties that are compatible with the lognormal distribution. Because tests for normality or lognormality (e.g., the Shapiro-Wilk or Kolmogorov tests) are not formulated to manage censored observations, we restricted the analysis to combinations of site, analyte, and species for which censored observations were not present. This restriction resulted in our analyzing only Aroclor 1260 for catfish and mercury for bluegill. The data distribution of Aroclor 1260 was thus assumed to be representative of the organic analytes and mercury of the inorganic analytes. That is, if the distribution for PCB or mercury was a member of a particular family of distributions (e.g., lognormal), then the other analytes within that group of analytes were assumed to be of the same family. In order to increase the sample size for evaluating the distribution types, sites were grouped together based on expectations of similar results due to their respective proximity to each other and contaminant point sources. Tests for normality and lognormality were performed on data from each group of sites. Except for one data set, the test for normality on the untransformed data was significant $(P<0.01$ ), indicating a non-normal distribution. When the data were log transformed, the normality test statistic increased in all cases to the point at which the lognormal distribution seemed appropriate, except for the single case mentioned previously. Based on these results, the assumption of lognormality for the distribution of the organic and inorganic analytes seemed appropriate, and this distribution was assumed for all subsequent analyses.

\section{D2 ESTIMATING MEANS FROM CENSORED DATA SETS}

Censored data sets are those which contain some observations reported only as greater or less than some value (less than an SQL in this case). Although various methods are available to obtain estimates of the mean and variance of censored data sets (such as replacing the censored observations with a value of 0 , half the SQL, or the SQL itself, and then proceeding as if the observations were uncensored), many of these methods make inefficient use of the available data. When the distribution of the censored data set can be assumed to be of a particular form (e.g., normal, lognormal, etc.), the maximum likelihood (MIL) method is known to be an efficient method of obtaining these estimates. ML estimates of the mean and variance of the analyte concentrations can be obtained with a method similar to that developed by Cohen (1963) for progressively censored samples. The results from an analysis of the PCB and mercury data distributions form the basis for assuming that the fish body burden data measured in Phase 1 are lognormally distributed. This assumption makes it possible to specify the distribution function needed in the likelihood function. The ML estimates of the unknown parameters needed to specify the lognormal distribution were obtained using the LIFEREG procedure from SAS (Version 6.06).

As the proportion of censoring increases and/or the sample size decreases, the confidence in the estimates of the distribution parameters decreases. This relationship is reflected in the general increase in the standard errors for the different parameter estimates as either of these occur. A plot of the relationship between the proportion of censoring and the relative 
standard error (std. error/mean) from the Phase 1 data suggests that the reliability of the ML method begins to decrease for those data sets where the censoring exceeds 60 to $70 \%$. The number of detectable observations in a sample is a simple measure which can also indicate a high degree of censoring or a small sample size (or both), either of which can produce less reliable ML estimates. Given this information, we considered the ML method inappropriate for calculating useful standard errors when the proportion of censoring exceeded $60 \%$ or when the number of detectable observations was less than three. When these criteria were exceeded, we deemed the estimation of a mean and variance by any method for the purpose of statistical analyses to be unsuitable.

\section{D.3 PAIR-WISE COMPARISON OF CONTAMINANT CONCENTRATIONS}

We adapted current statistical procedures to evaluate the difference in concentration between each affected site and the reference site on a pair-wise basis. A description of this method follows. Let $\hat{m}_{\mathrm{i}}$, the estimates of the means of the two lognormal distributions, be

$$
m_{i}=\exp \left(\hat{r}_{1}+\frac{\partial_{i}^{2}}{2}\right)
$$

where

$$
\begin{aligned}
& i=1,2, \\
& \hat{\mu}_{i}=\text { estimated mean for the transformed (log) data at site } i,
\end{aligned}
$$

and

$\hat{\sigma}_{i}^{2}=$ estimated variance for the transformed log data at site $i$.

The two means of interest correspond to the affected and reference sites. Since differences in the $\hat{m}_{i}$ 's would be reflected by differences in the terms $\hat{\mu}_{i}+\hat{\sigma}_{i}^{2} / 2$, the comparison of the two distributions will be done in terms of these latter quantities. An asymptotic z-test was used to compare the two means with the test statistic calculated as

$$
z=\frac{\ln \left(m_{1}\right)-\ln \left(m_{2}\right)}{\sqrt{\left(s_{1}\right)^{2}+\left(S_{2}\right)^{2}}}
$$

where

$$
s_{1}=\sec \left(\hat{\beta}_{1}+\frac{\partial_{l}^{2}}{2}\right)
$$


The $\mathrm{z}$ value was then compared with a standard normal distribution. This test was adequate only when a reliable mean and s.e. could be calculated for both sites $i$ and $j$. That is, either by standard procedures if there was no censoring, or by the maximum likelihood method for censored data if censoring did not exceed $60 \%$ and the number of detectable results was greater than 2.

If a reliable mean and s.e. could only be calculated for either site $\mathrm{i}$ or $\mathrm{j}$ (but not both), then a second method of site comparison was required. First, a $95 \%$ confidence interval on the mean of the untransformed data was calculated for the site with the reliable mean. If none of the individual values for the other site fell within the confidence interval, we concluded that there was a strong indication that the two sites were different. Otherwise we concluded that the data was insufficient to determine any significant difference between the two sites.

Lastly, if reliable means and s.e.'s were not attainable for both sites which were being compared, we considered the data to be insufficient to draw any conclusions about the similarity of the two sites.

\section{D.4 REFERENCE FOR APPENDDX D}

Cohen, A.C. 1963. Progressively censored samples in life testing. Technometrics 5:327-339. 
D-6

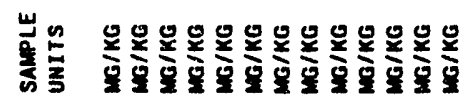

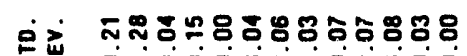

ตั

岁岂 సโ์

०ण0000000000

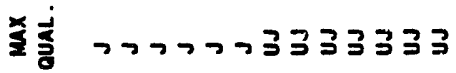

롤

产

$0=0-00000000$

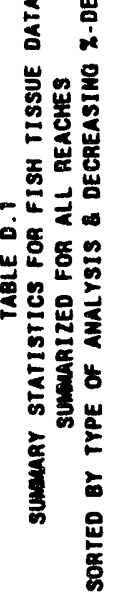

88 뚀

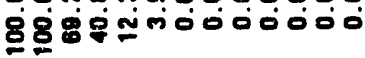

$8 \% \equiv 8000000000$

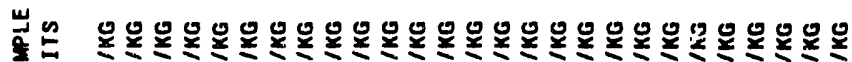

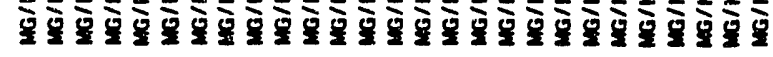

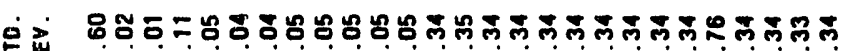

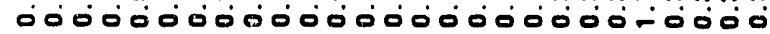

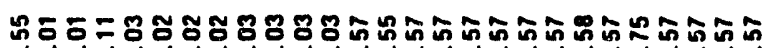
0000000000000000000000N0000

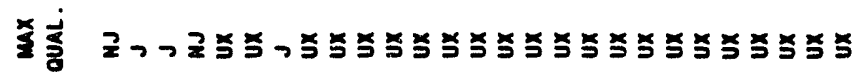

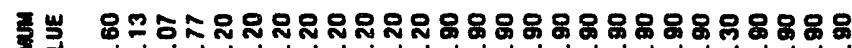

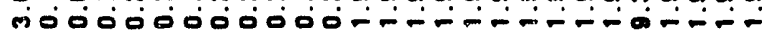

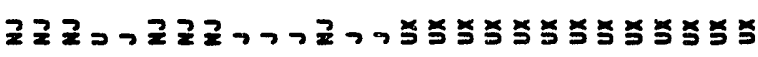

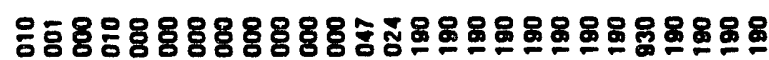
000000000000000000000000000

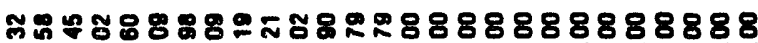

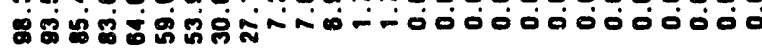
站

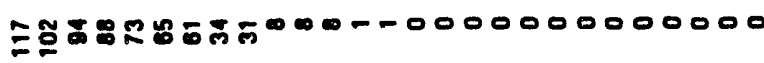

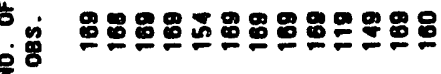

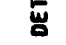

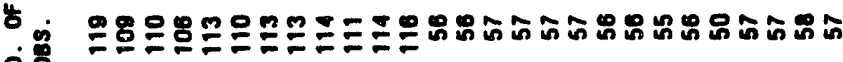

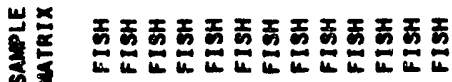

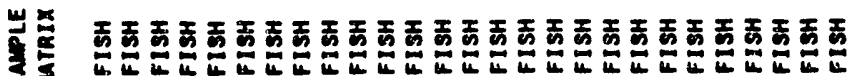

总宽宽

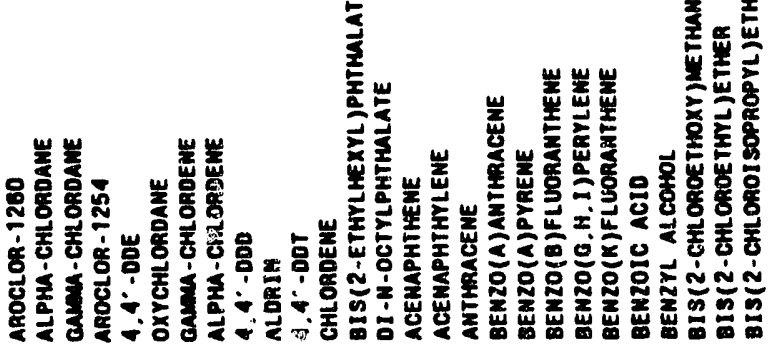


D-7

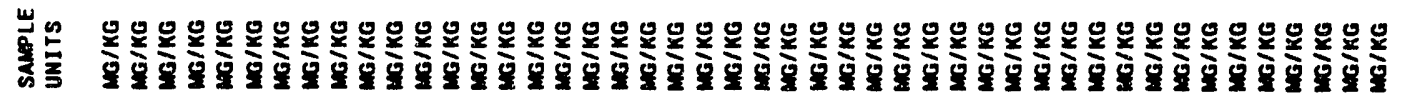

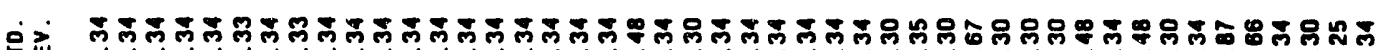

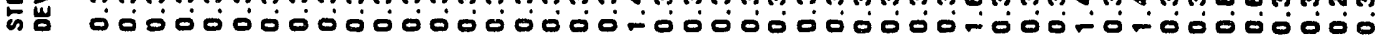

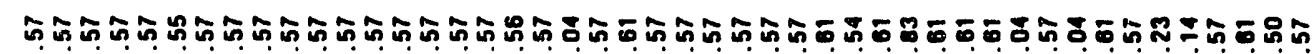

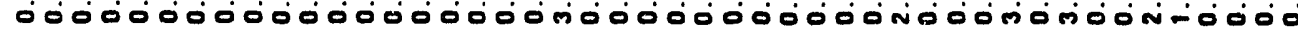

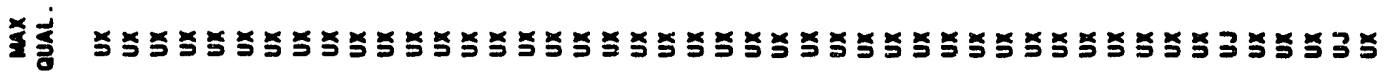

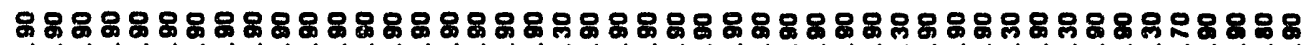

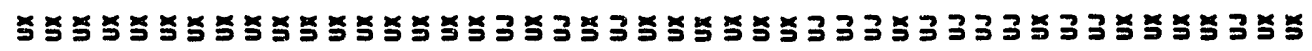
疍岂

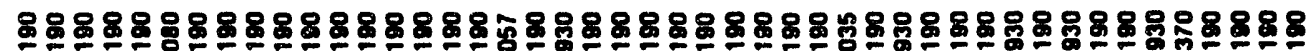

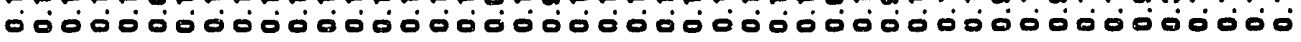

888888888888888888888888888888888888888888888

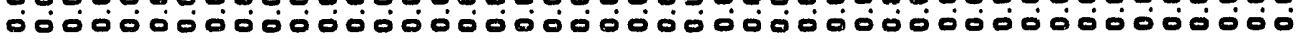
焉

0000000000000000000000000000000000000000000000 울

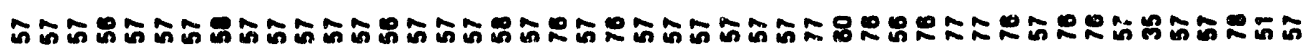
宝宽

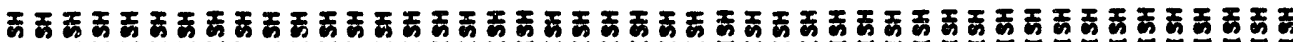

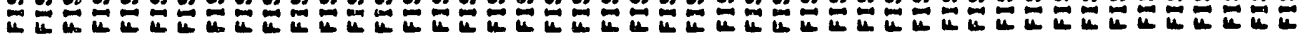

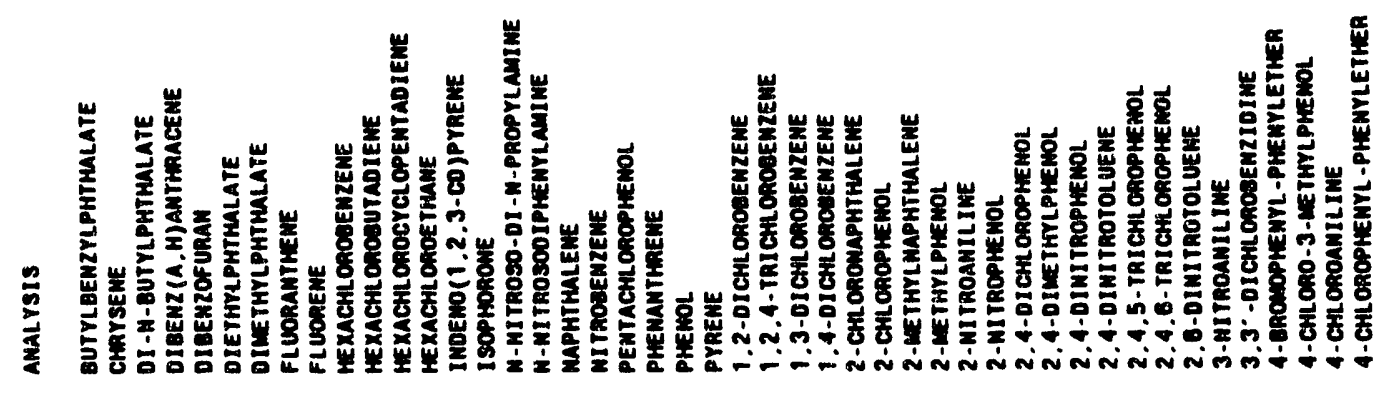


D-8

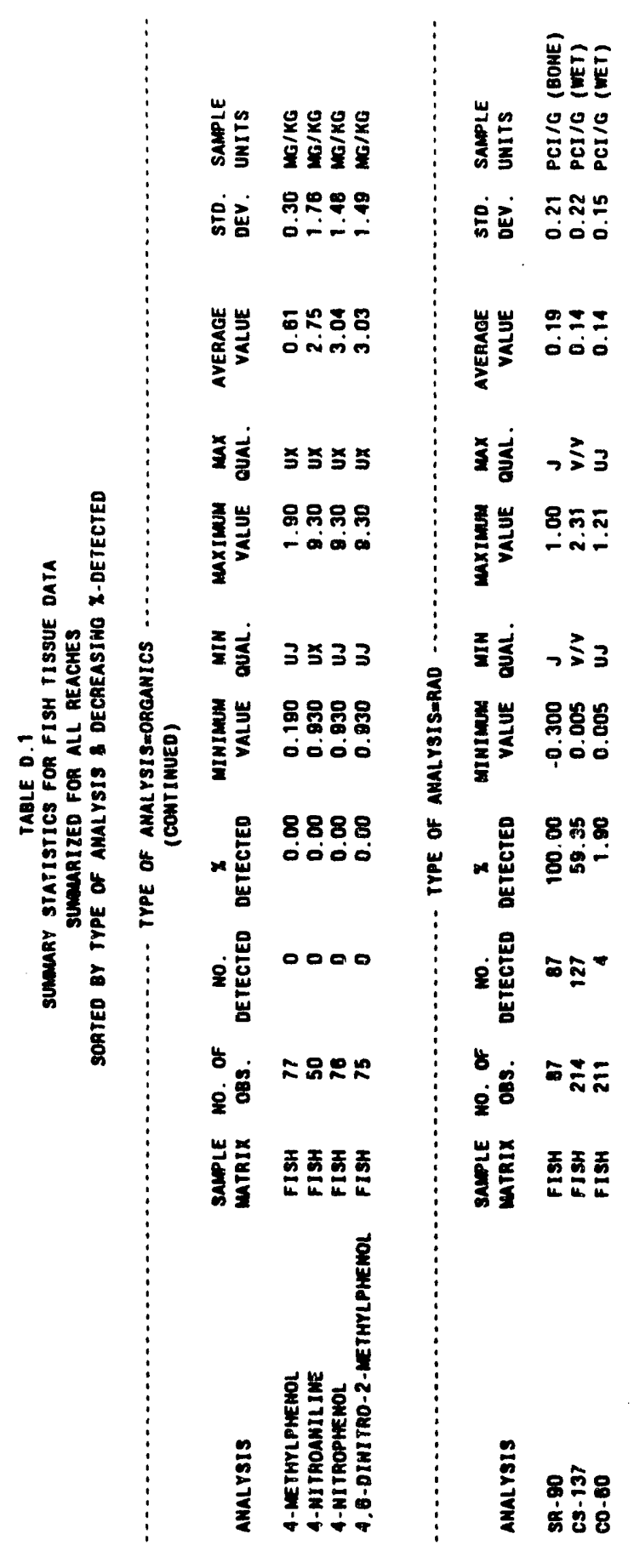


D-9

苟 言空

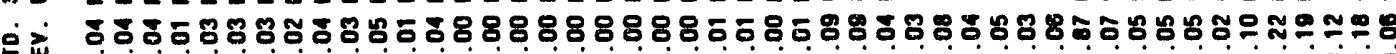

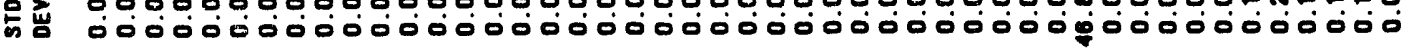

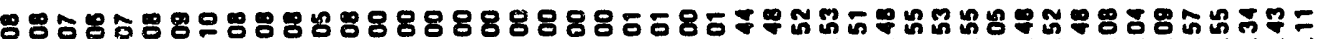
0ं00

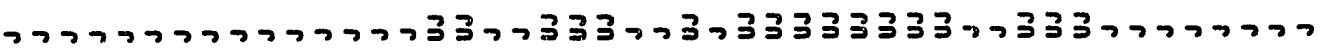

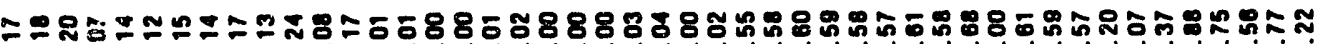

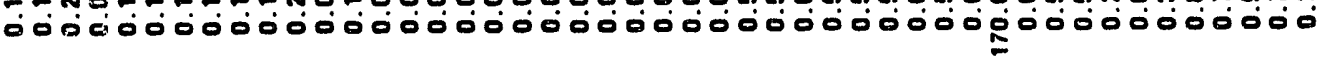

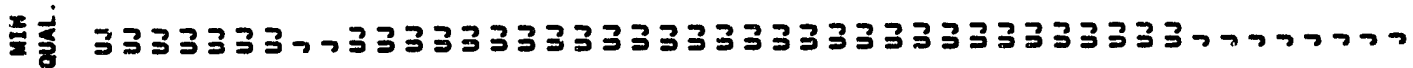

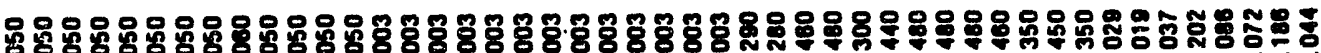
00000000000000000000000000000000000000000000000

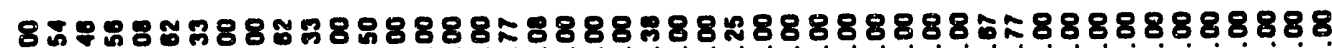

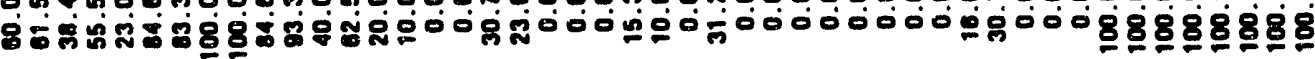

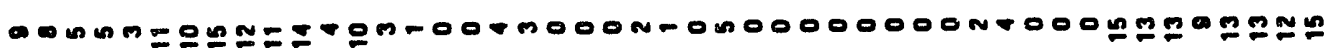

o.

คะ

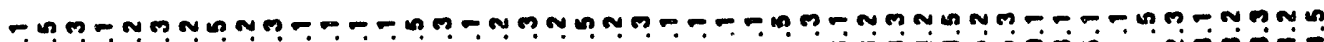

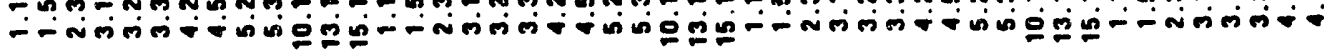

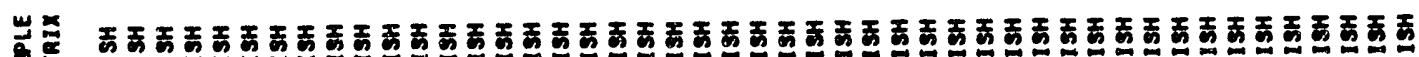

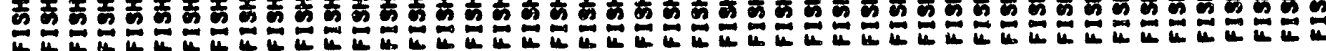


次 กิ

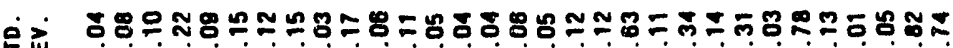

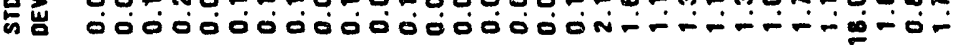

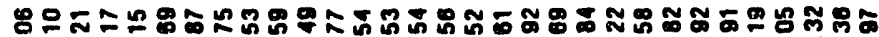

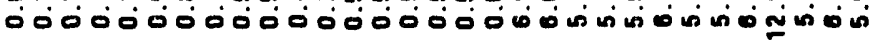

冬妾

空

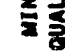

赵岂

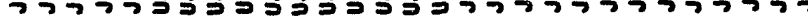

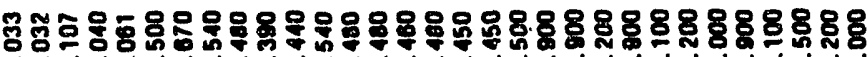

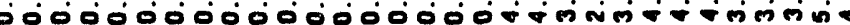

$88888 \% 58885888 \% 888888888888888$

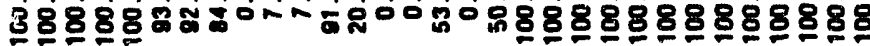

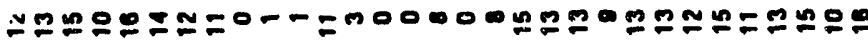

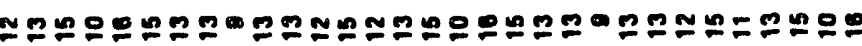

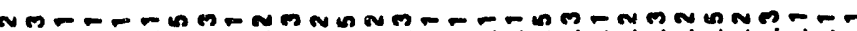
nं

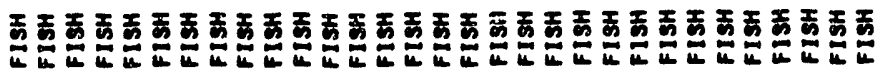

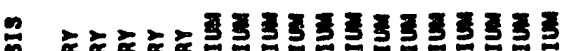

$\frac{2}{\frac{3}{3}}$

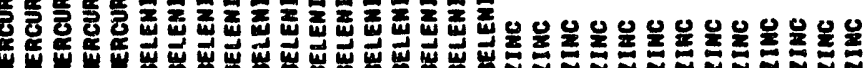

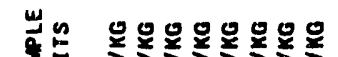

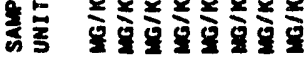

궁 8808888

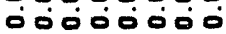

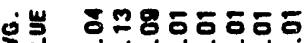

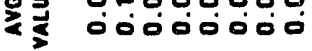

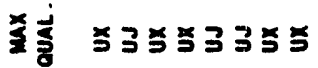

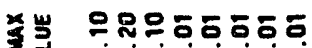
०000000

줓 청

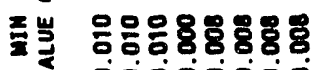

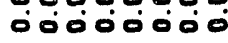

$888 \% 888$

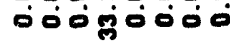

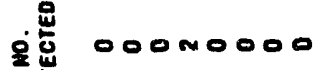

若 옹

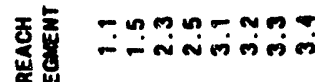

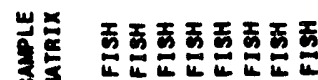

命安

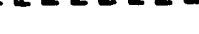

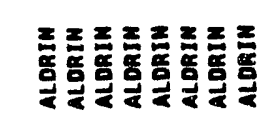


D-11

บํ. 15

ต้

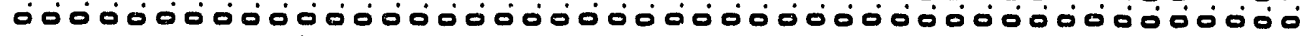

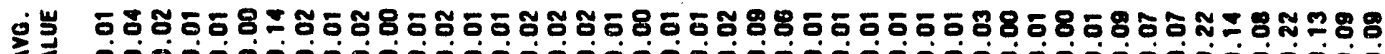
ऐ

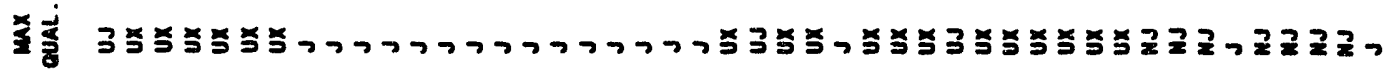

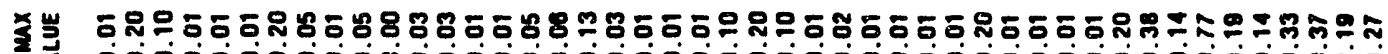
0000000000000000000000000000000000000000000000

졿

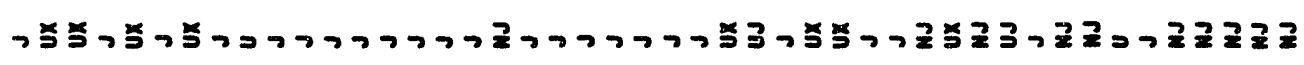

폴

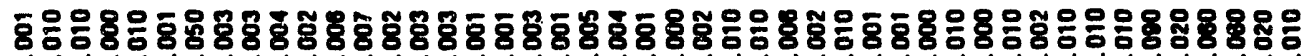

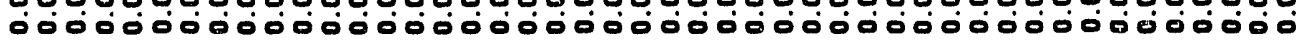

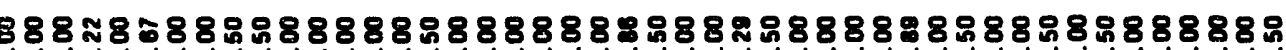

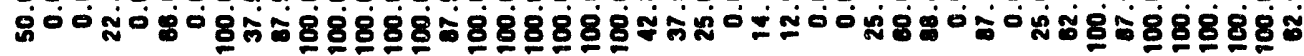

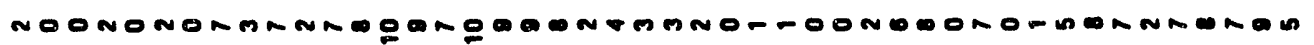

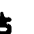

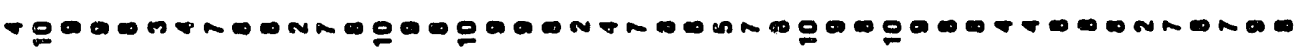

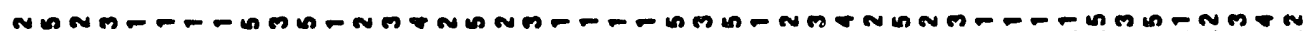

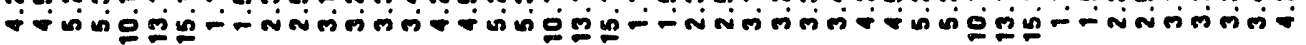

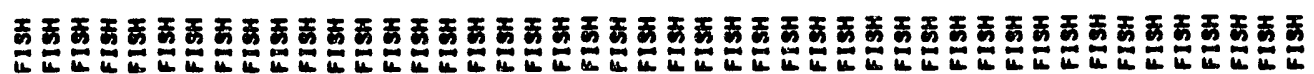

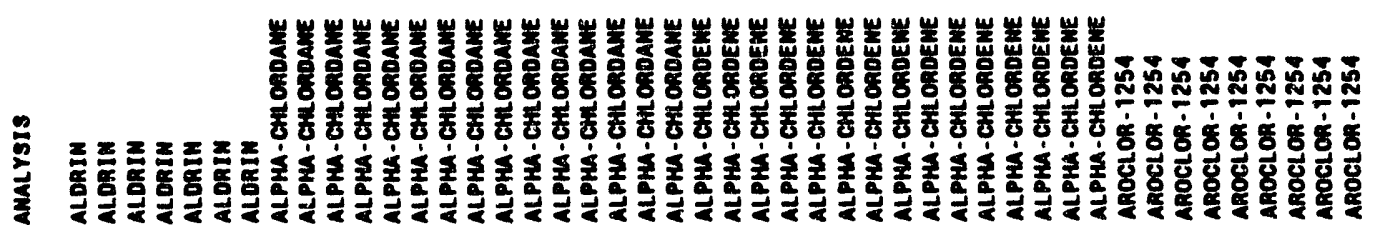


D-12

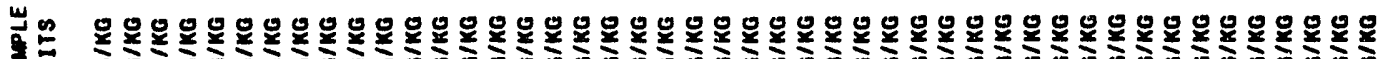
旁节 현 8 के 000000000000000-00000000000 000000000000000000

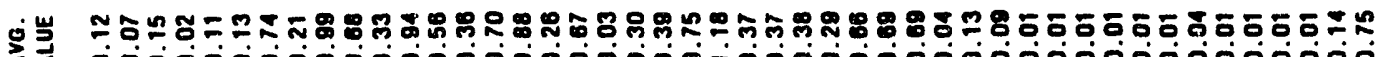

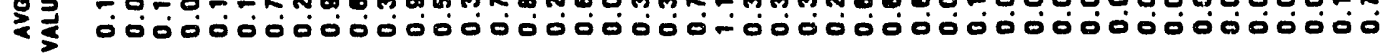

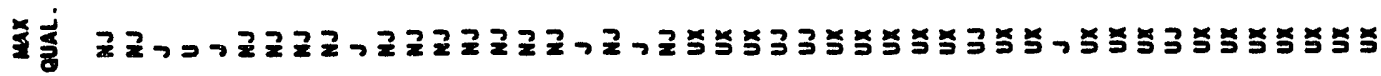

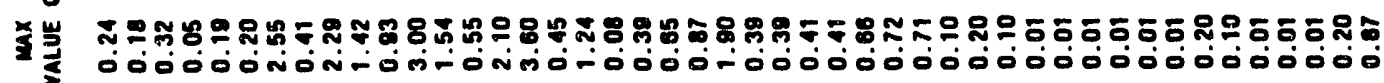

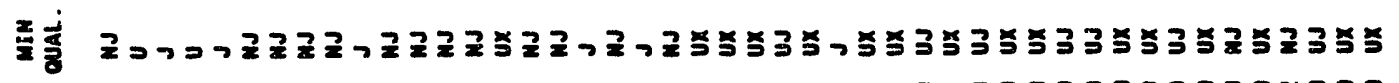

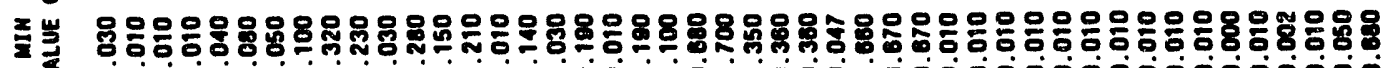

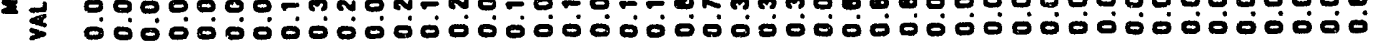

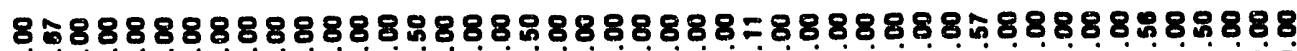

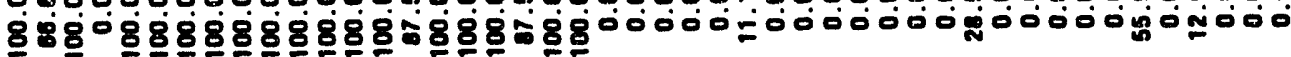
4

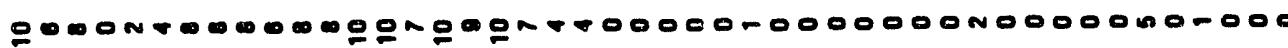
4

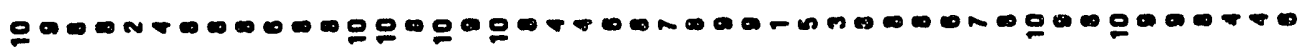

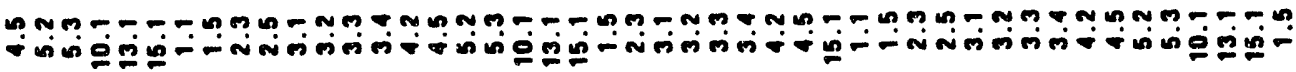

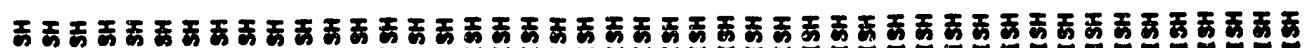

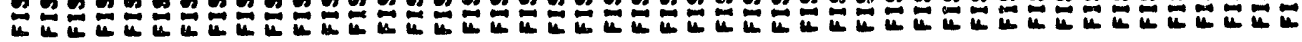

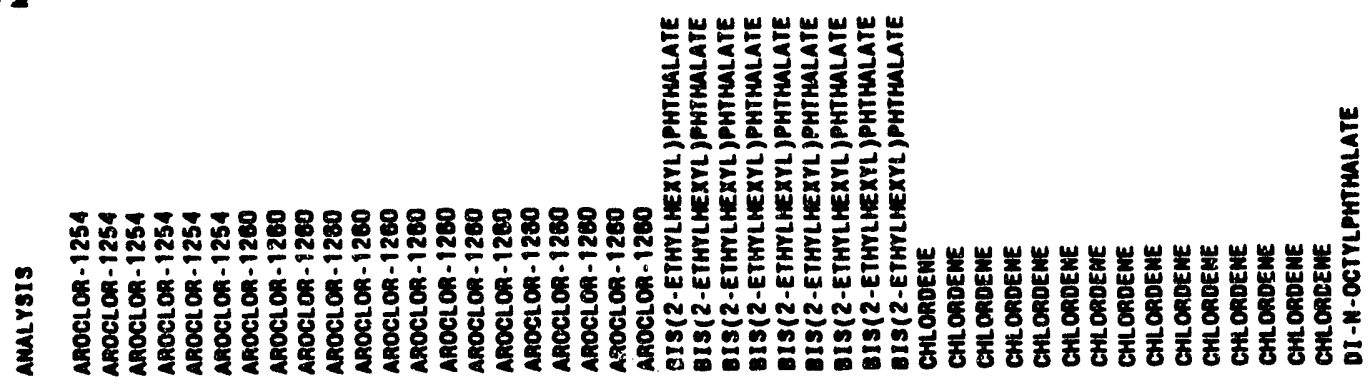




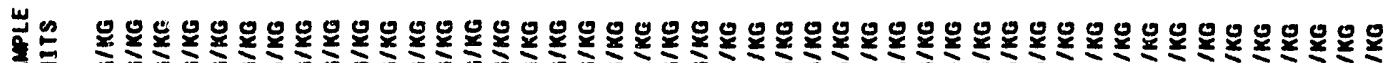

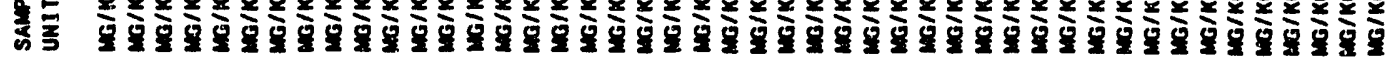
현

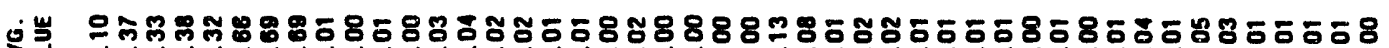

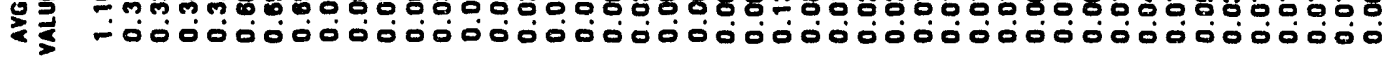

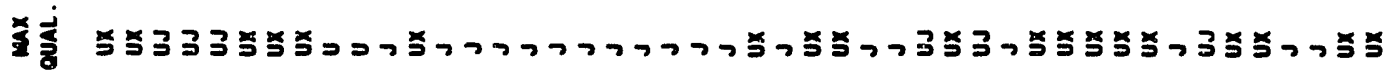

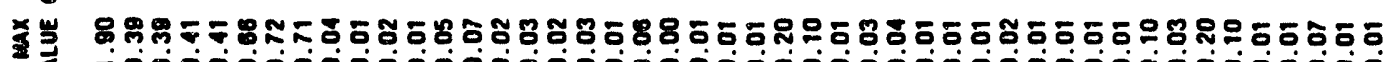

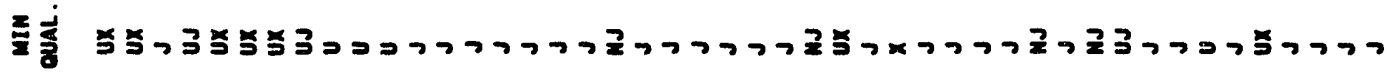

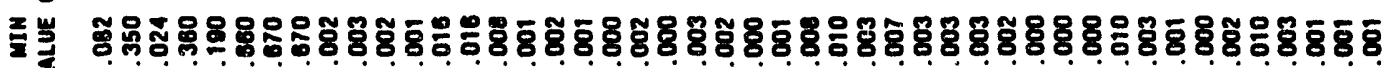

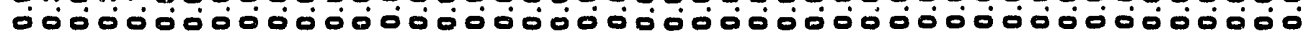

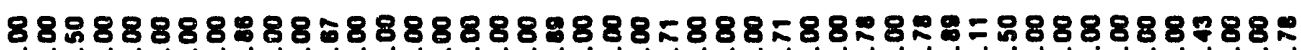

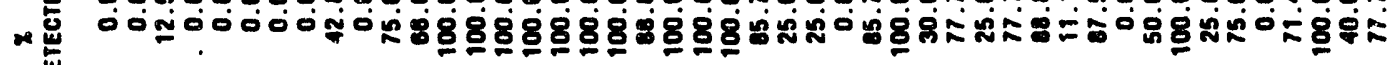

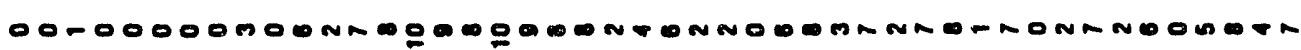
\% is

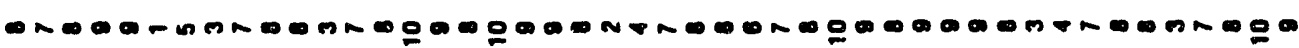

ח-

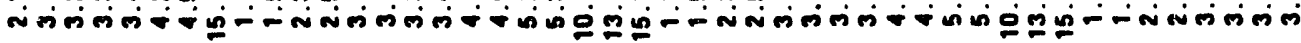

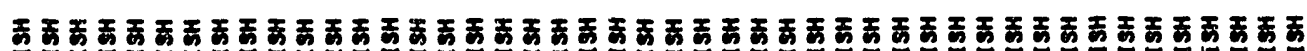

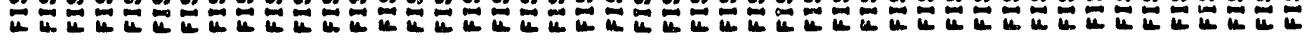

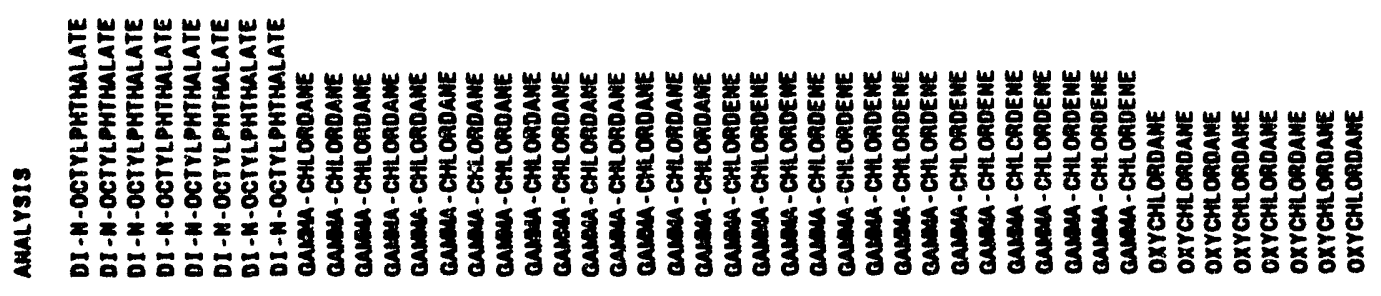


D-14

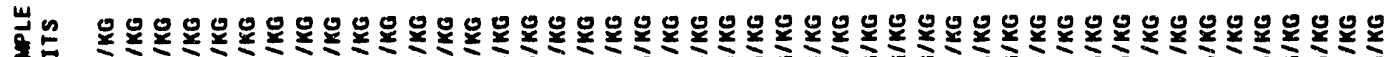

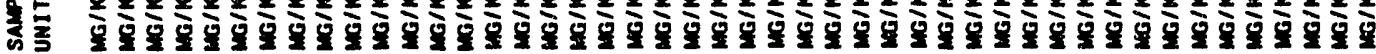
궁

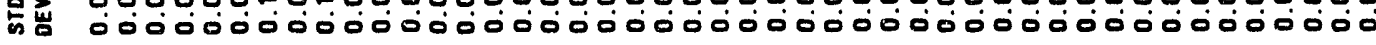

ن य 00000000000000000000000000000000000000000000

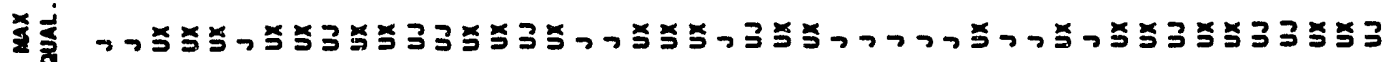

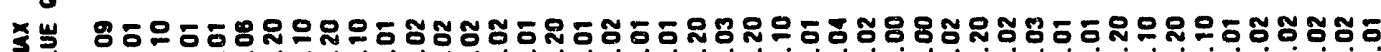
इ

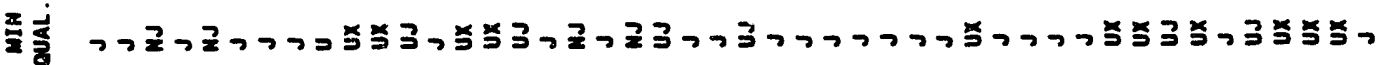

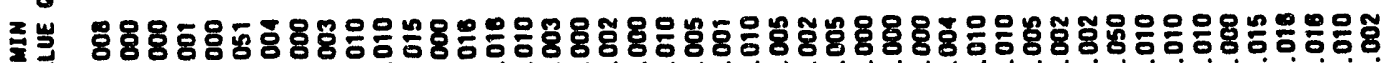

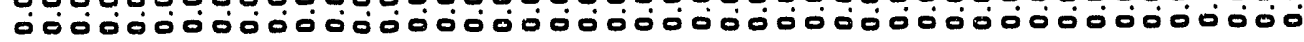

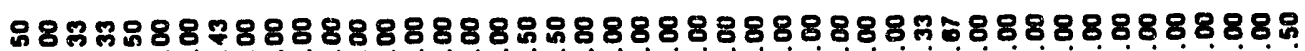

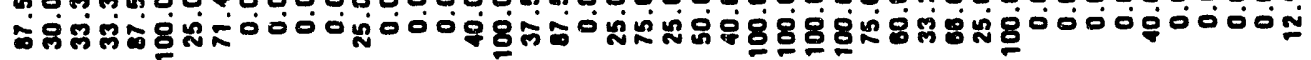

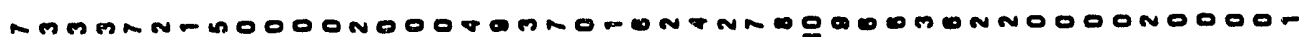

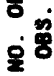

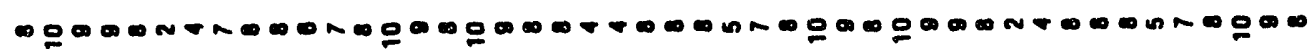

ר n

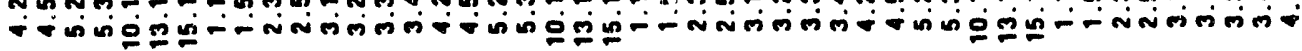

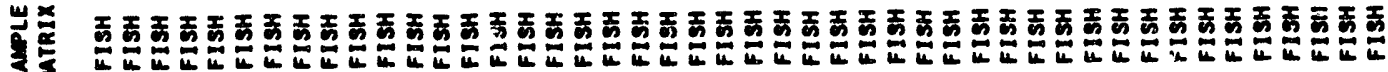


D-15

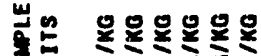 \\ क力 \\ 这 888888 \\ 解 \\ نั \\ रुक्ष 000000

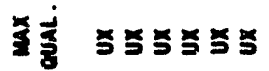

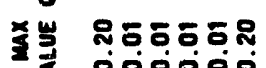

这范

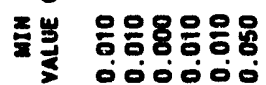

\section{$88 \% 888$ 00 ino} is

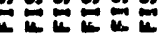

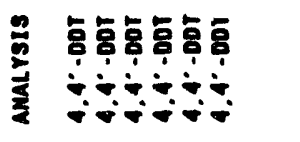

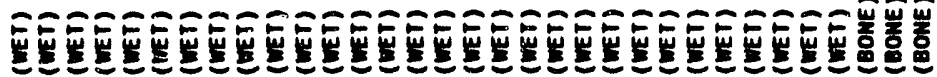
000000000000000000000000000000000

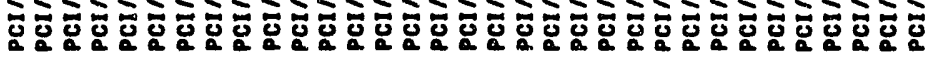

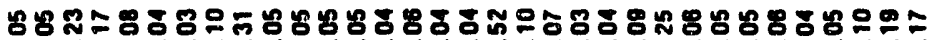

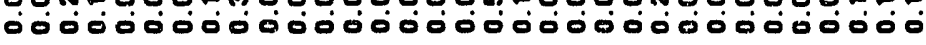

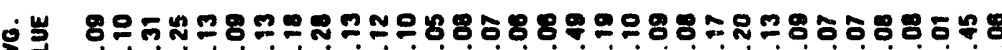
000000000000000000000000000000000

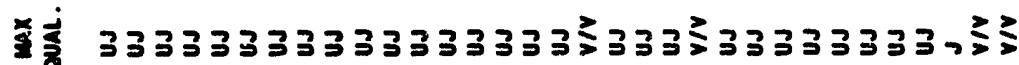

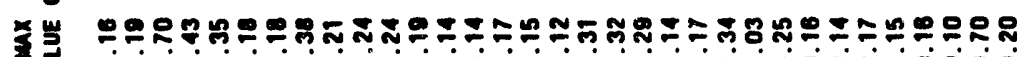

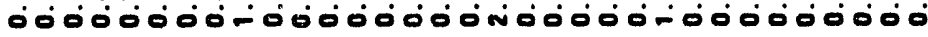

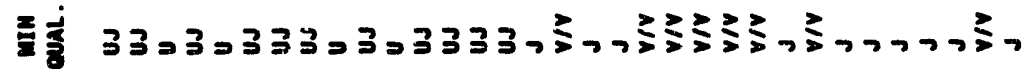

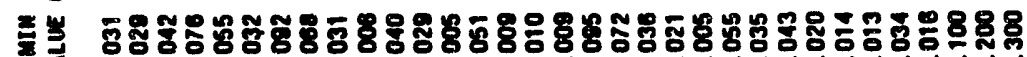

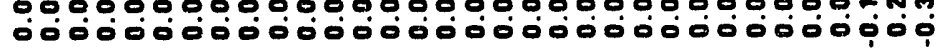
$588888 \% 88888$ \%8\%"

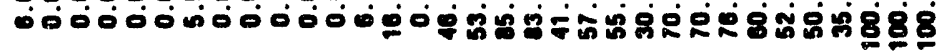

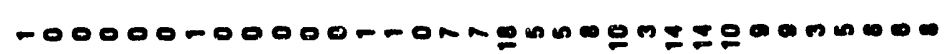

エะก・

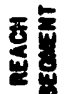

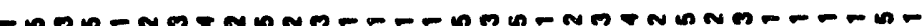

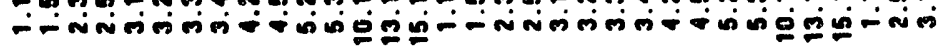

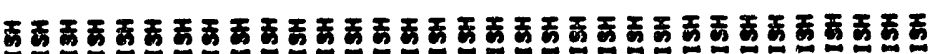

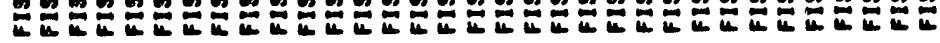

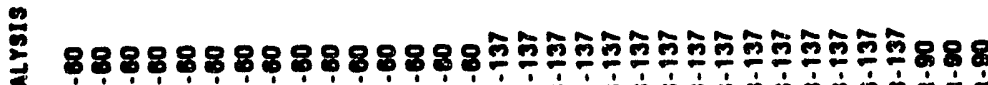

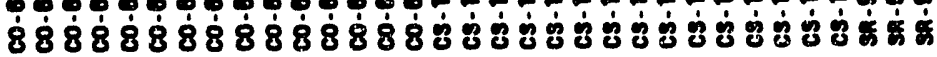


D-16

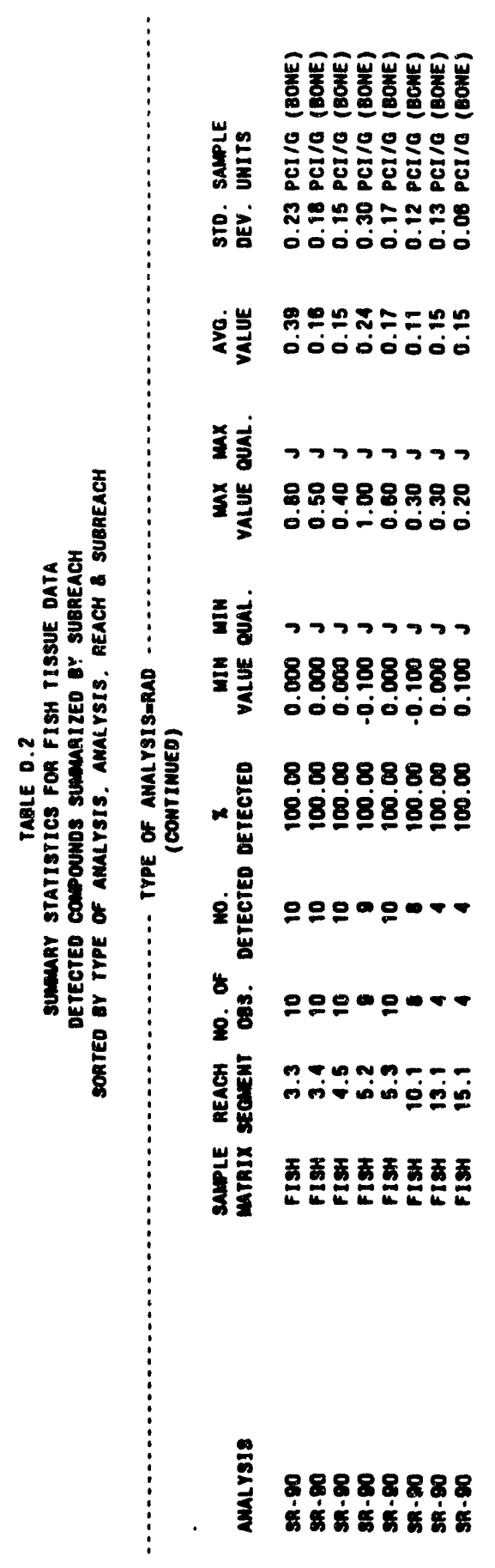


Appendix E

HUMAN HEALTH RISK METHODS 


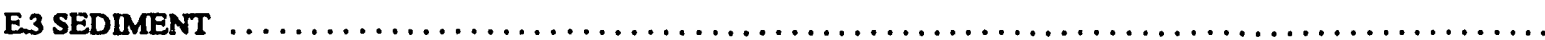

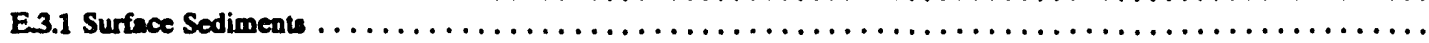

E.3.2 Corce

\section{TABLES AND FIGURES}

Table E.1

Table E.2

Table E.3

Table E.4

Table ES

Table E.6

Table E.7

Table E.8

Table E.9

Table E.10

Table E.11

Table E.12

Table E.13

Table E.14

Table E.15

Table E.16

Table E.17

Table E.18

Table E19

Figure E.1
Receiving reaches for Oak Ridge Reservation source monitoring and surface water environmental monitoring stations

Ukage and expocure factors for conservative and nonconservative screening

Reference doee factors and slope (cancer potency) factors for inorganic compounds ........... E-10

Reference doee factors and slope (cancer potency) factors for organic compounds ............. E-11

Slope (cancer potency) factors for radionuclides $\ldots \ldots \ldots \ldots \ldots \ldots \ldots \ldots \ldots \ldots \ldots \ldots \ldots$ E-15

Summary of carcinogens in the secondary pathways identified as low priority for further inveatigation .... E-16

Summary of noncarcinogensin the secondary pathways identified as low priority for further

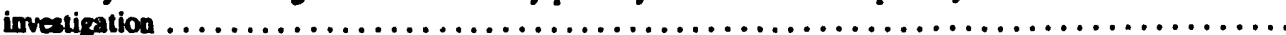

Results of adult nonconservative screening for carcinogens in fish, surfsce sediment, and water where at leasl oae measurement in a reach was above detection limits

Results of adult nonconservative screening for nonconcarcinogens in fish, surface sediment, and water where at least one measurement in a reach was above detection limits

Results of adult conservative screening for carcinogens in fish, surface sediment, and water where at least one measurement in a reach was above detection limits

Rewuls of adult conservative screening for noncarcinogens in fish, surface sediment, and water where at least one measurement in a reach was above detection limits

Resulk of child conservative screening for noncarcinogens in fiah, surface sediment, and water where at least one measurement in a reach was above detection limits

Recults of adult coneervative screening for carcinogens in dredged sediments where at least ose measurement in a reach was above detection limils

Rewults of adult conservative screening for noncarcinoyens in dredged sediments where at least ose measurement in a reach was above detection lirnits

Reuults of adult nonconservative screening for carcinogens in fish and water where no measurement in a reach was above detection limils.

Reaults of adult ncoconservative screening for noncarcinogens in fish and water where no meseurement in a reach we above detection limits.

Recults of adult nonconservative screening for carcinogens in dredged sediments where no mensurements in a reach were above detection limits

Results of adult nonconservative screening for noncarcinogens in dredged sediments where no measurements in a reach were above detection limits

Uaclaesified analyrea

Location of NPDES monitoring sites in Clinch River/Watts Bar Syatem 


\section{E1 HUMAN HEALTH SCREENING RISK ASSESSMENTS}

Conservative and nonconservative screening risk analyses were performed for selected media and primary and secondary exposure pathways. Primary pathways are those most realistic and likely to be encountered. Secondary pathways are less likely scenarios or potential and/or future pathways of exposure. A listing of risk assessment scenarios, usage, and exposure factors used for the human health screening is given in Table E.2. Tables E.3 through E.5 give toxicity reference doses and cancer factors for those contaminants considered in the risk analyses. Screening results are presented in Tables E.6 through E.18.

\section{Media and Primary Expasure Pathways}

1. Fish:

- $\quad$ ingestion by adult and child.

2. Surface Sediment:

- $\quad$ external exposure to sediments for adult,

- $\quad$ ingestion of sediments for adult and child, and

- inhalation of sediments for adult.

3. Water:

- ingestion by adult and child.

\section{Media and Secondary Expasure Pathway}

Buried Sediment (dredging of deep sediments):

- $\quad$ external exposure to dredged sediments for adult;

- $\quad$ ingestion of dredged sediments for adult;

- $\quad$ inhalation of dredged sediments for adult; and

- $\quad$ ingestion of milk, meat, and vegetables produced on dredged sediments for adult.

The results of the analyses for the selected analytes (see Table A.1) provided a comprehensive view of the extent of contamination in the selected media. Actuality, only $10 \%$ of the determinations exceeded their method detection limits. This is a common occurrence for regulatory-driven environmental sampling and analysis activities. For the screening risk analyses, a distinction was made between detected contaminants, contaminants with at least one detected value in a given reach, and nondetected contaminants, contaminants with no detected values in a reach. Separate analyses and interpretations of these results were done for detected and the nondetected contaminants.

The following sections describe the specific data manipulations performed for each of the selected media.

\section{E2 FISH}

Except for PCBs data were combined for all fish species within a reach. Only catfish results were used for PCBs because catifish values are typically much greater than bass and are useful for the conservative screening. Only detected chlordane isomer values were summed. The average detection limit was used when all chlordane isomers were nondetects. 
Given the potential for means of distributions with numerous non-detect values (censored data) to be positively biased, the upper $95 \%$ confidence limit of the arithmetic mean and the geometric mean were calculated using a maximum likelihood estimator (SAS PROC LIFEREG). The UCL was compared with the actual maximum value, and whichever is smaller was used in the conservative risk calculation as detected contaminants. The geometric mean was used for nonconservative calculations. Only a nonconservative calculation using the minimum detection limit was done for nondetected contaminants.

\section{E3 SEDIMENT}

\section{E3.1 Surface Sediments}

All grabs are summarized for each reach.

Surface sediment samples in a reach were used on the screening analysis. The upper $95 \%$ confidence limit of the arithmetic mean and the geometric mean were calculated using a maximum likelihood estimator (SAS PROC LIFEREG). The UCL was compared with the actual maximum value and which ever is smaller was used in the conservative risk calculations: for detected contaminants the geometric mean will be used for nonconservative calculations.

Only a nonconservative calculation using the minimum detection limit was done for the nondetected contaminants.

\section{E.32 Cores}

A mass-weighted average concentration was calculated to a depth of $1 \mathrm{~m}$. For cores shorter than $1 \mathrm{~m}$, the mass-weighted average of what was collected was calculated and was assumed to represent the concentration in the top $1 \mathrm{~m}$ of sediment. When there was more than one core per reach, the mass-weighted average for each core was calculated and the upper $95 \%$ confidence limit of the average of the core averages, or the maximum core average, (whichever is smaller) was used as the reach value for conservative screening. The arithmetic mean of the core averages was used for nonconservative screening. Only a nonconservative calculation using the minimum detection limit of the core averages was done for the nondetected contaminants.

\section{E4 WATER}

The description of the water data used in the screening analyses requires some additional explanation. CR-ERP sampling consisted of a single grab sample collected at the same times (late 1989 and early 1990) and sites as the initial sediment and fish samples. To better represent the water quality of the CR/WBR system, additional data were obtained from ORR compliance and environmental monitoring programs. Table E.1 lists the sources of these data for each reach. The sampling locations relative to DOE facilities are shown in Fig. E.1. The source monitoring data are from samples collected at permitted outfalls to determine regulatory compliance with NPDES and DOE Order 5400.1. These samples were collected and analyzed at varying frequencies for the analytes specified in each outfall permit. Environmental monitoring samples were generally collected quarterly from locations upstream and downstream from DOE facilities. The quality of the analytical data is good, but not as well documented as the CR-ERP. Standard EPA sampling and analytical 


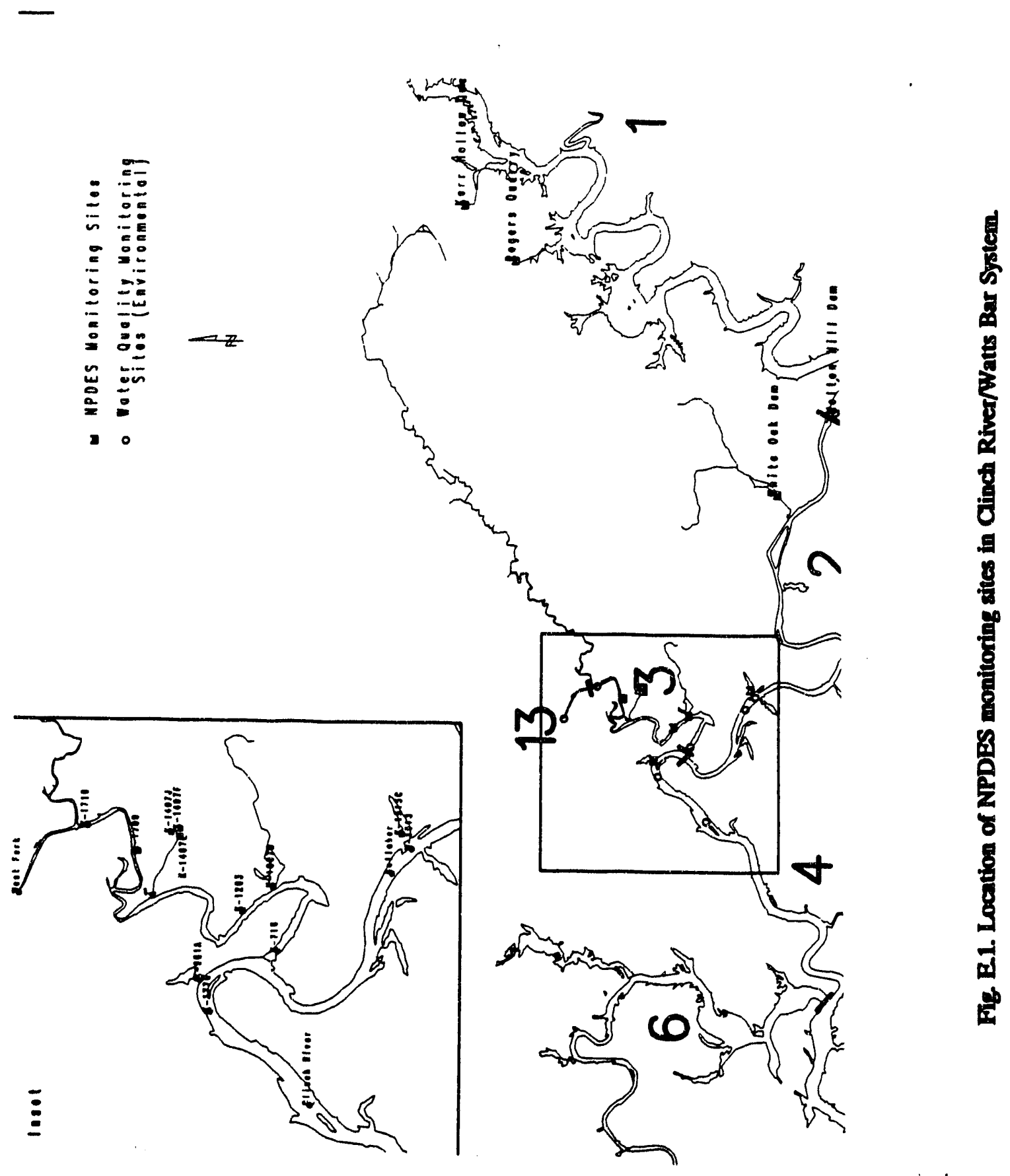


Table E.1. Receiving reaches for Oak Ridge Reservation source monitoring and surface water environmental monitoring stations. Source monitoring data are collected in support of NPDES permits and DOE Order 5400.1. (Data from these locations for years 1990, 1991, and part of 1992, were used in the human health and ecological risk screening analyses).

\begin{tabular}{|c|c|c|}
\hline Reach & Location & Source Type \\
\hline 1 & Kerr Hollow Quarry & Source Monitoring \\
\hline 1 & Rogers Quarry & Source Monitoring \\
\hline 1 & Melton Hill Dam & Environmental Monitoring \\
\hline 2 & White Oak Dam & Source Monitoring \\
\hline 2 & K-1513 & Environmental Monitoring \\
\hline 2 & $\mathrm{~K}-1515 \mathrm{C}$ & Source Monitoring \\
\hline 2 & Gallaher Bridge & Environmental Monitoring \\
\hline 3 & K-1710 & Environmental Monitoring \\
\hline 3 & K-1700 & Source Monitoring \\
\hline 3 & K-1407E & Source Monitoring \\
\hline 3 & $\mathrm{~K}-1407 \mathrm{~F}$ & Source Monitoring \\
\hline 3 & $\mathrm{~K}-1407 \mathrm{~J}$ & Source Monitoring \\
\hline 3 & K-1203 & Source Monitoring \\
\hline 3 & K-1007B & Source Monitoring \\
\hline 3 & $K-716$ & Environmental Monitoring \\
\hline 4 & K-901A & Source Monitoring \\
\hline 4 & K-1770 & Environmental Monitoring \\
\hline 4 & $\begin{array}{l}\text { Clinch River } \\
\text { (Brashar Island) }\end{array}$ & Environmental Monitoring \\
\hline 4 & Kingston & Environmental Monitoring \\
\hline 13 & West Fork Poplar Creek & Environmental Monitoring \\
\hline
\end{tabular}


methods were used, but the results were not validated against the EPA functional guidelines for CERCLA as was done for CR-ERP. These data were integrated with CR-ERP results and all of the data used in the human health risk screening analyses.

Combining data from various organizations, collected and analyzed for different purposes, makes interpretation of the summarized data more difficult. For example, the CR-ERP gamma spectroscopy results which were less than detection limits were reported as a minimum detectable activity along with a data qualifier for the value. Similar source monitoring gamma results were reported as background corrected values and associated counting uncertainty. Therefore, negative and very small values were common, and distinguishing non-detected values was not possible. These results were used as is and included as detected contaminants in the screening analyses. Resulting risk summary tables, therefore, list numerous radionuclides with very low risk values and, more importantly, indicate that these radionuclides were detected in all samples (See ratio of detected to total analyses in Tables E.8 thru E.12.).

Results of analyses performed on raw/unfiltered water samples (e.g., total aluminum) were used when available. The data for the water pathways included samples collected by both the CRERP and by the ORR compliance and monitoring organizations.

The values used for the risk screening analyses for a given contaminant in a reach were calculated by first averaging all results by location and then determining the upper $95 \%$ confidence limit of the arithmetic mean of the location averages. The UCL or the maximum location average (whichever is smaller) was used as the value for conservative screening for each reach. The arithmetic mean of the location averages was used for nonconservative screening. 


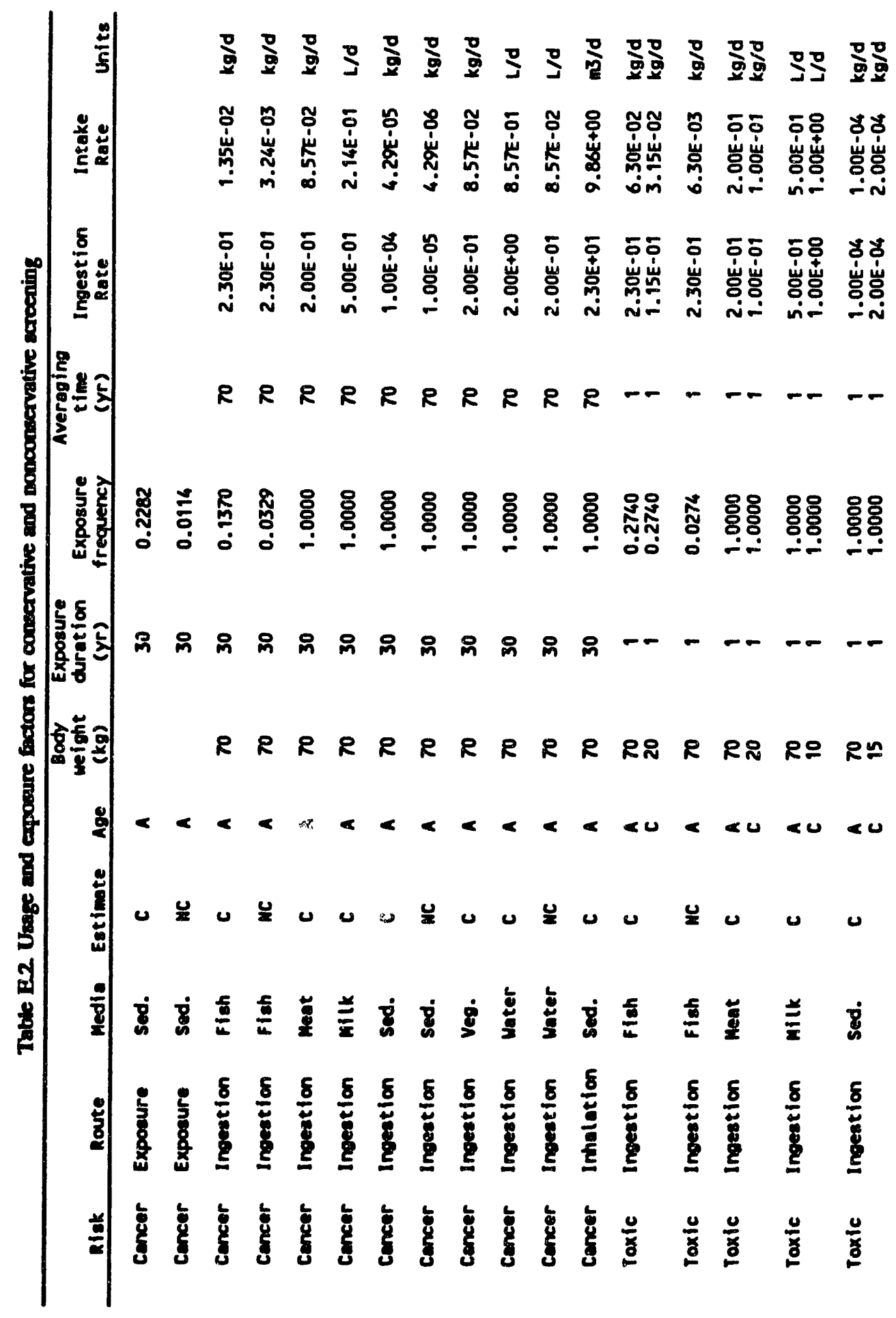




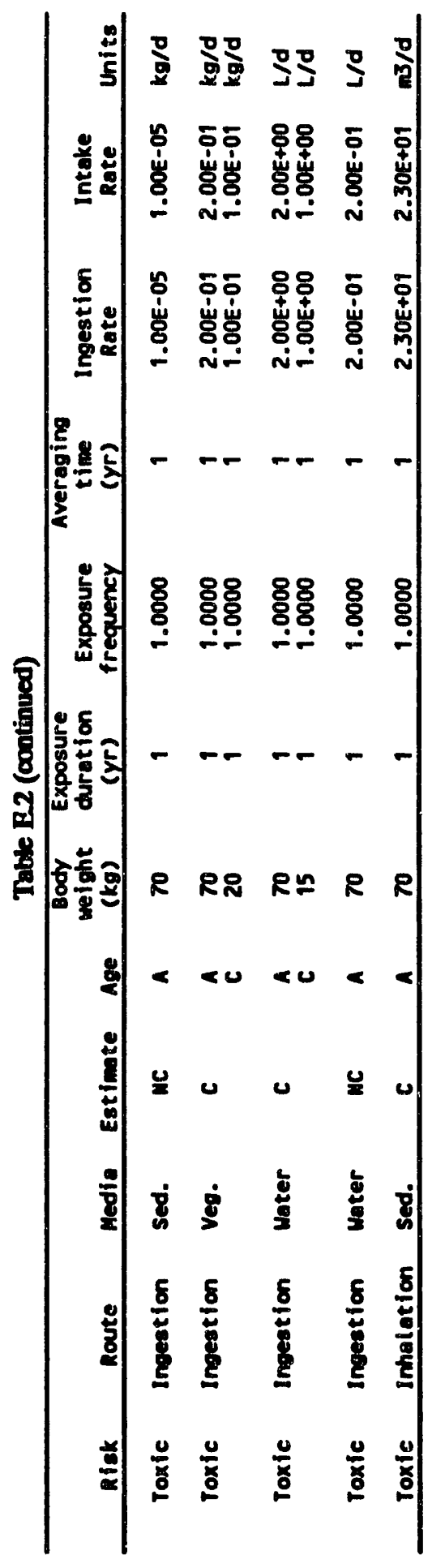


E-10

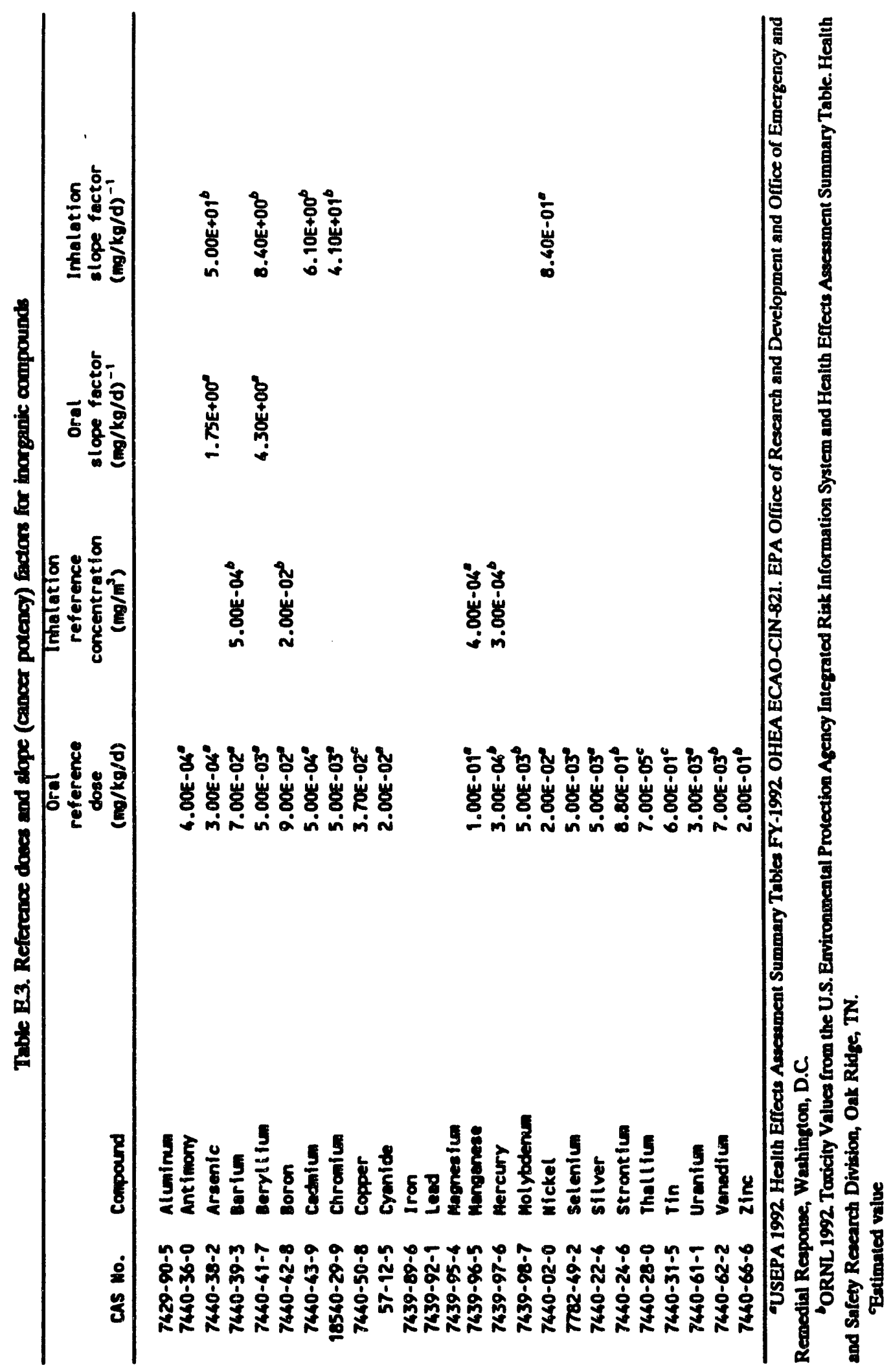


E-11

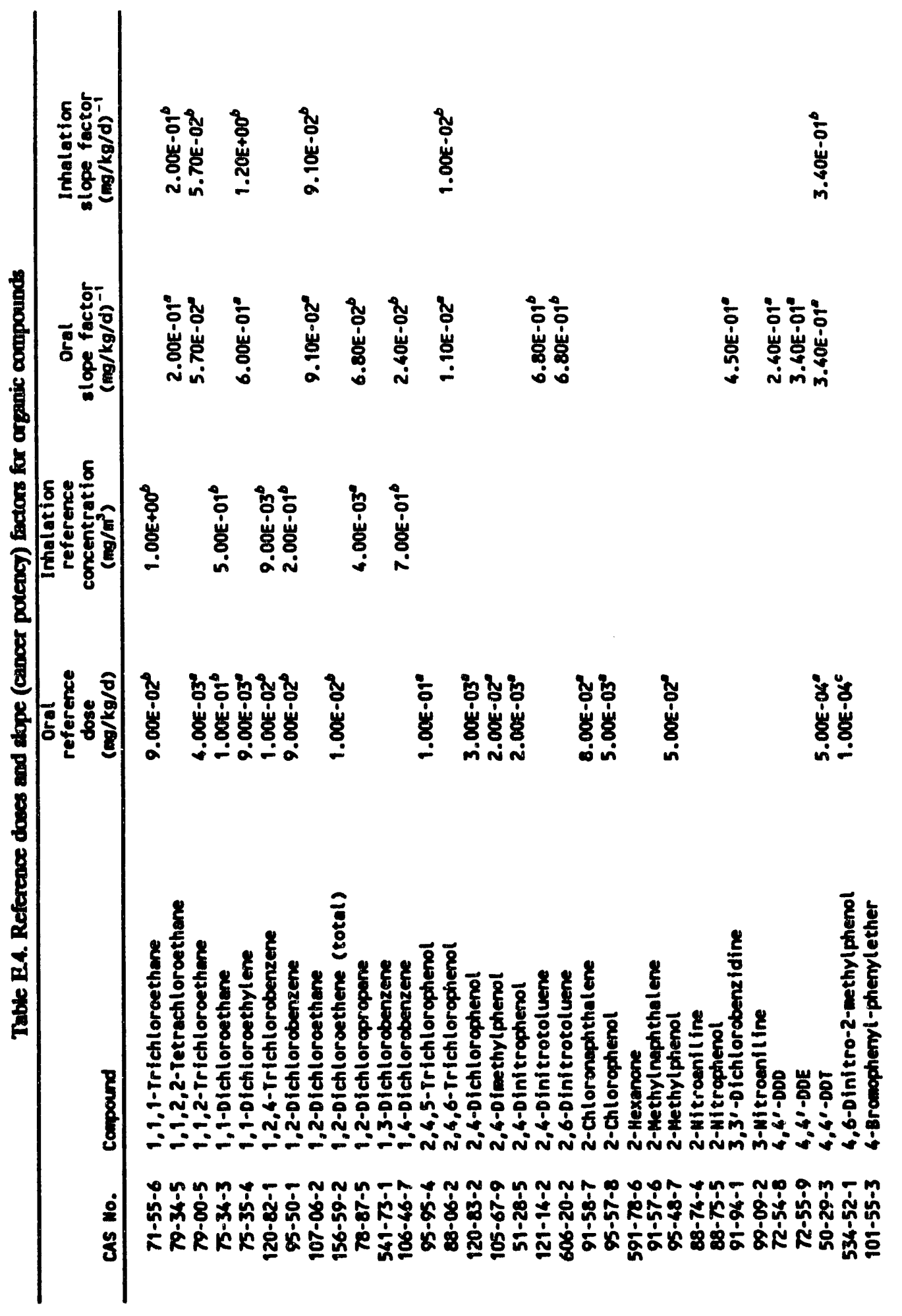




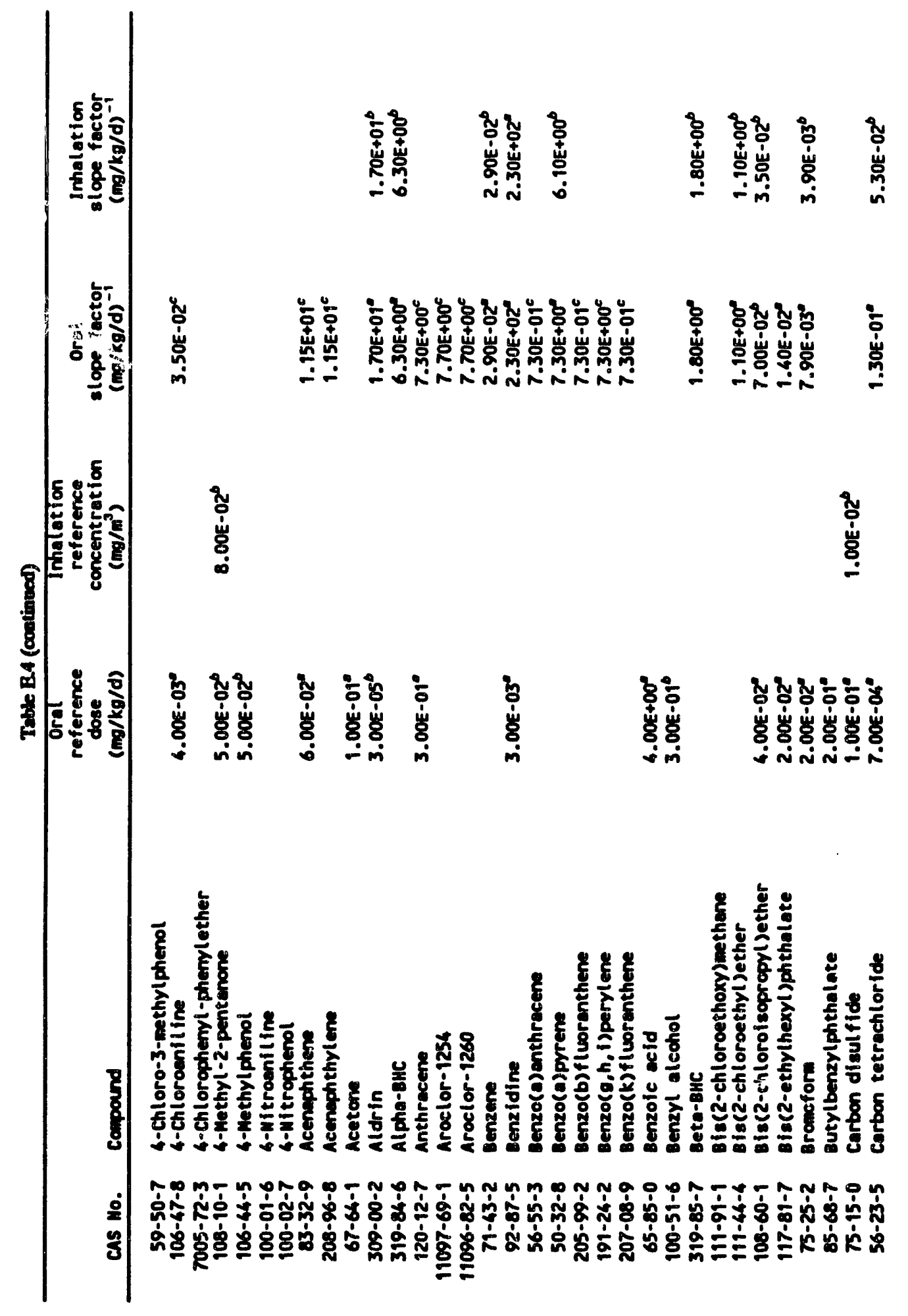


E-13

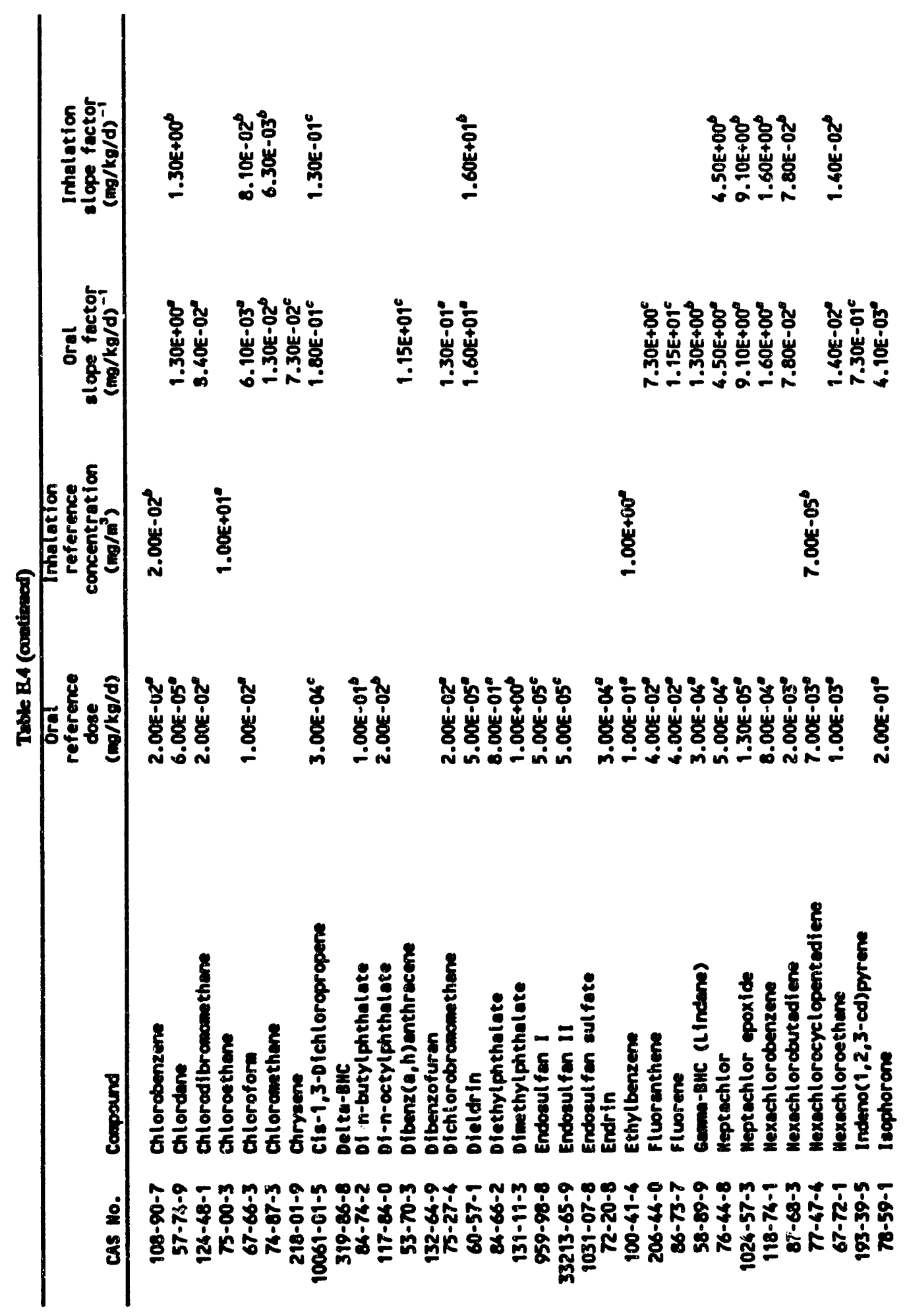




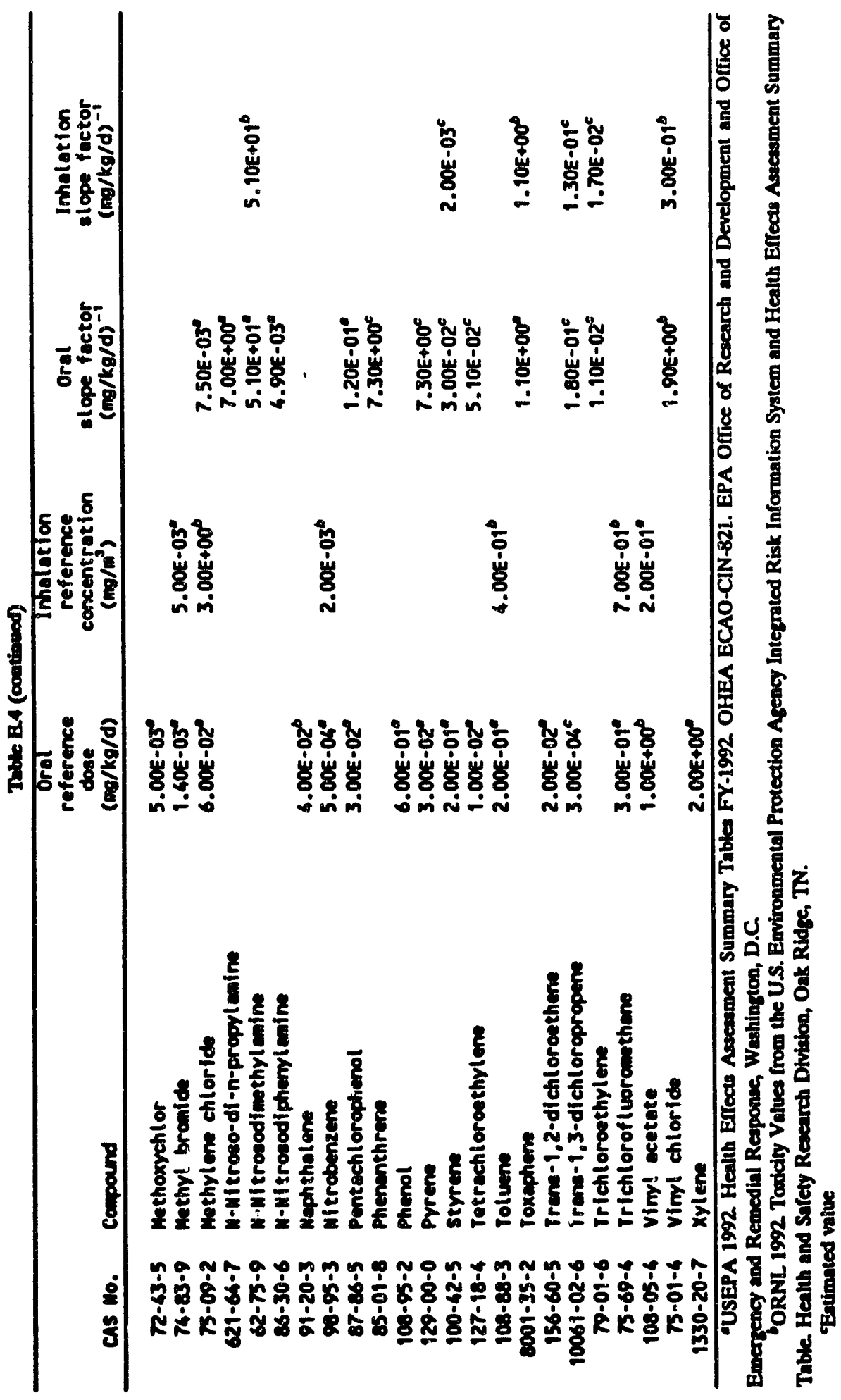


E-15

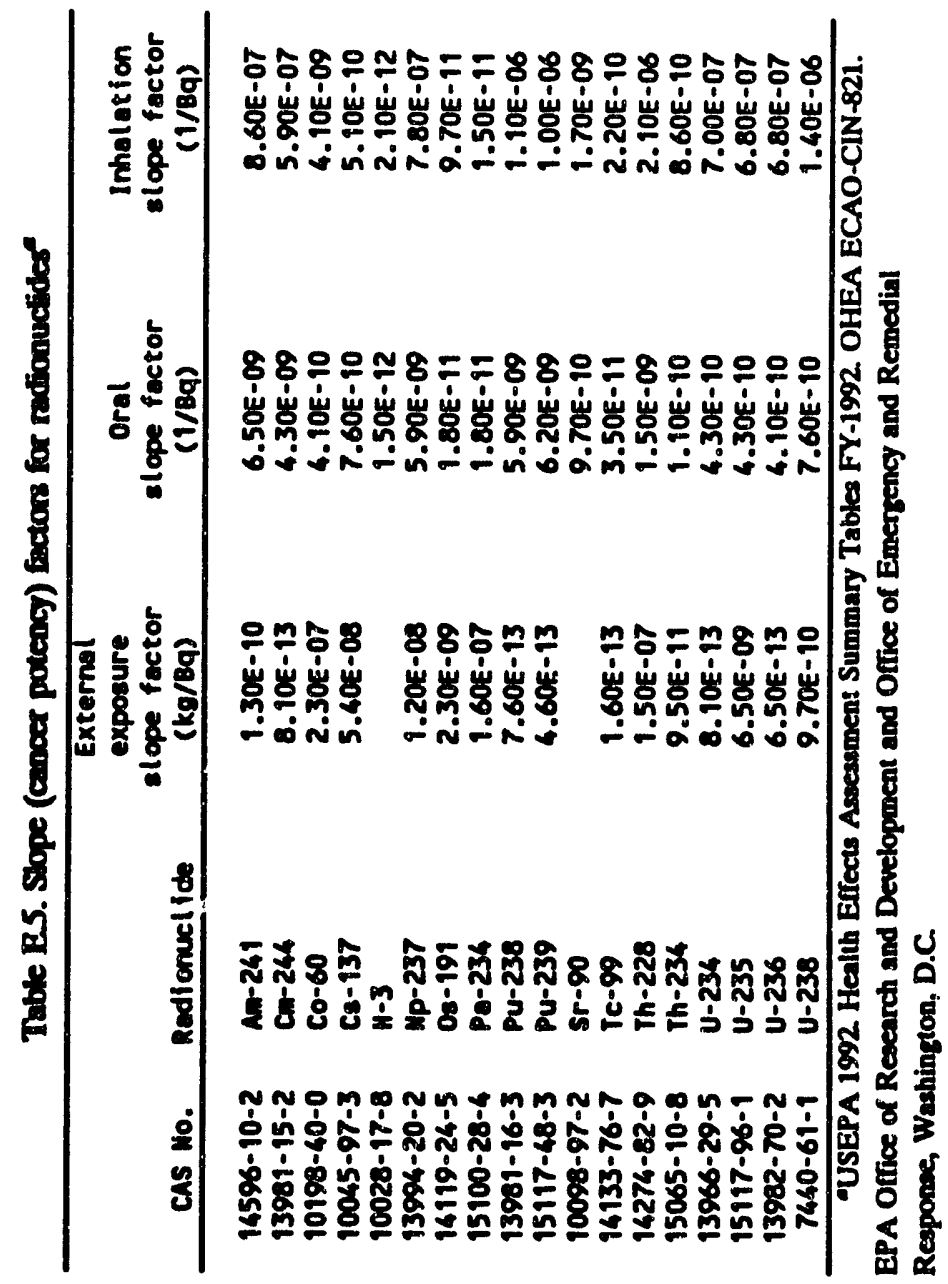


Table E.6 Summary of carcinogens in the secondary pathways identified as low priority for further investigation

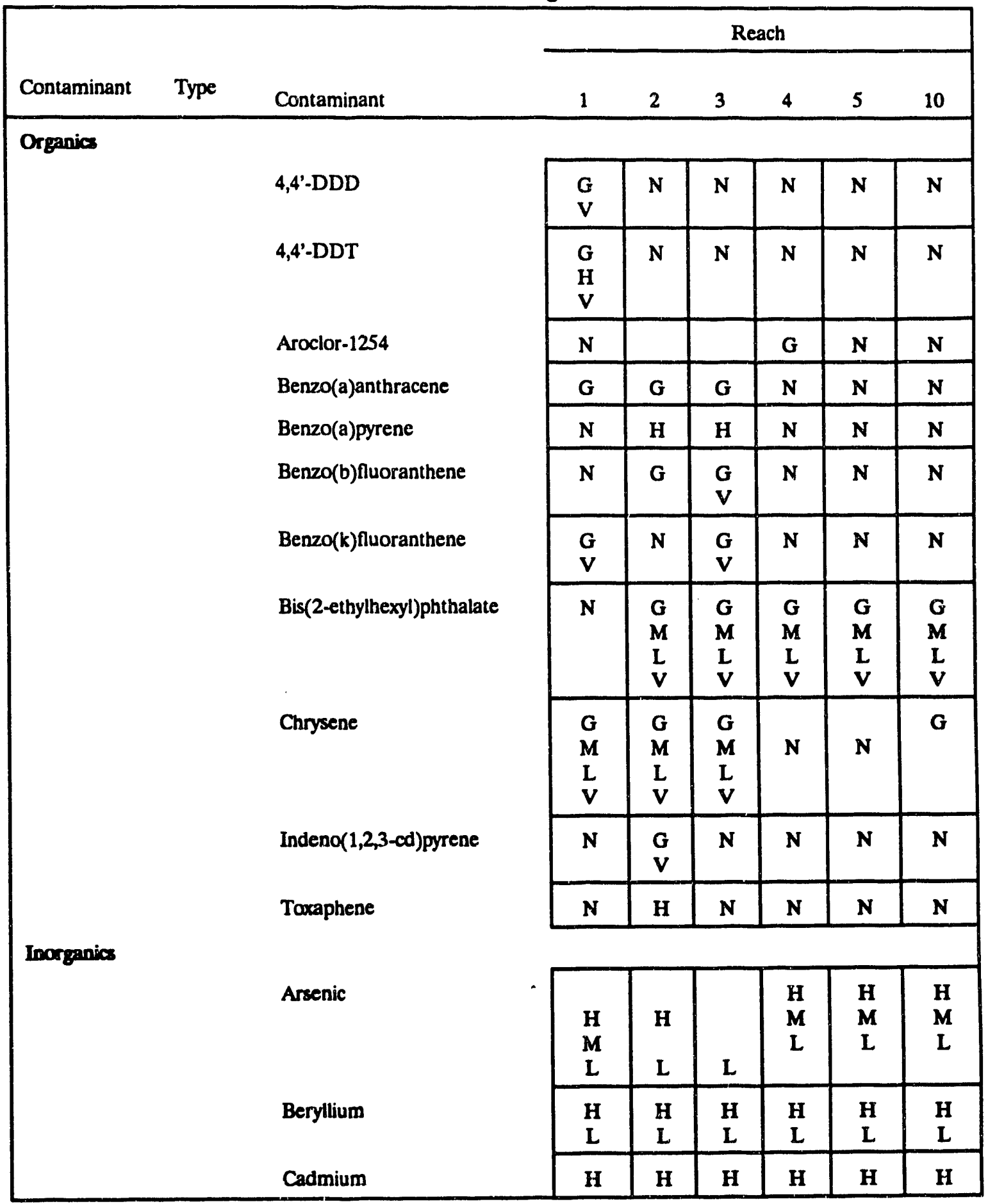


Table E.6 (continued)

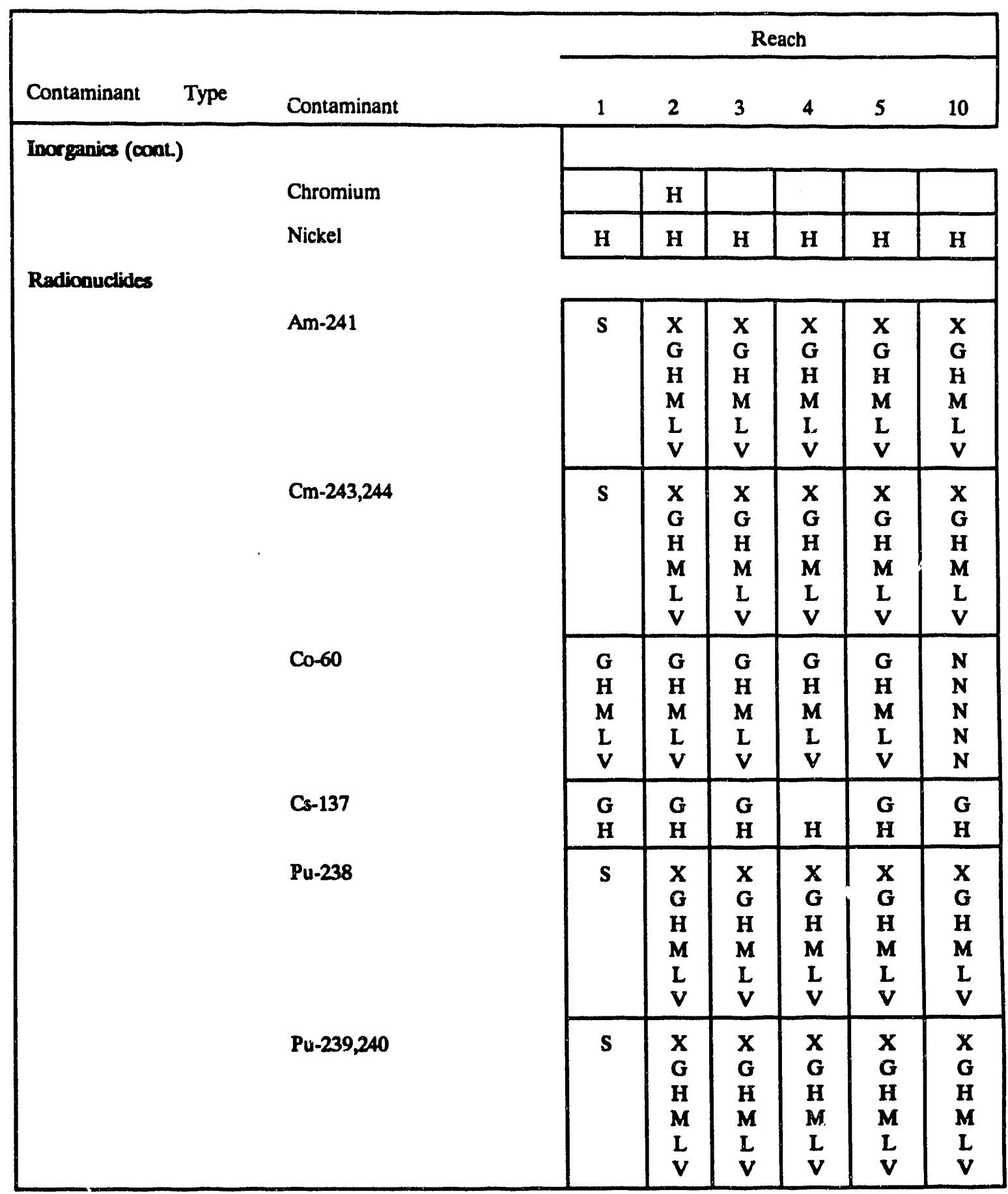


Table E6 (continued)

\begin{tabular}{|c|c|c|c|c|c|c|c|c|}
\hline \multirow[b]{2}{*}{ Contaminant } & \multirow[b]{2}{*}{ Type } & \multirow[b]{2}{*}{ Contaminant } & \multicolumn{6}{|c|}{ Reach } \\
\hline & & & 1 & 2 & 3 & 4 & 5 & 10 \\
\hline & & Sr -90 & $\mathbf{S}$ & $\begin{array}{l}\mathbf{G} \\
\mathbf{H} \\
\mathbf{M}\end{array}$ & $\begin{array}{c}\mathbf{G} \\
\mathbf{H} \\
\mathbf{M} \\
\mathbf{L}\end{array}$ & $\begin{array}{l}\mathbf{G} \\
\mathbf{H} \\
\mathbf{M}\end{array}$ & $\begin{array}{l}\mathbf{G} \\
\mathbf{H} \\
\mathbf{M}\end{array}$ & $\begin{array}{c}\mathbf{G} \\
\mathbf{H} \\
\mathbf{M} \\
\mathbf{L}\end{array}$ \\
\hline & & U-234 & $\mathbf{S}$ & $\begin{array}{l}X \\
G \\
\mathbf{H} \\
\mathbf{M} \\
\mathbf{L} \\
\mathbf{V}\end{array}$ & $\begin{array}{l}X \\
G \\
H \\
\text { L } \\
\text { V }\end{array}$ & $\begin{array}{l}\mathbf{X} \\
\mathbf{G} \\
\mathbf{H} \\
\mathbf{M} \\
\mathbf{L} \\
\mathbf{V}\end{array}$ & $\begin{array}{l}\mathbf{X} \\
\mathbf{G} \\
\mathbf{H} \\
\mathbf{M} \\
\mathbf{L} \\
\mathbf{V}\end{array}$ & $\begin{array}{l}\mathbf{X} \\
\mathbf{G} \\
\mathbf{H} \\
\mathbf{M} \\
\mathbf{L} \\
\mathbf{V}\end{array}$ \\
\hline & & U-235 & $\mathbf{S}$ & $\begin{array}{l}\mathbf{X} \\
\mathbf{G} \\
\mathbf{H} \\
\mathbf{M} \\
\mathbf{L} \\
\mathbf{V}\end{array}$ & $\begin{array}{l}\mathbf{X} \\
\mathbf{G} \\
\mathbf{H} \\
\mathbf{M} \\
\mathbf{L} \\
\mathbf{V}\end{array}$ & $\begin{array}{l}\mathbf{X} \\
\mathbf{G} \\
\mathbf{H} \\
\mathbf{M} \\
\mathbf{L} \\
\mathbf{V}\end{array}$ & $\begin{array}{l}\mathbf{X} \\
\mathbf{G} \\
\mathbf{H} \\
\mathbf{M} \\
\mathbf{L} \\
\mathbf{V}\end{array}$ & $\begin{array}{l}\mathbf{X} \\
\mathbf{G} \\
\mathbf{H} \\
\mathbf{M} \\
\mathbf{L} \\
\mathbf{V}\end{array}$ \\
\hline & & U-238 & $\mathbf{S}$ & $\begin{array}{l}\mathbf{X} \\
\mathbf{G} \\
\mathbf{H}\end{array}$ & $\begin{array}{l}\text { G } \\
\text { H } \\
\text { L }\end{array}$ & $\begin{array}{l}\mathbf{X} \\
\mathbf{G} \\
\mathbf{H} \\
\mathbf{M} \\
\mathbf{L} \\
\mathbf{V}\end{array}$ & $\begin{array}{l}\mathbf{X} \\
\mathbf{G} \\
\mathbf{H} \\
\mathbf{M} \\
\mathbf{L} \\
\mathbf{V}\end{array}$ & $\begin{array}{c}\mathbf{X} \\
\mathbf{G} \\
\mathbf{H} \\
\mathbf{M} \\
\mathbf{L} \\
\mathbf{V}\end{array}$ \\
\hline
\end{tabular}

$X$ Carcinogens having conservative screening indices $<10^{\circ}$ for direct external exposure to radionuclides in dredged sediment.

G Carcinogens having conservative screening indices $<10^{-}$for direct ingestion of dredged sediment.

H Carcinogens having conservative screening indices $<10^{6}$ for inhalation of air contaminated by dredged rediment.

$M$ Carcinogens having conservative screening indices $<10^{\circ}$ for ingestion of meat.

L Carcinogens having conservative screening indices $<10^{-6}$ for ingeation of milk.

V Carcinogens having conservative screening indices $<10^{\circ}$ for ingestion of vegetables grown in dredged sodiment.

Nondetects - contaminant concentrations were below detection limits. 
E-19

Table E.7 Summary of noncarcinogens in the secondary pathways identified as low priority for further investigation

\begin{tabular}{|c|c|c|c|c|c|c|c|}
\hline \multirow[b]{2}{*}{$\begin{array}{l}\text { Contaminant } \\
\text { Type }\end{array}$} & \multirow[b]{2}{*}{ Contaminant } & \multicolumn{6}{|c|}{ Reach } \\
\hline & & 1 & 2 & 3 & 4 & 5 & 10 \\
\hline \multicolumn{8}{|l|}{ Organics } \\
\hline & 4,4'-DDT & $\begin{array}{l}\mathbf{G} \\
\mathbf{M} \\
\mathbf{L} \\
\mathbf{V}\end{array}$ & $\mathbf{N}$ & $\mathbf{N}$ & $\mathbf{N}$ & $\mathbf{N}$ & $\mathbf{N}$ \\
\hline & Anthracene & $\mathbf{N}$ & $\mathbf{N}$ & $\begin{array}{c}\mathbf{G} \\
\mathbf{M} \\
\mathbf{L} \\
\mathbf{V}\end{array}$ & $\mathbf{N}$ & $\mathbf{N}$ & $\begin{array}{c}\mathbf{G} \\
\mathbf{M} \\
\mathbf{L} \\
\mathbf{V}\end{array}$ \\
\hline & Bis(2-ethylluexyl)phthalate & $\mathbf{N}$ & $\begin{array}{l}\mathbf{G} \\
\mathbf{M} \\
\mathbf{L} \\
\mathbf{V}\end{array}$ & $\begin{array}{c}\mathbf{G} \\
\mathbf{M} \\
\mathbf{L} \\
\mathbf{V}\end{array}$ & $\begin{array}{l}\mathbf{G} \\
\mathbf{M} \\
\mathbf{L} \\
\mathbf{V}\end{array}$ & $\begin{array}{l}\mathbf{G} \\
\mathbf{M} \\
\mathbf{L} \\
\mathbf{V}\end{array}$ & $\begin{array}{c}\mathbf{G} \\
\mathbf{M} \\
\mathbf{L} \\
\mathbf{V}\end{array}$ \\
\hline & Di-n-butylphthalate & $\mathbf{N}$ & $\begin{array}{l}\mathbf{G} \\
\mathbf{M} \\
\mathbf{L} \\
\mathbf{V}\end{array}$ & $\begin{array}{l}\mathbf{G} \\
\mathbf{M} \\
\mathbf{L} \\
\mathbf{V}\end{array}$ & $\mathbf{N}$ & $\mathbf{N}$ & $\mathbf{N}$ \\
\hline & Diethylphthlalate & $\mathbf{N}$ & $\begin{array}{l}\mathbf{G} \\
\mathbf{M} \\
\mathbf{L} \\
\mathbf{V}\end{array}$ & $\mathbf{N}$ & $\mathbf{N}$ & $\mathbf{N}$ & $\mathbf{N}$ \\
\hline & Dimethylphthalate & $\mathbf{N}$ & $\mathbf{N}$ & $\begin{array}{l}\mathbf{G} \\
\mathbf{M} \\
\mathbf{L} \\
\mathbf{V}\end{array}$ & $\mathbf{N}$ & $\mathbf{N}$ & $\mathbf{N}$ \\
\hline & Fluoranthene & $\begin{array}{l}\mathbf{G} \\
\mathbf{M} \\
\mathbf{L} \\
\mathbf{V}\end{array}$ & $\begin{array}{c}\mathbf{G} \\
\mathbf{M} \\
\mathbf{L} \\
\mathbf{V}\end{array}$ & $\begin{array}{l}\mathbf{G} \\
\mathbf{M} \\
\mathbf{L} \\
\mathbf{V}\end{array}$ & $\begin{array}{l}\mathbf{G} \\
\mathbf{M} \\
\mathbf{L} \\
\mathbf{V}\end{array}$ & $\mathbf{N}$ & $\begin{array}{l}8 \\
8 \\
8 \\
8\end{array}$ \\
\hline & Naphthalene & $\mathbf{N}$ & $\begin{array}{l}\mathbf{G} \\
\mathbf{M} \\
\mathbf{L} \\
\mathbf{V}\end{array}$ & $\begin{array}{l}\mathbf{G} \\
\mathbf{M} \\
\mathbf{L} \\
\mathbf{V}\end{array}$ & $\mathbf{N}$ & $\mathbf{N}$ & w \\
\hline & Pyrene & $\begin{array}{l}\mathbf{G} \\
\mathbf{M} \\
\mathbf{L} \\
\mathbf{V}\end{array}$ & $\begin{array}{l}\mathbf{G} \\
\mathbf{M} \\
\mathbf{L} \\
\mathbf{V}\end{array}$ & $\begin{array}{l}\mathbf{G} \\
\mathbf{M} \\
\mathbf{L} \\
\mathbf{V}\end{array}$ & $\begin{array}{l}j \\
w \\
I \\
V\end{array}$ & $\mathrm{Hi}$ & $\begin{array}{l}\mathbf{G} \\
\mathbf{M} \\
\mathbf{L} \\
\mathbf{V}\end{array}$ \\
\hline
\end{tabular}


Table E7 (continued)

\begin{tabular}{|c|c|c|c|c|c|c|c|}
\hline \multirow[b]{2}{*}{$\begin{array}{l}\text { Contaminant } \\
\text { Type }\end{array}$} & \multirow[b]{2}{*}{ Contaminant } & \multicolumn{6}{|c|}{ Reach } \\
\hline & & 1 & 2 & 3 & 4 & 5 & 10 \\
\hline \multicolumn{8}{|l|}{ Inorganics } \\
\hline & Antimony & $\mathbf{N}$ & $\mathbf{S}$ & $\begin{array}{l}\mathbf{G} \\
\mathbf{M} \\
\mathbf{L} \\
\mathbf{V}\end{array}$ & $\begin{array}{l}\mathbf{G} \\
\mathbf{M} \\
\mathbf{L} \\
\mathbf{V}\end{array}$ & $\begin{array}{l}\mathbf{G} \\
\mathbf{M} \\
\mathbf{L} \\
\mathbf{V}\end{array}$ & $\begin{array}{c}\mathbf{G} \\
\mathbf{M} \\
\mathbf{L} \\
\mathbf{V}\end{array}$ \\
\hline & Arsenic & $\begin{array}{l}\mathbf{G} \\
\mathbf{M} \\
\mathbf{L}\end{array}$ & $\begin{array}{c}\mathbf{G} \\
\mathbf{M} \\
\mathbf{L}\end{array}$ & $\begin{array}{l}M \\
\mathrm{~L}\end{array}$ & $\begin{array}{l}\mathbf{G} \\
\mathbf{M} \\
\mathbf{L}\end{array}$ & $\begin{array}{l}G \\
M \\
\mathbf{L} \\
\mathbf{V}\end{array}$ & $\begin{array}{c}\mathbf{G} \\
\mathbf{M} \\
\mathbf{L} \\
\mathbf{V}\end{array}$ \\
\hline & Beryllium & $\begin{array}{l}\mathbf{G} \\
\mathbf{M} \\
\mathbf{L} \\
\mathbf{V}\end{array}$ & $\begin{array}{c}\mathbf{G} \\
\mathbf{M} \\
\mathbf{L} \\
\mathbf{V}\end{array}$ & $\begin{array}{l}\mathbf{G} \\
\mathbf{M} \\
\mathbf{L} \\
\mathbf{V}\end{array}$ & $\begin{array}{l}\text { G } \\
\mathbf{M} \\
\mathbf{L} \\
\mathbf{V}\end{array}$ & $\begin{array}{l}\mathbf{G} \\
\mathbf{M} \\
\mathbf{L} \\
\mathbf{V}\end{array}$ & $\begin{array}{c}\mathbf{G} \\
\mathbf{M} \\
\mathbf{L} \\
\mathbf{V}\end{array}$ \\
\hline & Cadmium & $\begin{array}{l}\mathbf{G} \\
\mathbf{M}\end{array}$ & $\begin{array}{l}\mathbf{G} \\
\mathbf{M}\end{array}$ & $\begin{array}{l}\mathbf{G} \\
\mathbf{M}\end{array}$ & $\mathbf{G}$ & $\mathbf{G}$ & $\begin{array}{l}\mathbf{G} \\
\mathbf{M}\end{array}$ \\
\hline & Chromium & $\begin{array}{l}\mathbf{G} \\
\mathbf{L}\end{array}$ & $\begin{array}{l}\mathbf{G} \\
\mathbf{L} \\
\mathbf{V}\end{array}$ & $\mathbf{G}$ & $\begin{array}{l}\mathbf{G} \\
\mathbf{L}\end{array}$ & G & $\begin{array}{l}\text { G } \\
\text { L }\end{array}$ \\
\hline & Copper & $\mathbf{G}$ & $\begin{array}{l}\mathbf{L} \\
\mathbf{G} \\
\mathbf{V}\end{array}$ & $\mathbf{G}$ & $\mathbf{G}$ & & $\begin{array}{l}\mathbf{G} \\
\mathbf{V}\end{array}$ \\
\hline & Mercury & $\begin{array}{l}\mathbf{G} \\
\mathbf{H} \\
\mathbf{L}\end{array}$ & $\begin{array}{l}\mathbf{G} \\
\mathbf{H} \\
\mathbf{L}\end{array}$ & $\begin{array}{l}\mathbf{G} \\
\mathbf{H} \\
\mathbf{L}\end{array}$ & $\begin{array}{l}\mathbf{G} \\
\mathbf{H}\end{array}$ & $\begin{array}{l}\mathbf{G} \\
\mathbf{H}\end{array}$ & $\begin{array}{c}\mathbf{G} \\
\mathbf{H} \\
\mathbf{L} \\
\mathbf{M}\end{array}$ \\
\hline & Nickel & $\begin{array}{c}\mathbf{G} \\
\mathbf{M} \\
\mathbf{L}\end{array}$ & $\begin{array}{l}\mathbf{G} \\
\mathbf{M} \\
\mathbf{L}\end{array}$ & $\begin{array}{l}\mathbf{G} \\
\mathbf{M} \\
\mathbf{L}\end{array}$ & $\begin{array}{l}\mathbf{G} \\
\mathbf{M} \\
\mathbf{L}\end{array}$ & $\begin{array}{l}\mathbf{G} \\
\mathbf{M} \\
\mathbf{L}\end{array}$ & $\begin{array}{l}\mathbf{G} \\
\mathbf{M} \\
\mathbf{L}\end{array}$ \\
\hline & Selenium & $\begin{array}{l}\mathbf{G} \\
\mathbf{L} \\
\mathbf{V}\end{array}$ & $\begin{array}{l}\mathbf{G} \\
\mathbf{I} \\
\mathbf{V}\end{array}$ & $\mathbf{G}$ & $\begin{array}{l}\mathbf{G} \\
\mathbf{V}\end{array}$ & $\mathbf{N}$ & $\mathbf{N}$ \\
\hline & Silver & $\begin{array}{c}\mathbf{G} \\
\mathbf{M} \\
\mathbf{L} \\
\mathbf{V}\end{array}$ & $\begin{array}{c}\mathbf{G} \\
\mathbf{M} \\
\mathbf{L} \\
\mathbf{V}\end{array}$ & $\begin{array}{l}\mathbf{G} \\
\mathbf{M} \\
\mathbf{V}\end{array}$ & $\begin{array}{l}\mathbf{G} \\
\mathbf{M}\end{array}$ & $\begin{array}{l}\mathbf{G} \\
\mathbf{M} \\
\mathbf{V}\end{array}$ & \\
\hline & Thallium & $\mathbf{N}$ & $\mathbf{N}$ & $\mathbf{G}$ & $\mathbf{N}$ & $\mathbf{N}$ & $\mathbf{N}$ \\
\hline
\end{tabular}


Table E7 (continued)

\begin{tabular}{|ll|c|c|c|c|c|c|c|}
\hline & & \multicolumn{7}{c|}{ Reach } \\
\cline { 3 - 9 } $\begin{array}{l}\text { Contaminant } \\
\text { Type }\end{array}$ & Contaminant & I & 2 & 3 & 4 & 5 & 10 \\
\hline & Uranium & S & G & G & G & & G \\
& & & M & L & M & M & M \\
& & & V & L & L & L & L \\
& Zinc & & G & G & G & G & G & G \\
\cline { 3 - 9 } & &
\end{tabular}

\begin{tabular}{|c|c|}
\hline $\mathbf{X}$ & $\begin{array}{l}\text { Noncarcinogens having conservative screening indices }<0.1 \text { for direct external exposure to radionuclides in dredged } \\
\text { sediment. }\end{array}$ \\
\hline $\mathbf{G}$ & Noncarcinogens having conservative screening indices $<0.1$ for direct ingestion of dredged sediment. \\
\hline $\mathbf{H}$ & Noncarcinogens having conservative screening indices $<0.1$ for inhalation of air contaminated by dredged sediment. \\
\hline M & Noncarcinogens having conservative screening indices $<0.1$ for ingestion of meat. \\
\hline $\mathbf{L}$ & Noncarcinogens having conservative screening indices $<0.1$ for ingestion of milk. \\
\hline $\mathbf{V}$ & Noncarcinogens having conservative screening indices $<0.1$ for ingestion of vegetables grown in dredged sediment. \\
\hline $\mathbf{N}$ & Nondetects - contaminant concentrations were below detection limits. \\
\hline $\mathbf{S}$ & ailable. \\
\hline
\end{tabular}




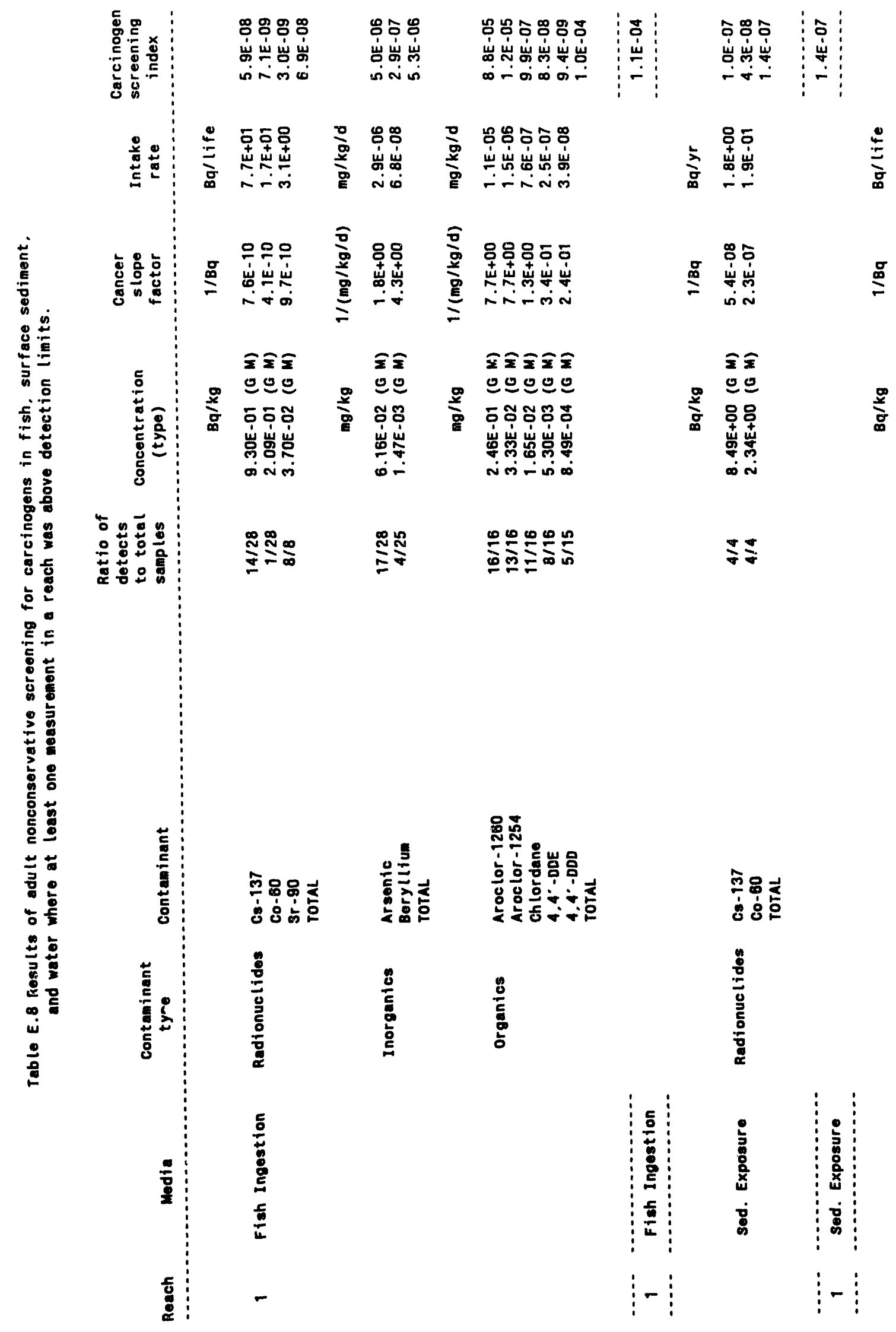




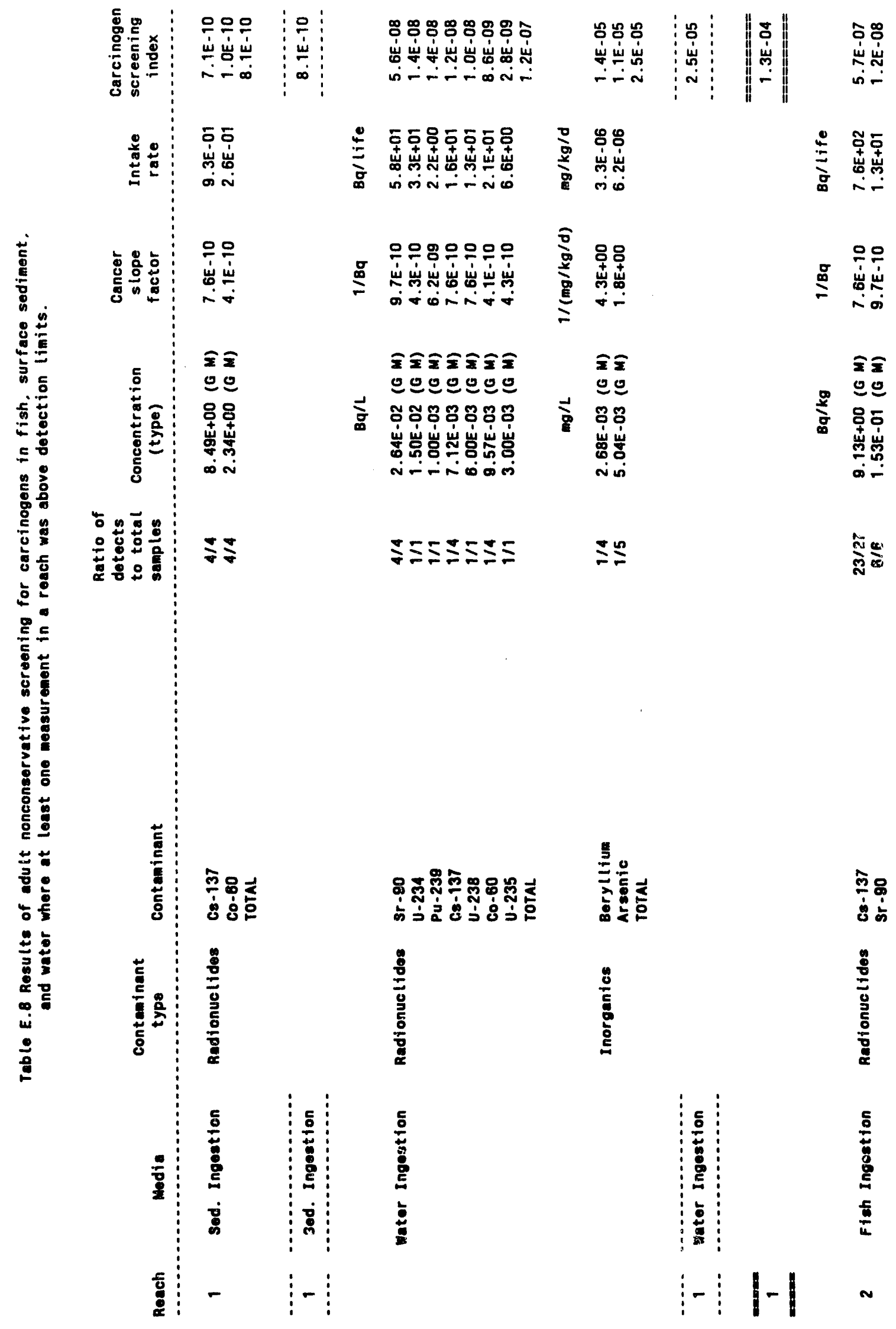




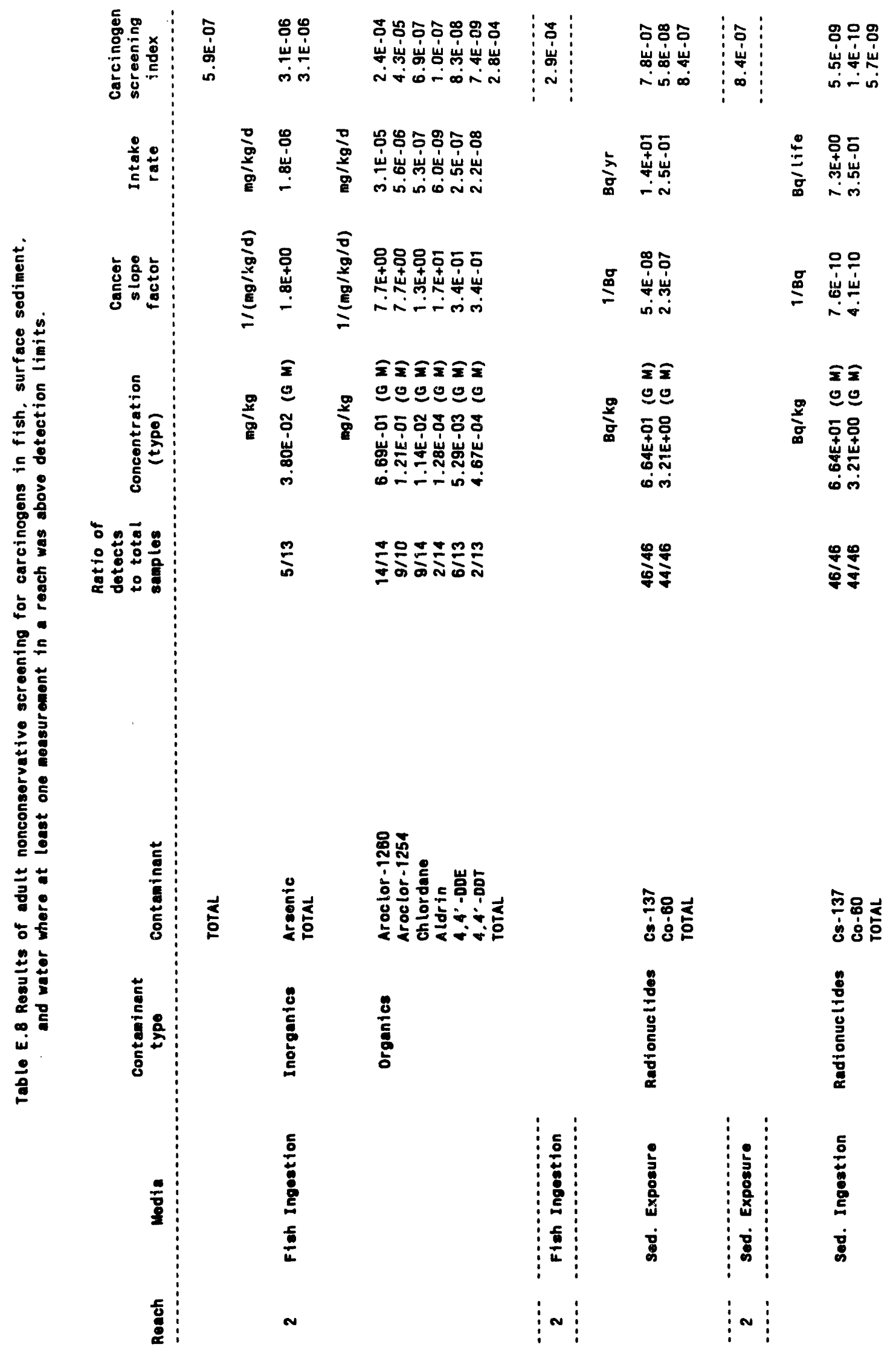




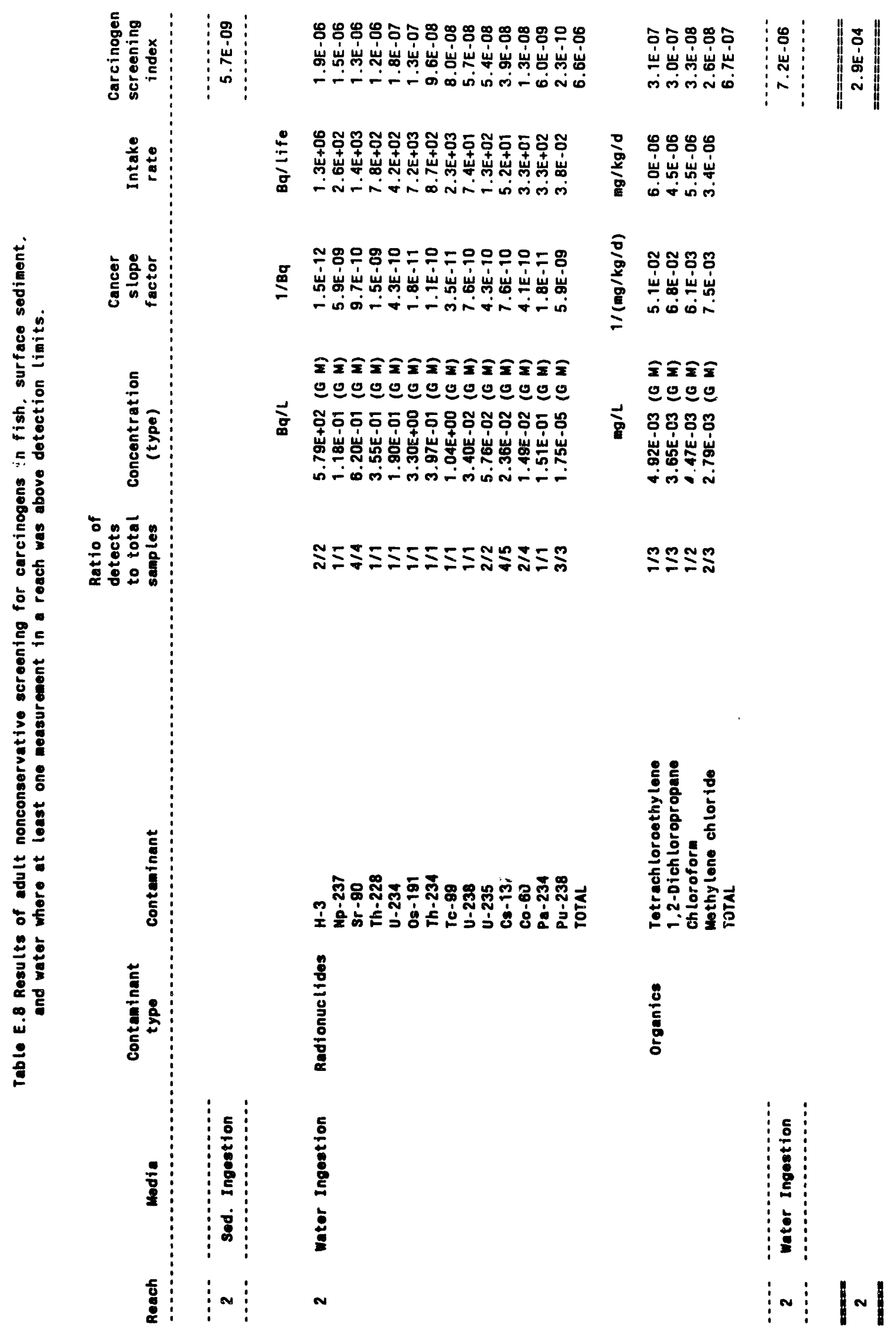




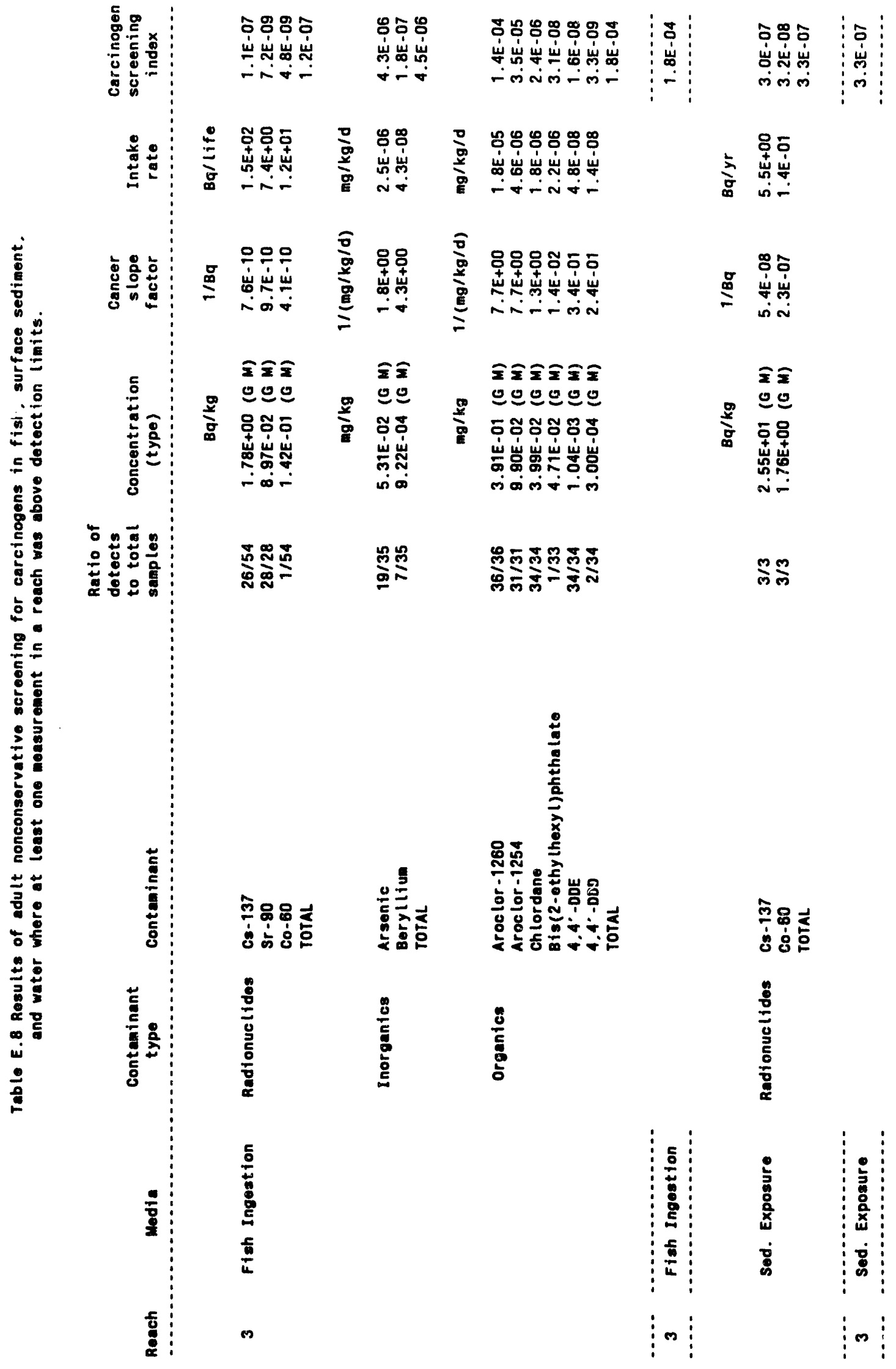




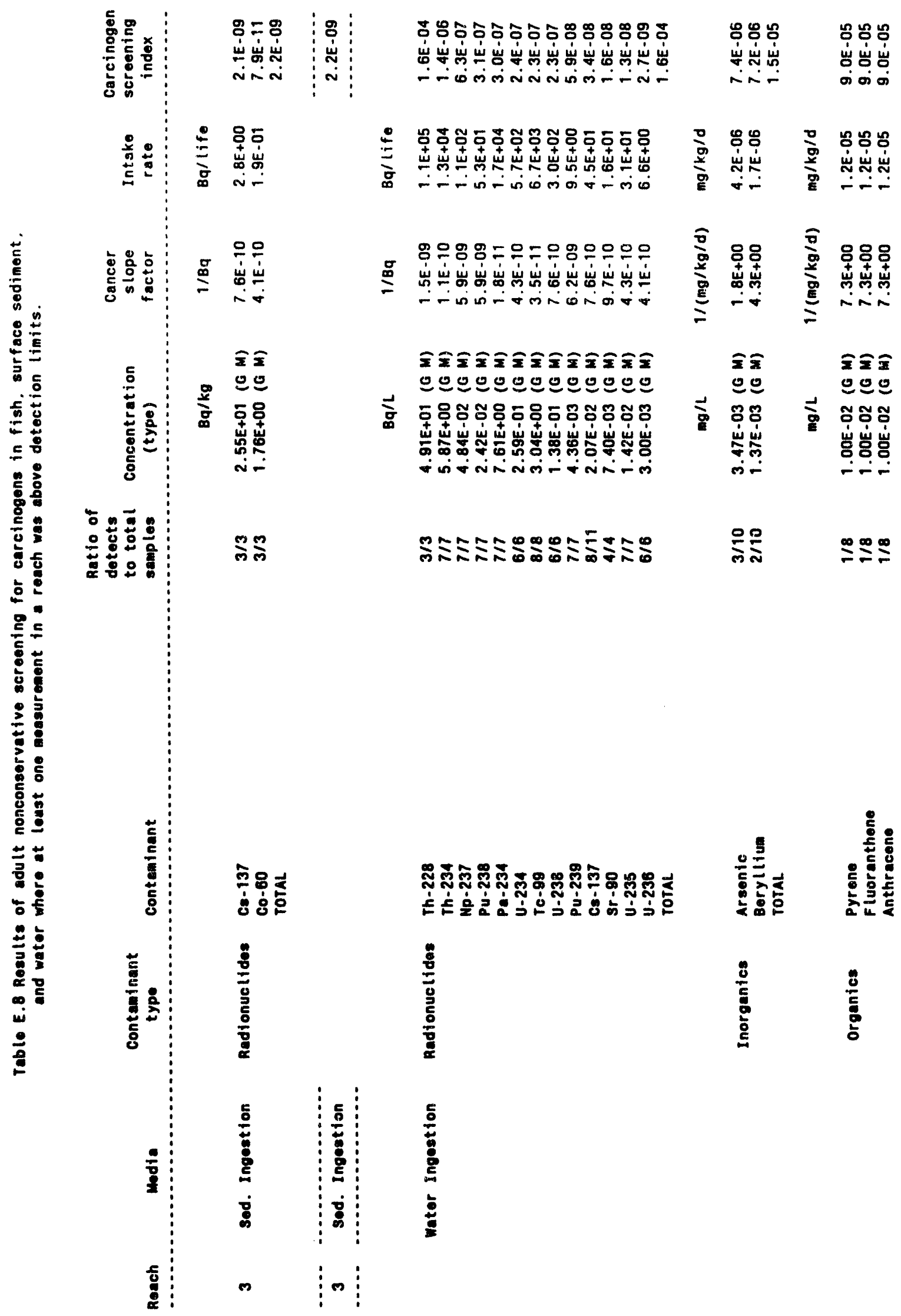




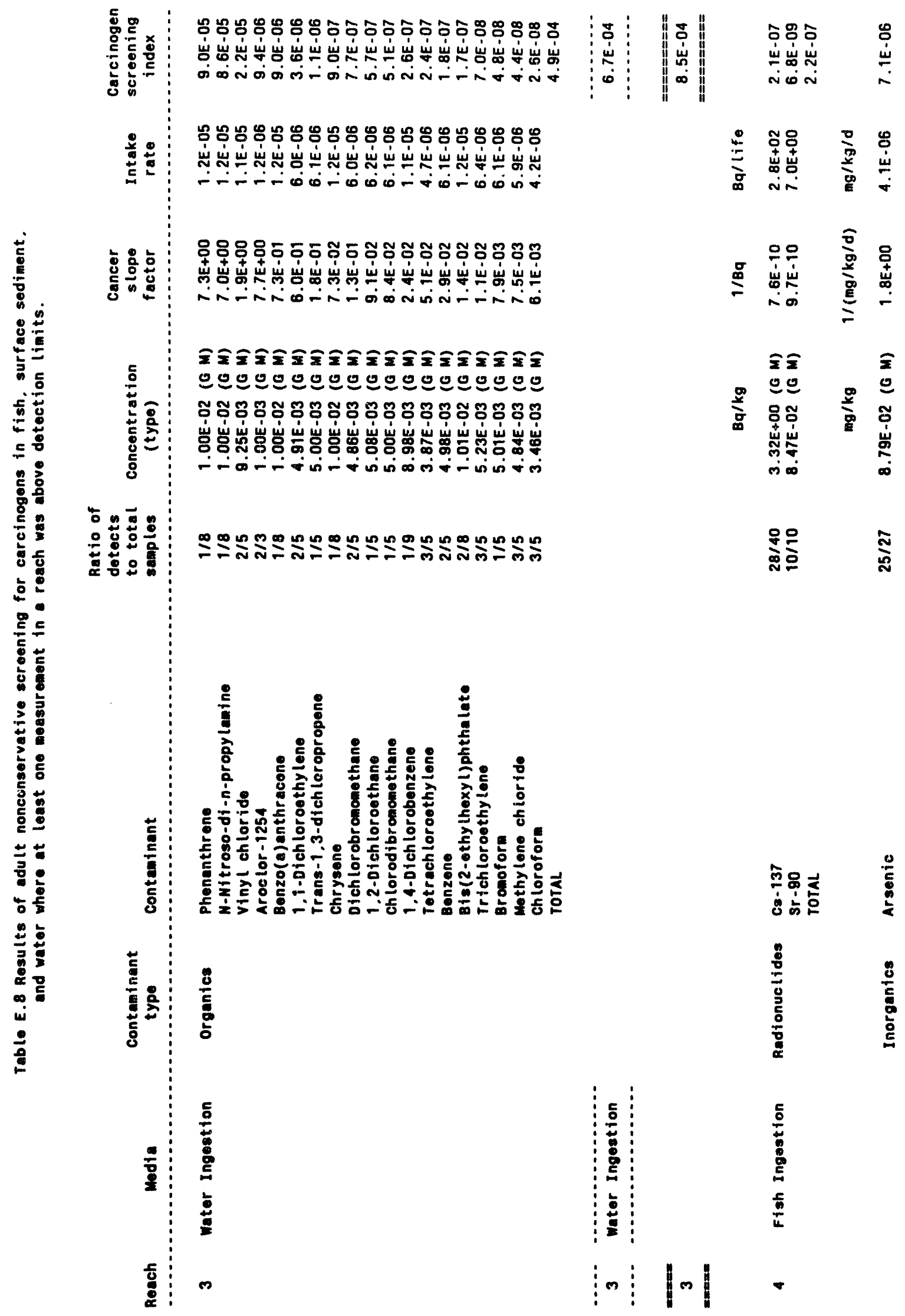




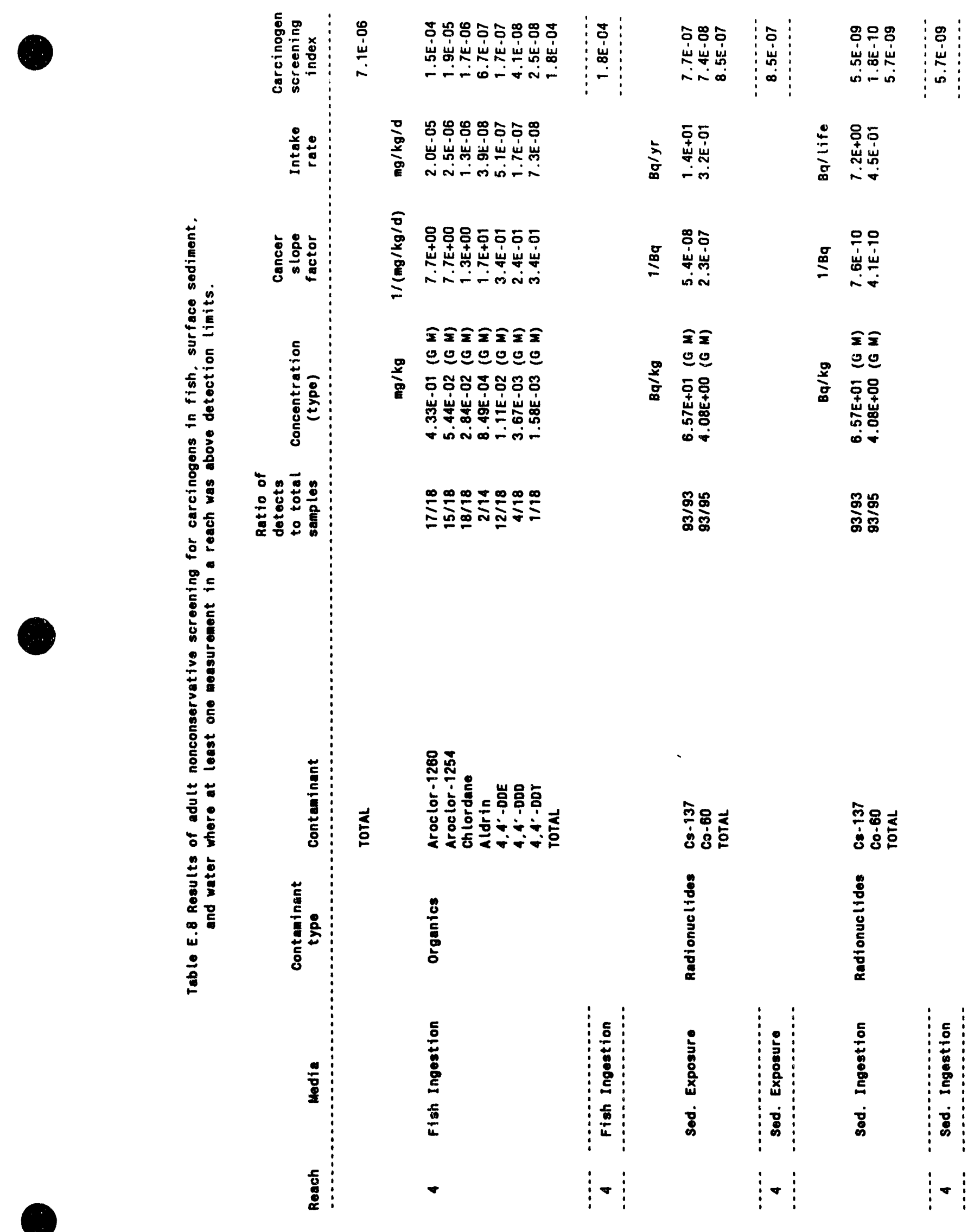




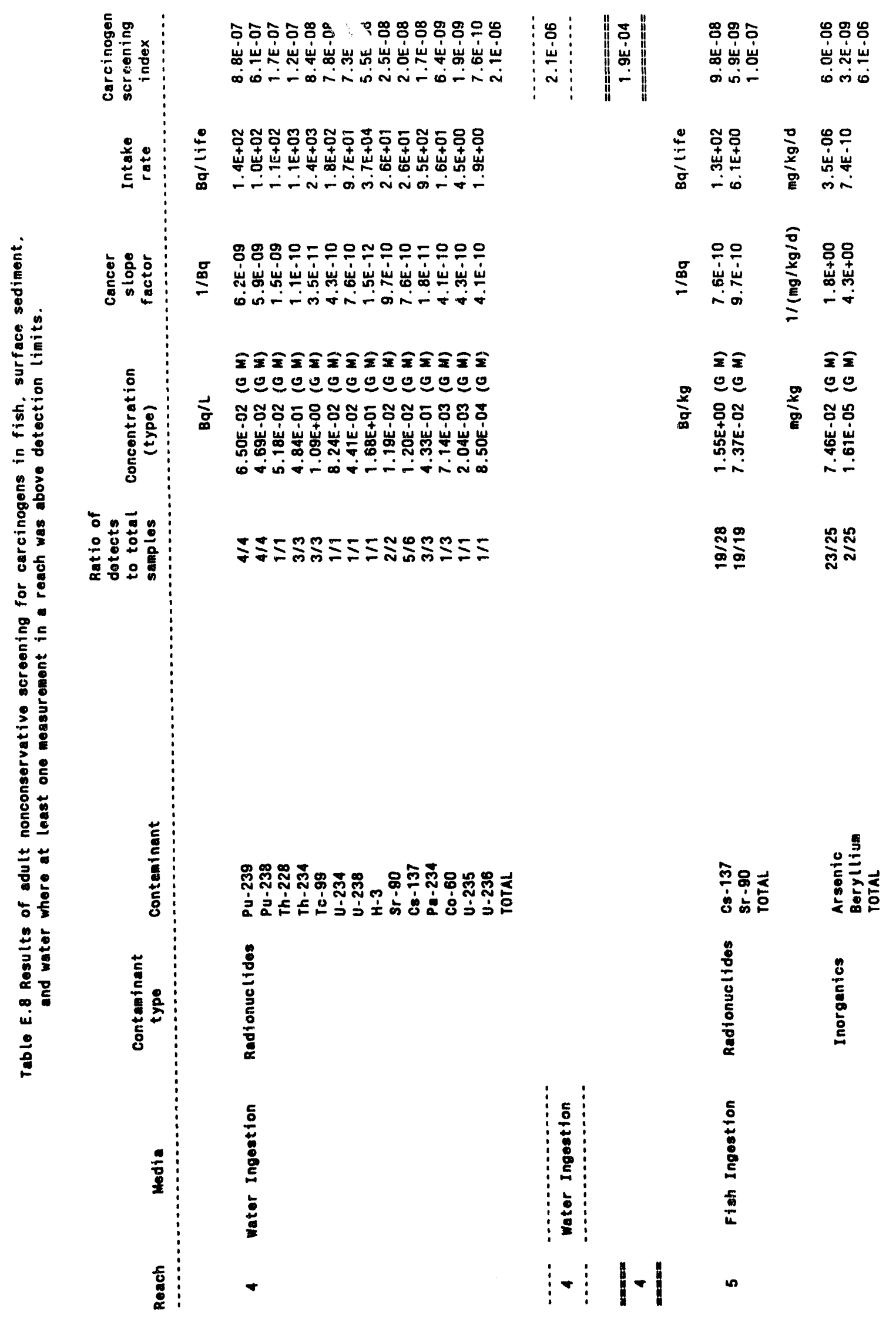


E-31

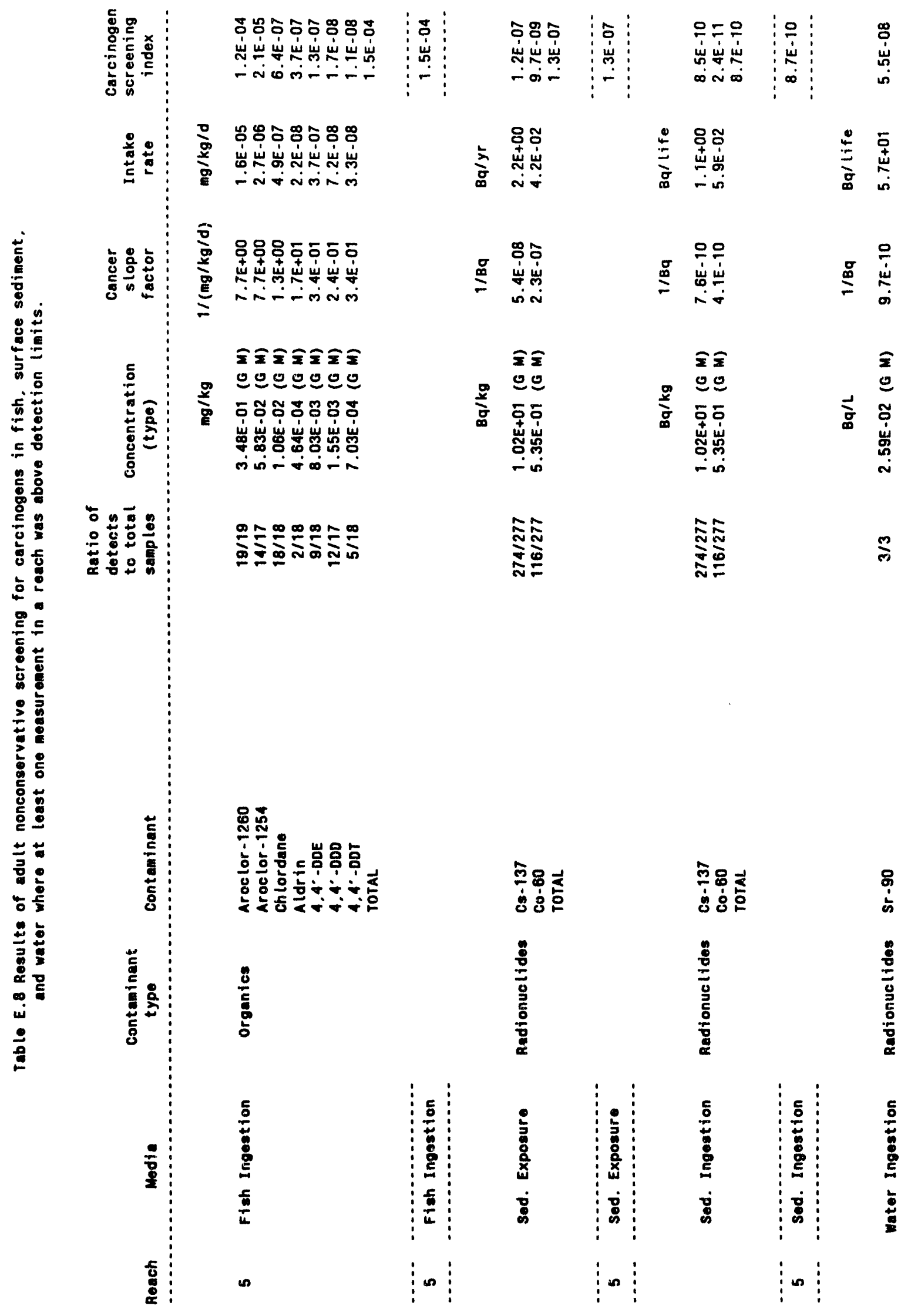




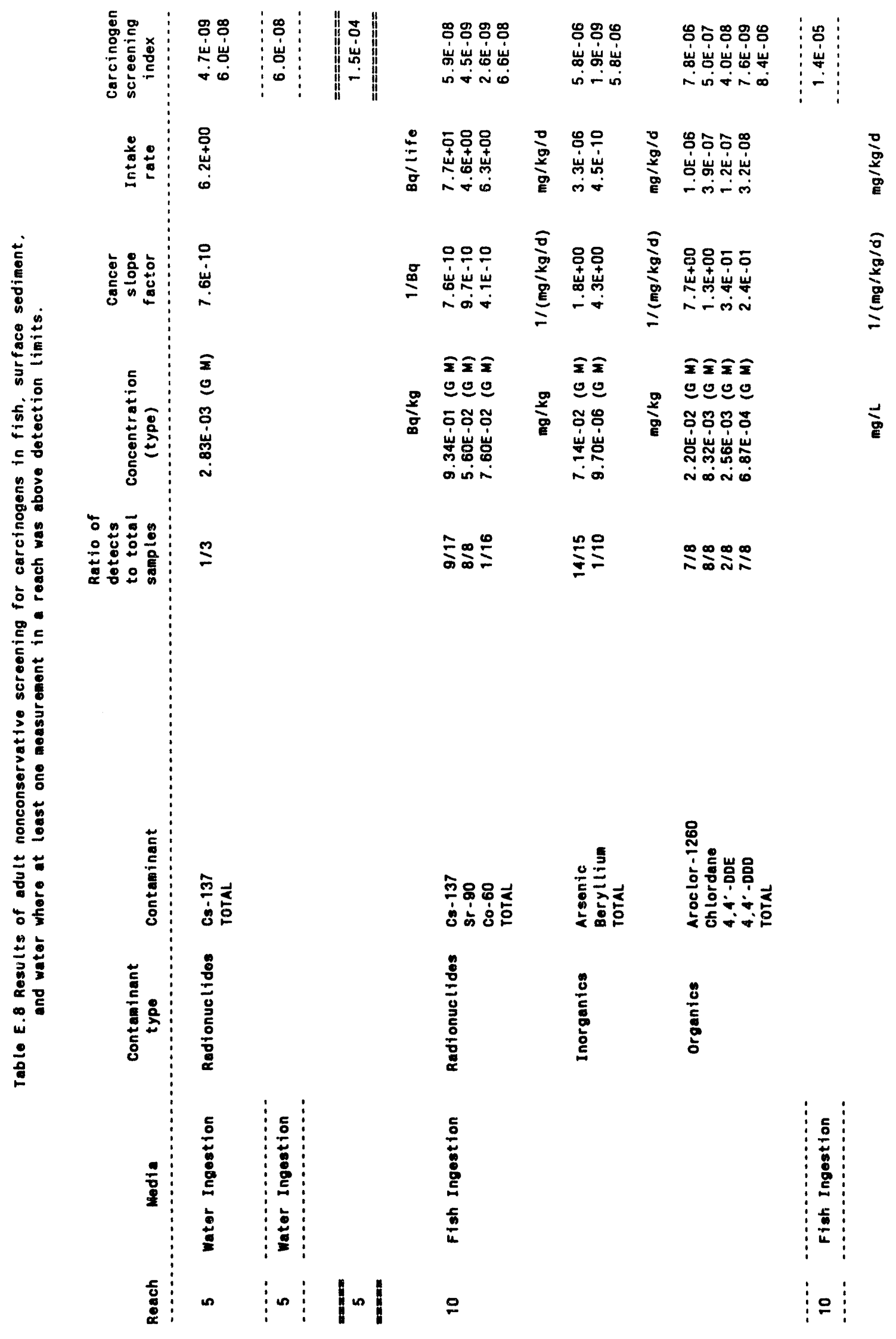


E-33

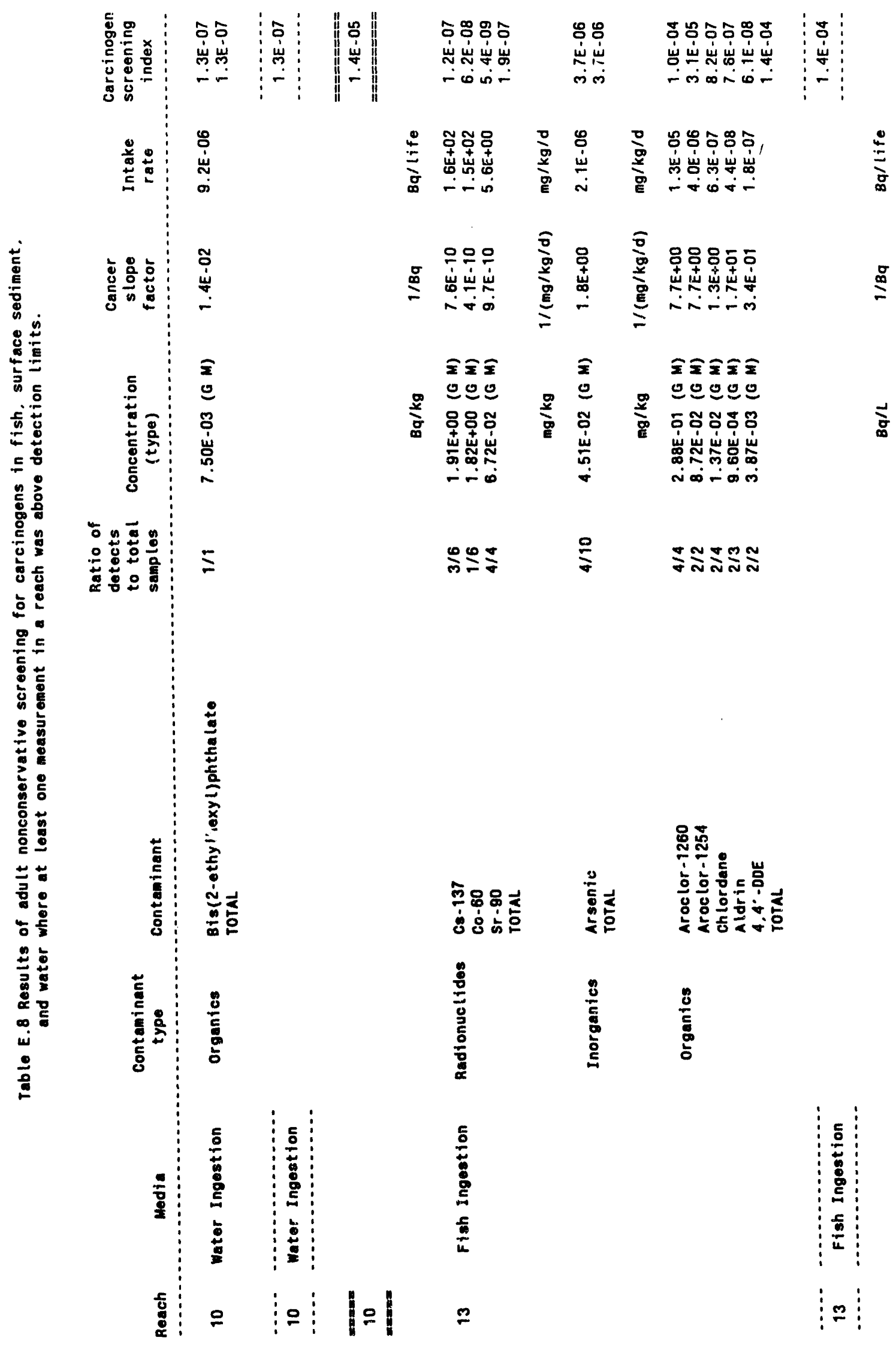


E-34

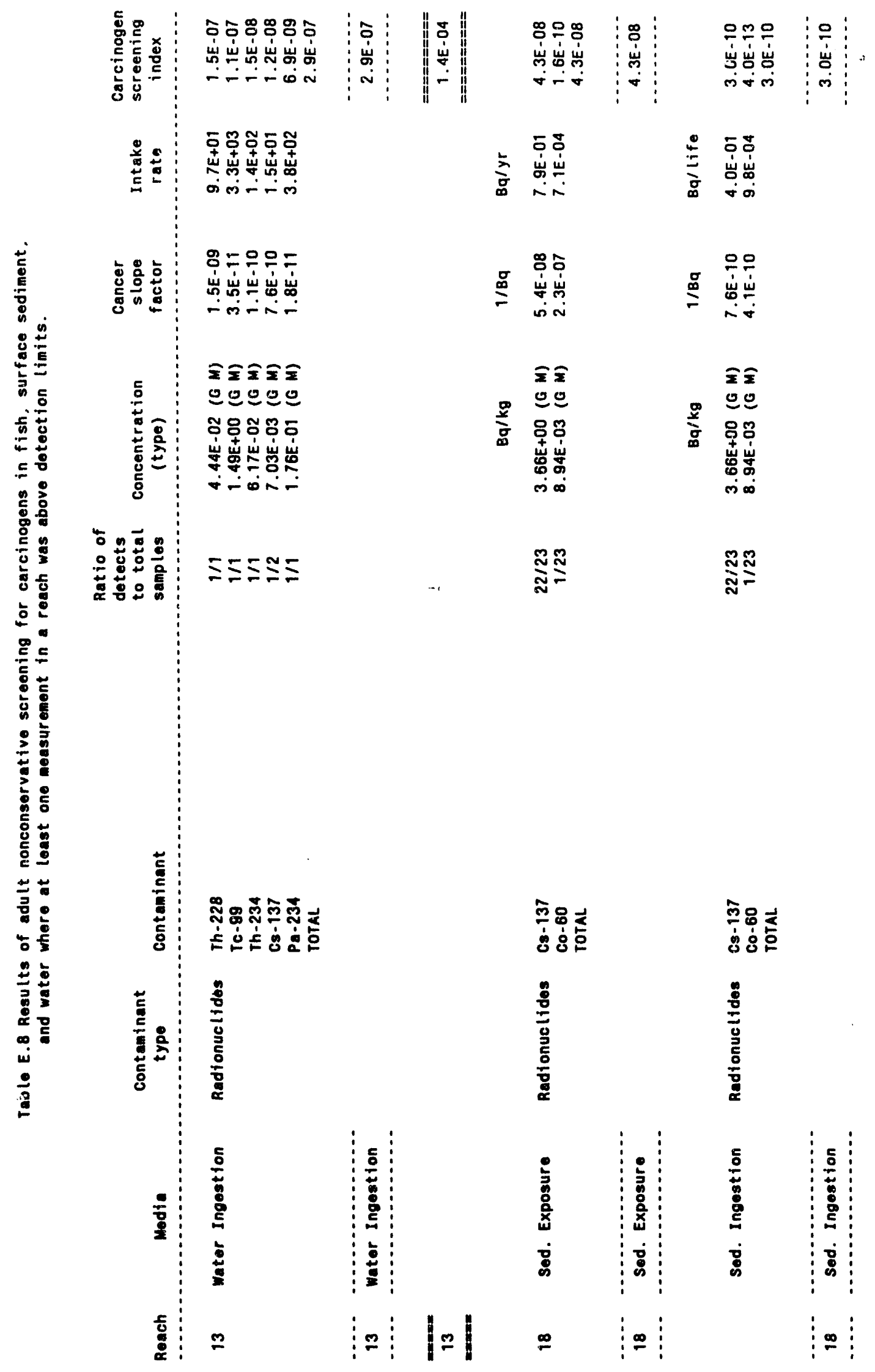




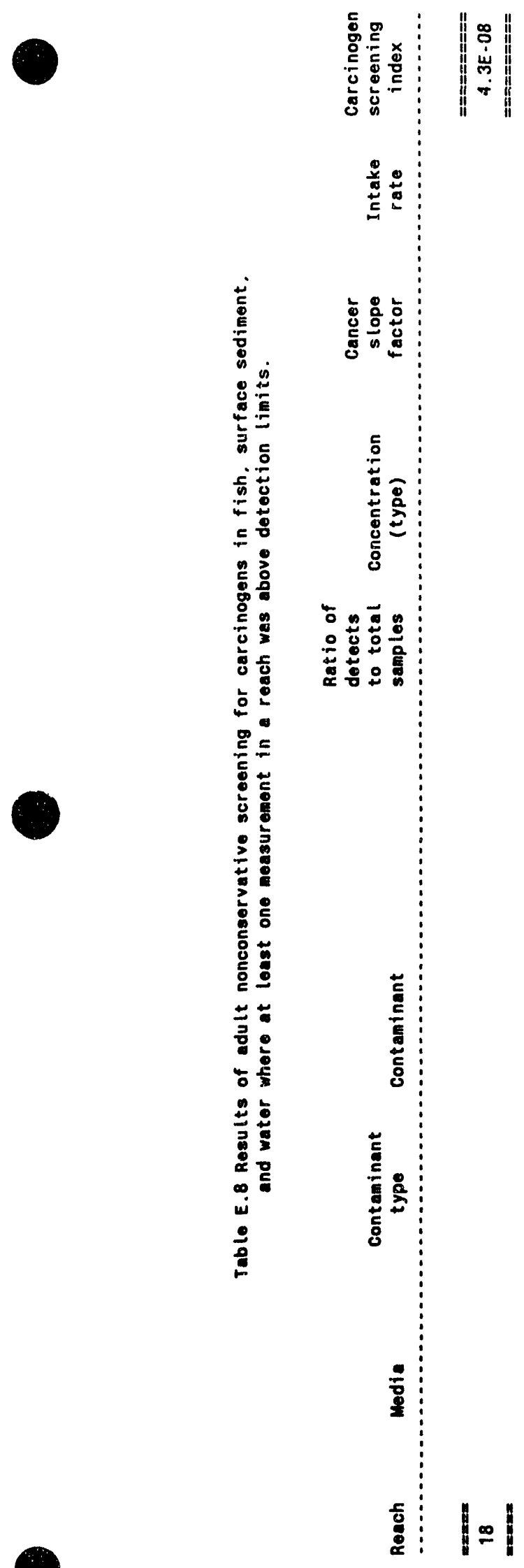




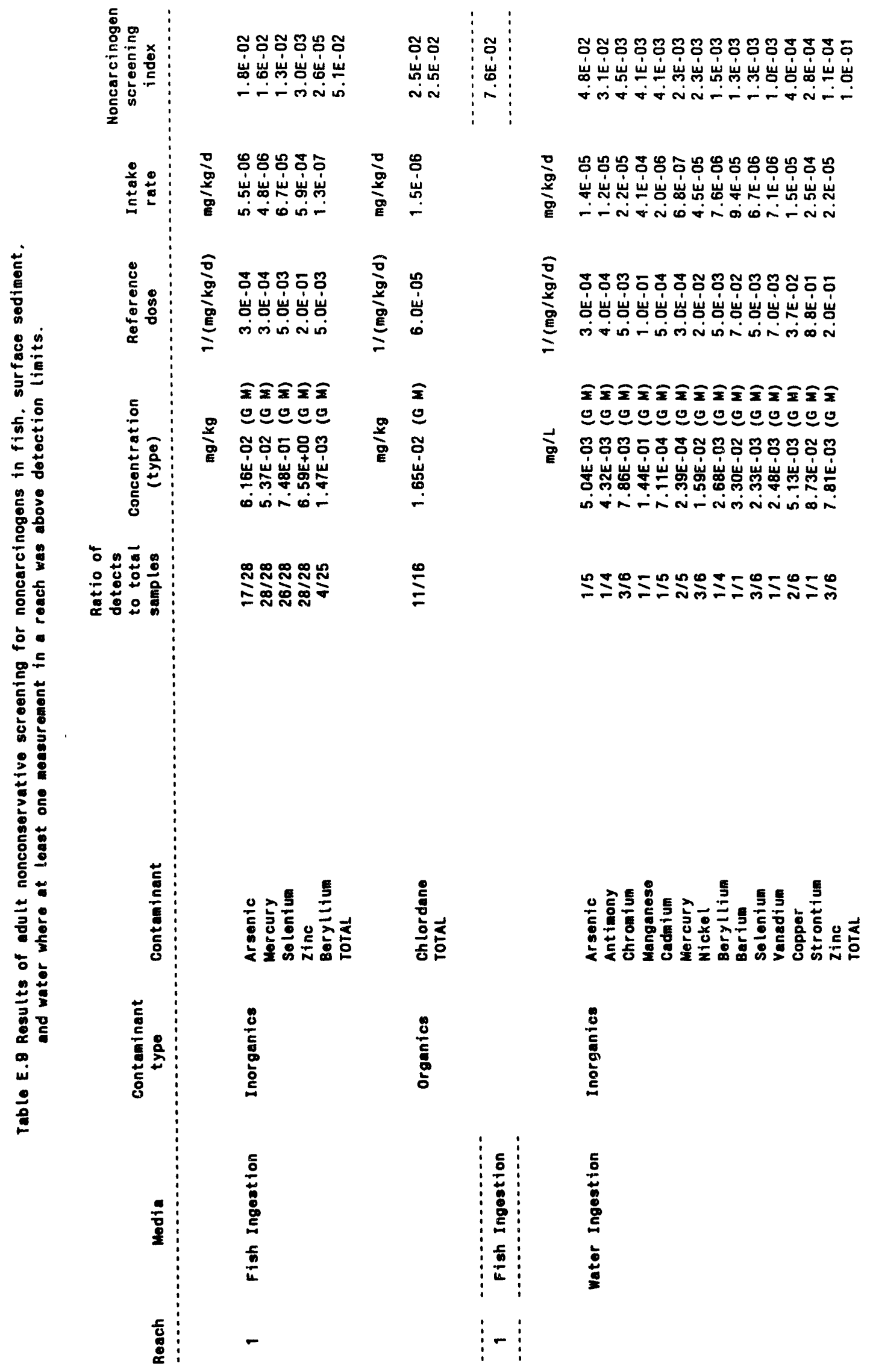


E-37

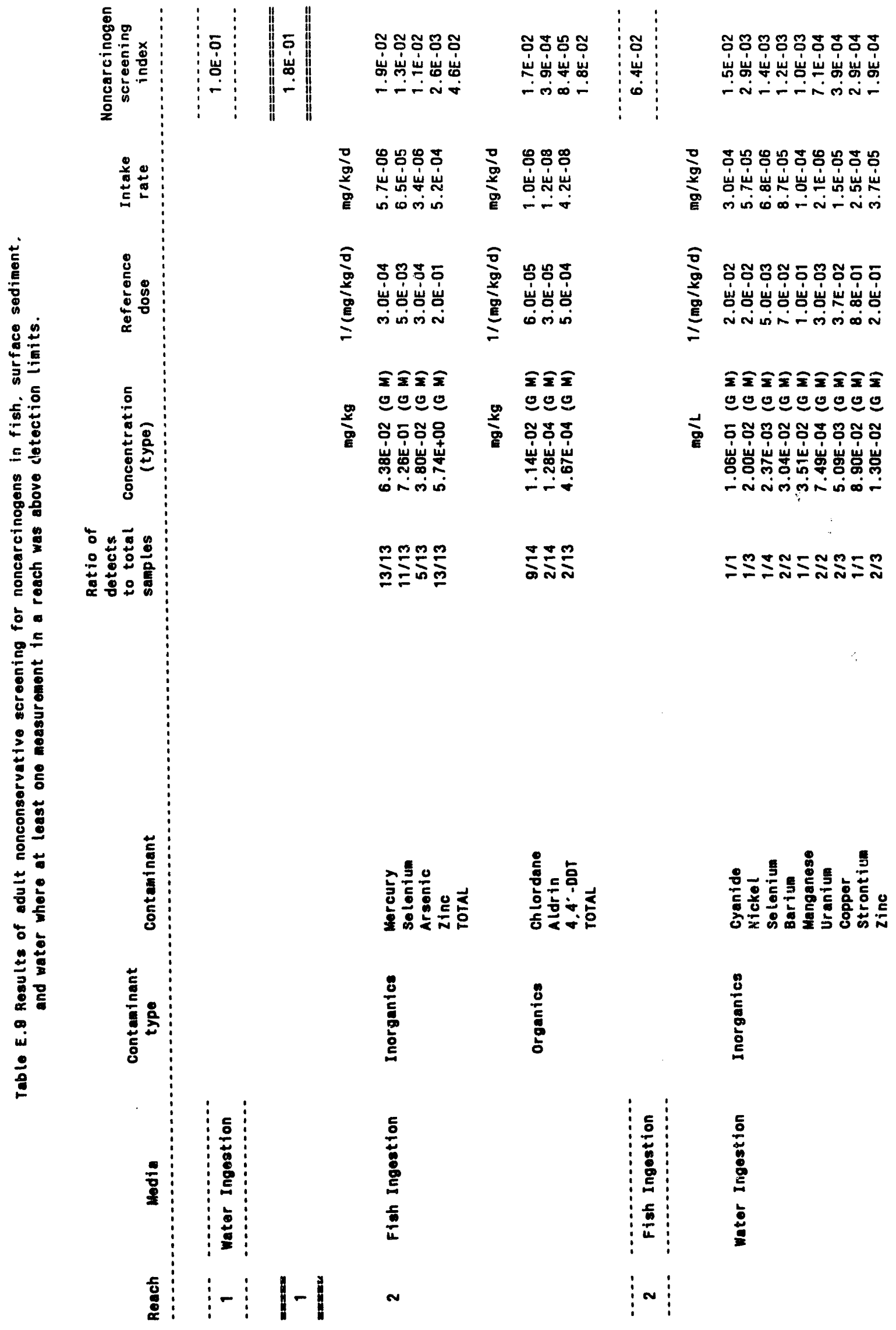


E-38

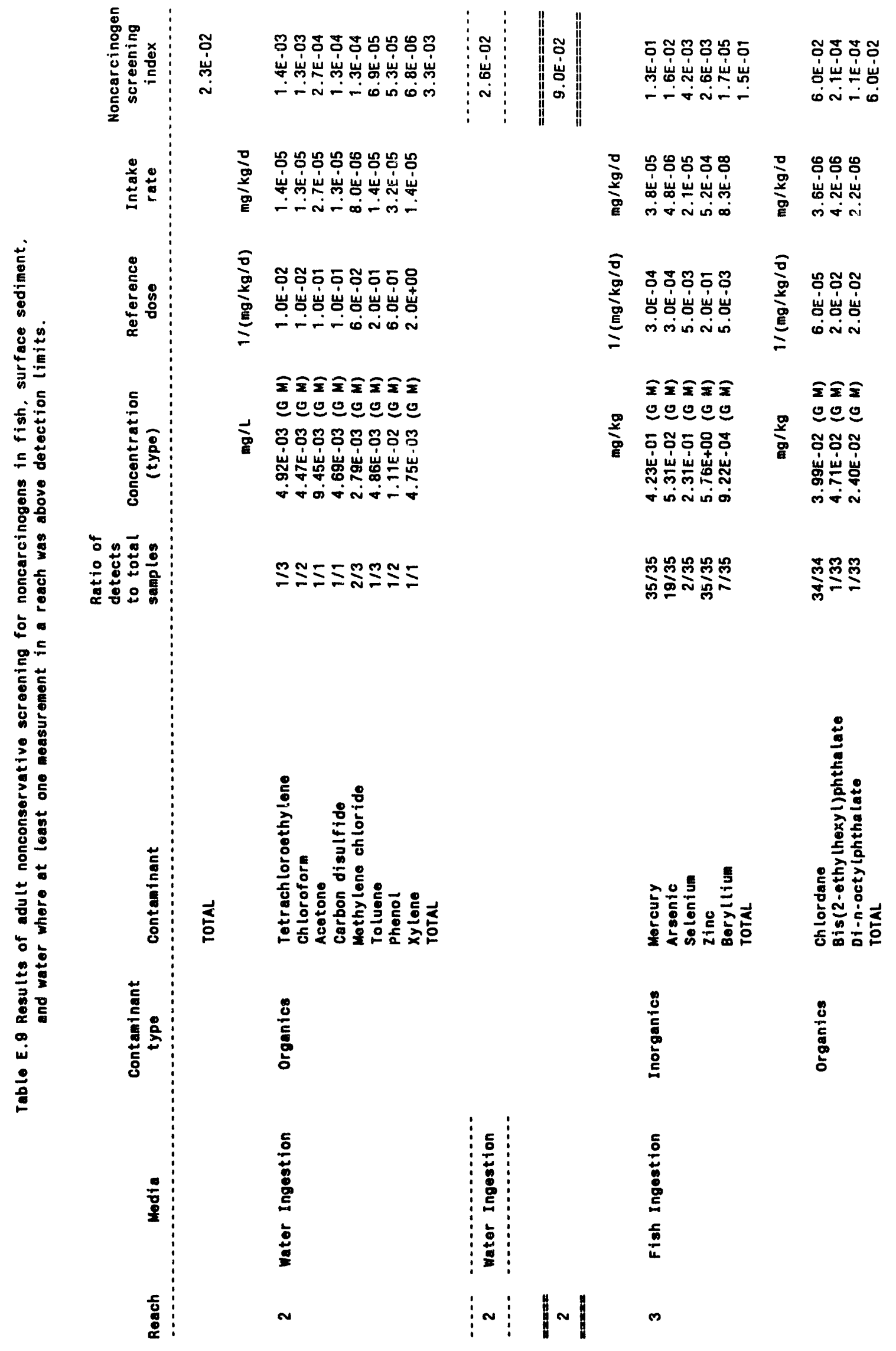




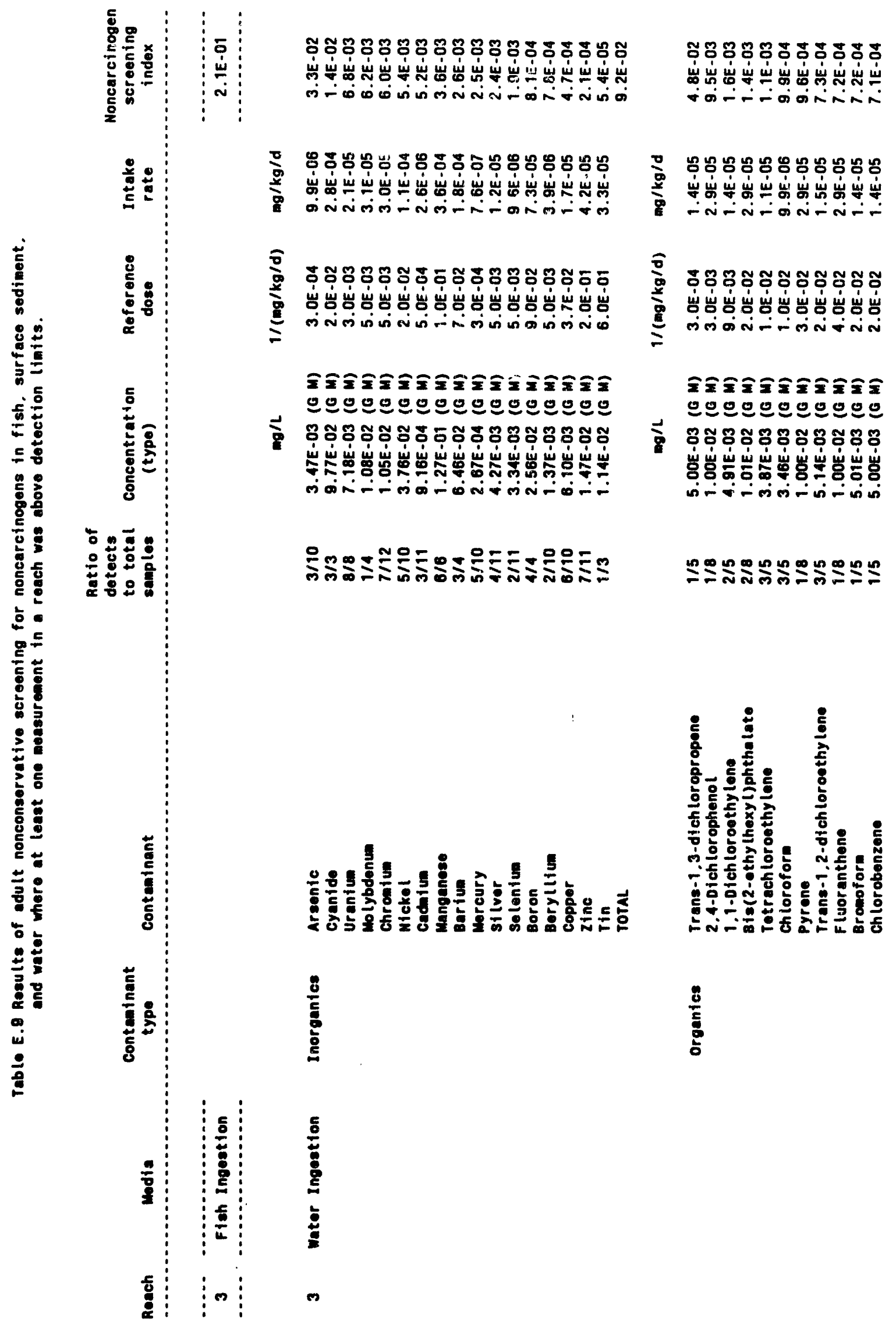




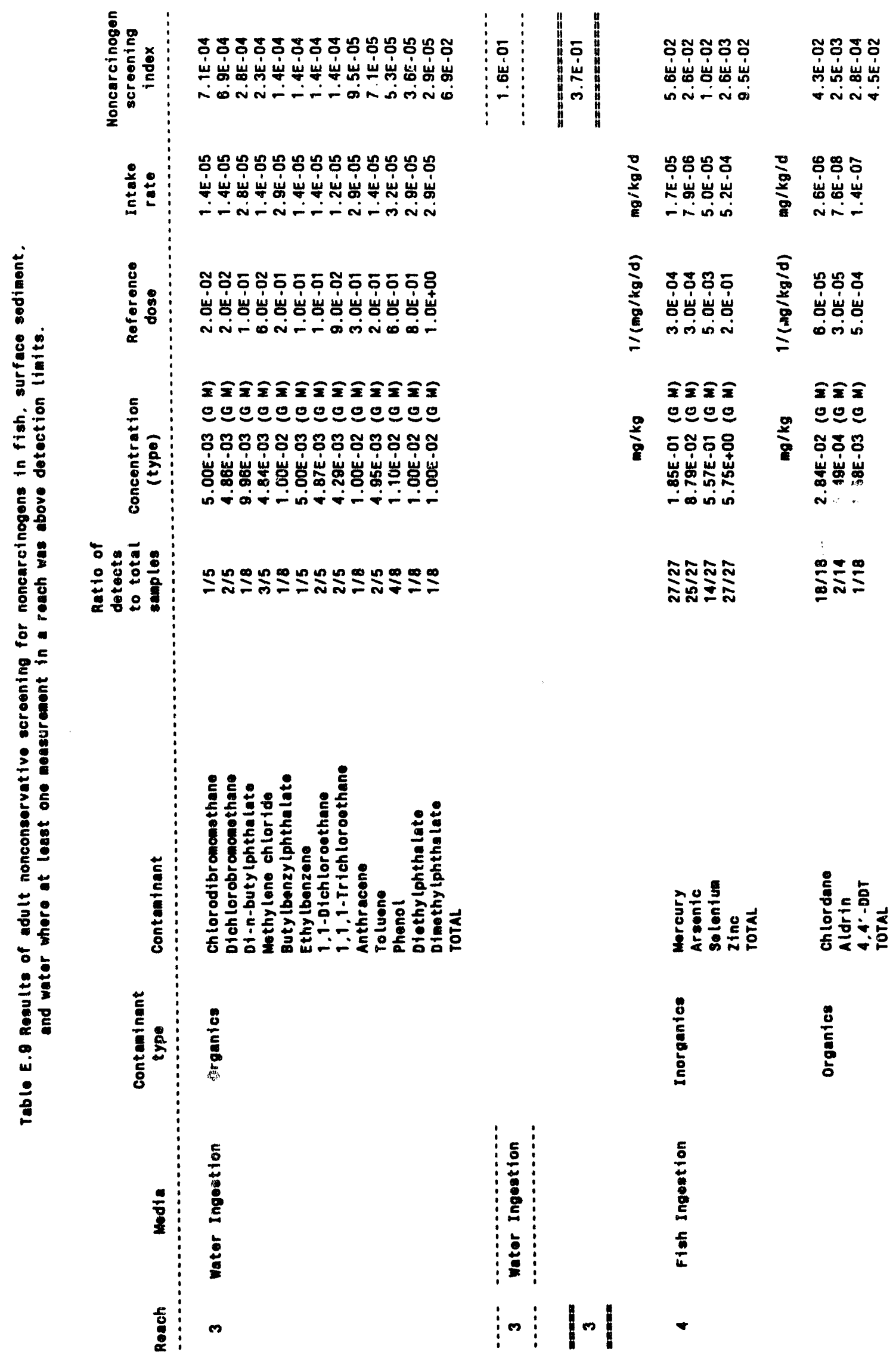




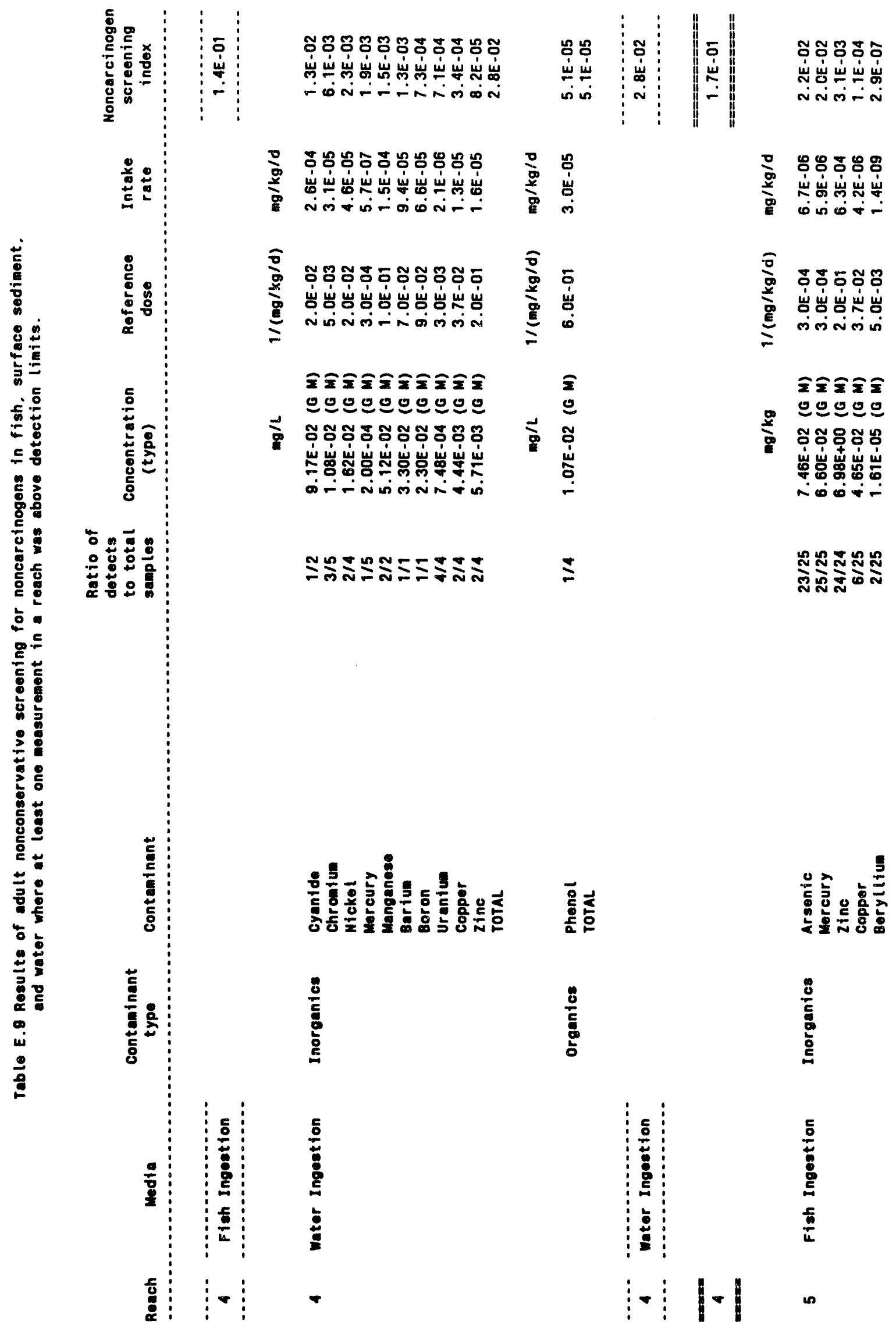


E-42

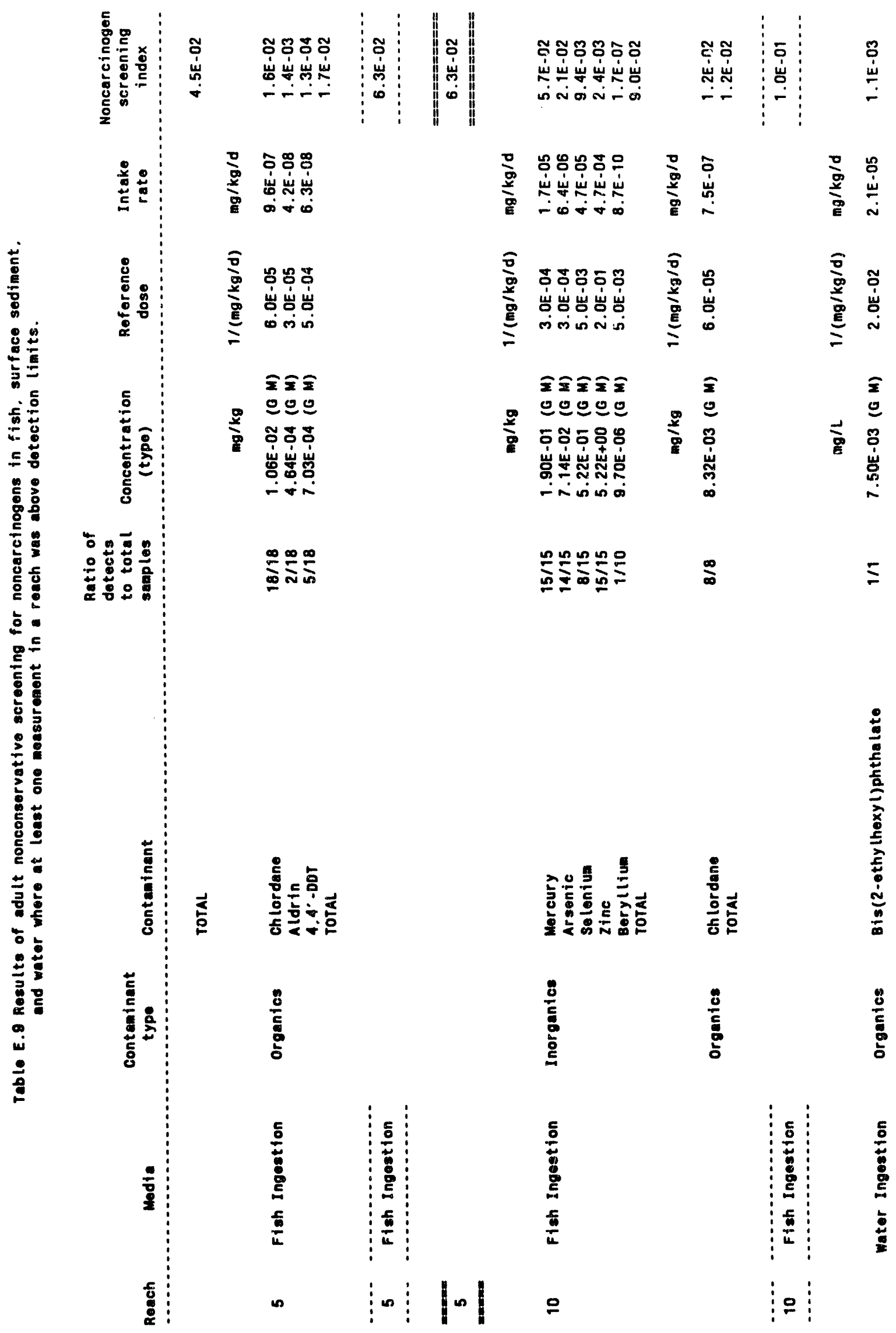




\section{E-43}

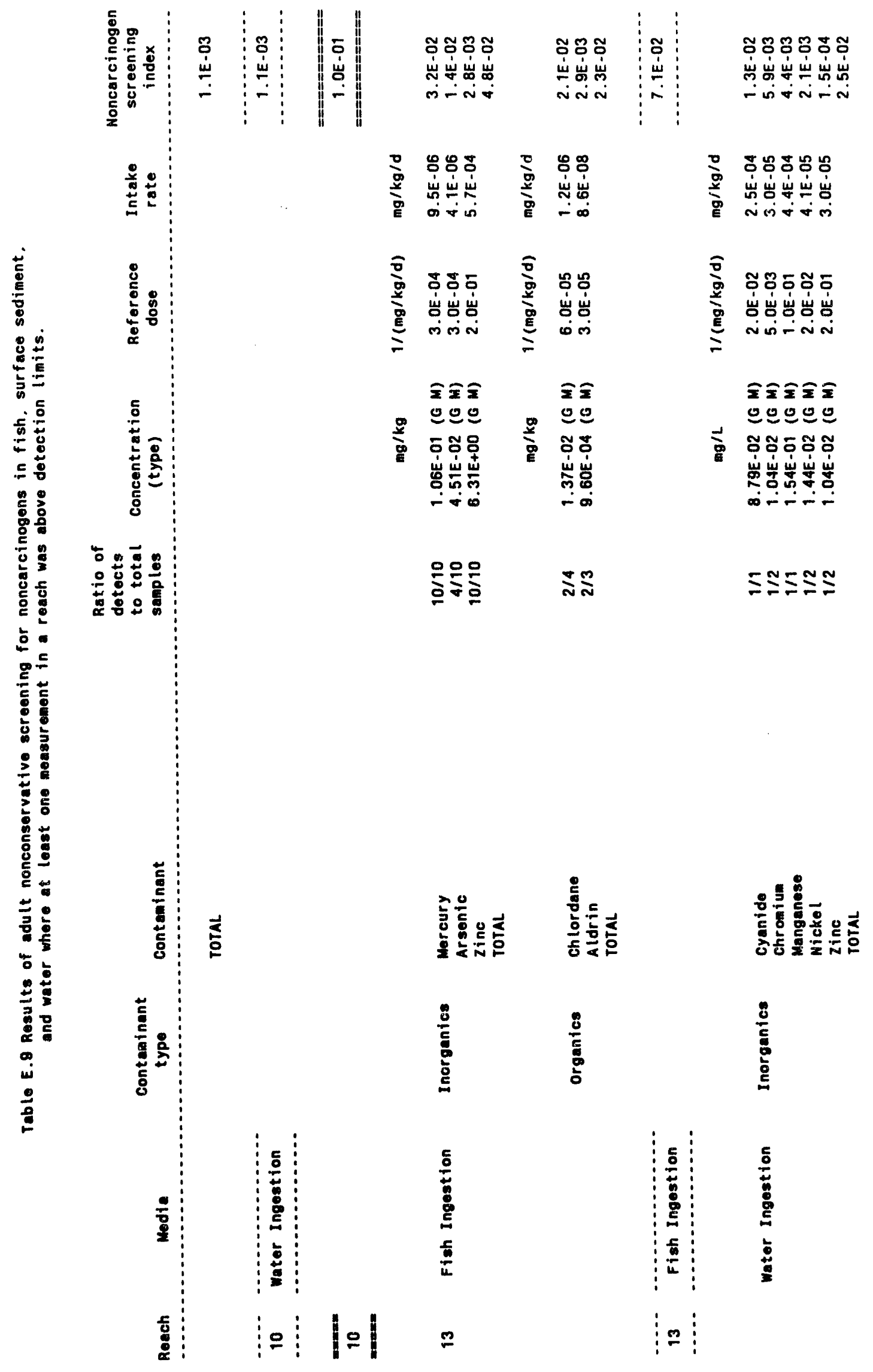




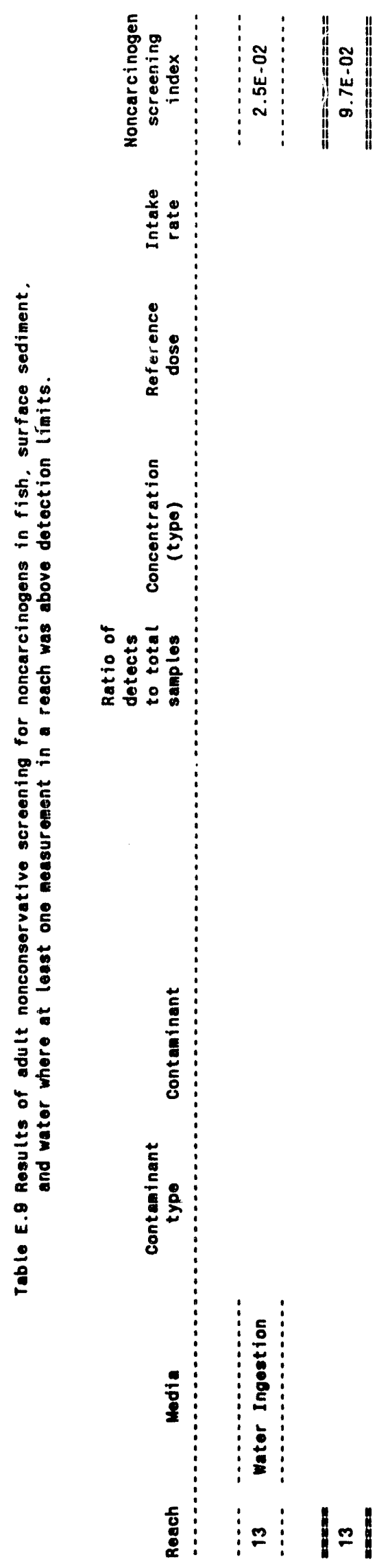




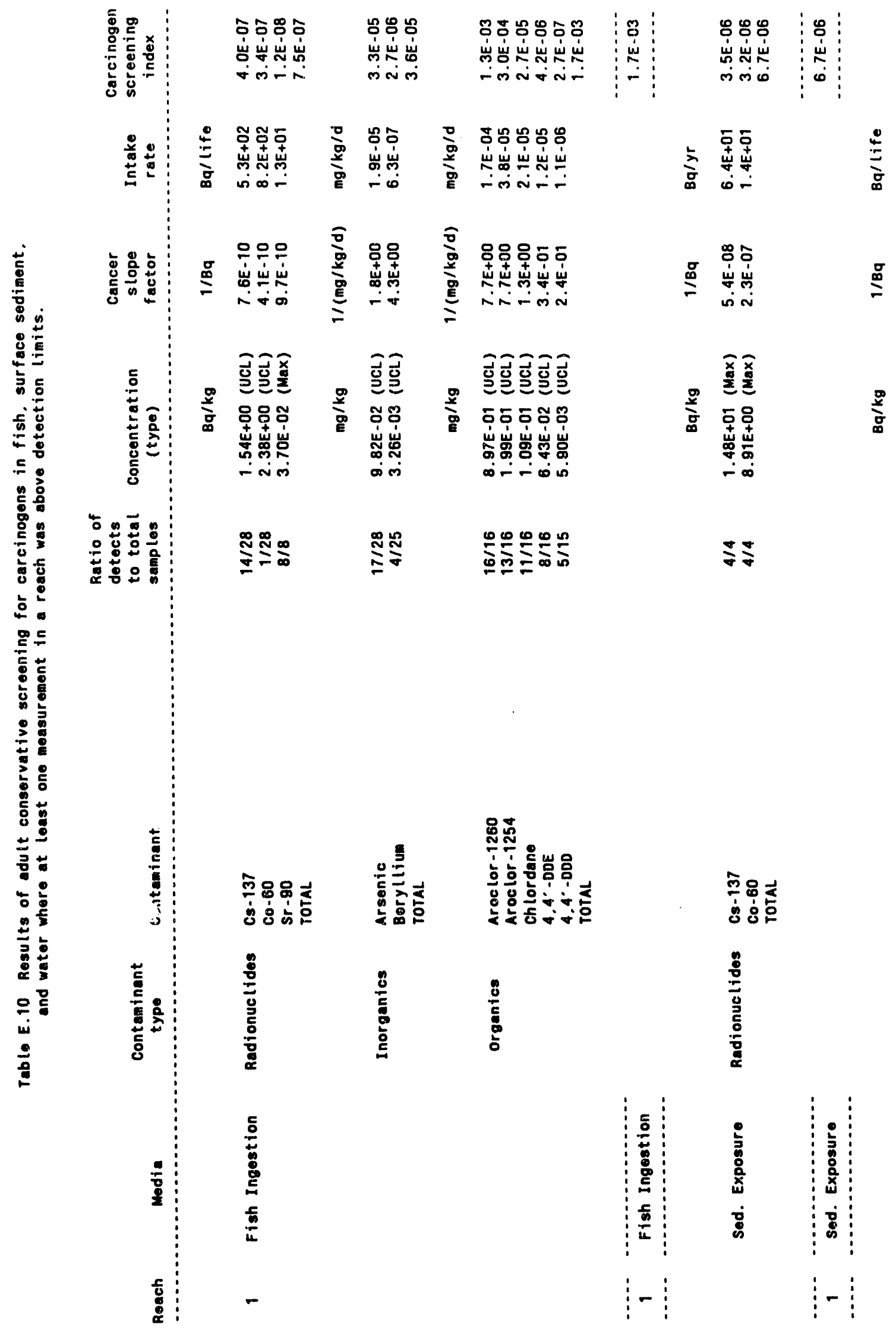




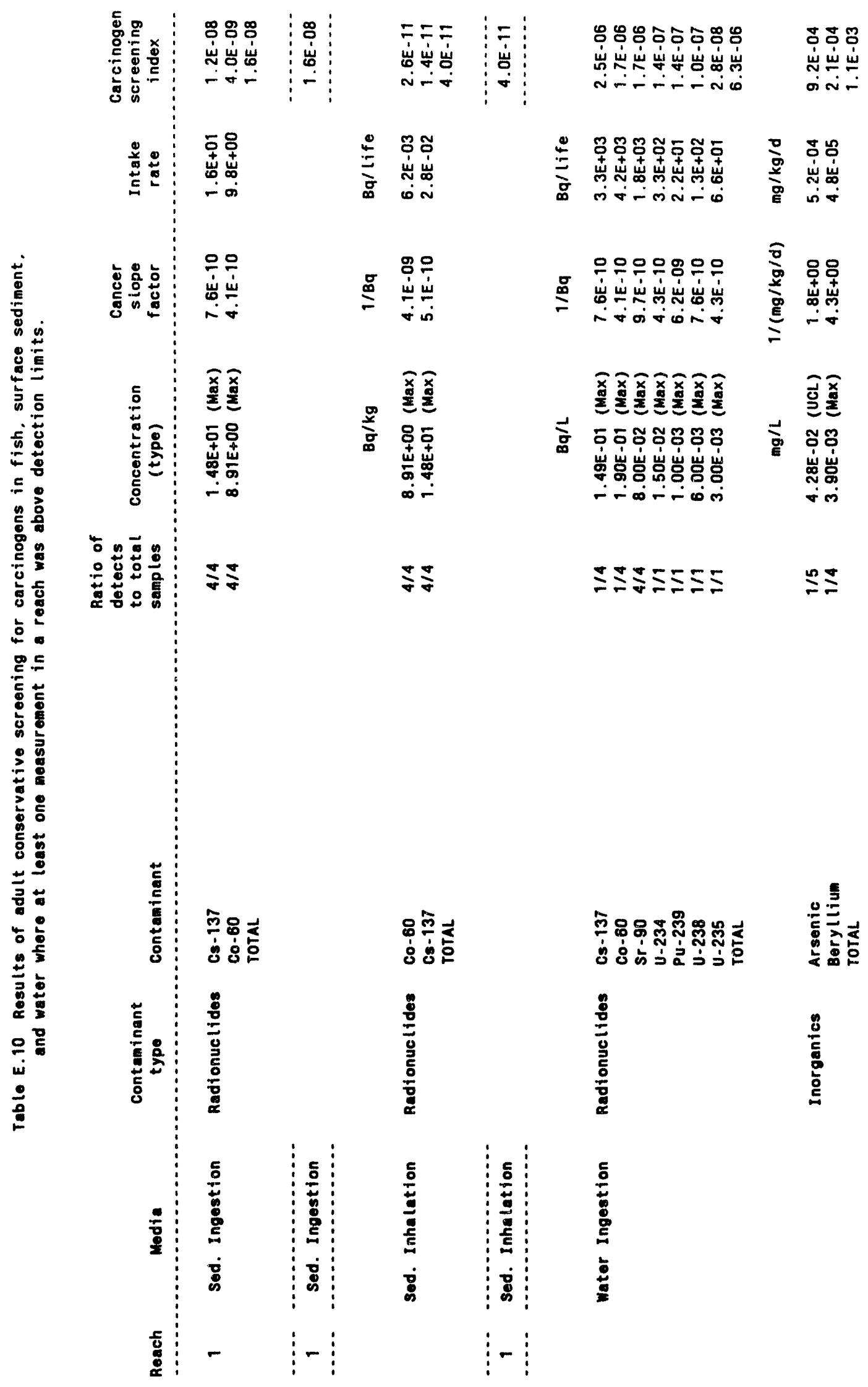




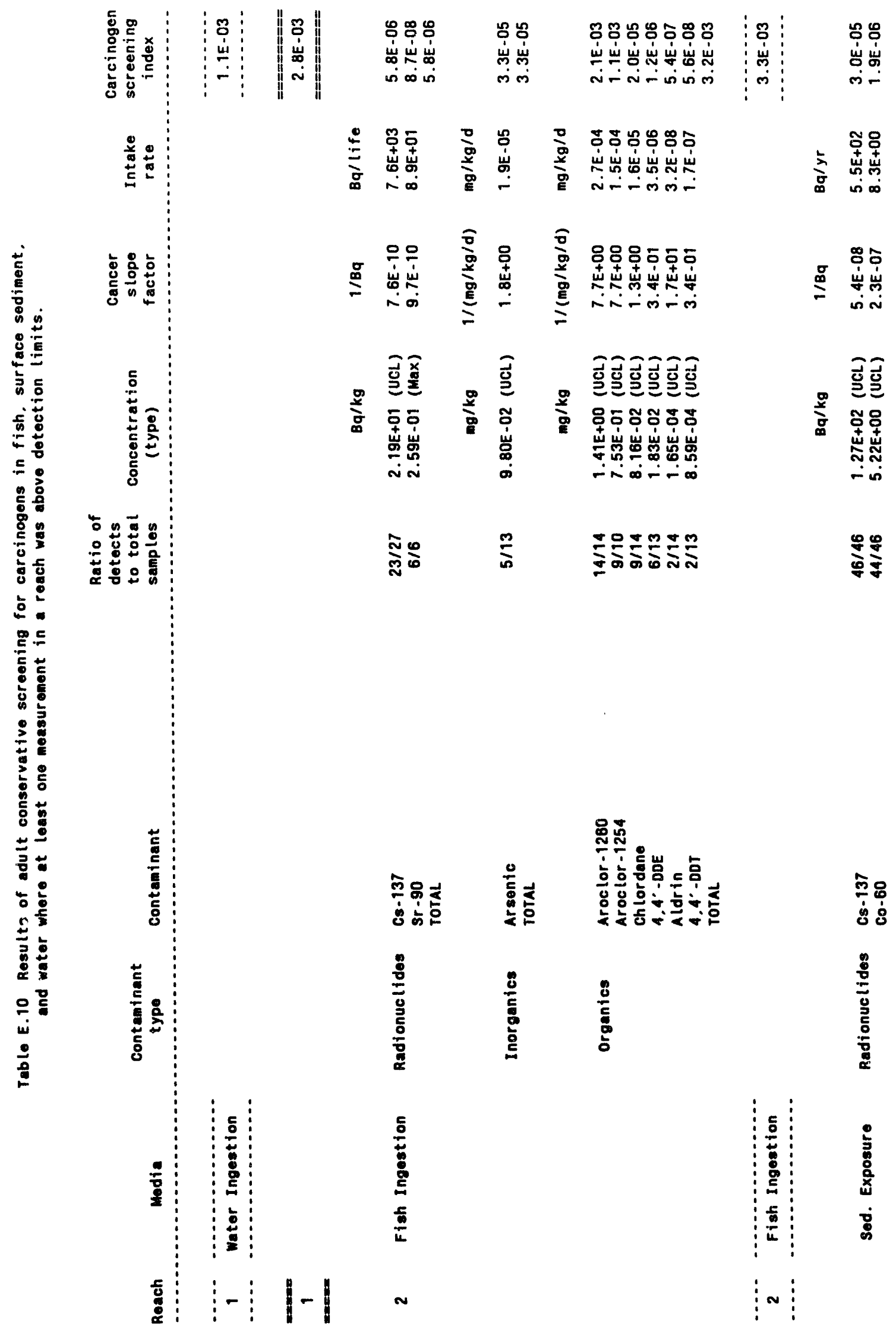


E-48

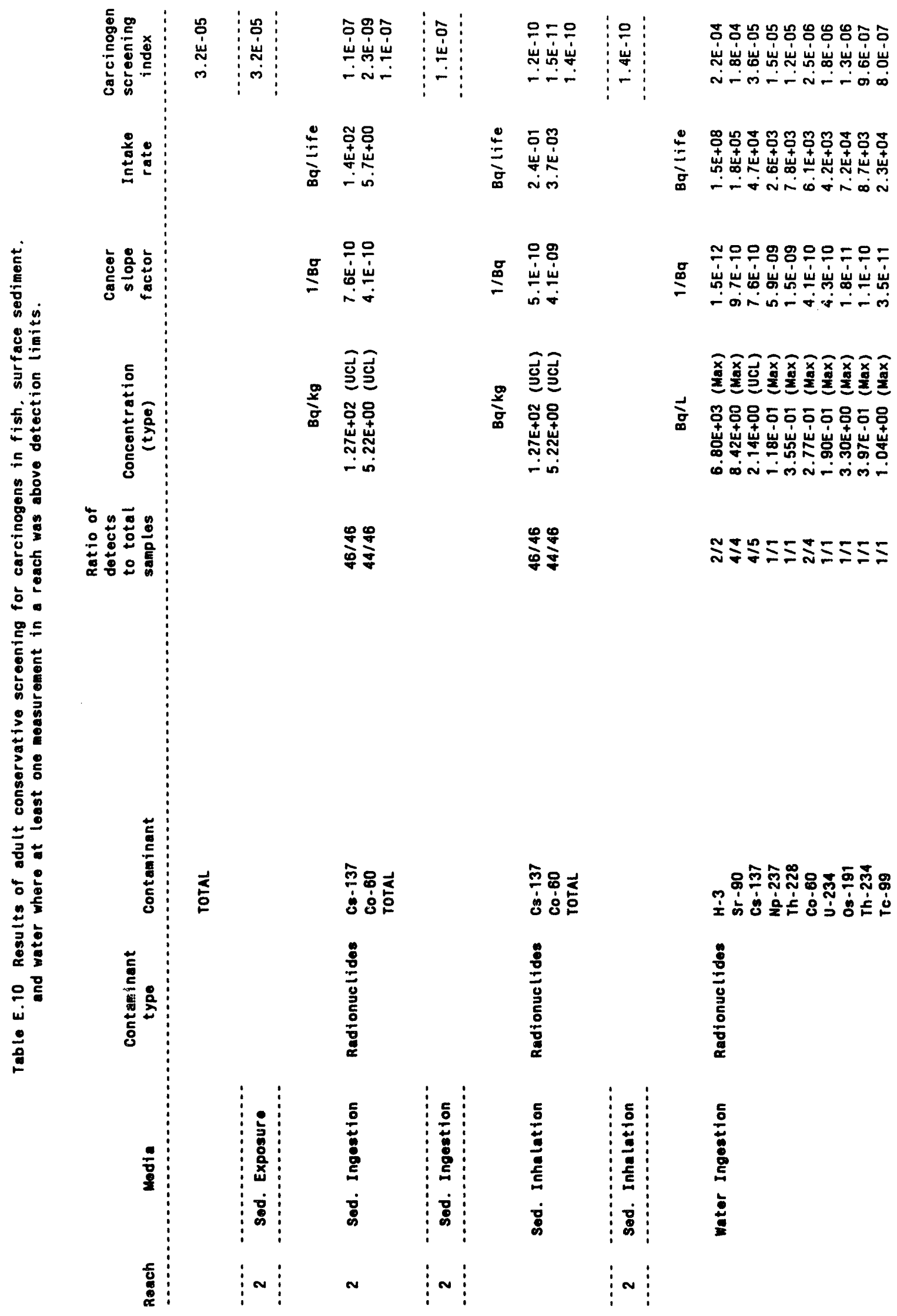




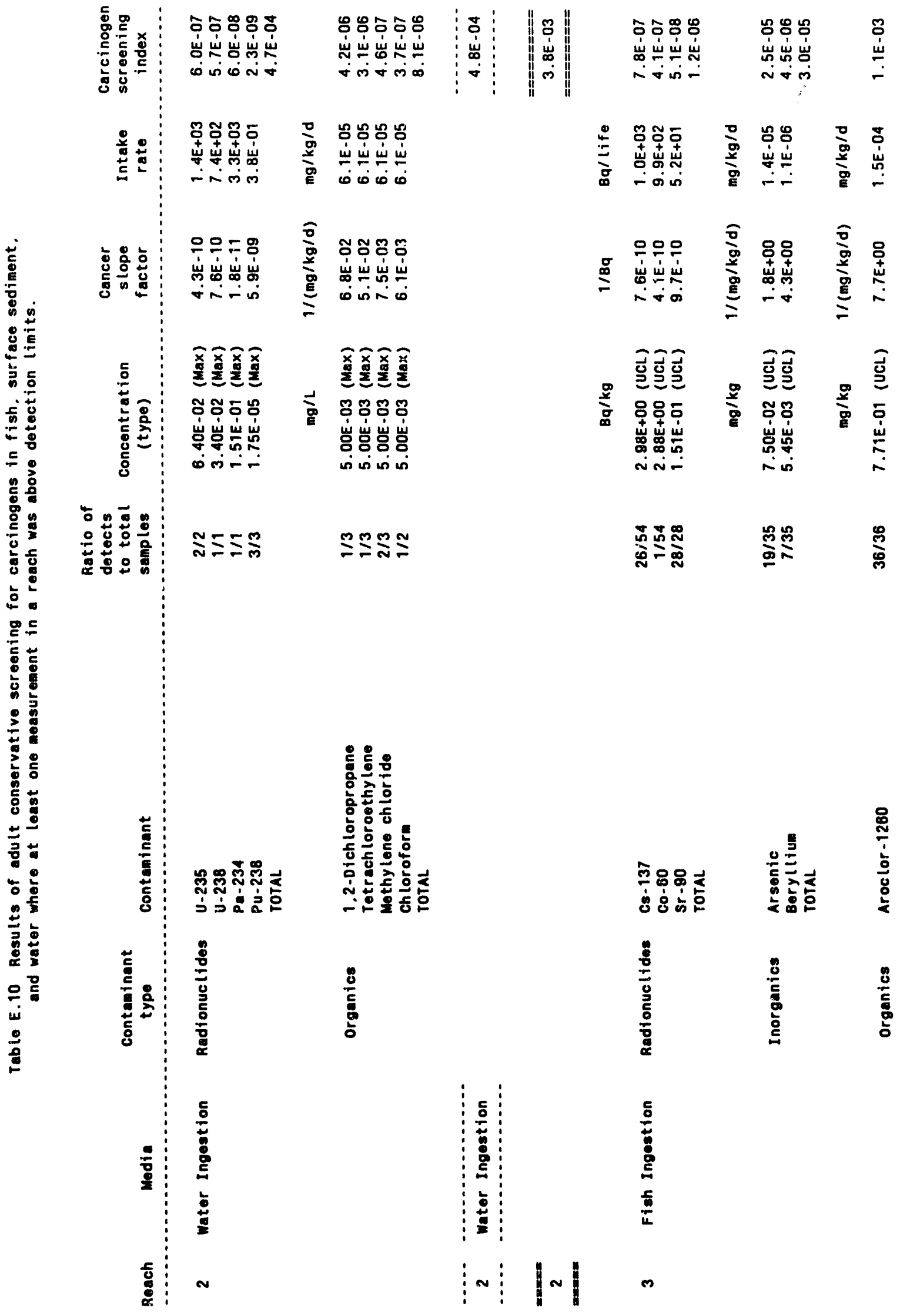




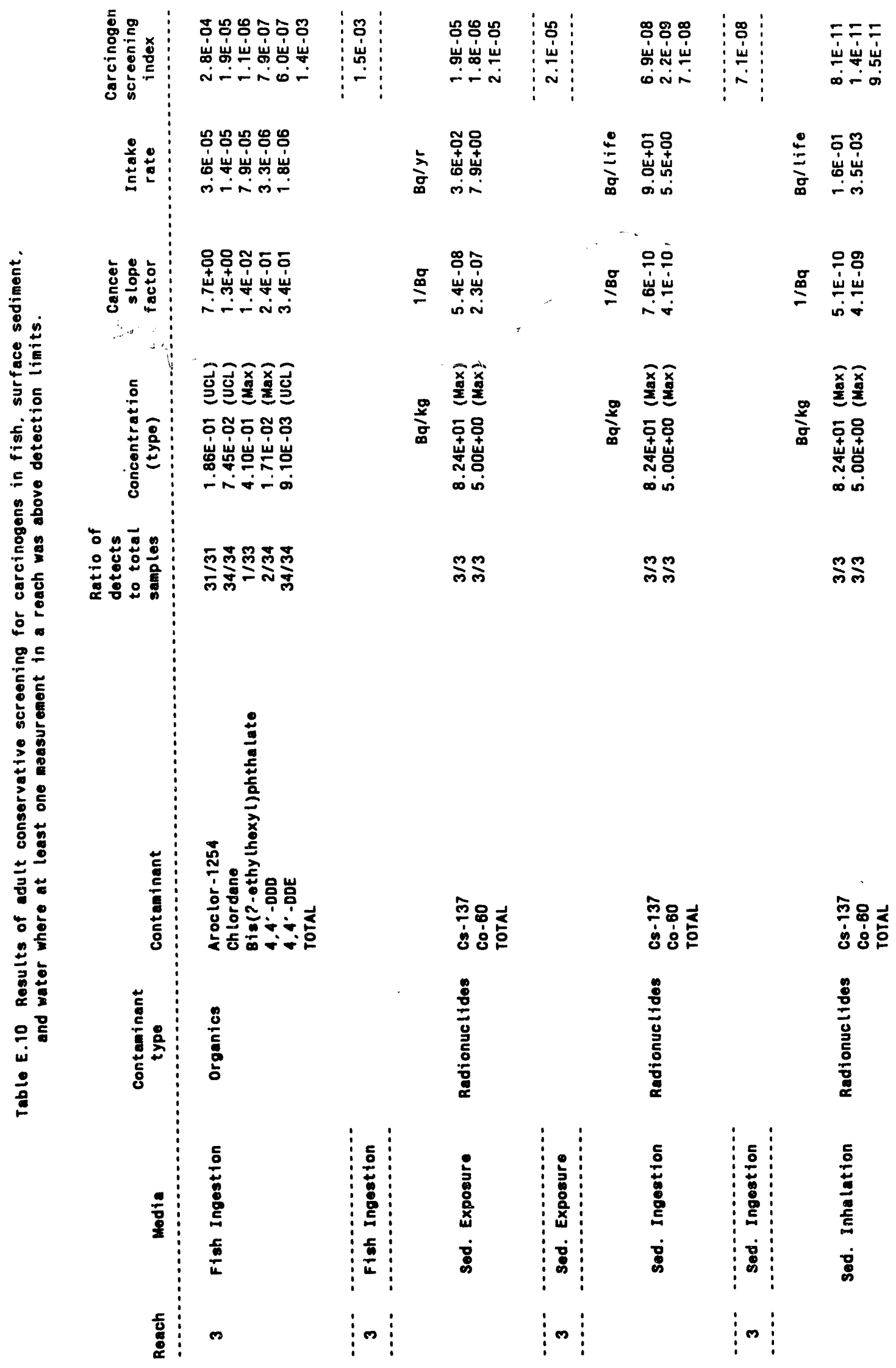




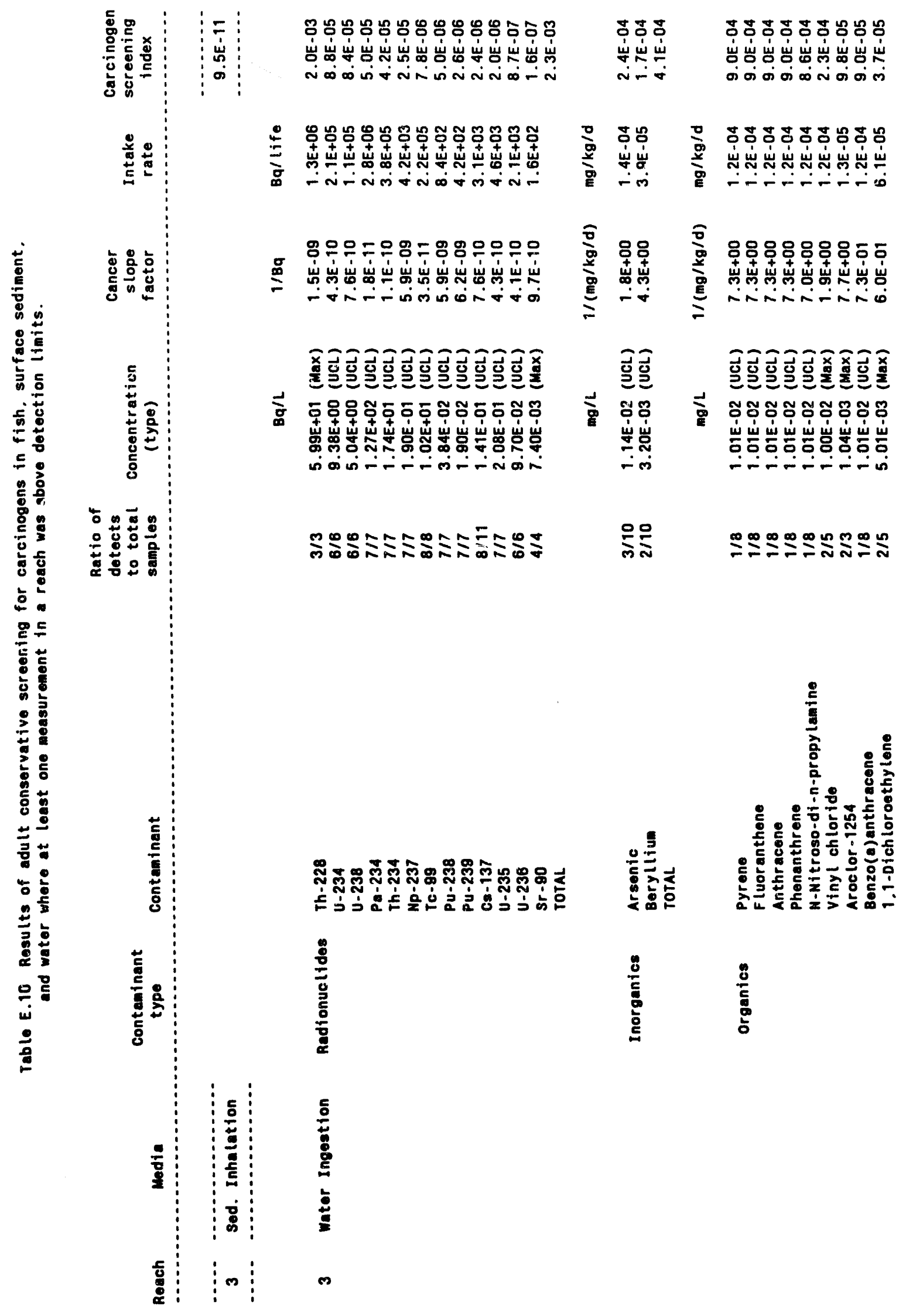


E-52

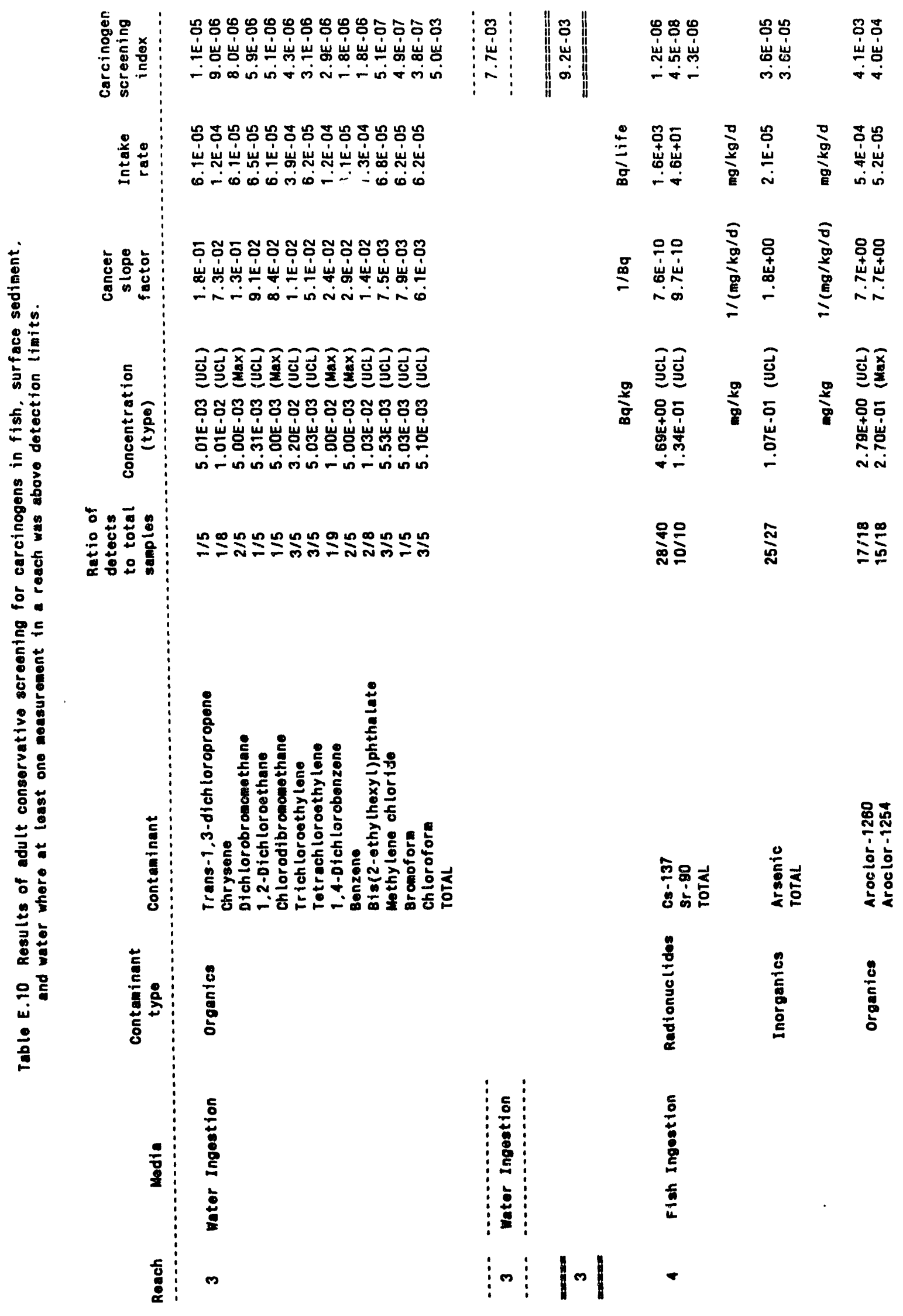




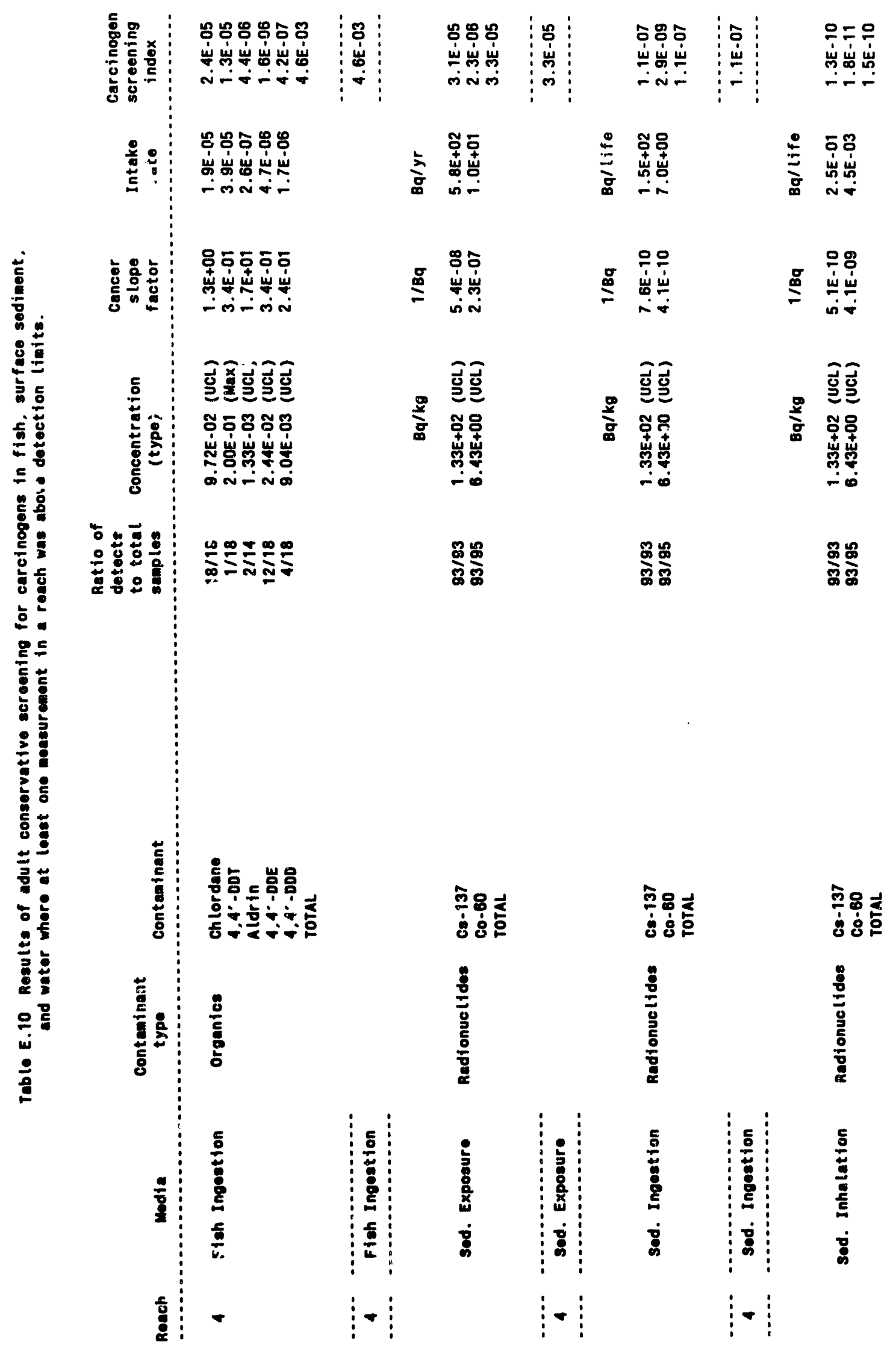




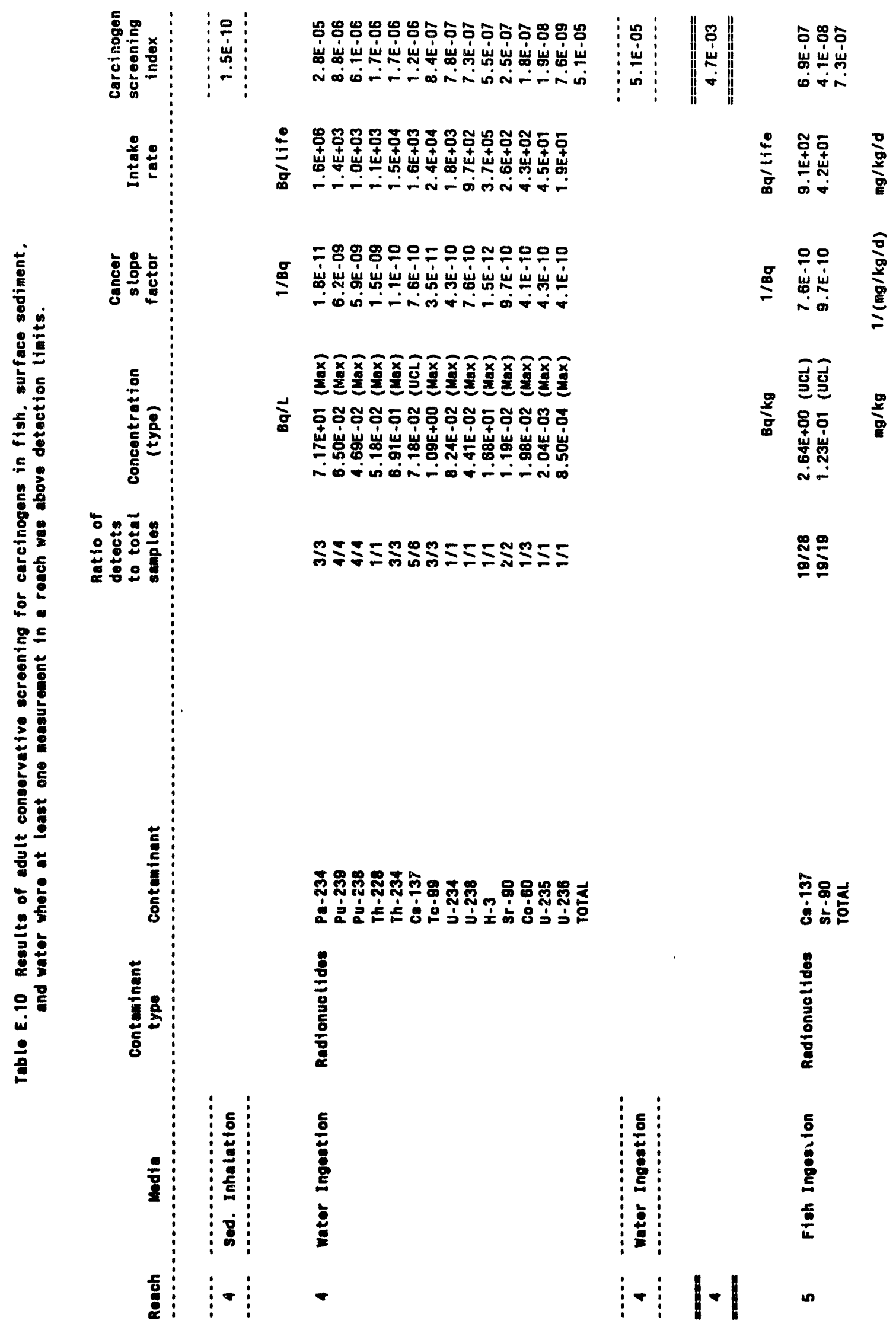




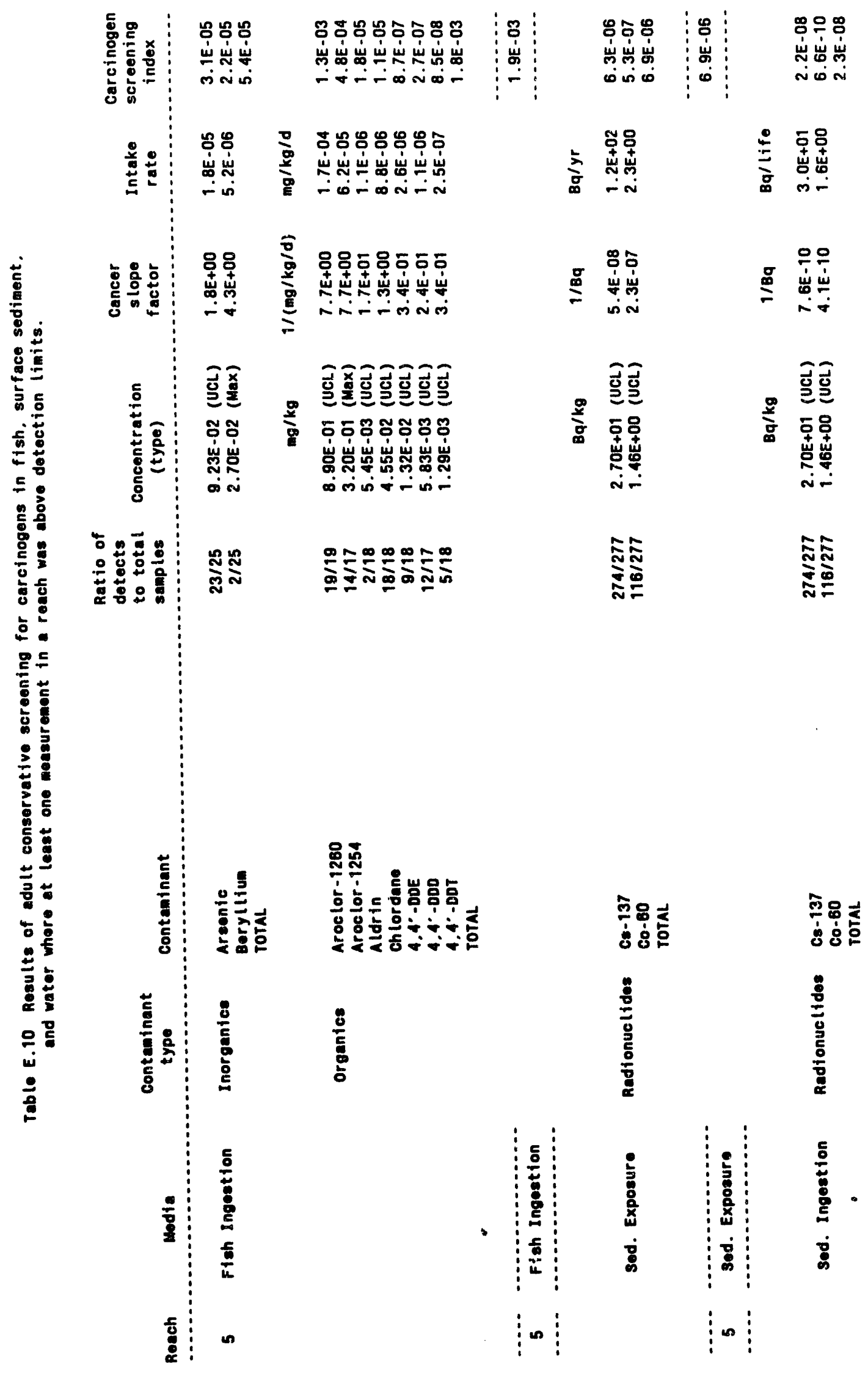




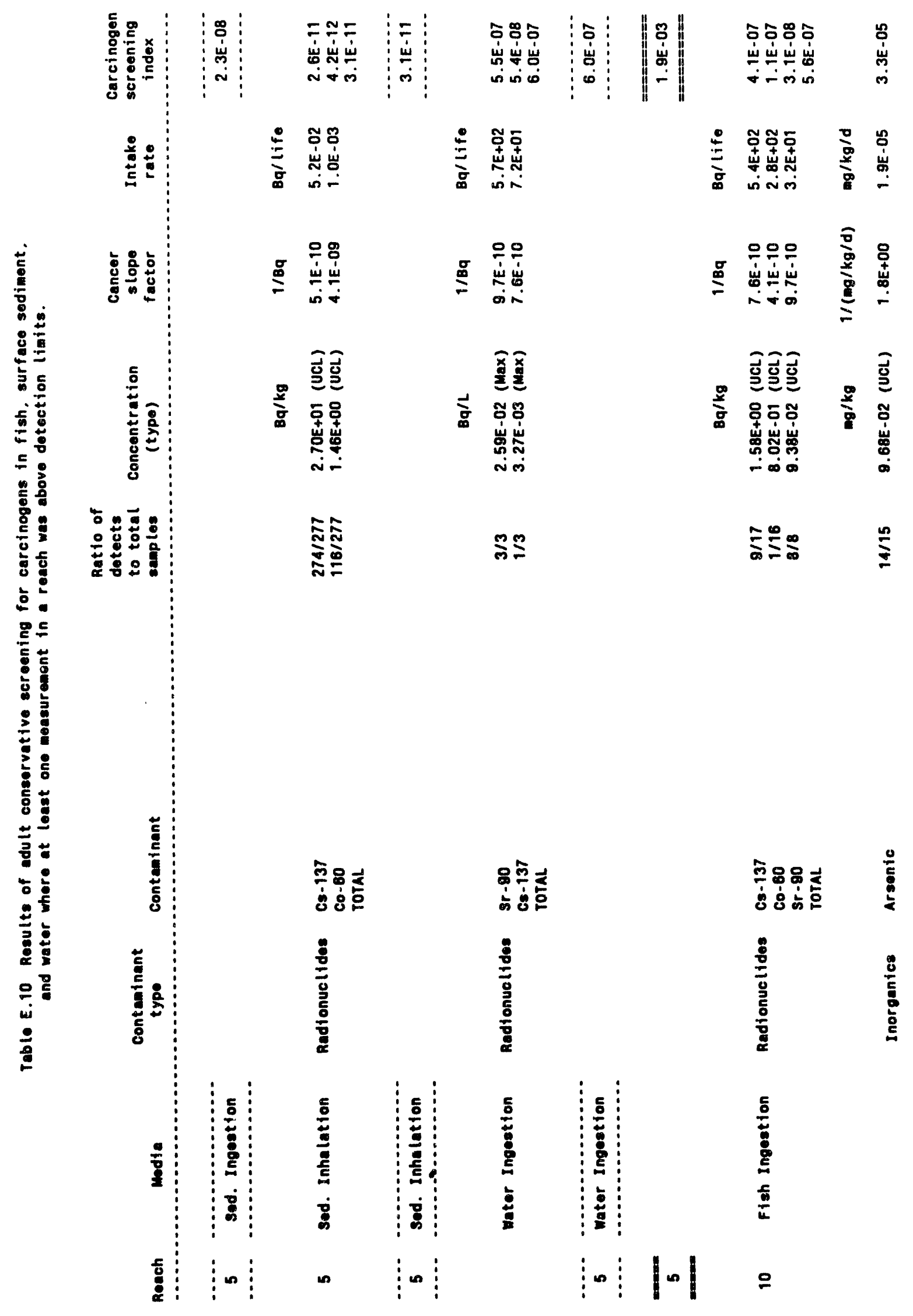




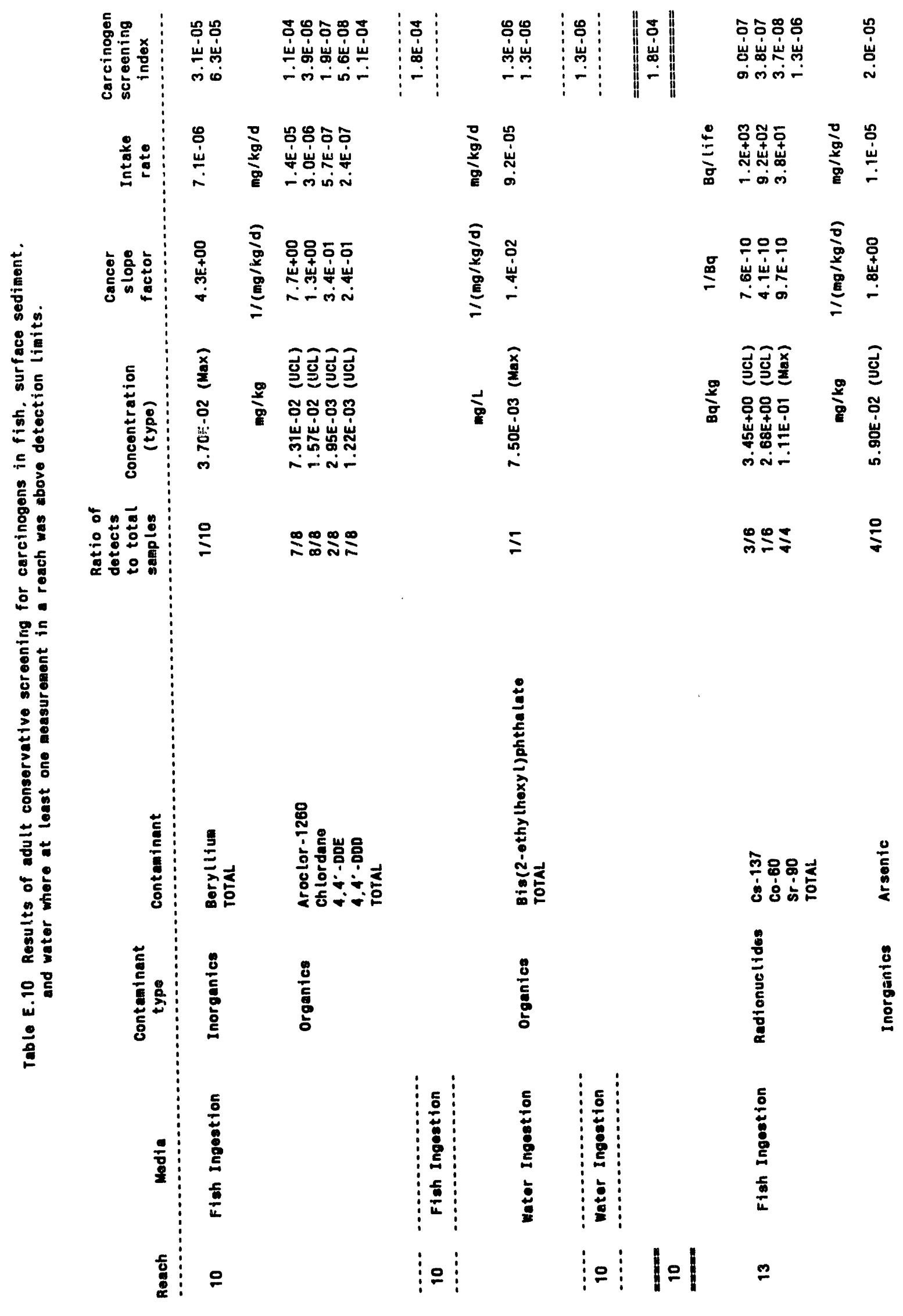




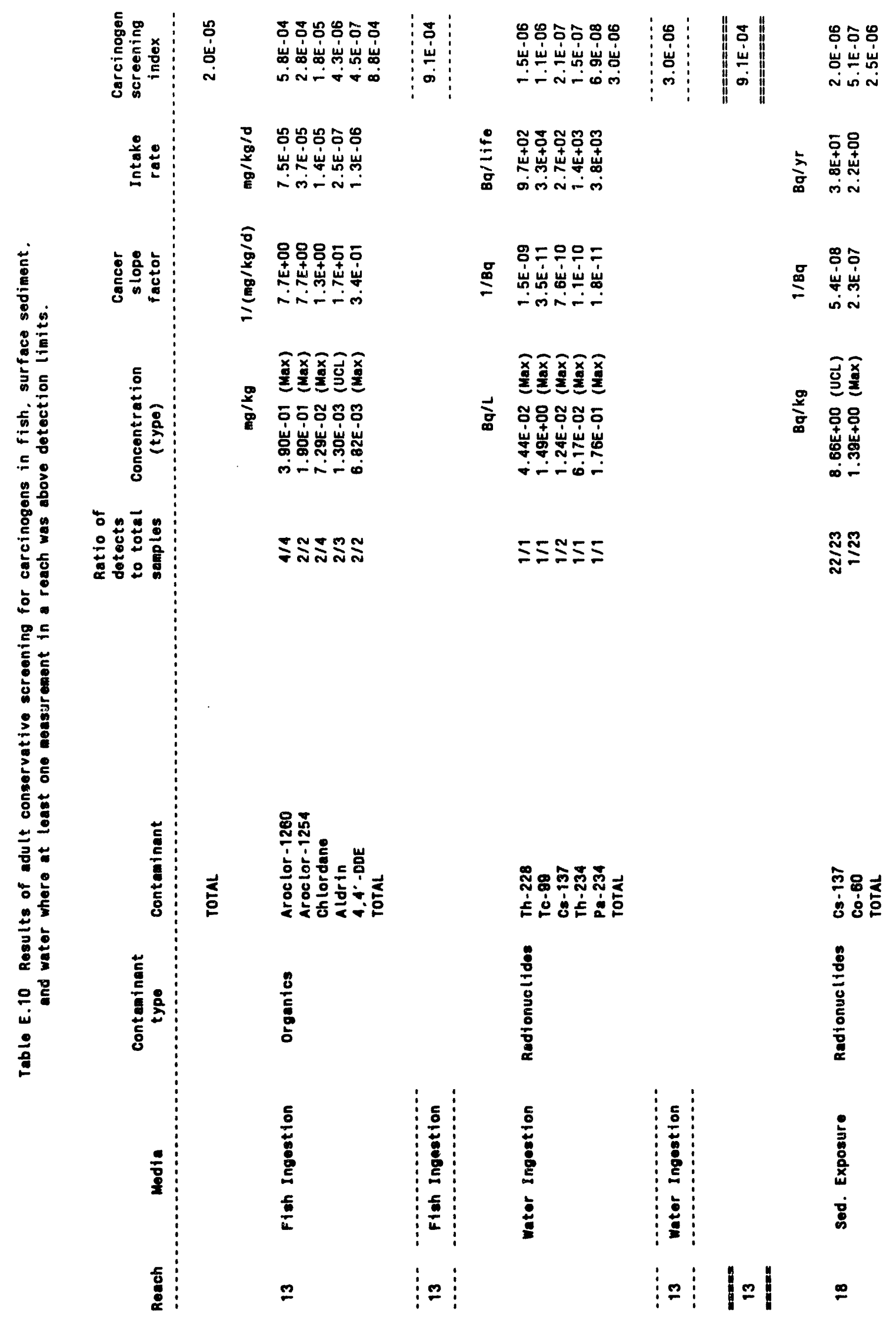


E-59

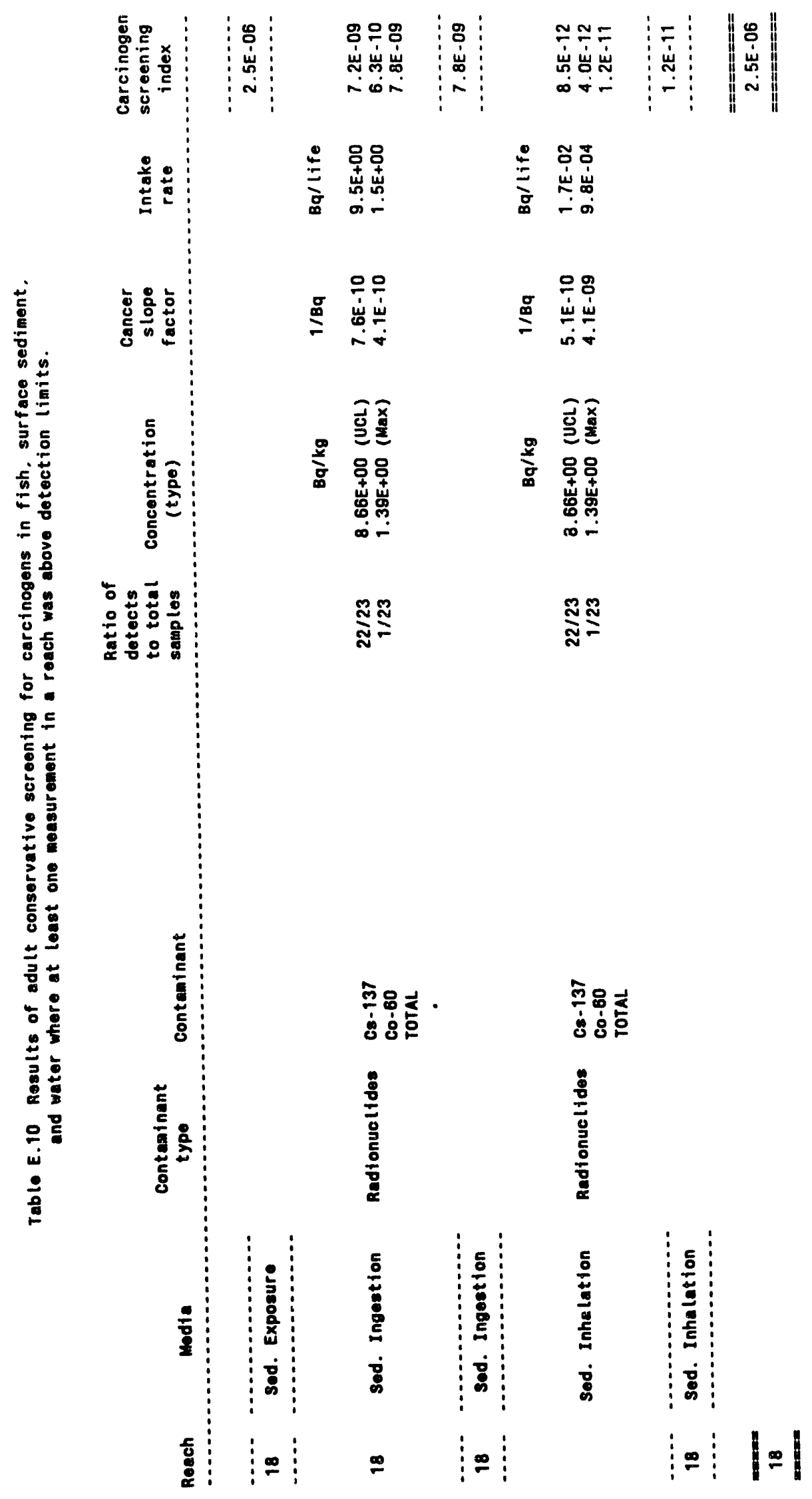


E-60

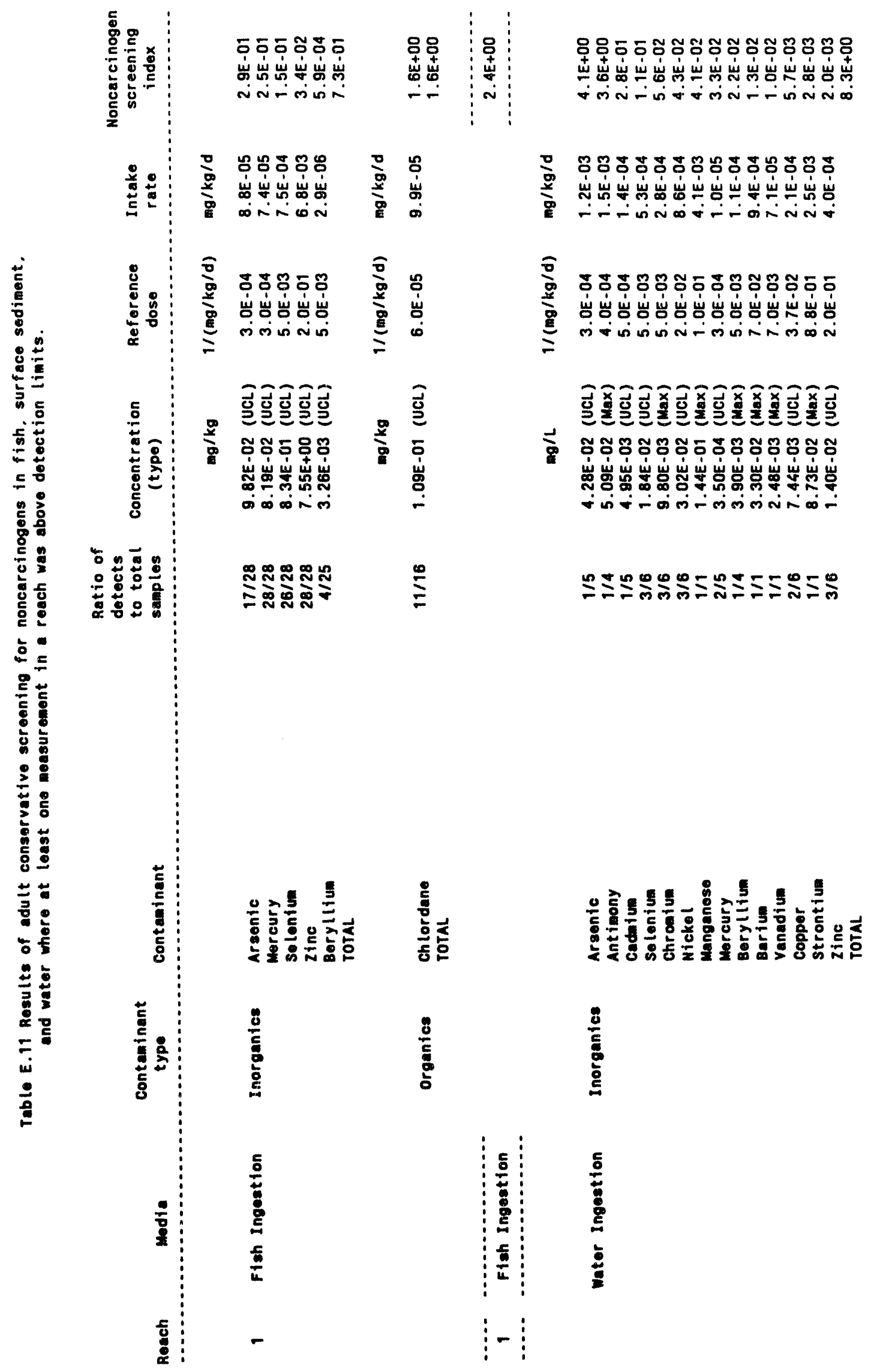




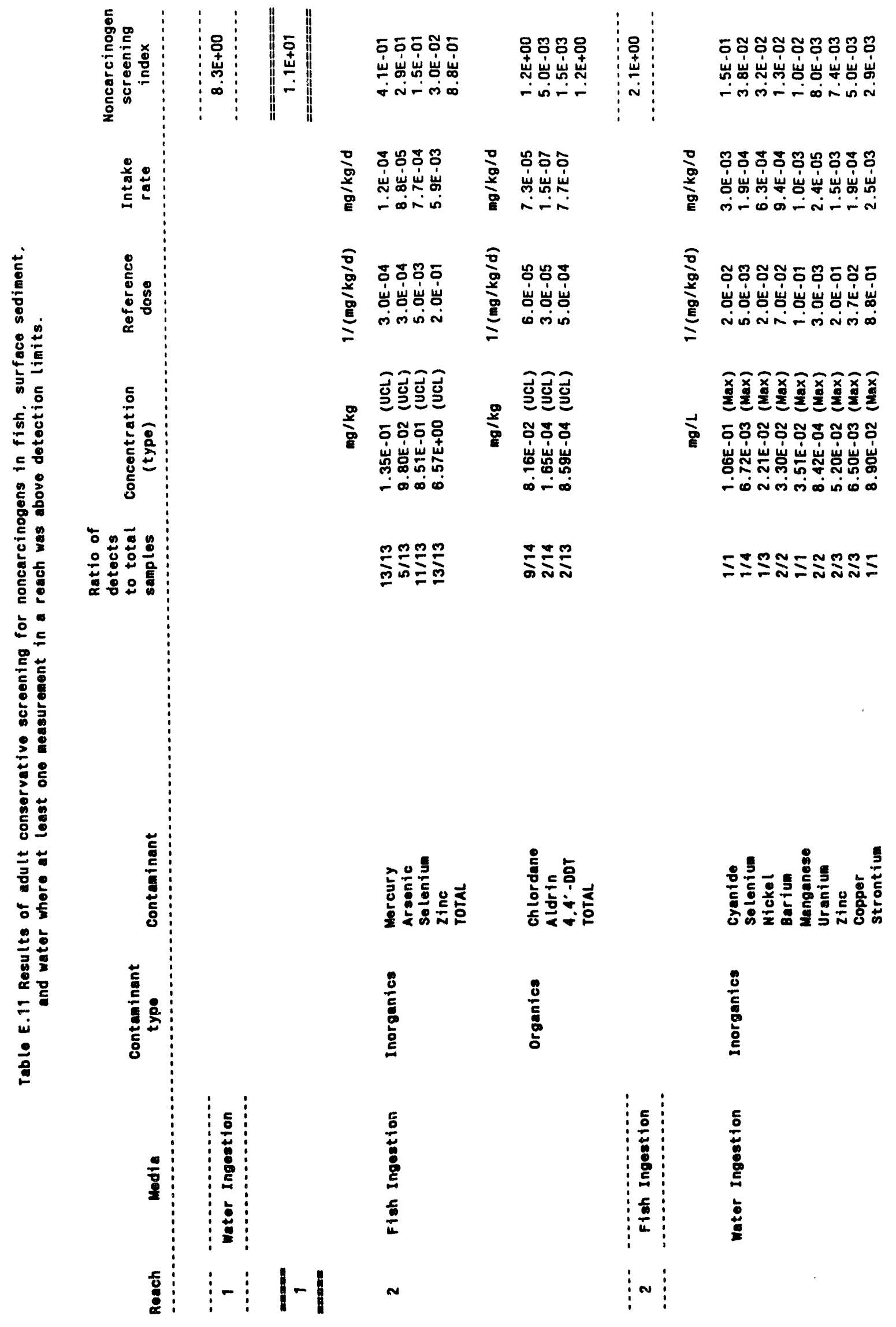


E-62

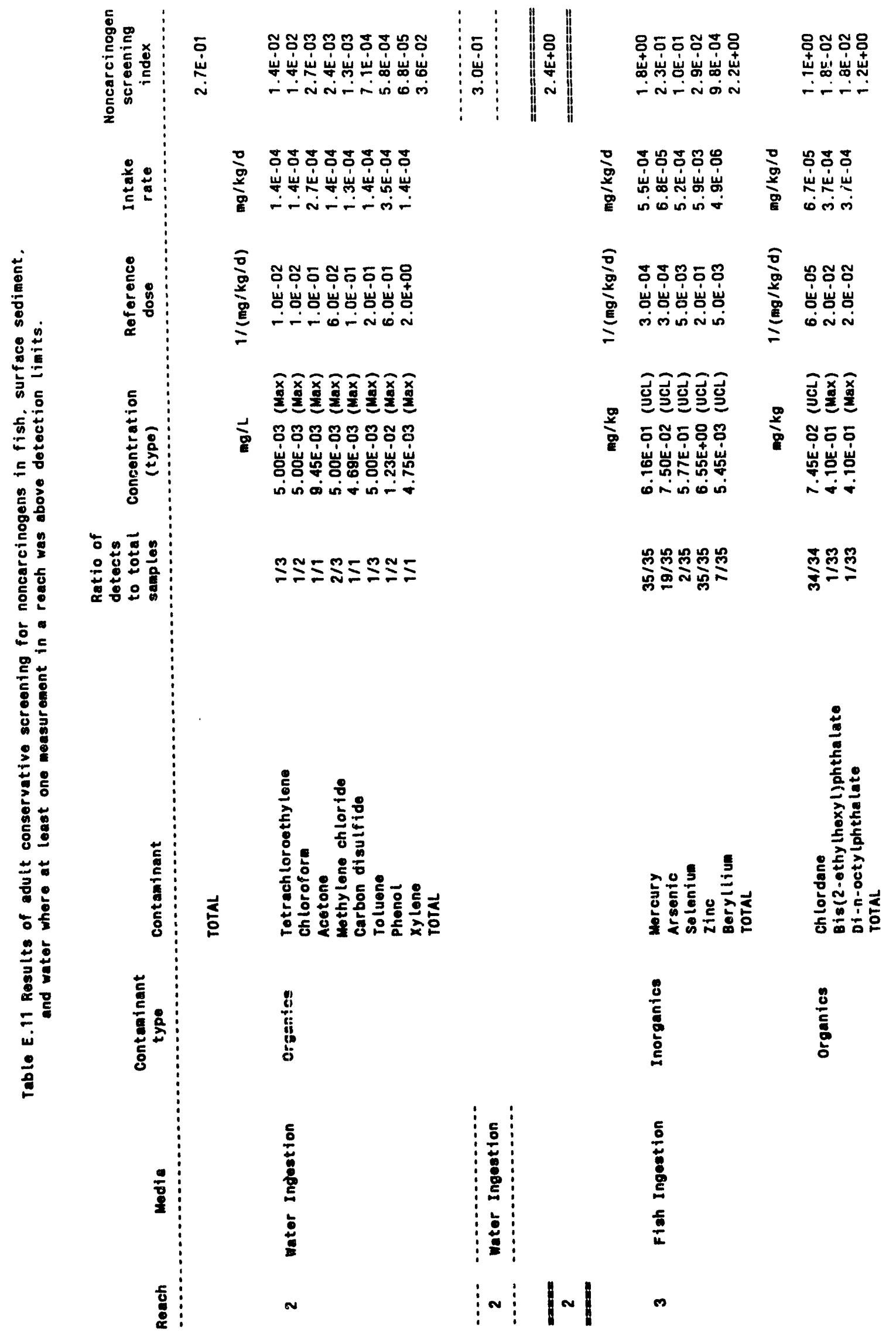




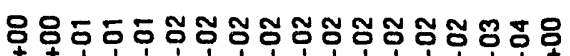

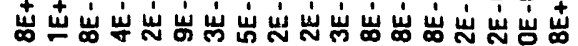

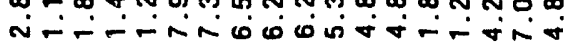

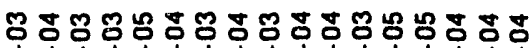

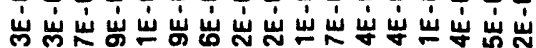

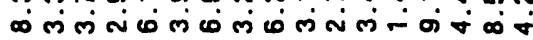

亩

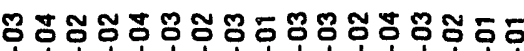

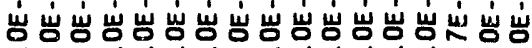

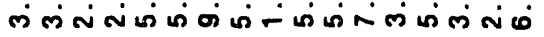

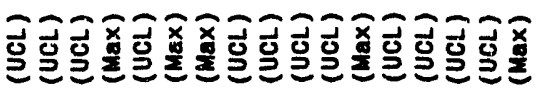
范

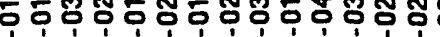

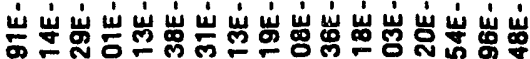
N- -

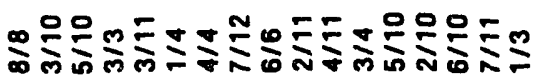

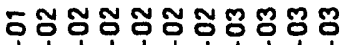

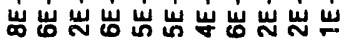

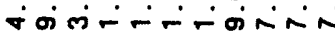

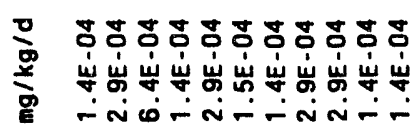

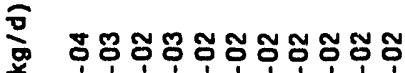

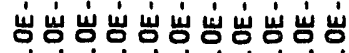

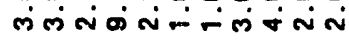

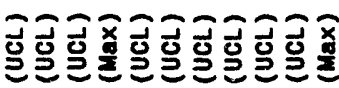

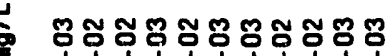

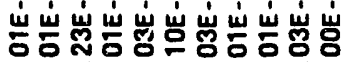

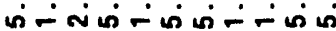

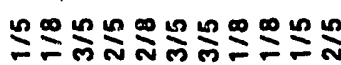

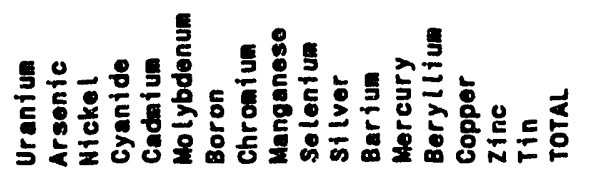

$\frac{8}{5}$<smiles>C#CCOCC#C</smiles>

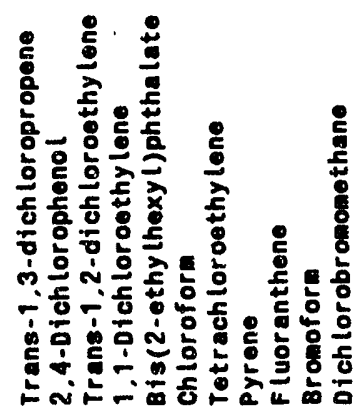




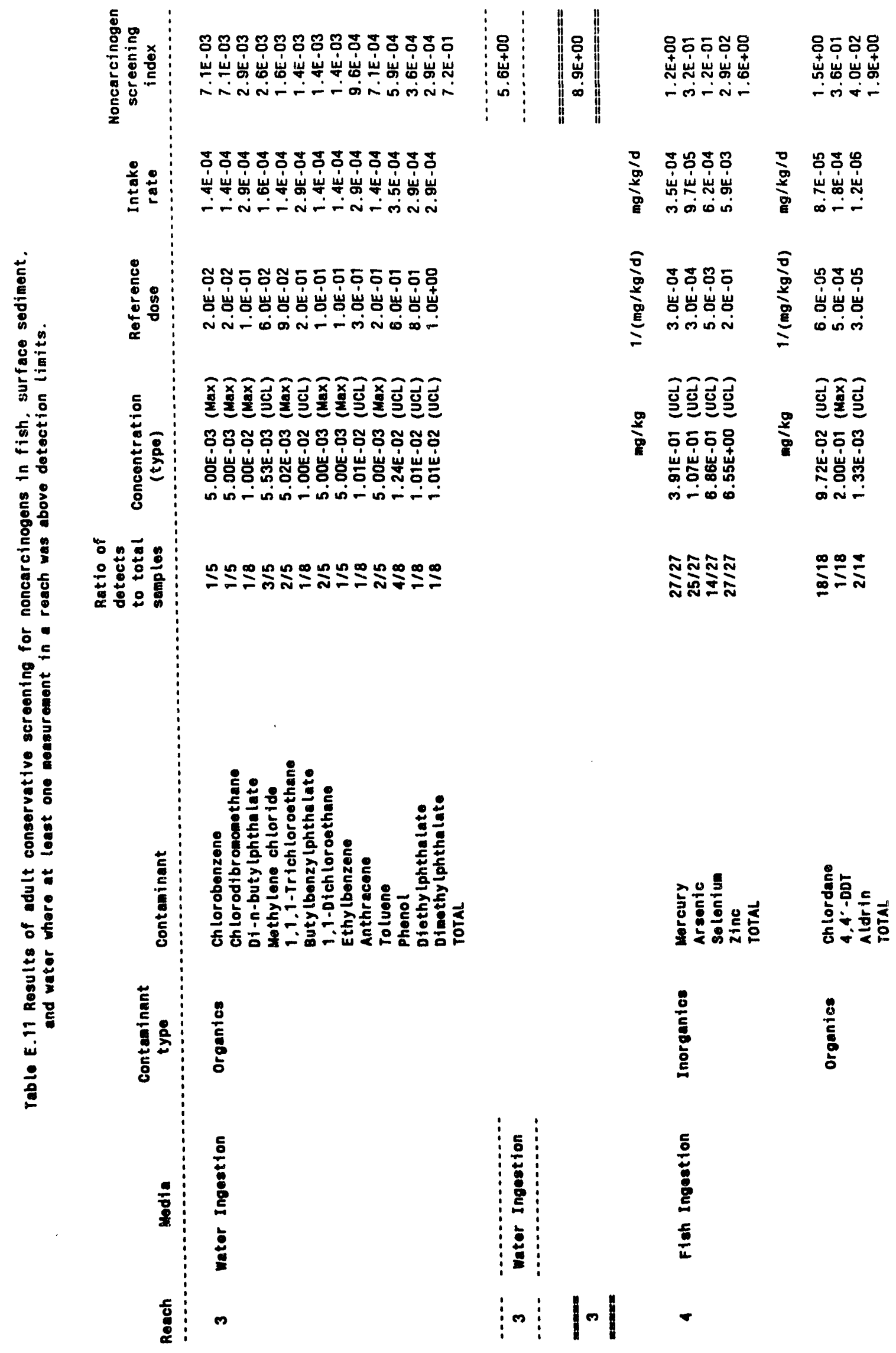


E-65

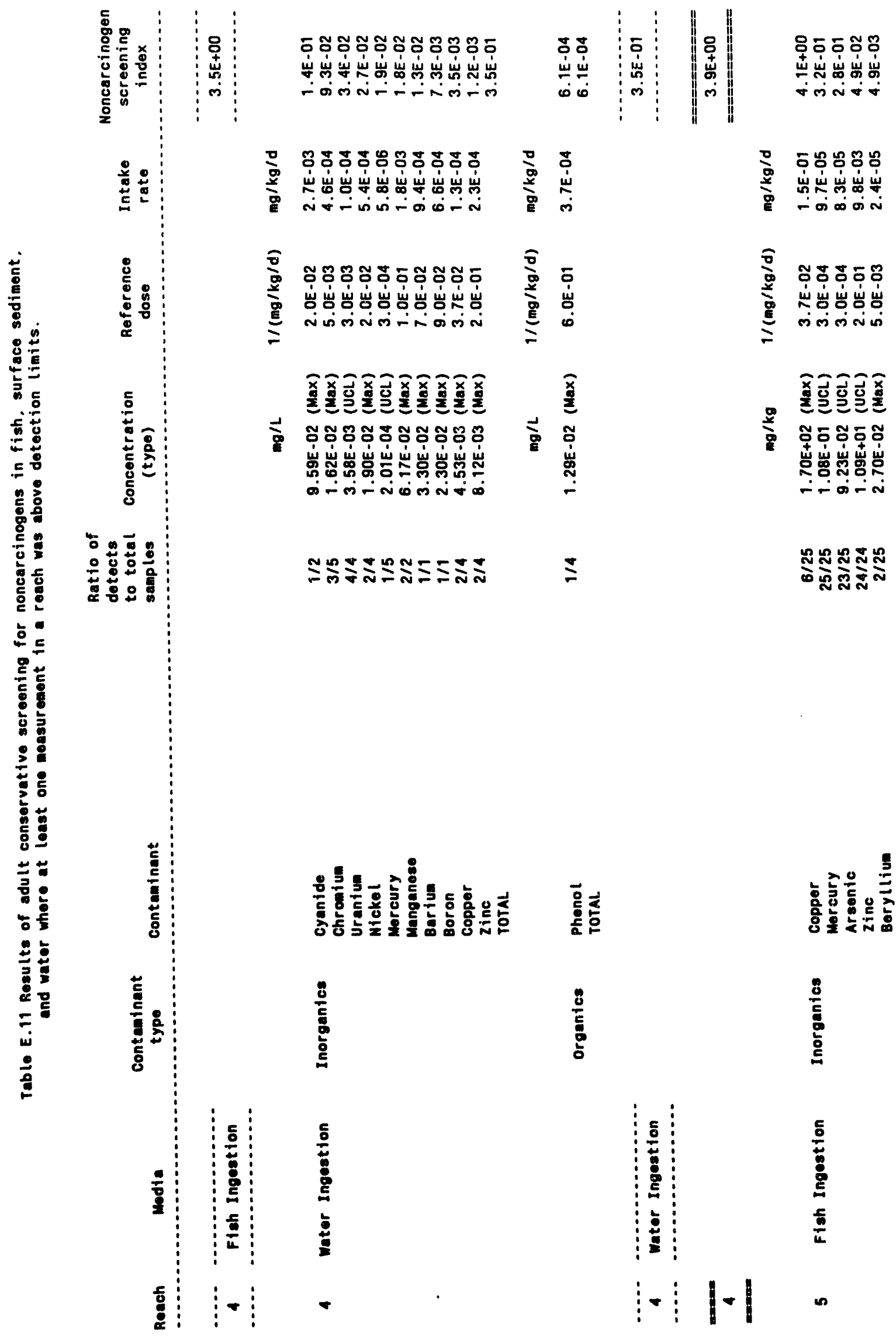




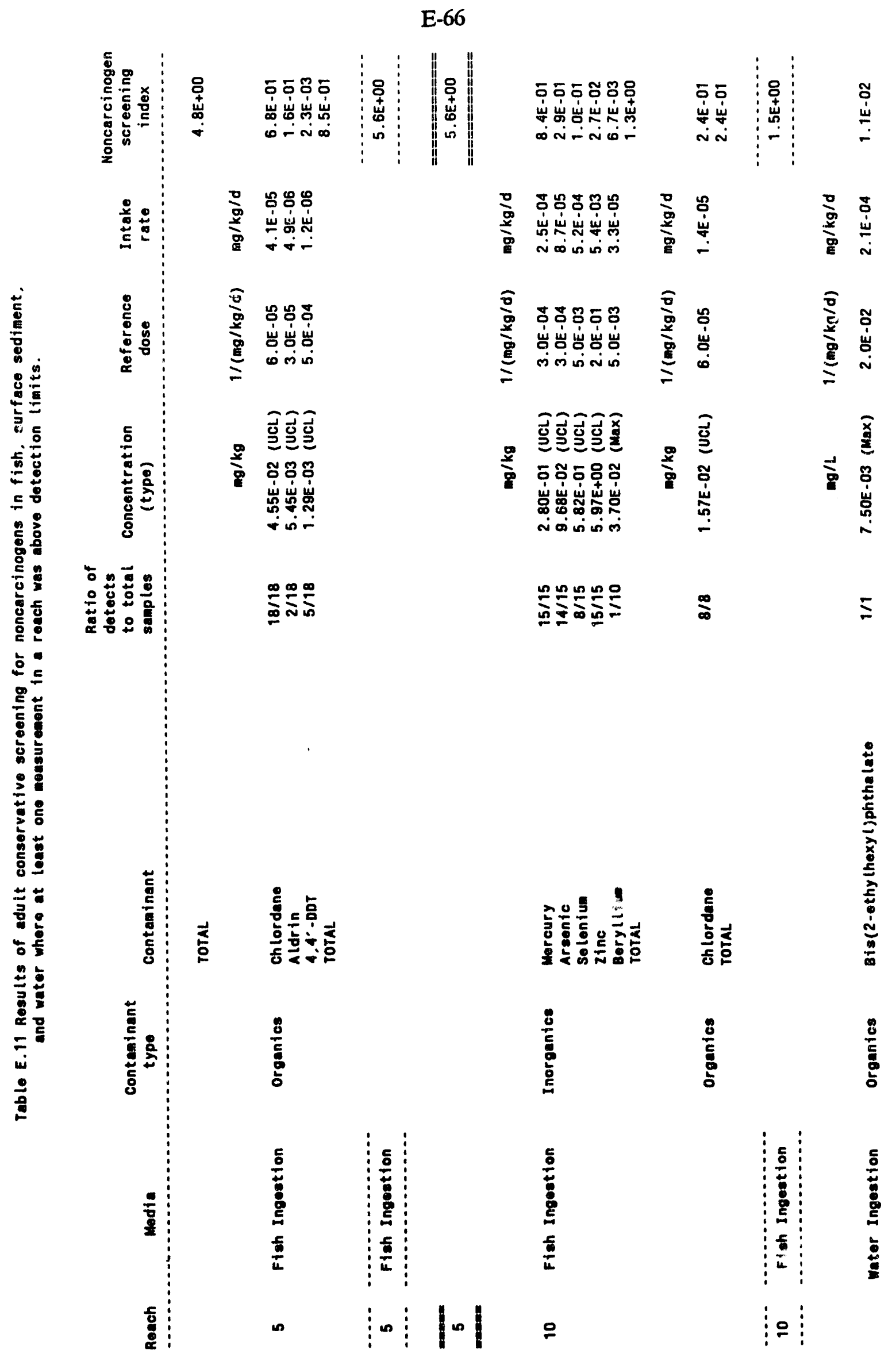




\section{E-67}

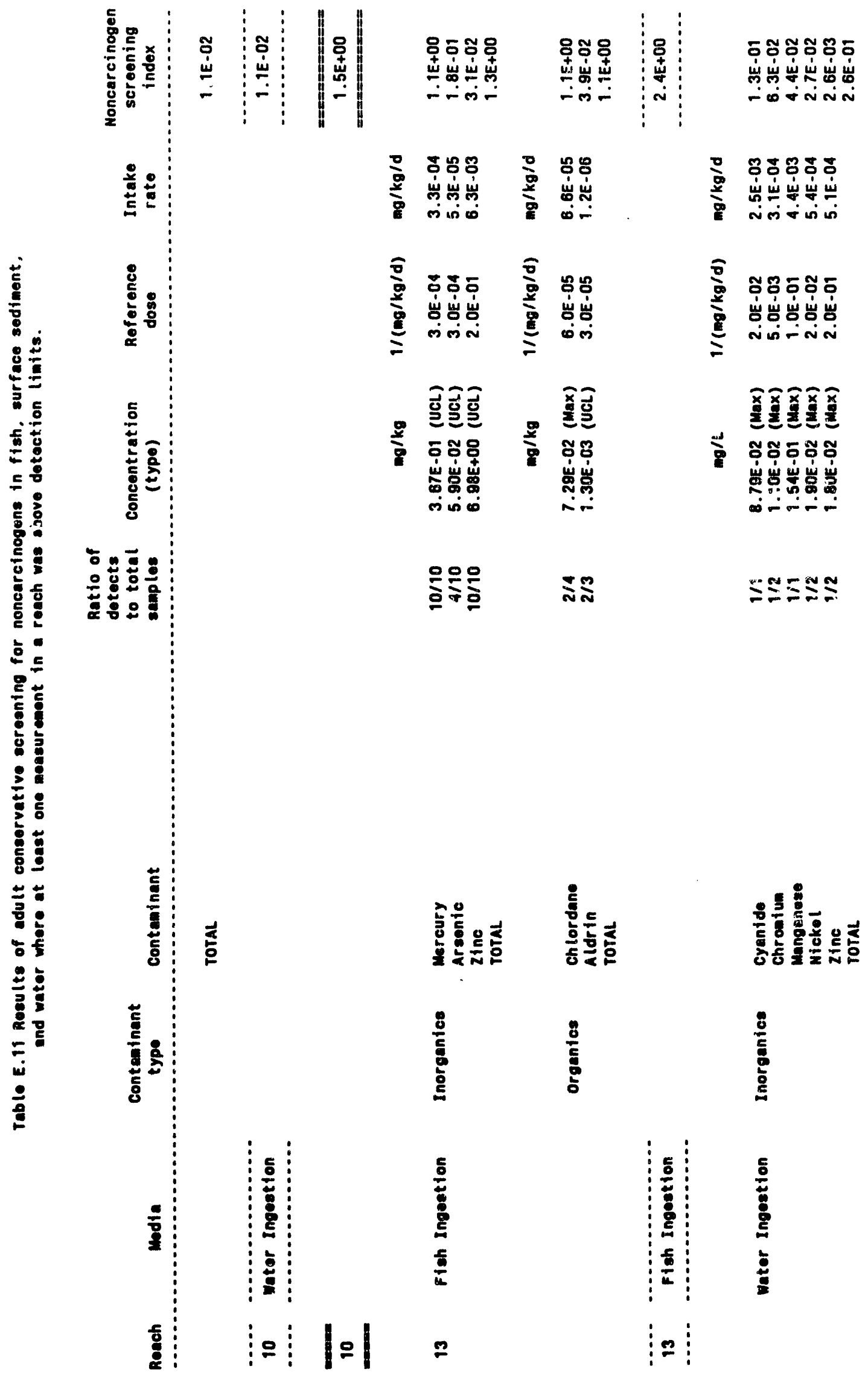


E-68

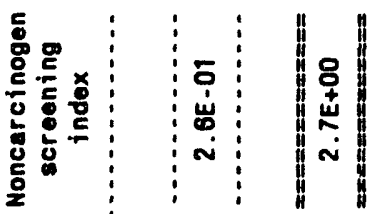

:

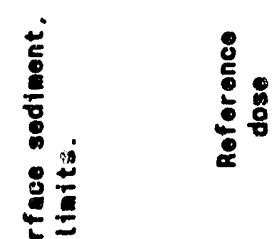

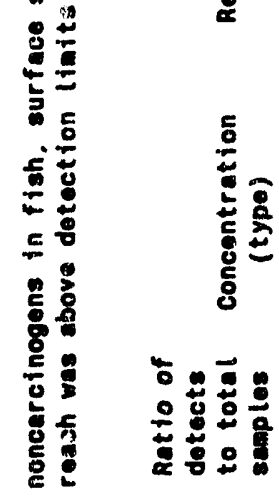

돈

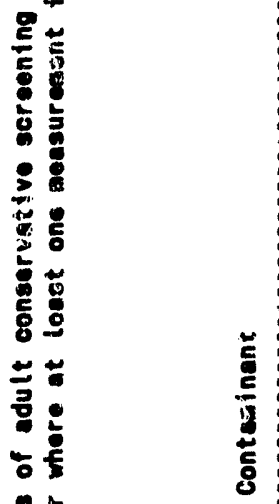

:

:

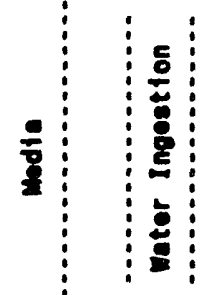

I : $: 1$ 


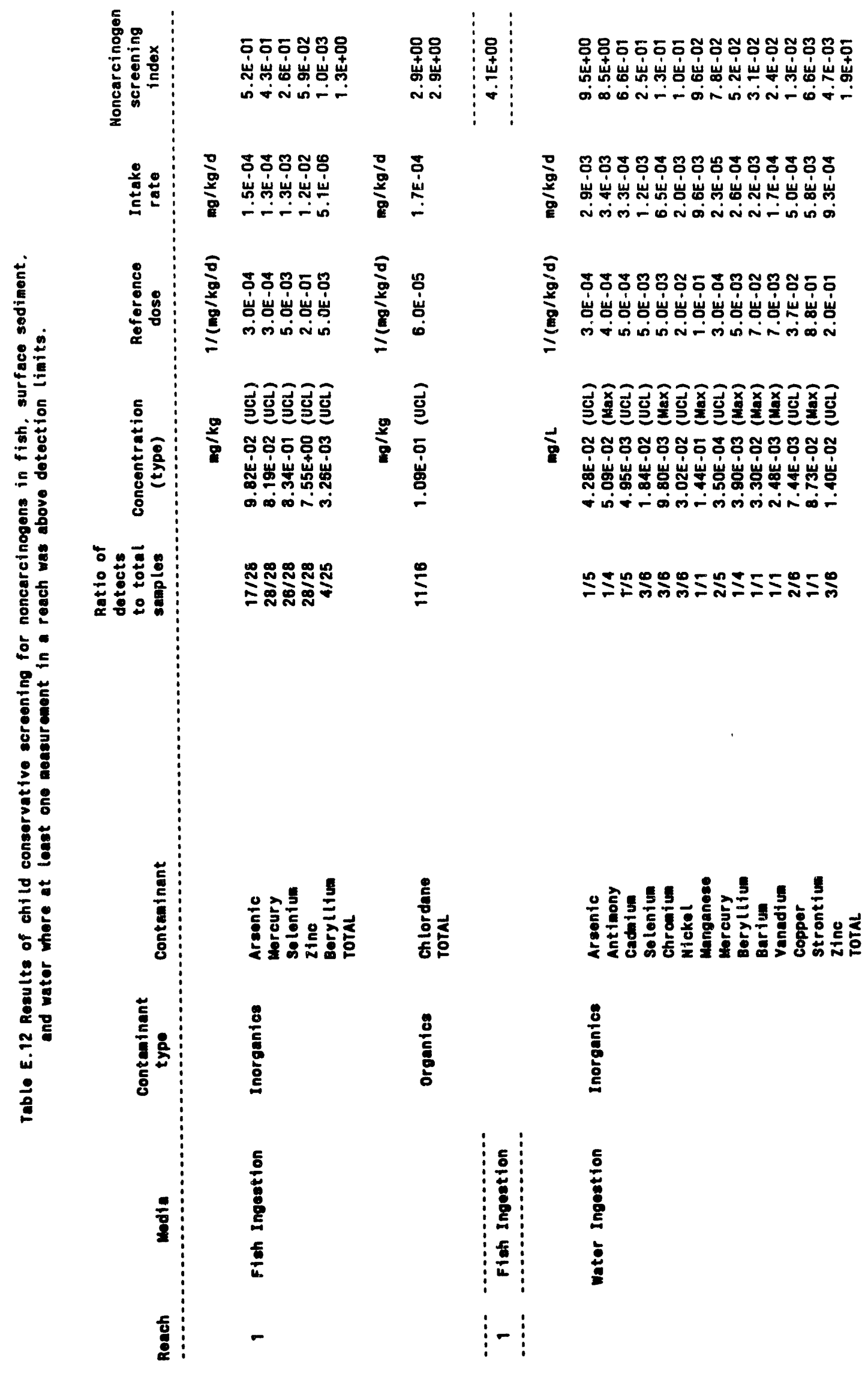




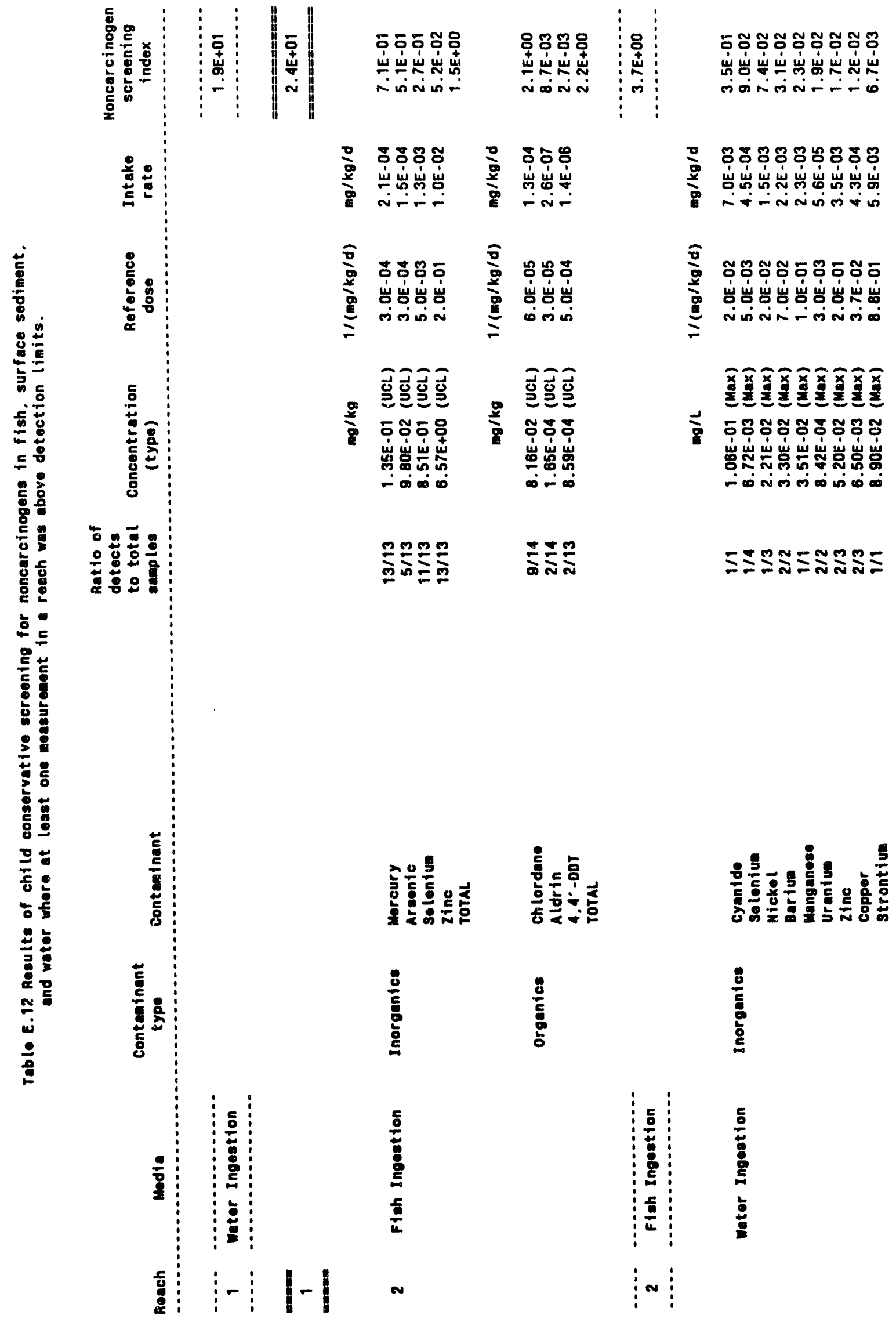


E-71

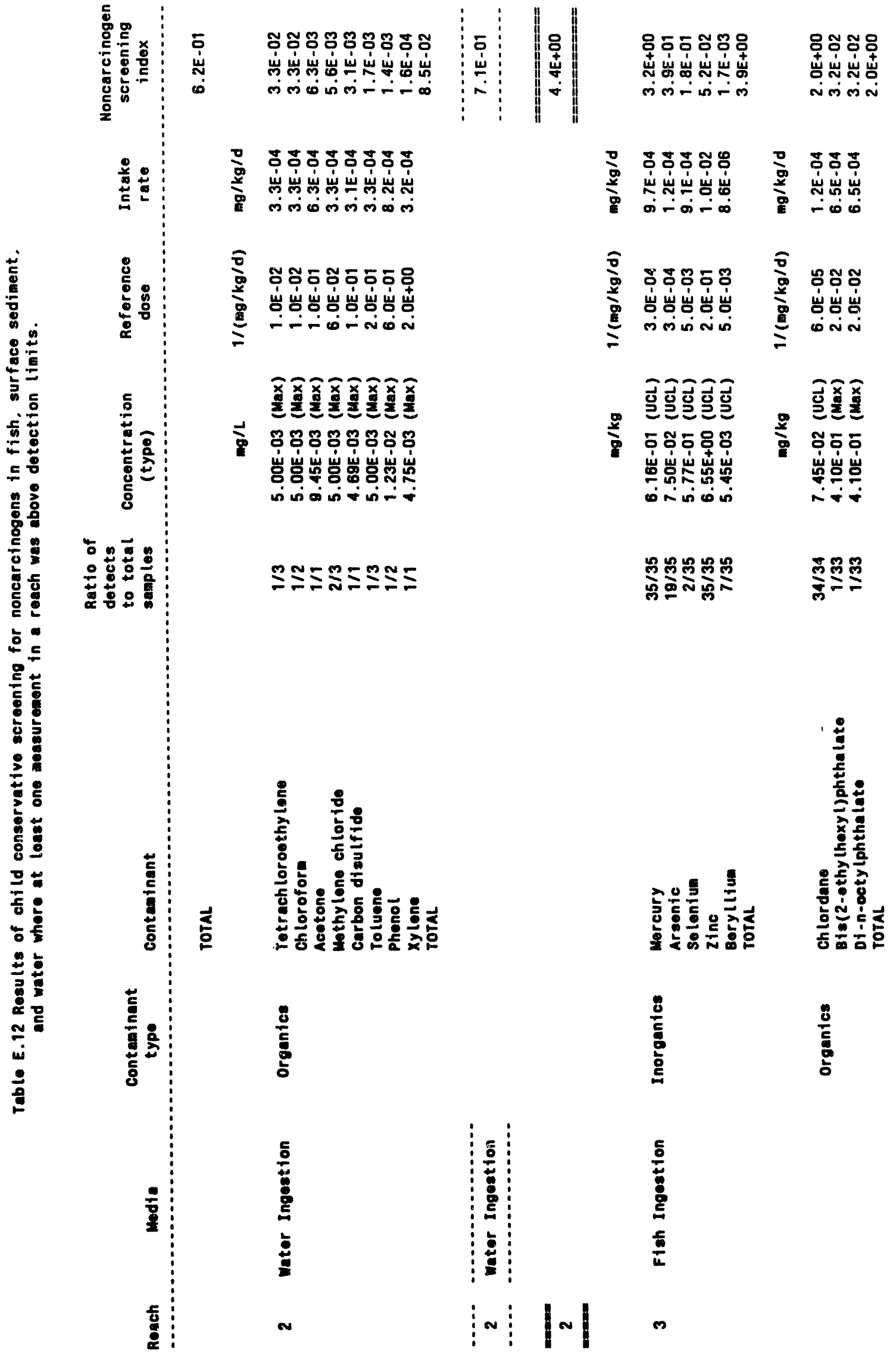




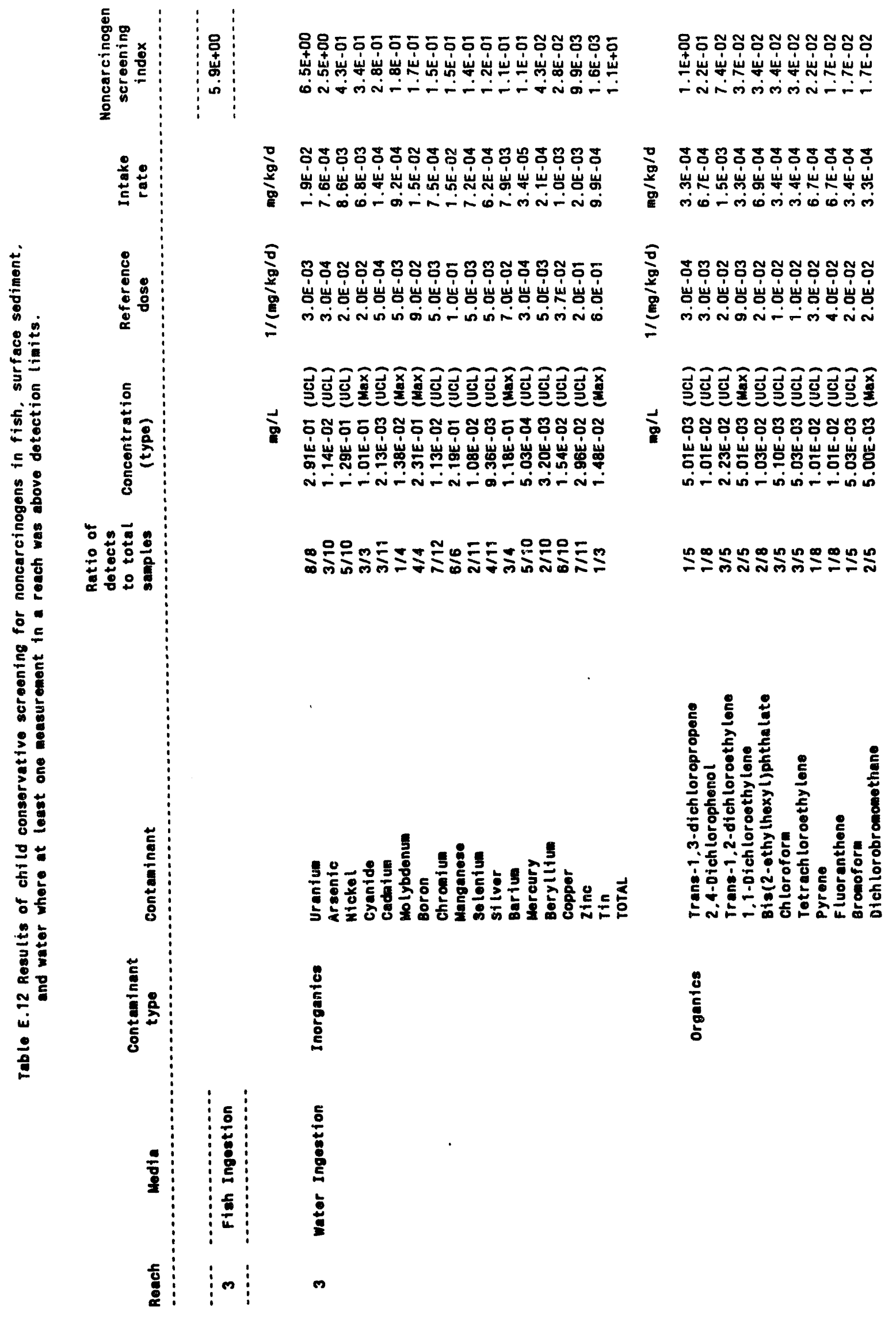


E-73

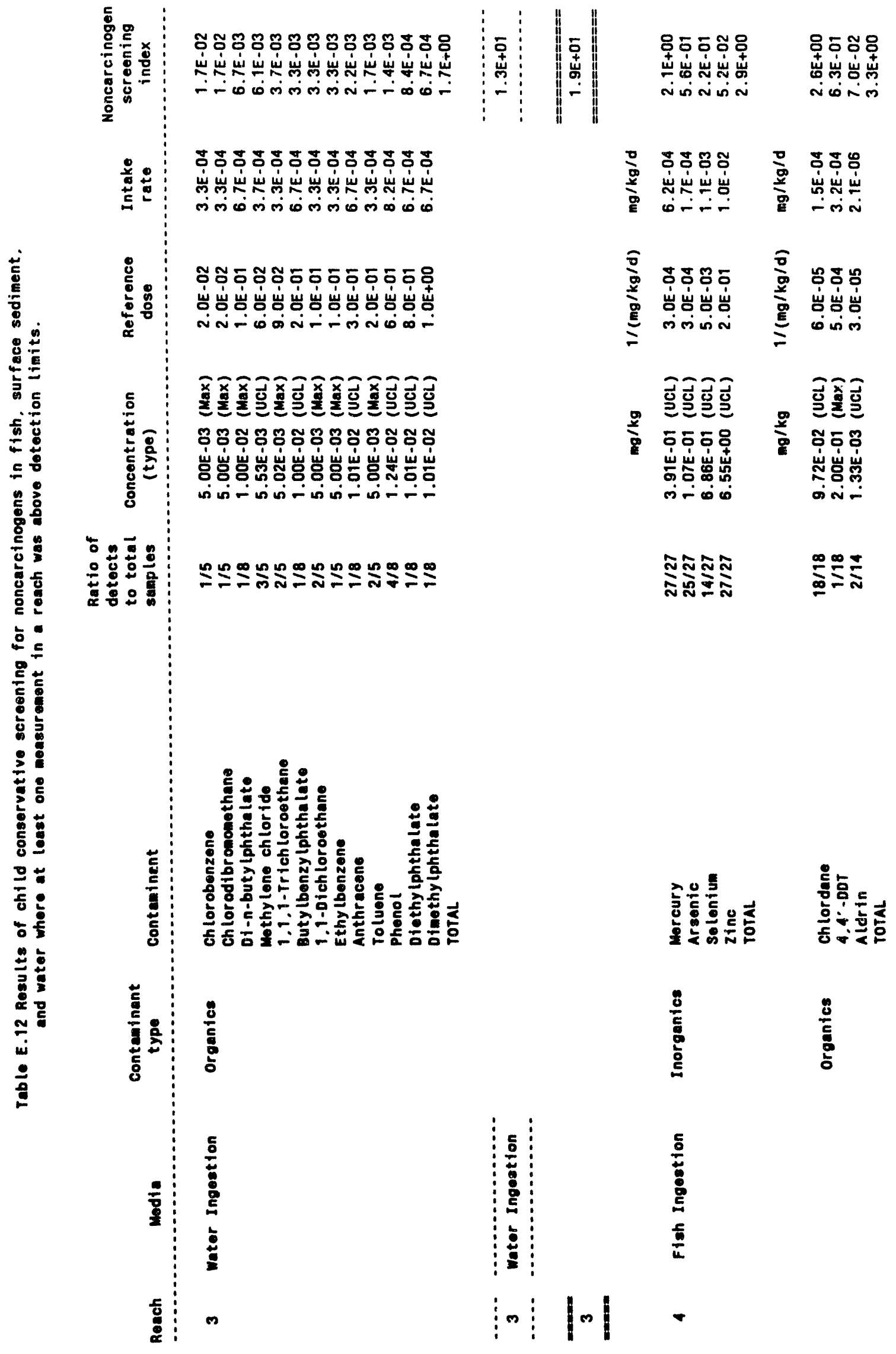




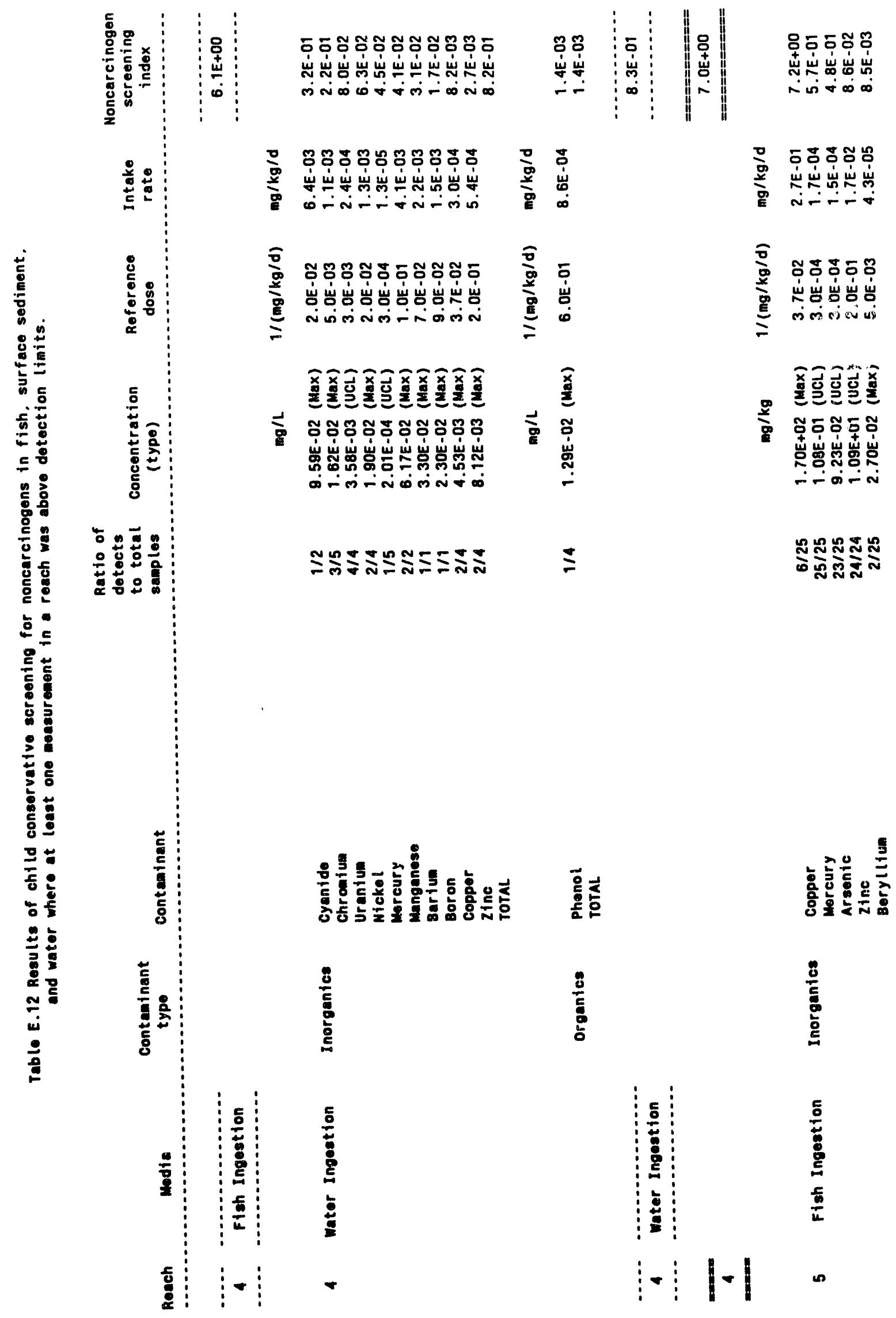


E-75

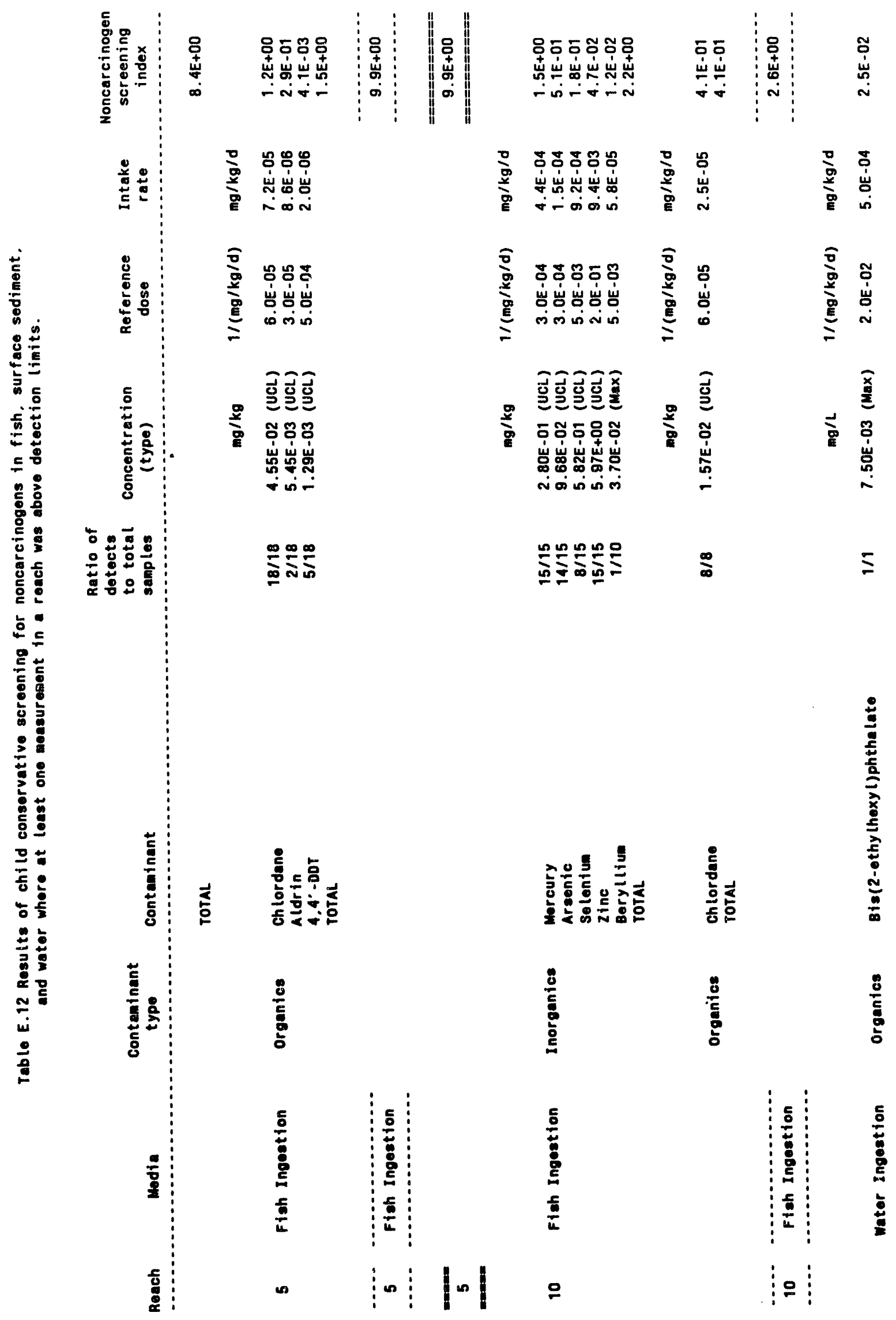


E-76

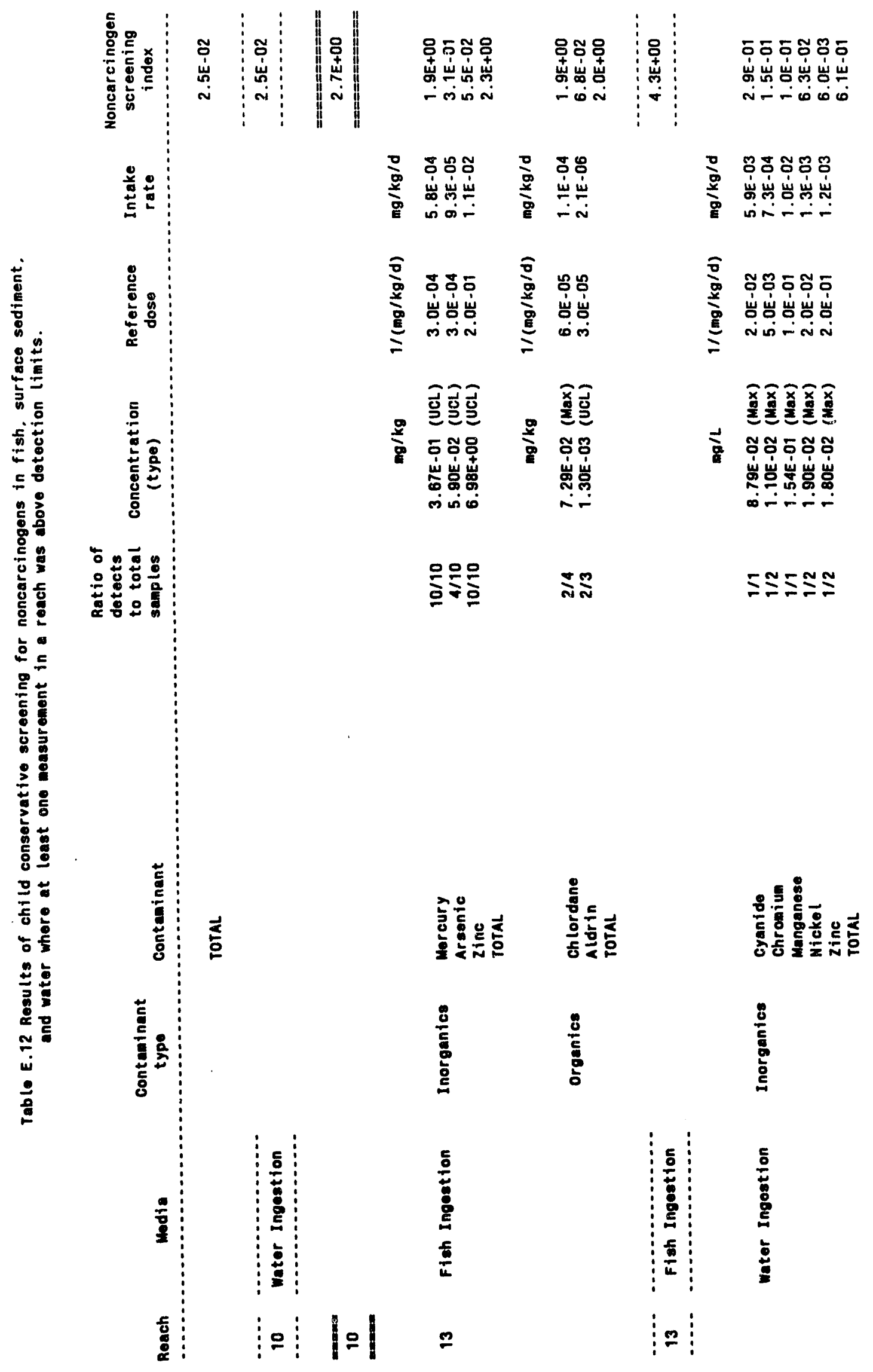


E-77

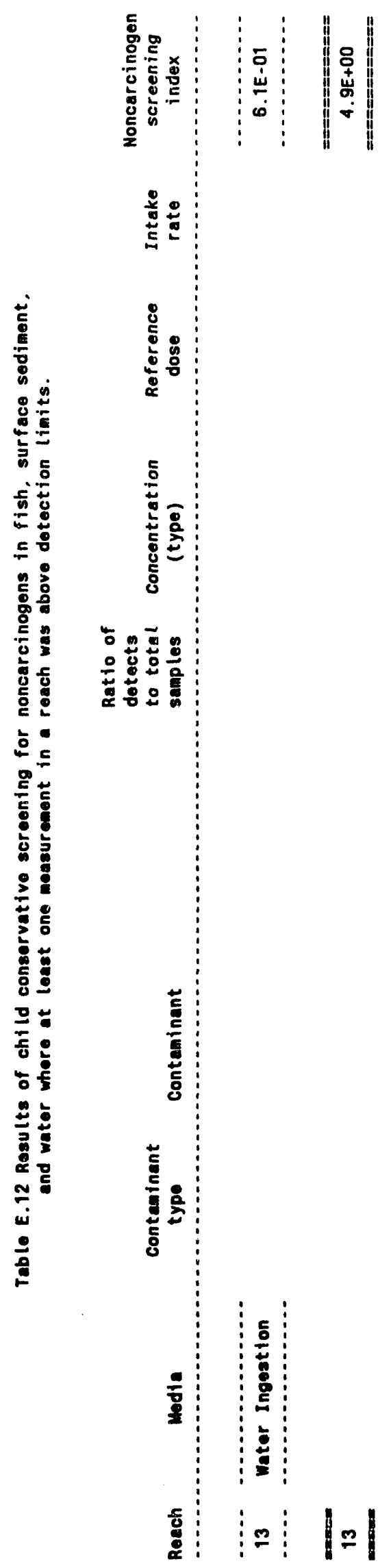


E-78

\begin{tabular}{|c|c|c|c|c|c|c|}
\hline 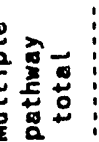 & 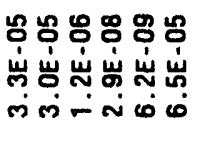 & 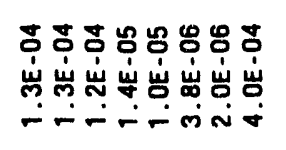 & 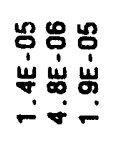 & $\mid \begin{array}{c}0 \\
\vdots \\
\dot{w} \\
\dot{\sigma} \\
\dot{\sigma}\end{array}$ & 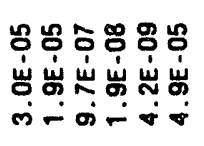 & 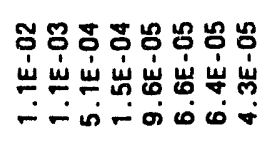 \\
\hline 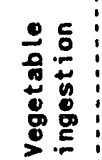 & 究号 & 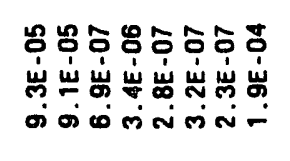 & 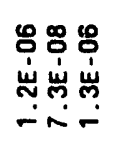 & $\left|\begin{array}{c}0 \\
0 \\
w \\
n \\
n\end{array}\right|$ & 范 & 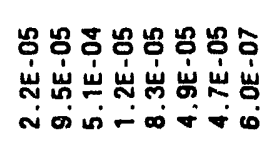 \\
\hline 产 & 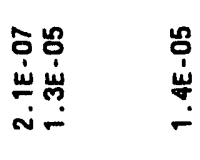 & 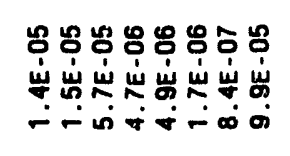 & 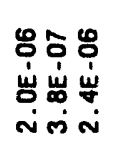 & 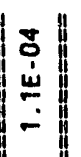 & 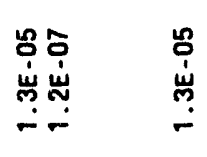 & 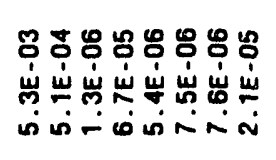 \\
\hline 旁总 & 萬 & 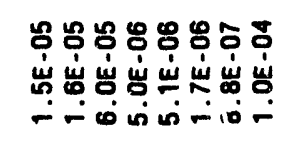 & 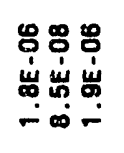 & 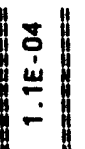 & 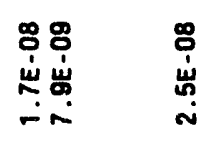 & 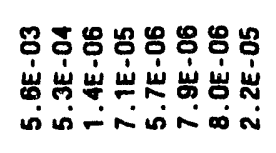 \\
\hline 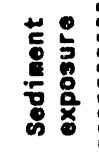 & & & 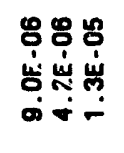 & $\mid$ & & \\
\hline 象 & 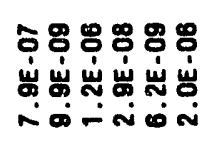 & 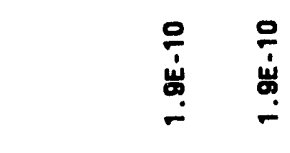 & 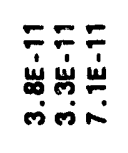 & $\mid$ & 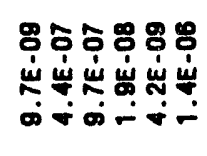 & 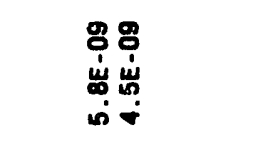 \\
\hline & ن & 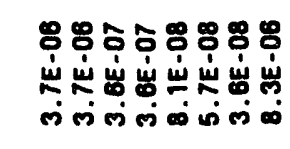 & 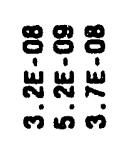 & 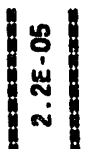 & 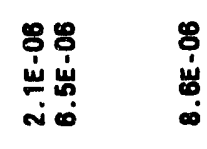 & 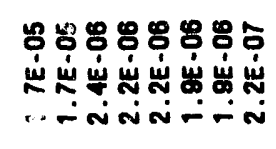 \\
\hline
\end{tabular}

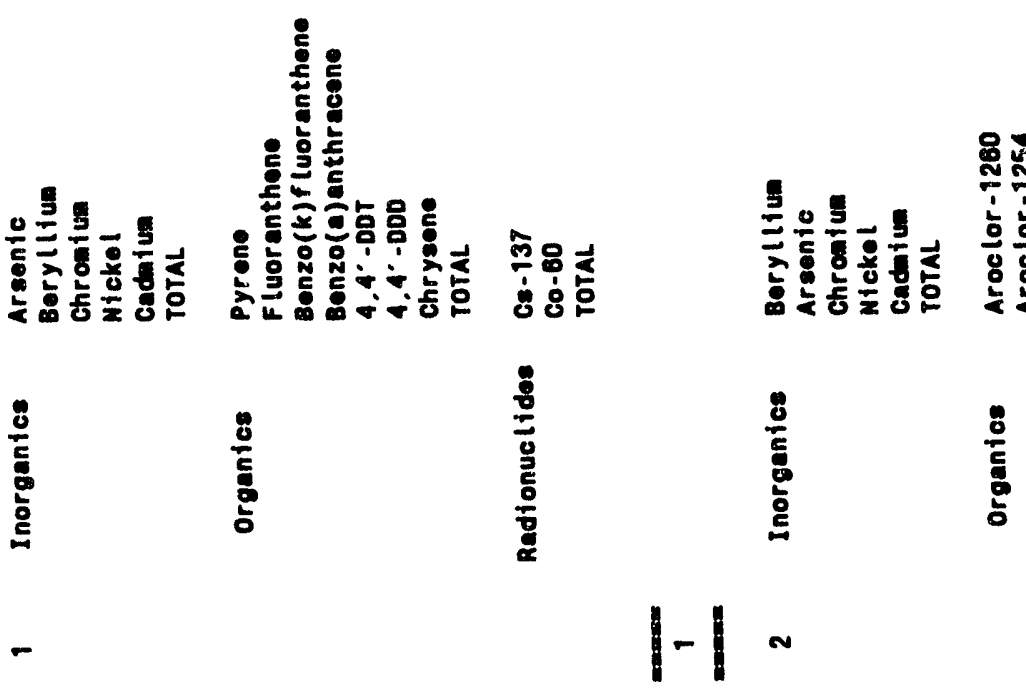




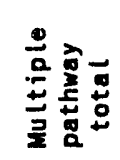

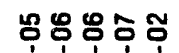

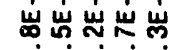

我穴-

\section{ㅇํㅇํํㅇํㅇ}

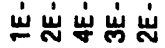

$\because \dot{\sim}-\infty$

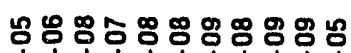

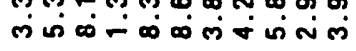

옹ํํ웅

岁㟔岕岩岁

क in in in

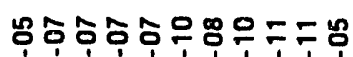

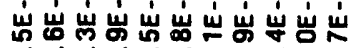

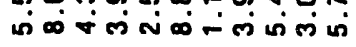

웅요용

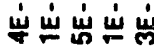

को का कित

.

8.

高

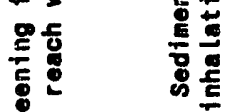

突这

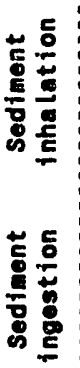

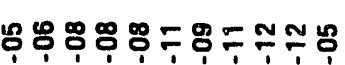

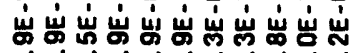

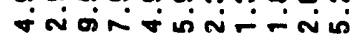

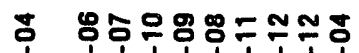

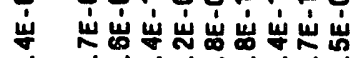

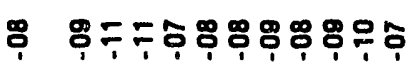

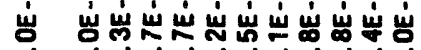

훙ํㅇㅇㅇㅇㅇㅇㅇㅇ

嵌岕㟧㟧

vinis:

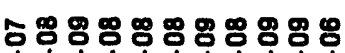

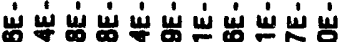

काषित

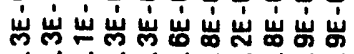

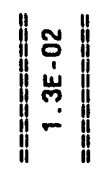

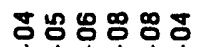

峛岕岕岁岕岁

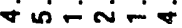

$\left\|\begin{array}{c} \pm \\ \dot{c} \\ \dot{u} \\ 0 \\ \infty\end{array}\right\|$

प্口

㟧

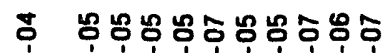

in

$\| \begin{aligned} & 0 \\ & 1 \\ & 1 \\ & 0 \\ & 0\end{aligned}$

04

㟧飠

i

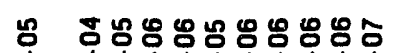

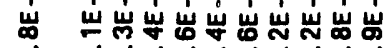

Na

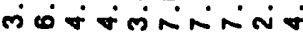

$\left\|\begin{array}{l}0 \\ \dot{u} \\ 0 \\ 0\end{array}\right\|$

ธơ

岗 岁

-

$\| \begin{aligned} & 0 \\ & \vdots \\ & \omega \\ & 心\end{aligned}$

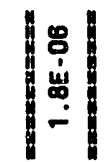

농

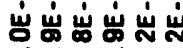

ㅁำ

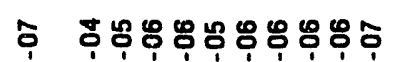

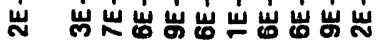

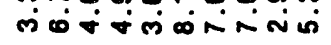

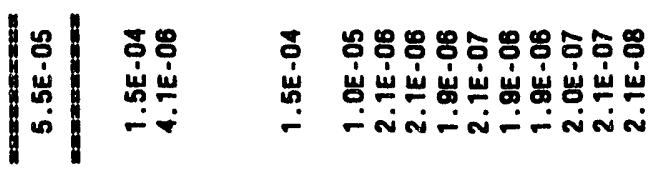

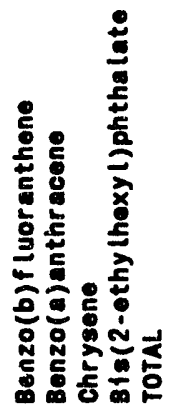

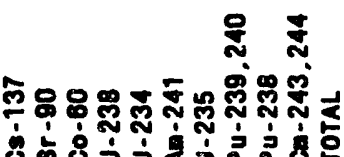

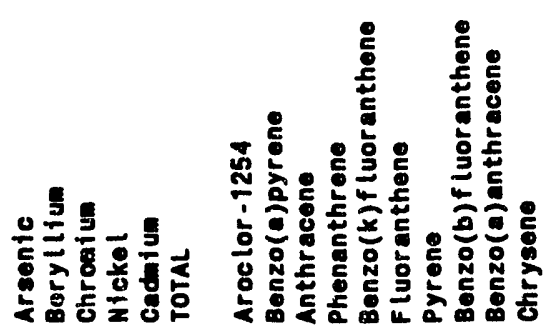

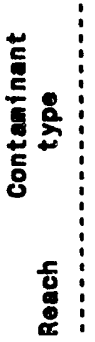

$\frac{8}{0}$

$\frac{8}{5}$

$\frac{8}{5}$

N

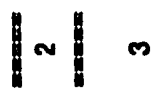




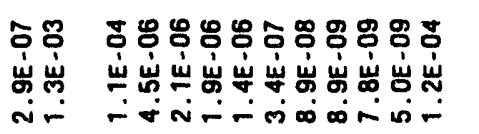

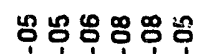

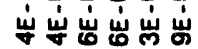

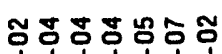

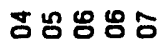

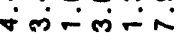

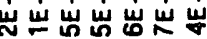

嵌岁岕岕

$\infty-\infty-\infty$

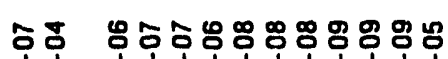

$\left\|\begin{array}{c}z \\ \vdots \\ \dot{u} \\ 0\end{array}\right\|$

草

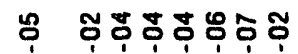

ํㅗㅇำธำล

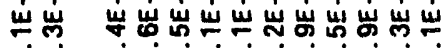

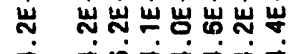

㟧岗岁㟧㟧

八

$\| \begin{gathered}\square \\ \dot{1} \\ \dot{\alpha} \\ \dot{\sigma} \|\end{gathered}$

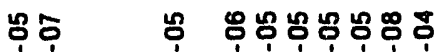

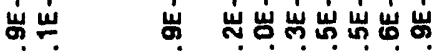

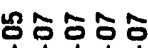

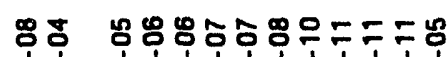

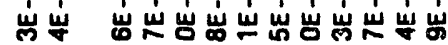

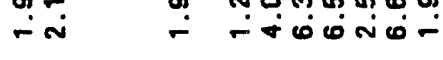

岁岕出岩㟧

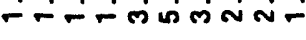

$\| \begin{aligned} & \square \\ & \vdots \\ & \dot{u} \\ & 0 \\ & \dot{\sigma}\end{aligned}$

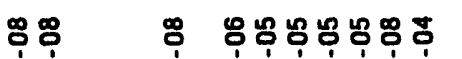

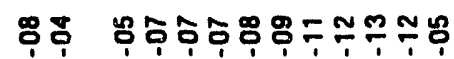

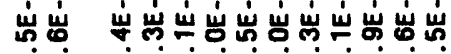

-

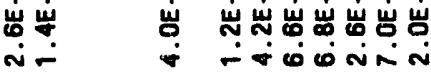

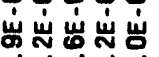

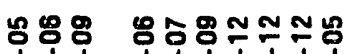

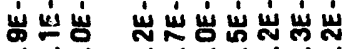

$\| \stackrel{0}{0}$

동ㅇㅇ

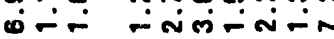

岁.

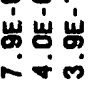

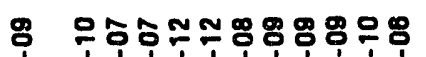

站

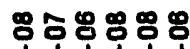

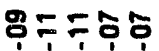

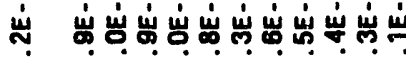

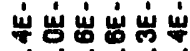

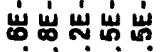

용 क्ष

तरिंक का

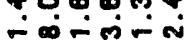

○这-

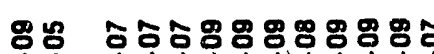

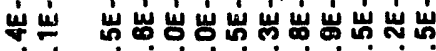

文

오옹

แㅃํ

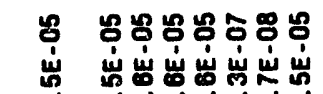

웅웅웅

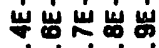

$\infty$ i

i-

iा -

-

- - is is क

主

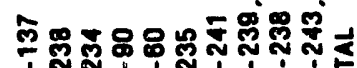

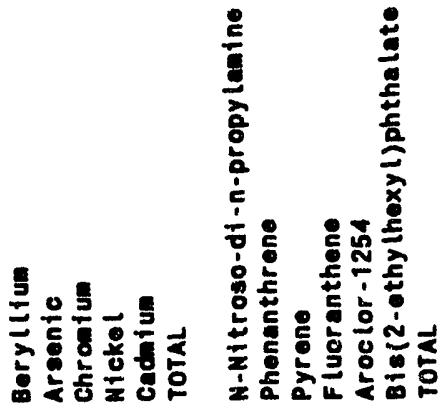

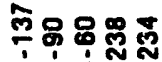

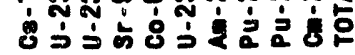

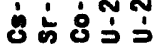

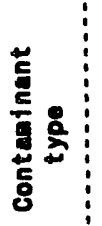

$\frac{8}{8}$

$\stackrel{8}{:}$

$\frac{8}{6}$

을

둥
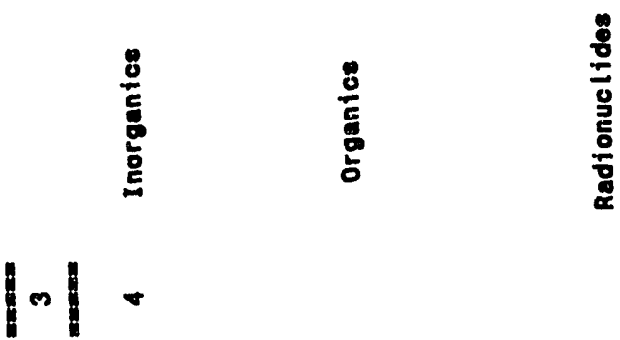


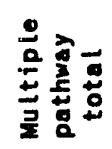

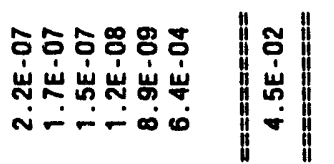

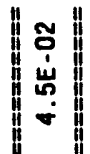

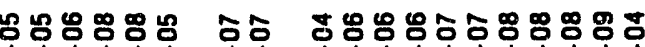

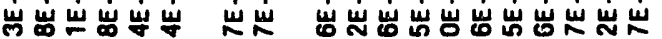

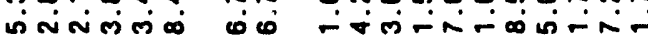

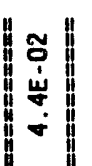

옹우으융

$\mid$
48

岁悹

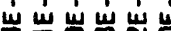

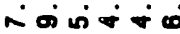

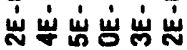

तिकाषण

|c|

농ำ

岗免

i -

$g=\mp \div \simeq \&$

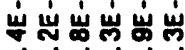

|

曲

崖嵌

लि-

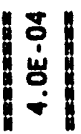

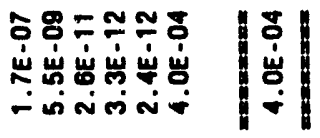

영용용우웅

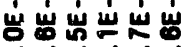

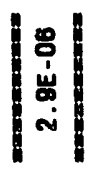

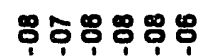

岕岕出㟧岩

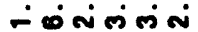

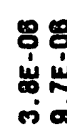

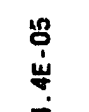

ồ

㐫岗

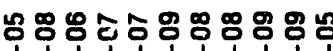

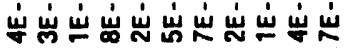

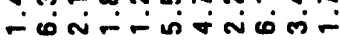

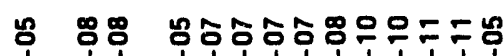

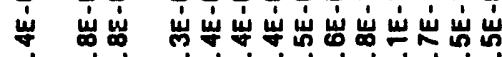

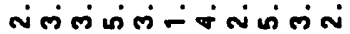

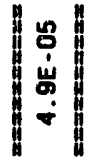

농

世ّ

N-

क-तiñ

$8 \% 88 \%$

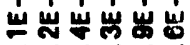

तis

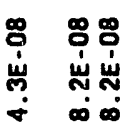

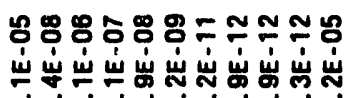

in

:

岕

N

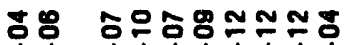

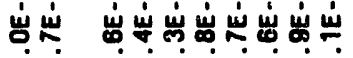

亭

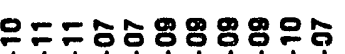

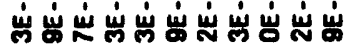

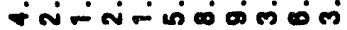
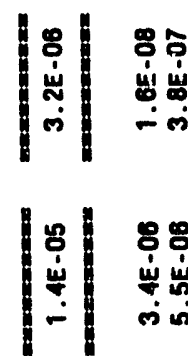

$8:$

岸㟧 is is
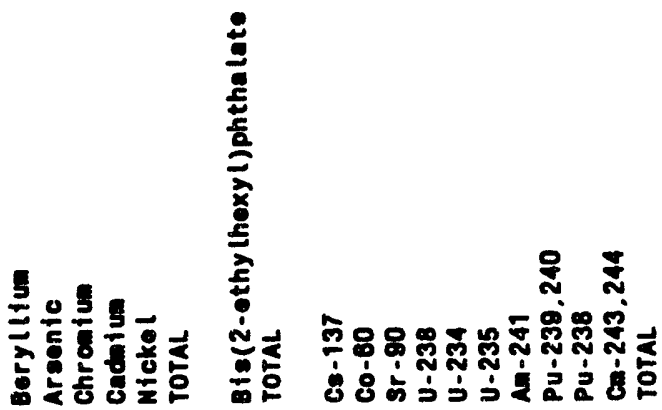

罗。

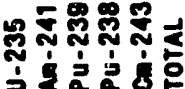

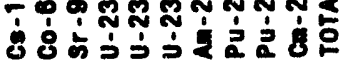

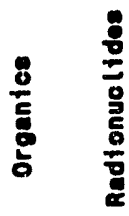

$\stackrel{8}{5}$

\begin{tabular}{l:c}
\hline \\
\hline 0
\end{tabular}

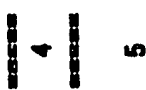

$\frac{8}{0}$

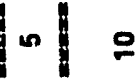




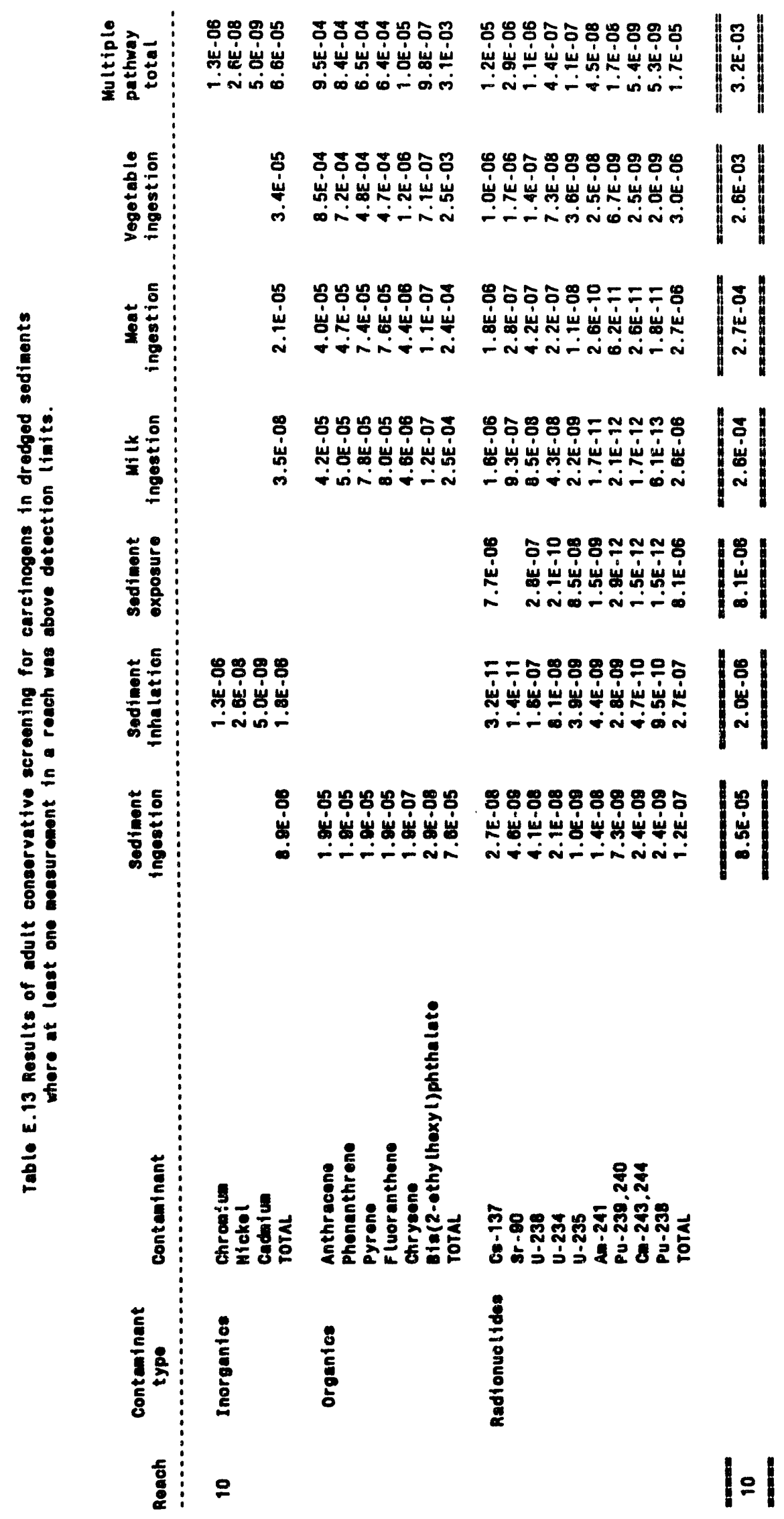




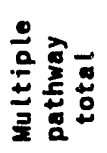

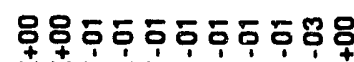

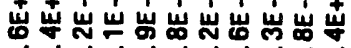

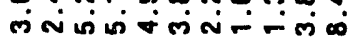

ธ무음 岁出岕出 -

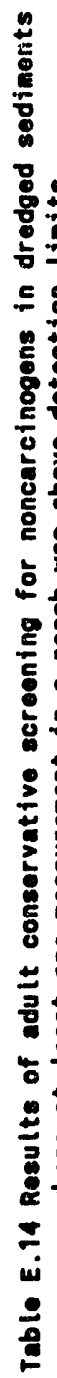

ธำธธธธธธธธุรั

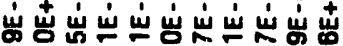

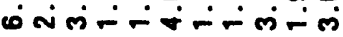

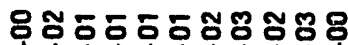

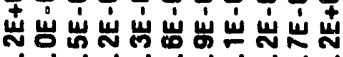

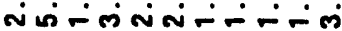
(1)

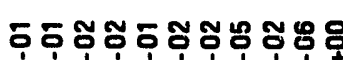

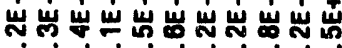

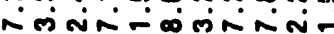<smiles>CC(C)C</smiles>

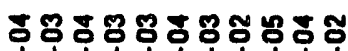

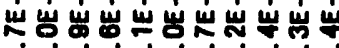

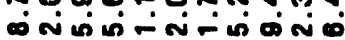

$\stackrel{\circ}{\stackrel{\leftrightarrow}{\sharp}}$
용요

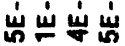
$\because-\infty 0^{\circ}$

ธัธธัธ 岕岗㟧岕 뚱

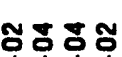
㟧嵌出 $\infty-\infty$

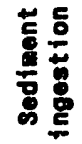

$88 \%$

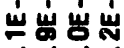

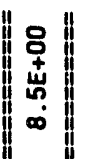

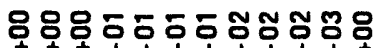

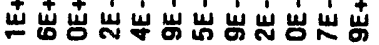

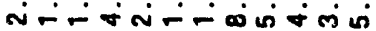

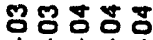
岁出出岩 N $-\infty$ i

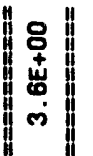

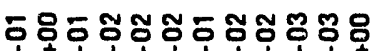

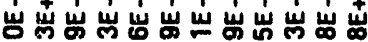
-

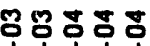
岁嵌岩岸岩 N- 0 i

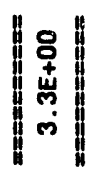

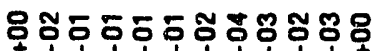

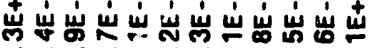

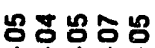

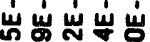

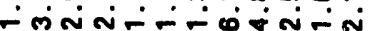
- काति

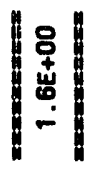

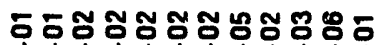

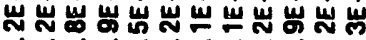

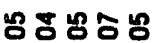
岁岁㤩岕嵌

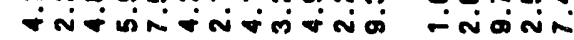

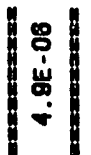

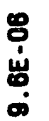

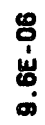

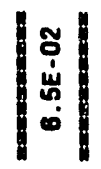

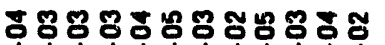

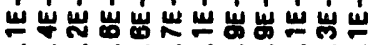

농용용홍ㅇㅇ

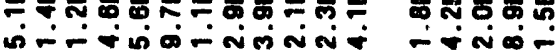

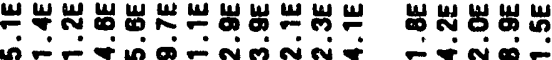
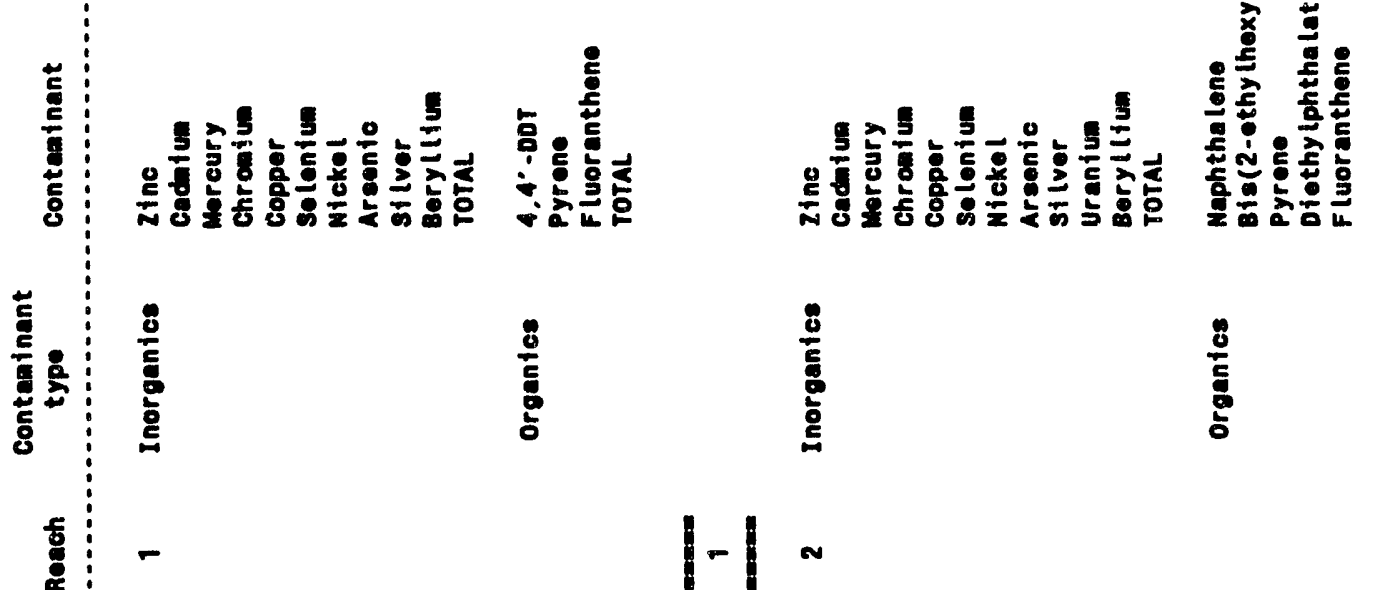

递

$\frac{8}{5}$
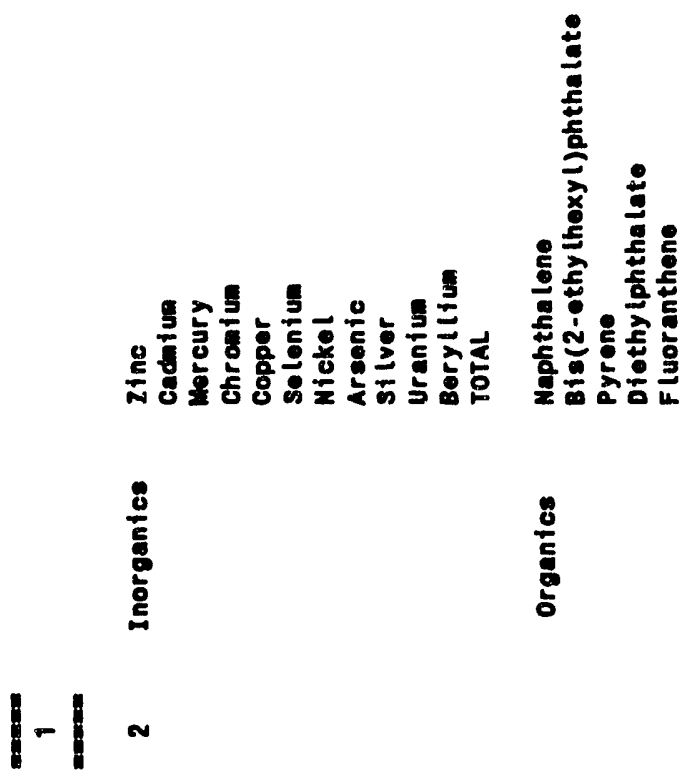


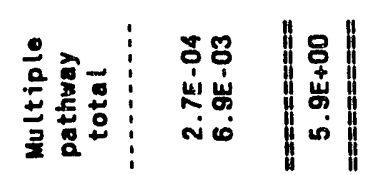

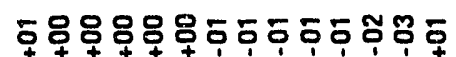

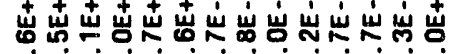

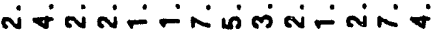

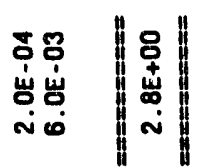

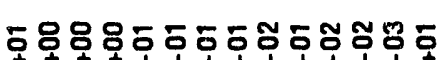

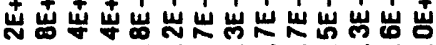

-

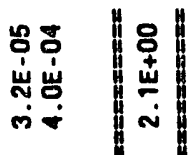

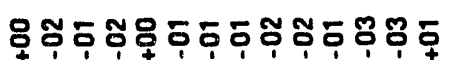

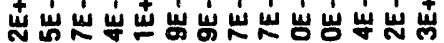

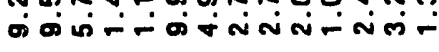

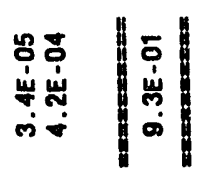

$\mid$\begin{tabular}{c|c|}
0 \\
0 \\
$\dot{\alpha}$ \\
0 \\
0
\end{tabular}

움

岁岩.

苍

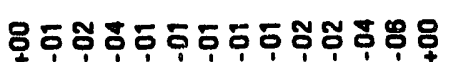

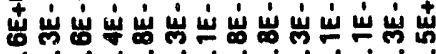

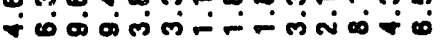

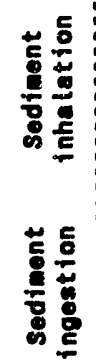

高

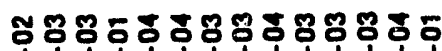

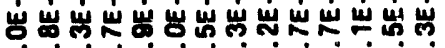

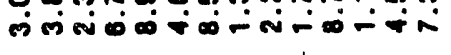

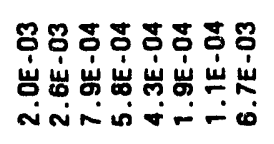

$\| \begin{aligned} & -\overline{+} \\ & \vdots \\ & 0\end{aligned}$

5855 岃㟔㟔㟔 政舟

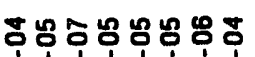

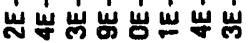

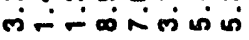

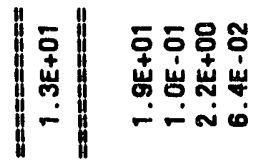

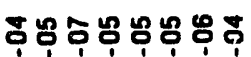

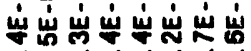

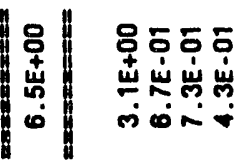

荌

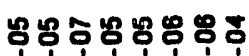

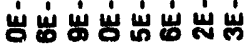
- -

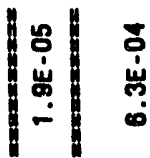

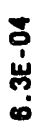

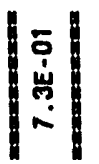

กัธ์ 岁额岕要 i車的
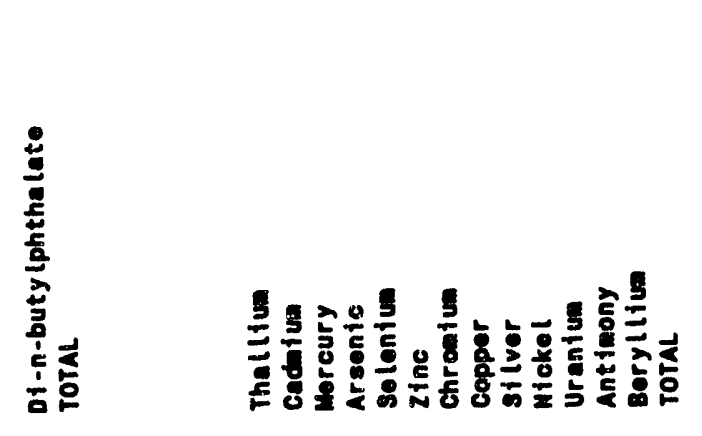

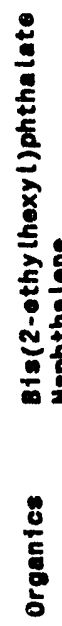

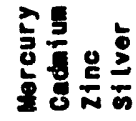

蒙

$\frac{8}{5}$

$\frac{8}{c}$

¿

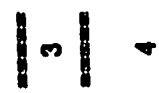


흏ํํํํํํํำ

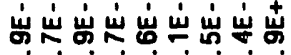

को

ธํํํํํํํํํํํำ

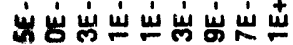

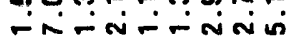

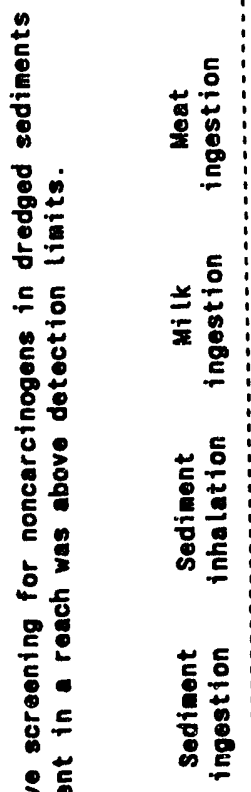

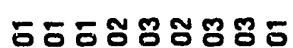

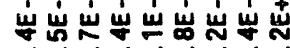

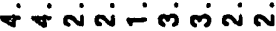

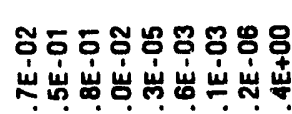

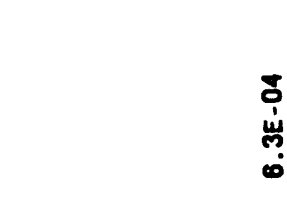

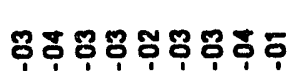

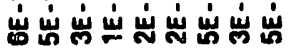

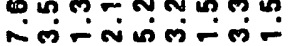

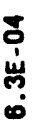

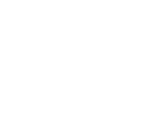

ठั 世出出
ํํㅇํํㅇ 岗岁岩出

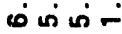

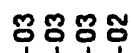

岁岁出峞

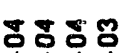

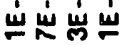

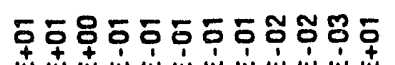

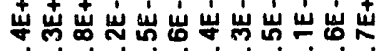
$\because-N$ OD

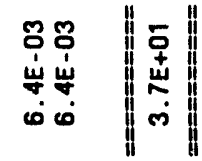

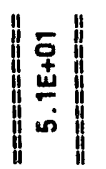

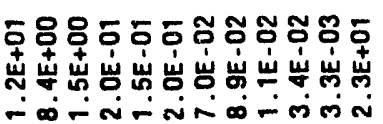

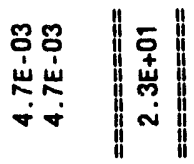

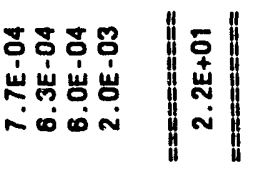

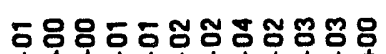

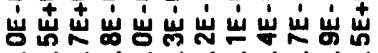

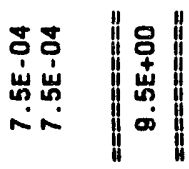

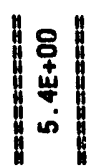

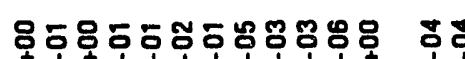

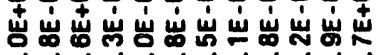

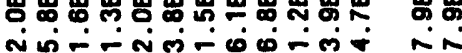

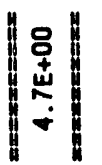

章

品

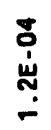
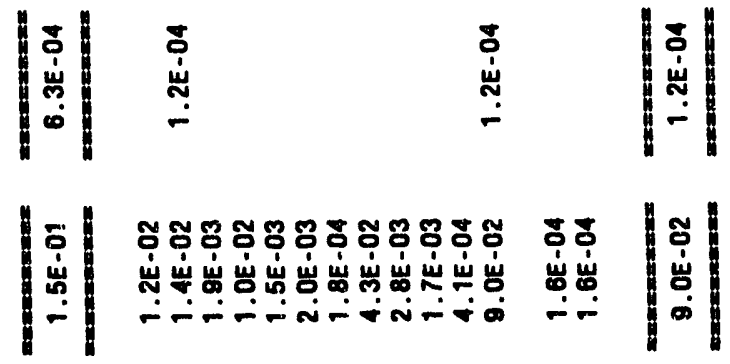

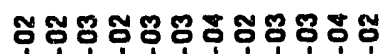

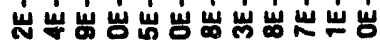

\section{ธั 容}
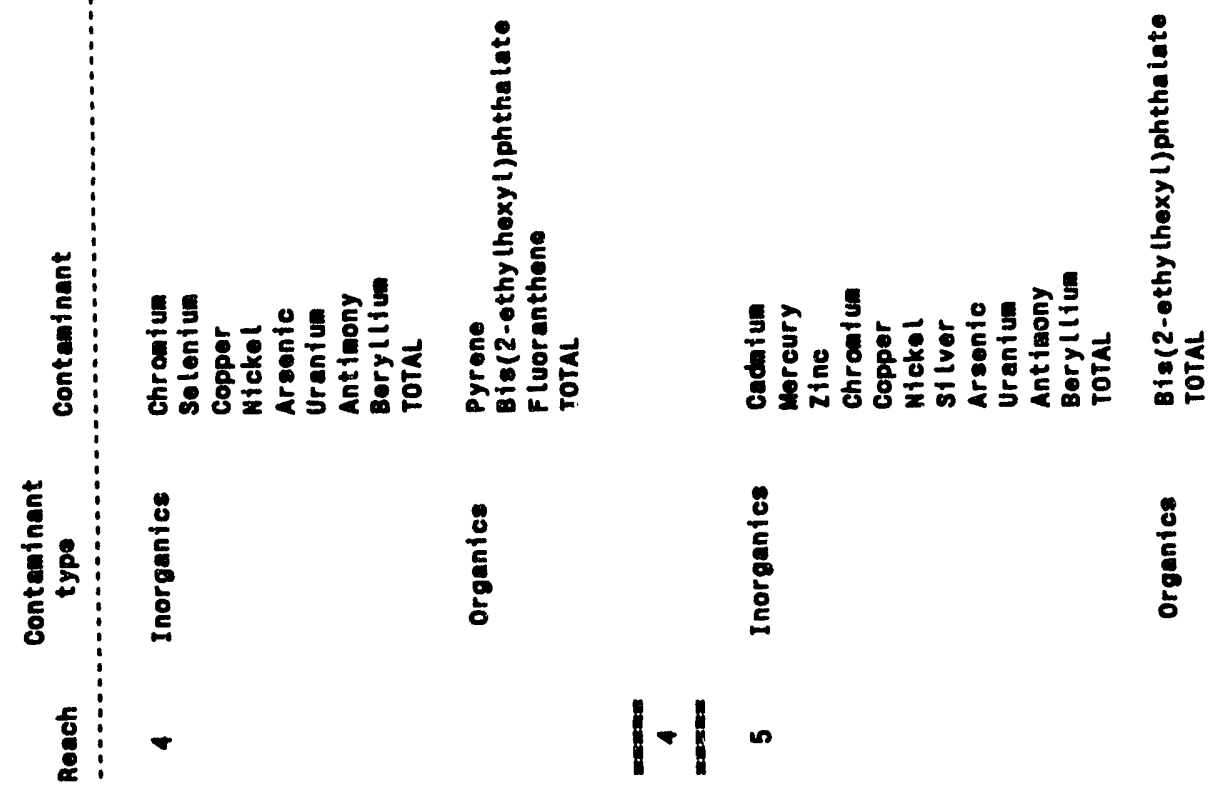

$\frac{8}{5}$

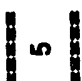




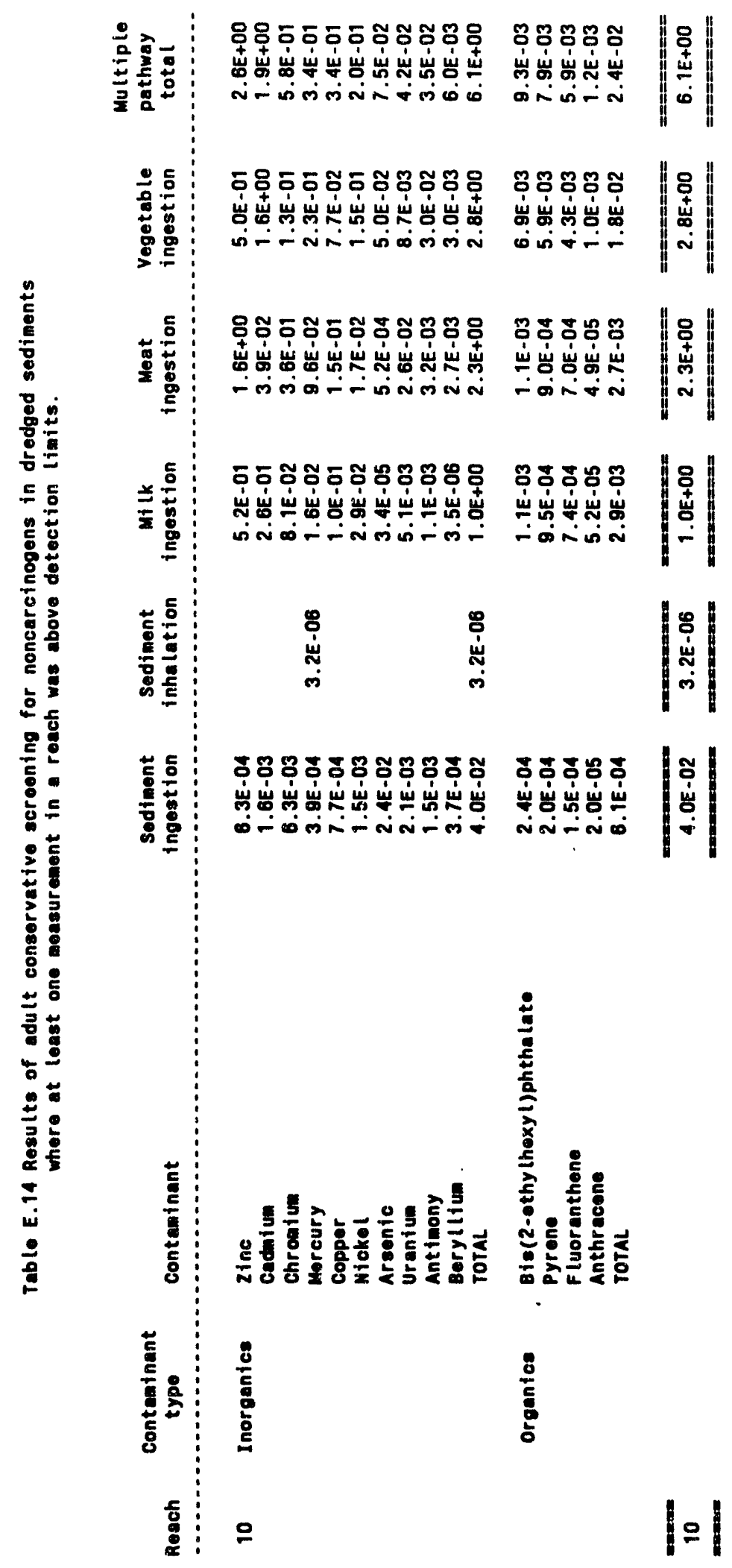



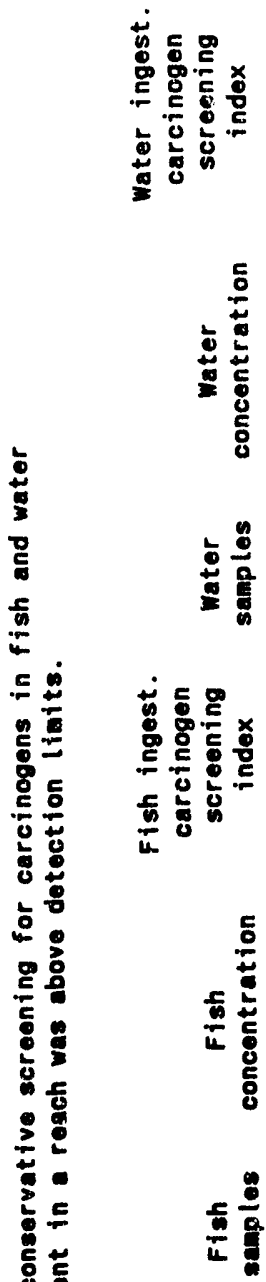

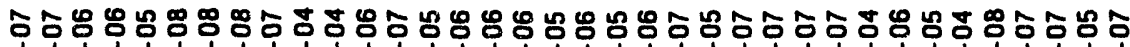

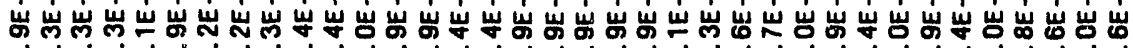

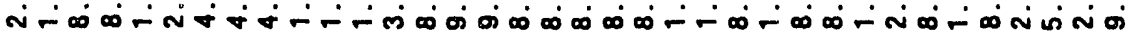

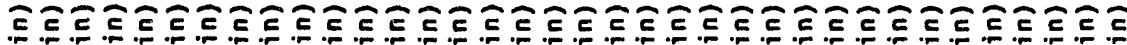

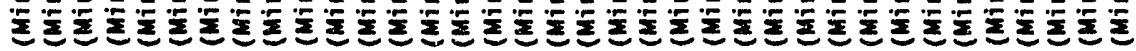

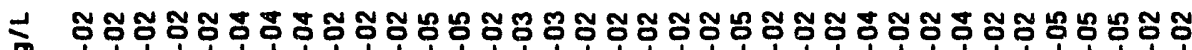

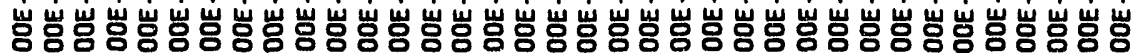
-

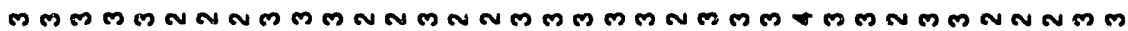

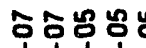
㟧岕出出幽 तिक्षित

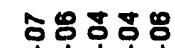
岁出出岕岁 $\because$ 的
웅형요영

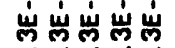
iñ⿰氵丶龴⿱乛⿻

농웅우 崩岕离 in i:
\&

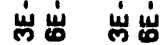
तi Nं
웅

㟧出

\begin{tabular}{|c|c|c|c|c|c|c|}
\hline 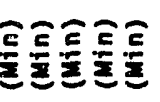 & 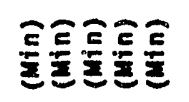 & $\overline{\underline{E}}$ & 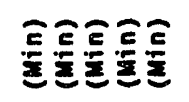 & 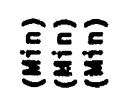 & 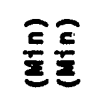 & 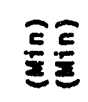 \\
\hline 5558 & 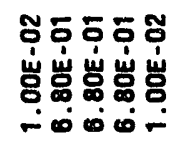 & $\begin{array}{l}\overline{\dot{d}} \\
\dot{\omega} \\
\dot{0} \\
\dot{0}\end{array}$ & 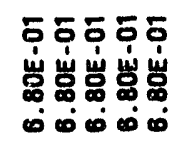 & 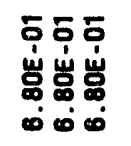 & 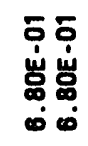 & 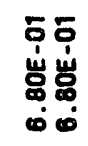 \\
\hline
\end{tabular}

00000 Ф0000

$\infty \omega \infty \omega \infty \omega \infty \omega \infty \omega \infty$

$\infty \boldsymbol{\infty}$

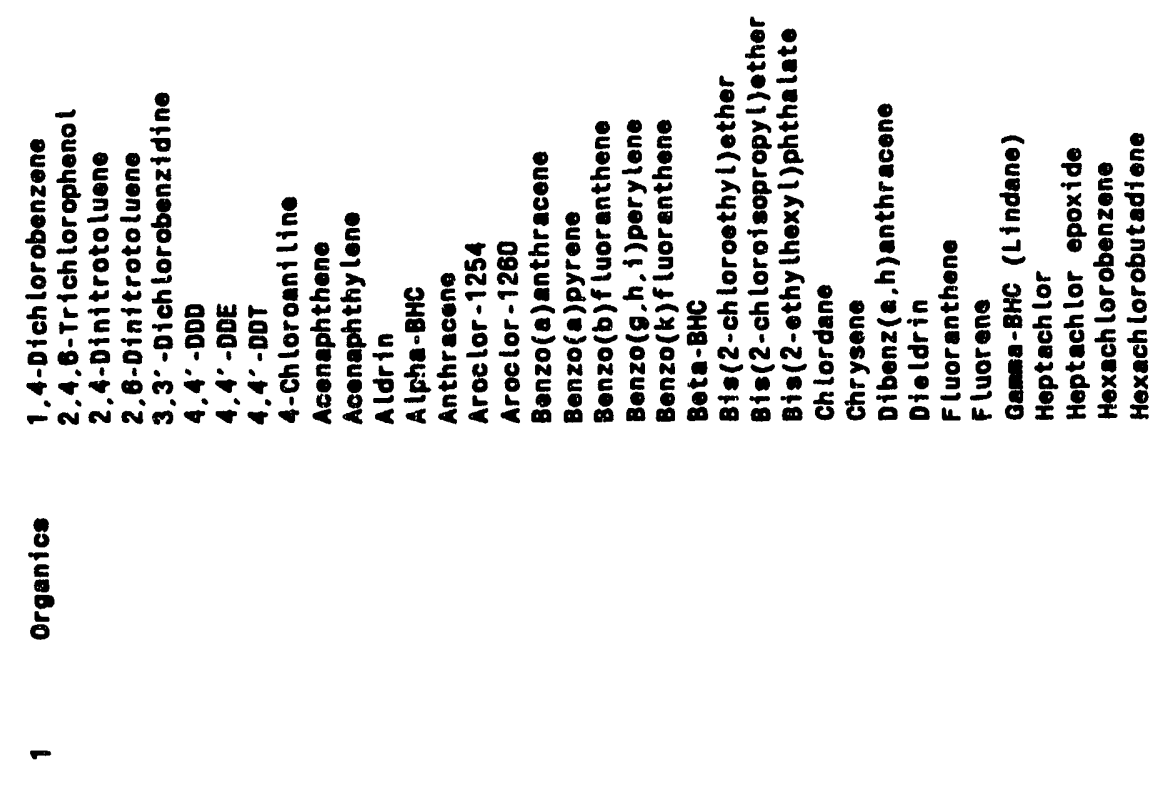




\section{E-88}

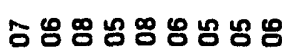

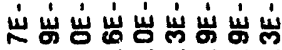
$\therefore \infty \dot{\infty} \dot{\infty} \dot{\infty} \dot{\infty} \infty$

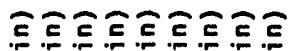

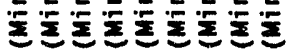

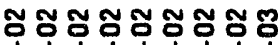
岁岁岁岁岩岩岩岩岩 SOAOSOSOSOAN

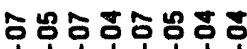

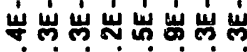
ชn-n-भin

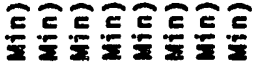

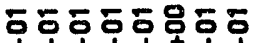

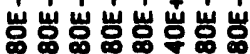
由ं

$\infty \infty 000000$
ஜே

岗菂.

$\stackrel{\infty}{i-2}$

\section{E.}

용

ह

峞客

mo

㻤

产

$\frac{8}{8}$

章

兵竞

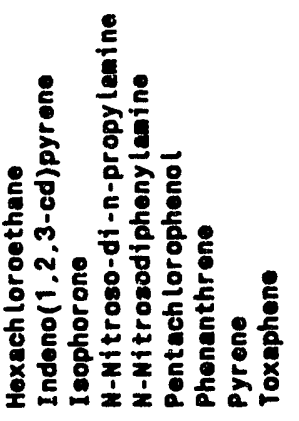

宸

$\frac{8}{5}$

$\frac{8}{5}$

$\mathbf{N}$

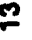

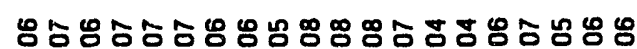

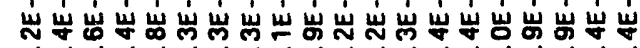
$\because \dot{\infty}$ in

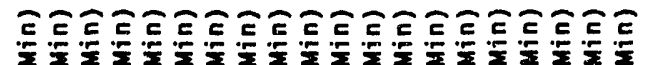

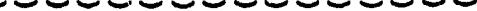

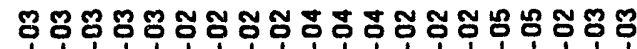

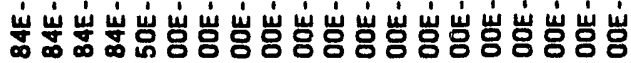

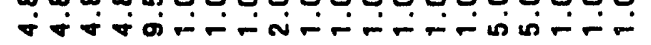

mmmmmammmannammanman

\begin{tabular}{|c|c|}
\hline 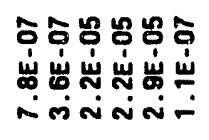 & 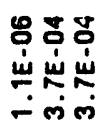 \\
\hline 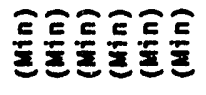 & 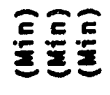 \\
\hline 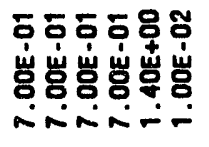 & 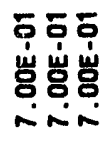 \\
\hline$\infty \infty \infty \infty \infty \Phi$ & $\sim \infty \infty$ \\
\hline
\end{tabular}

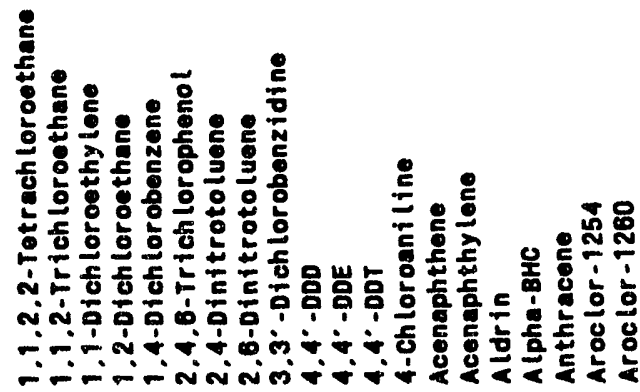

$\frac{8}{5}$

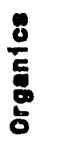




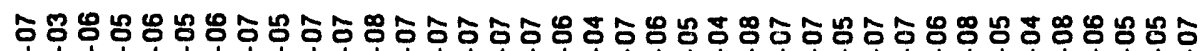

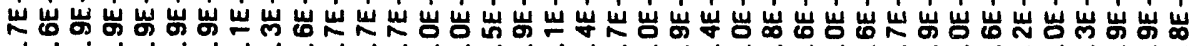

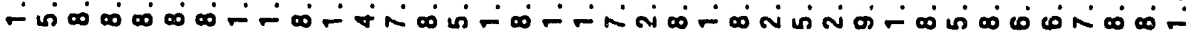

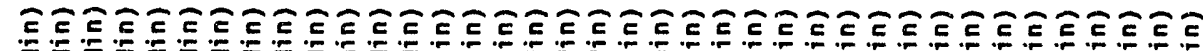

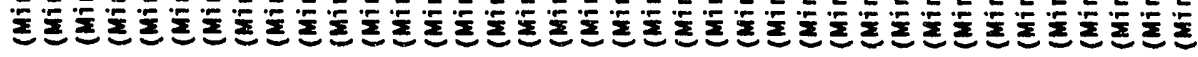

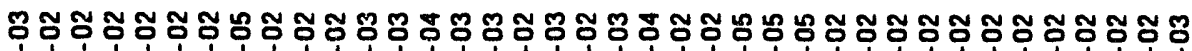

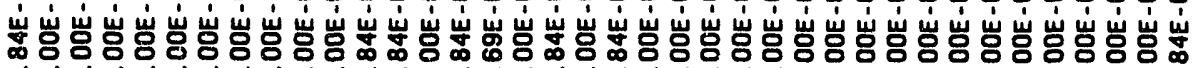

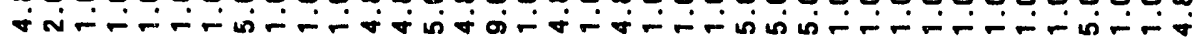

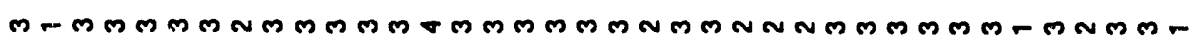

\begin{tabular}{|c|c|c|c|c|c|c|}
\hline 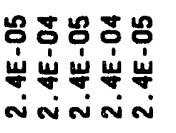 & 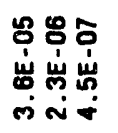 & 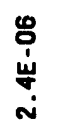 & 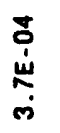 & 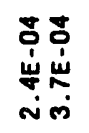 & 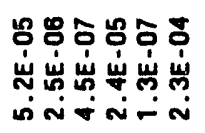 & 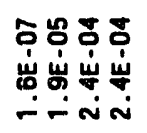 \\
\hline 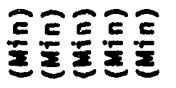 & 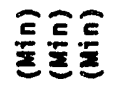 & $\overline{\underline{\underline{\varepsilon}}}$ & 曈 & 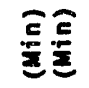 & 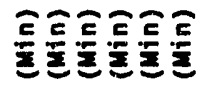 & 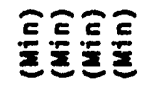 \\
\hline 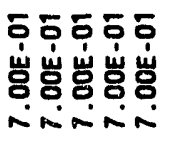 & كَ & 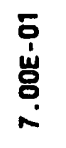 & 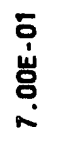 & 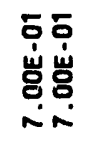 & 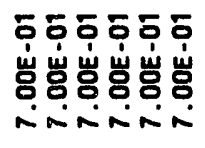 & 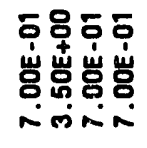 \\
\hline , & & $\infty$ & & & $\infty \infty \infty \infty \infty \infty$ & $\infty \infty$ \\
\hline
\end{tabular}




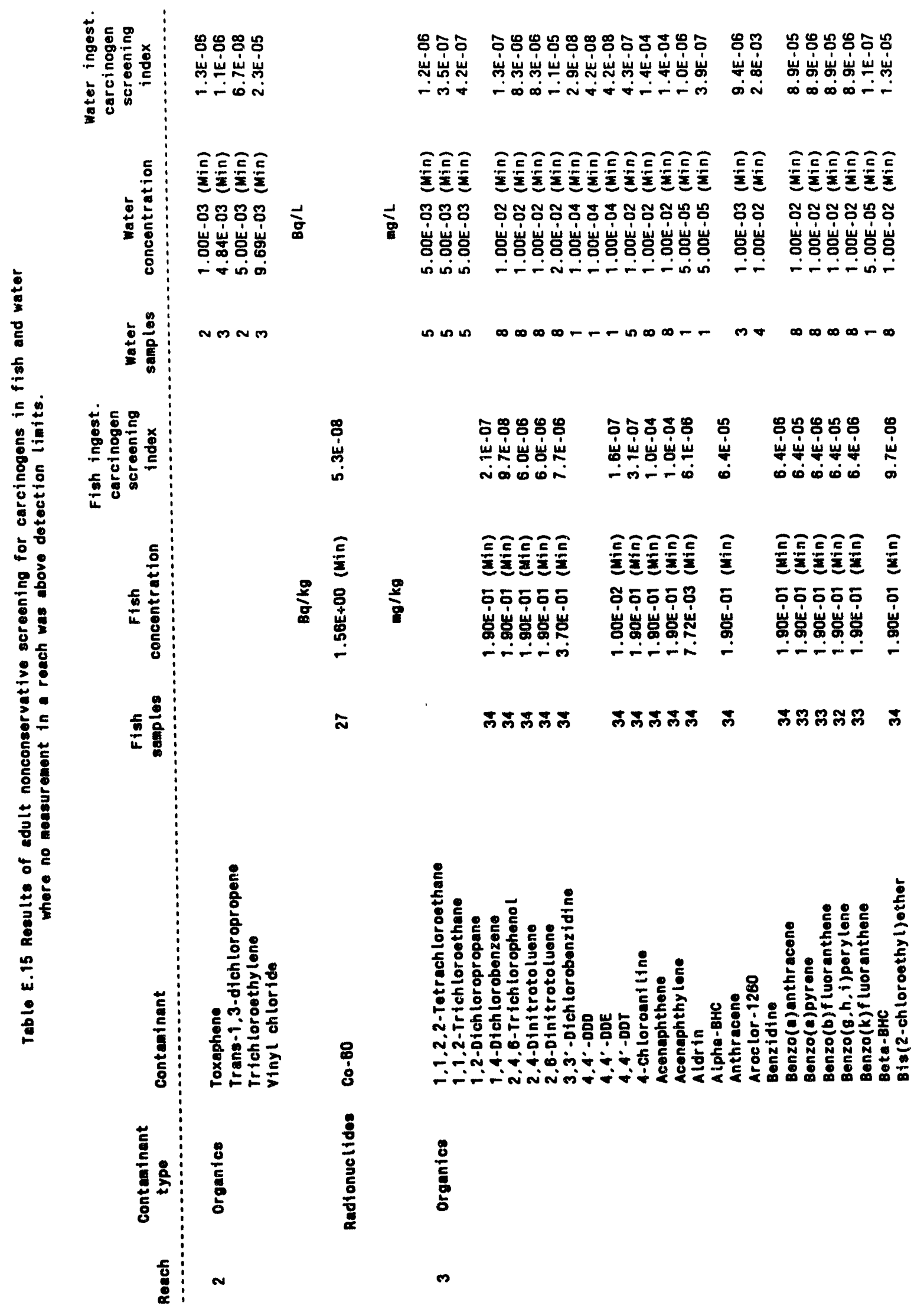




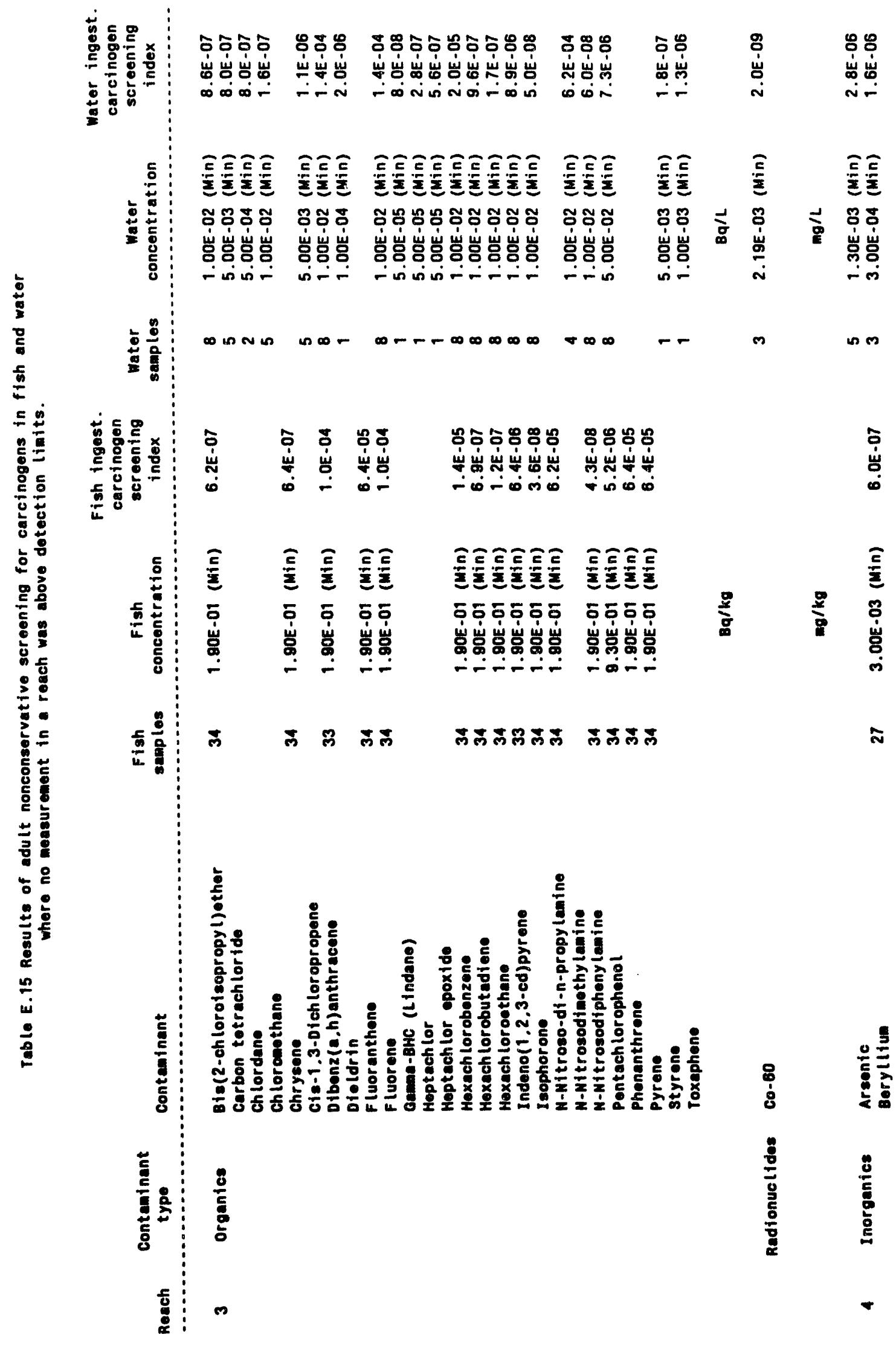



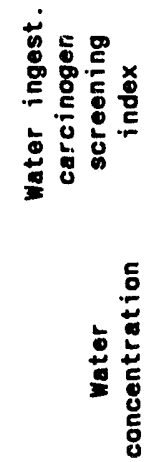

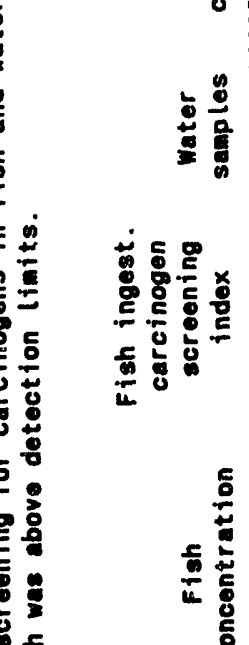

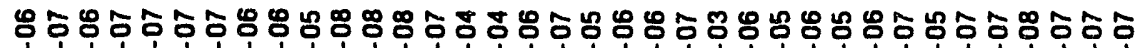

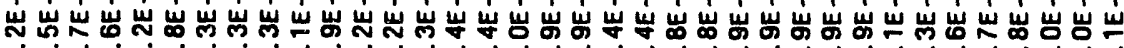
$\because$ 问闹

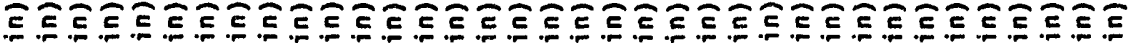

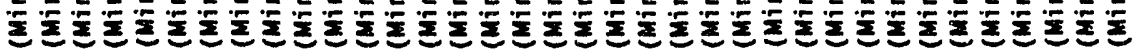

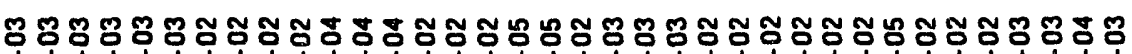

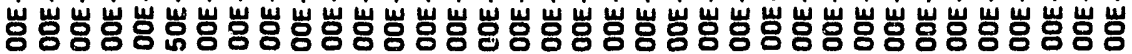
i vis si

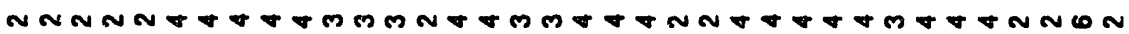

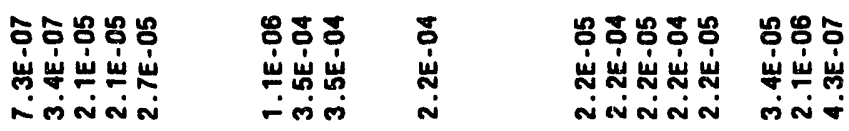

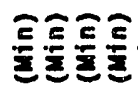

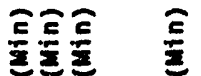

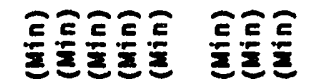

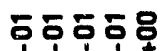

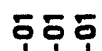

㟧岩岩岩离

岩岩岩

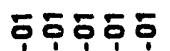

$\bar{c} \overline{1} \overline{1}$

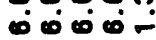

$\infty \infty^{\circ} \infty$

岩岩岩岩岩

峞岩崖

किष्ठ

$\infty \nsubseteq \infty \infty$

$\infty \infty$

$\infty 0000 \sim \infty$

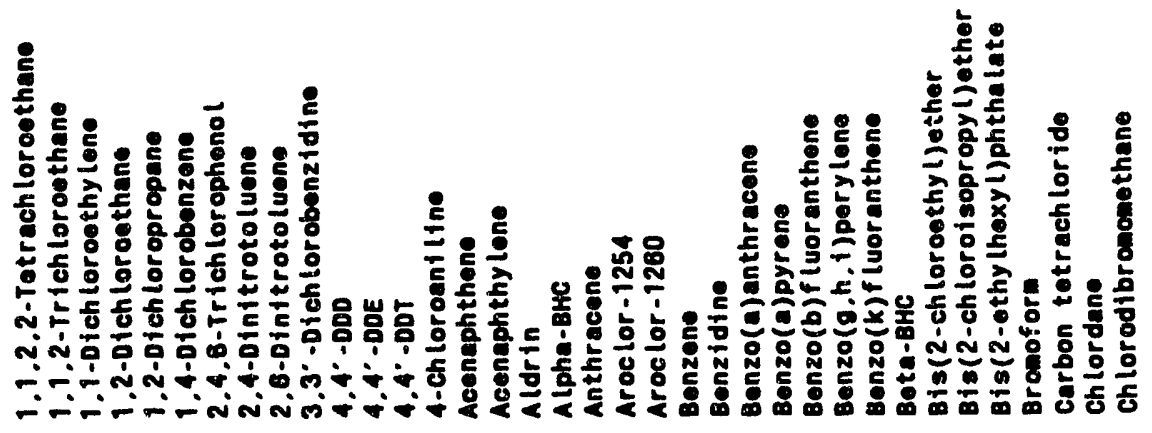

蒙

$\frac{8}{5}$ 


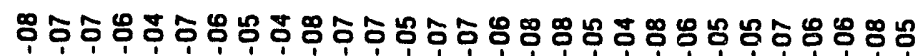

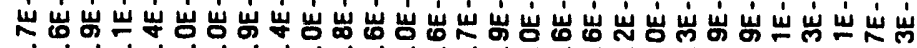

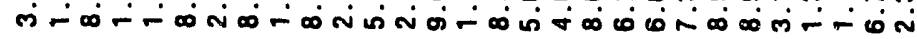

\&

㟧

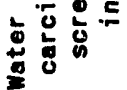

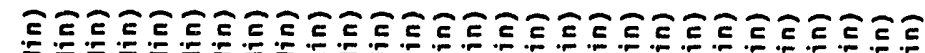

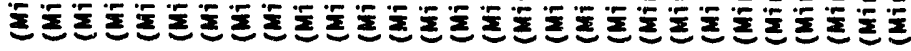

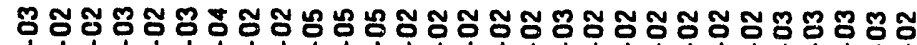

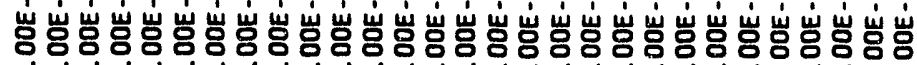

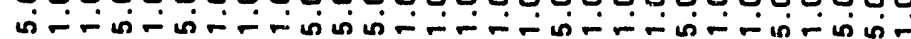

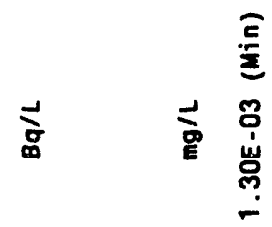

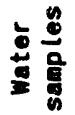

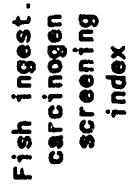

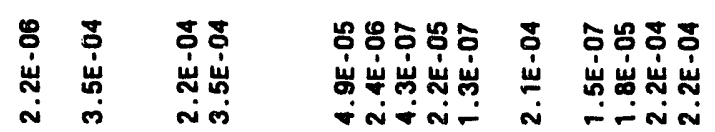
: 崩

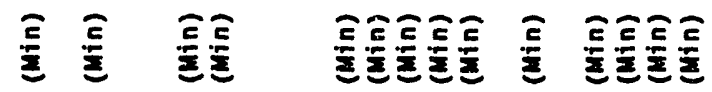

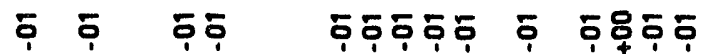

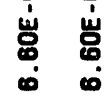
峞峞

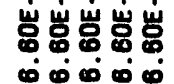
岩峞岩岩 i im - $-\infty$ - 00000000 怘

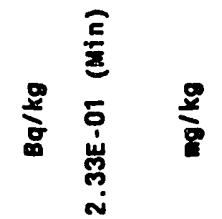

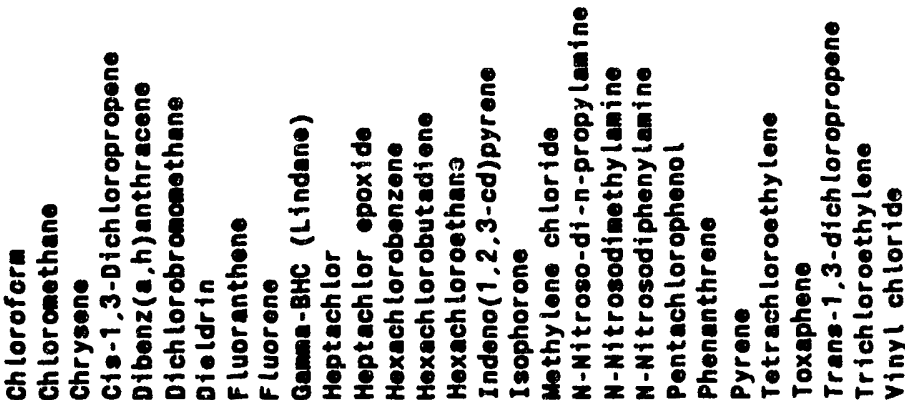
$\frac{5}{4}$ 


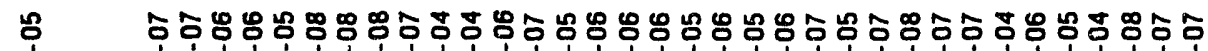

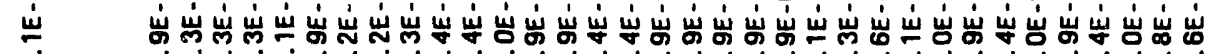

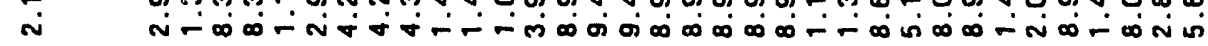

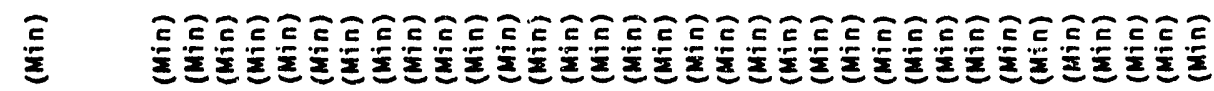

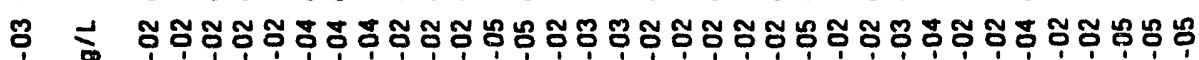

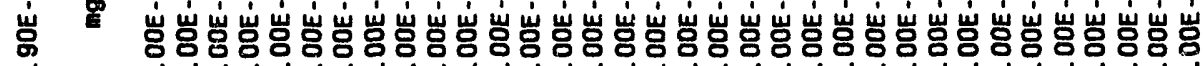

s

$\stackrel{\dot{m}}{\dot{m}}$

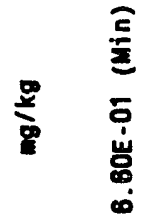

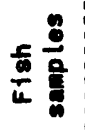

$\infty$

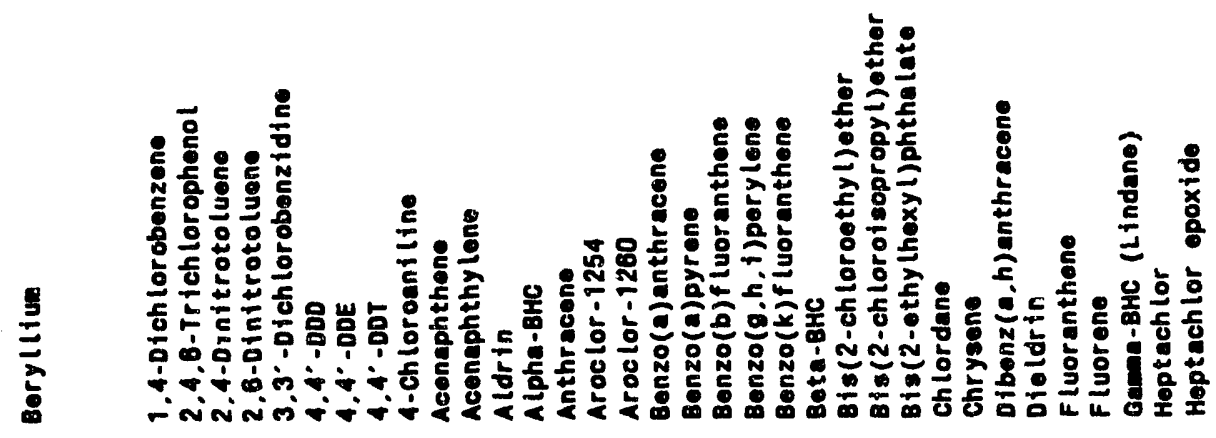

蒙

$\frac{8}{5}$
$\vdots$
$\vdots$
0<smiles>O=COCCO</smiles> 
E-95

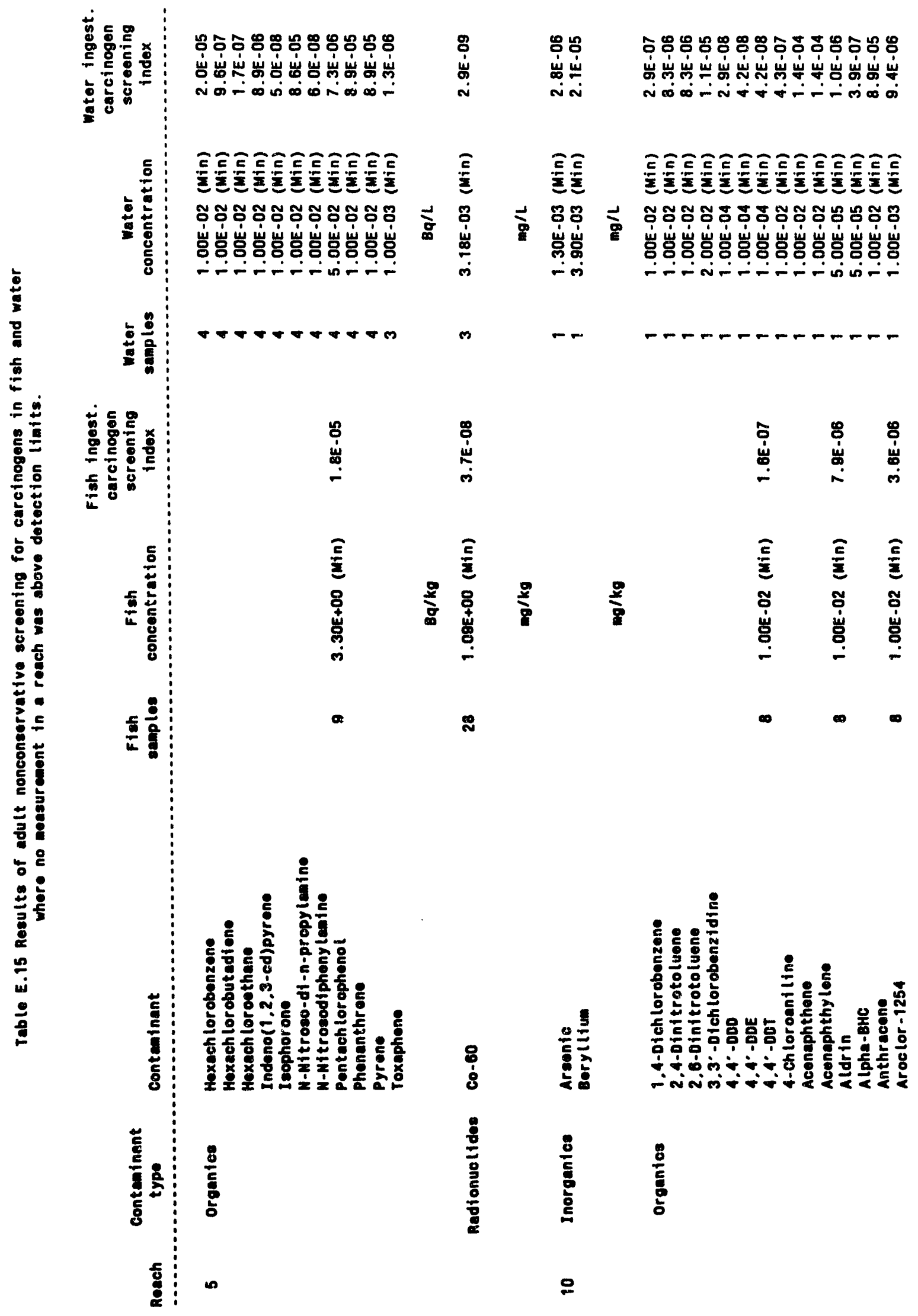




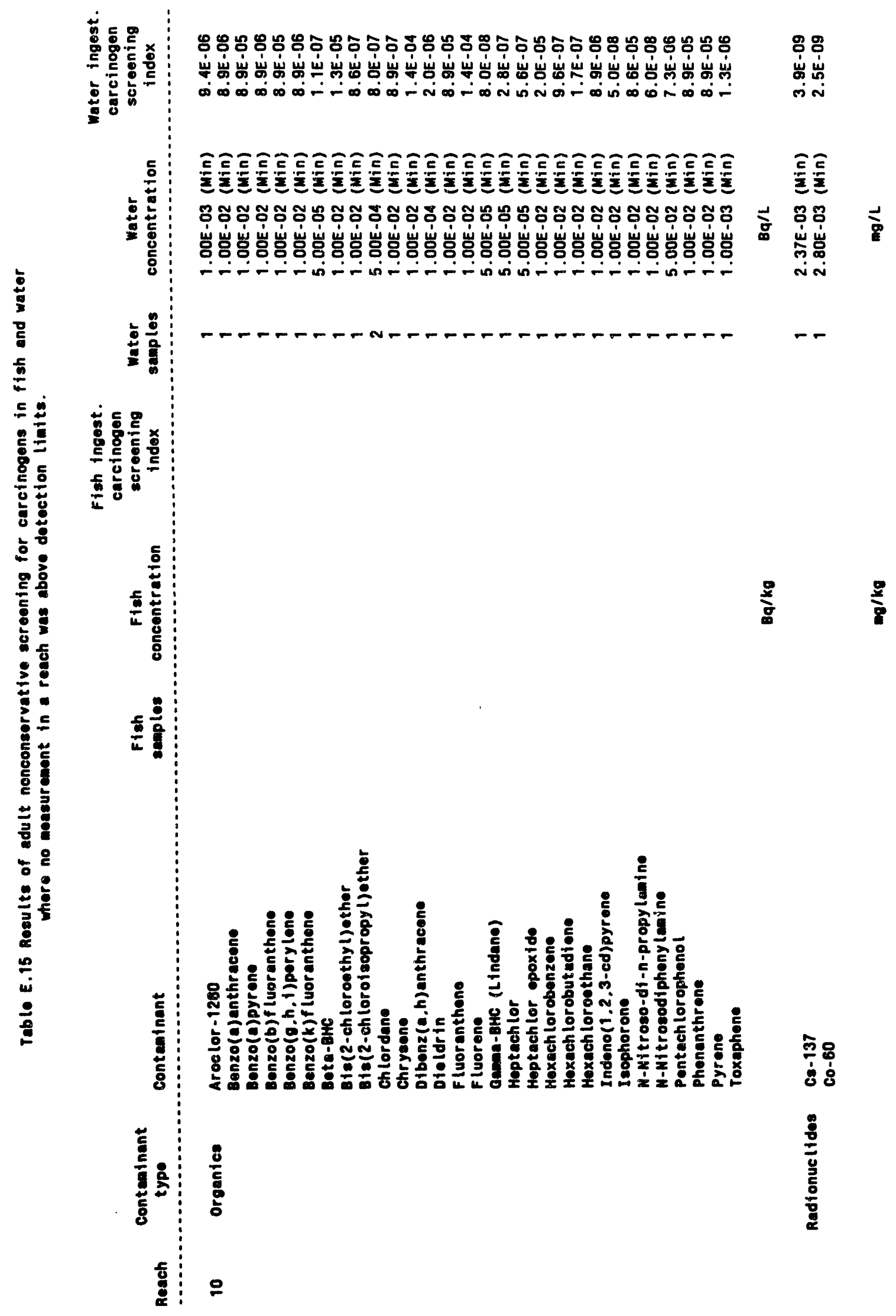




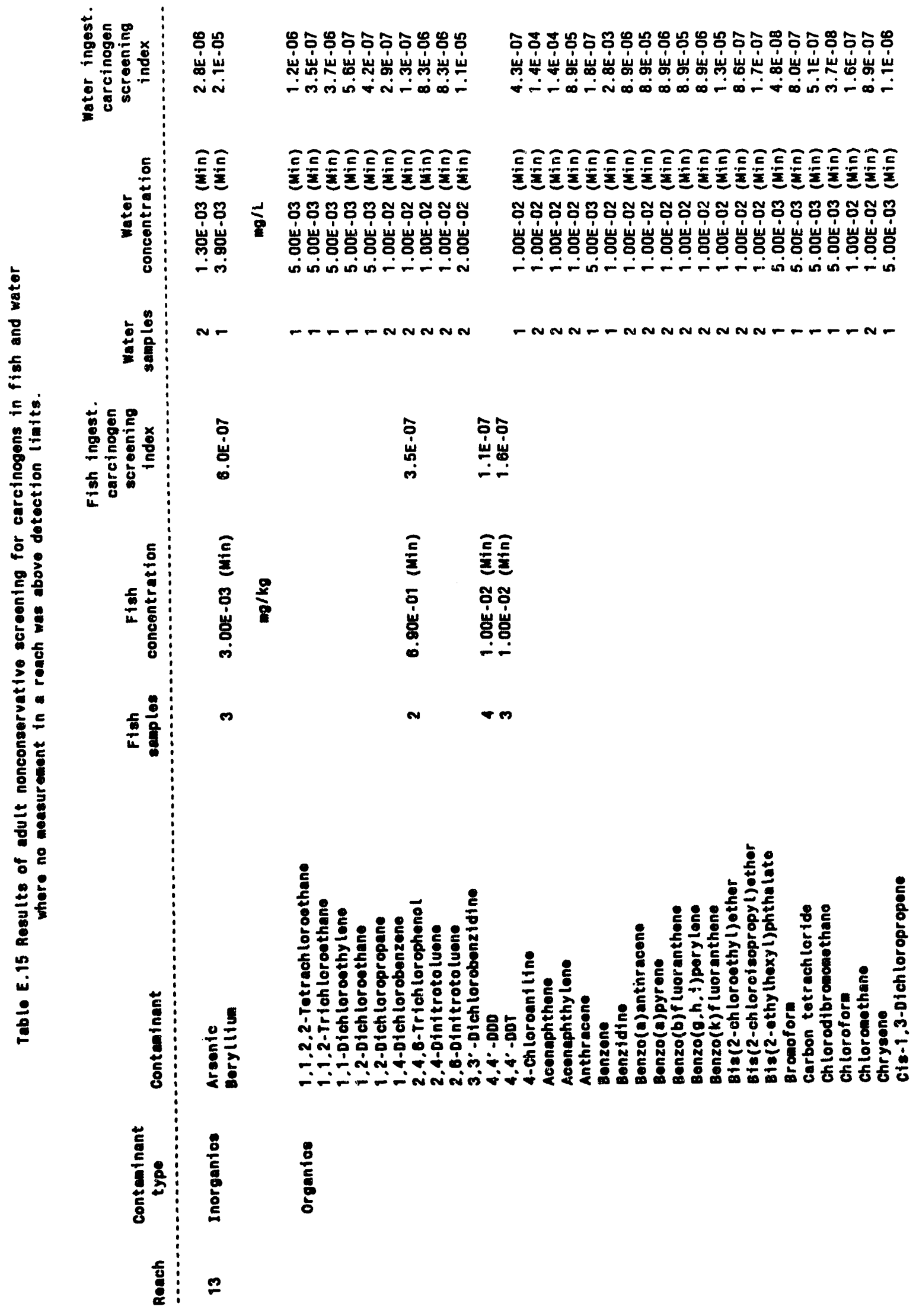




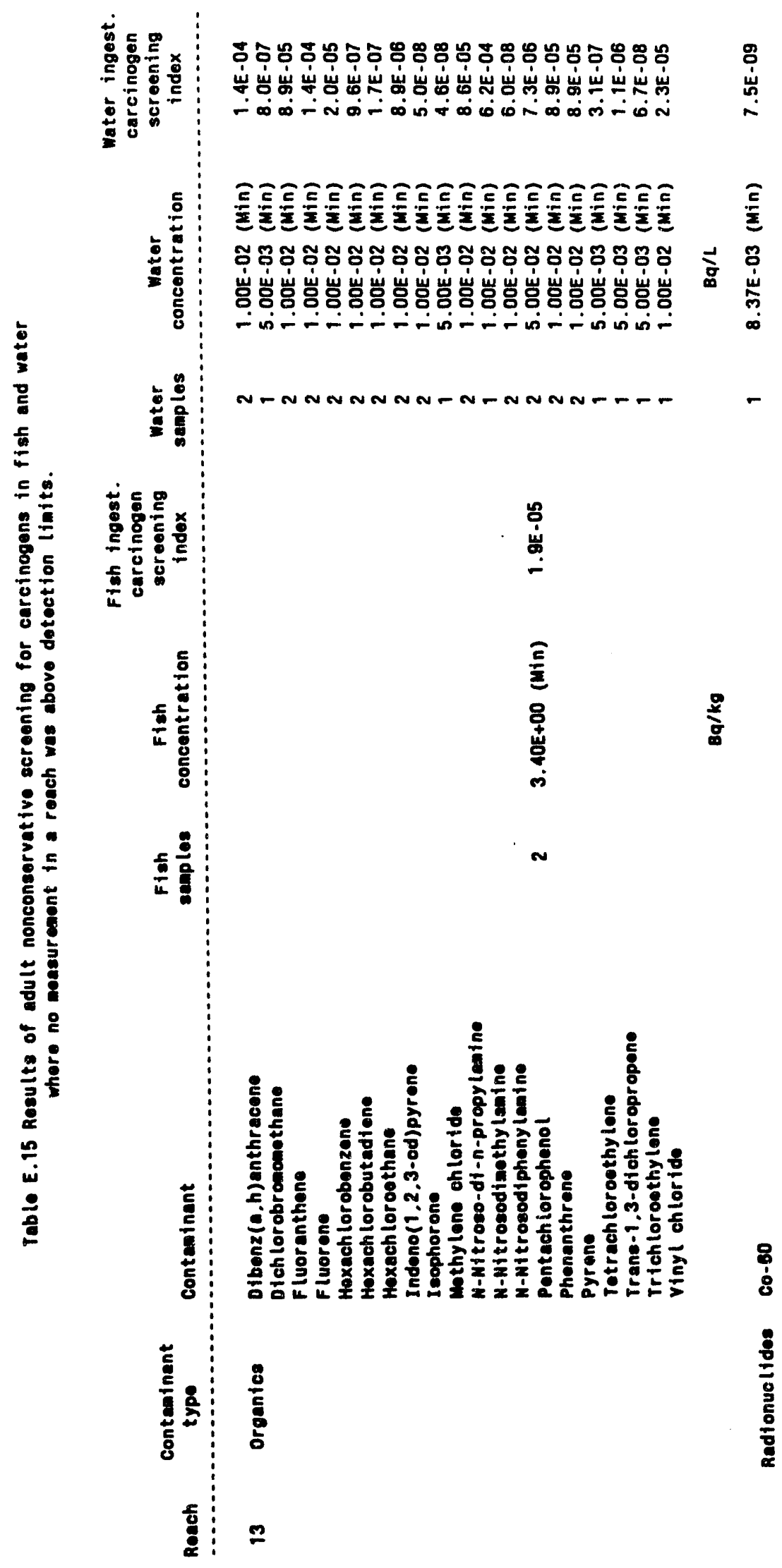




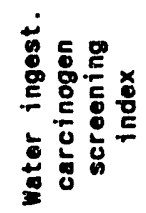

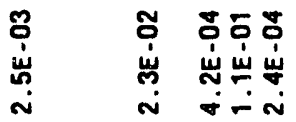

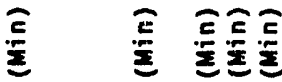

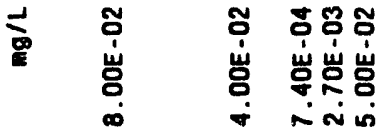

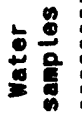

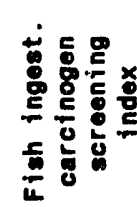

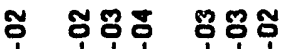

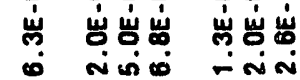

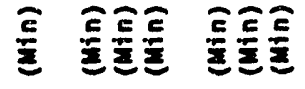

$\frac{8}{8}$

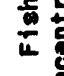

高

岁岩崖

实

ธ్ํำ

峞㟧总

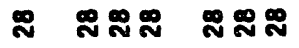

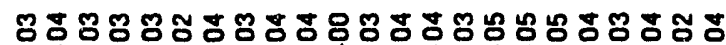

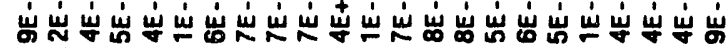

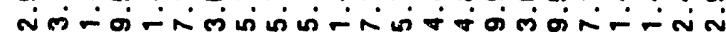

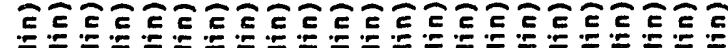

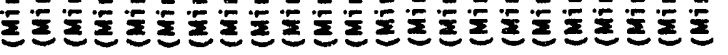

蹗

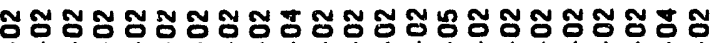

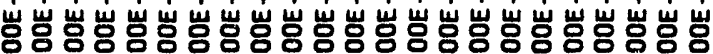
-

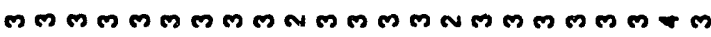

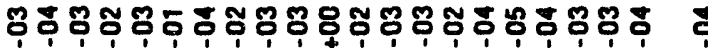

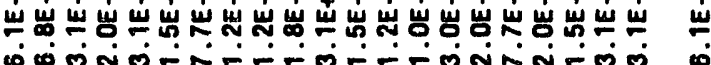

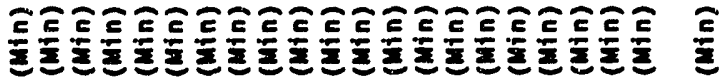

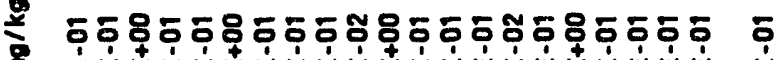

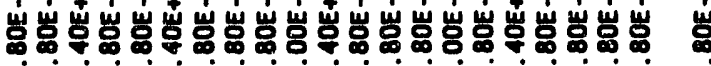

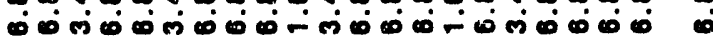

ம
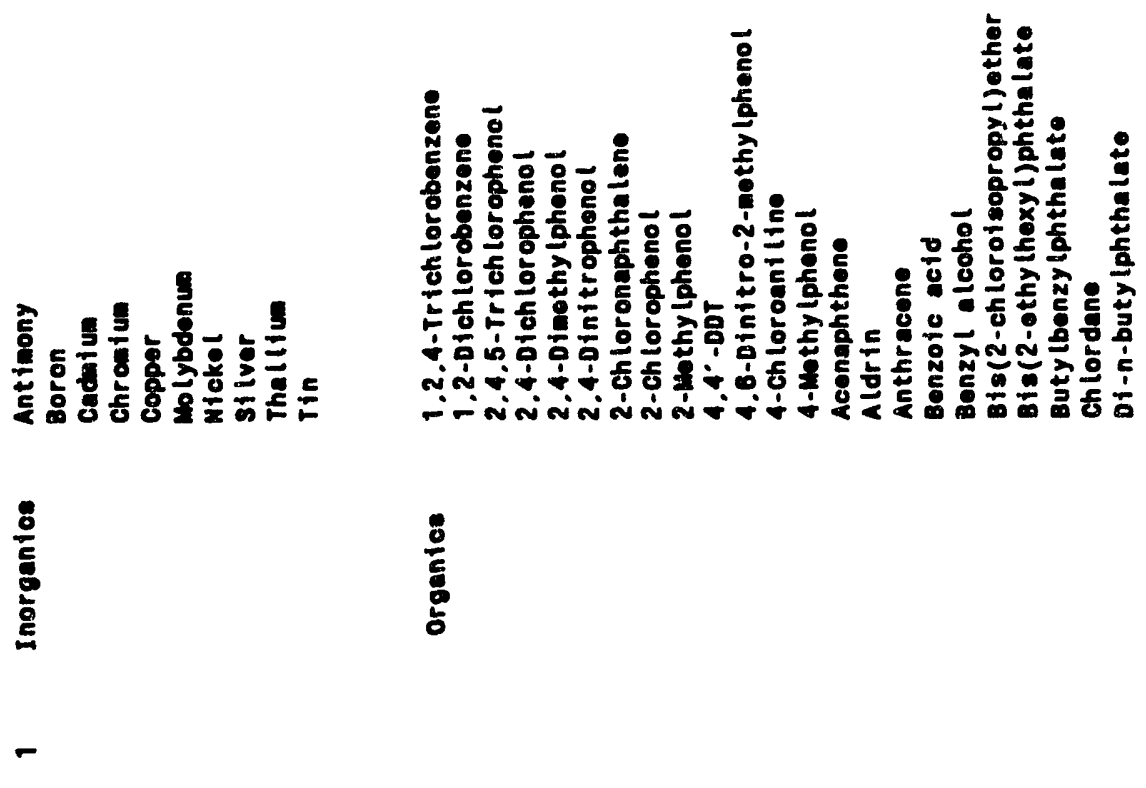

$\frac{8}{5}$ 


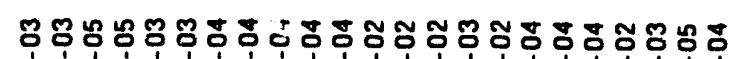

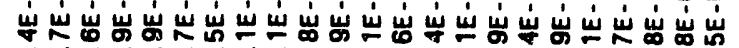

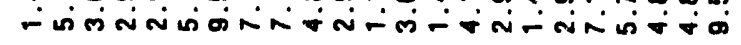

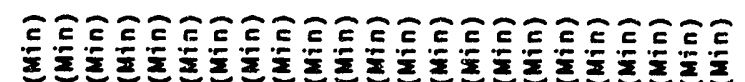

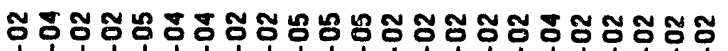

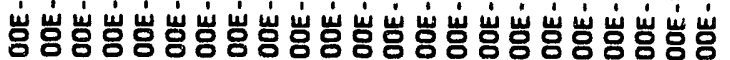

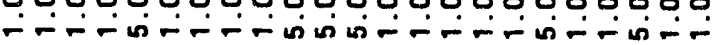

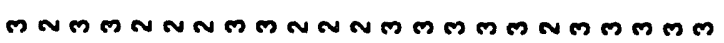
要

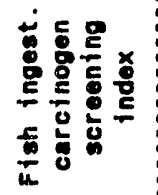

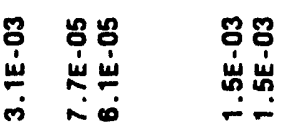

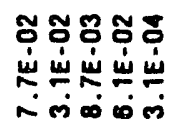

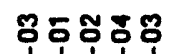

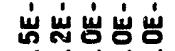
i $\sim \dot{\infty}^{\circ}$

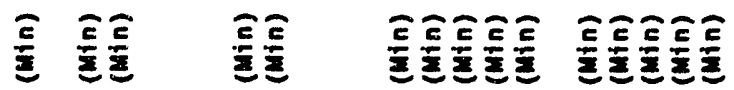
$55 \overline{0}$ 峞 岁峞

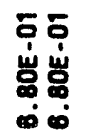
重量

$\infty \infty \infty$

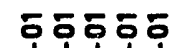

岩岩希峞

ம்

55855

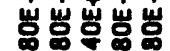

कं लिं

$\infty 00000000$

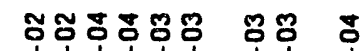

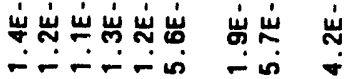

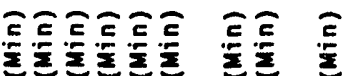

โ

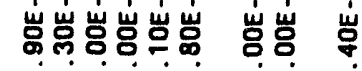

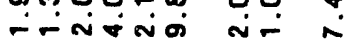

TmTnmm ma m

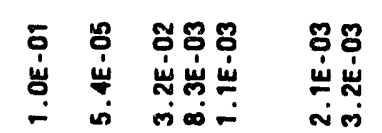

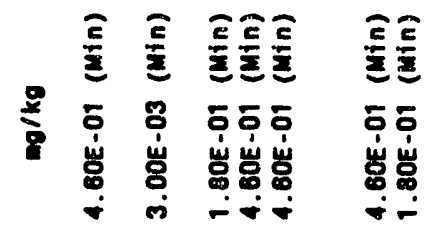

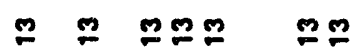

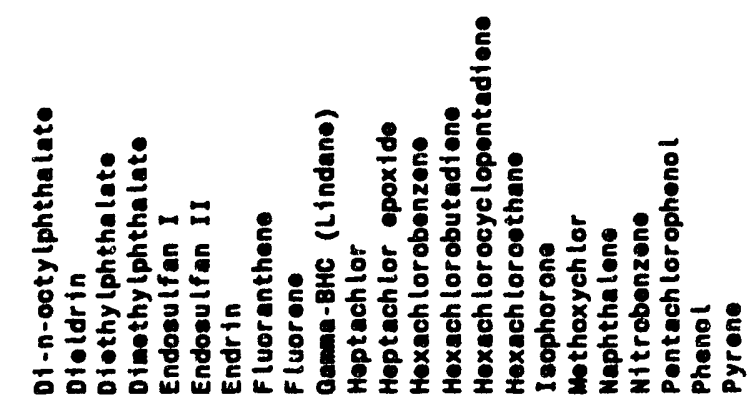

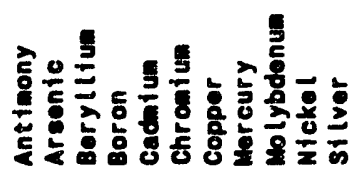

突

$\frac{8}{5}$

$\frac{8}{5}$

n 


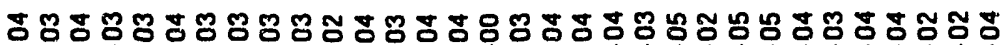
냈

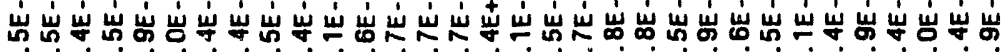

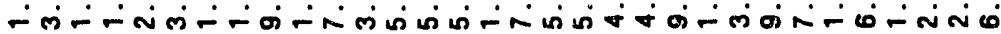

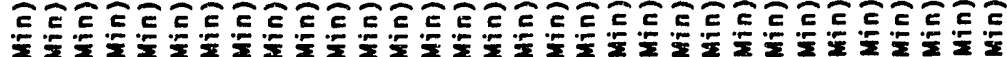
กำ 岩岩岩

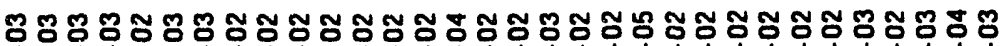
ín

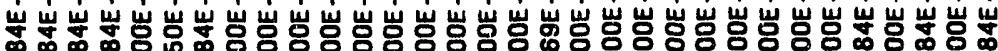
$\cos 2$ ma mmmmmm--NN-mN-NNN- MNm-NMmmmmm-

ธั

$\stackrel{\dot{\omega}}{\stackrel{4}{~}}$

N

$\frac{\bar{\varepsilon}}{\underline{\underline{z}}}$ 䓂 m

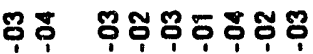

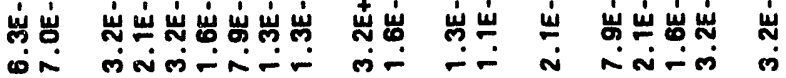

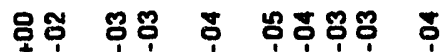

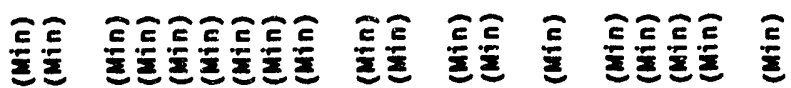

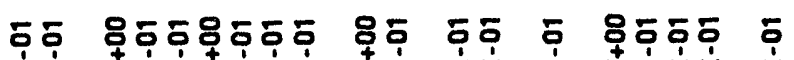

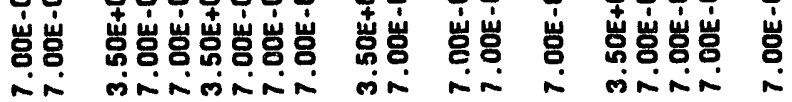
an an a mana a

$\infty \boldsymbol{\infty}$

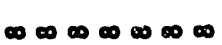

$\infty \sim$
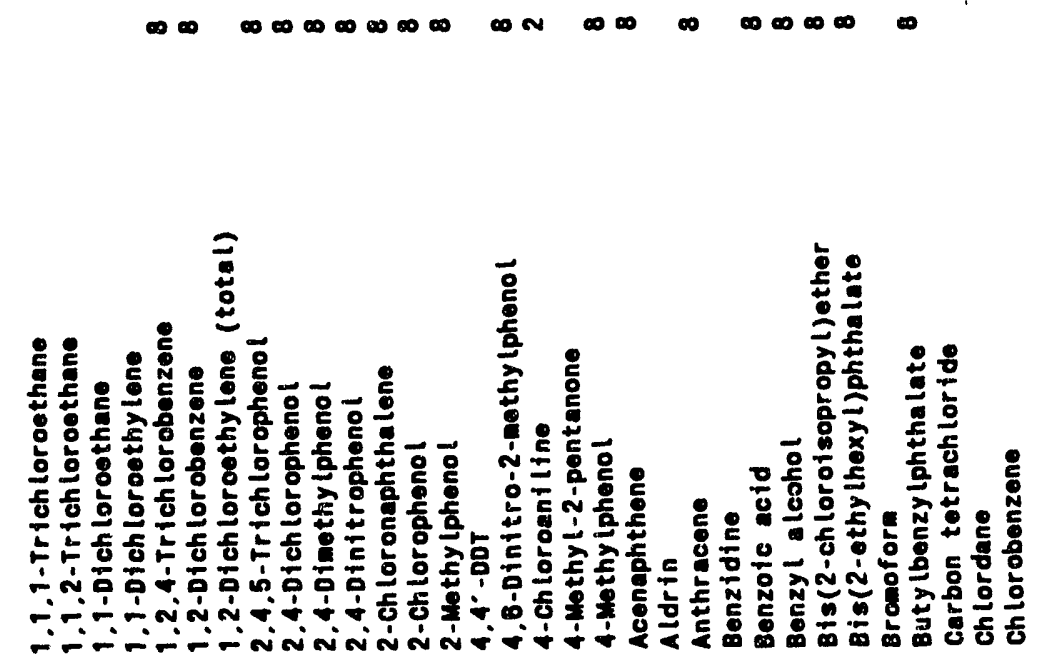
ఫั

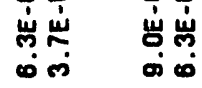

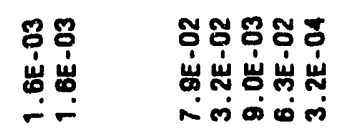

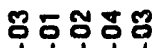

$\infty \infty$

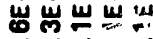

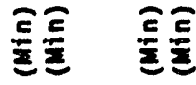

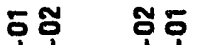

岁岕客岩

重焉

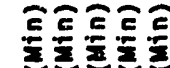

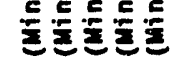

要

$\overline{1} \overline{1}$

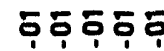

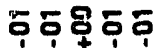

$\sim \infty$

岩岩

岁岩岁岩岩

岁岁岩岩岩

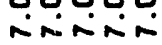

insin

की

$\infty$

$\infty \infty$

$\infty \infty$

$\infty \infty \infty \infty \infty$

$\infty \infty \infty \infty$

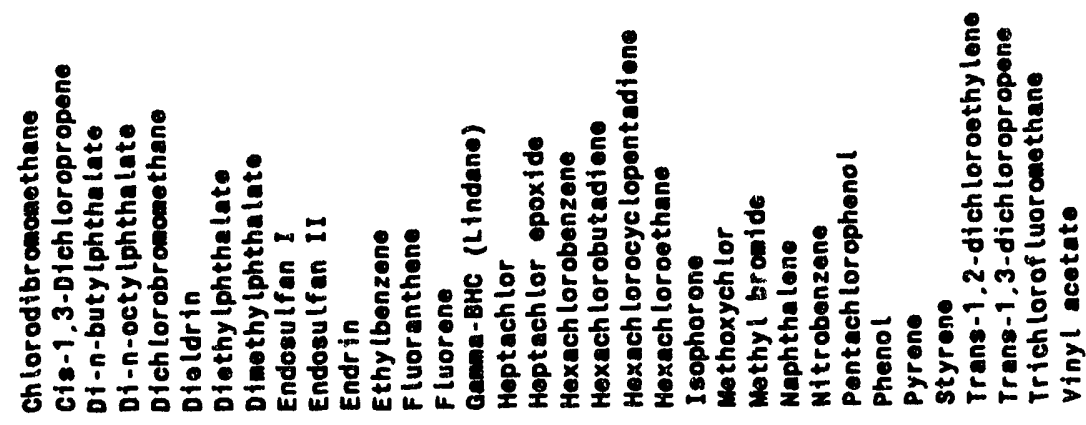

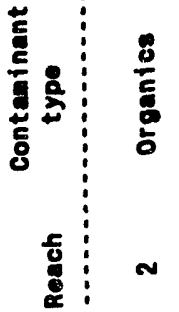




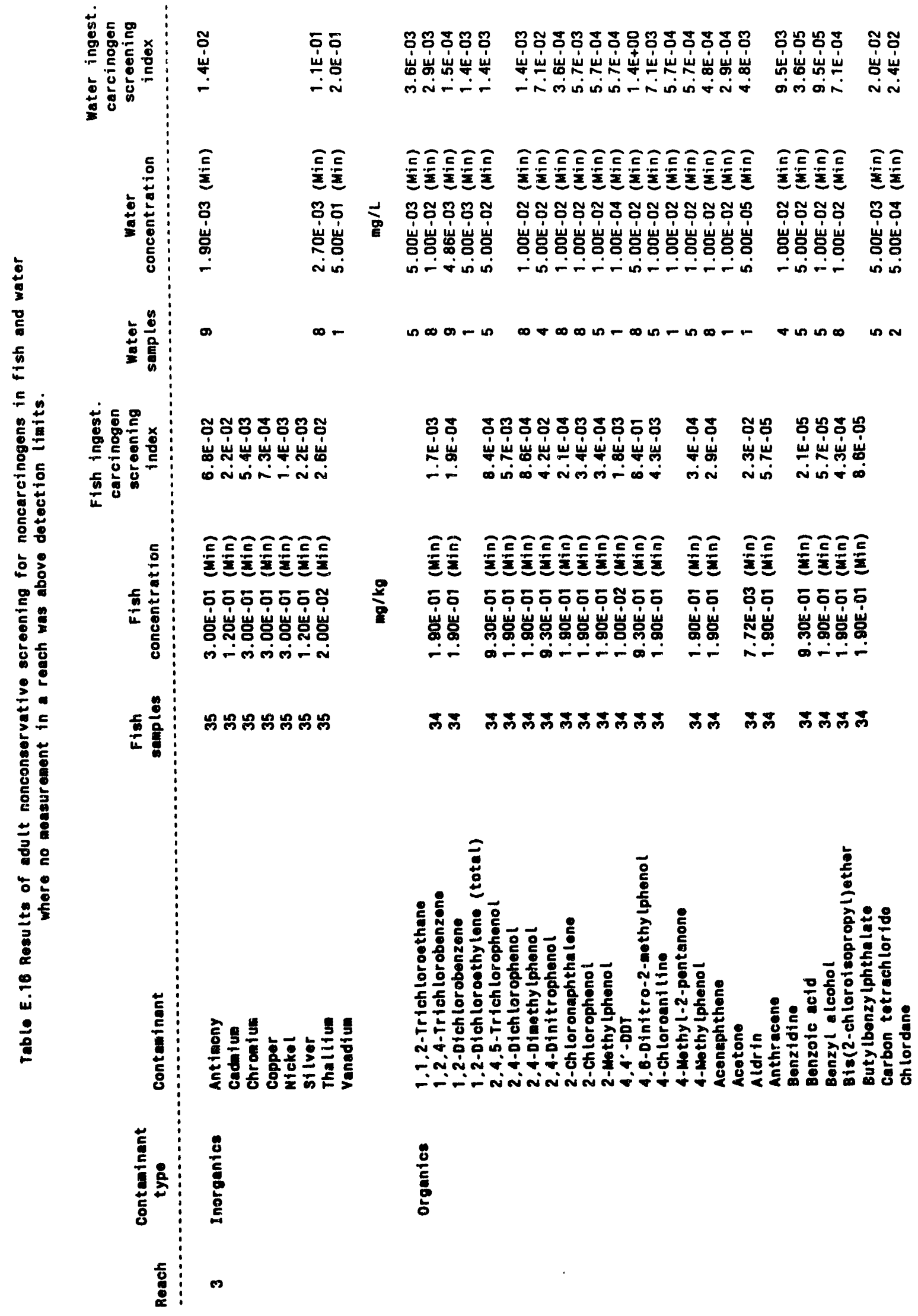




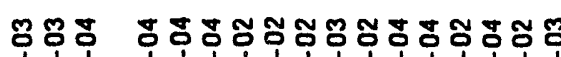

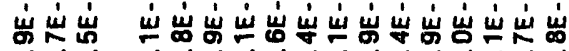

ㅇํㅇํํㅇㅇㅇㅇ

岃岕岕

กับักับ

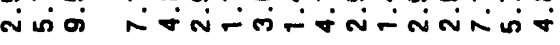

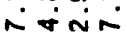

岁岕点

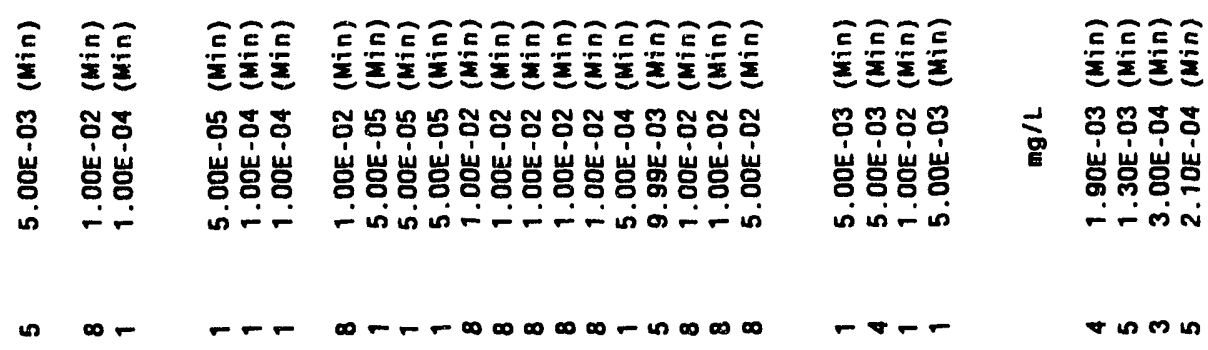

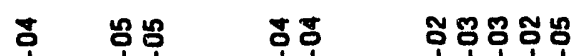

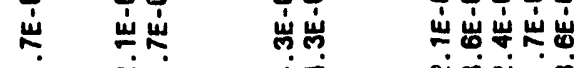

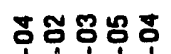

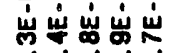

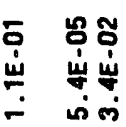

岳

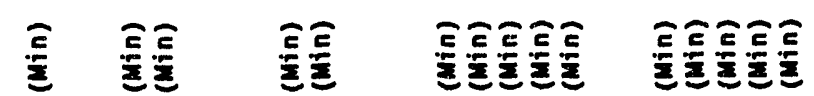

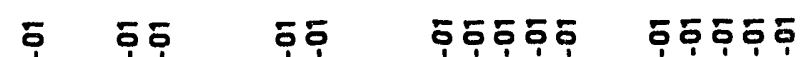

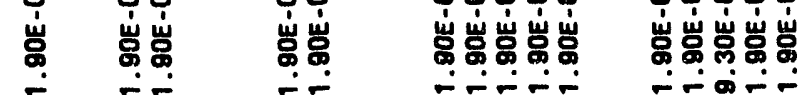

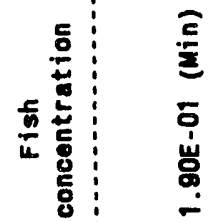

$\frac{5}{4} \frac{8}{6}$

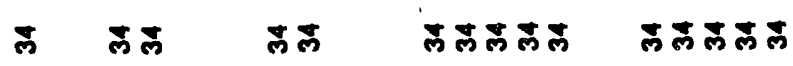

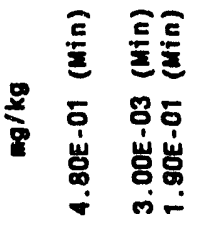

ก ลก

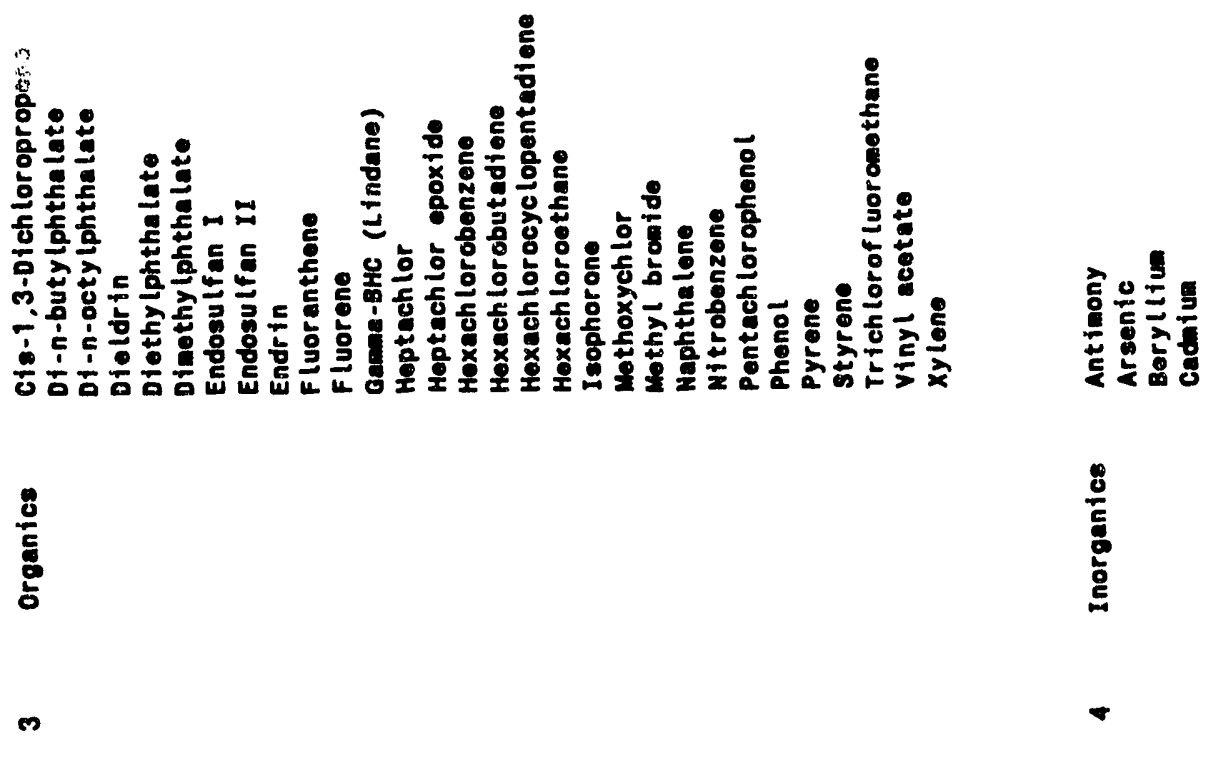




\section{要}

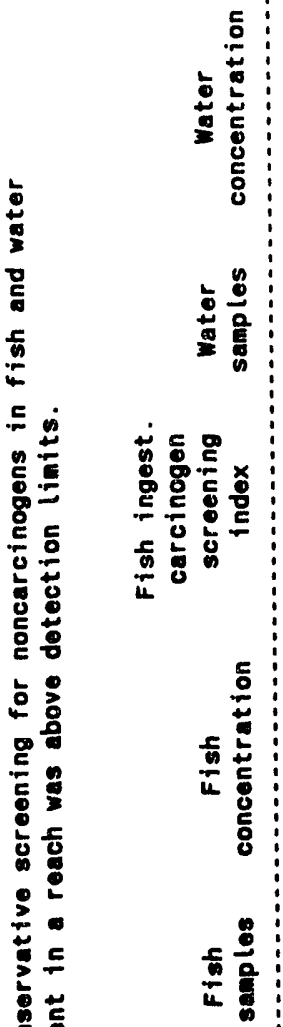

$\operatorname{cล~} ล$ ลก

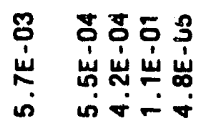

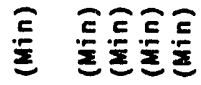

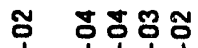

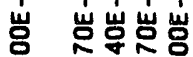

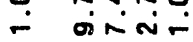

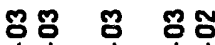

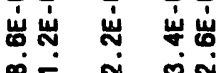

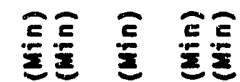

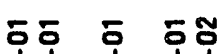

峞峞 峞 峞岩

$\dot{+}+\dot{-}-\dot{\sim}$

紊旁

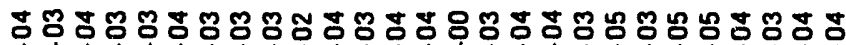

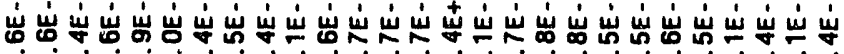
$\therefore \dot{-1}$ -

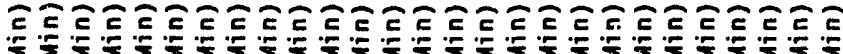

โ

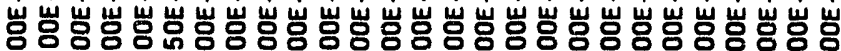
in

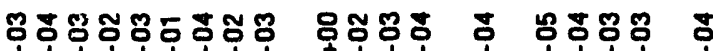

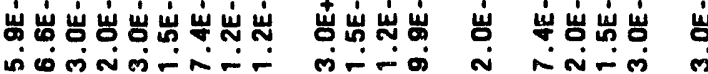

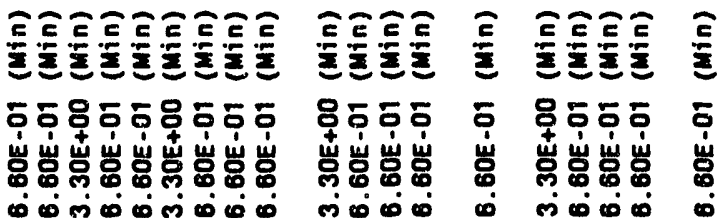

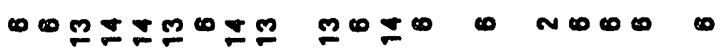

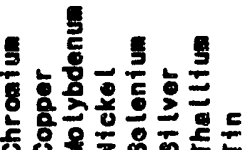

is




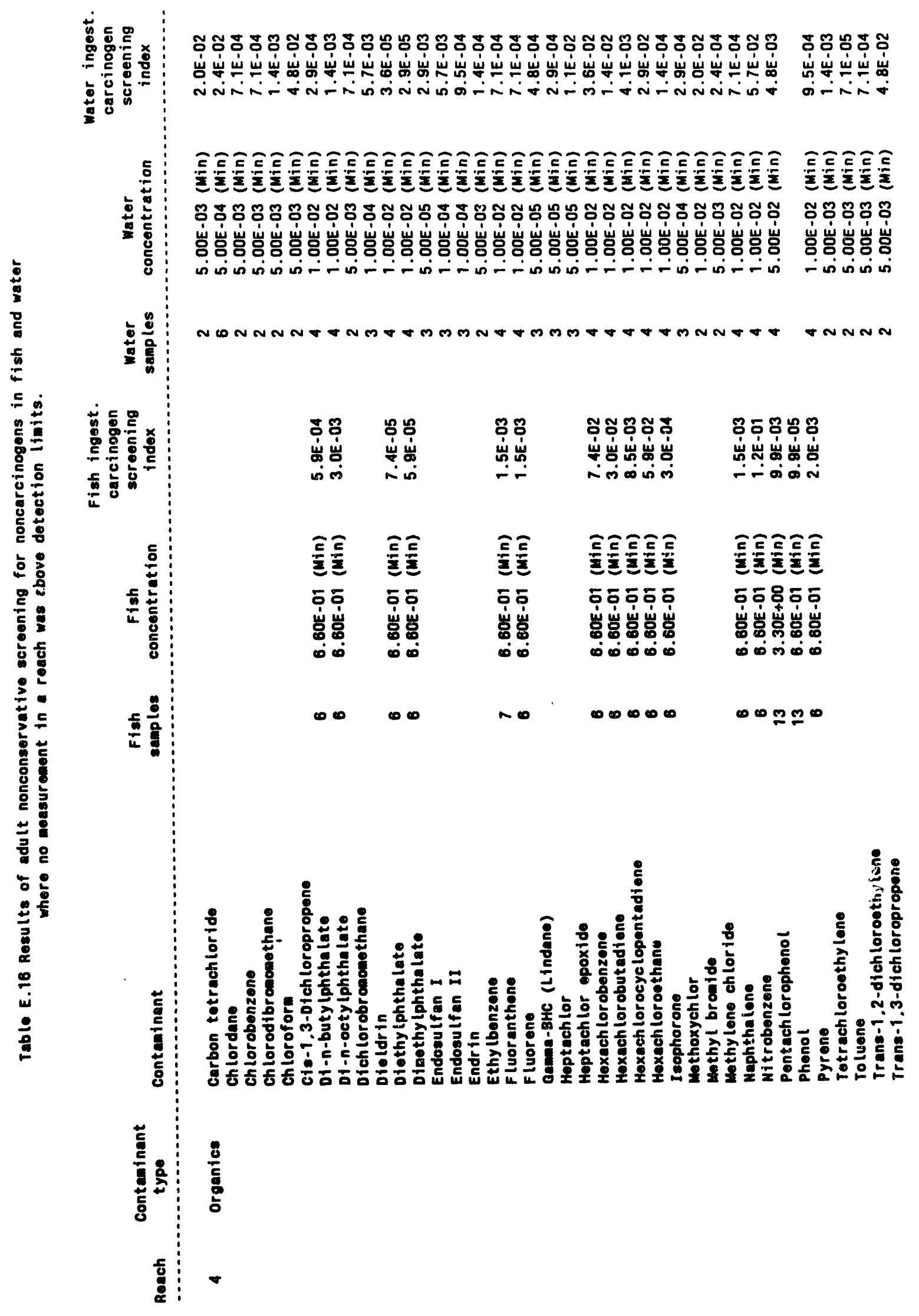




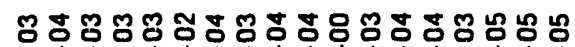

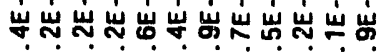

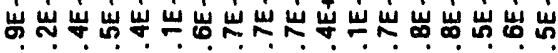

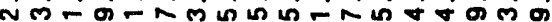

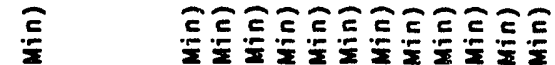

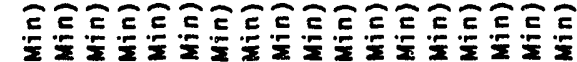

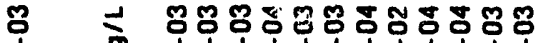

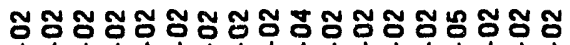

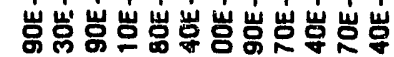

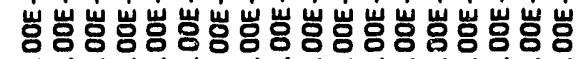
is $\because$ minotion

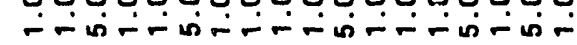

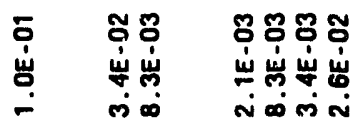

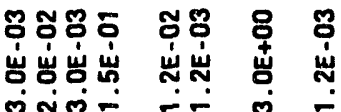

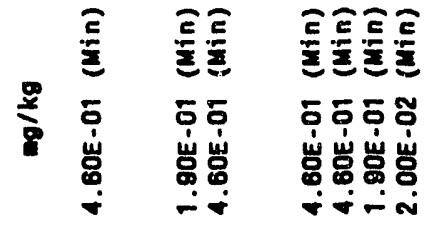

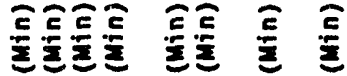

$\stackrel{9}{\mathrm{P}}$ 읗ㅇㅇ 후 8 후

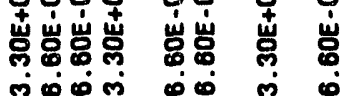

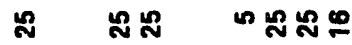

000000000

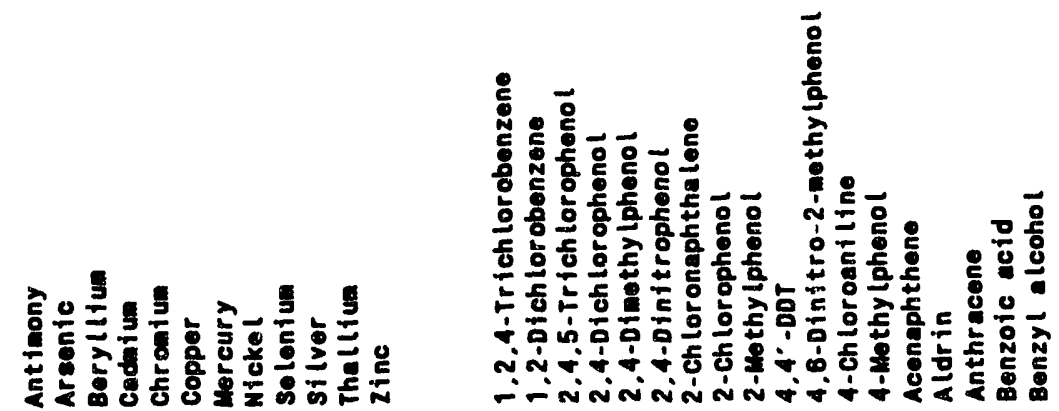

蒙

\begin{tabular}{ll}
8 & $\frac{8}{6}$ \\
\hline & 5 \\
\hline & 5
\end{tabular}

$\frac{8}{5}$ 


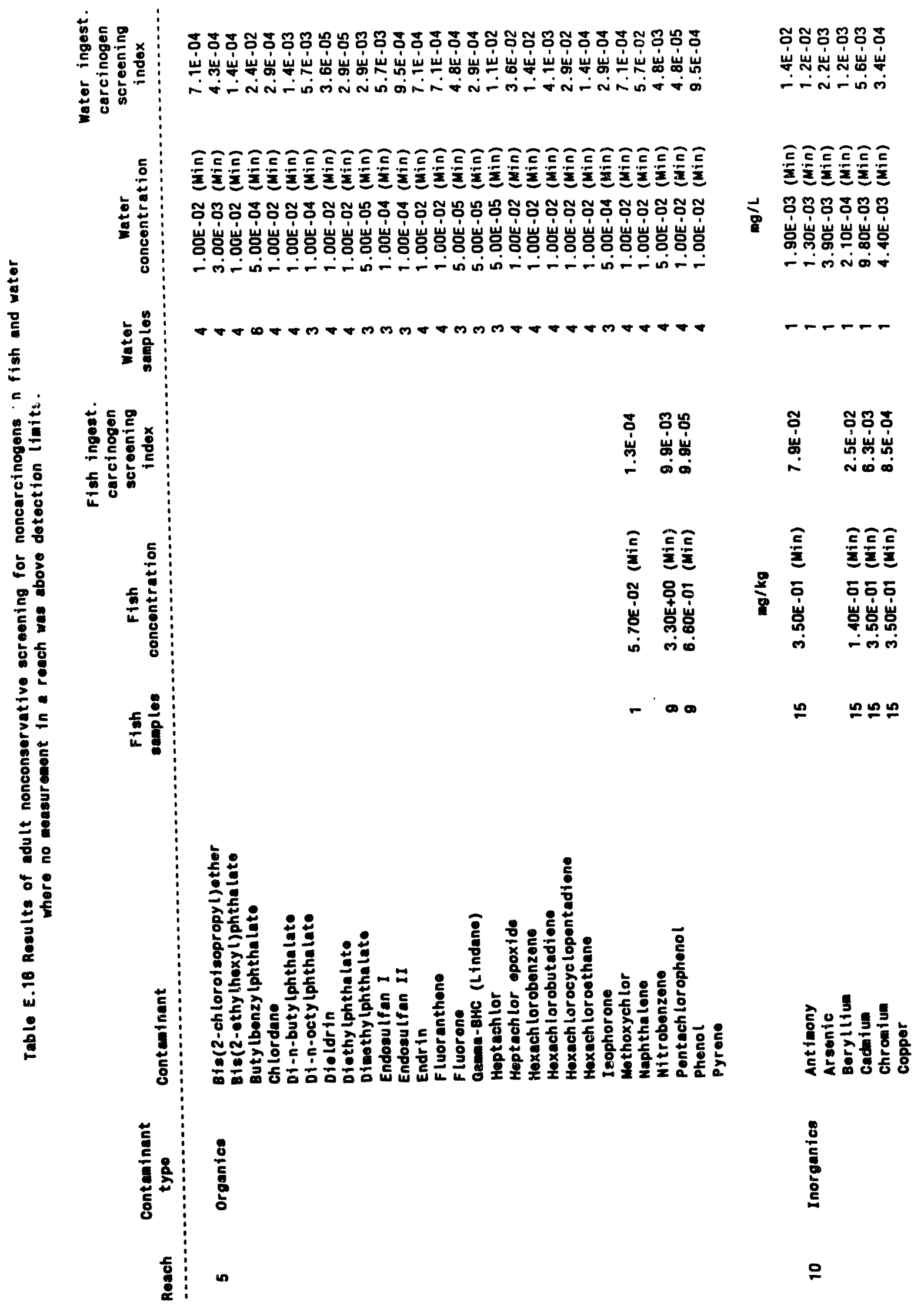




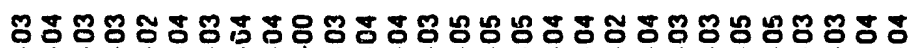
岩嵌岕岕出出

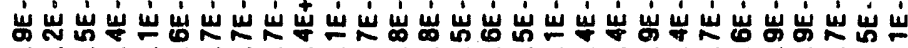

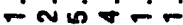

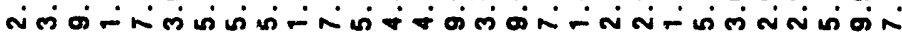

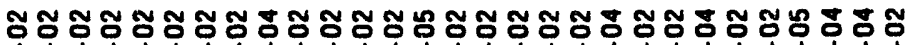
i-कiñ

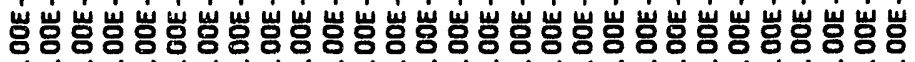

\% 용요

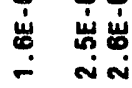

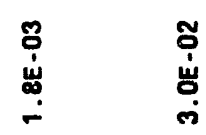

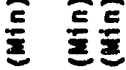

万人

岕 峞峞

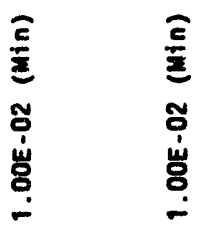

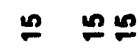

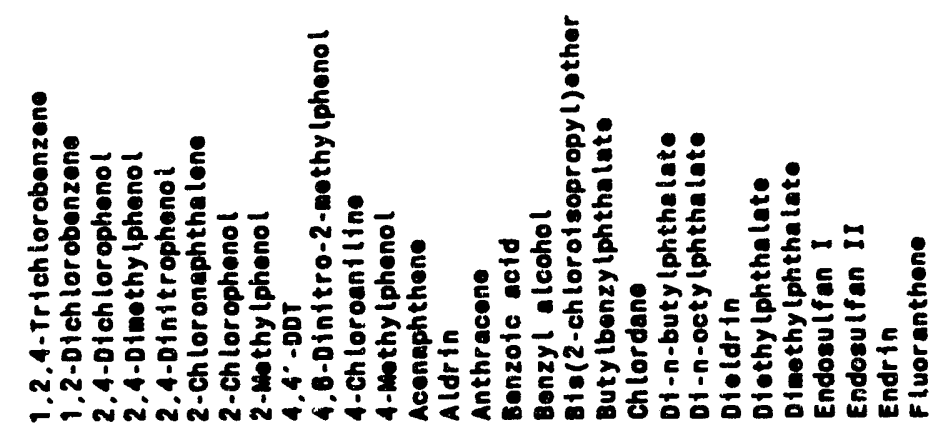

:

훌

$\underset{\dot{\omega}}{\tilde{\dot{\omega}}}$

产量

है

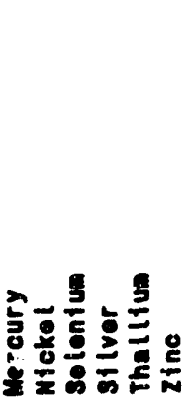

$$
\text { }
$$$$
\begin{array}{c:c}
\text { 동 } & \\
0 & 0
\end{array}
$$ 
E-110

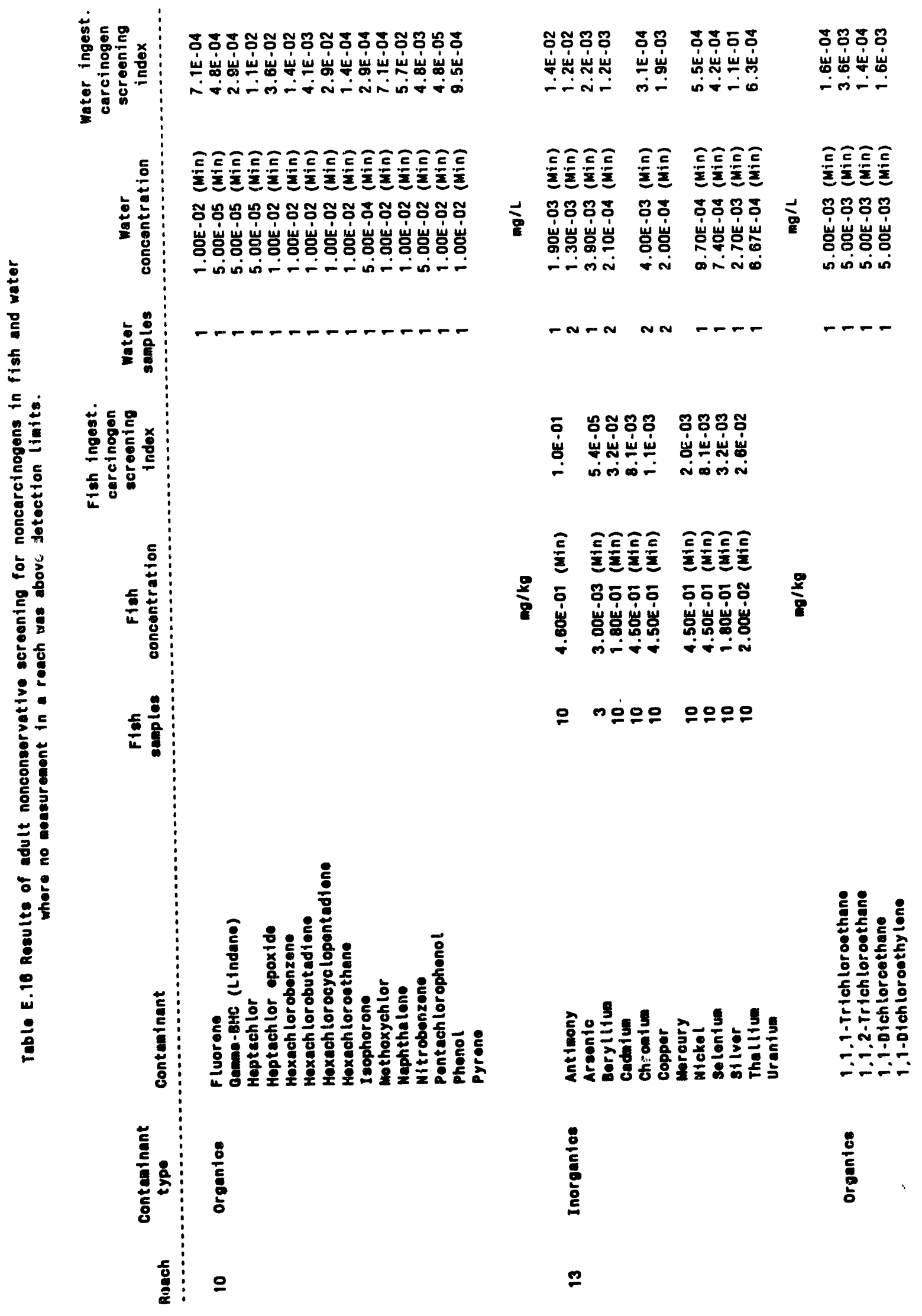




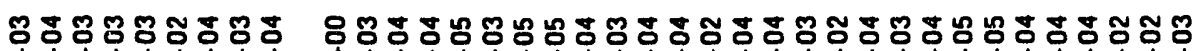

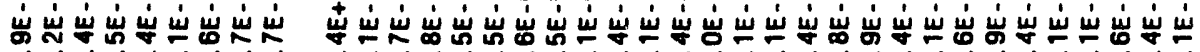

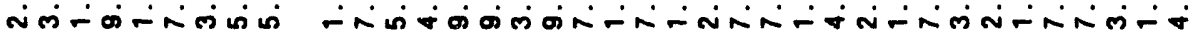

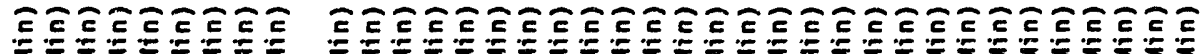

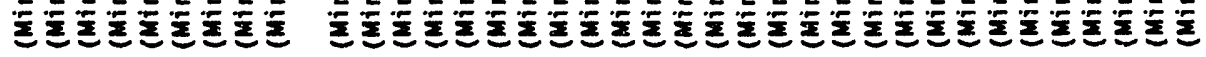

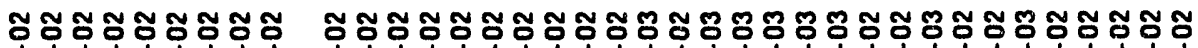

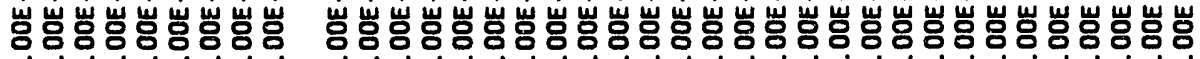

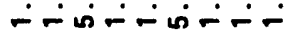
कि narnarann-mn- n-nn-n--h-nn-nn-nnnan

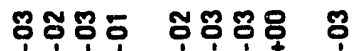

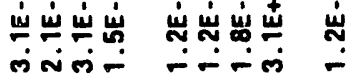

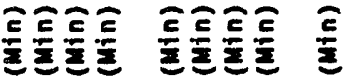

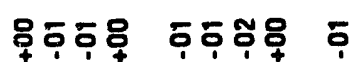

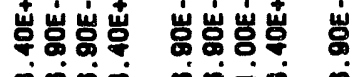

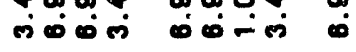

nenan namen n

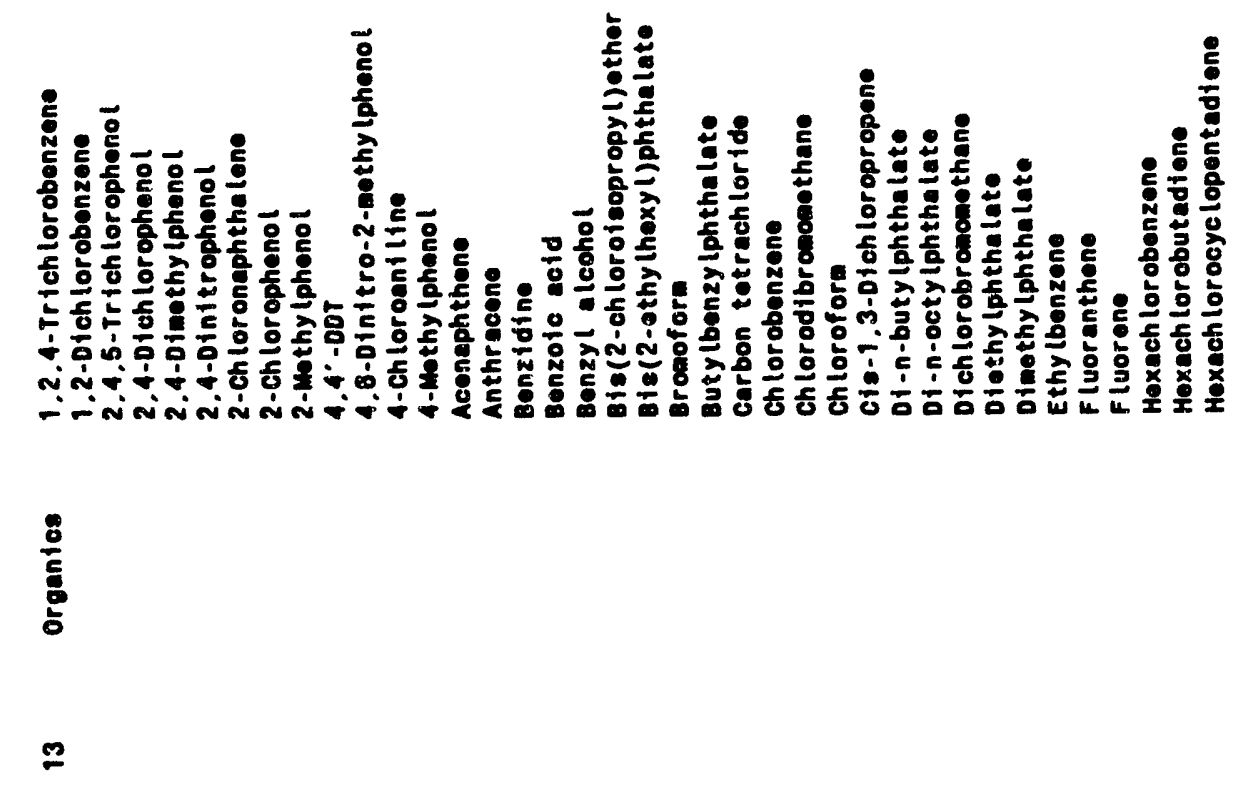




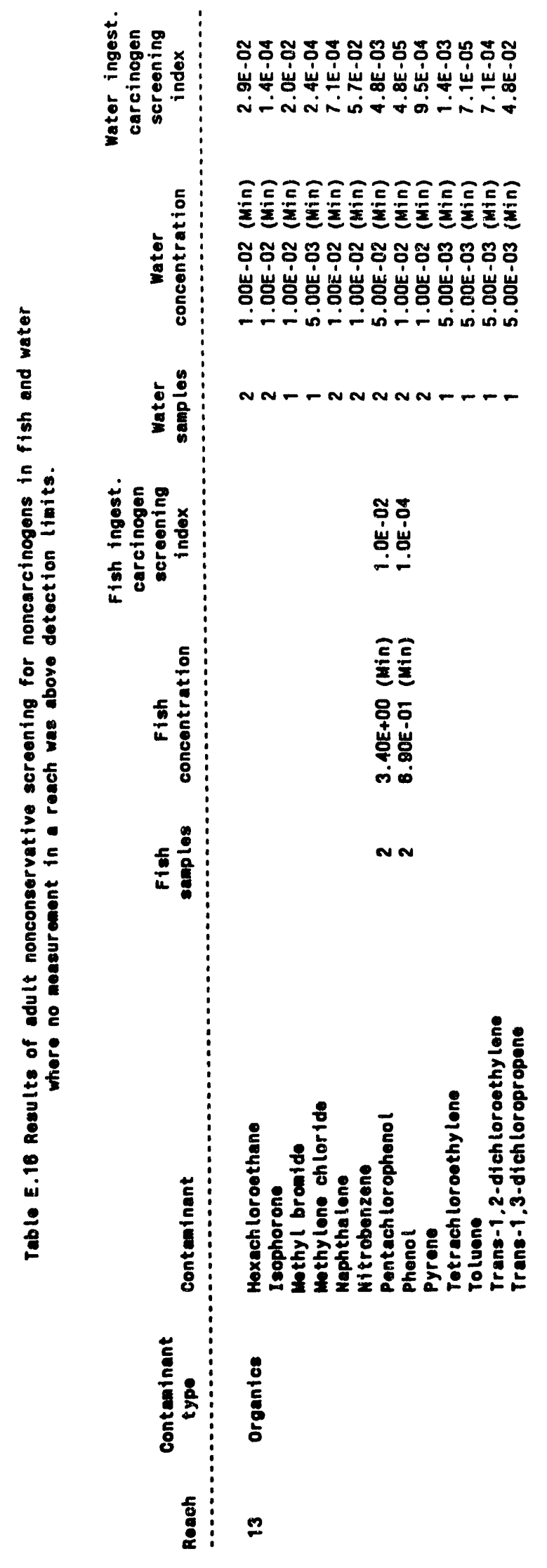




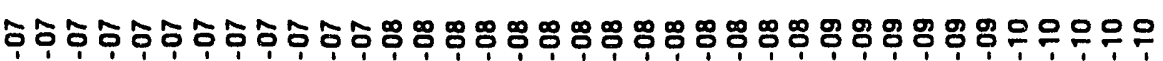

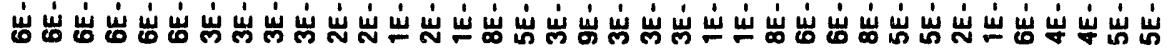
Bं

号

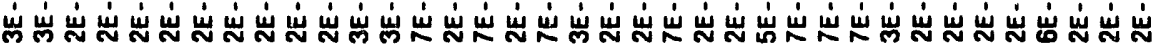

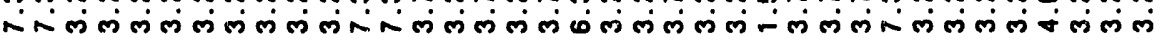

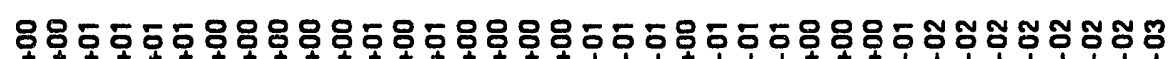

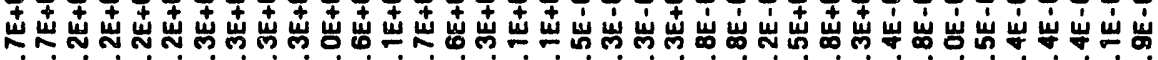

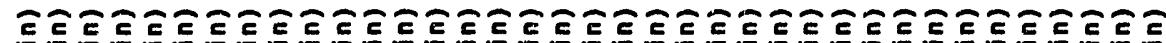

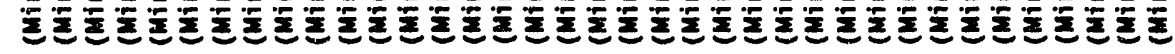

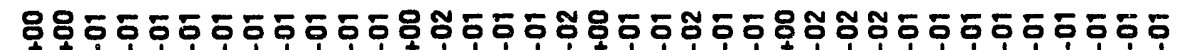

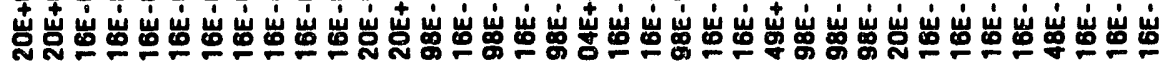

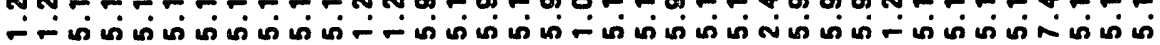

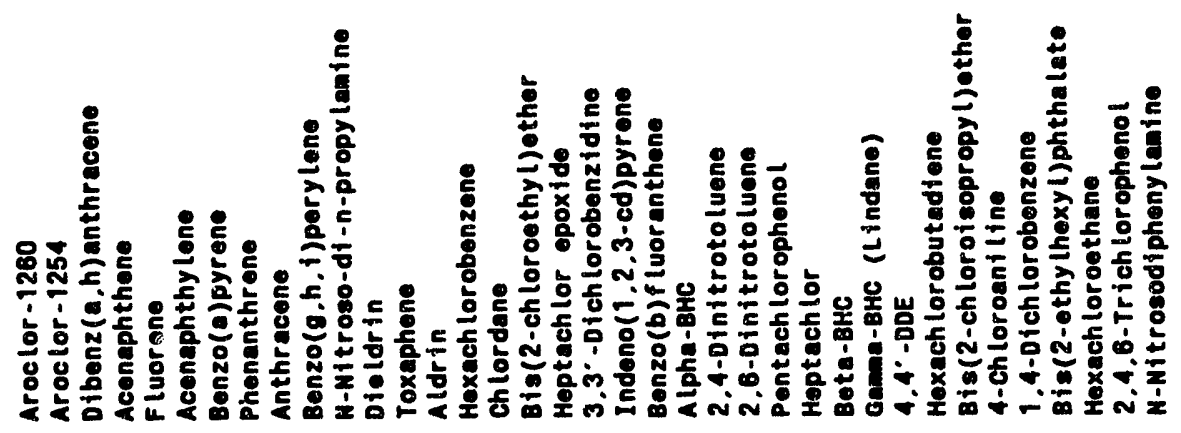


E-114

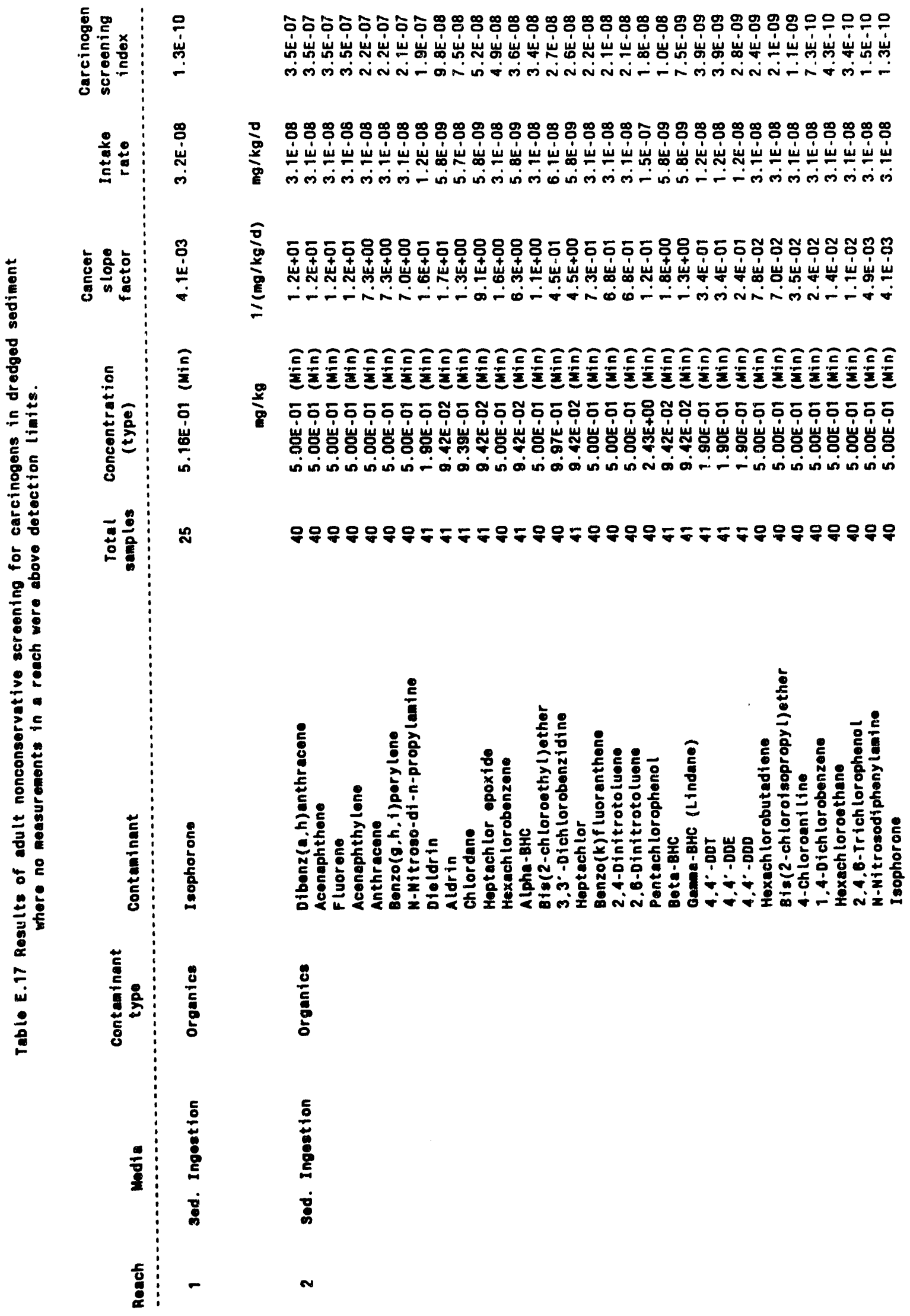




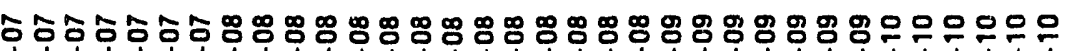

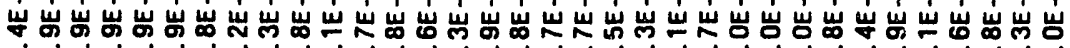
$\dot{\nabla}$ ก

央

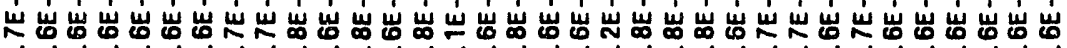

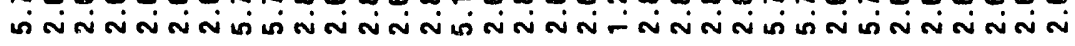

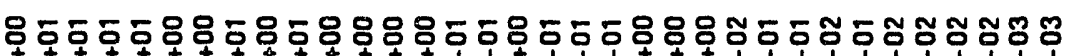

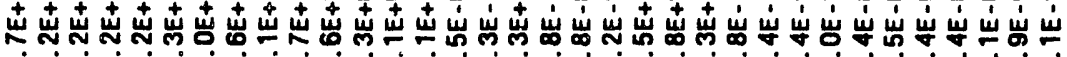

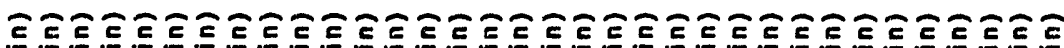

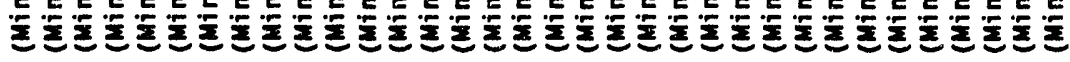

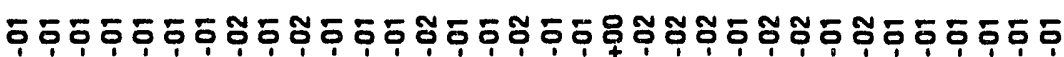

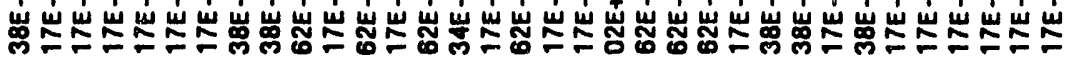

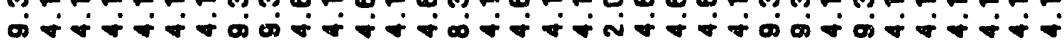

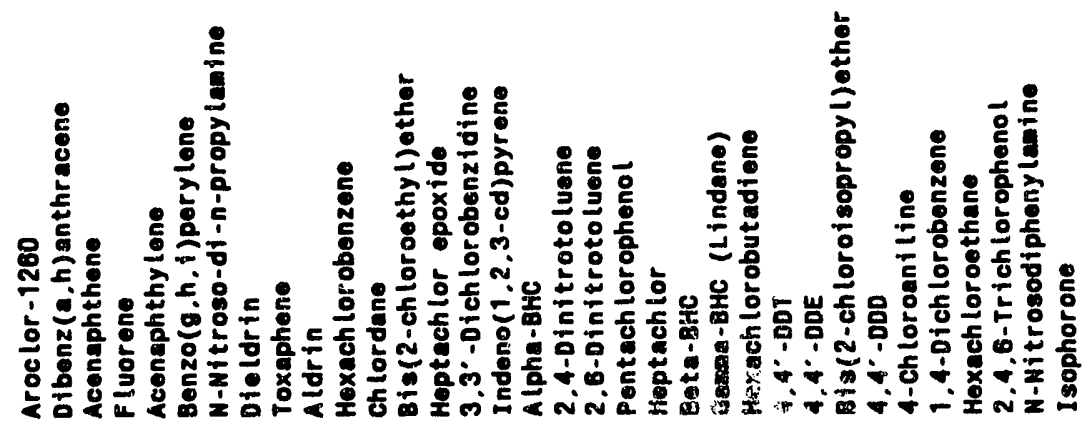

$\frac{8}{5}$

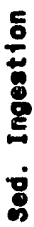

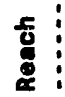

$\infty$ 


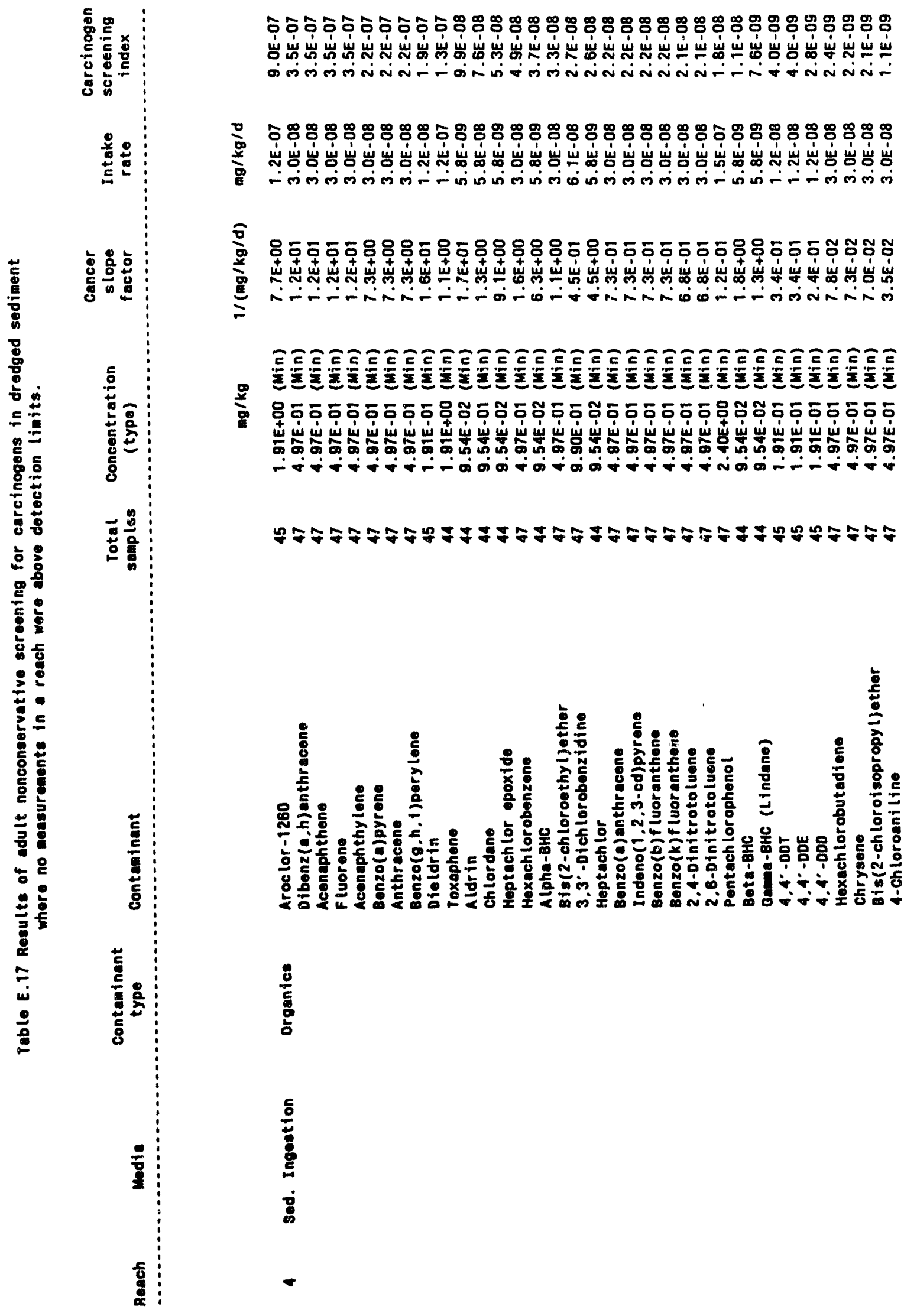




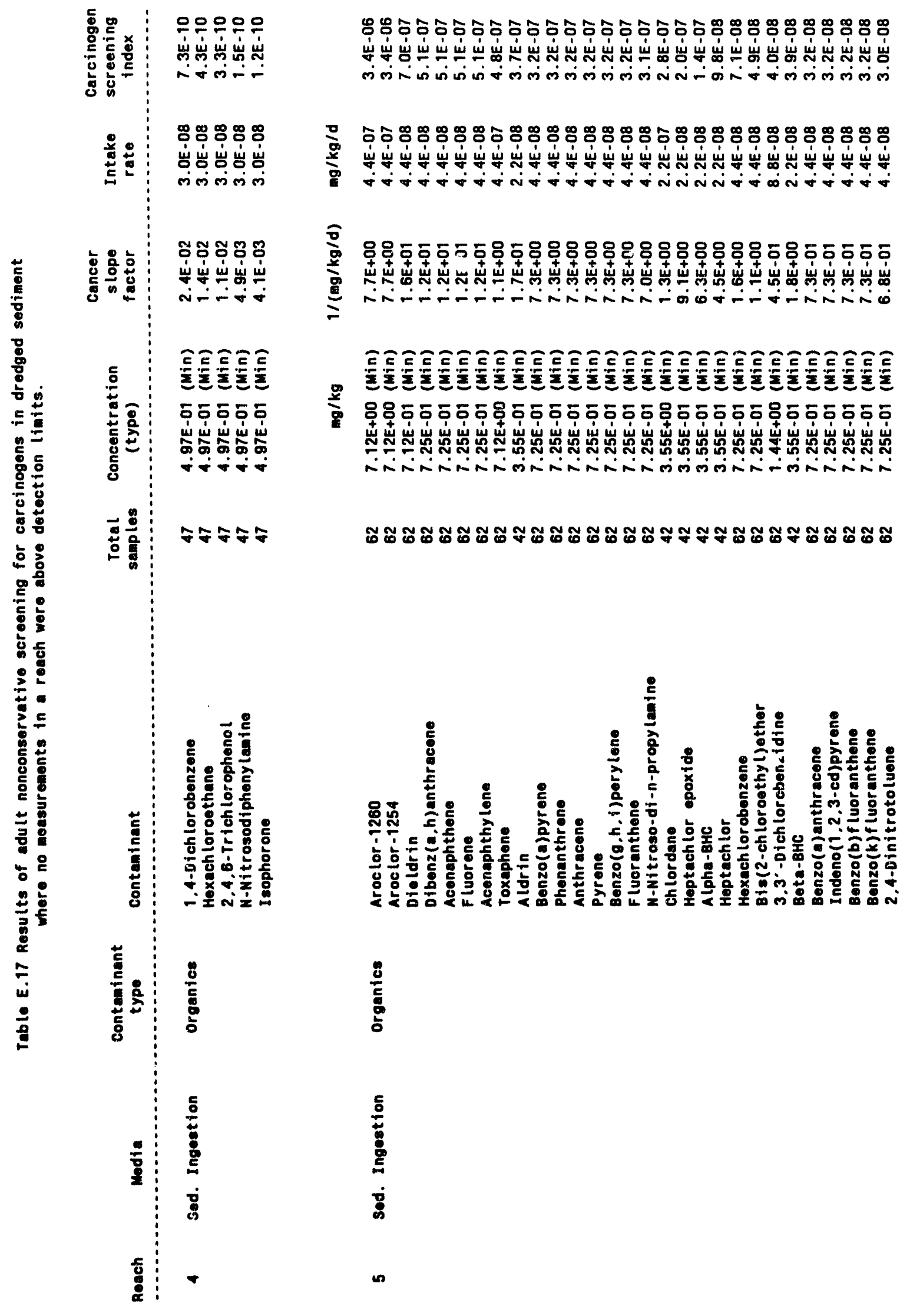




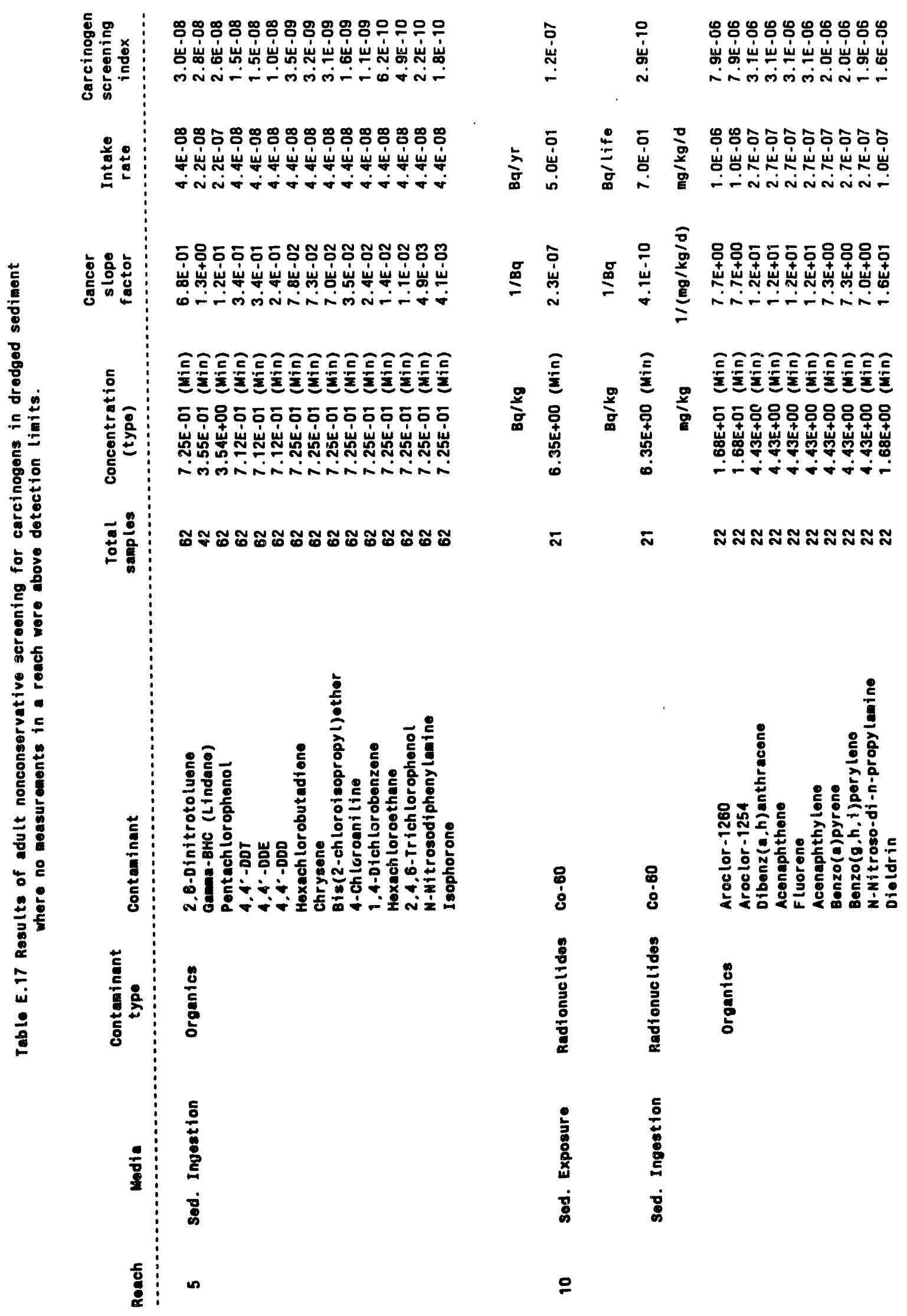




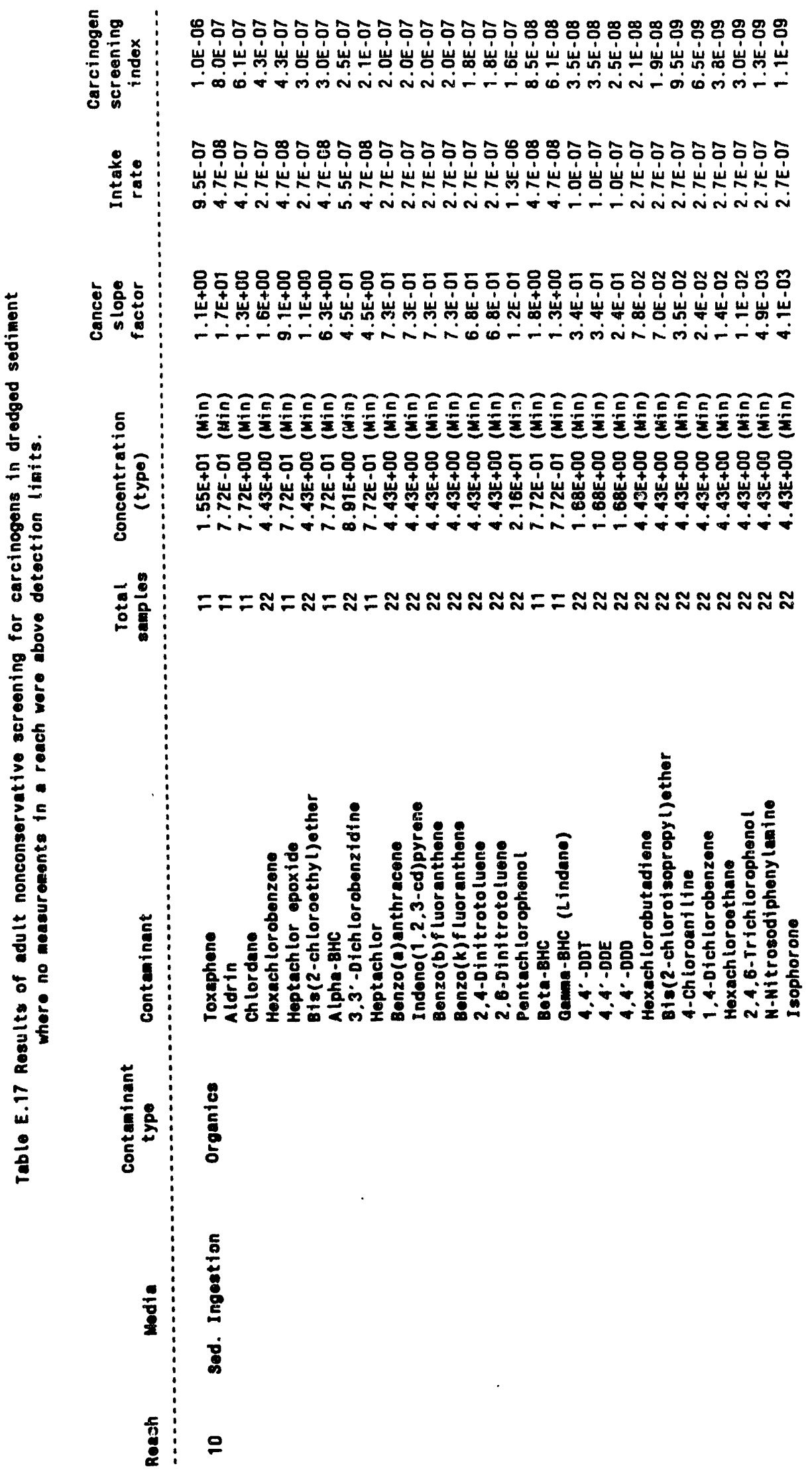




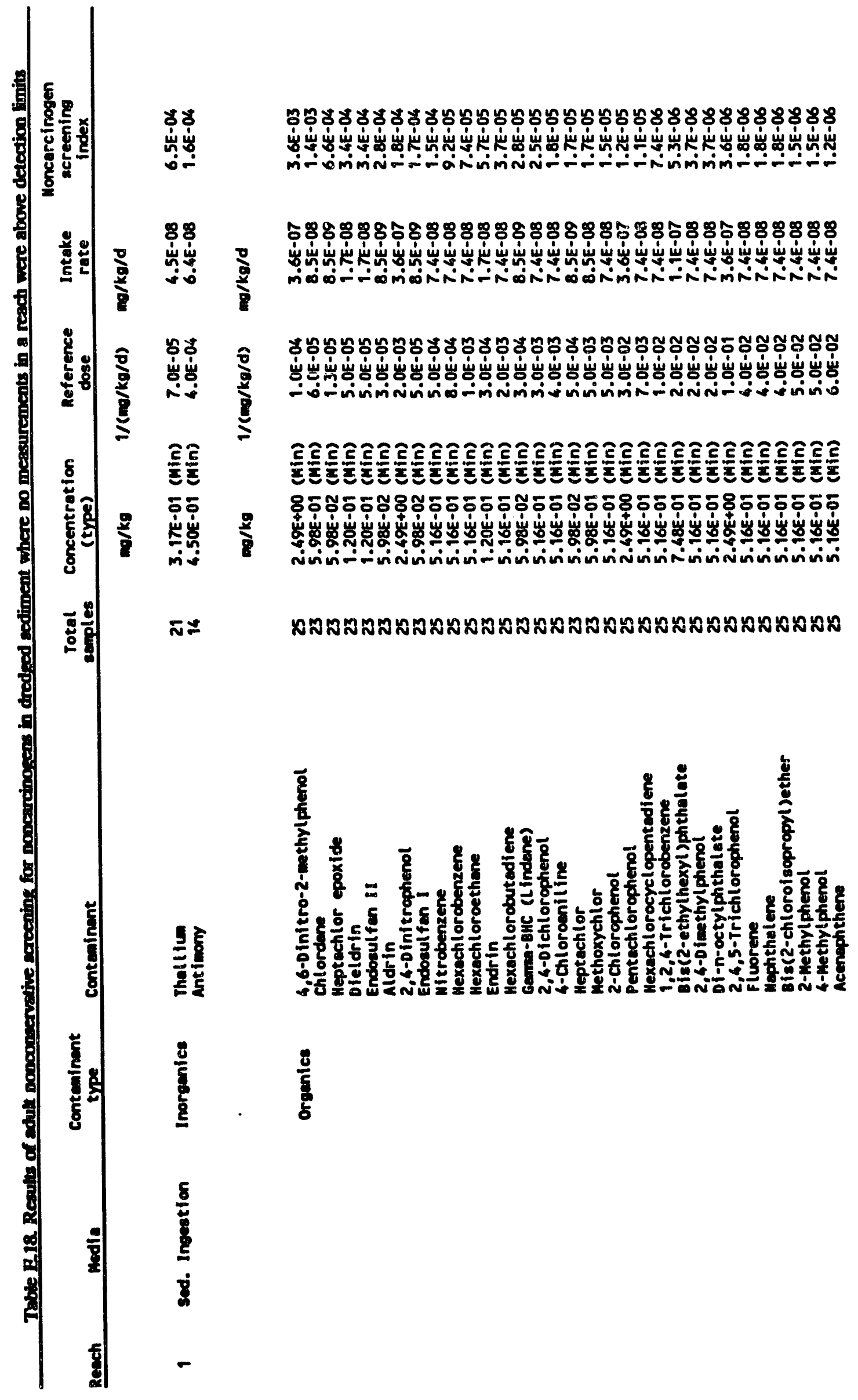




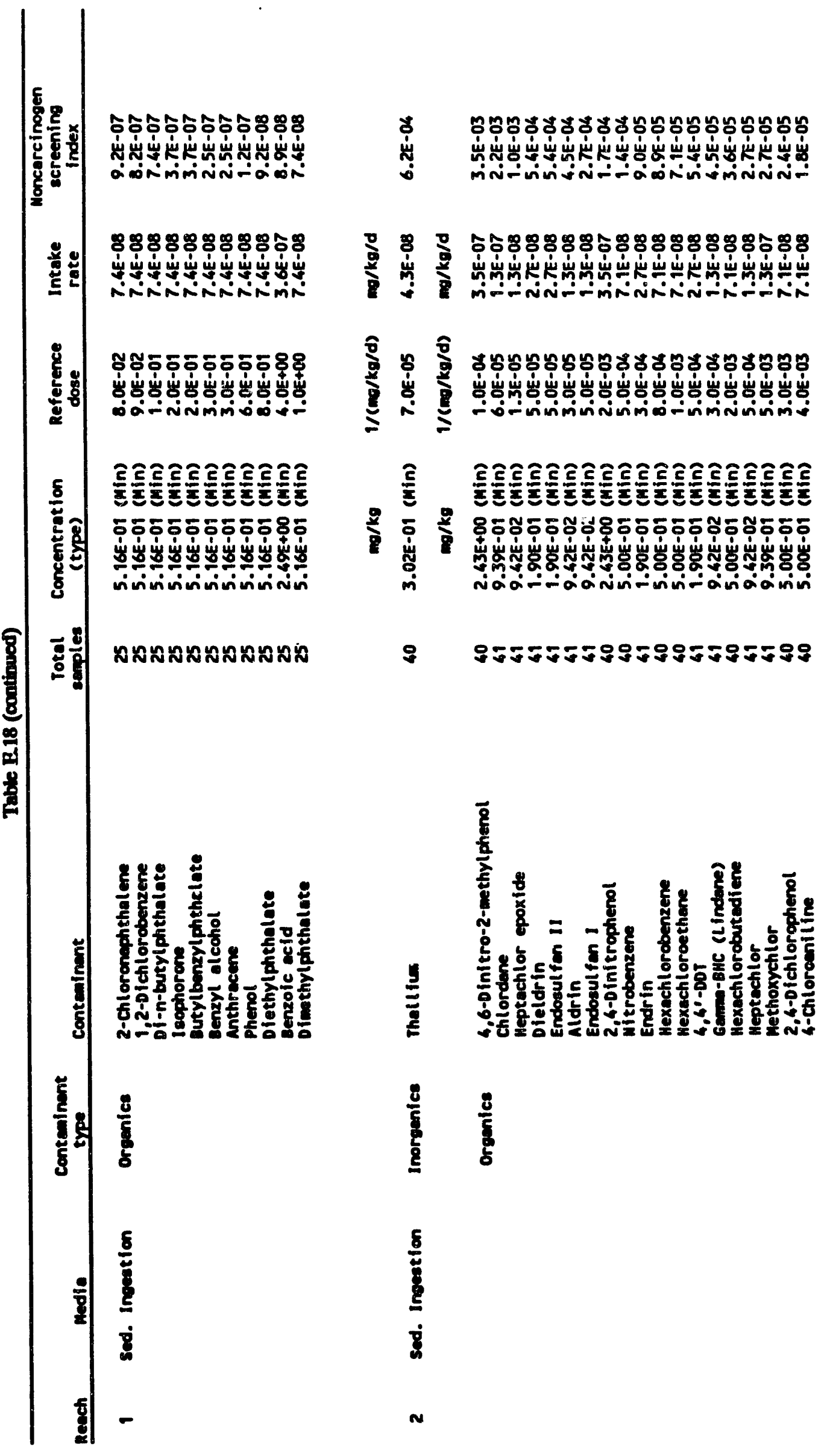




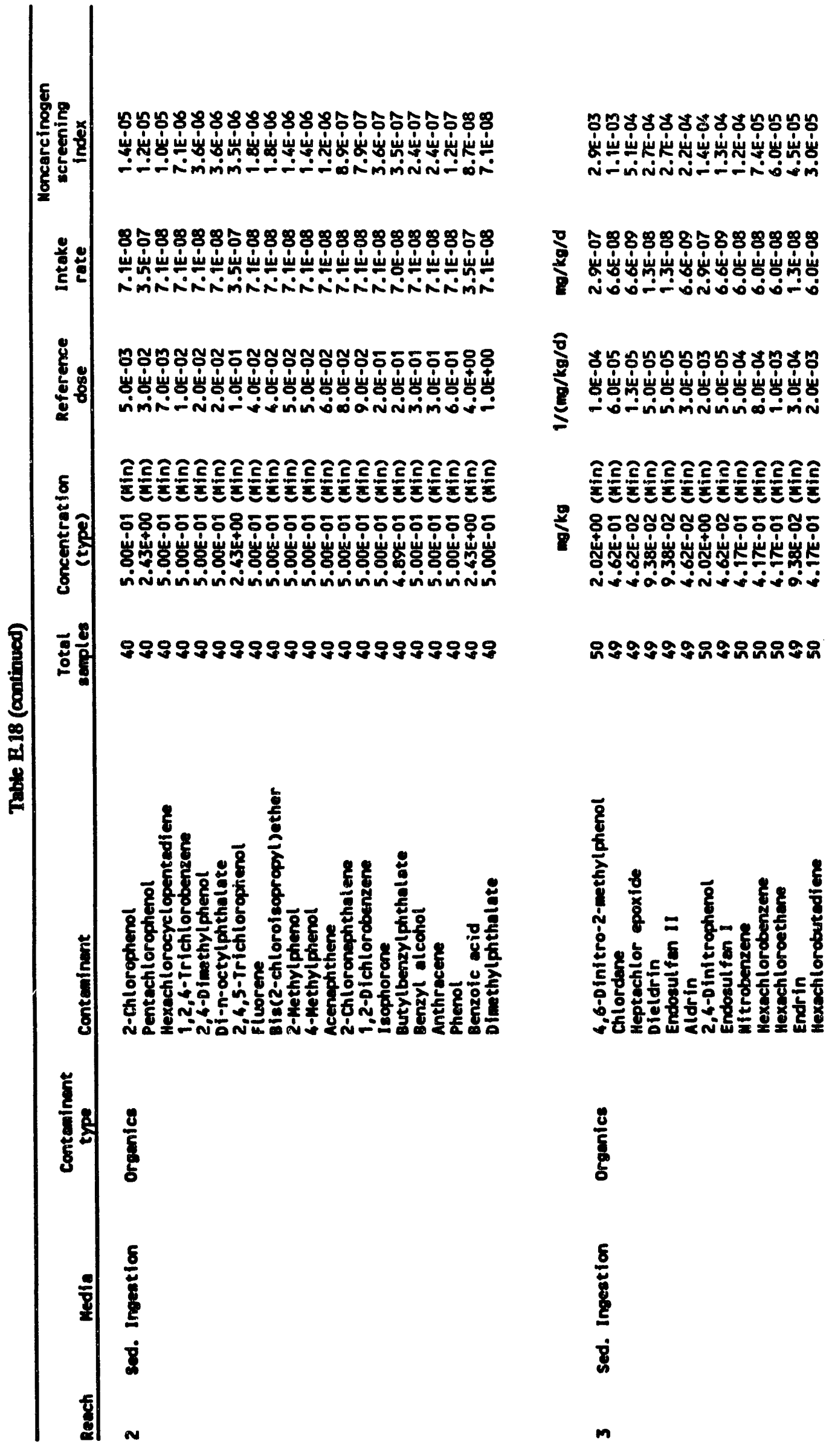




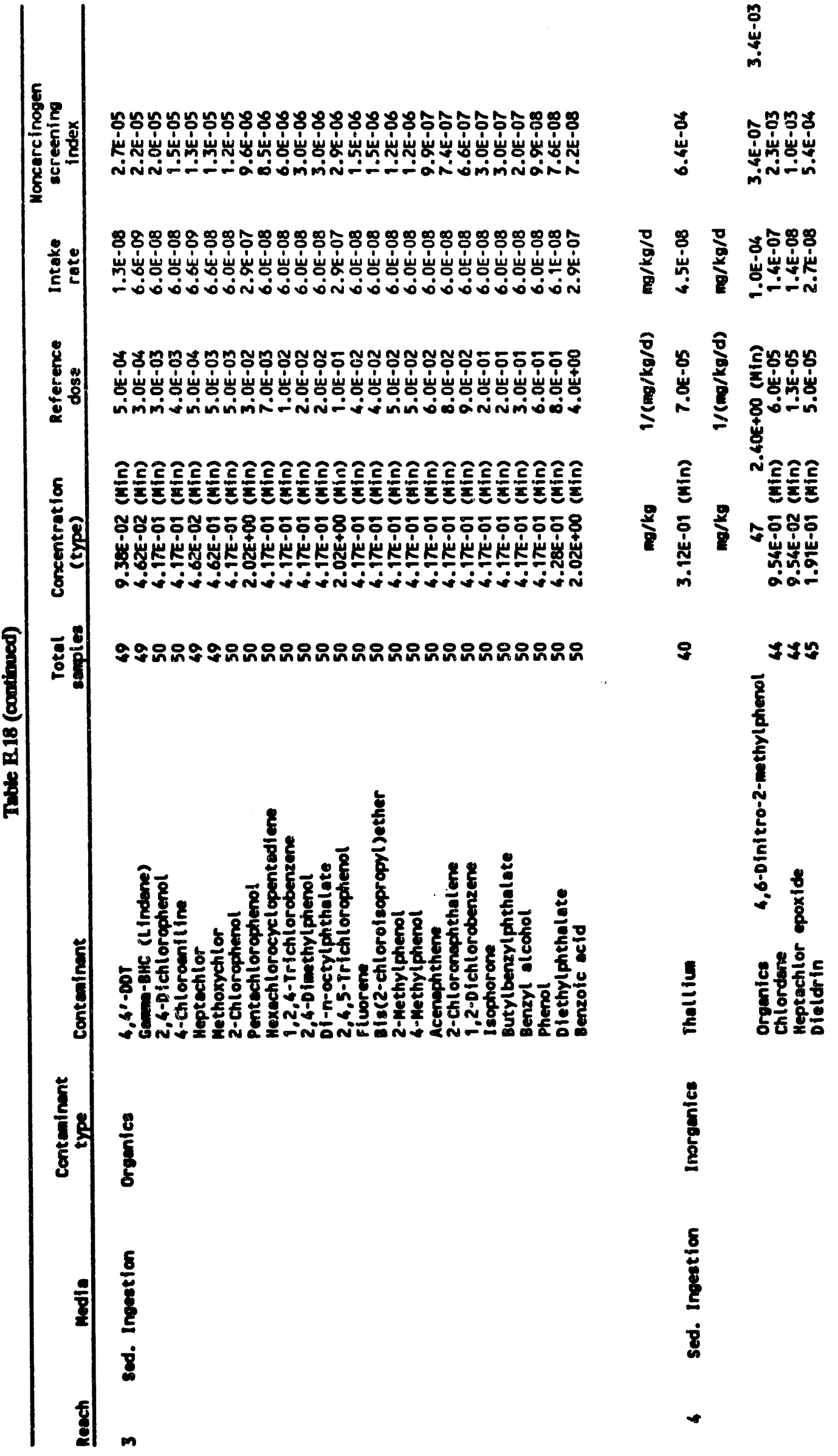




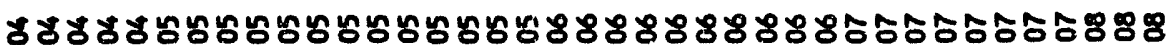

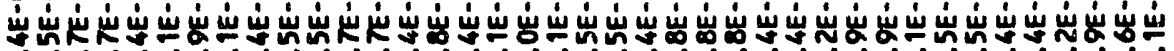

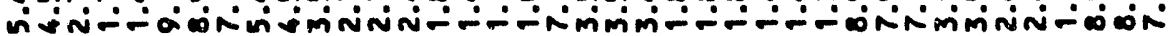

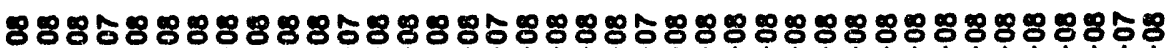

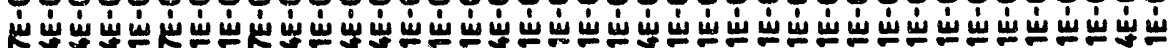

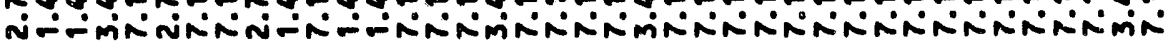

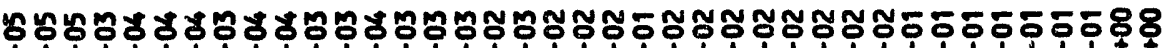

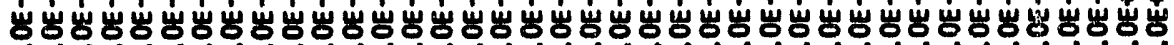

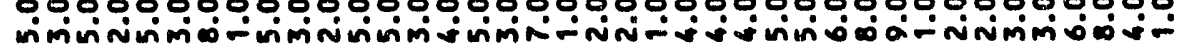

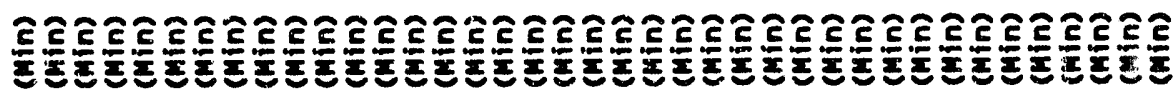

8

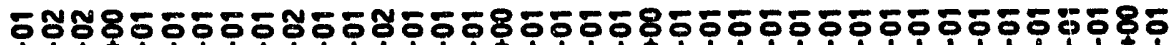

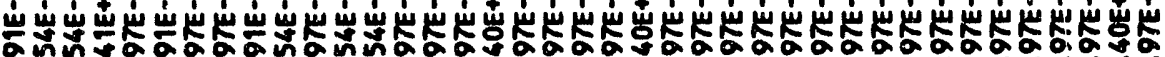

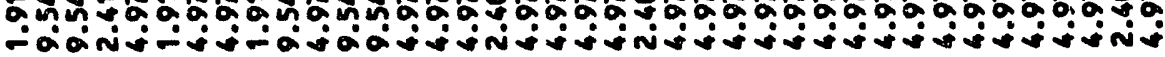
ठㅇ

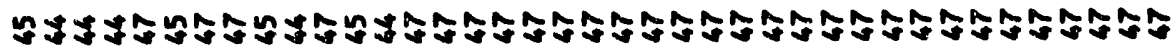


E-125

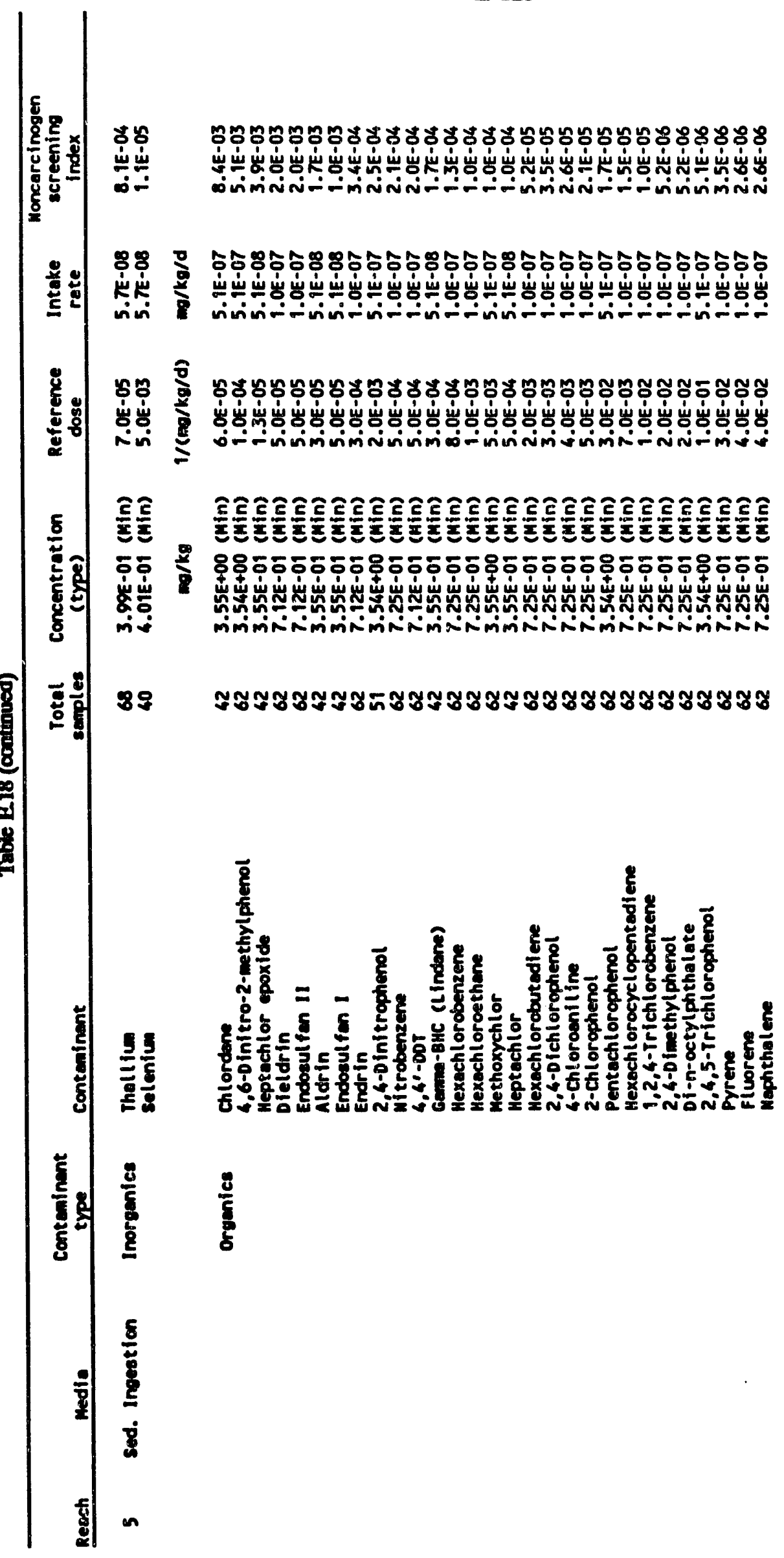




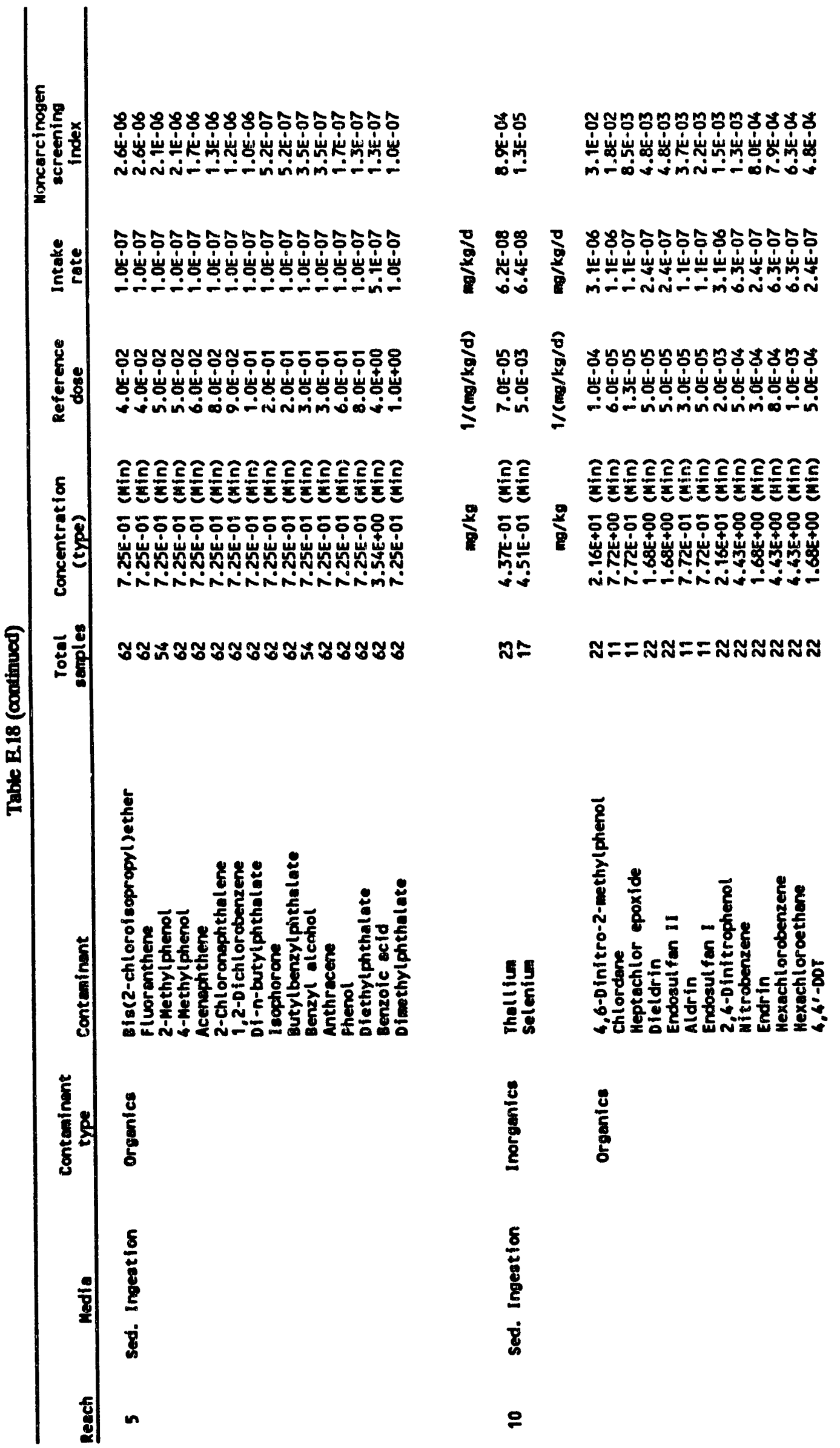



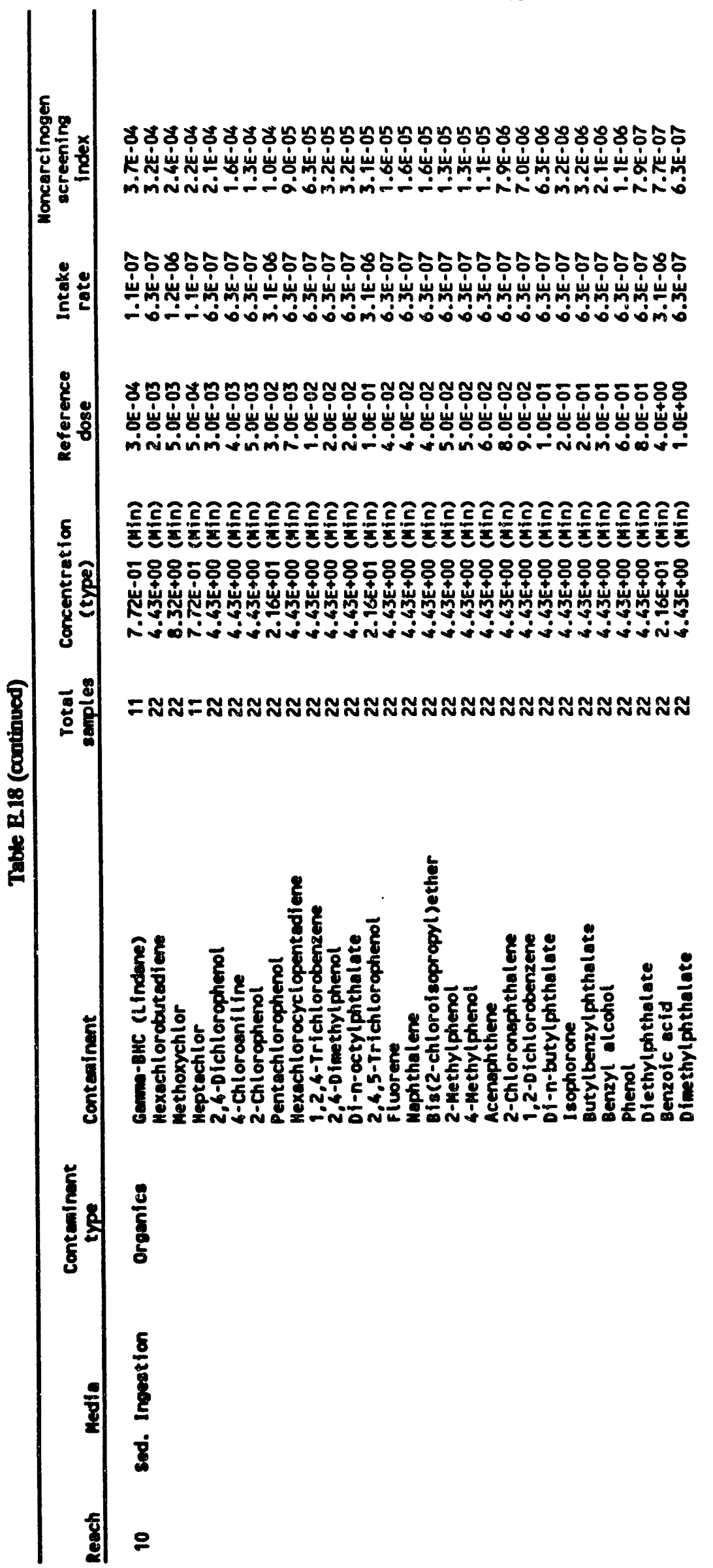


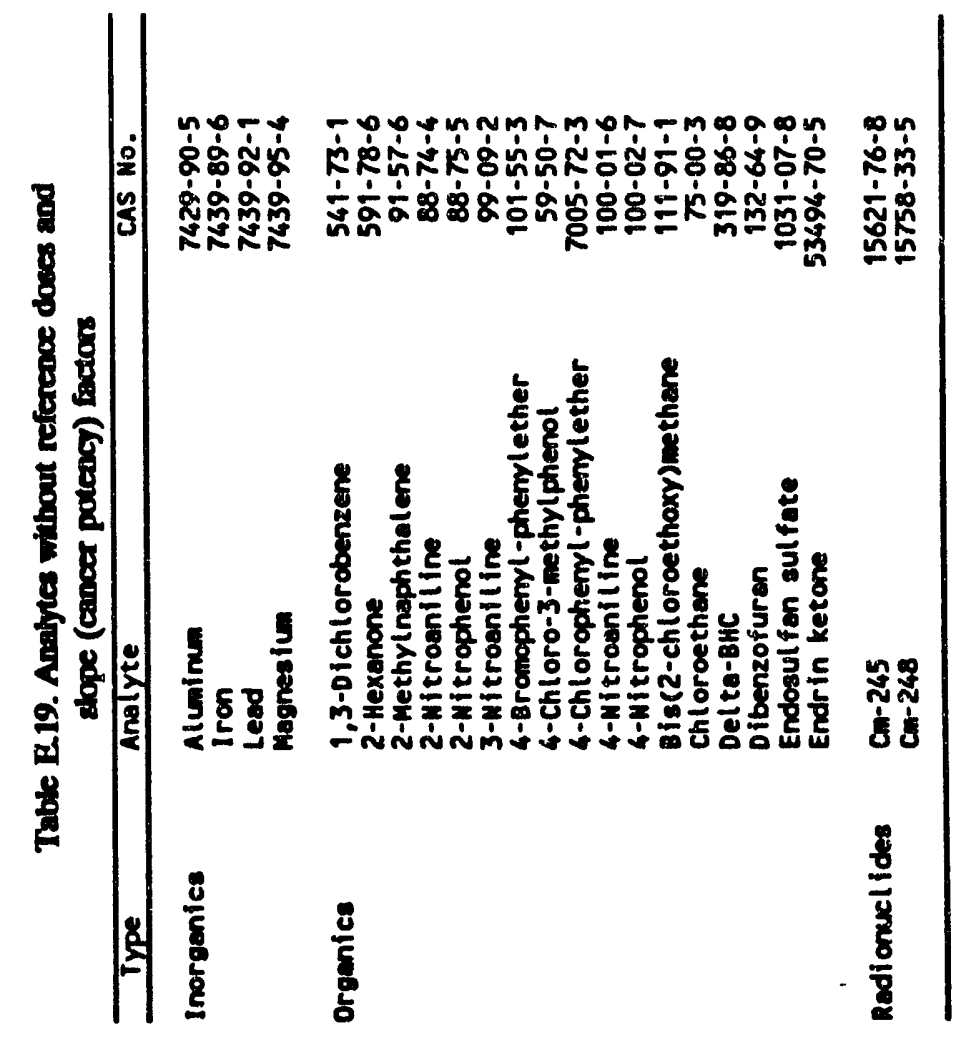


Appendix F

\section{ECOLOGICAL RISK METHODS}


CONTENTS OF APPENDIX F

F.1 DATA SUMMARIZATION FOR ECOLOGICAL RISK ASSESSMENT $\ldots \ldots \ldots \ldots \ldots \ldots$

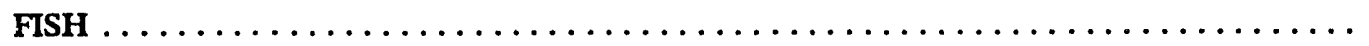

\section{TABLES}

F.1 Mean and upper confidence limit (UCL) concentrations of chemicals detected in the dissolved phase of CRRI water samples $(\mu g / L)$, toxicological benchmarks $(\mu g / L)$, and

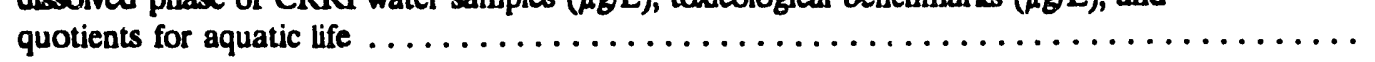

F.2 Limits of detection of chemicals not detected in the dissolved phase of the CRRI water samples $(\mu g / L)$, tocicological benchmarks $(\mu g / L)$, and quotients for aquatic life $\ldots \ldots \ldots \ldots \ldots$

F.3 Mean and upper confidence limit (UCL) concentrations of chemicals detected in NPDES water samples $(\mu g / L)$, toxicological benchmarks $(\mu g / L)$, and quotients for aquatic life

F.4 Limits of detection of chemicals not detected in NPDES water samples $(\mu \mathrm{g} / \mathrm{L})$, toxicological benchmarks $(\mu \mathrm{g} / \mathrm{L})$, and quotients for aquatic life .

F.5 Mean and upper confidence limit (UCL) concentrations of chemicals detected in fish $(\mu \mathrm{g} / \mathrm{L})$, bioconcentration factors, estimated exposure in water $(\mu \mathrm{g} / \mathrm{L})$, and quotients for exposure to that water concentration

F.6 Limits of detection of chemicals not detected in fish $(\mu \mathrm{g} / \mathrm{L})$, bioconcentration factors, estimated exposure in water $(\mu \mathrm{g} / \mathrm{L})$, and quotients for exposure to that water concentration ..... F-66

F.7 Concentrations of inorganic chemicals detected in sediment $(\mu \mathrm{g} / \mathrm{L})$, toxicological benchmarks $(\mu \mathrm{g} / \mathrm{L})$, and quotients for benthic aquatic life

F.8 Detection limits for inorganic chemicals not detected in sediment $(\mu \mathrm{g} / \mathrm{L})$, toricological benchmarks $(\mu g / L)$, and quotients for benthic aquatic life

F.9 Mean and upper confidence limit (UCL) concentrations of organic chemicals detected in sediment $(\mu \mathrm{g} / \mathrm{L})$, toxicological benchmarks $(\mu \mathrm{g} / \mathrm{L})$, and quotients for benthic aquatic life

F.10 Detection limits for organic chemicals not detected in sediment $(\mu \mathrm{g} / \mathrm{L})$, estimated pore water concentrations $(\mu \mathrm{g} / \mathrm{L})$, toricological benchmarks $(\mu \mathrm{g} / \mathrm{L})$, and quotients for benthic

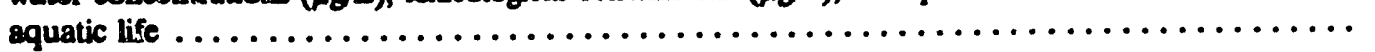

F.11 Mean and upper confidence limit (UCL) concentrations of chemicals in fish fillets (mg/kg), toxicological benchmarks for wildlife $(\mathrm{mg} / \mathrm{kg})$, and quotients for hazards to piscivorous wildife

F.12 Minimum and upper confidence limit (UCL) detection limits for chemicals not detected in fish fillets (mg/kg), taxicological benchmarks for wildlife ( $\mathrm{mg} / \mathrm{kg})$, and quotients for bazards to piscivorous wildlife 


\section{F.1 DATA SUMMMARIZATION FOR ECOLOGICAL RISK ASSESSMENT}

The presentation of results of the analyses for the selected analytes (Table A.1) provides a comprehensive view of the extent of contamination in the three media. However, for the risk assessment, these data must be summarized as typical and extreme exposure concentrations. For detected chemicals, mean concentrations and the upper $95 \%$ confidence limits of the mean concentrations were considered. The mean concentrations are assumed to represent typical chronic exposures. Upper $95 \%$ confidence limits may represent local extreme chronic concentrations or acute exposures. For undetected chemicals, minimum detection limits and the upper $95 \%$ confidence limits of the mean of the detection limits were the concentrations considered.

Only $10 \%$ of the determinations were above their respective method detection limit. This is a commor, observation for regulatory driven environmental sampling and analysis activities. It follows that $90 \%$ of the analyte determinations were not detected above their respective analytical method detection limits in CRRI samples. For the screening risk analyses, a distinction was made between detected contaminants, contaminants with at least one detected value in a given reach, and nondetected contaminants, contaminants with no detected values in a reach. Separate analyses and interpretations of these results were required.

The following sections describe the specific data manipulations performed for each of the selected media results.

\section{F2 FISH}

\section{F21 Subsetting}

Data were combined for all fish species within a reach for all chemicals except for PCBs. Only catfish results were used for PCBs. Only detected chlordane isomer values were summed. Only regular samples-no field duplicates-were used.

\section{F22 Summary Statistics}

\section{F221 Detected contaminants}

Given the potential for means of distributions with numerous non-detect values (censored data) to be positively biased, the upper 95\% confidence limit of the arithmetic mean and the geometric mean were estimated using maximum likelihood estimator calculations (SAS PROC LIFEREG). The upper 95\% confidence limit was compared with the actual maximum value and the lower value was used in the risk characterization. Detection limits were used as is.

\section{F222 Non-detected contaminants}

The upper $95 \%$ confidence limit of the arithmetic mean was calculated and compared to the maximum analyte detection limit. The smaller of the two values, along with the minimum detection limit were used for the exposure assessment. 


\section{F3 SEDIMENT CORES}

\section{F3.1 Subsetting}

Only analytical data for core segments from depths $\leq 6 \mathrm{~cm}$ were used.

\section{F3.2 Summary Statistics}

\section{F3.21 Detected contaminants}

The arithmetic mean concentration was calculated to a depth of $6 \mathrm{~cm}$. When there was more than one core per reach, the average for each core was calculated and then the upper 95\% confidence limit of the mean of the core averages, or the maximum core average, (whichever was smaller) was used as the value for the reach. The arithmetic mean of the core averages was used as the estimate of chronic exposure.

\section{F322 Non-detected contaminants}

The upper $95 \%$ confidence limit of the arithmetic mean was calculated and compared to the maximum analyte detection limit. The smaller of the two values, along with the minimum detection limit was used for the exposure assessment.

\section{F.4 WATER}

\section{F.4.1 Subsetting}

\section{F.4.1.1 Dissolved constituents}

Dissolved metal concentrations and total organic concentrations from CRRI samples were used for one set of exposure assessments. Organic analyses were performed on unfiltered CRRI samples.

\section{F.4.1.2 Total concentrations}

Because dissolved concentrations were available for only the limited CRRI samples, total metal concentrations from unfiltered CRRI samples and all contaminant results from unfiltered ORR NPDES and environmental monitoring samples (Table E.1 and Fig. E.1) were included, but exposures were analyzed and discussed separately.

\section{F.4.2 Summary Statistics}

\section{F.421 Detected contaminants}

The values for the screening assessment for a given contaminant in a reach were calculated by first averaging all results at a location and then determining the upper $95 \%$ confidence limit of the mean of the location averages. Either the upper $95 \%$ confidence limit or the maximum location average, whichever was smaller, was used as the value for the reach. 


\section{F.422 Nondetected contaminants}

The upper $95 \%$ confidence limit of the arithmetic mean was calculated and compared to the maximum analyte detection limit. The smaller of the two values, along with the minimum detection limit was used for the exposure assessment. 
F-6

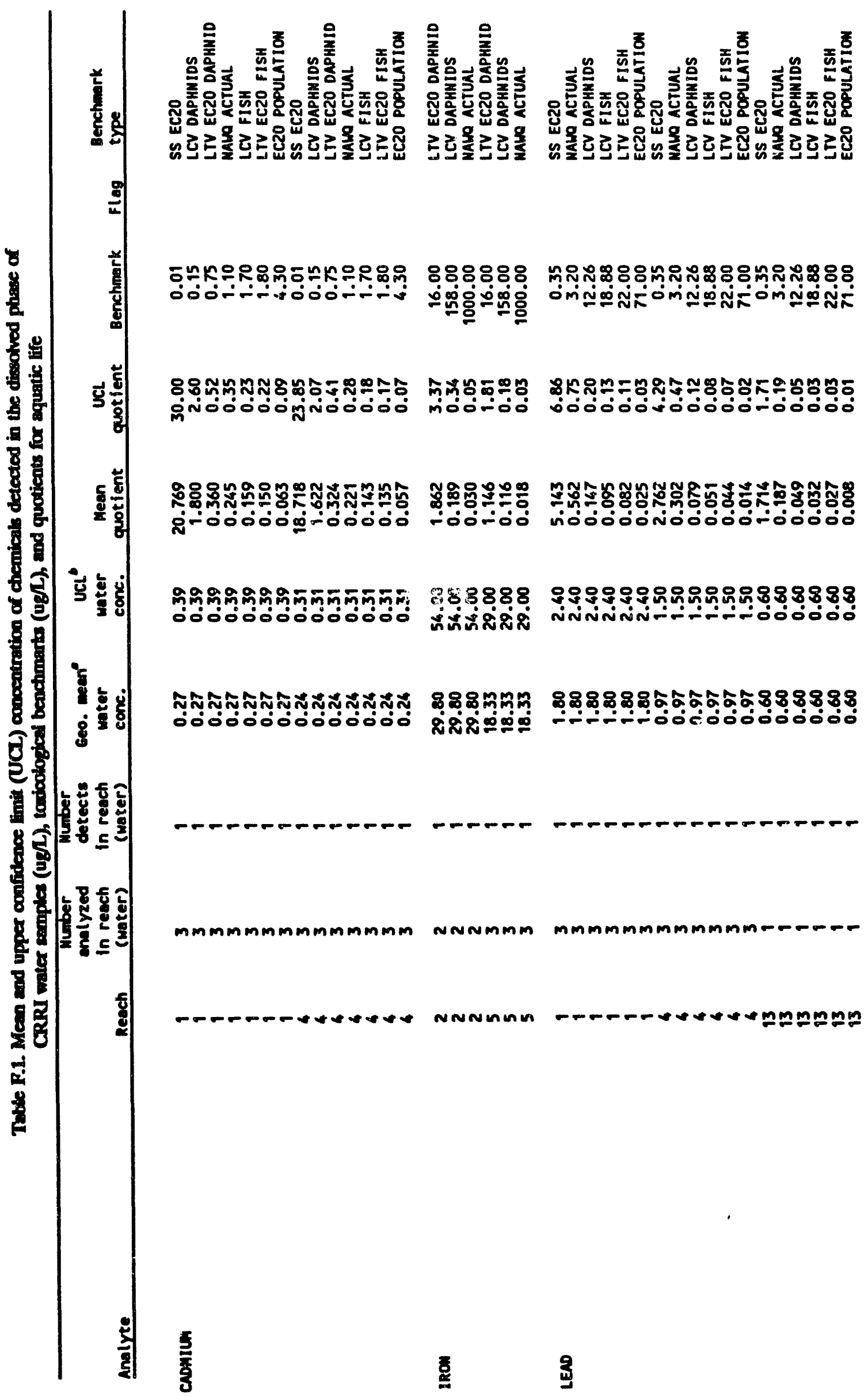


F-7

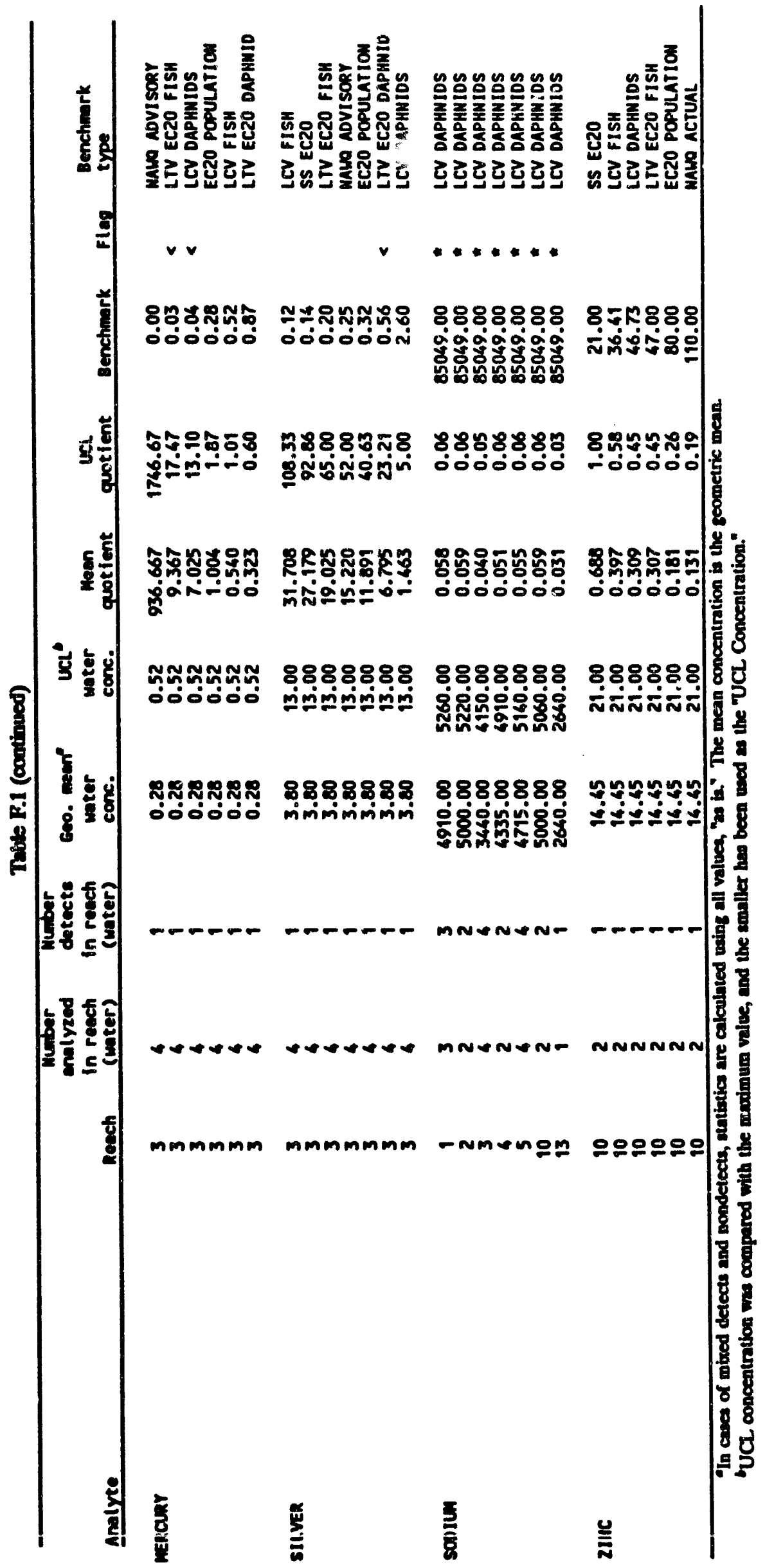




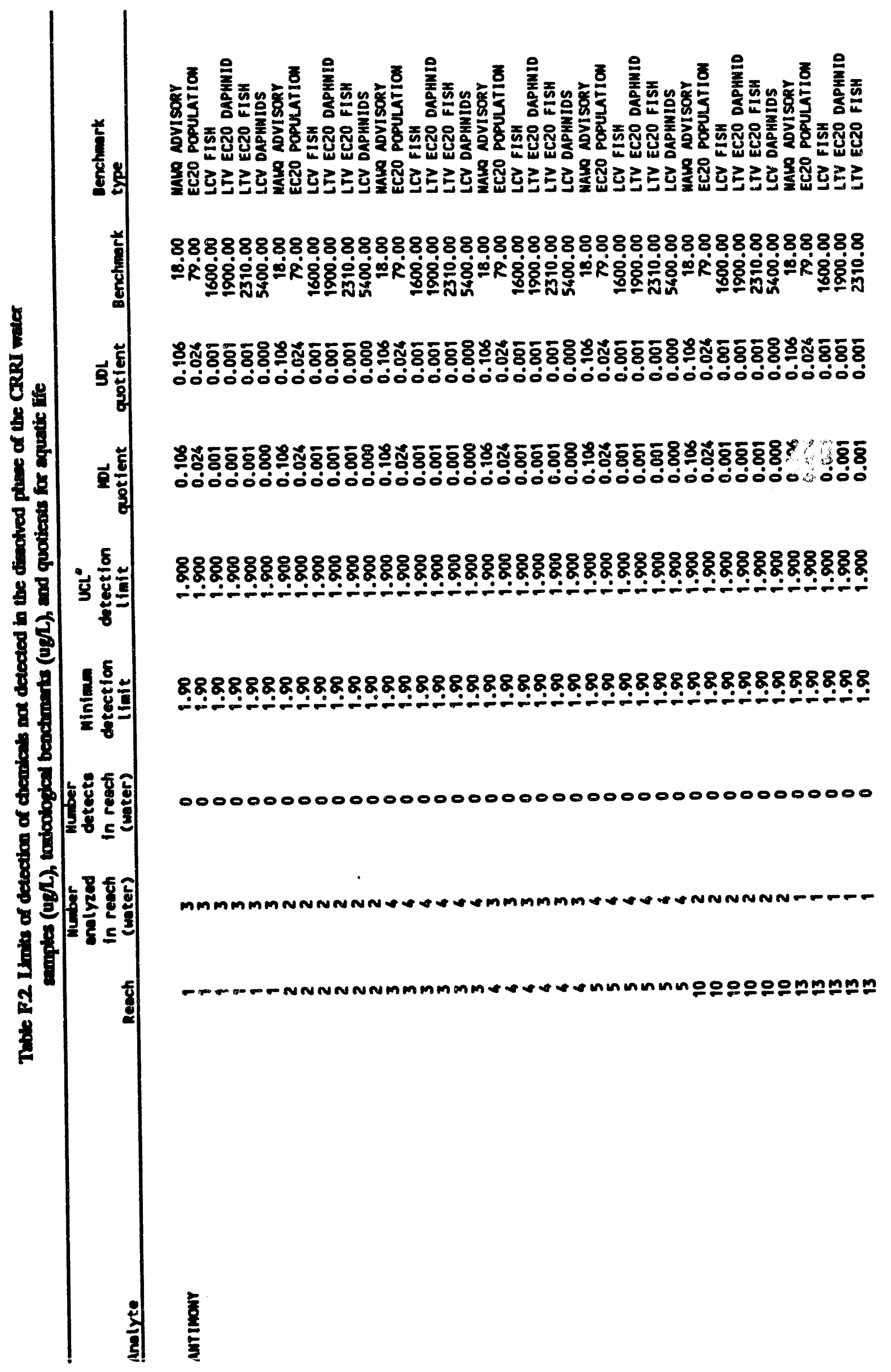




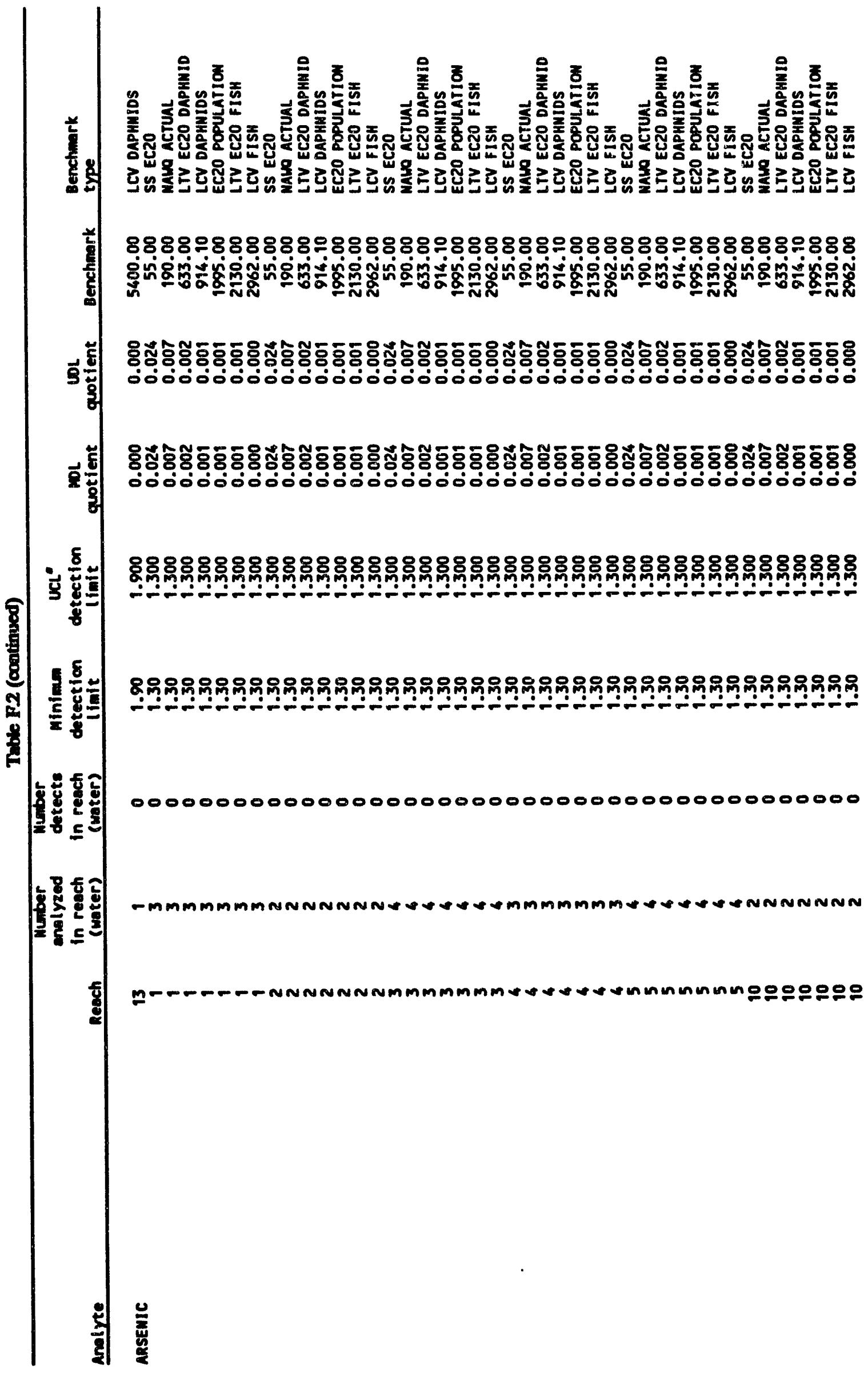




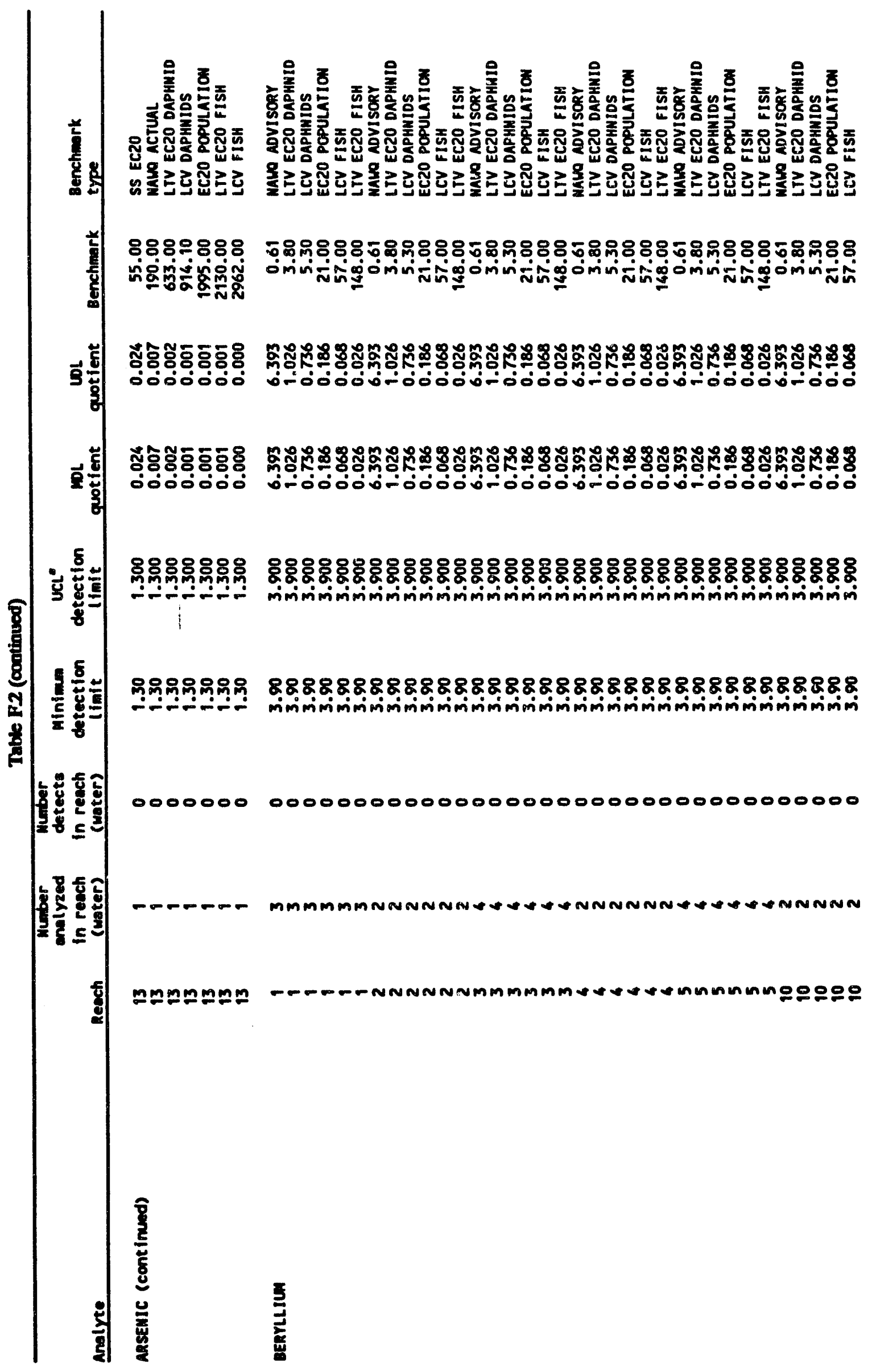




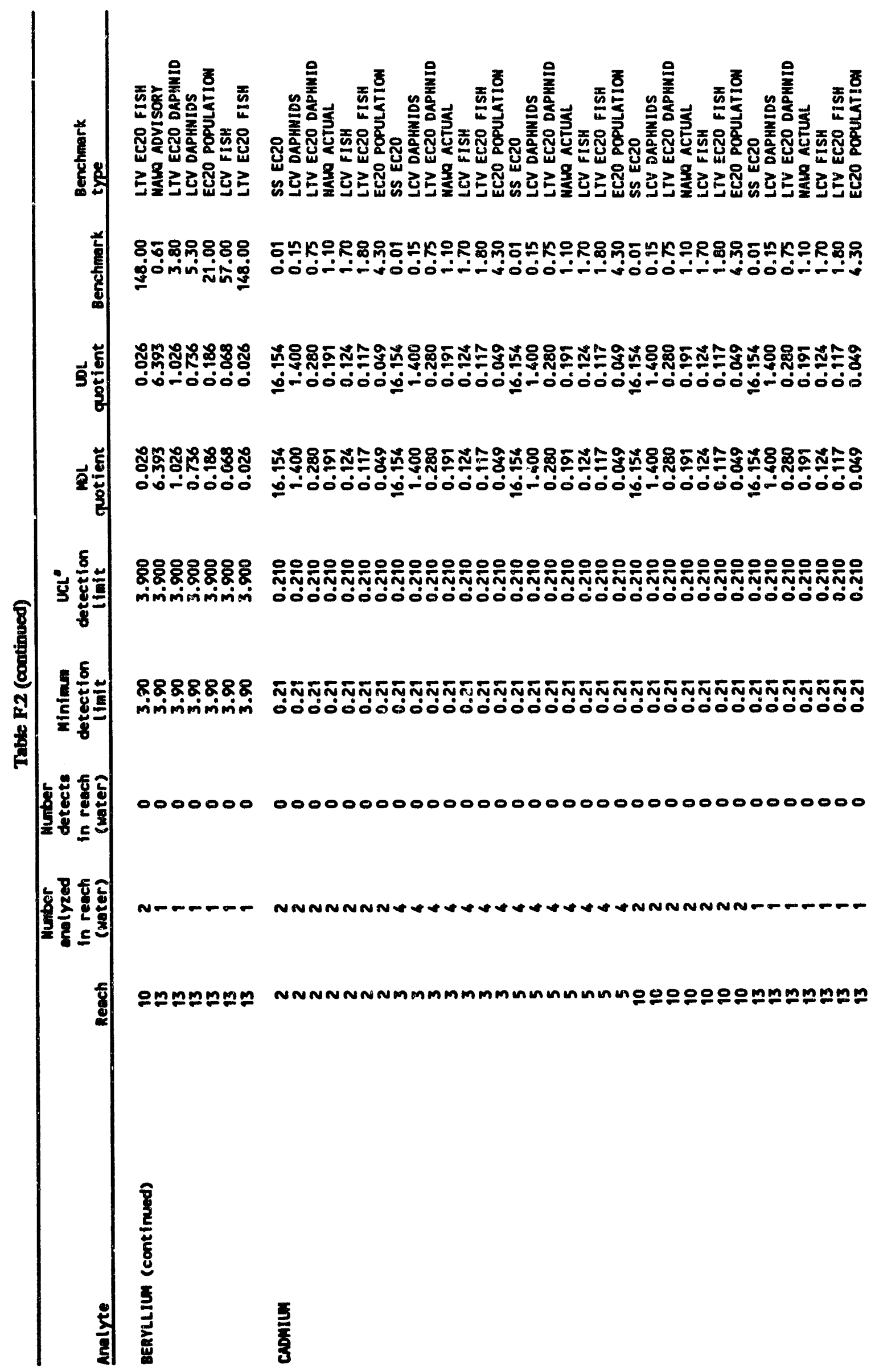




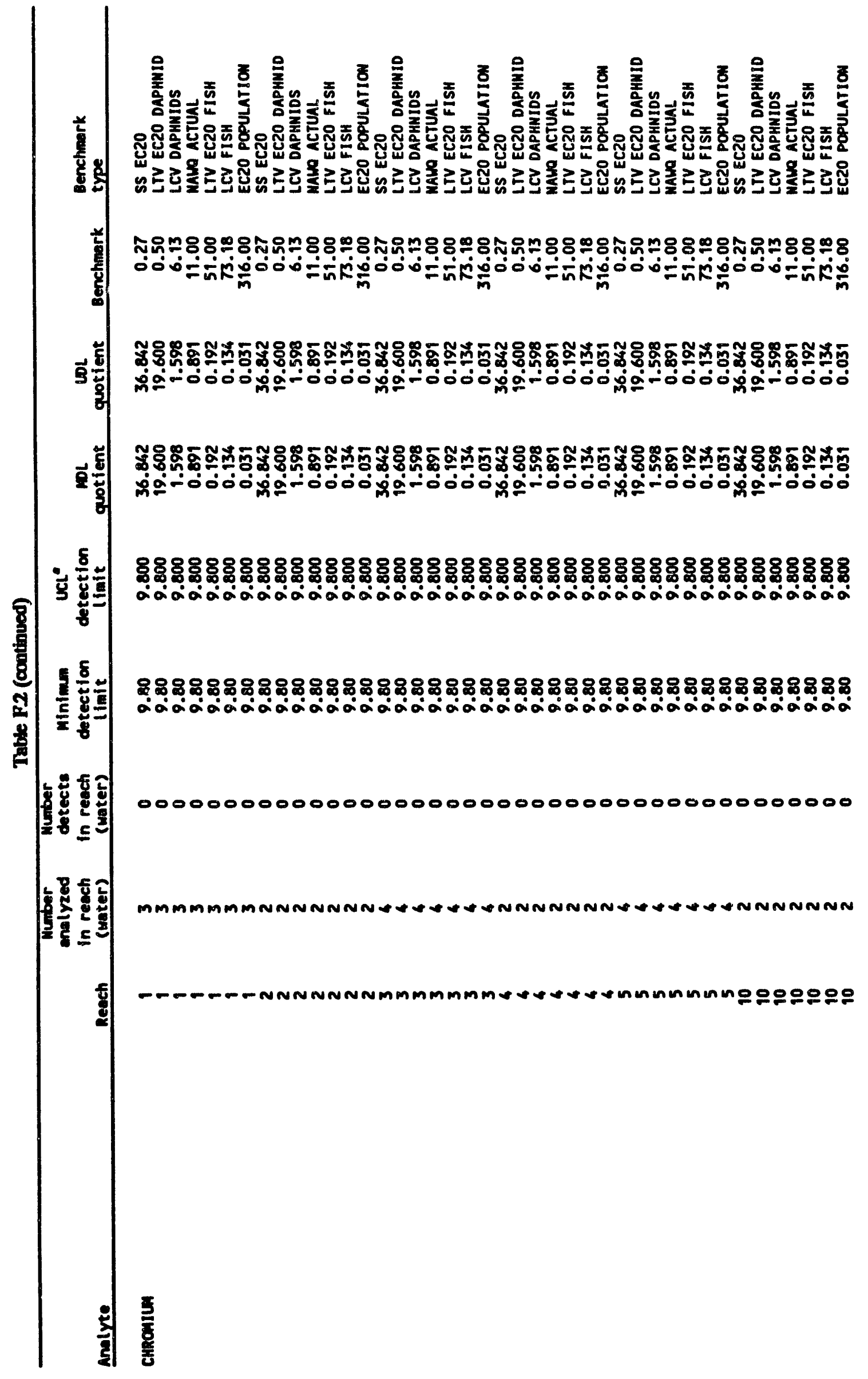




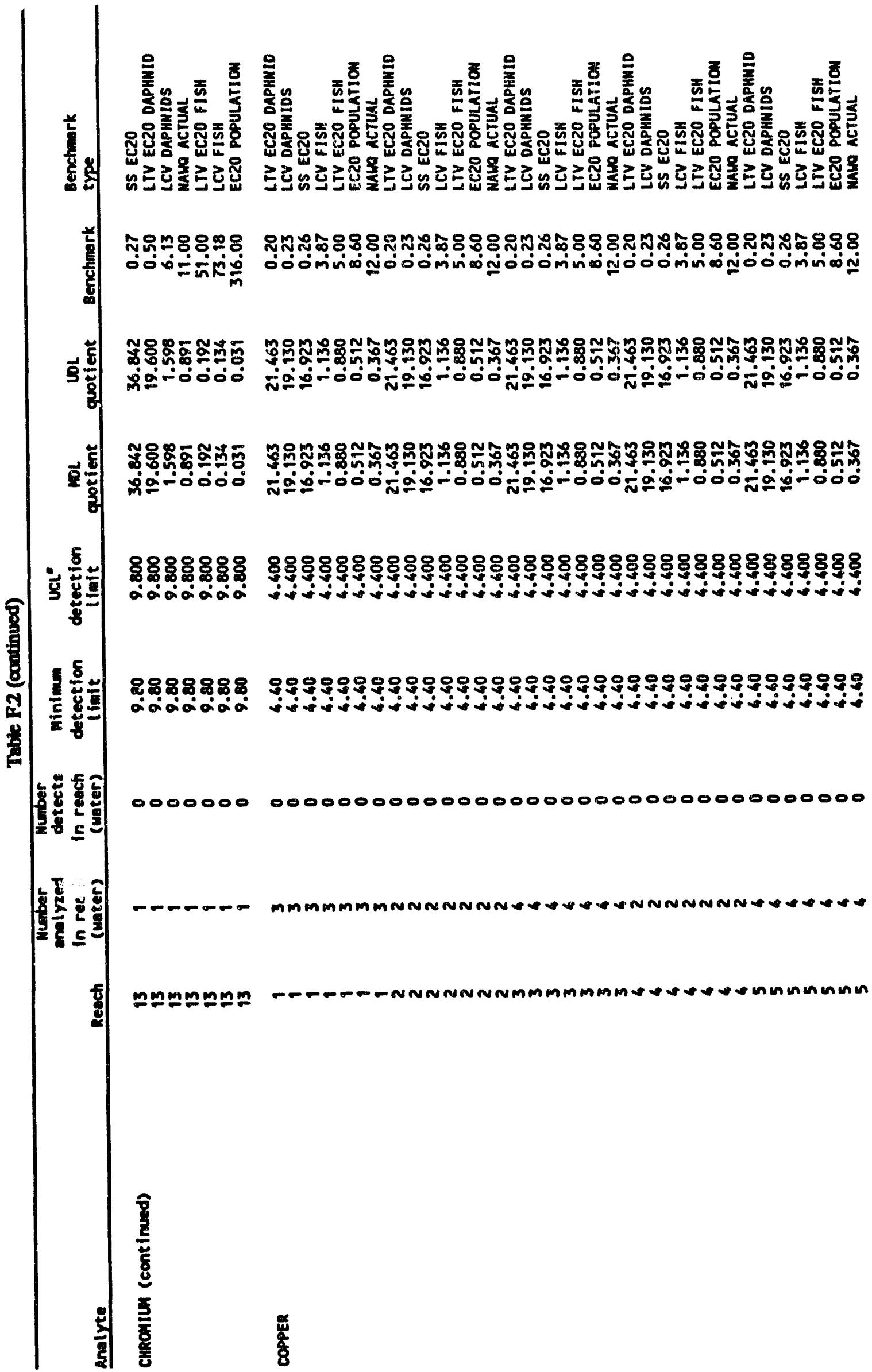




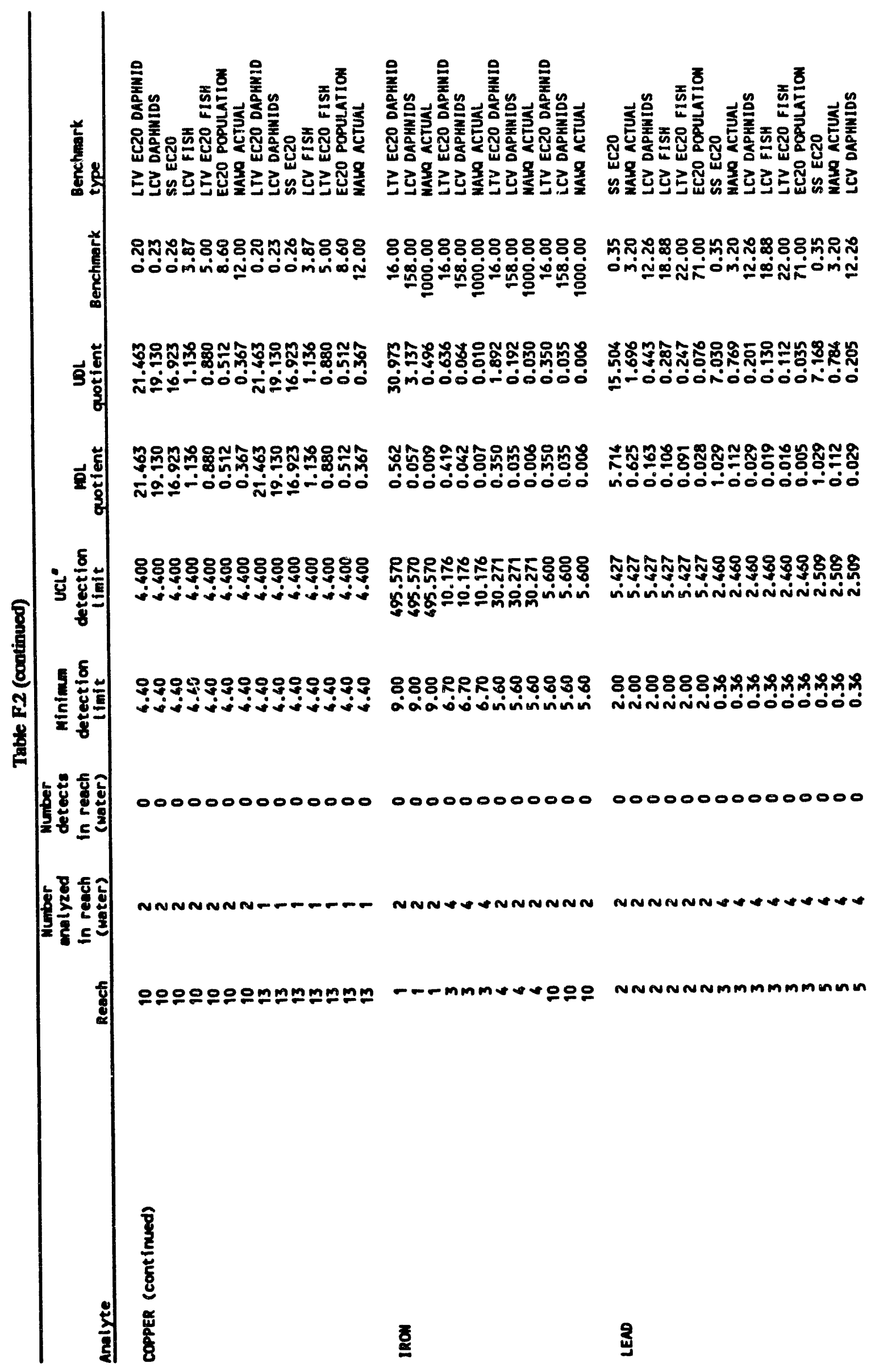




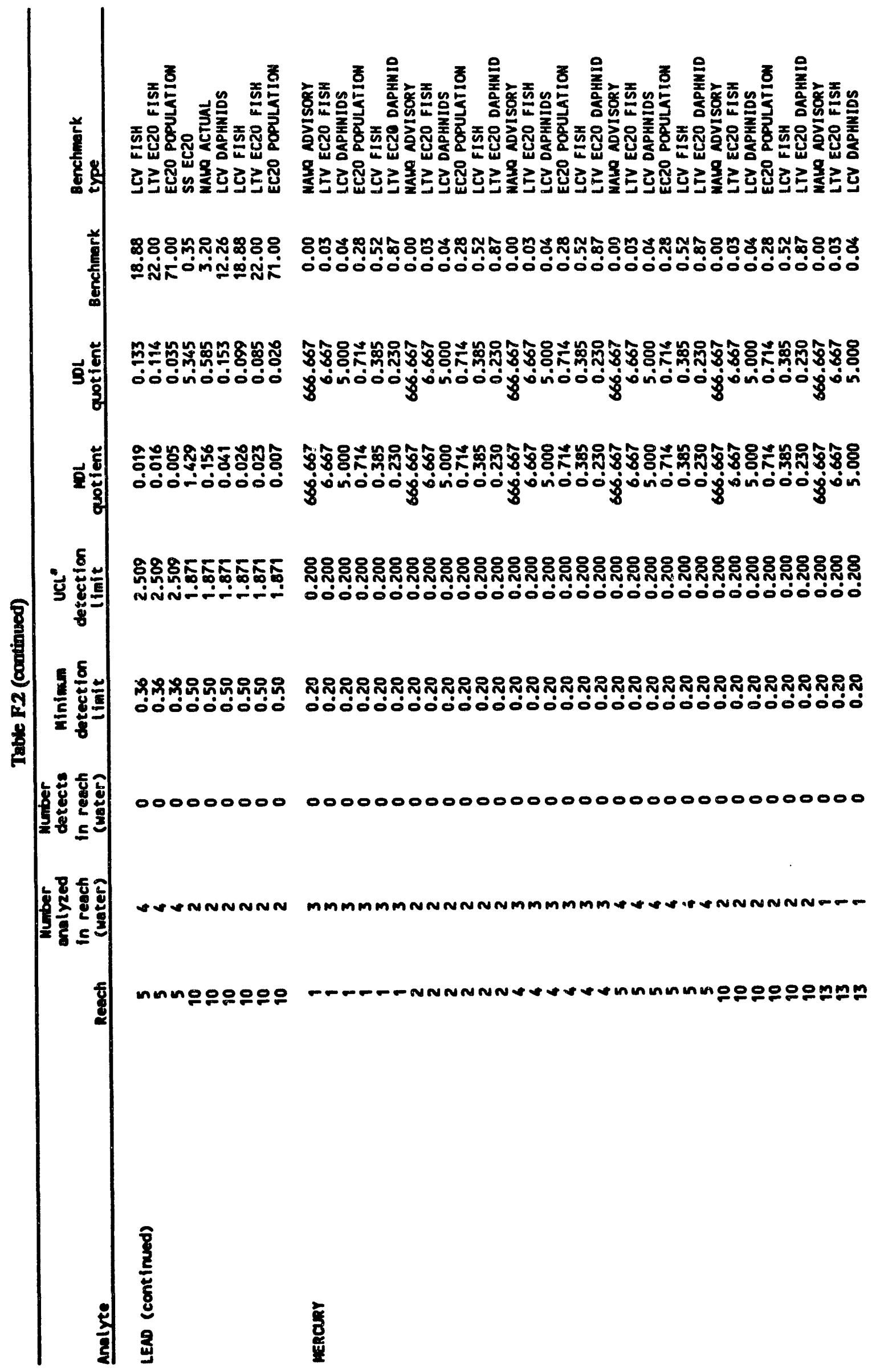




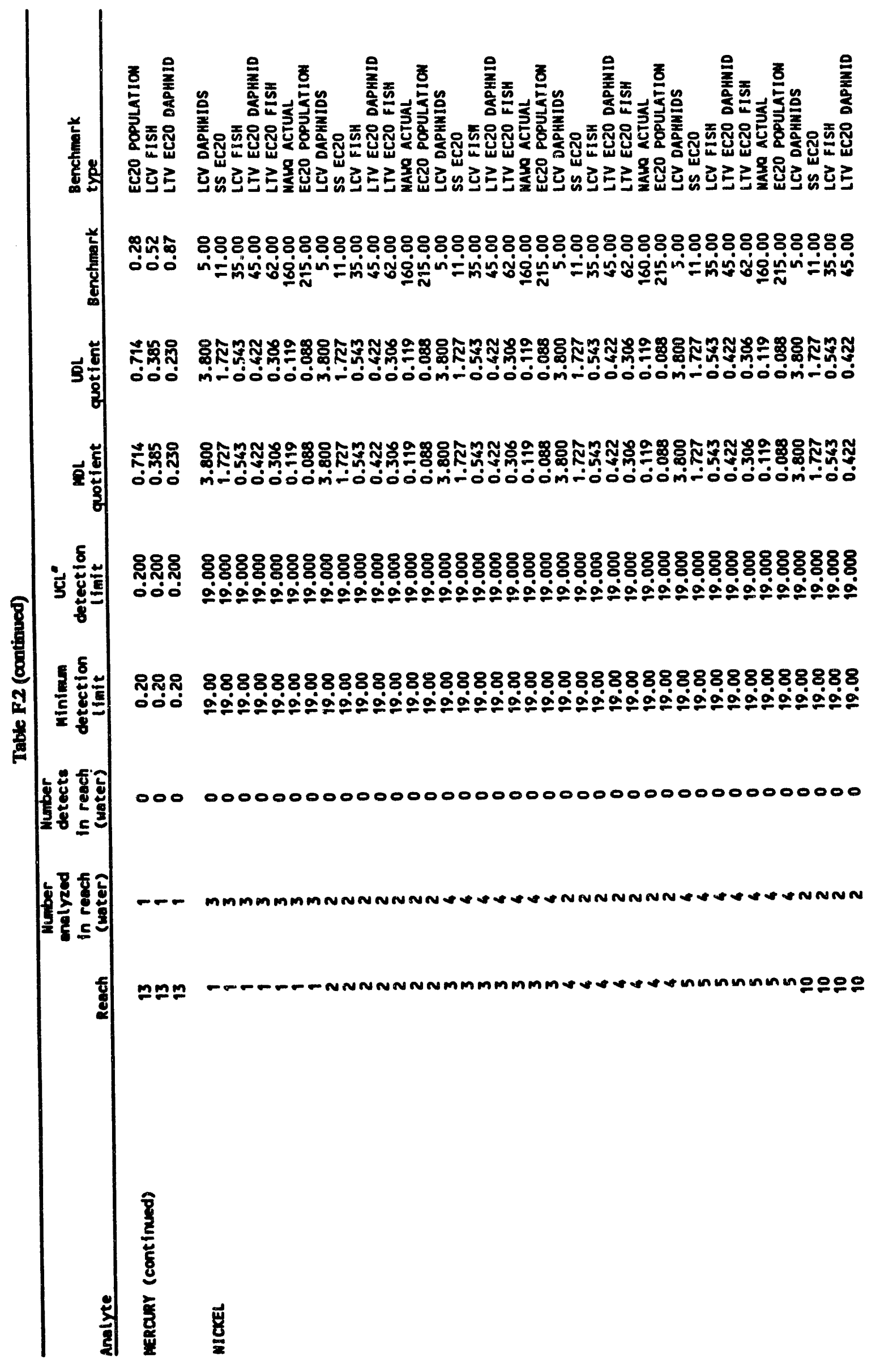




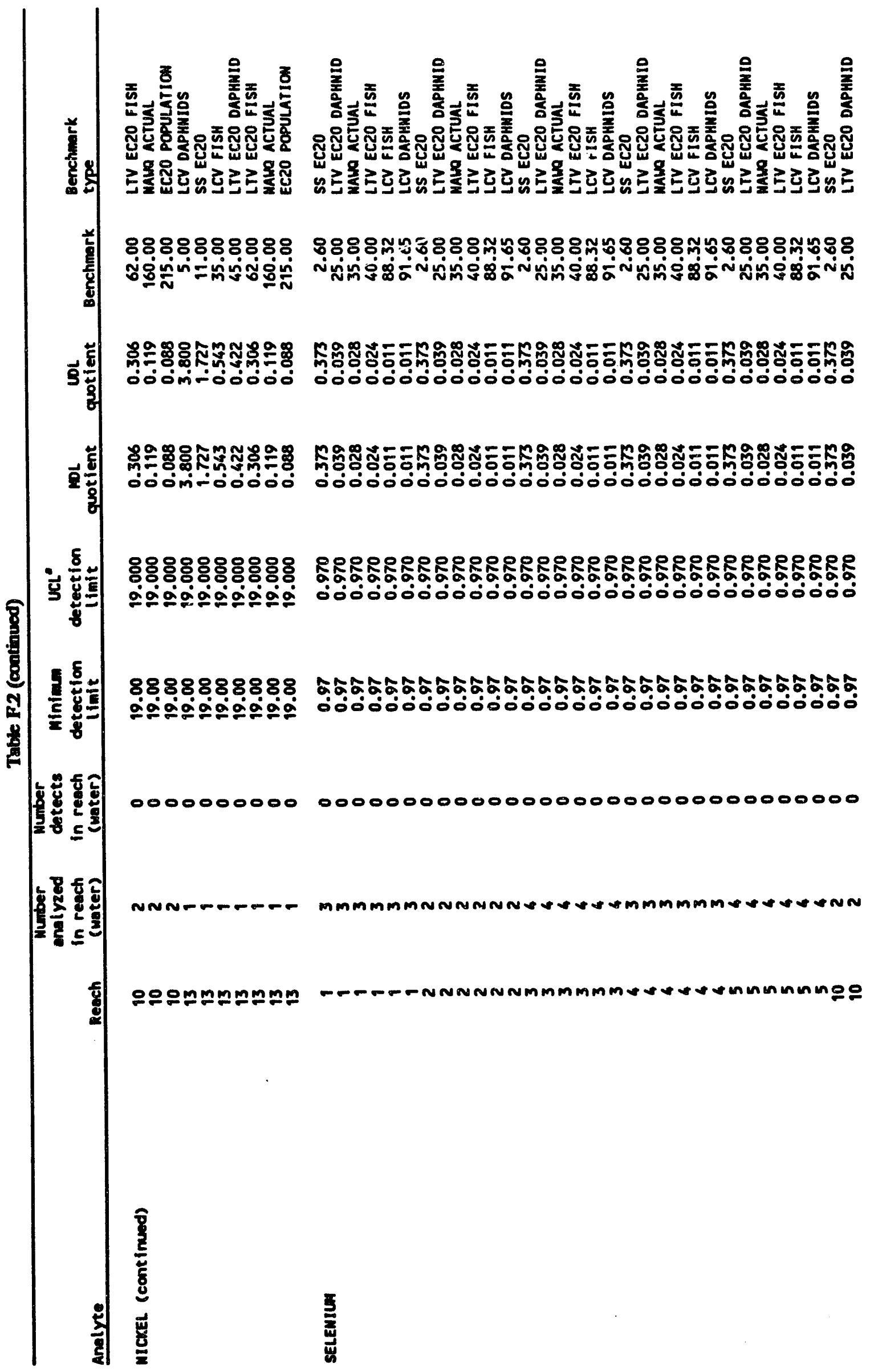




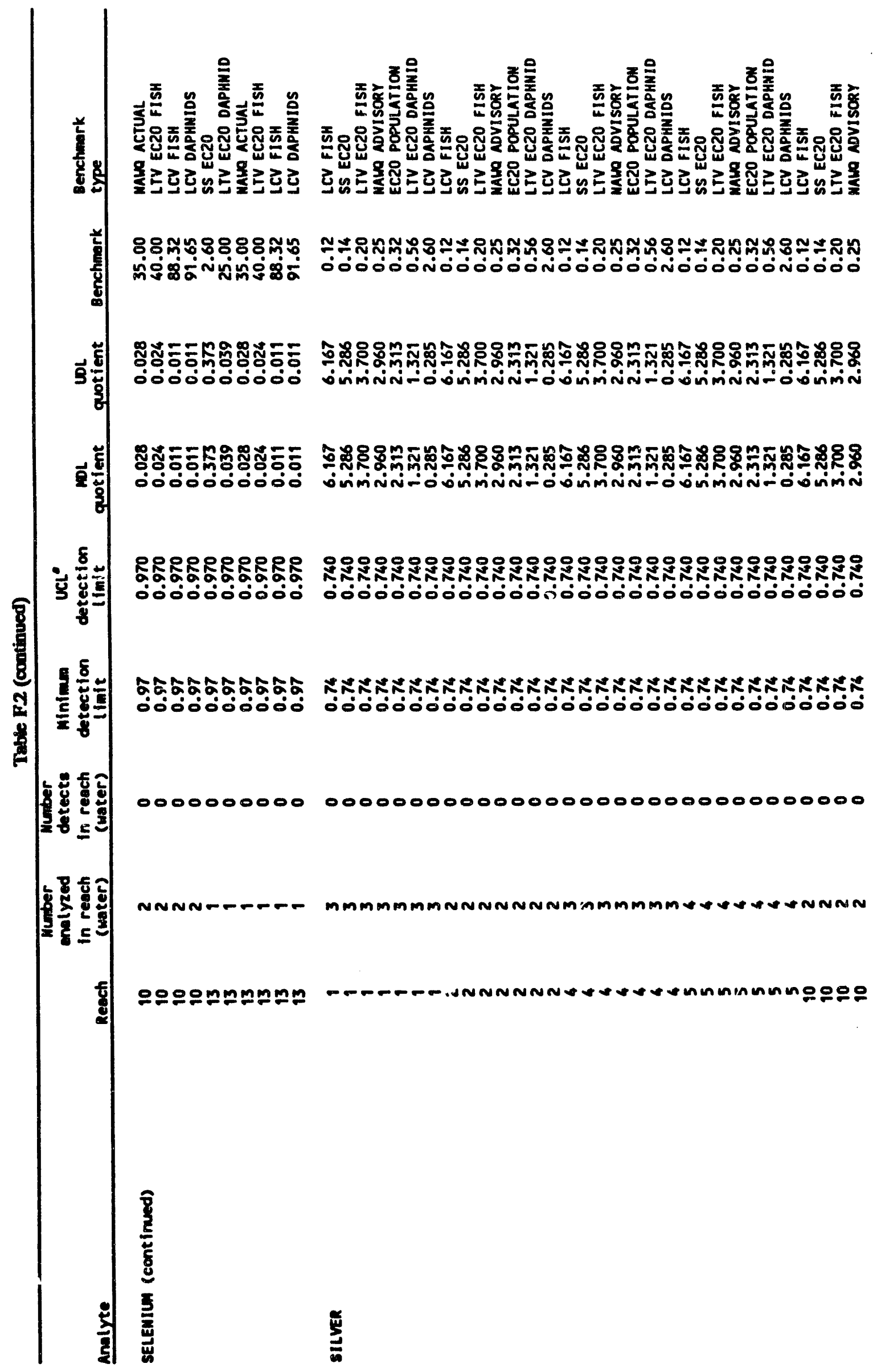




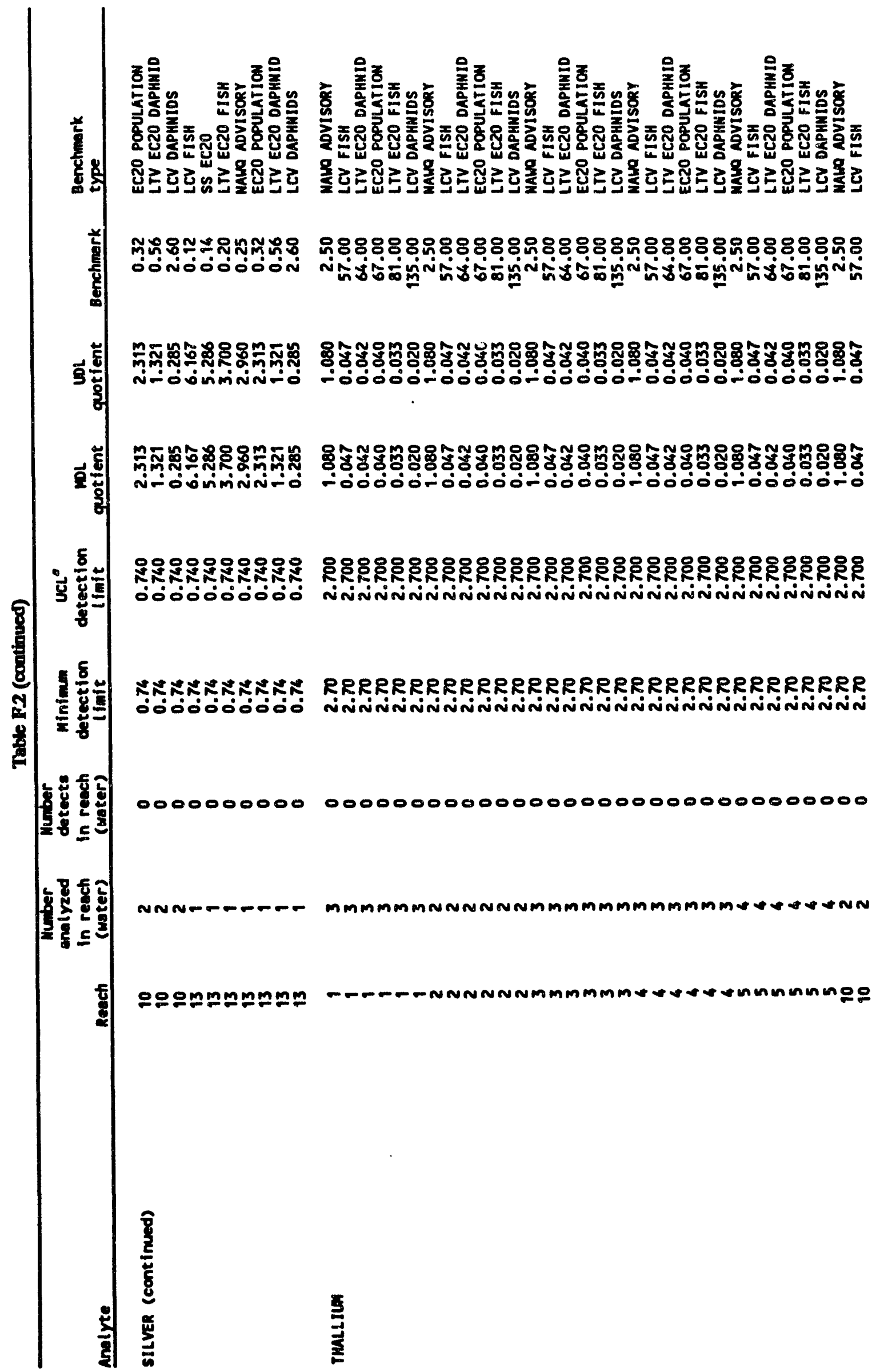




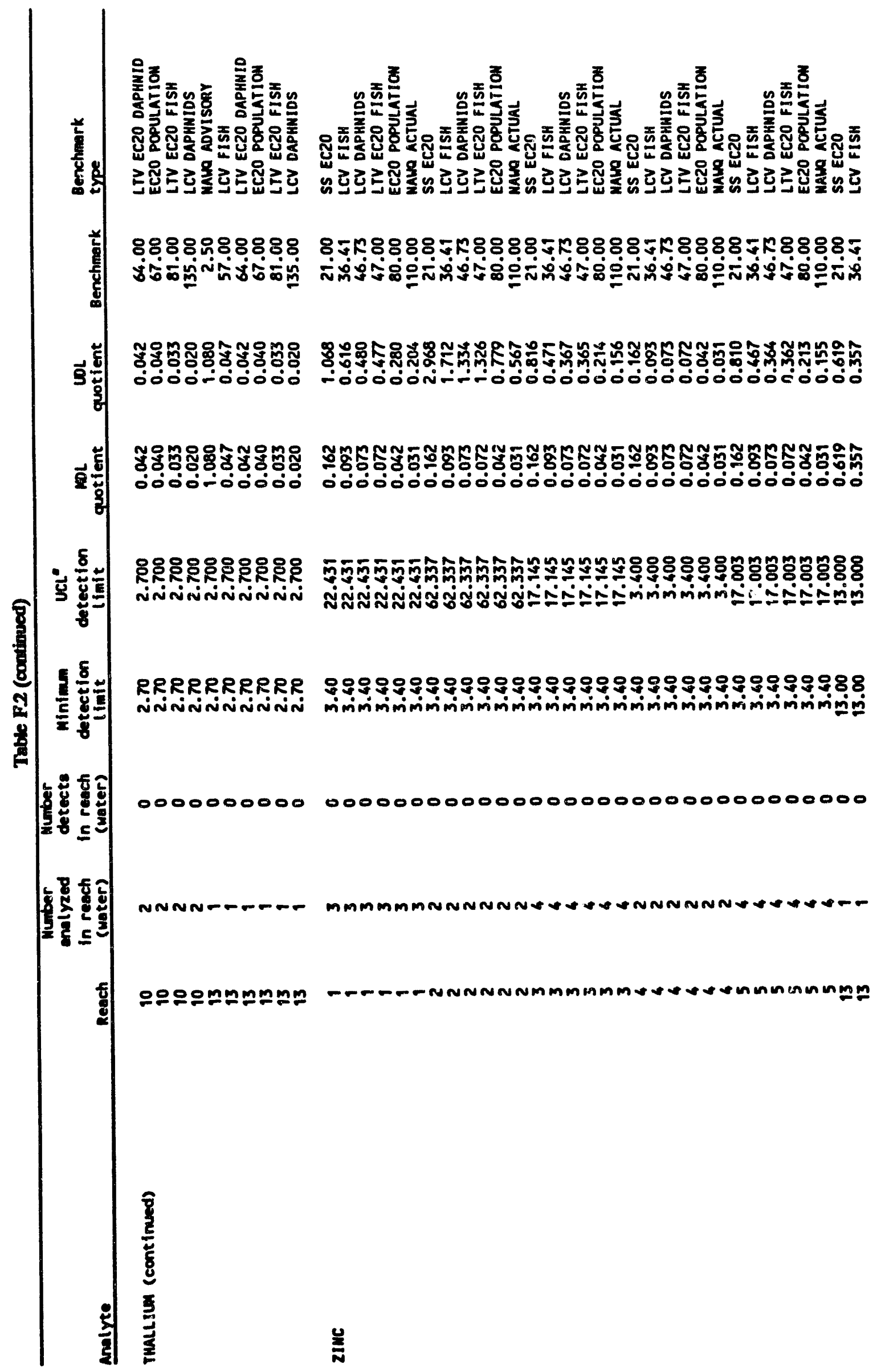




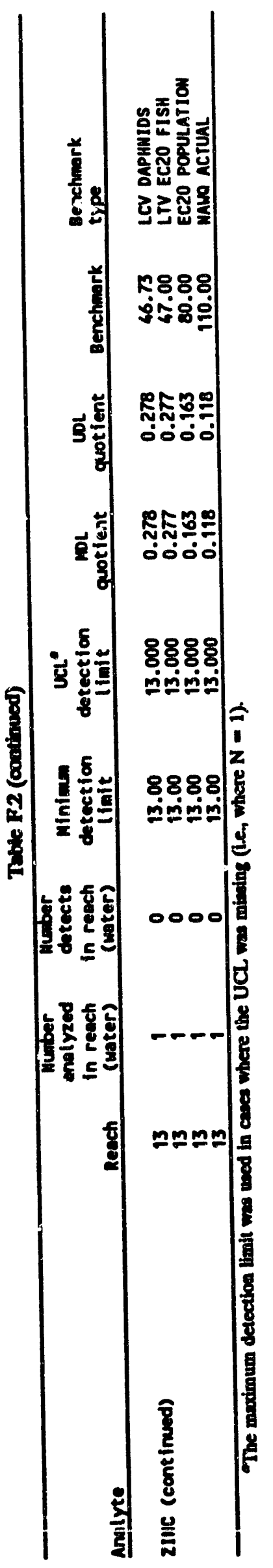




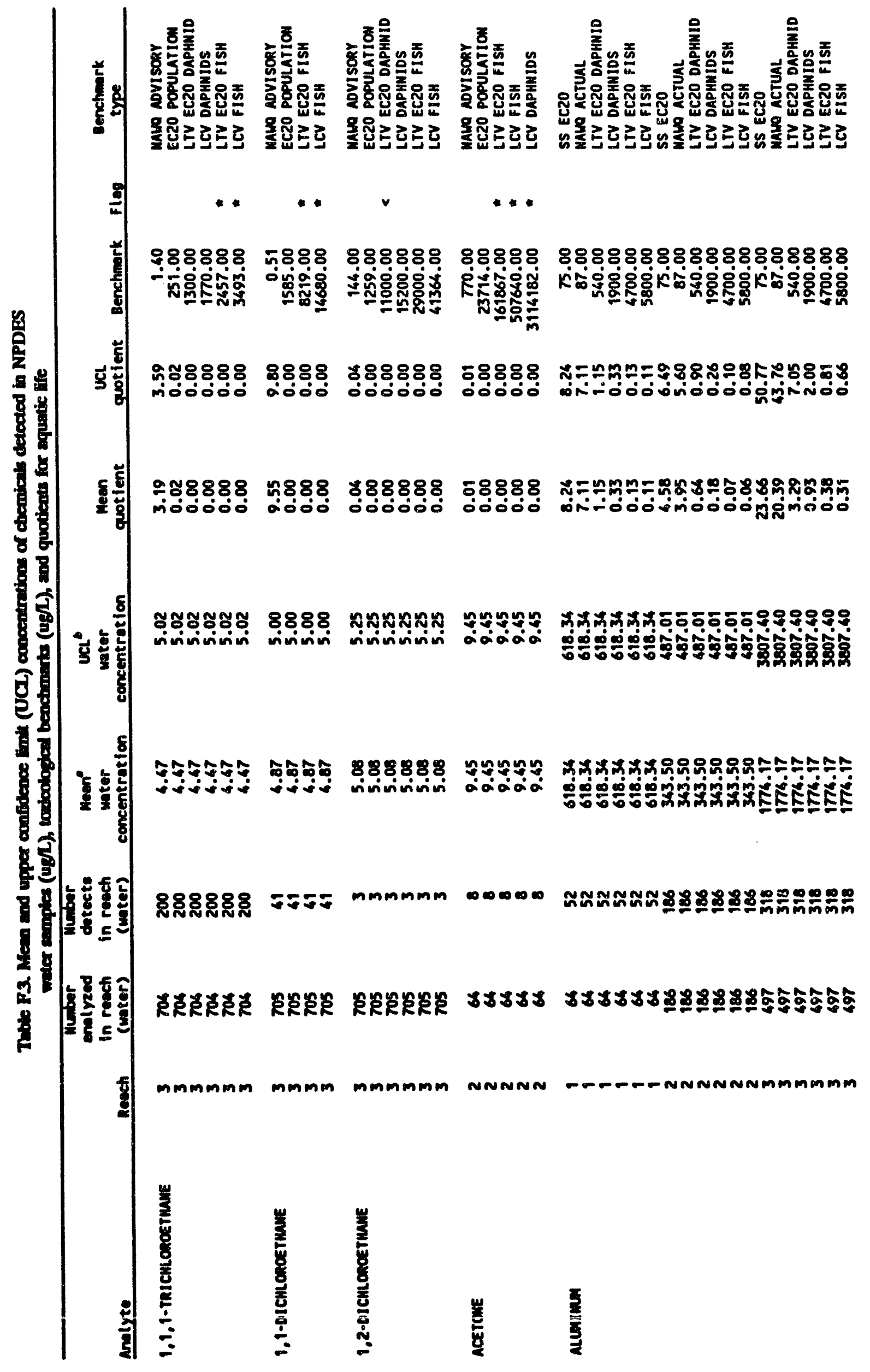




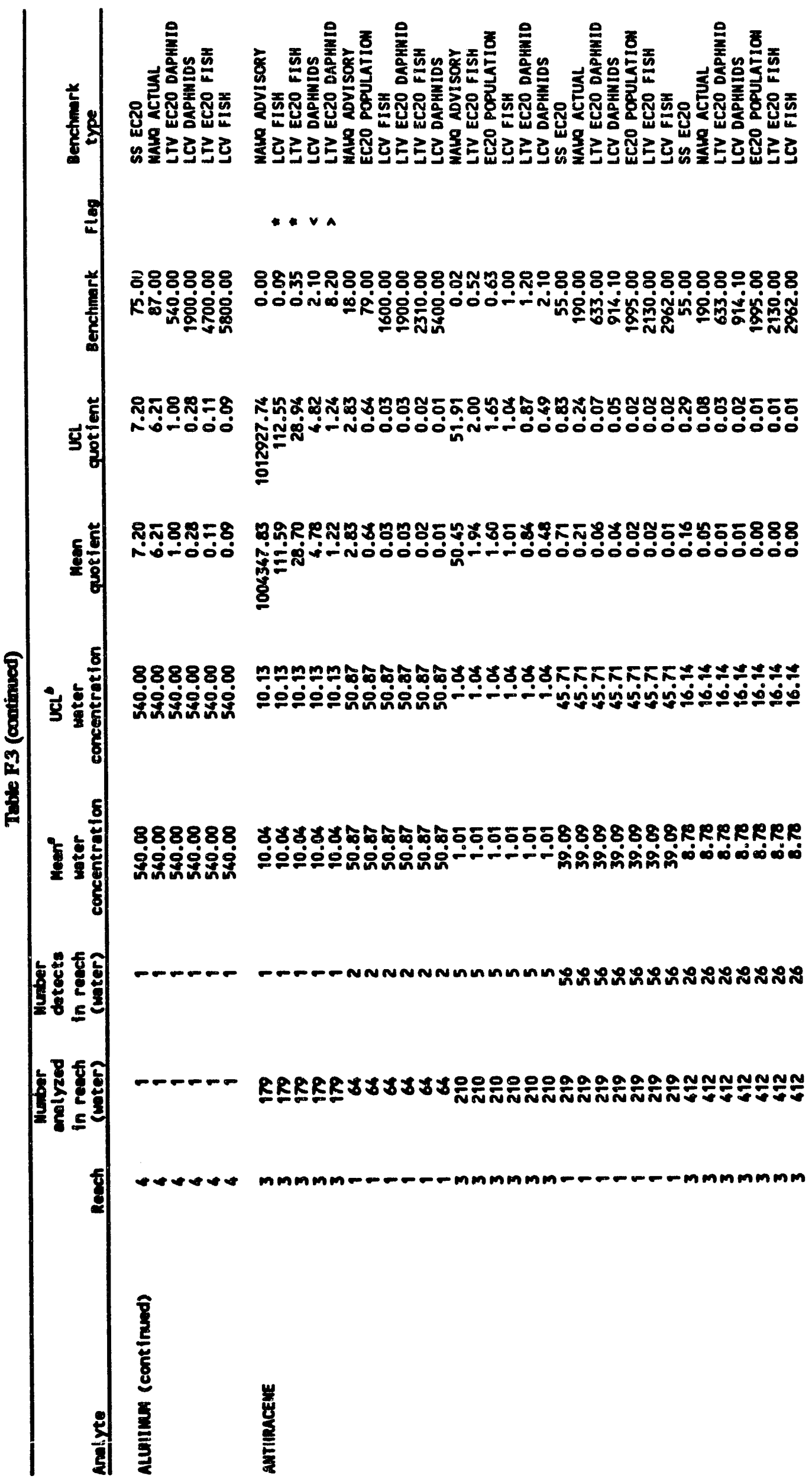




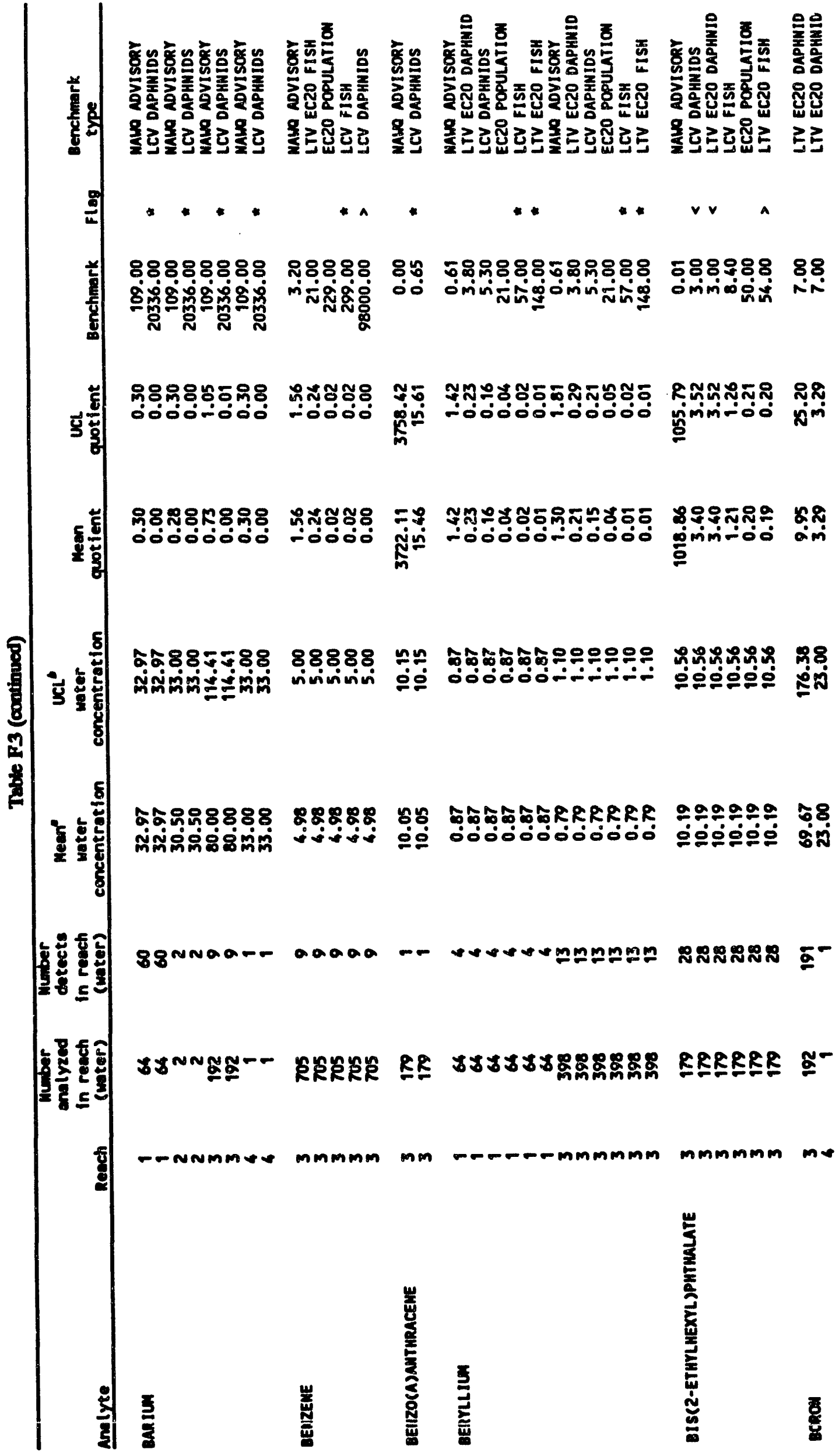




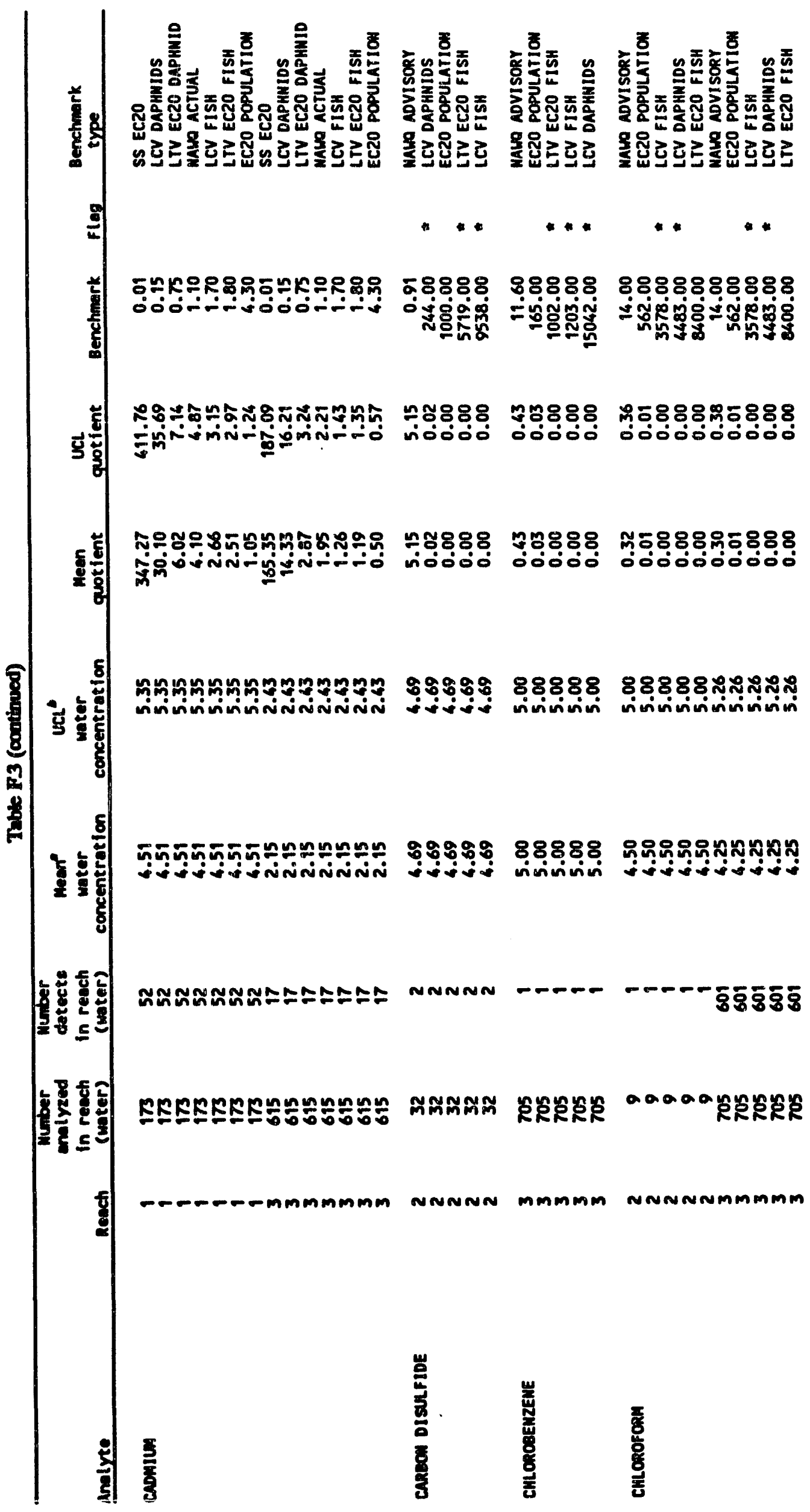


F-26

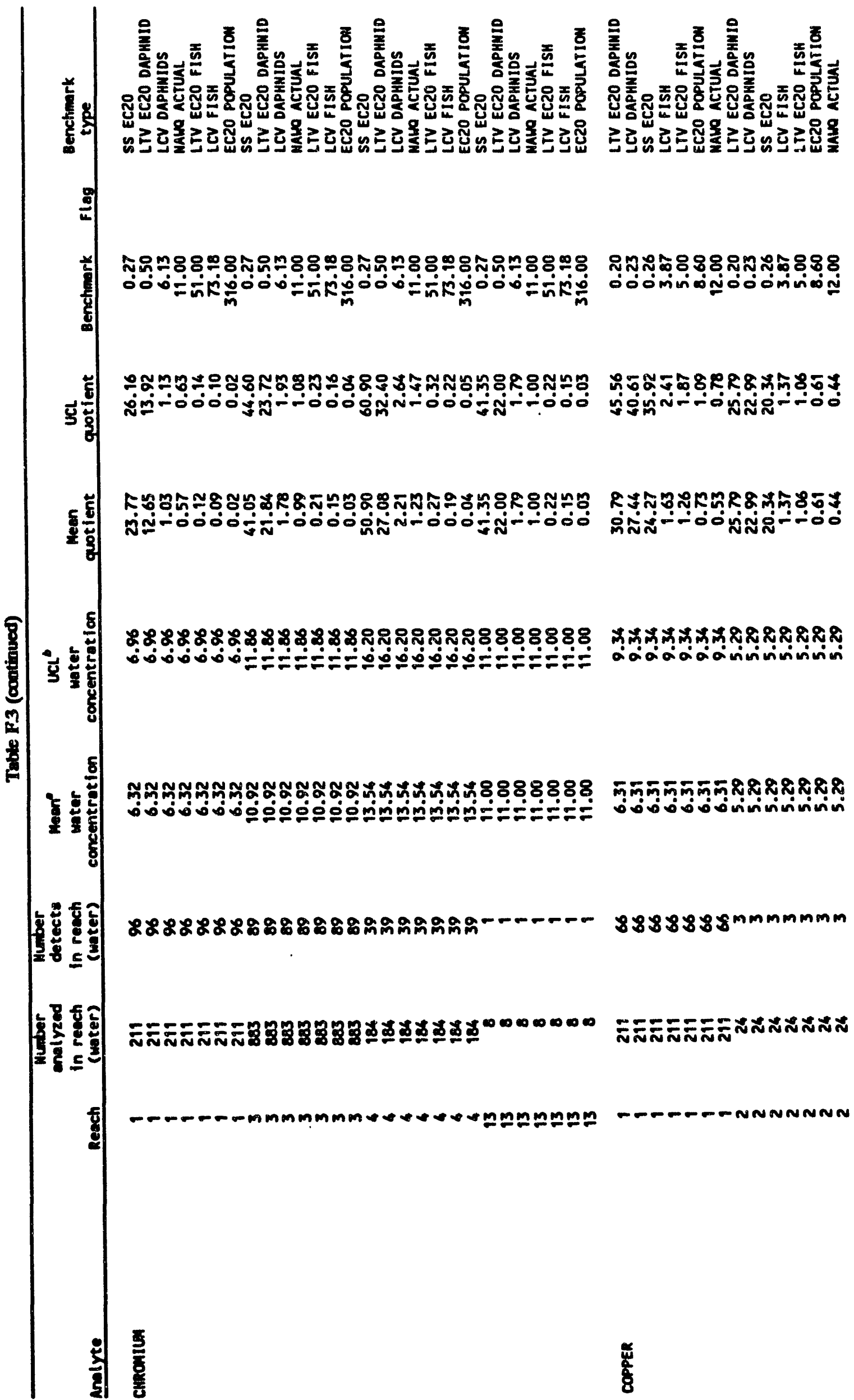




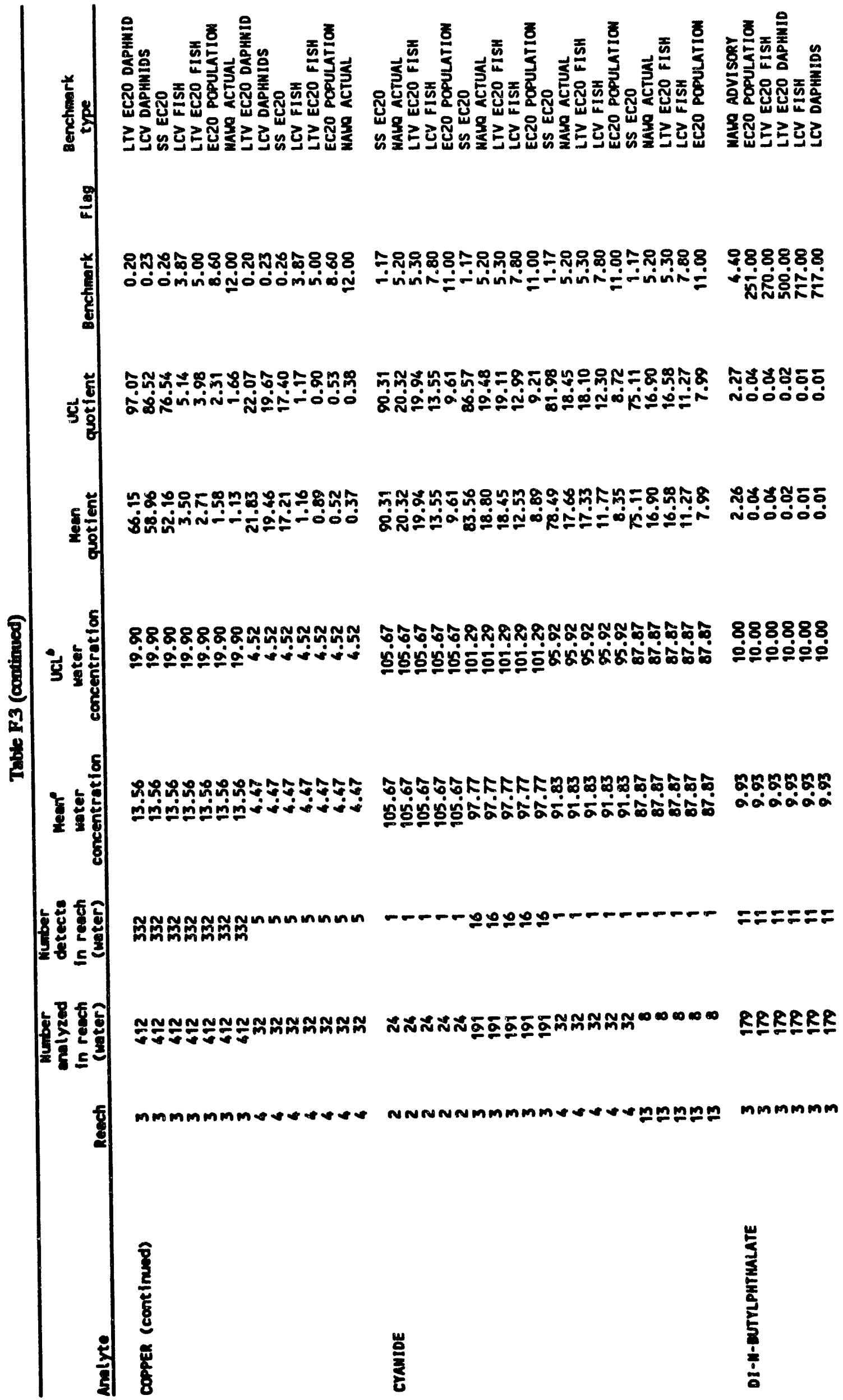




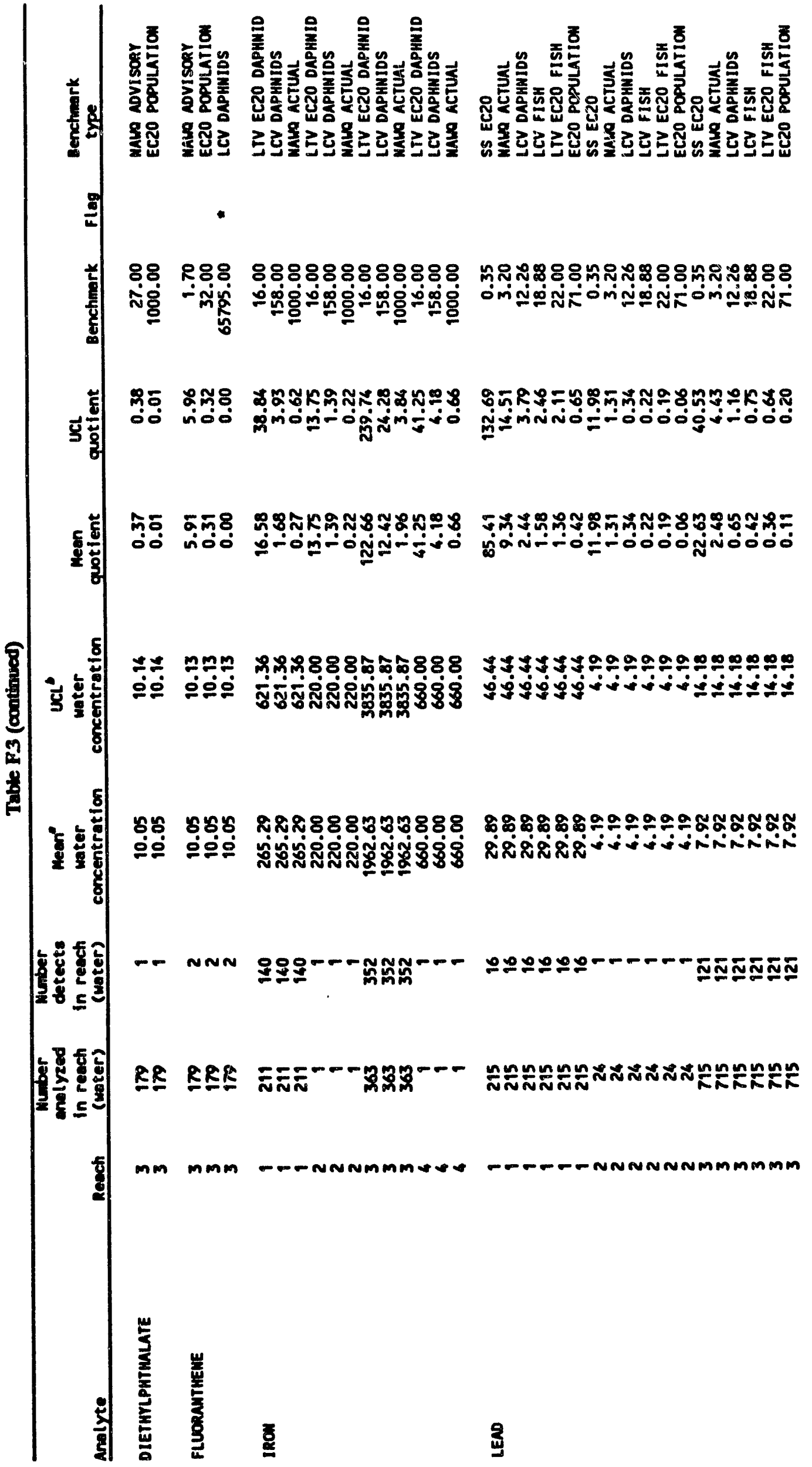


F-29

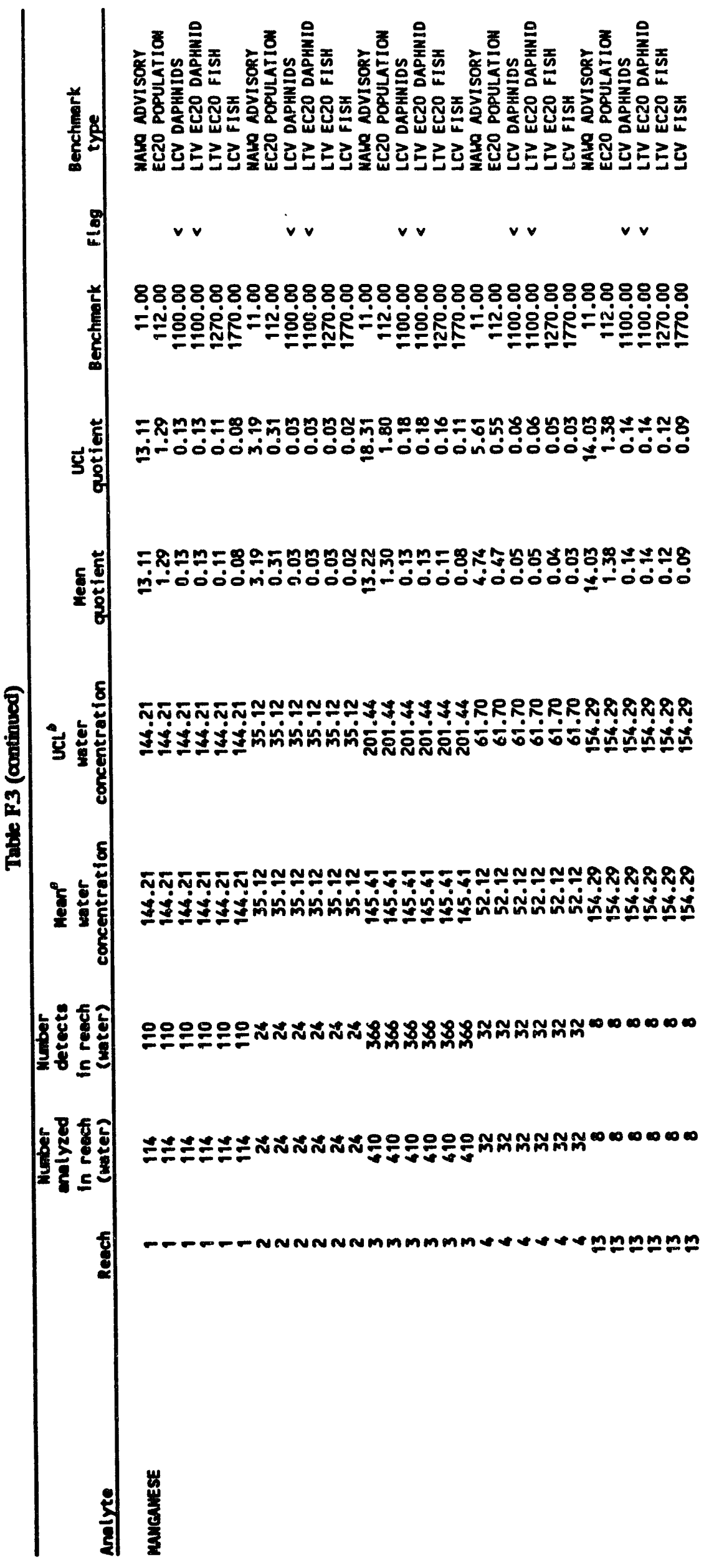


F-30

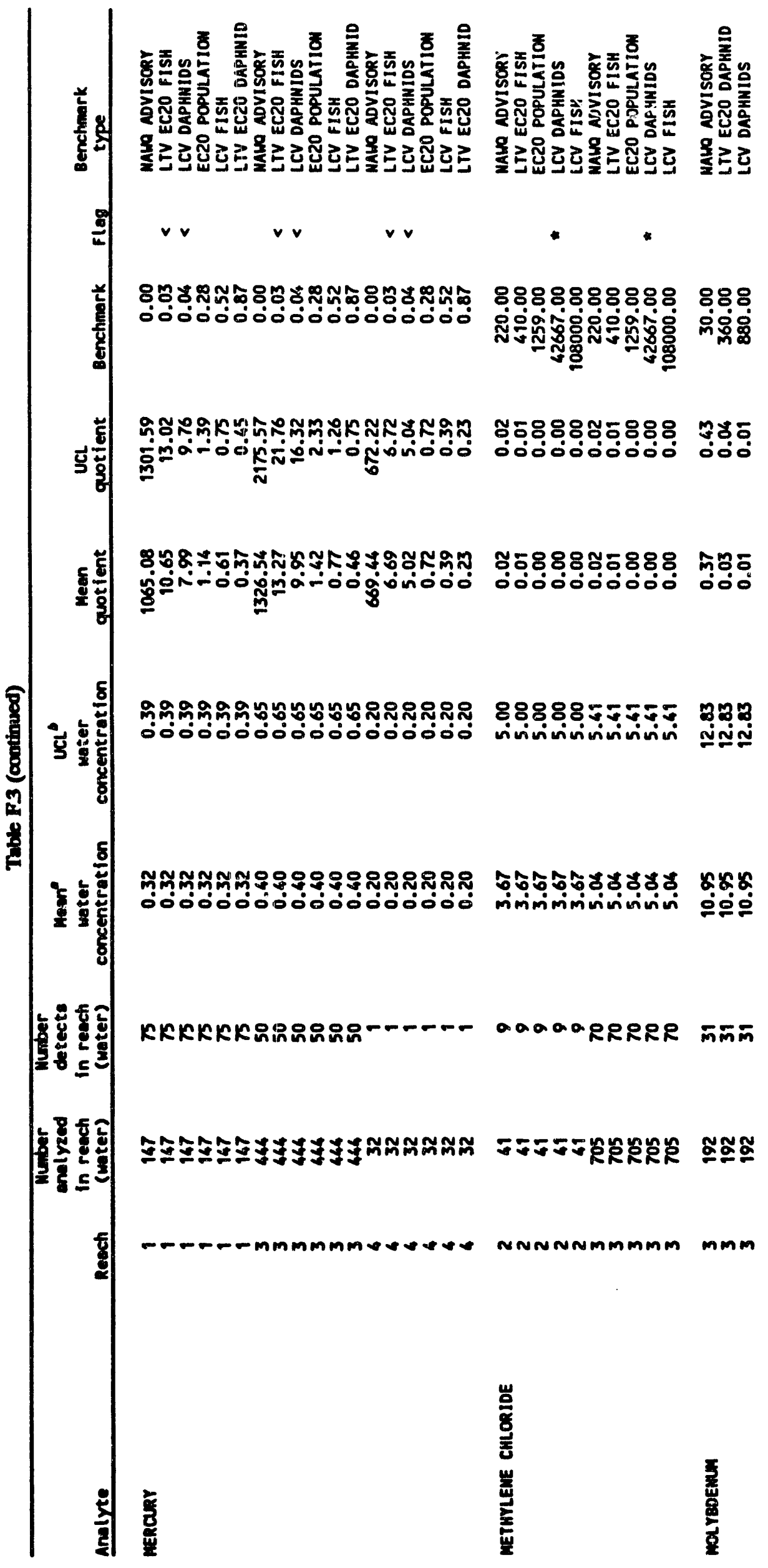


F-31

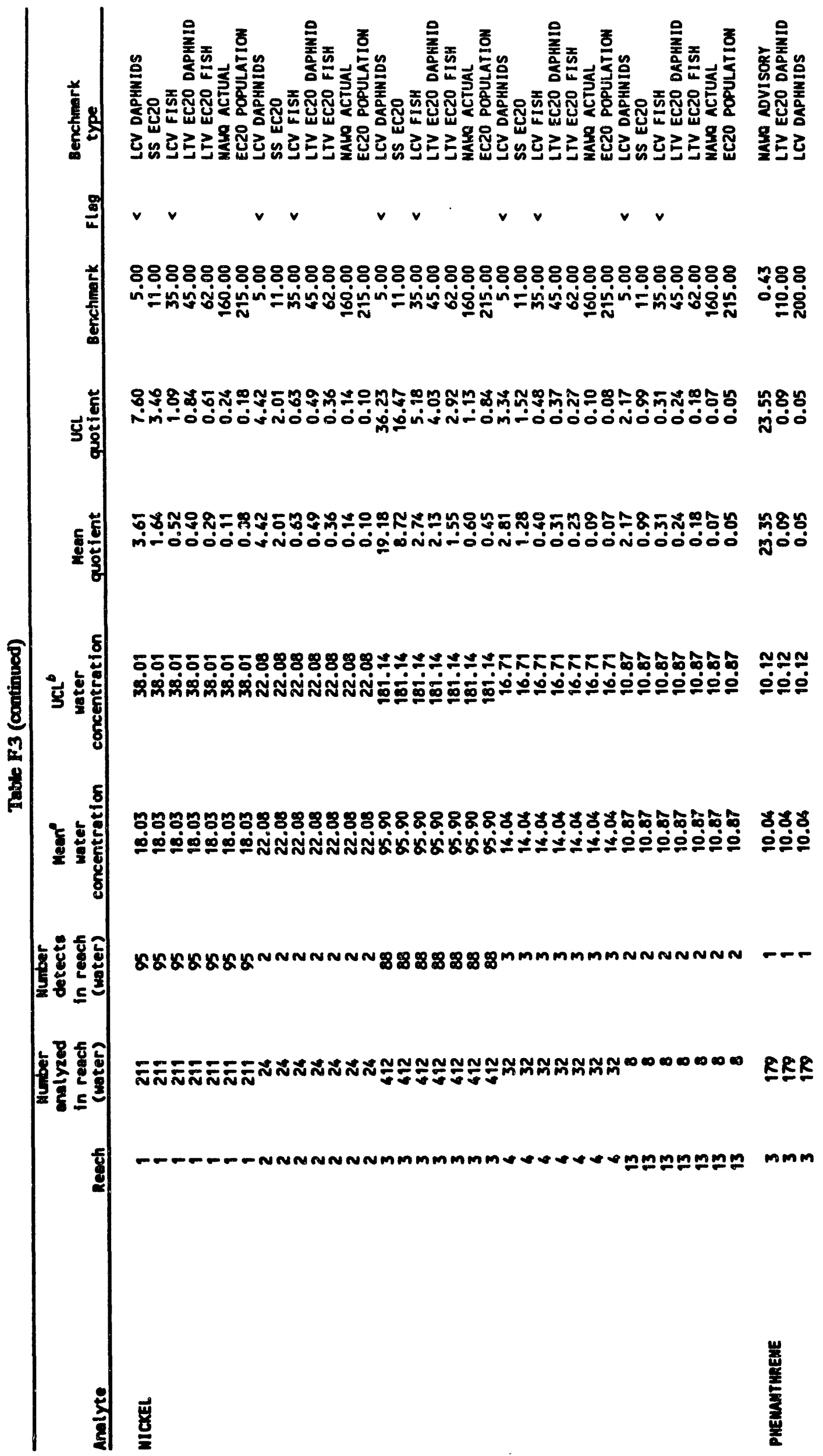


F-32

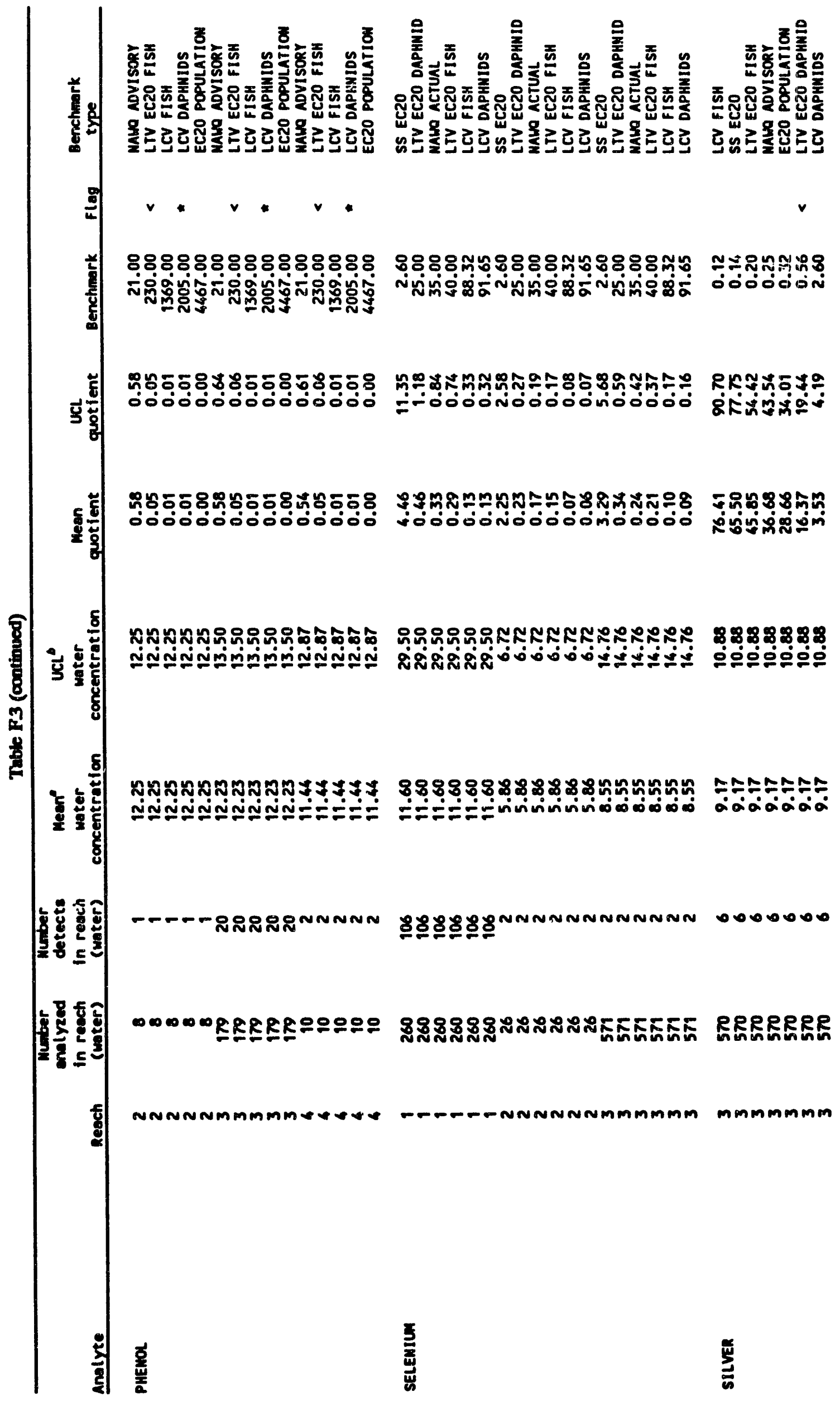


F-33

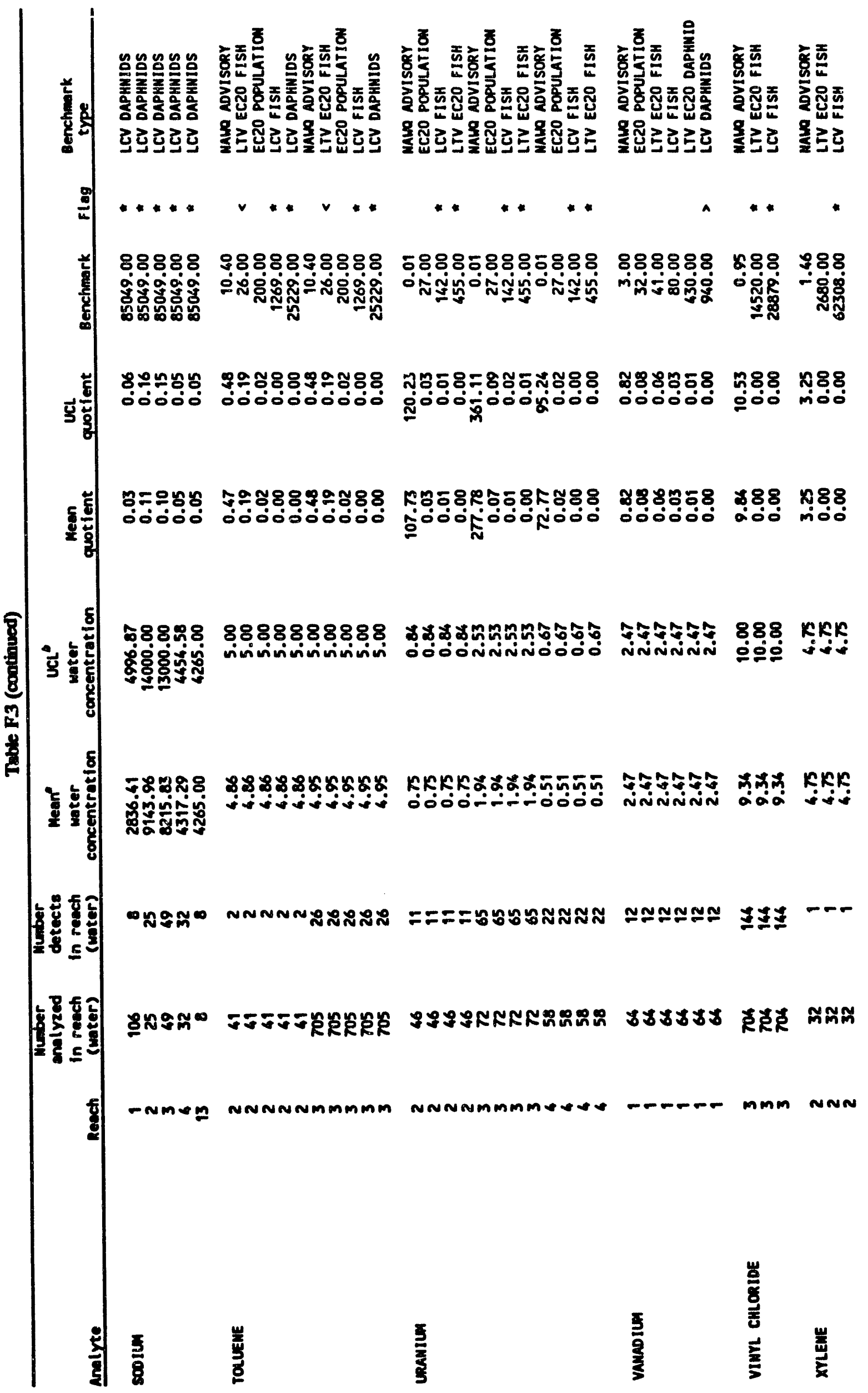




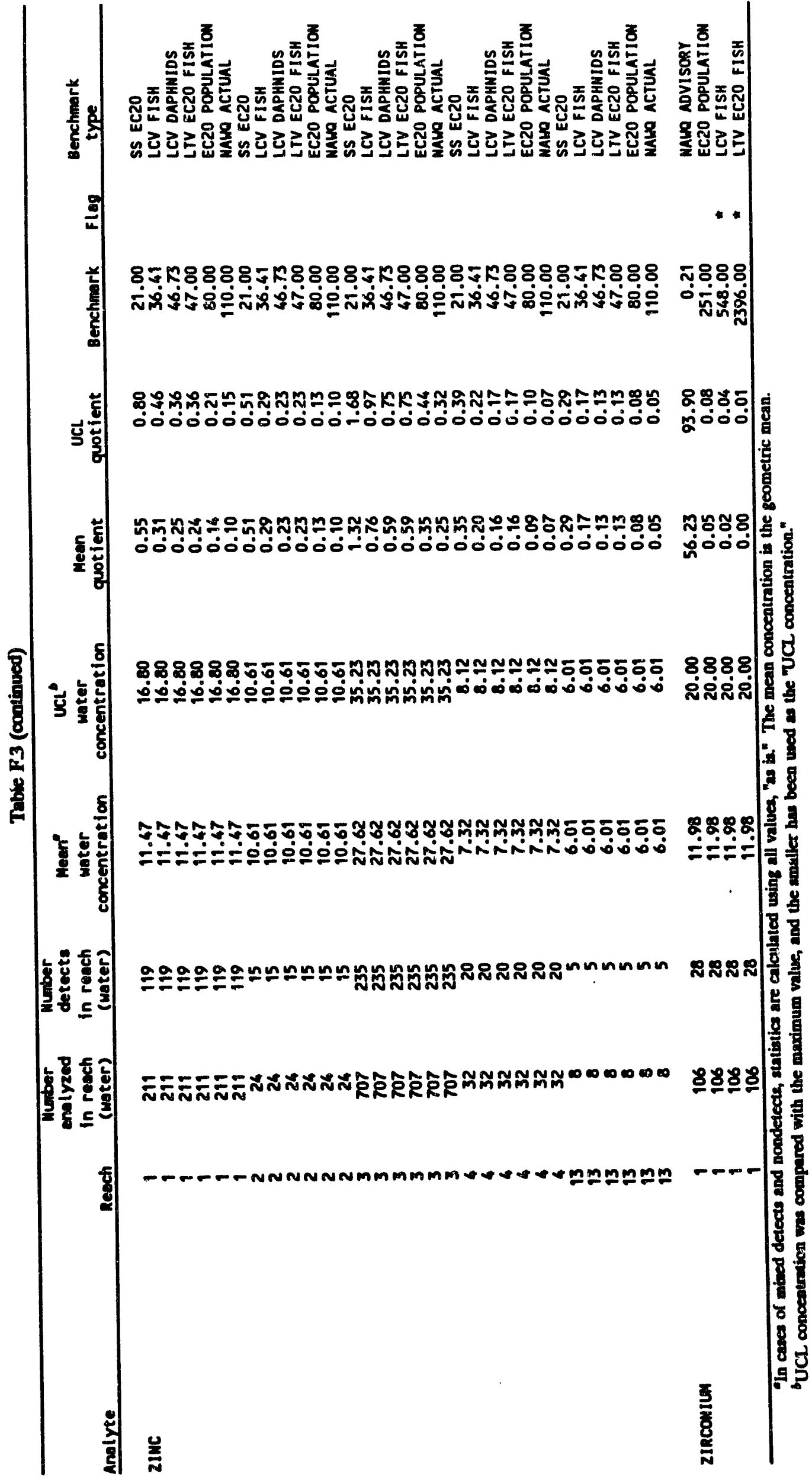




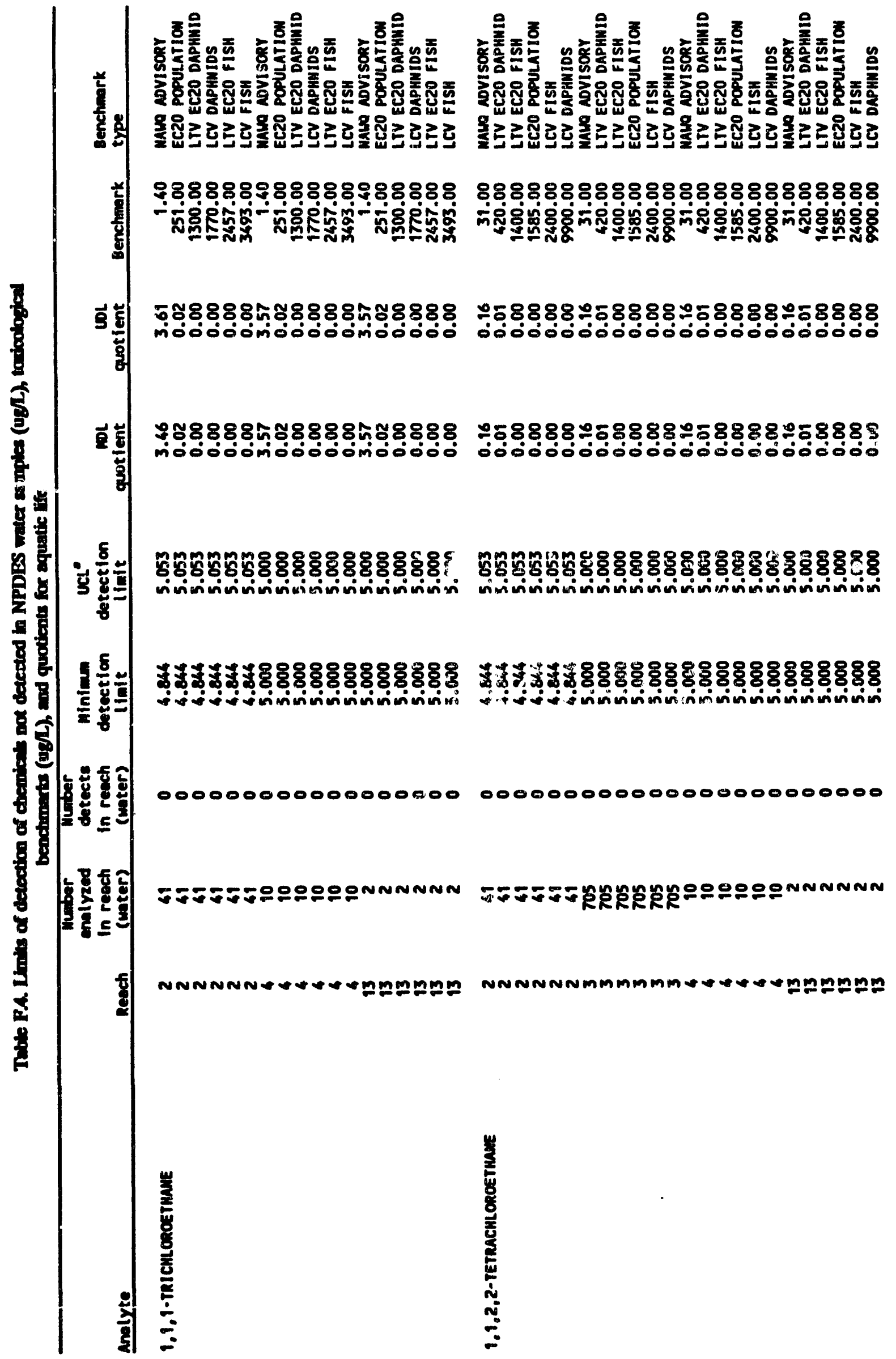




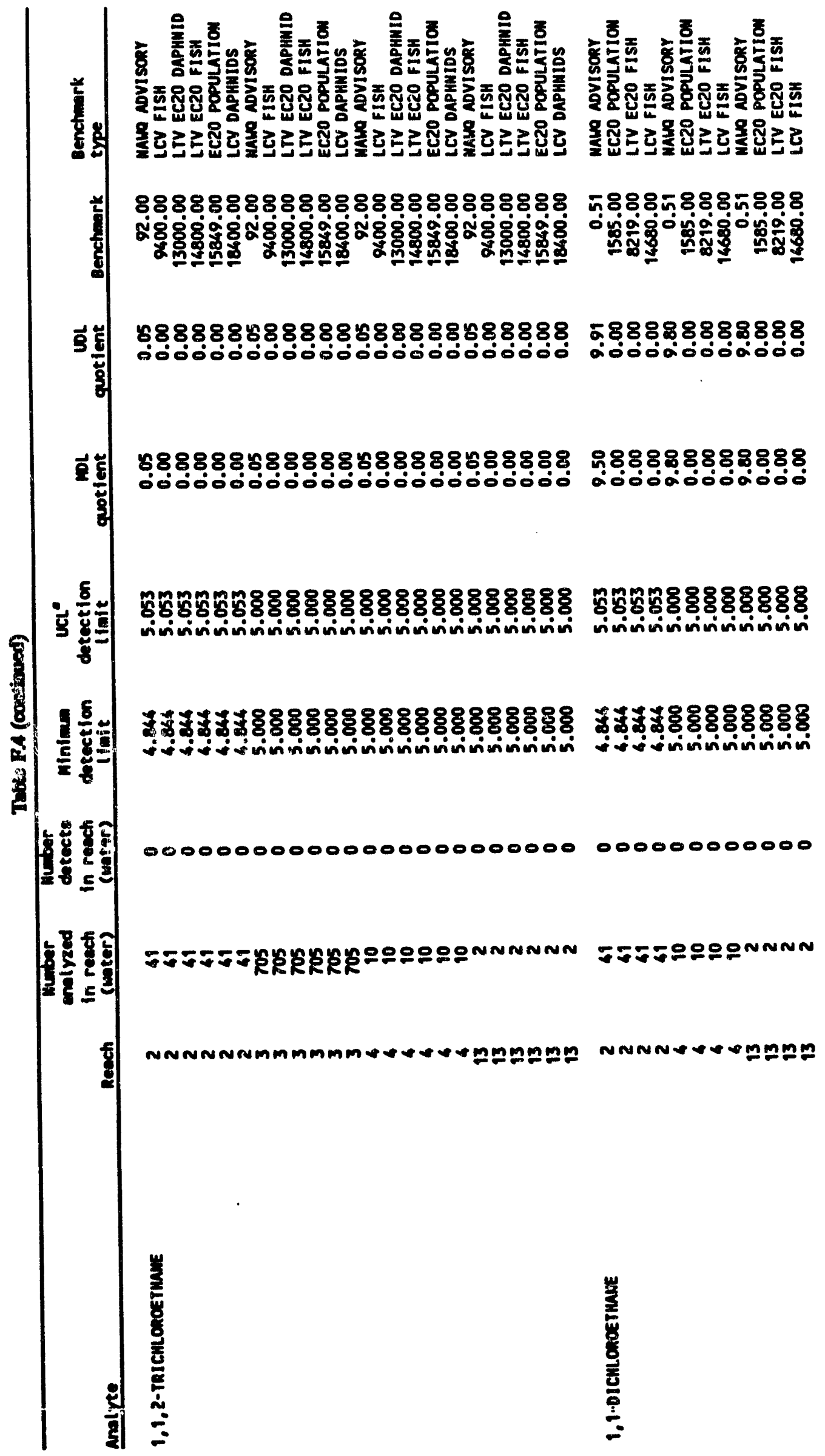




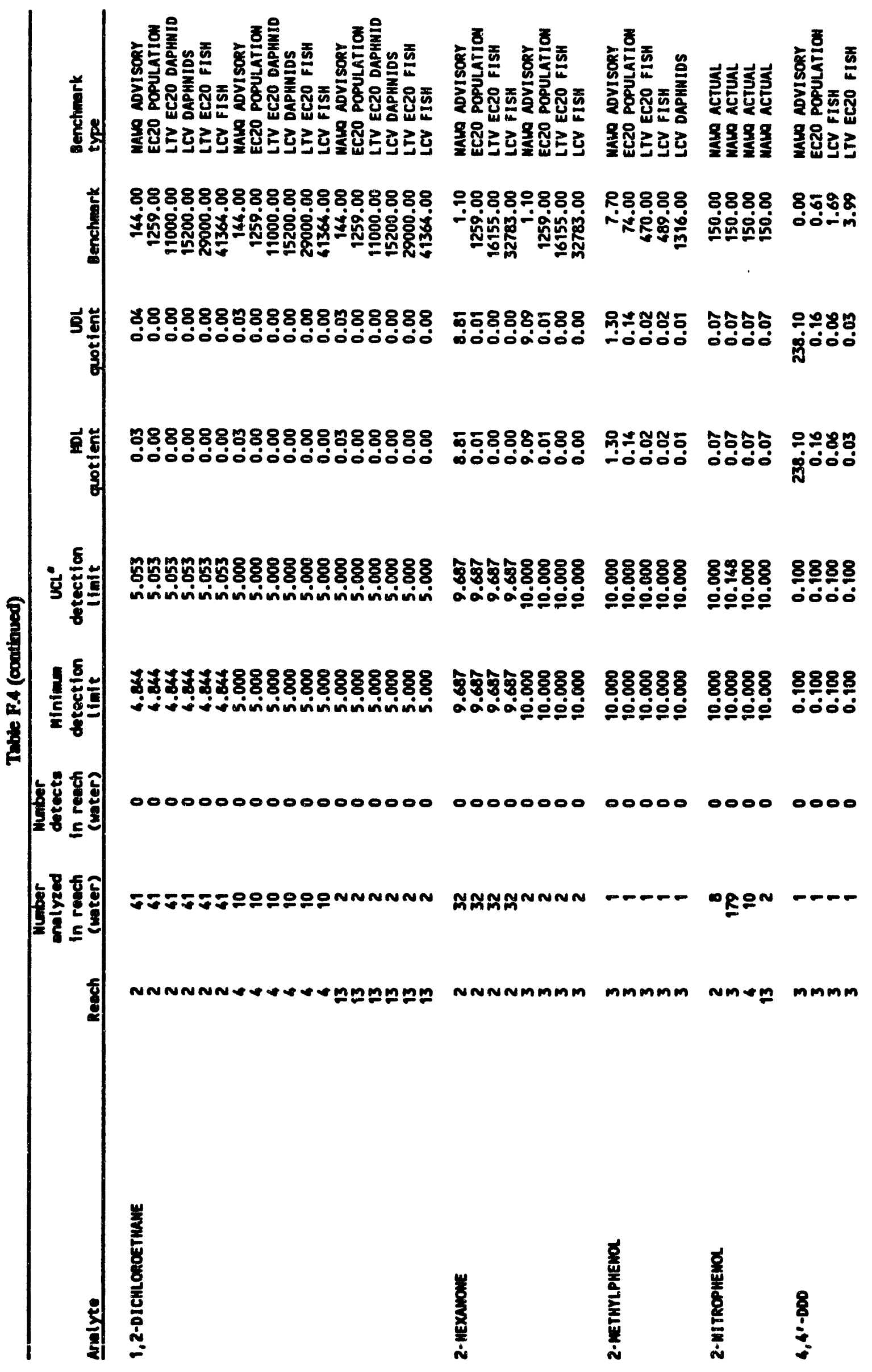




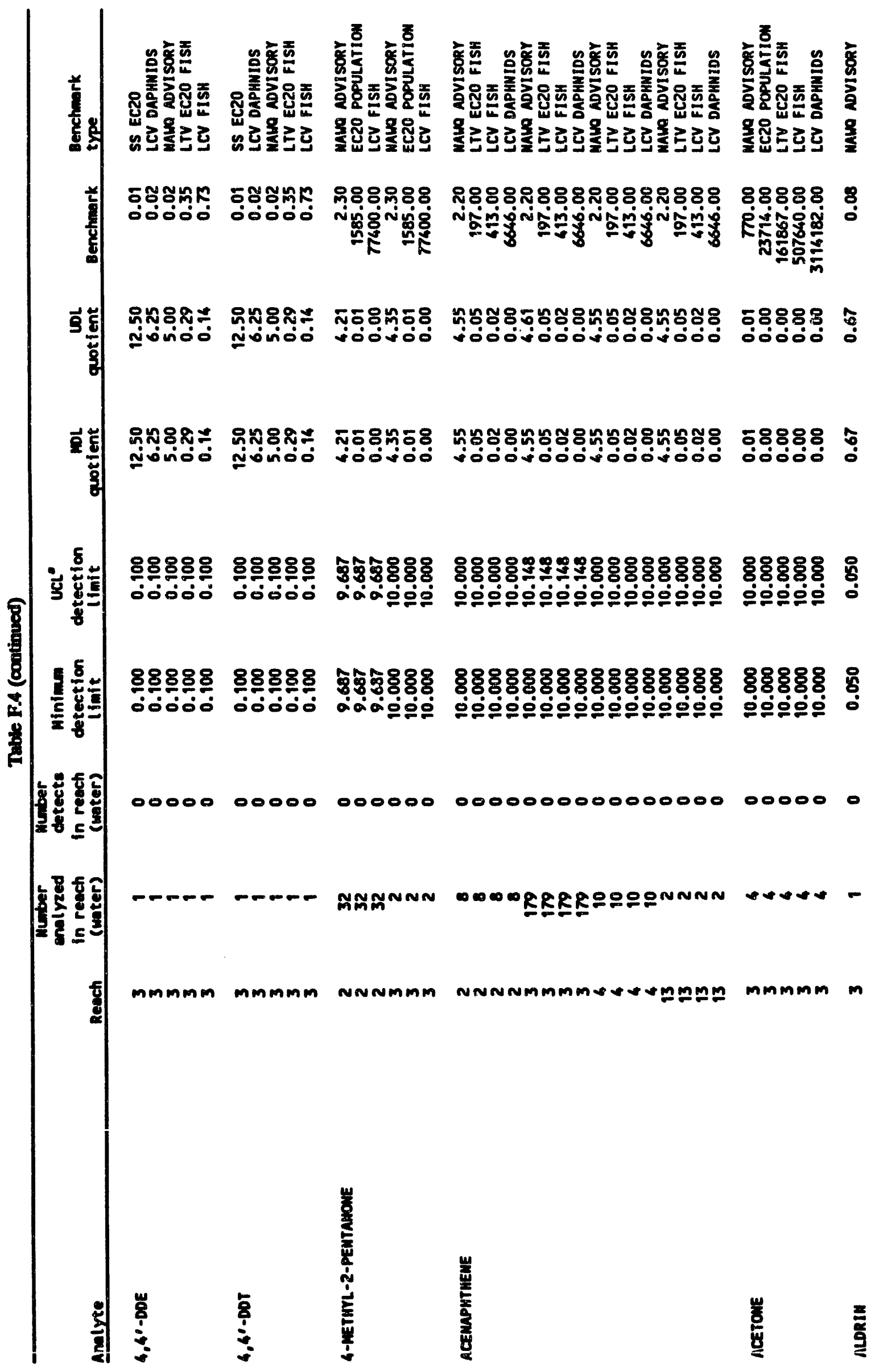




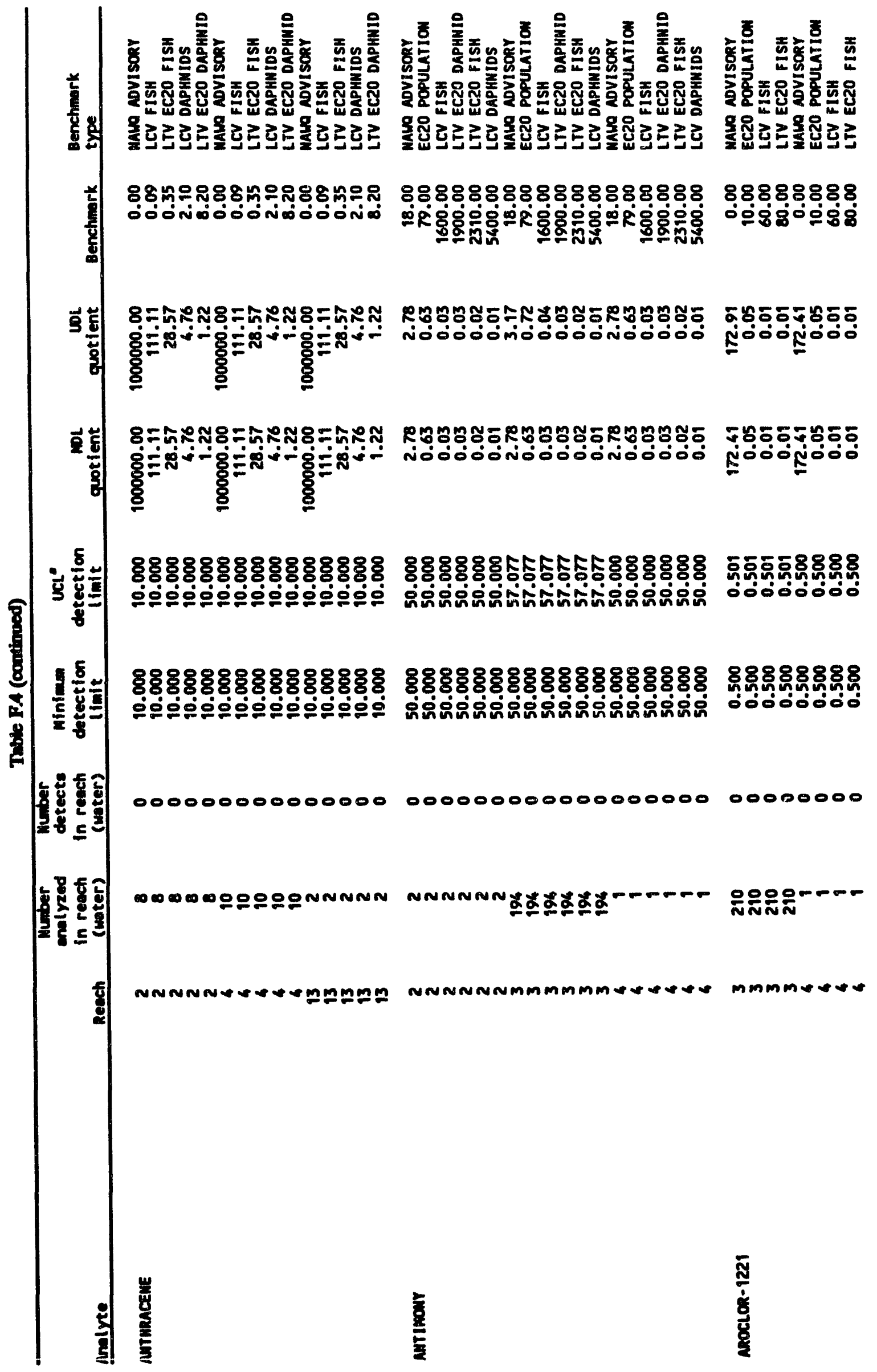




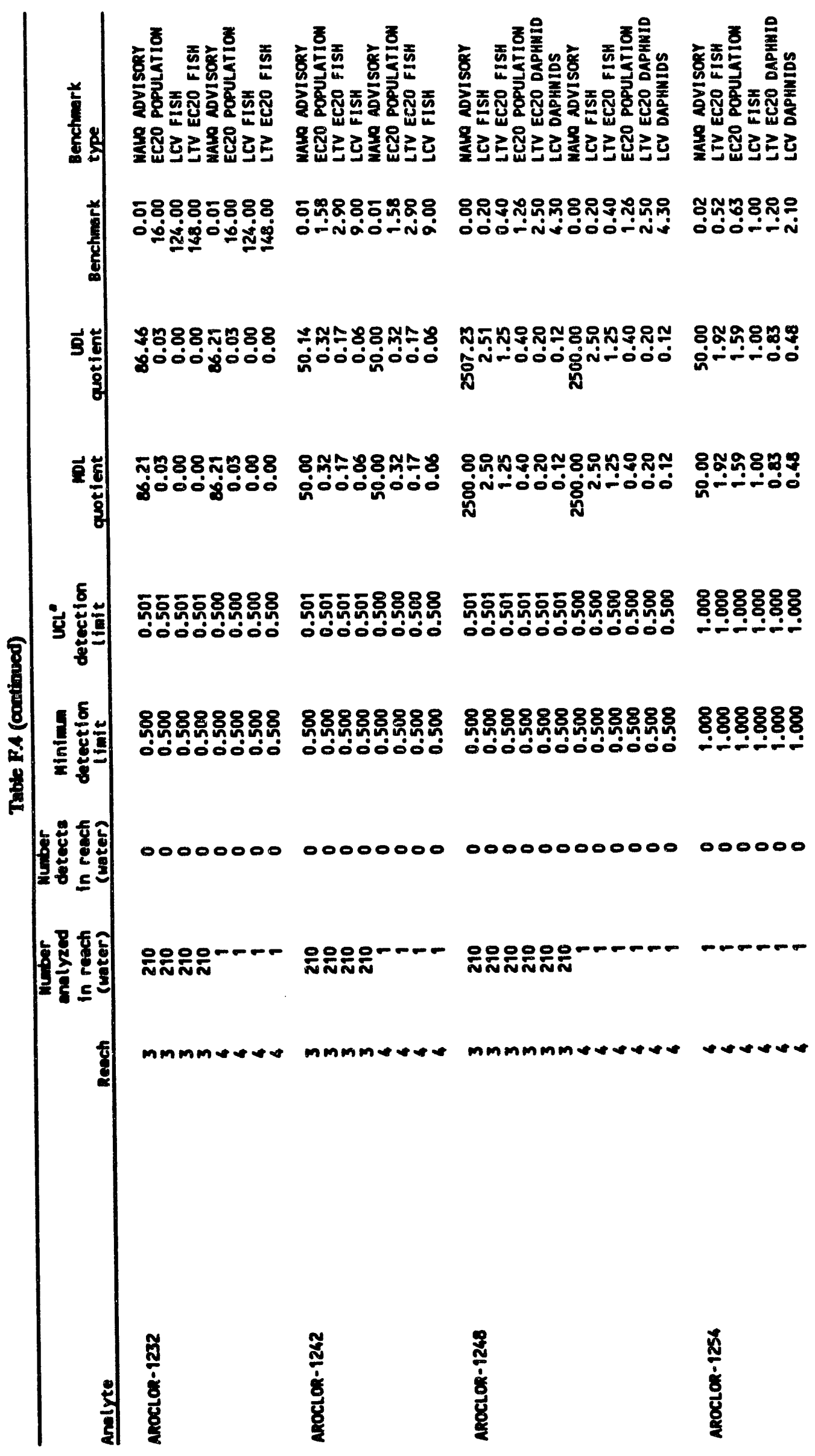




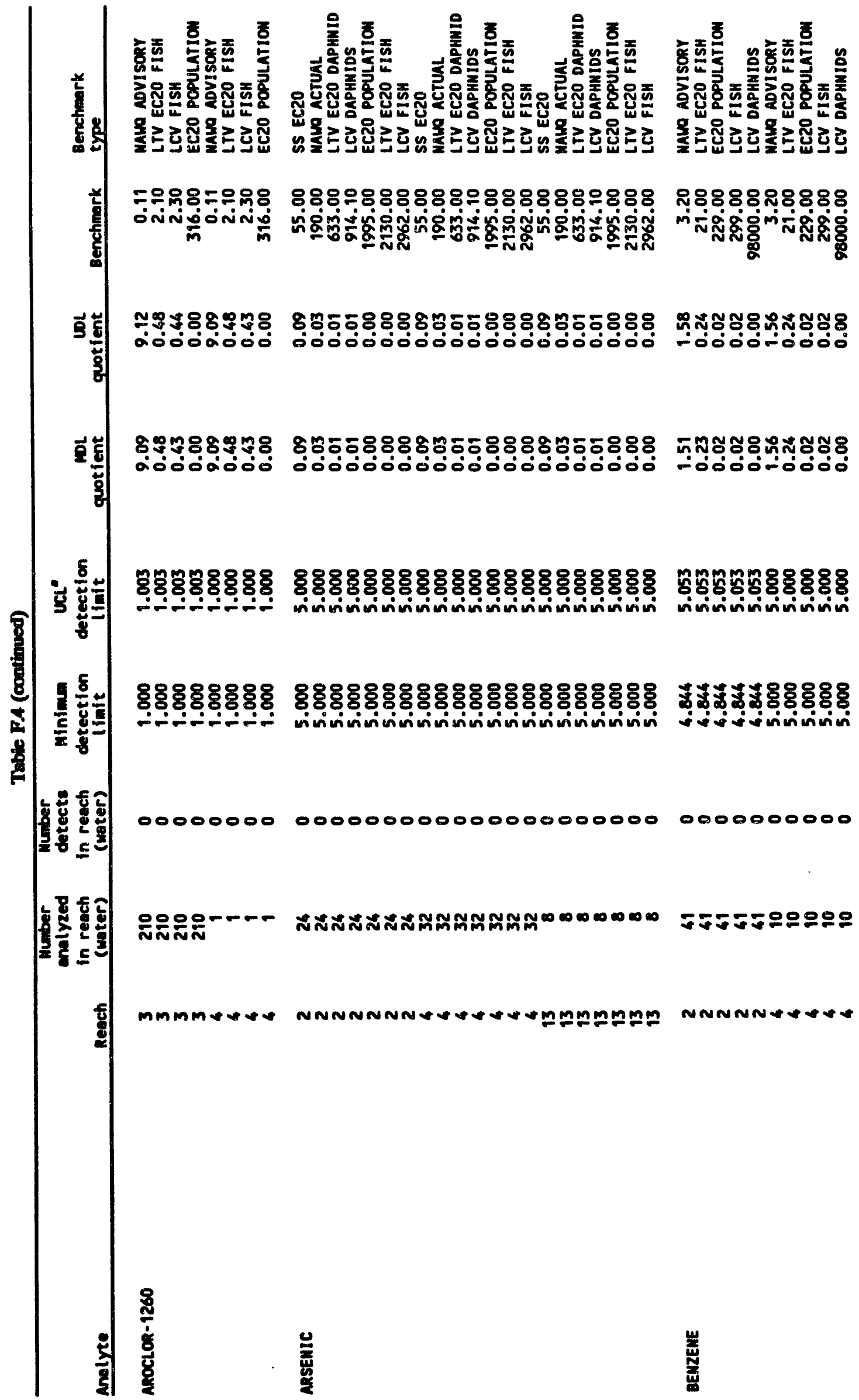




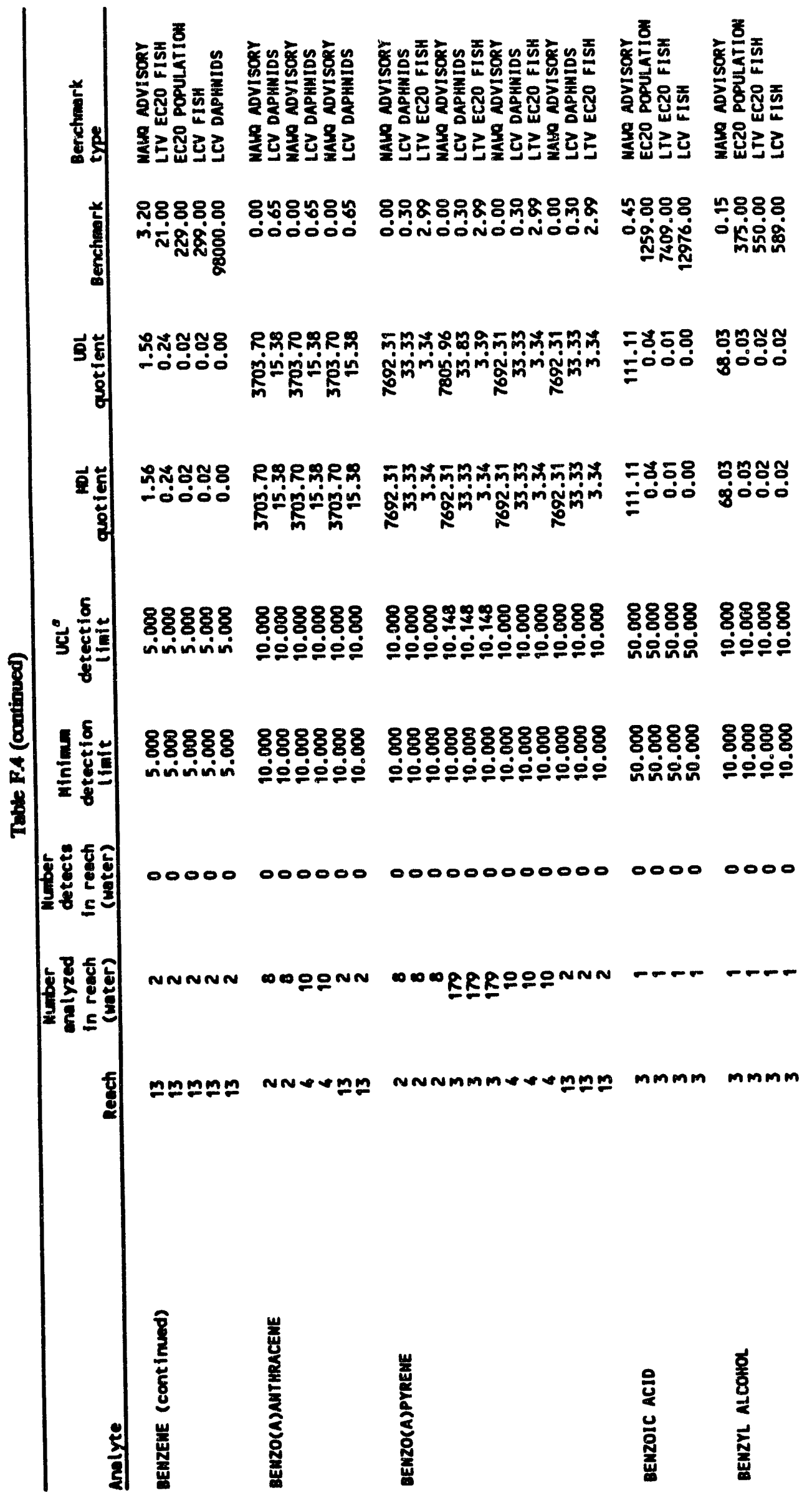




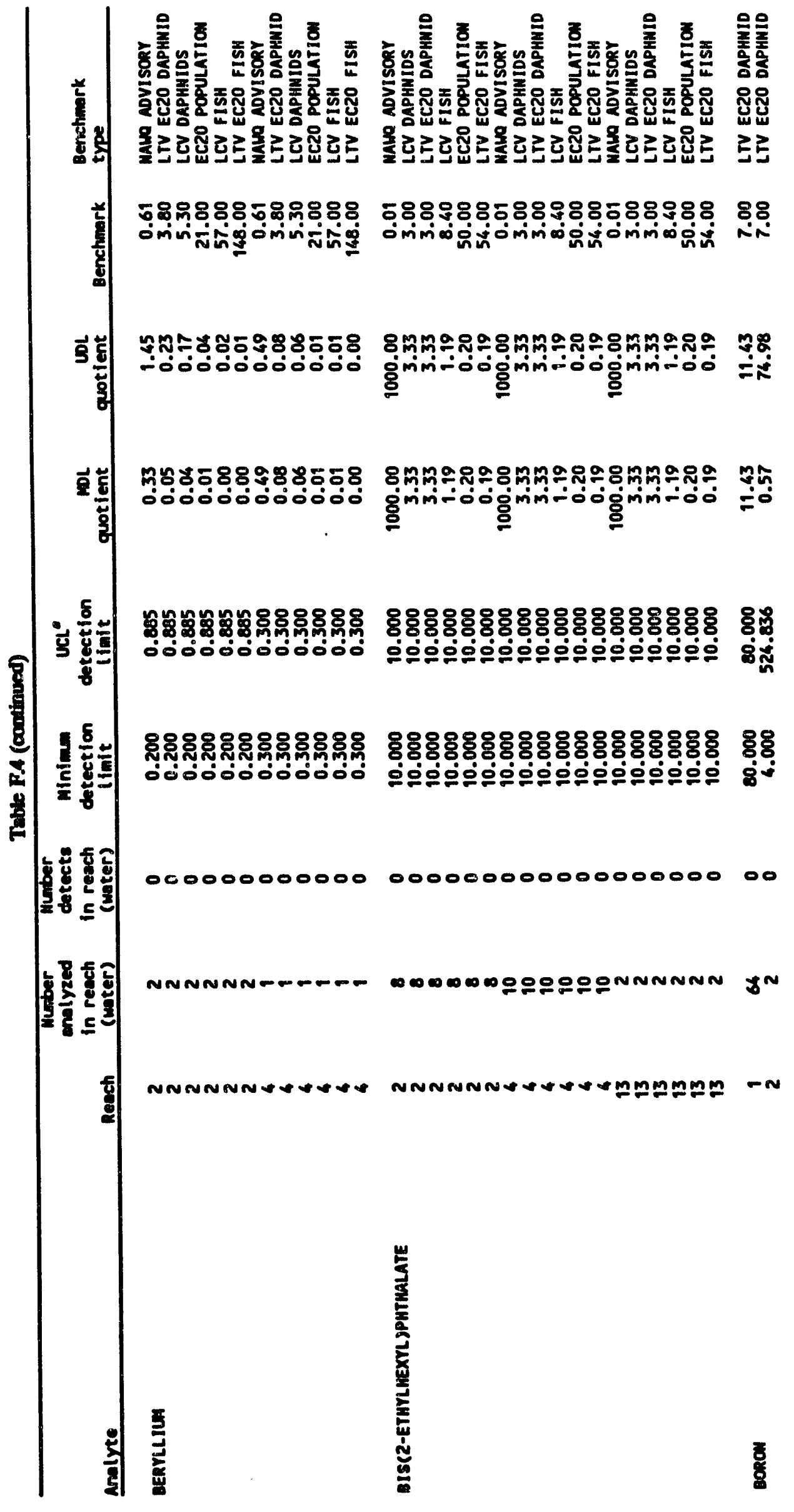




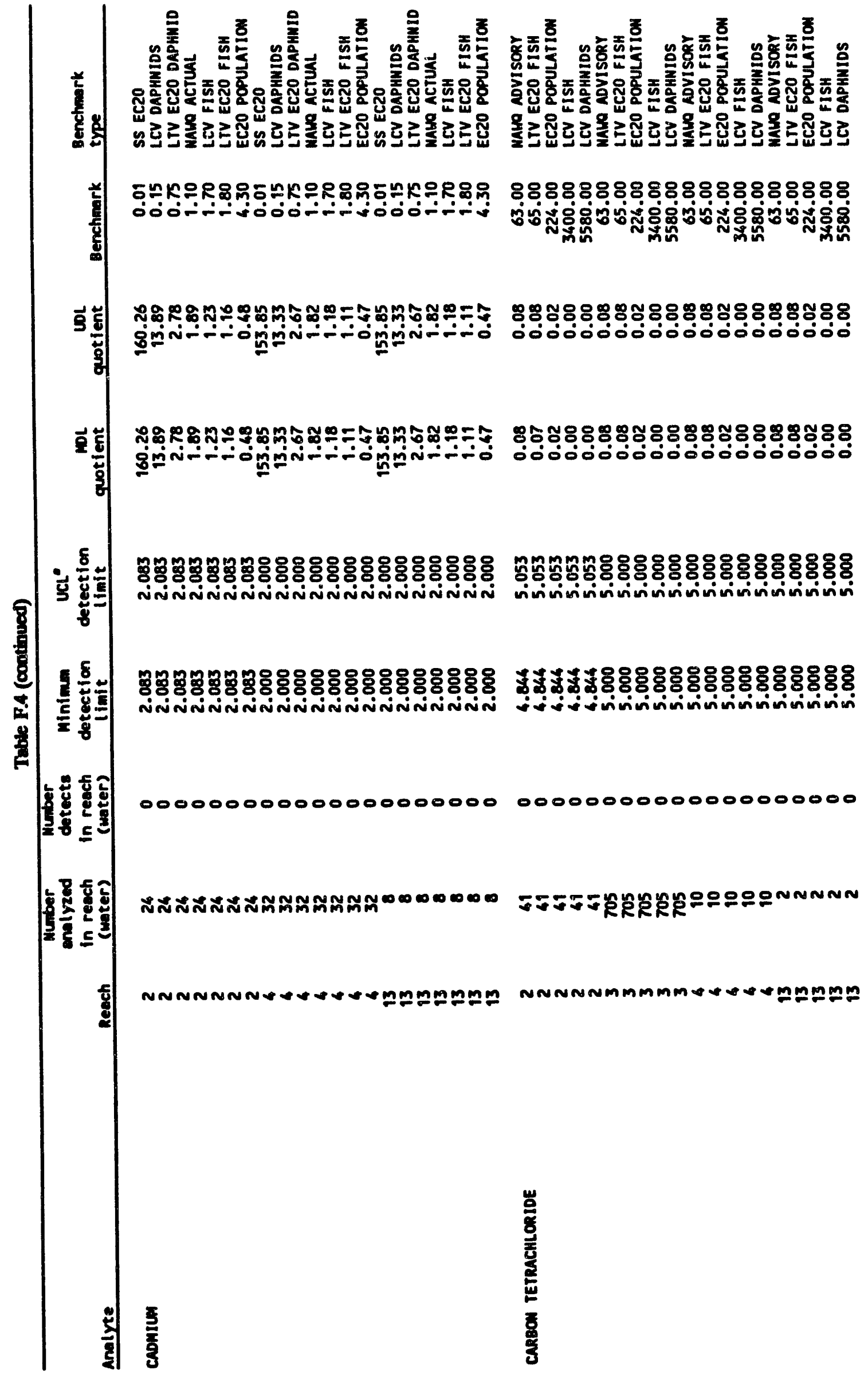




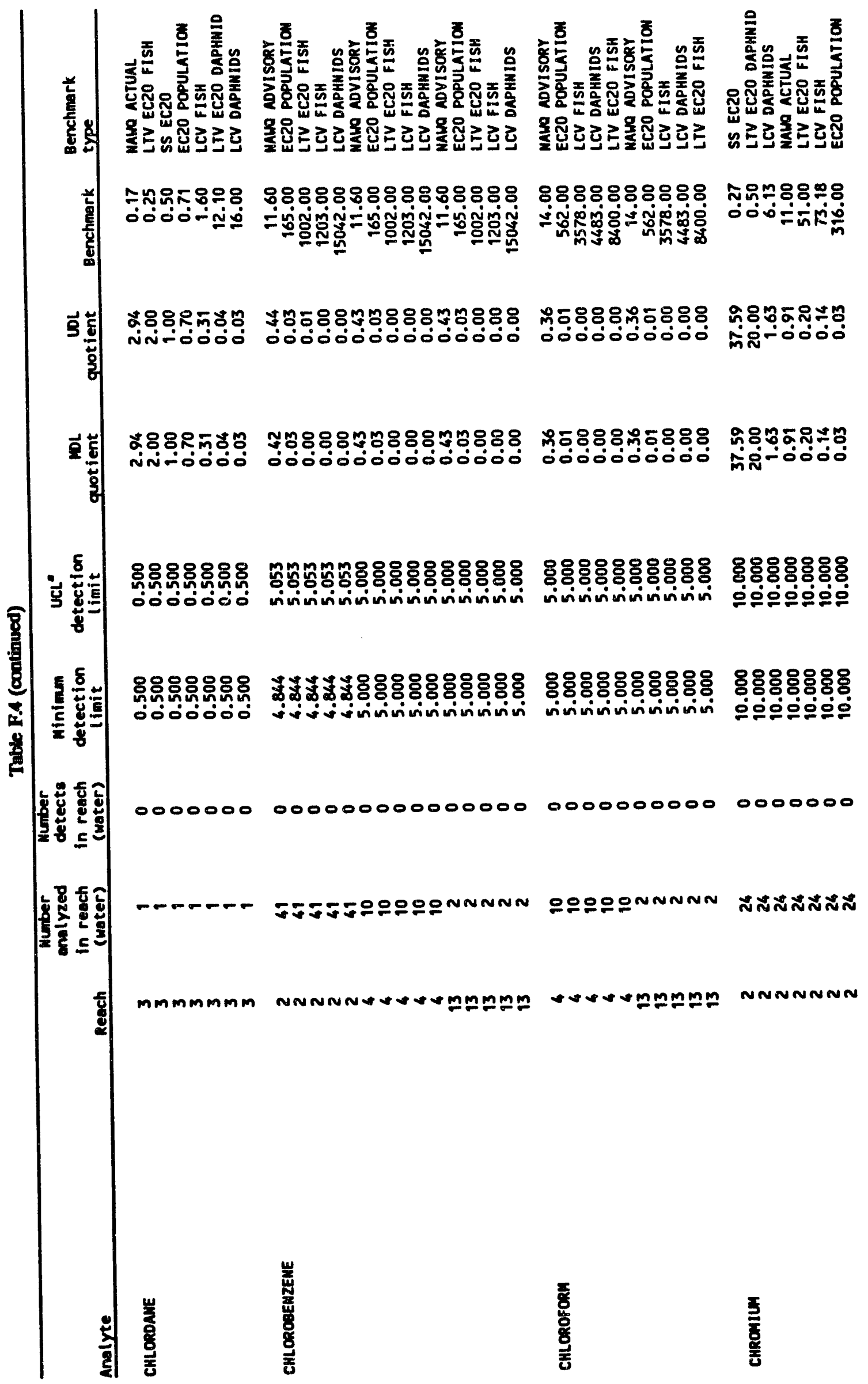




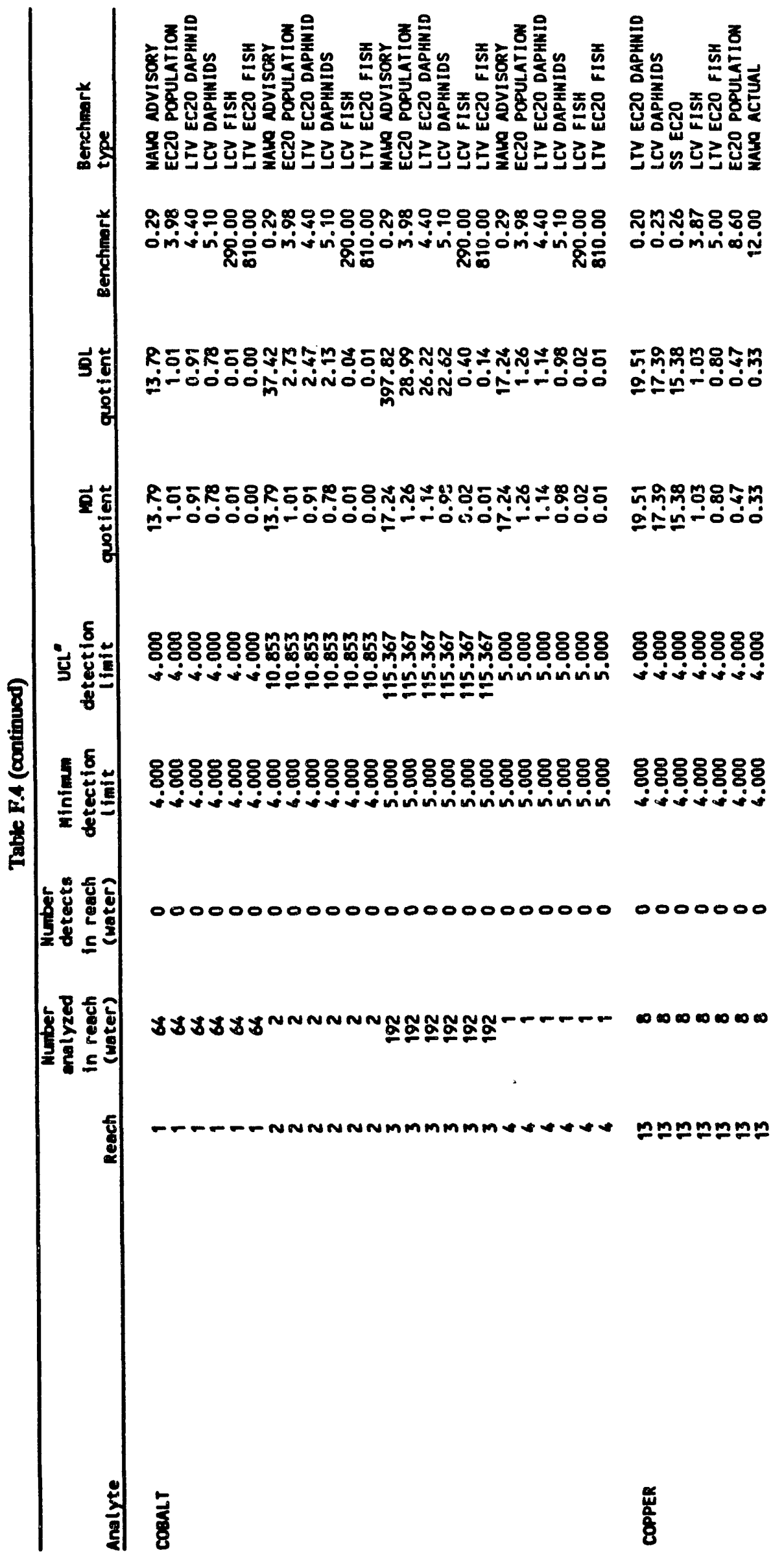




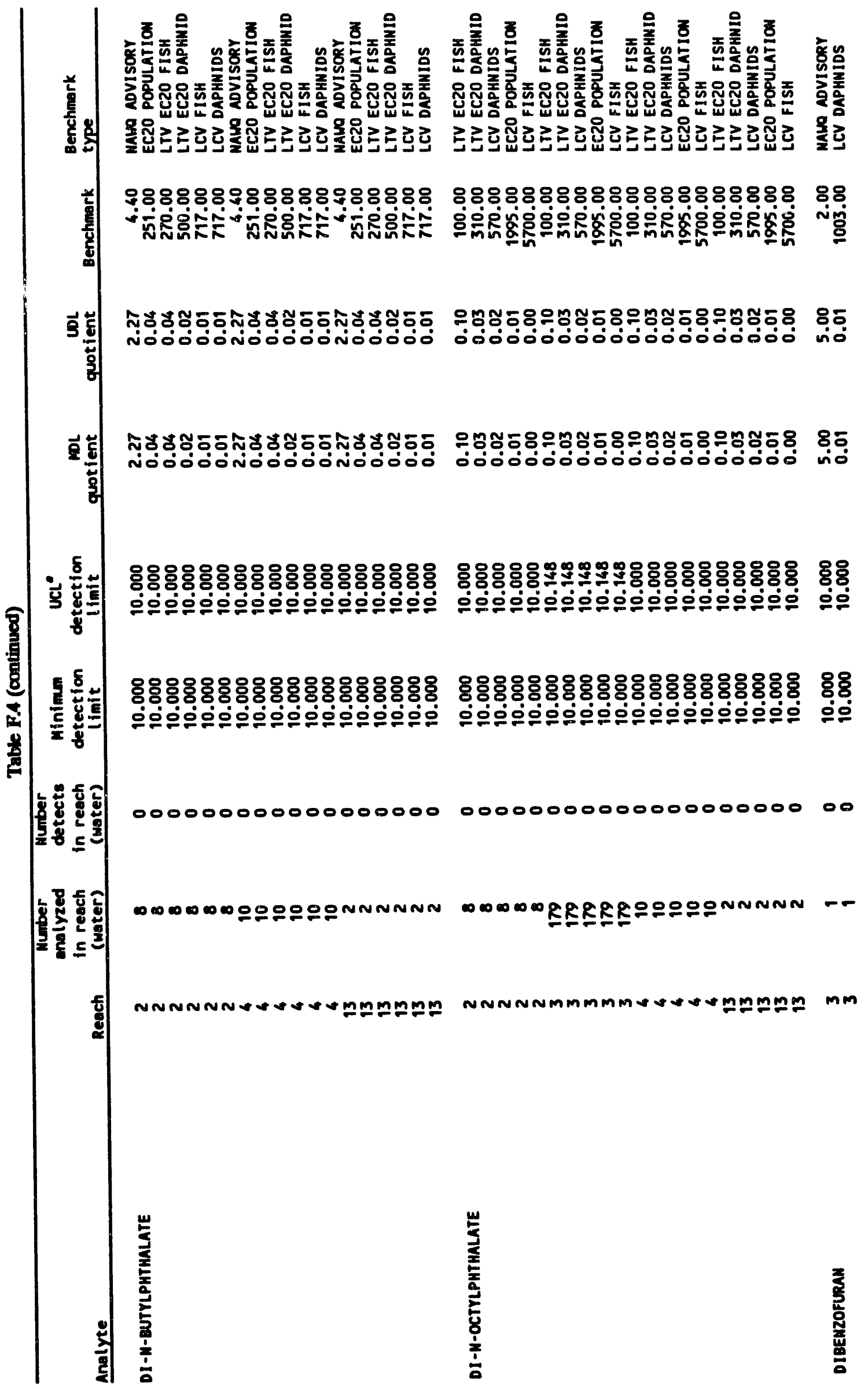




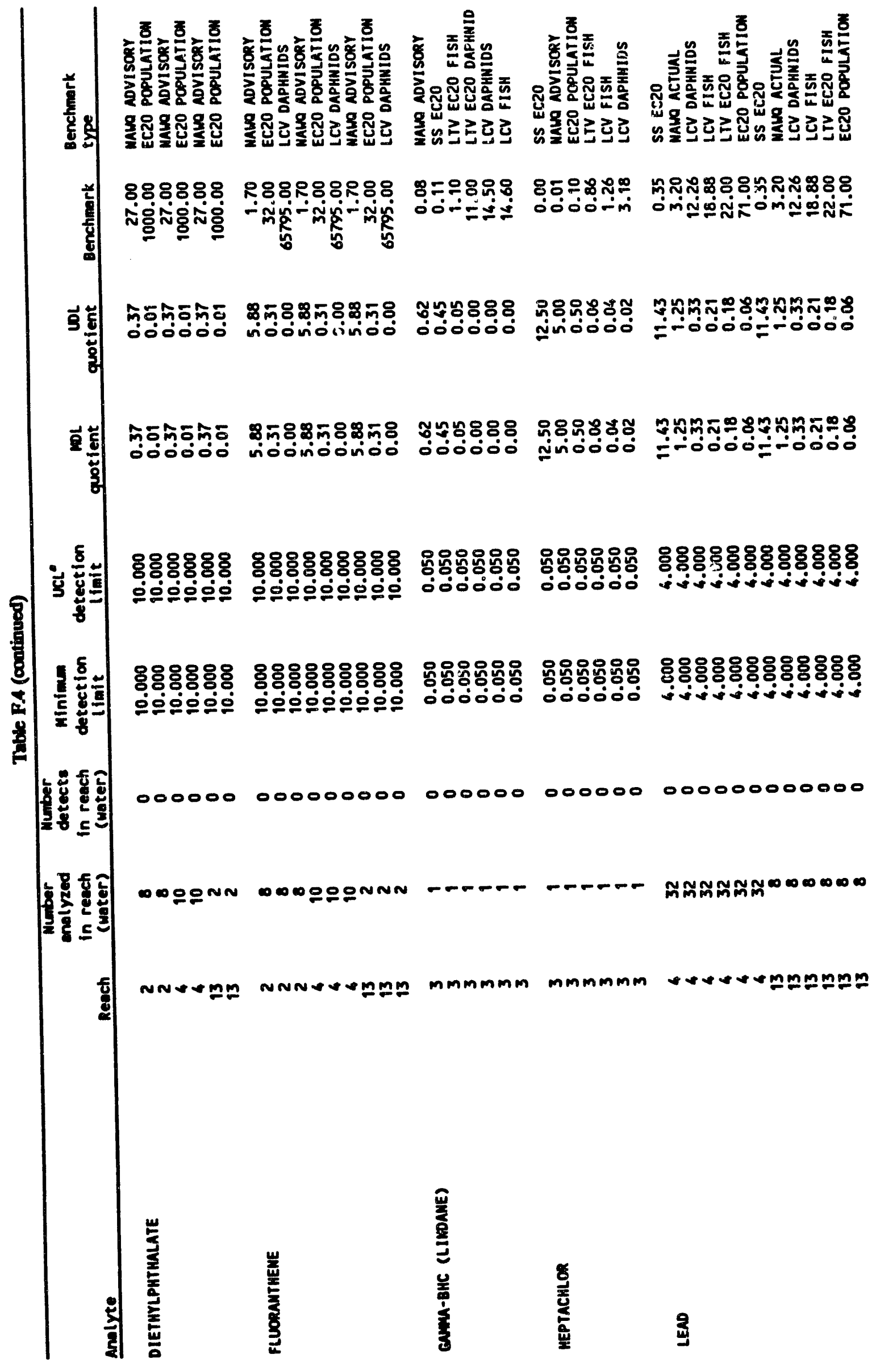




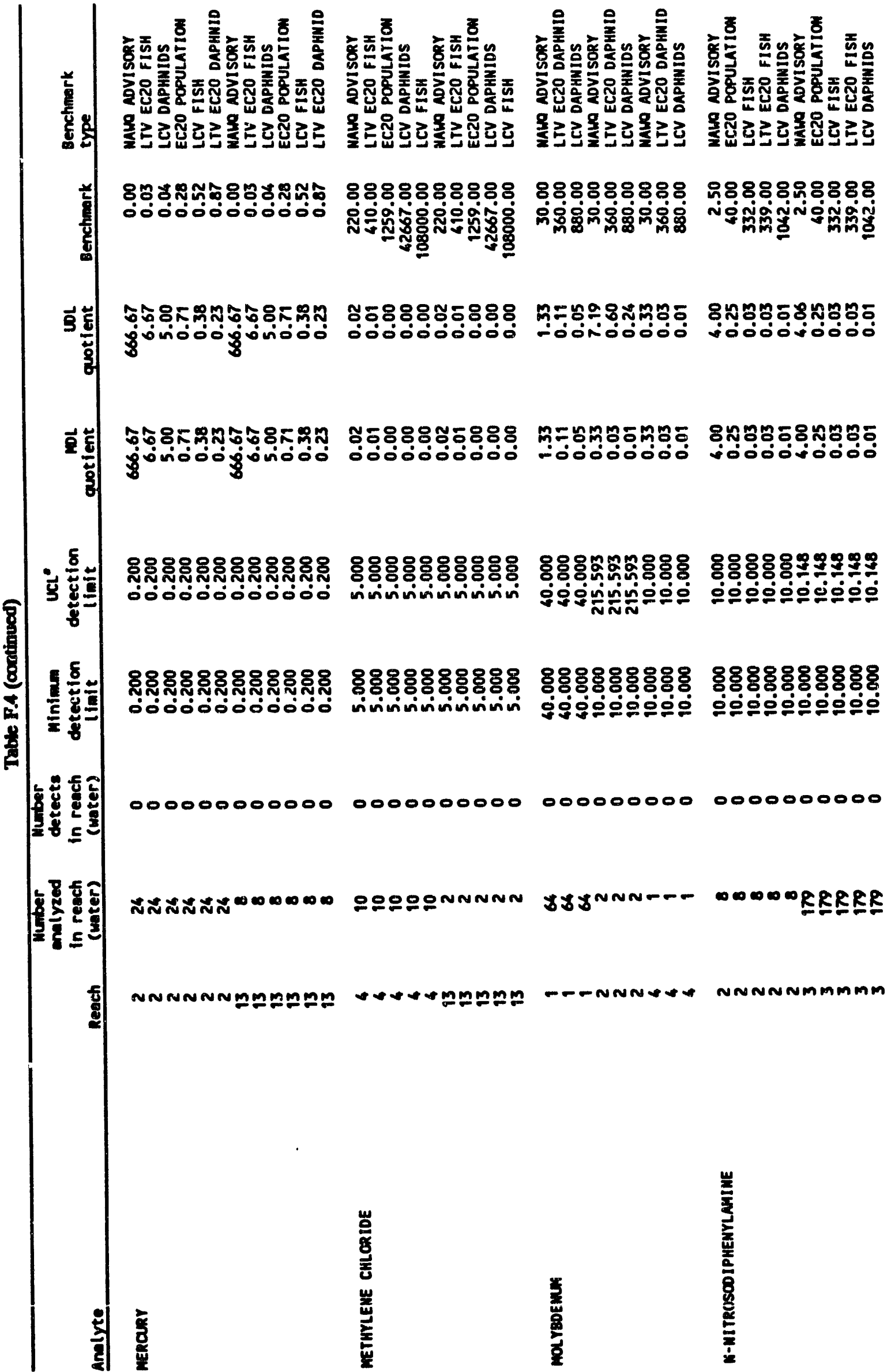




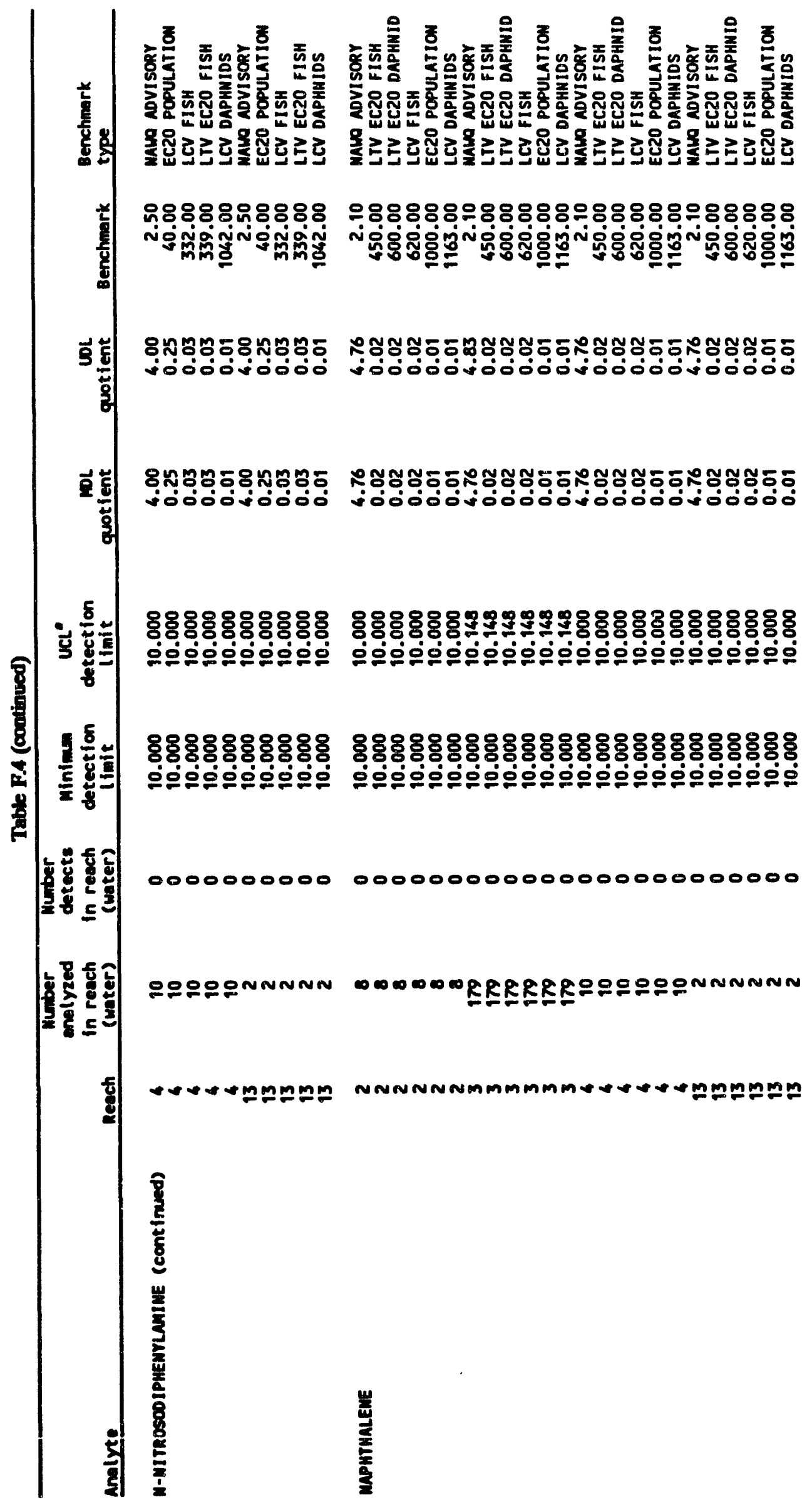




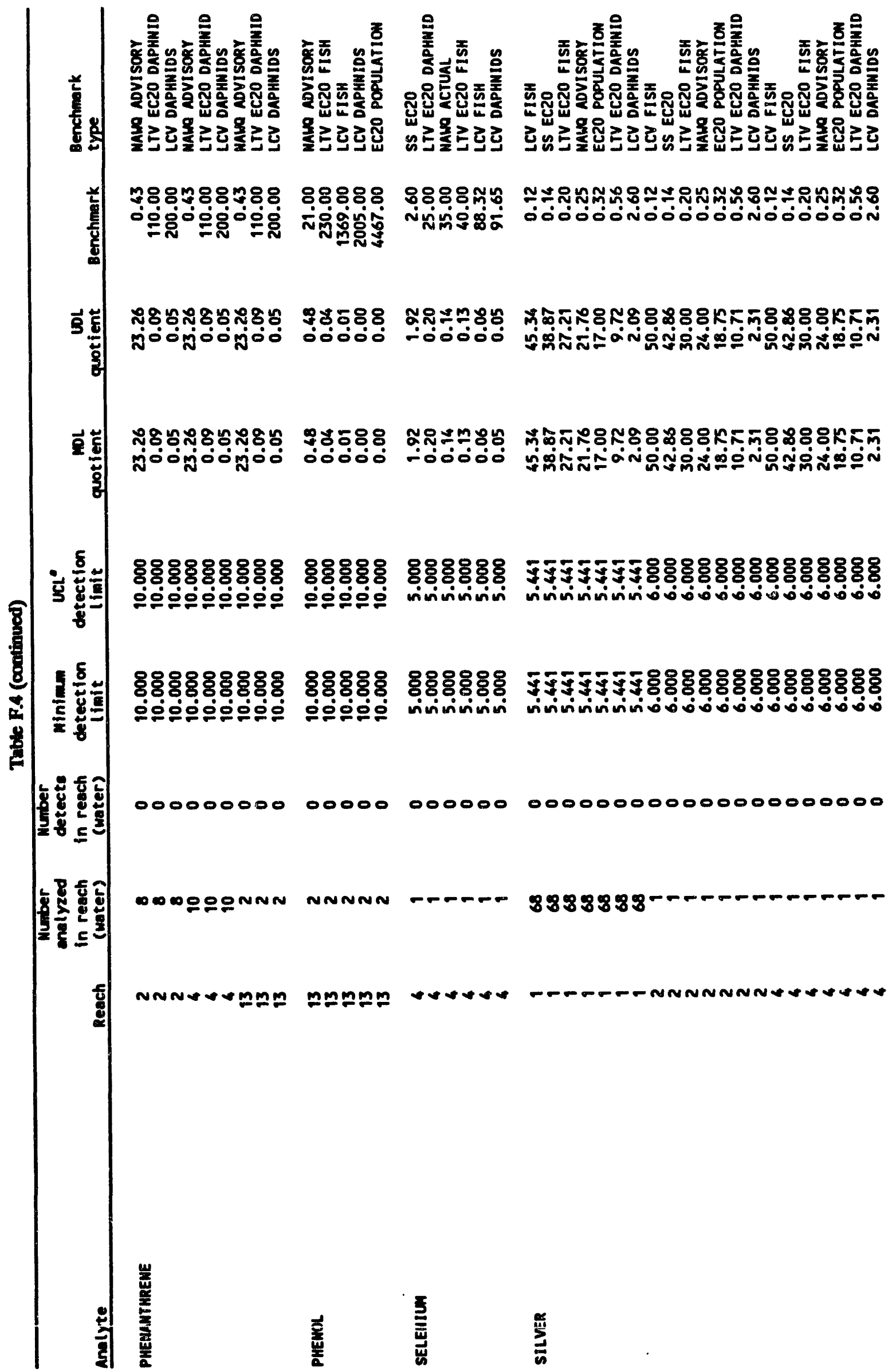




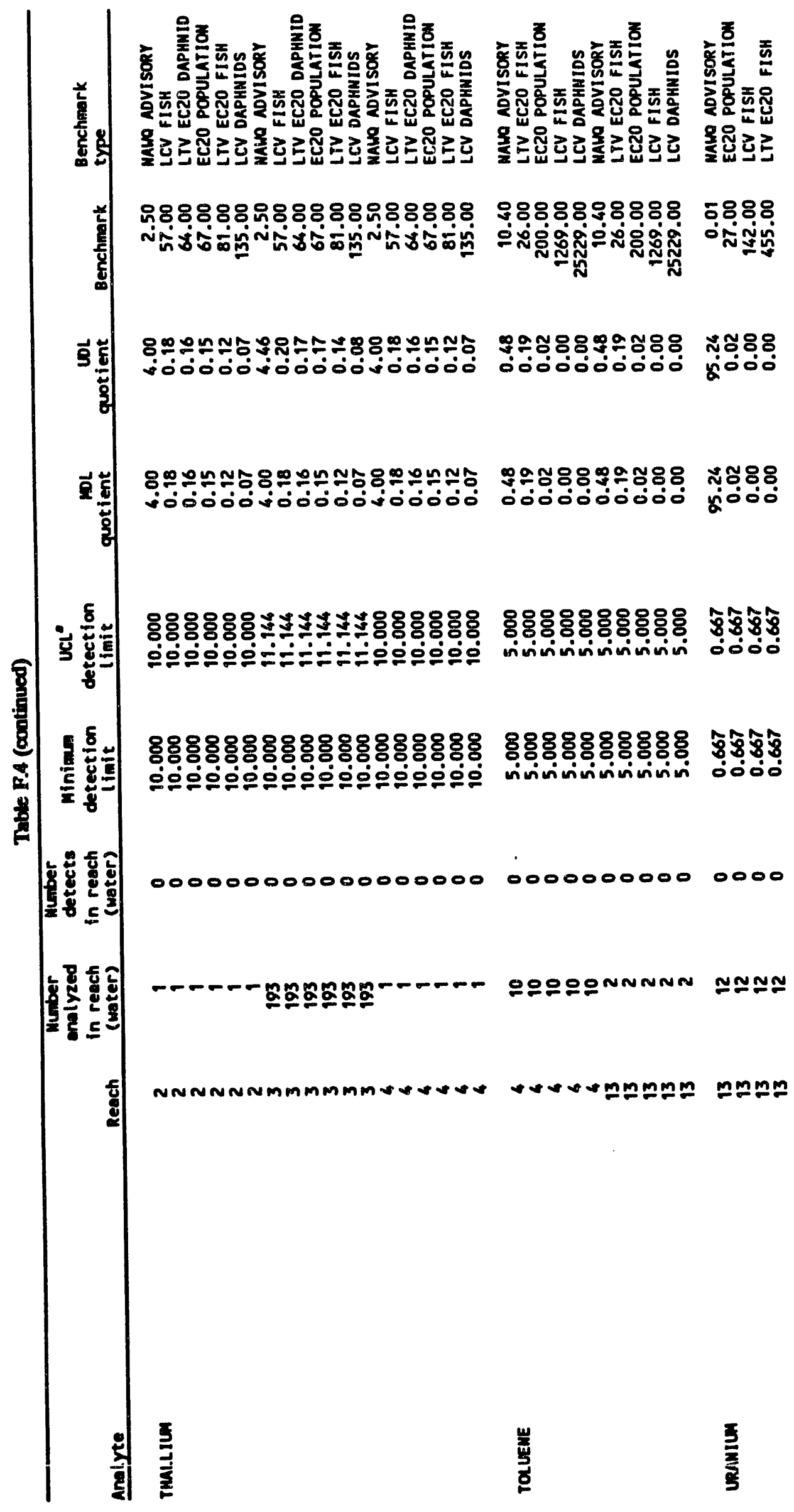




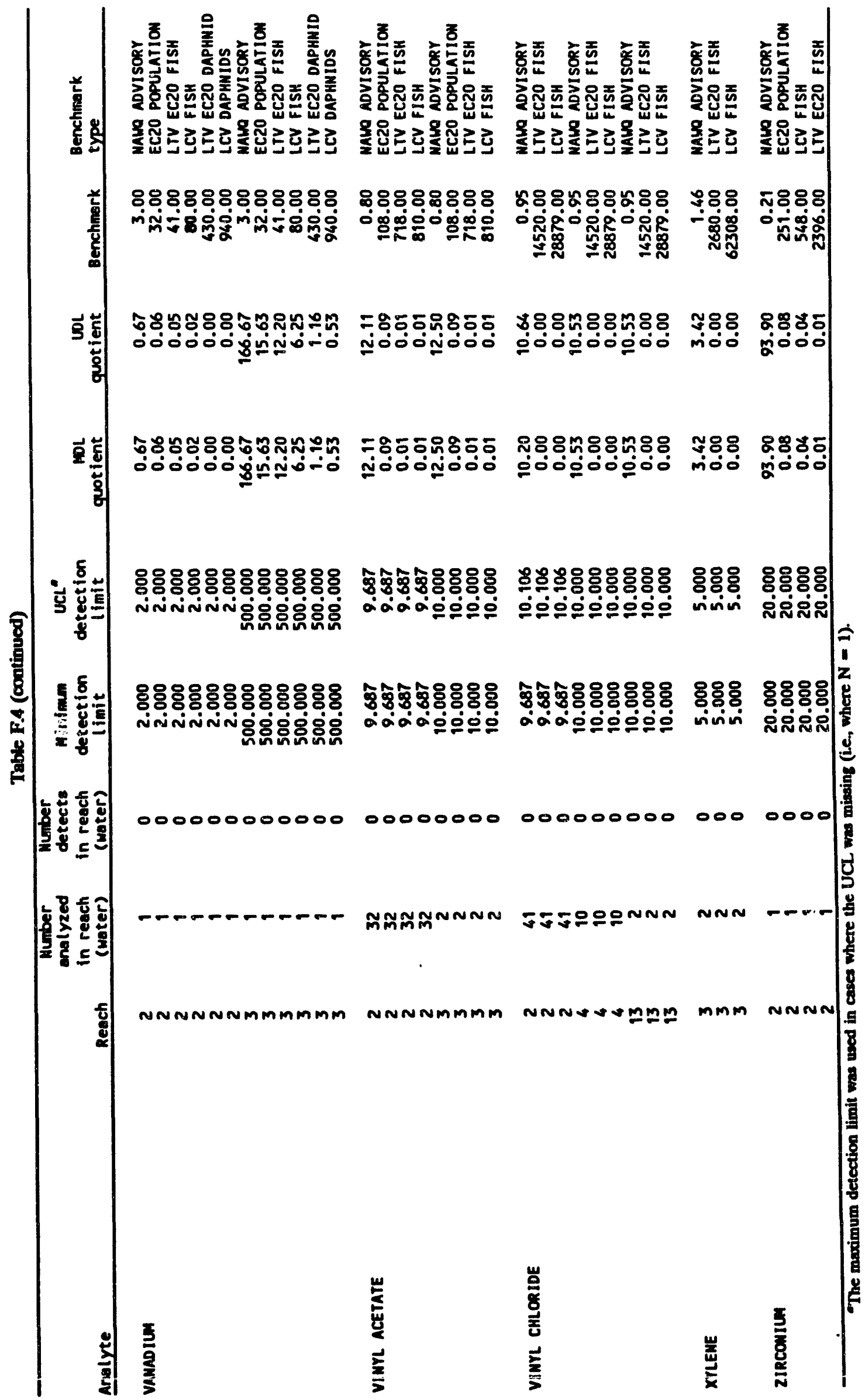




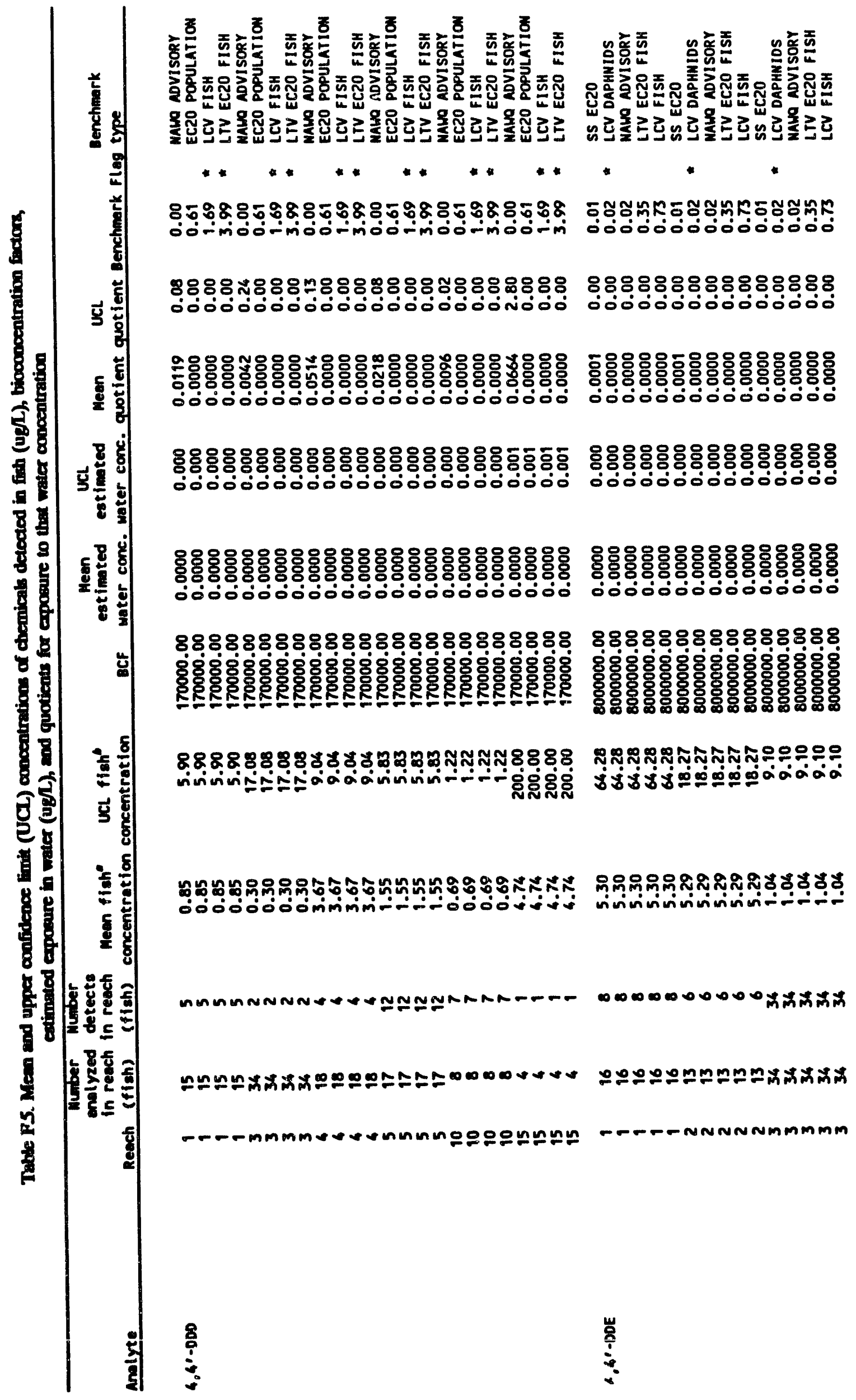




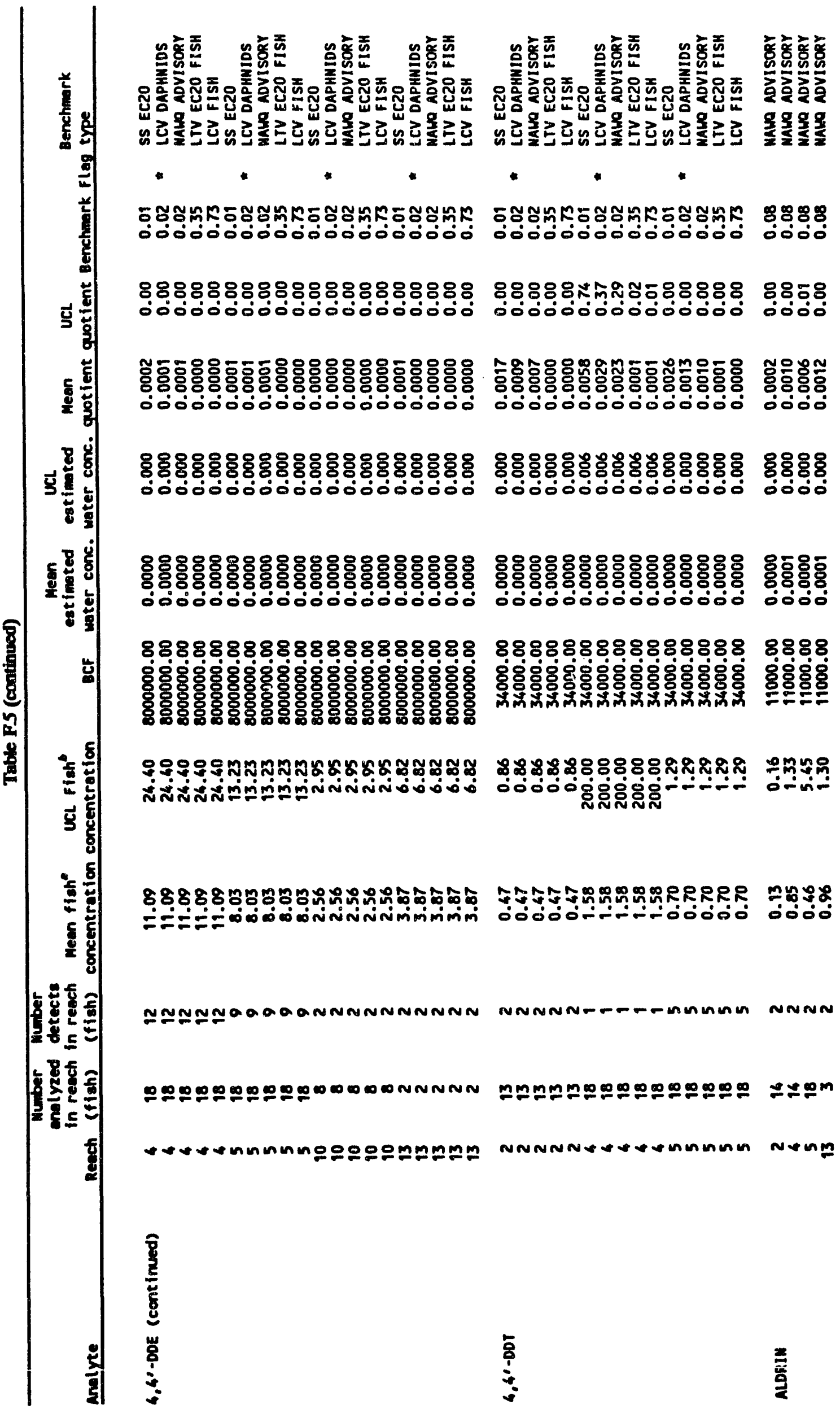




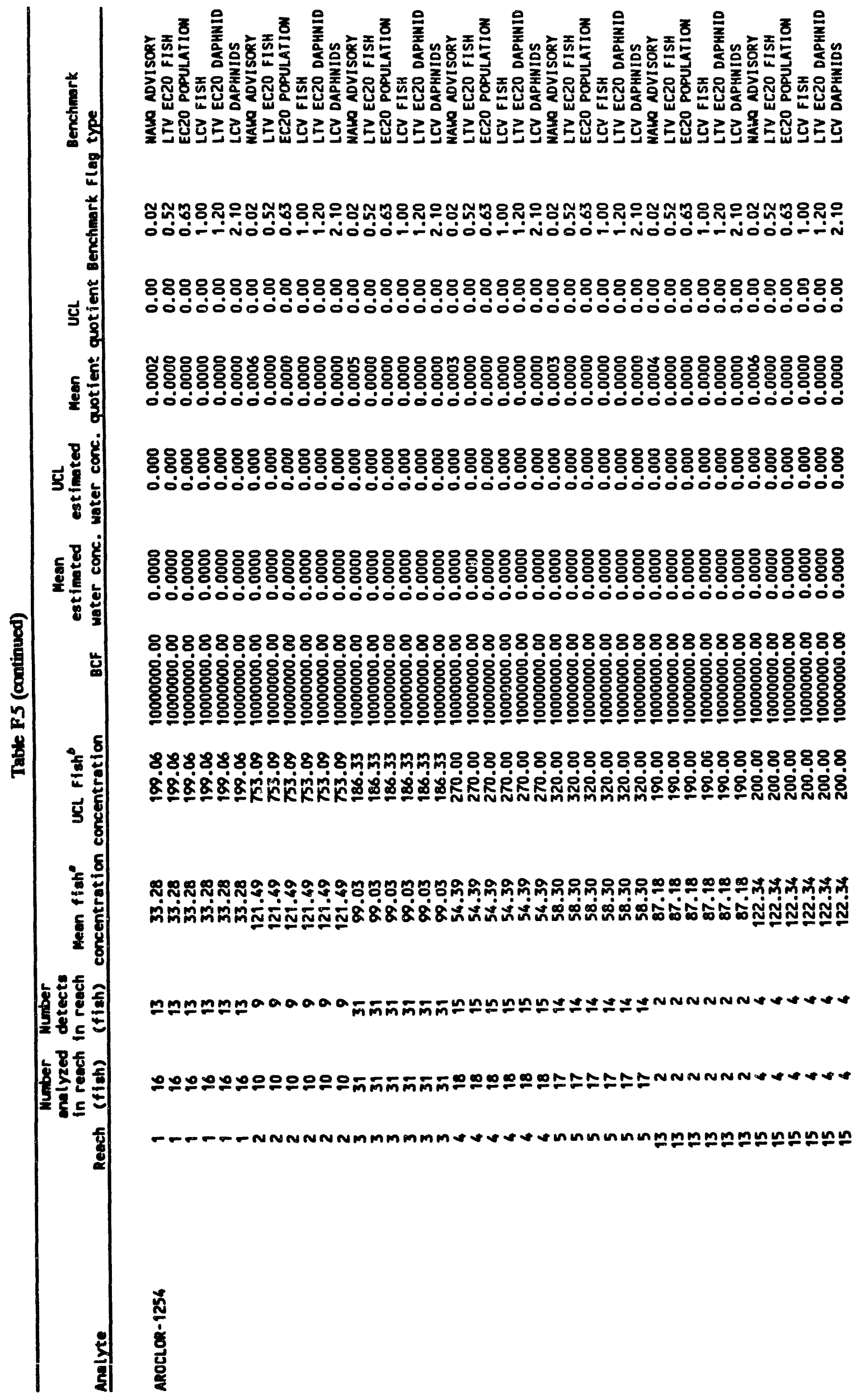




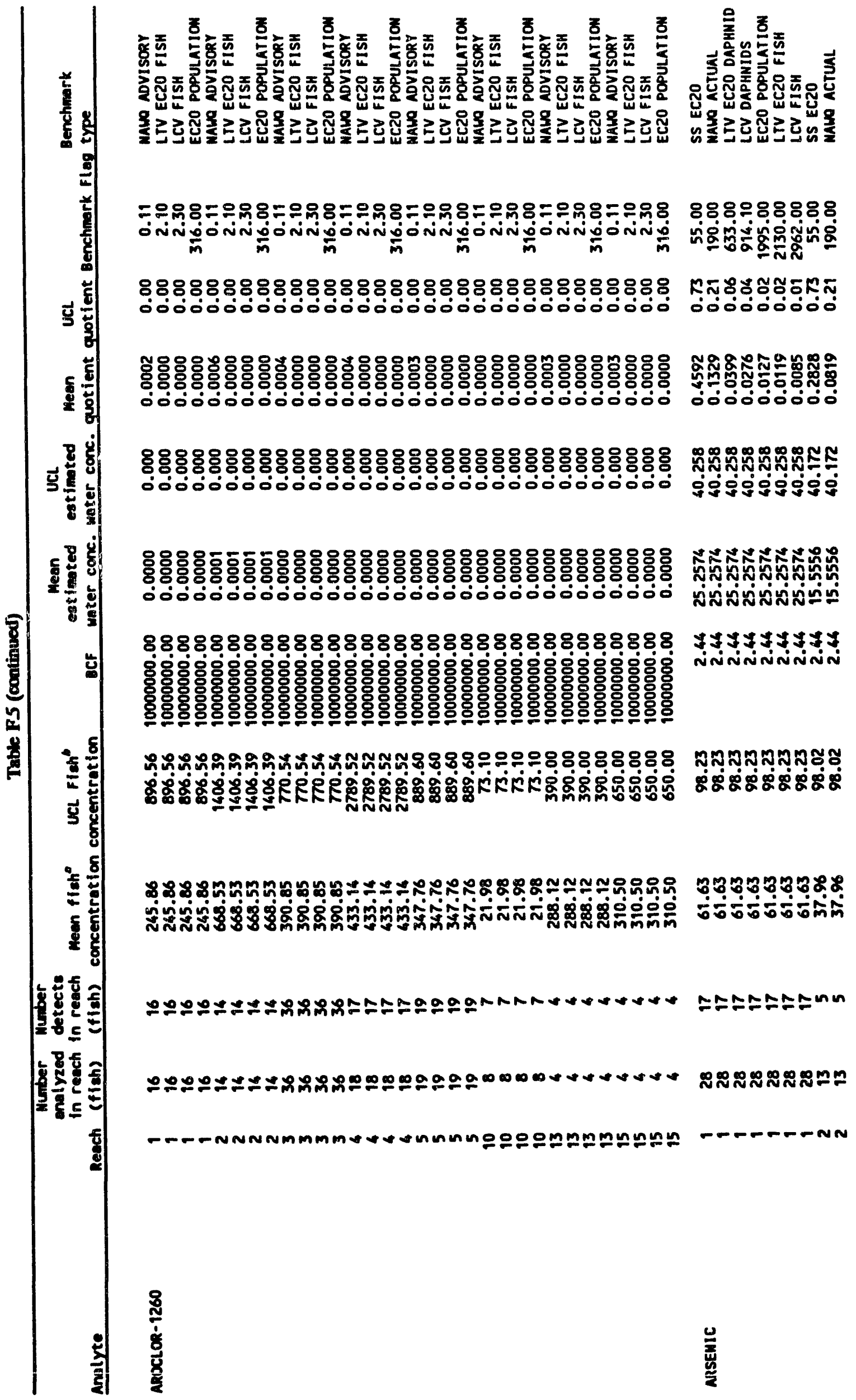


F-58

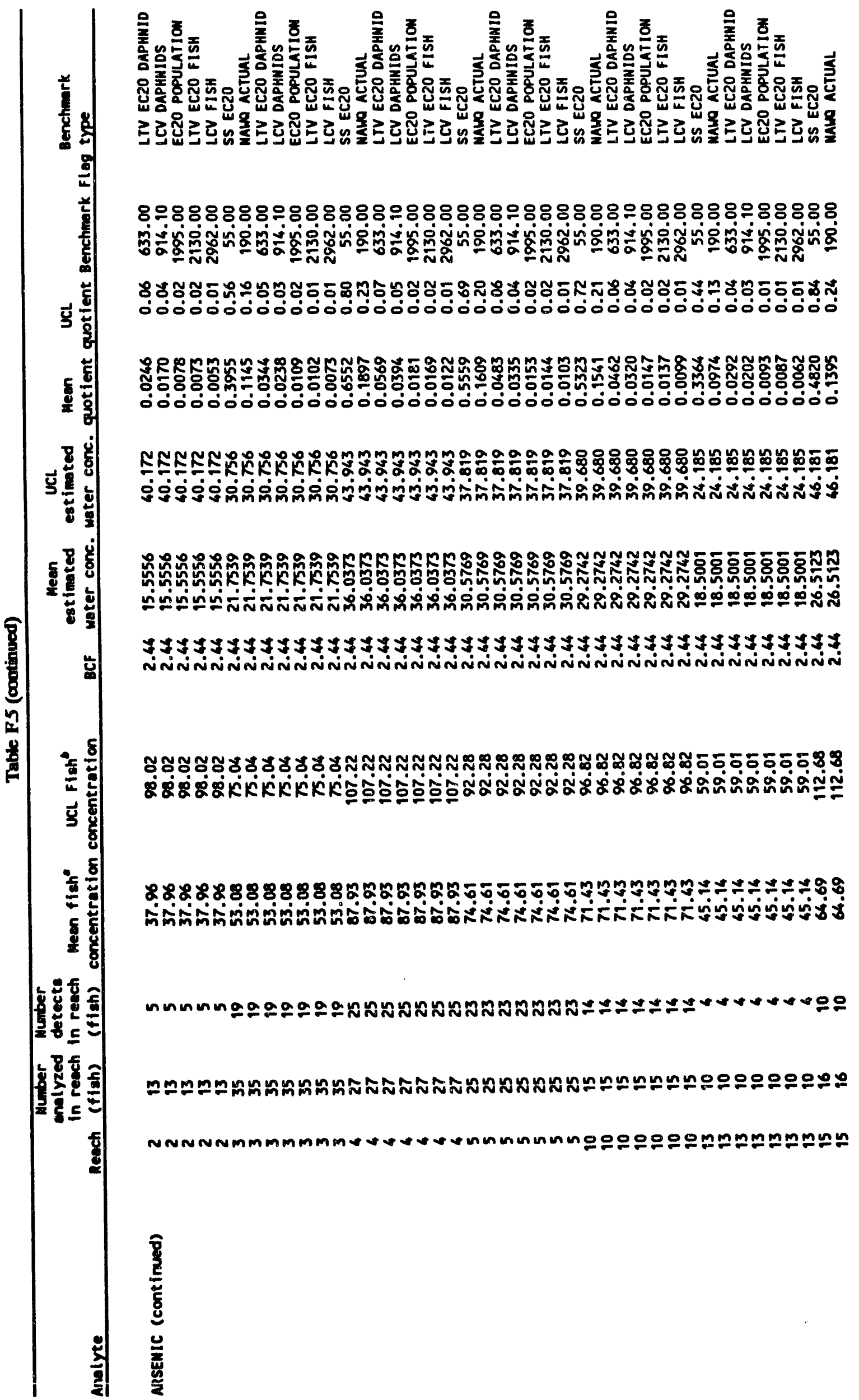


F-59

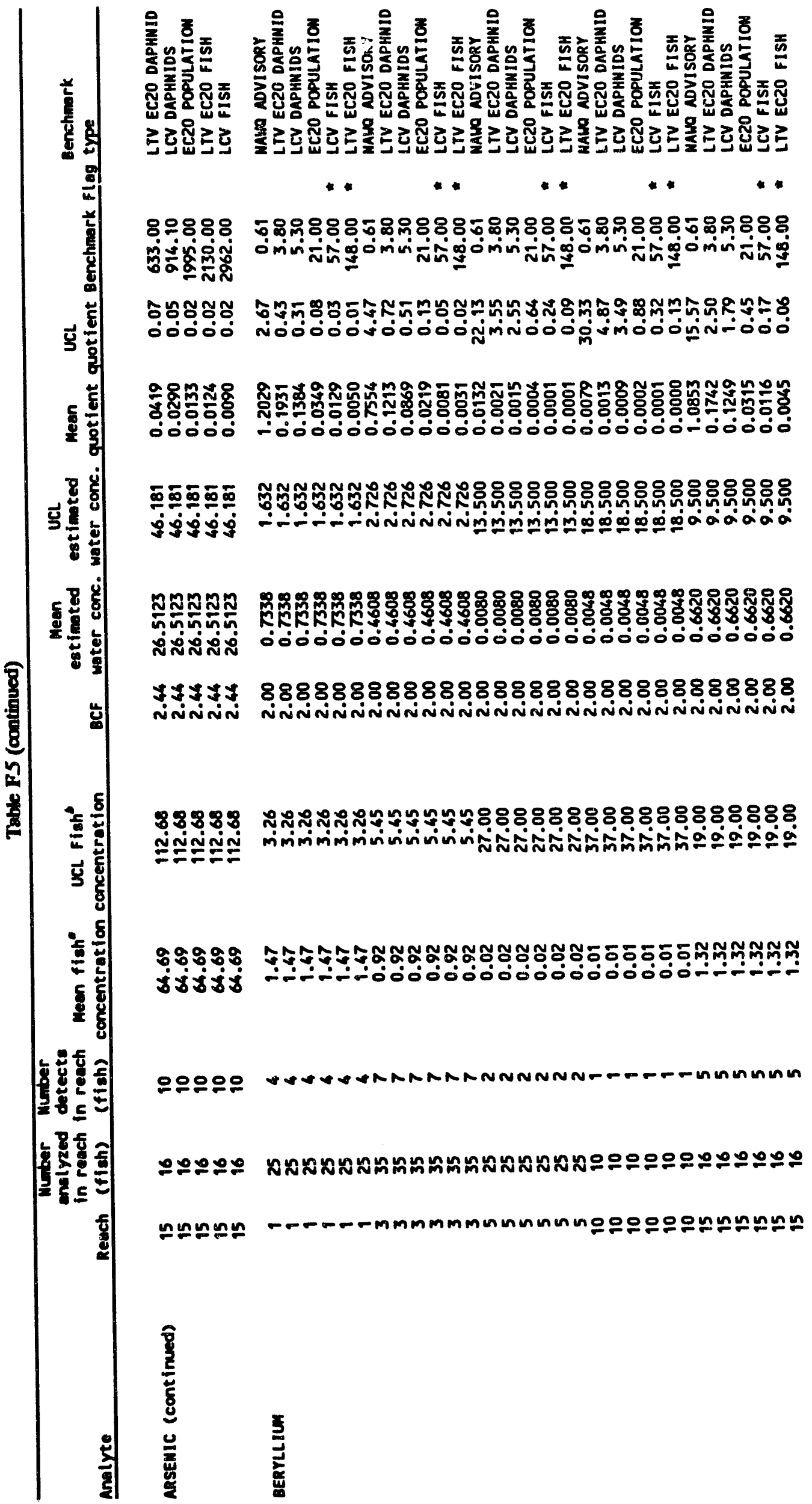




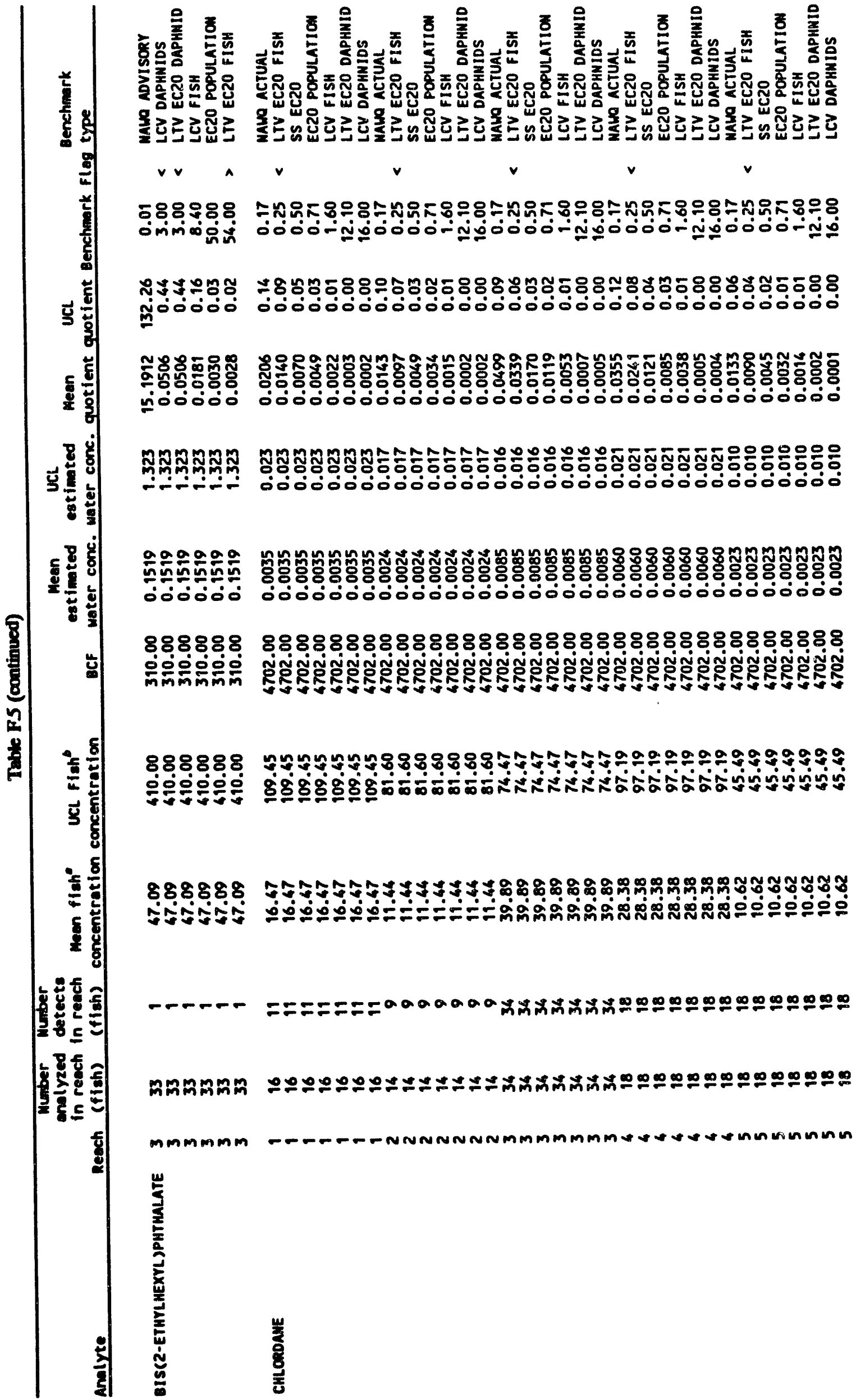




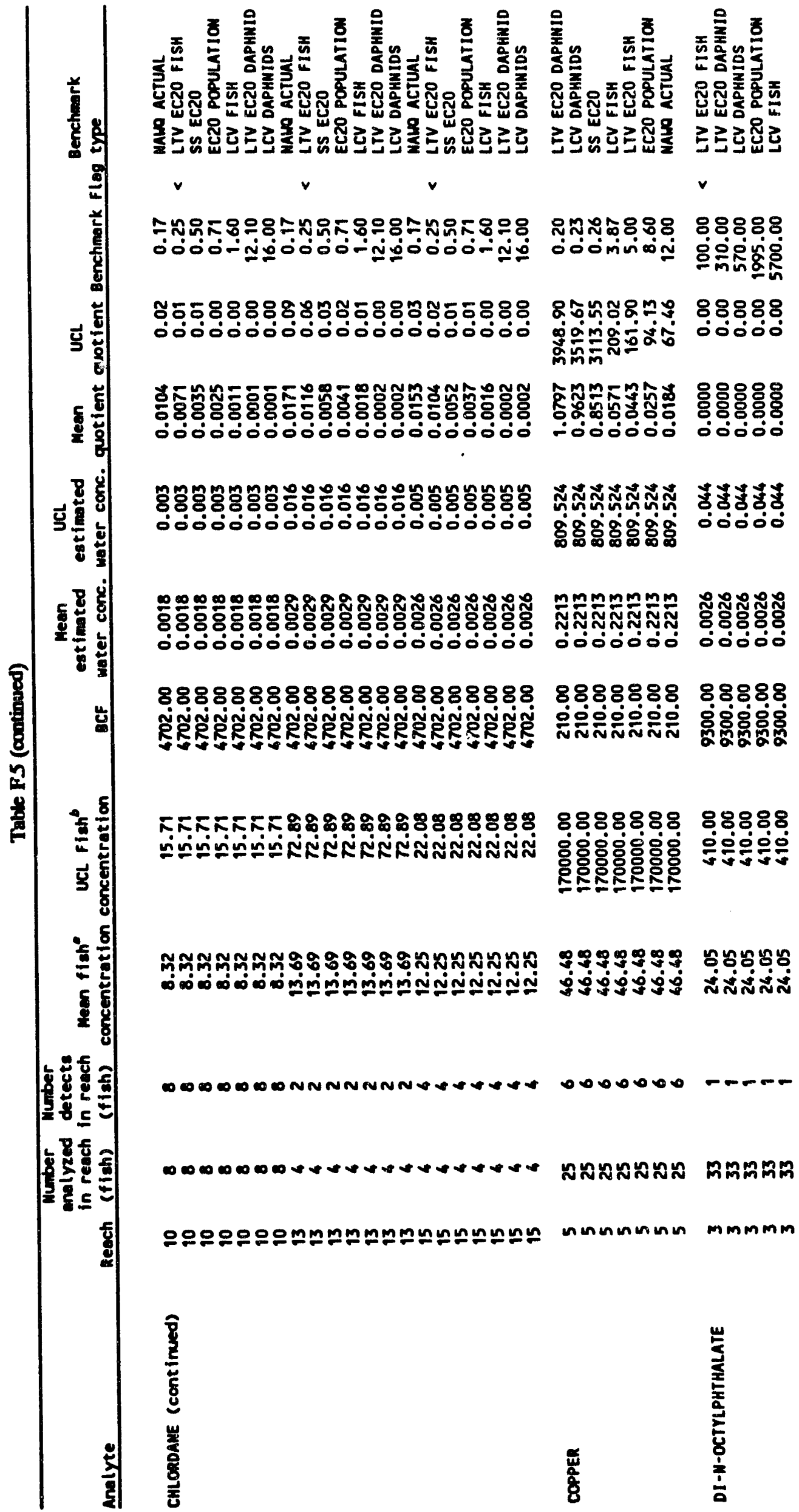




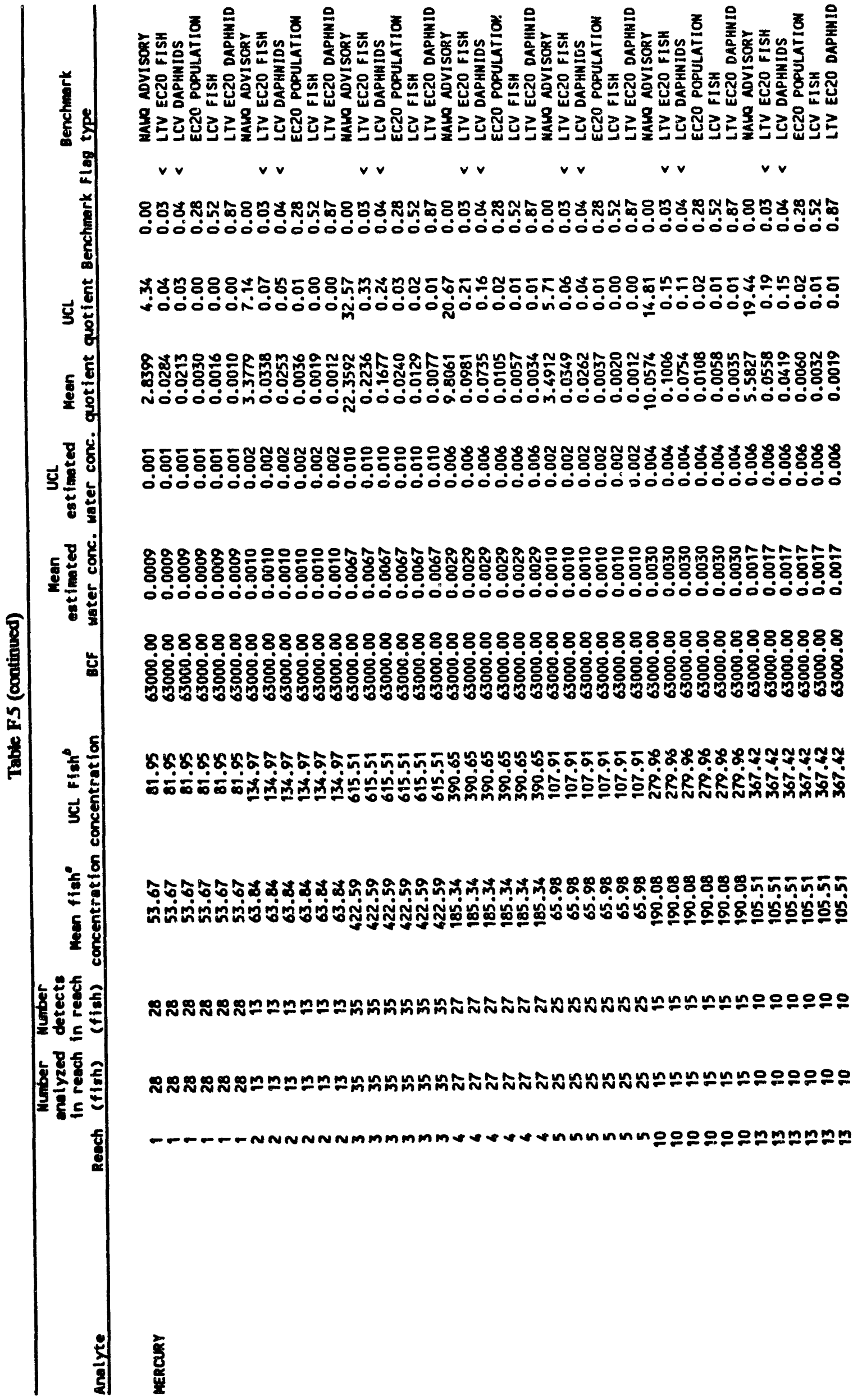




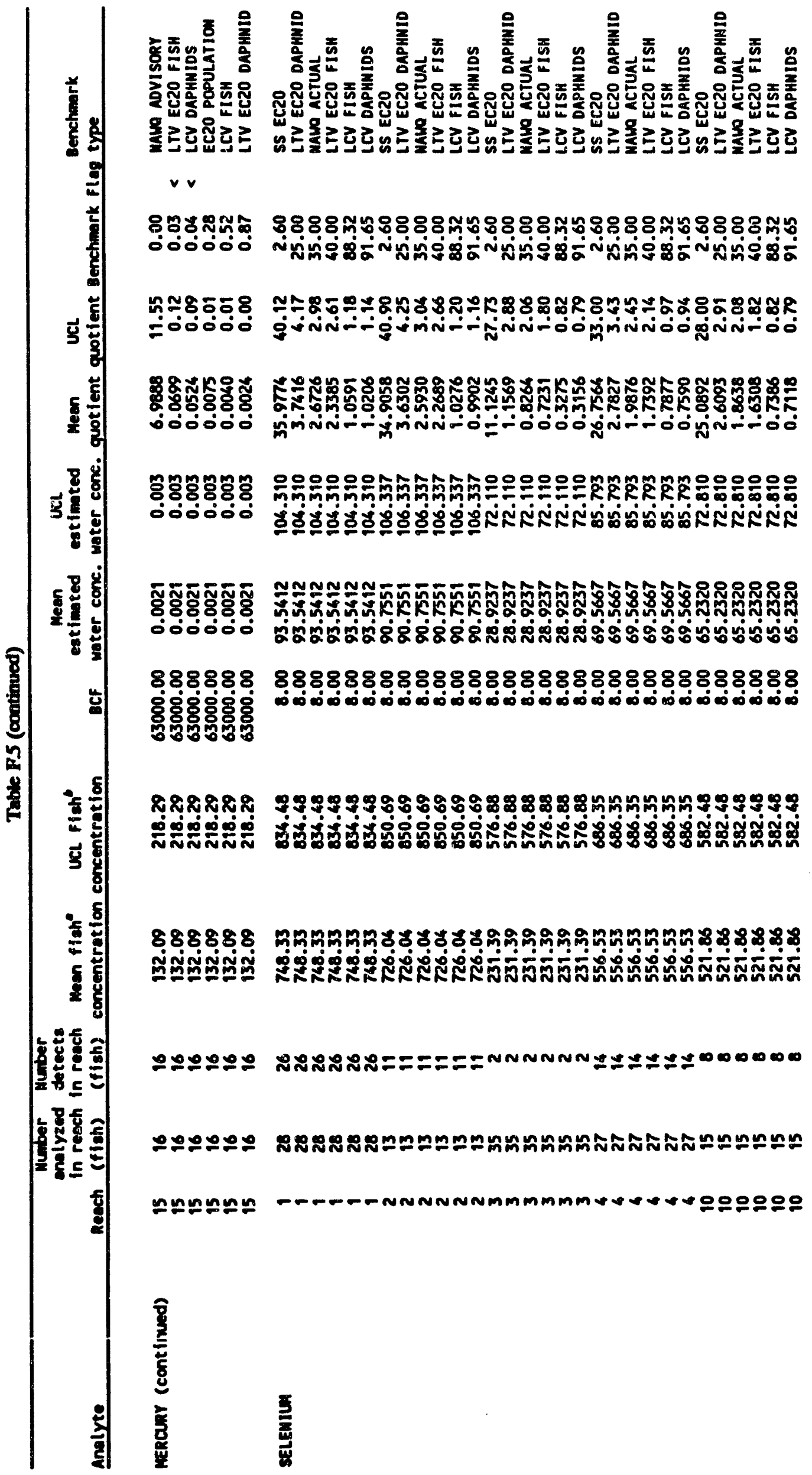




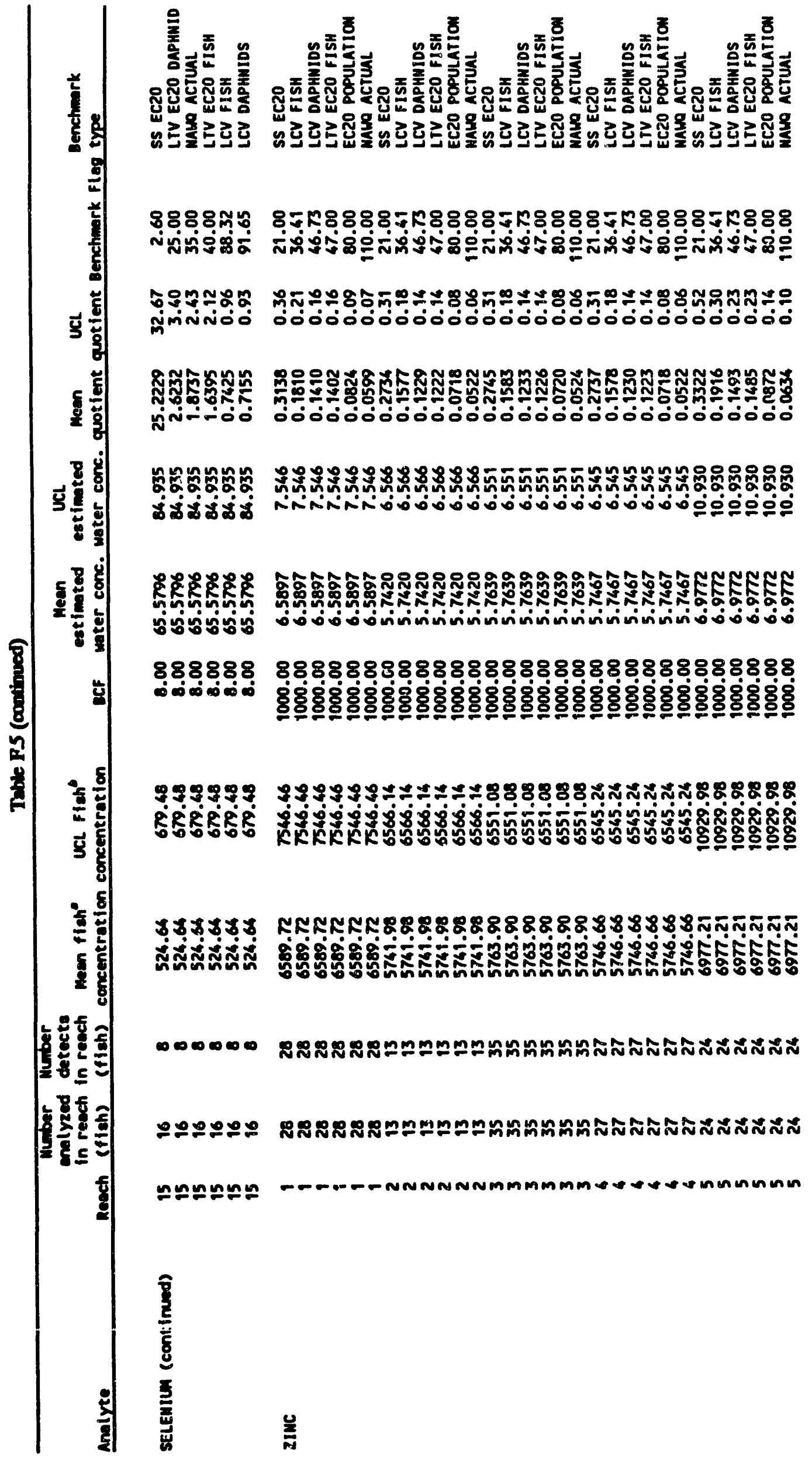




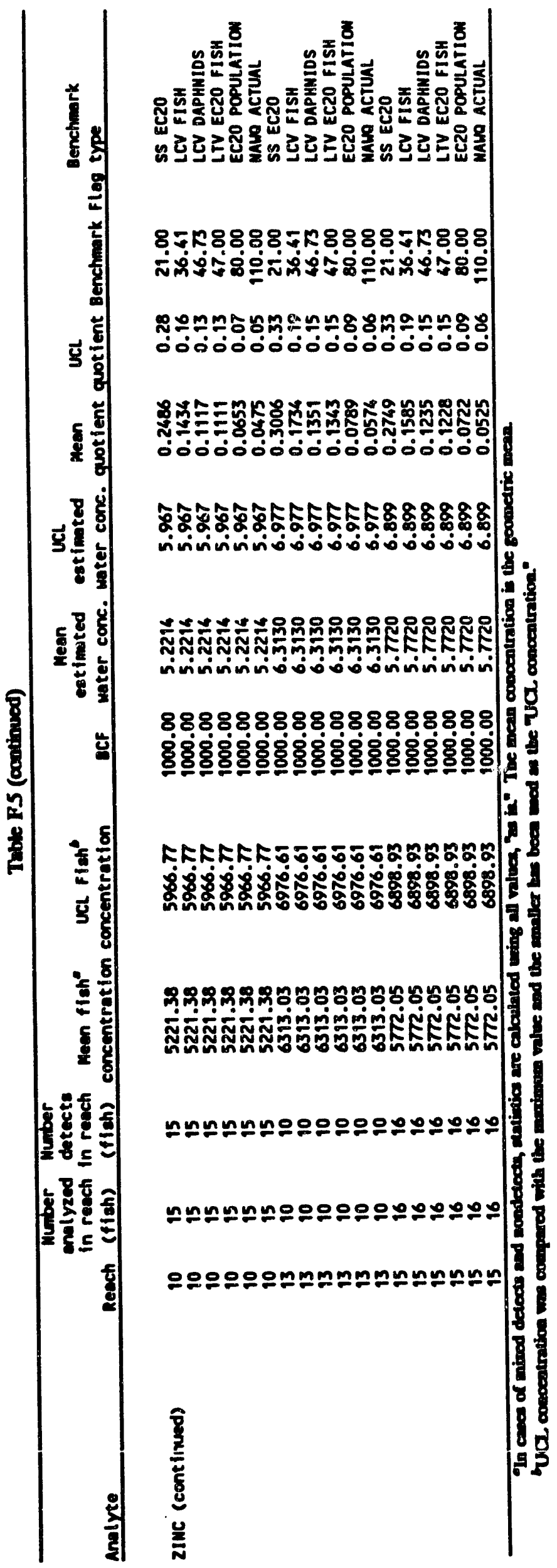




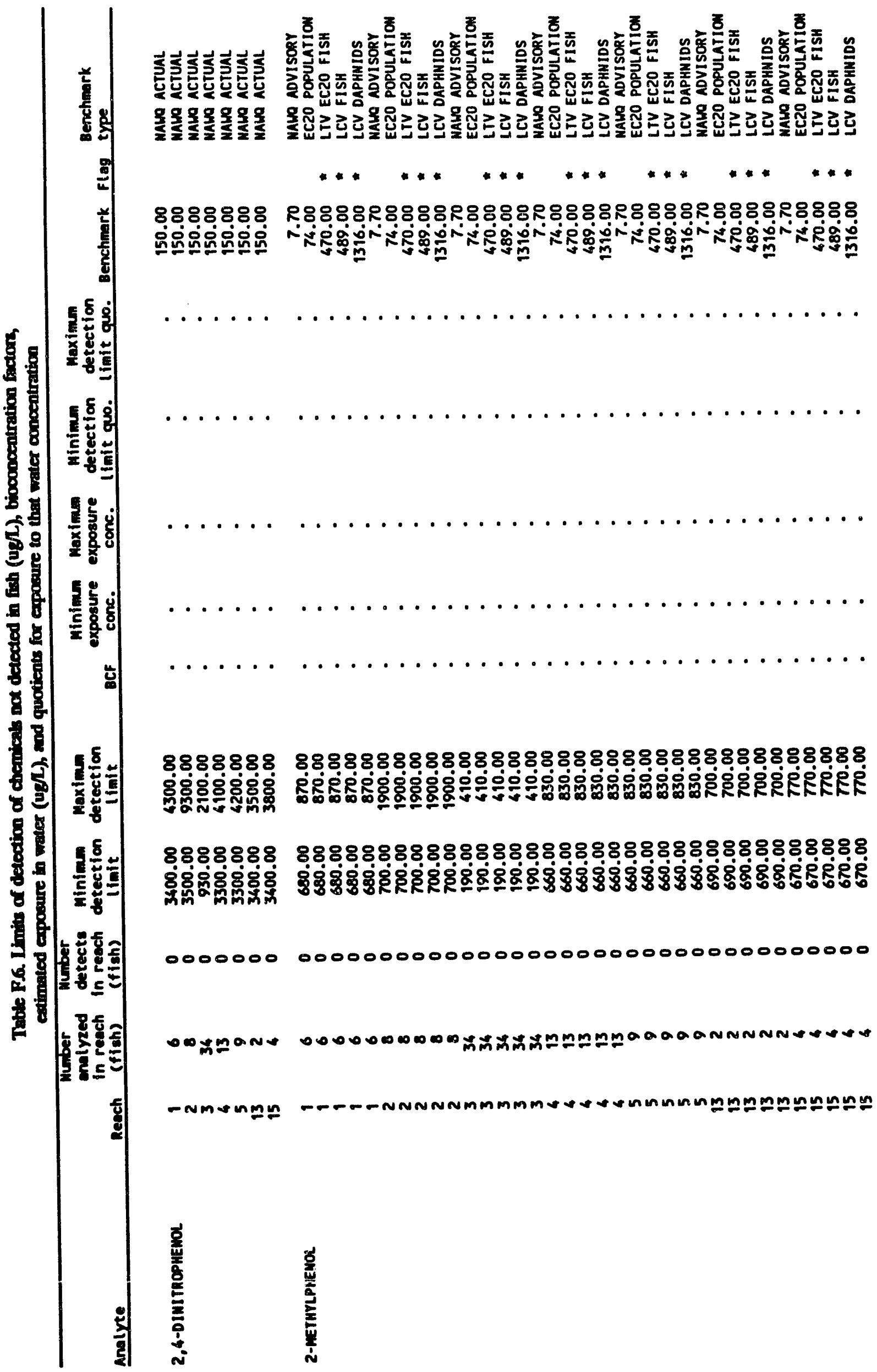




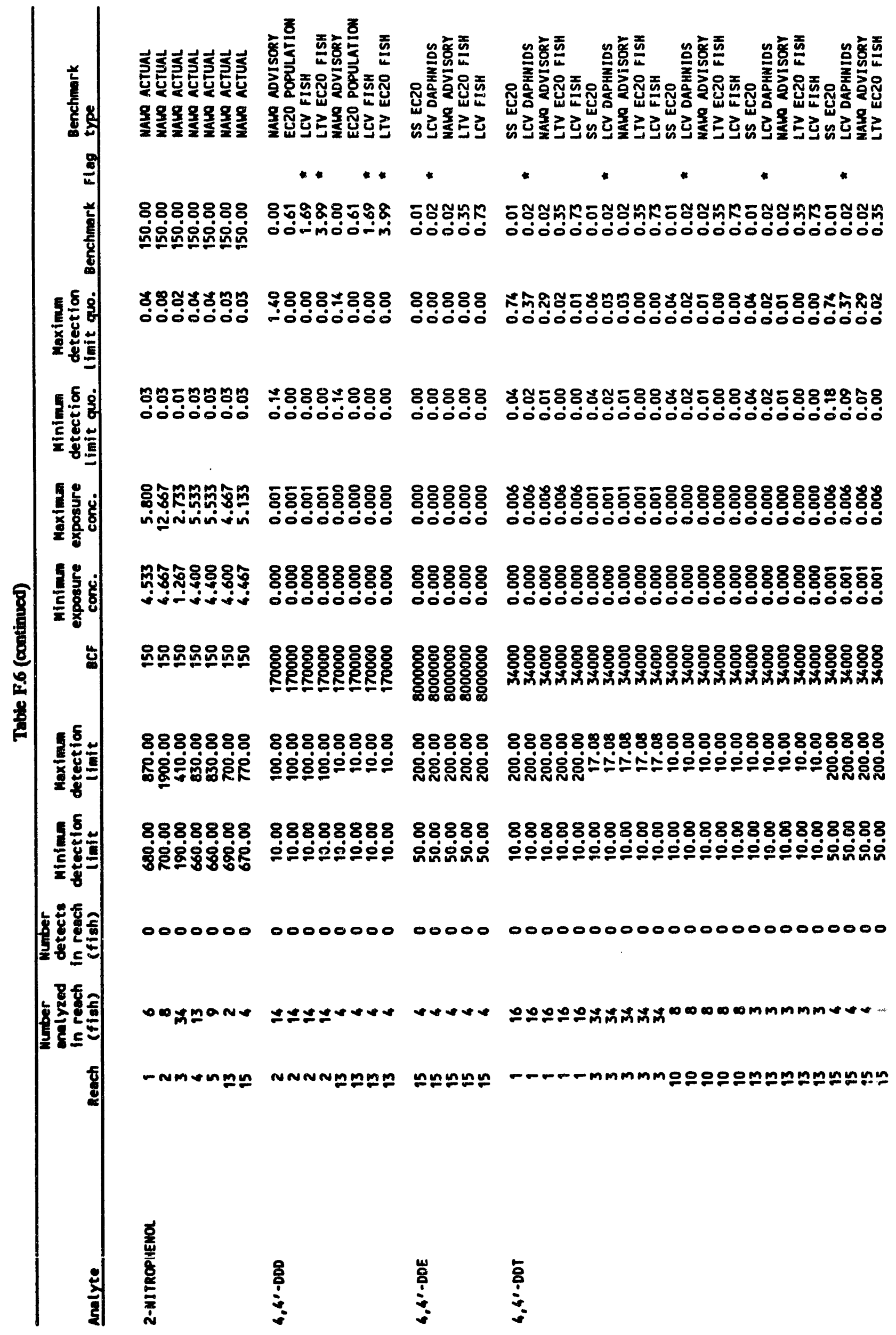




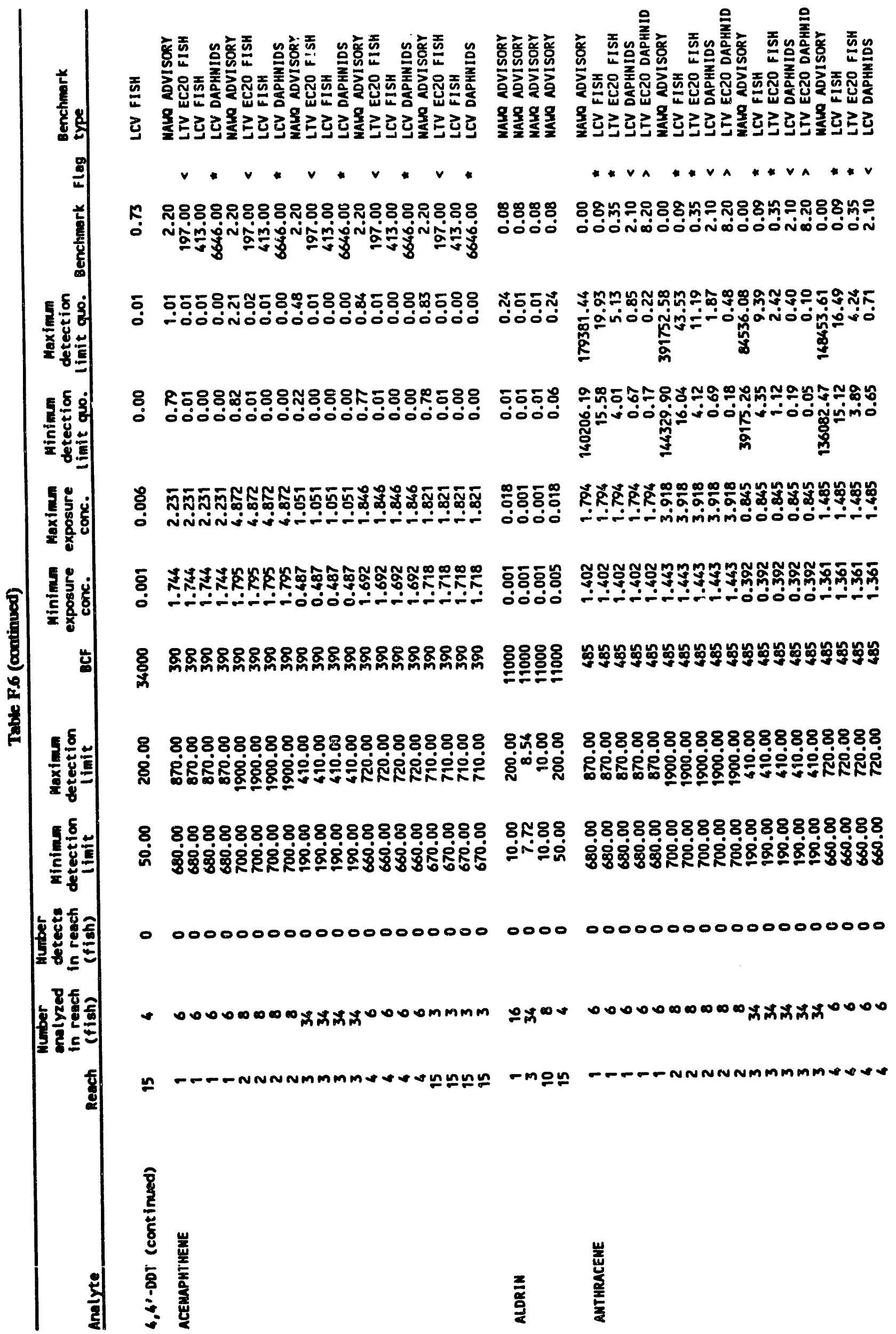




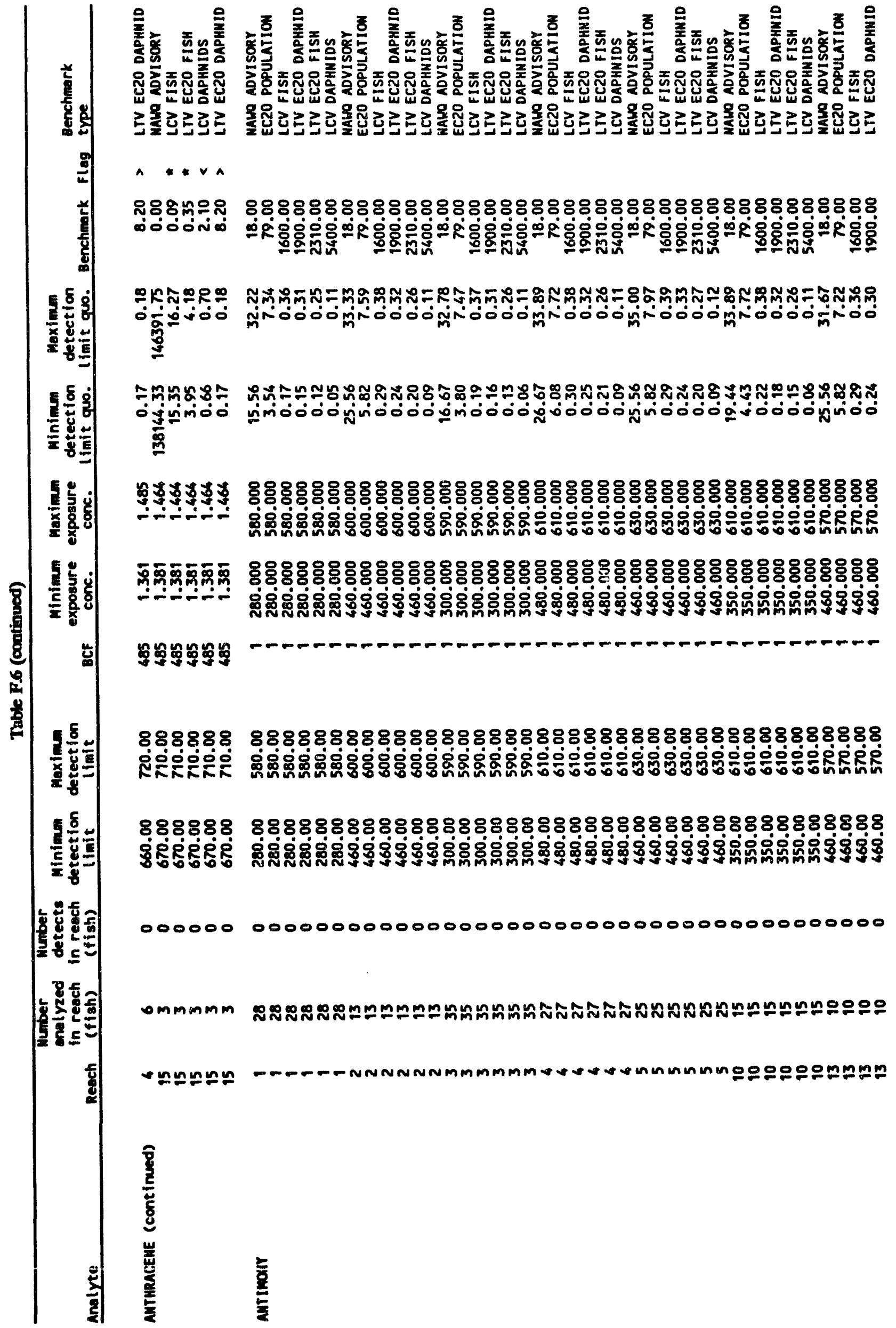




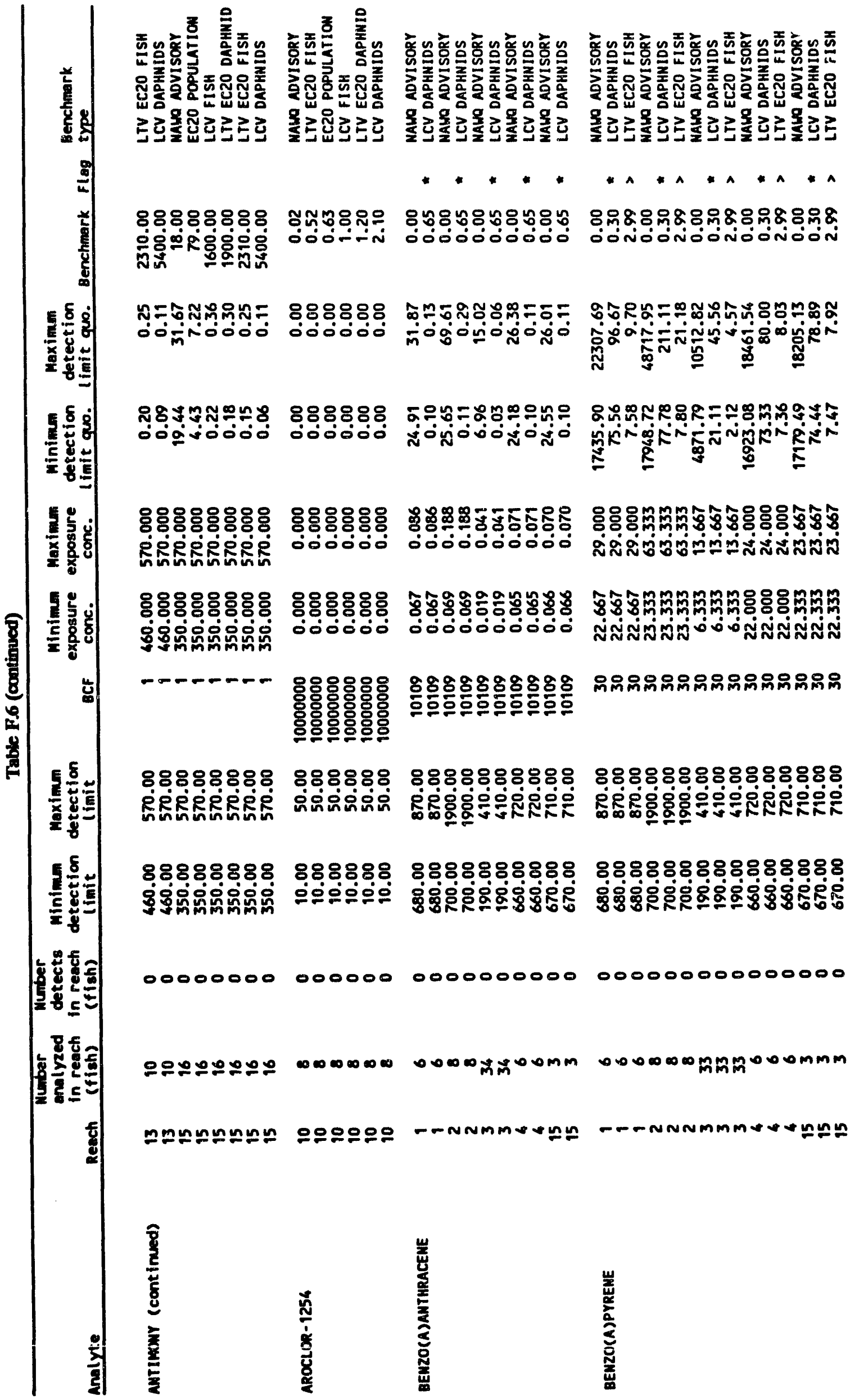




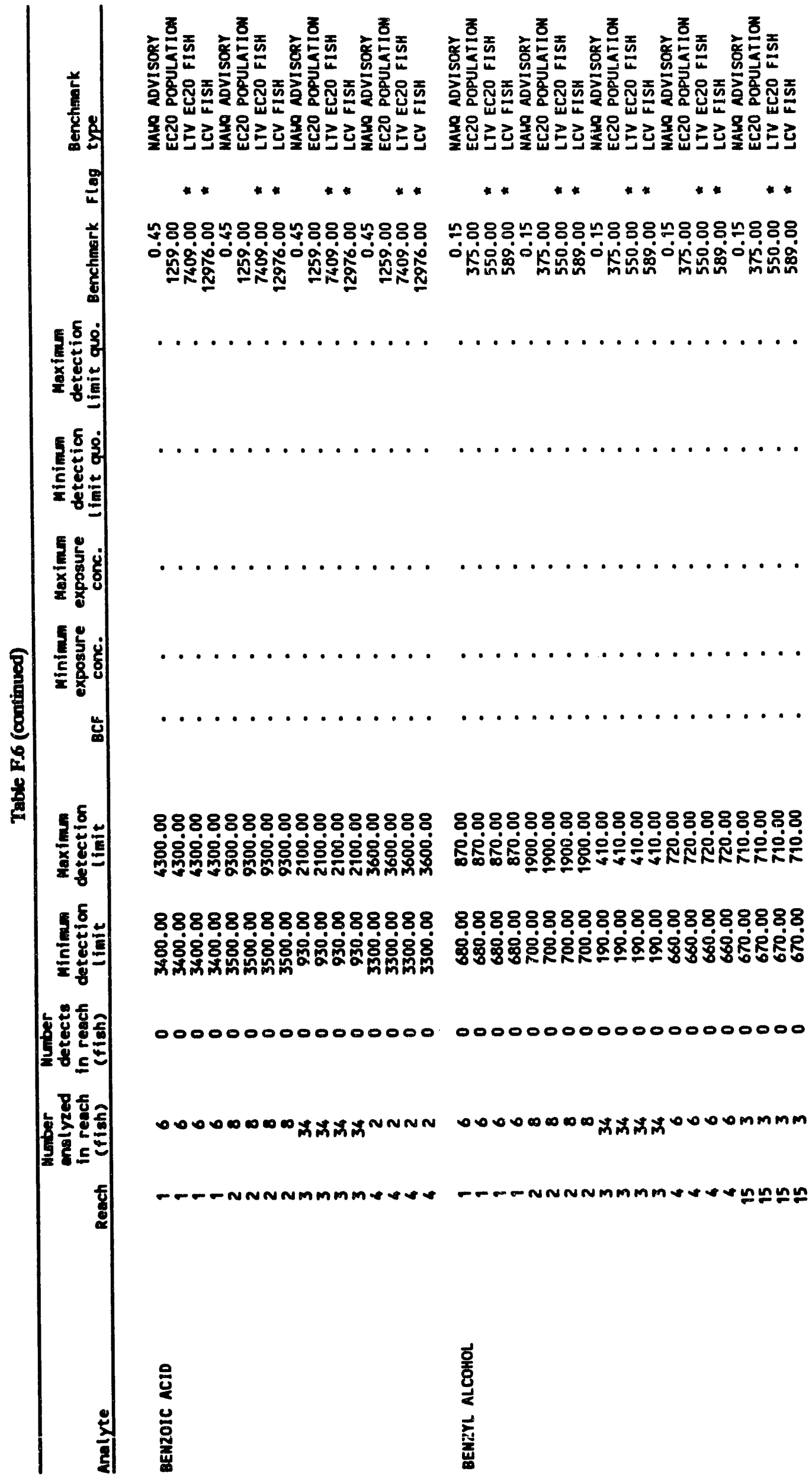


F-72

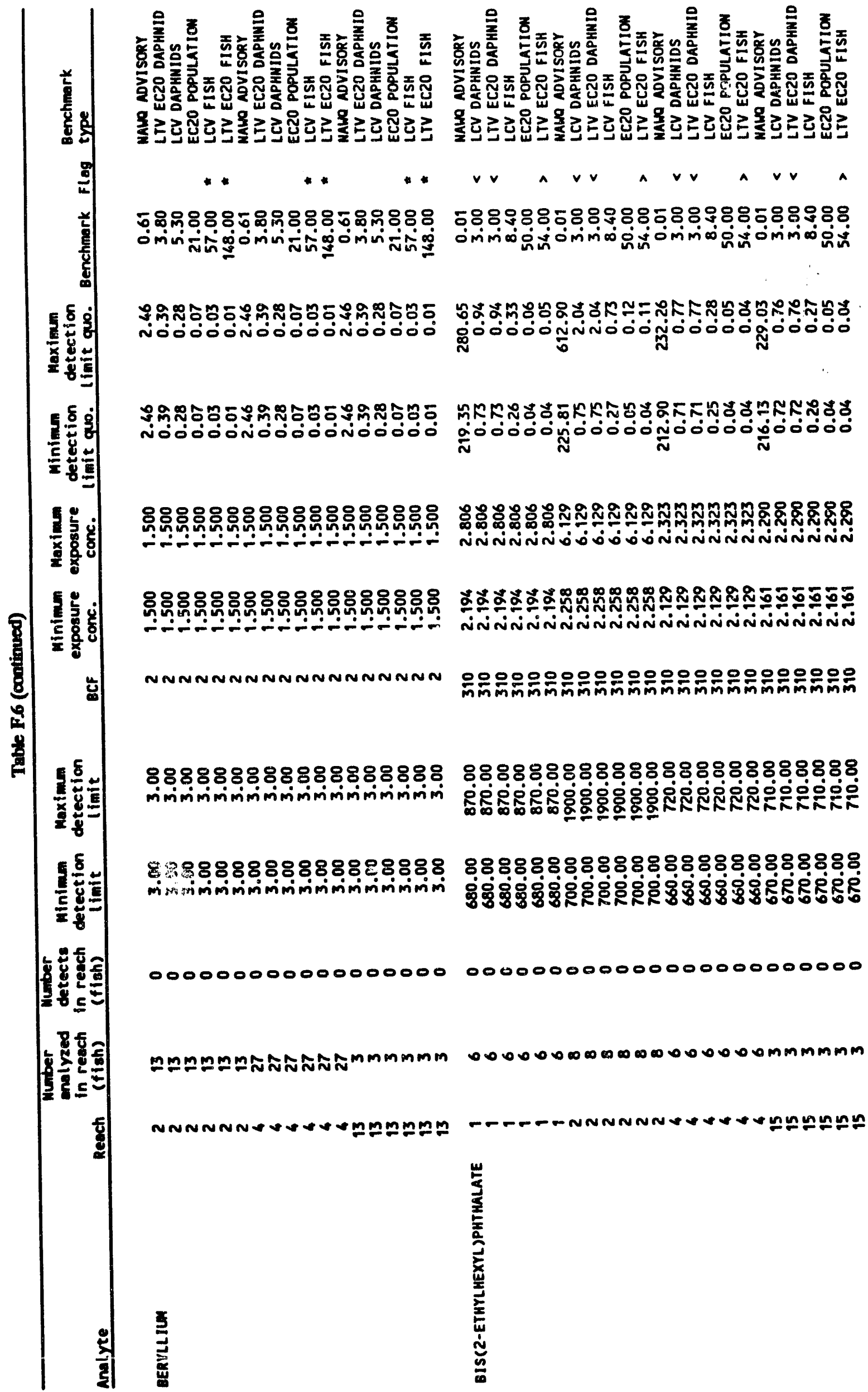




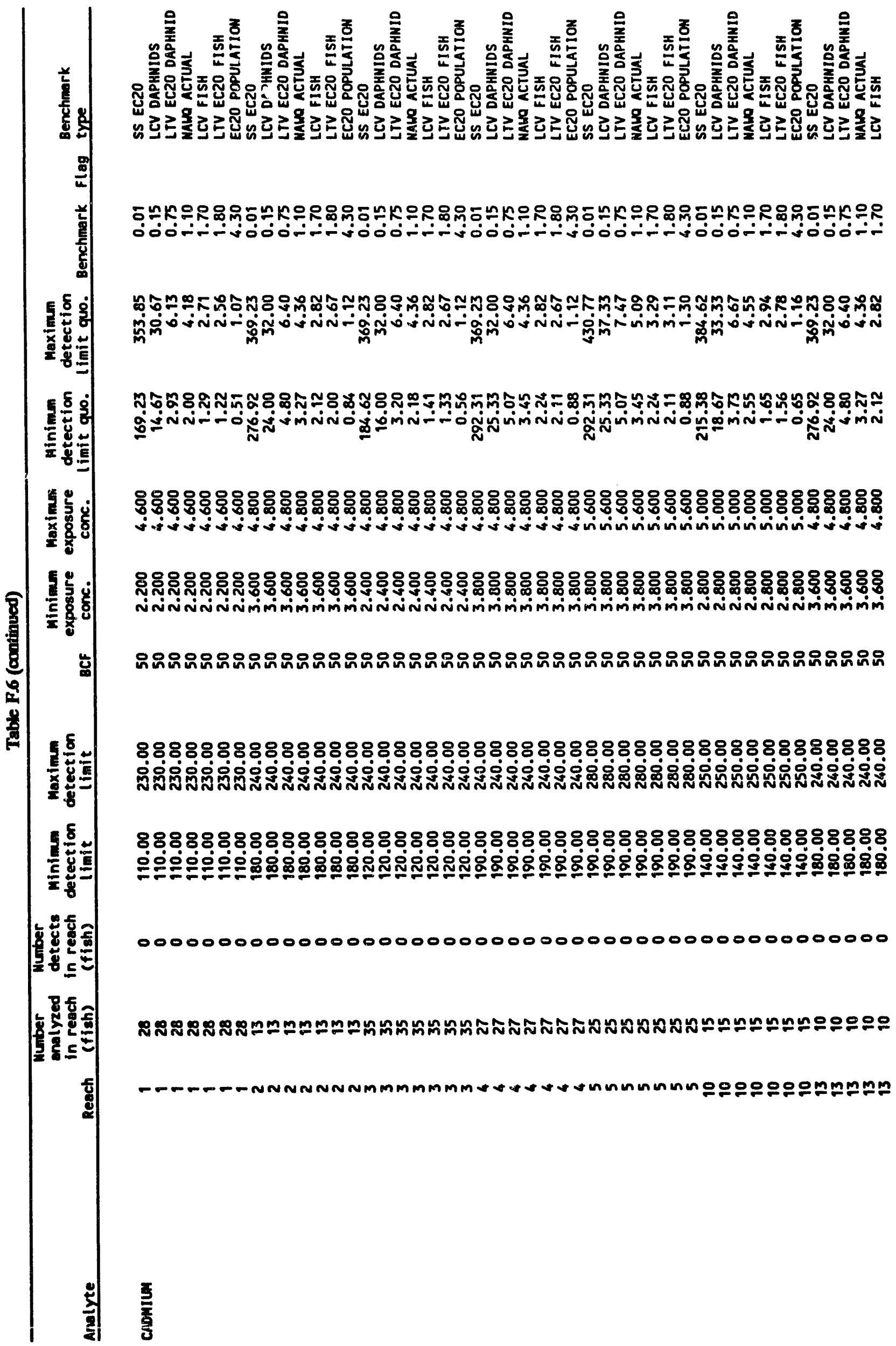


F-74

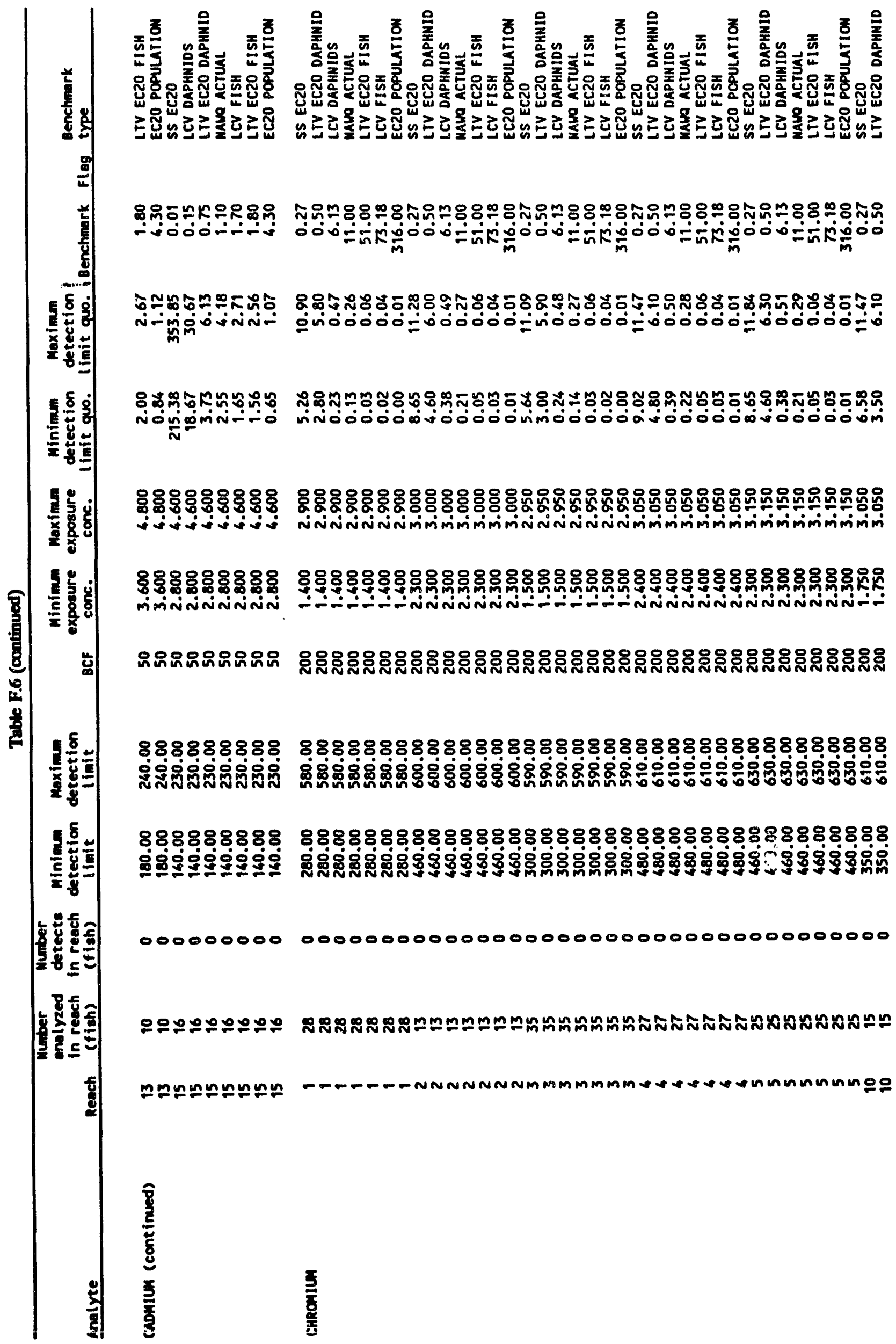




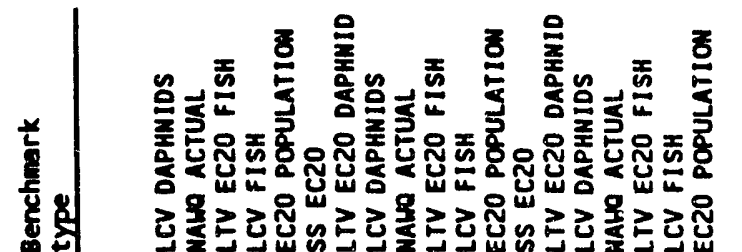

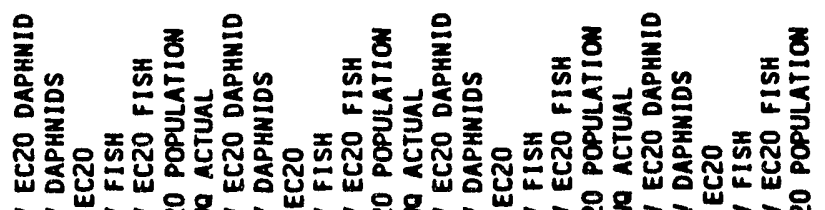

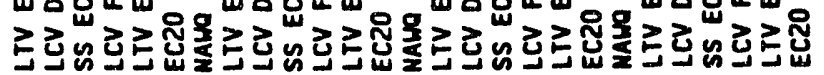

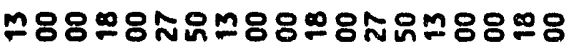

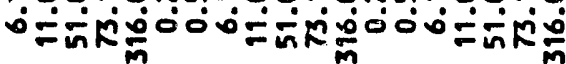

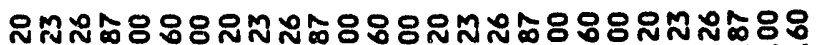

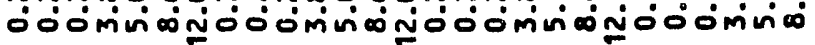

ทำํํㅇํㅇำ 00000

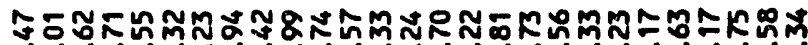

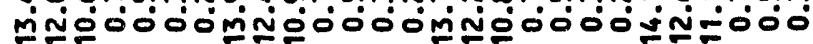

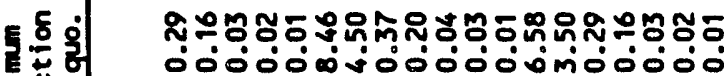

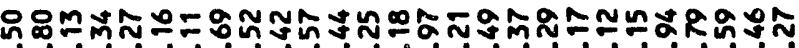

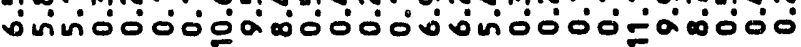

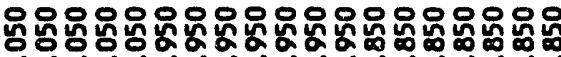
mimimininiñNiñNiñNiñN

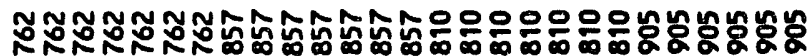

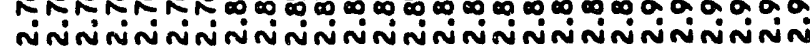

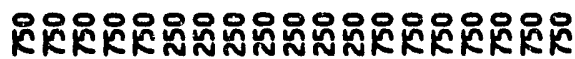

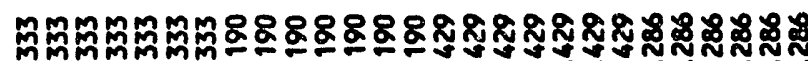

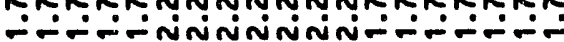

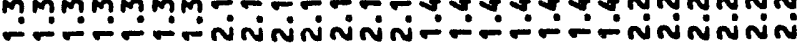

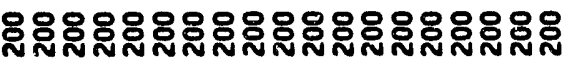

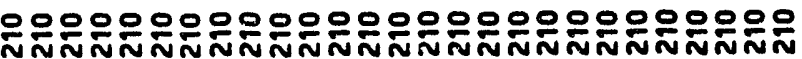

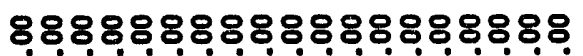

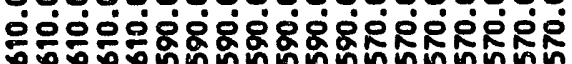

888888888888888888888888888

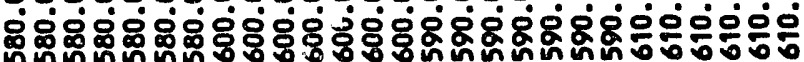

8888888888888888888

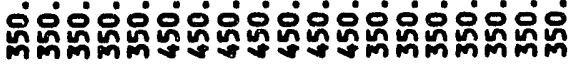

888888888888888888888888888

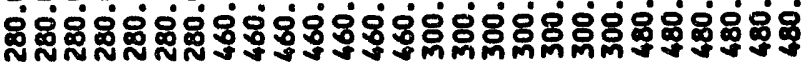

000000000000000000000000000

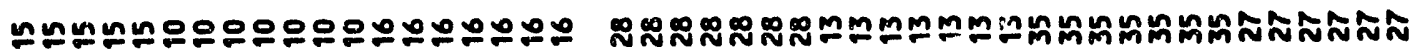

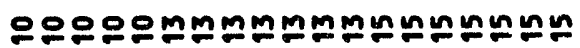




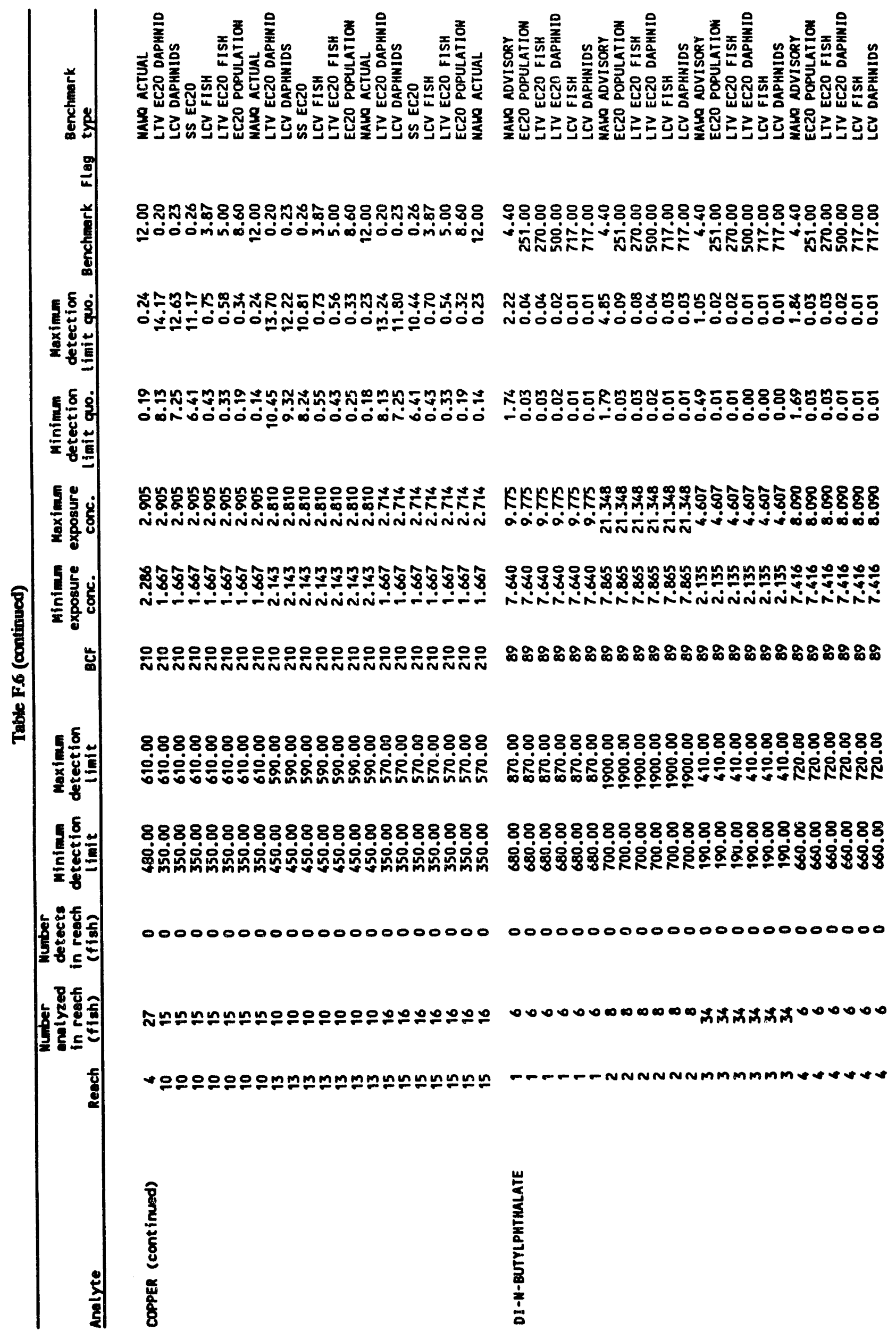




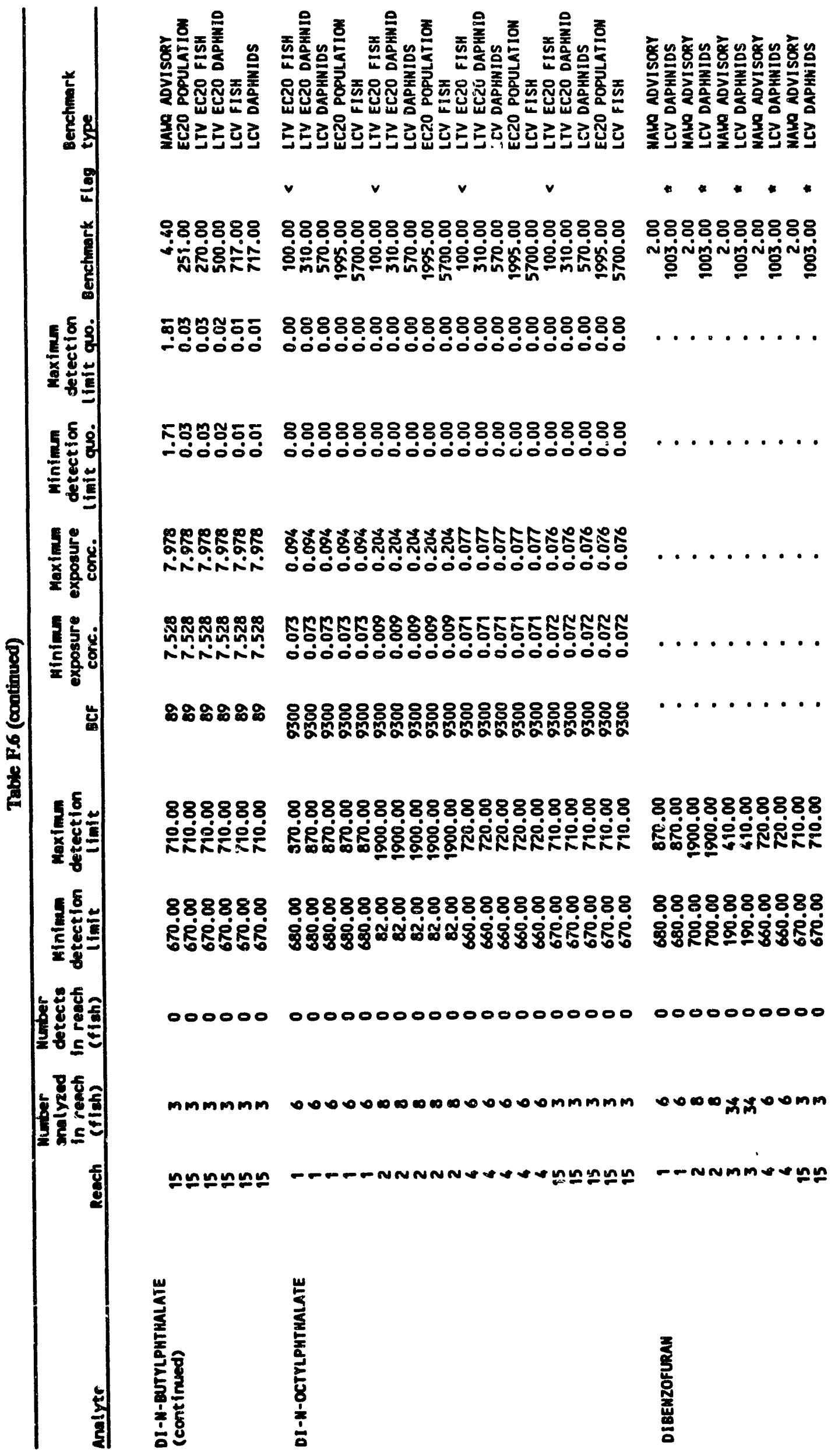




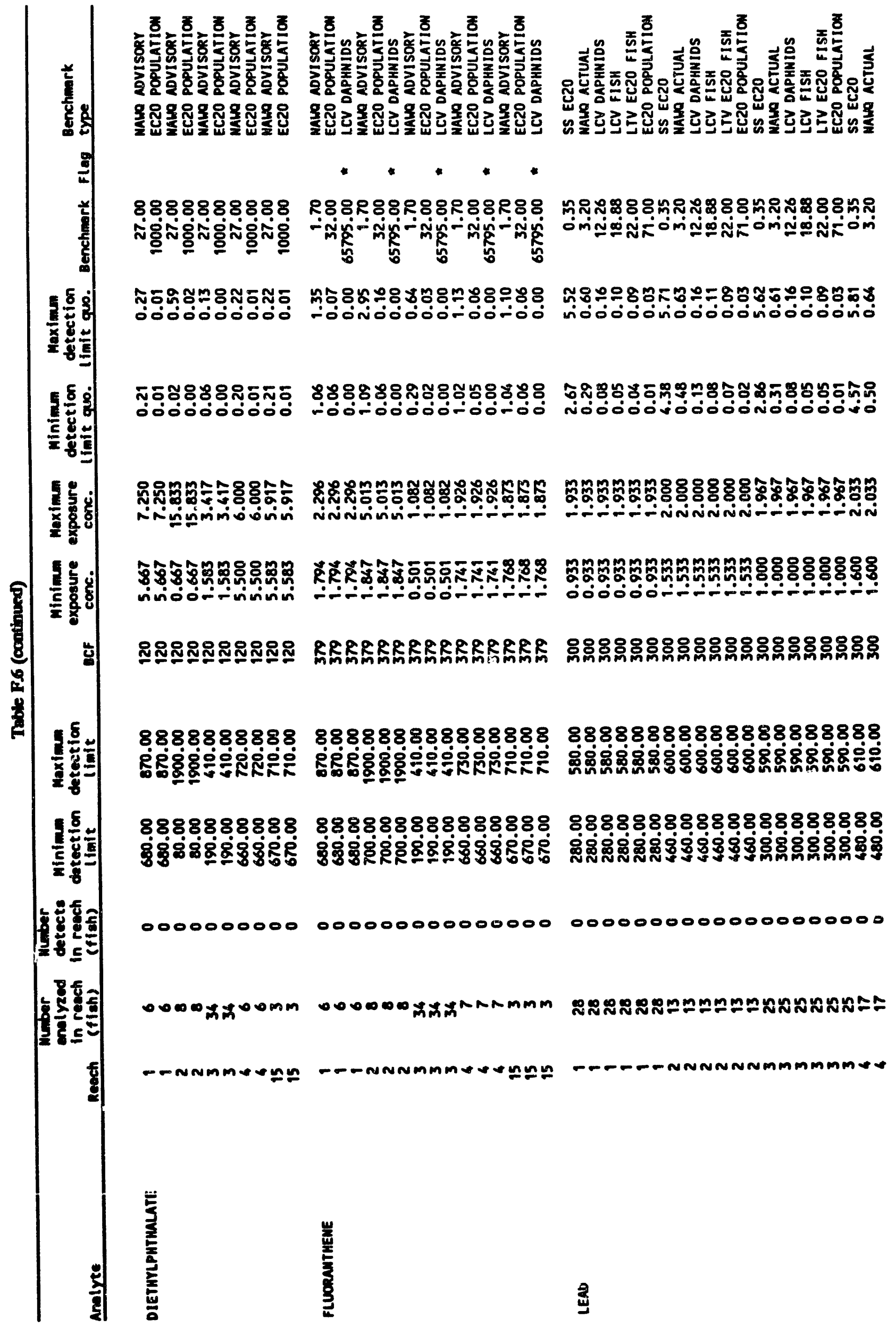




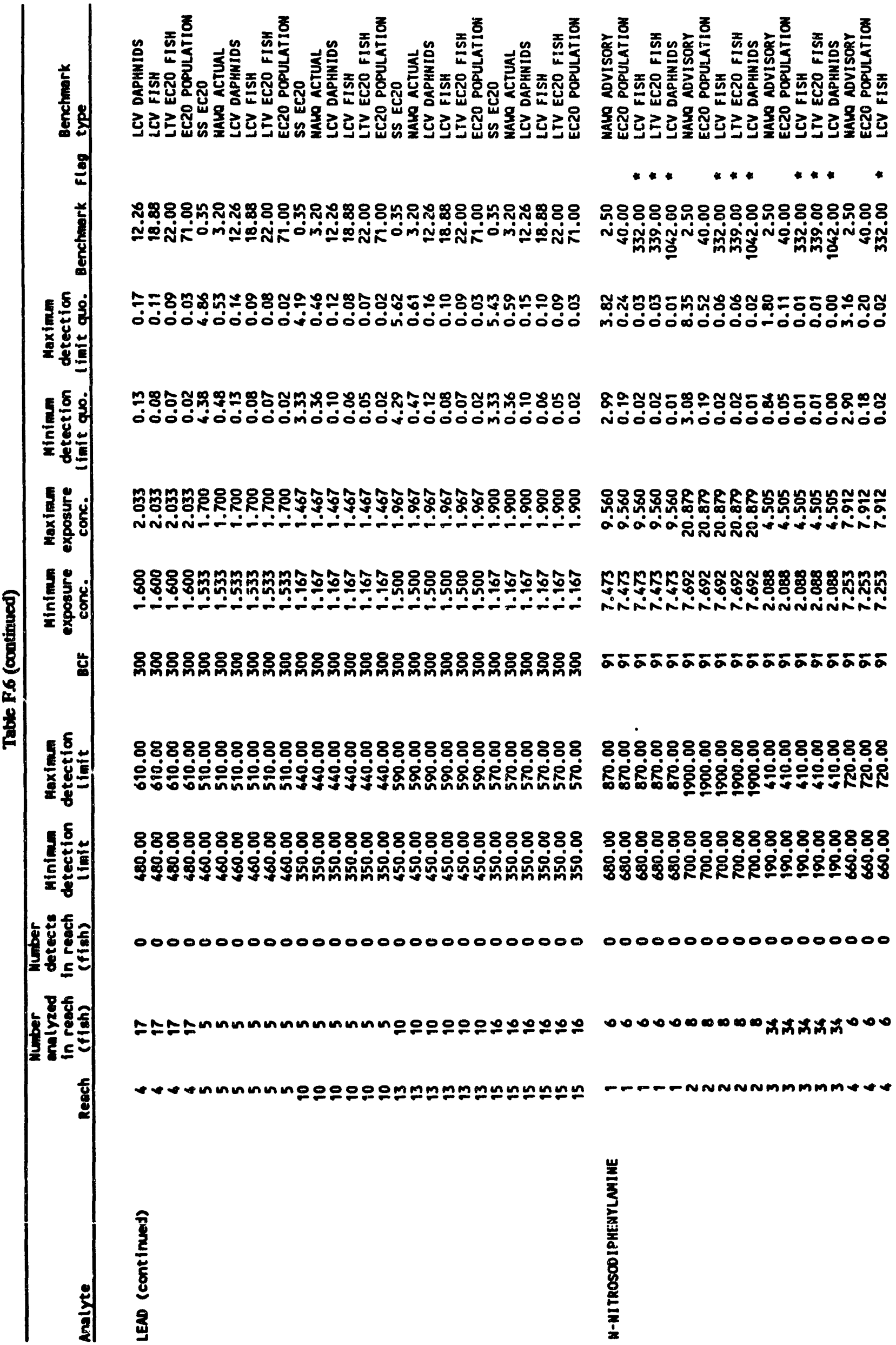




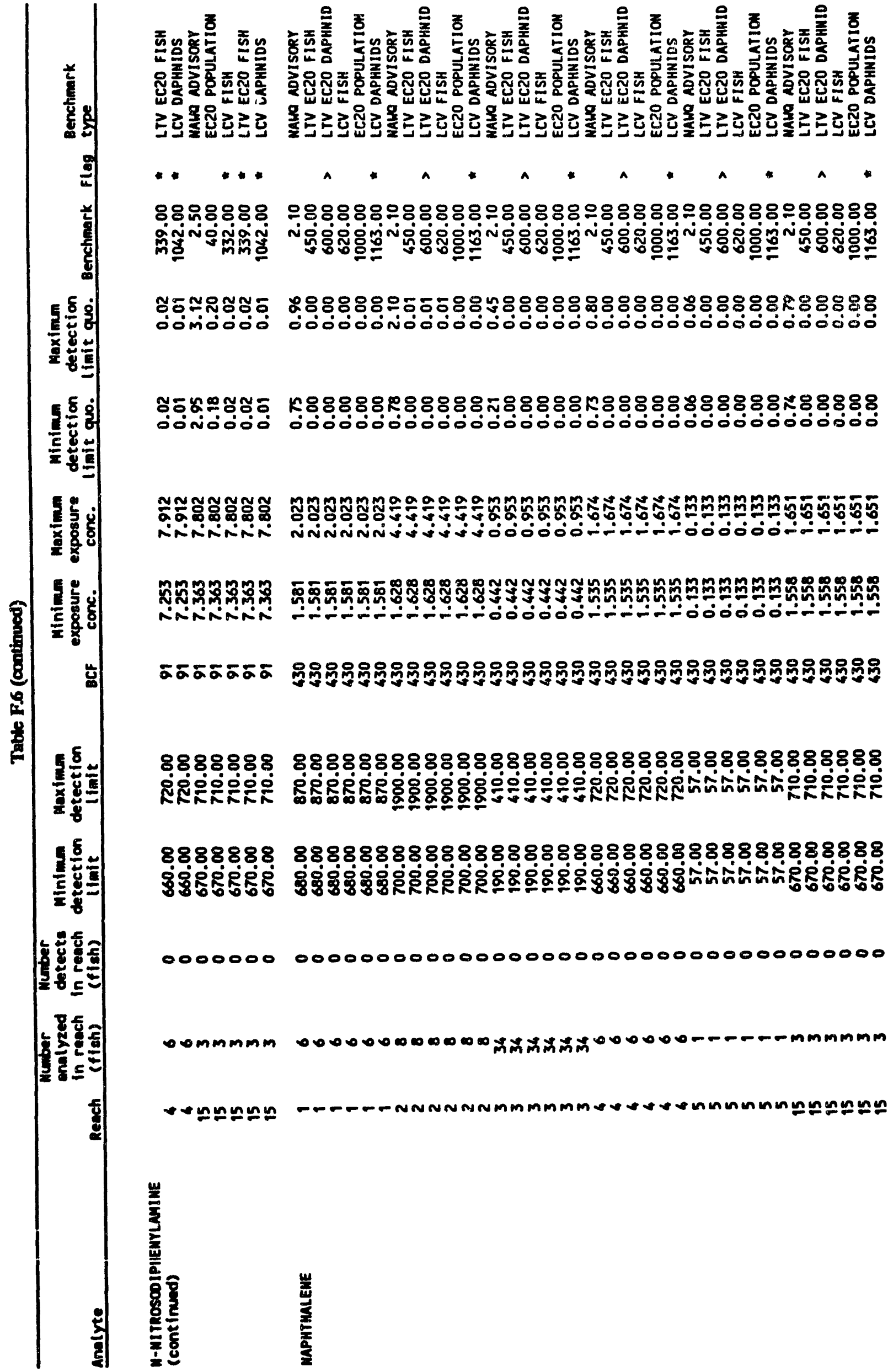




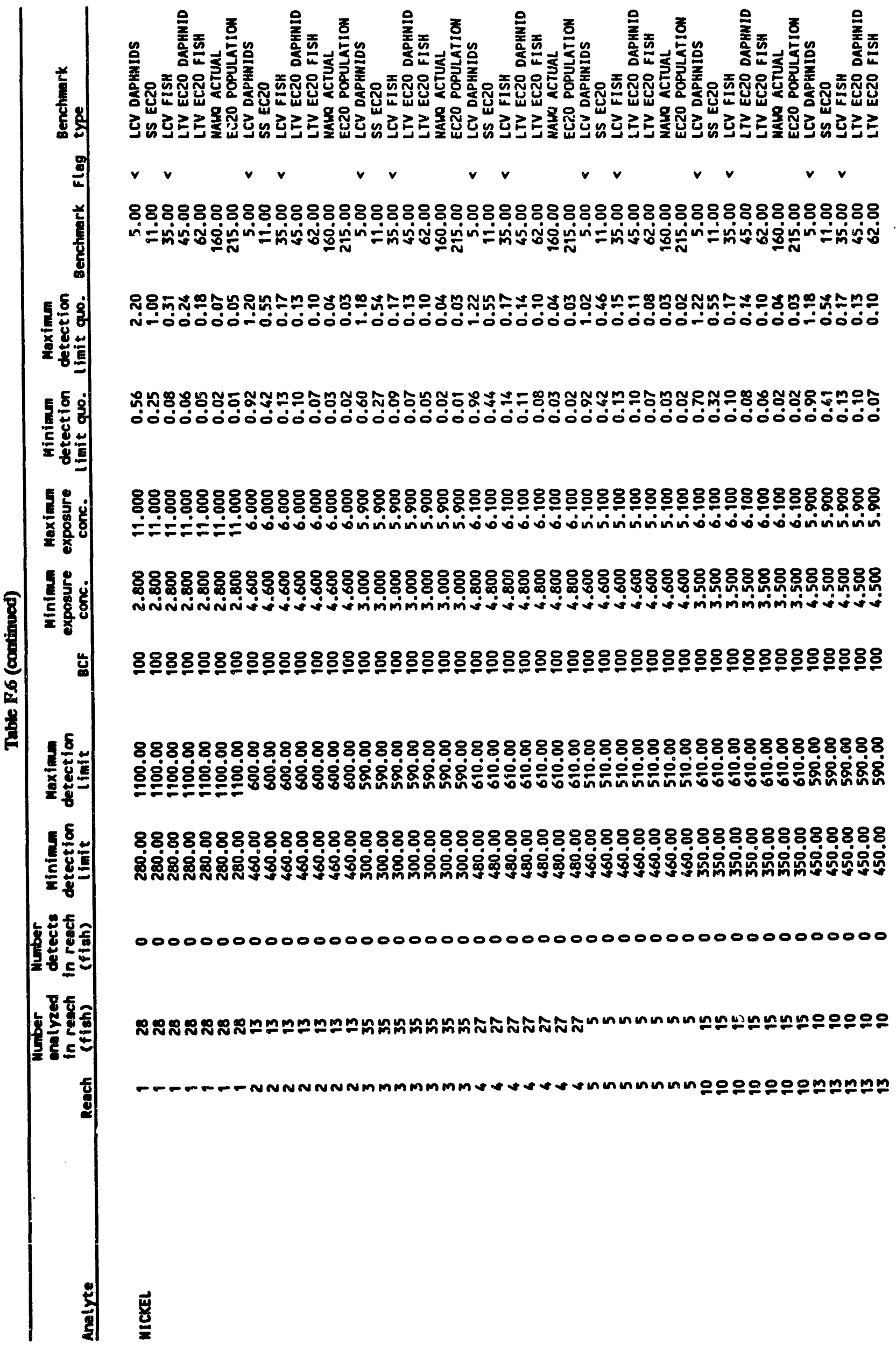




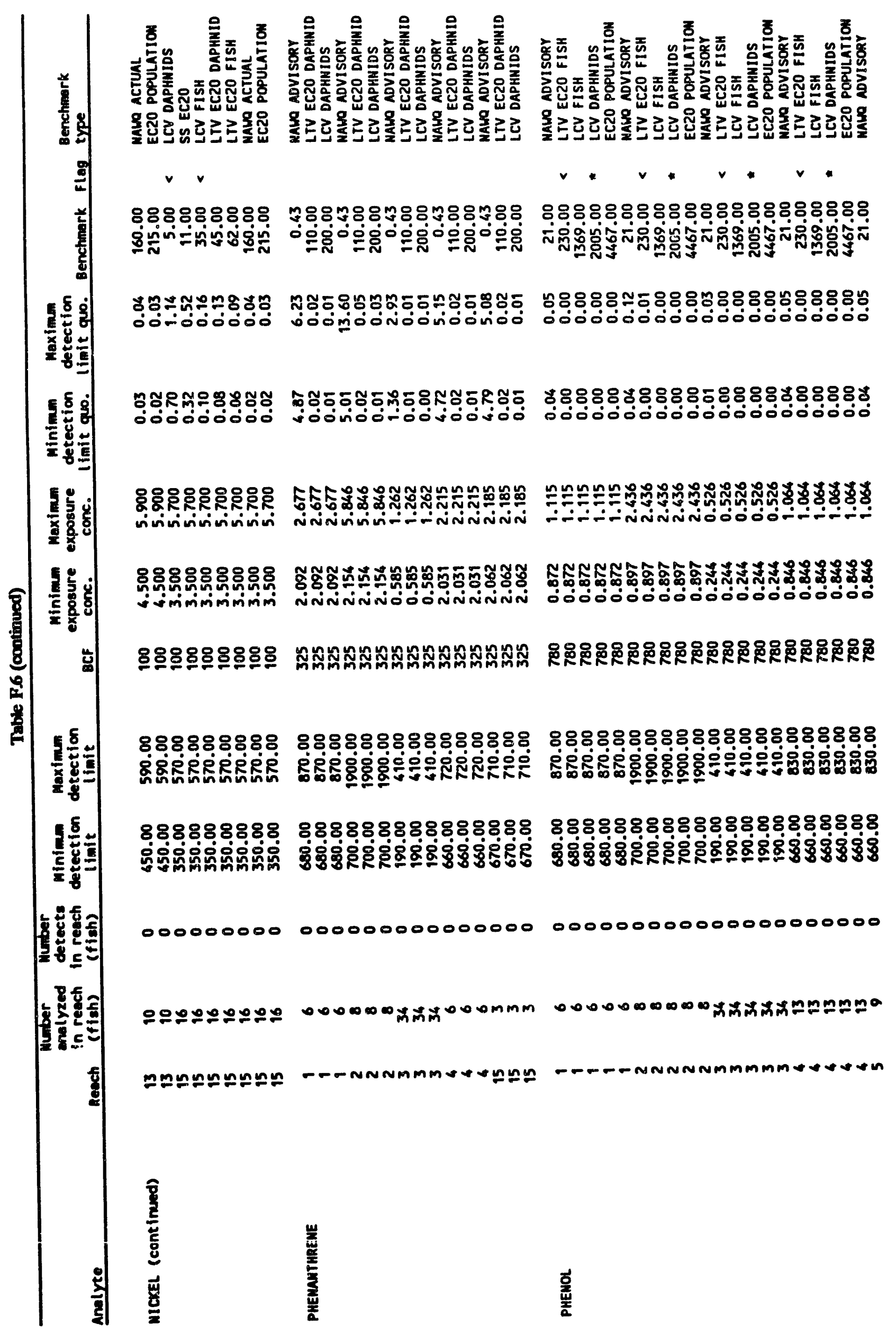




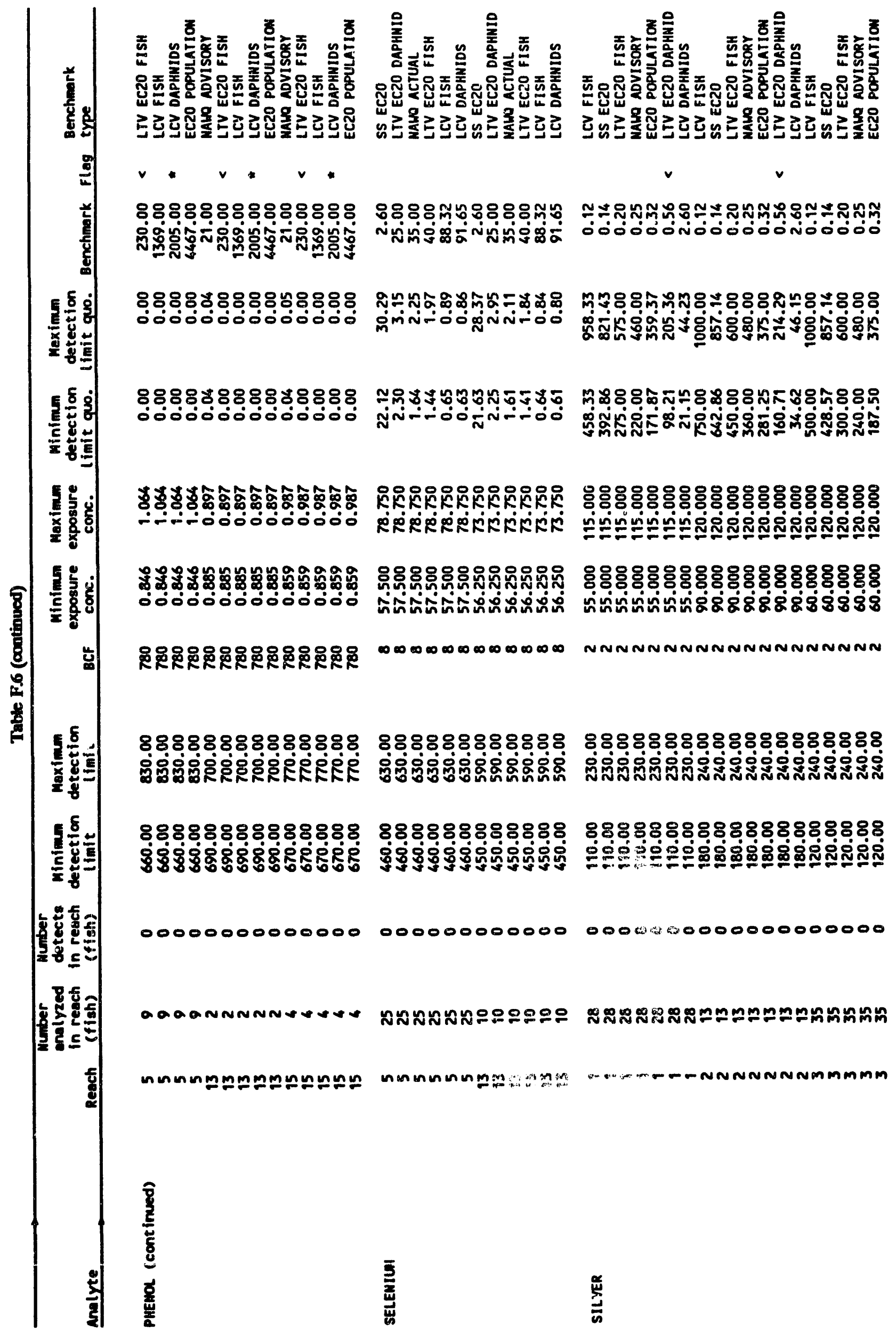




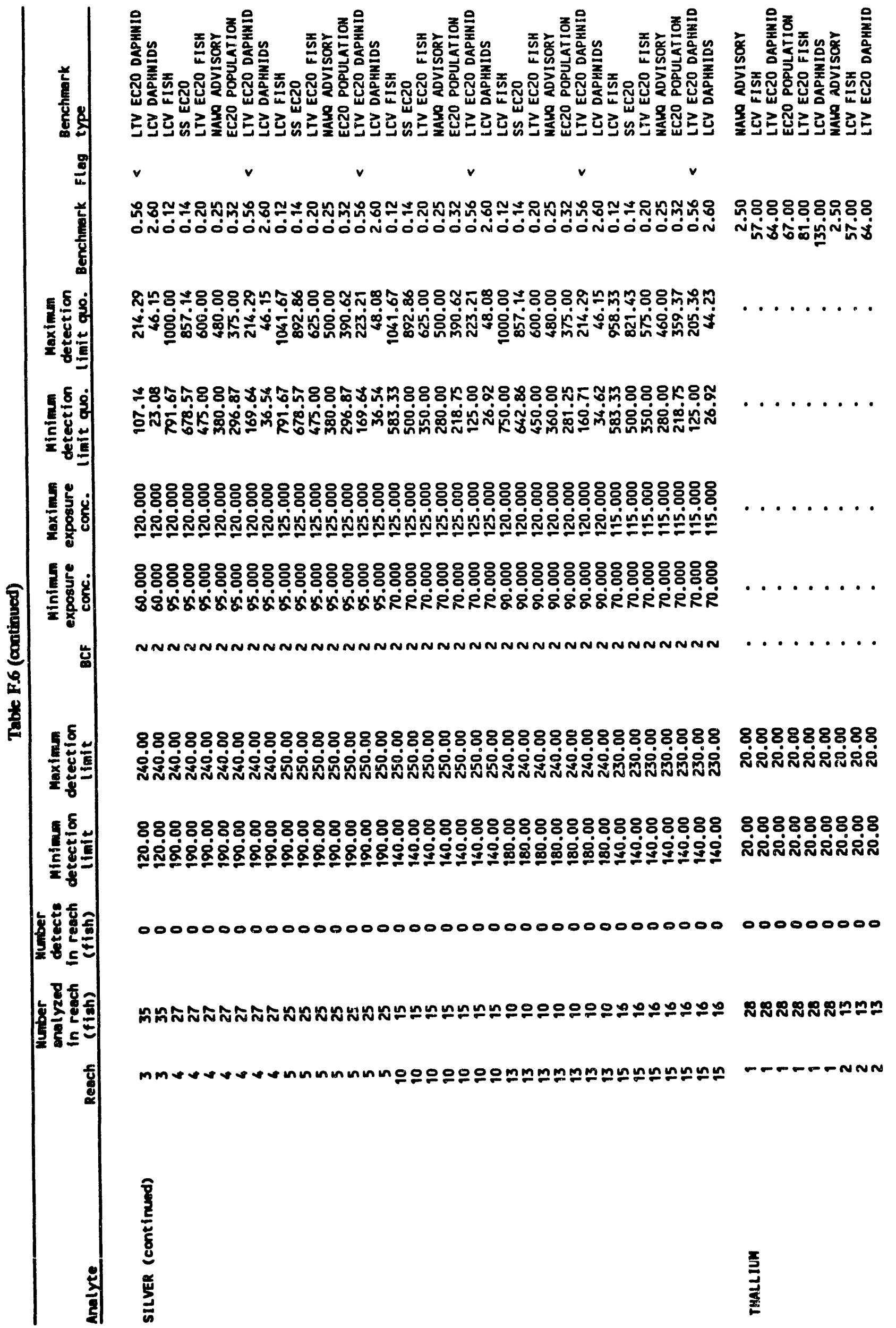




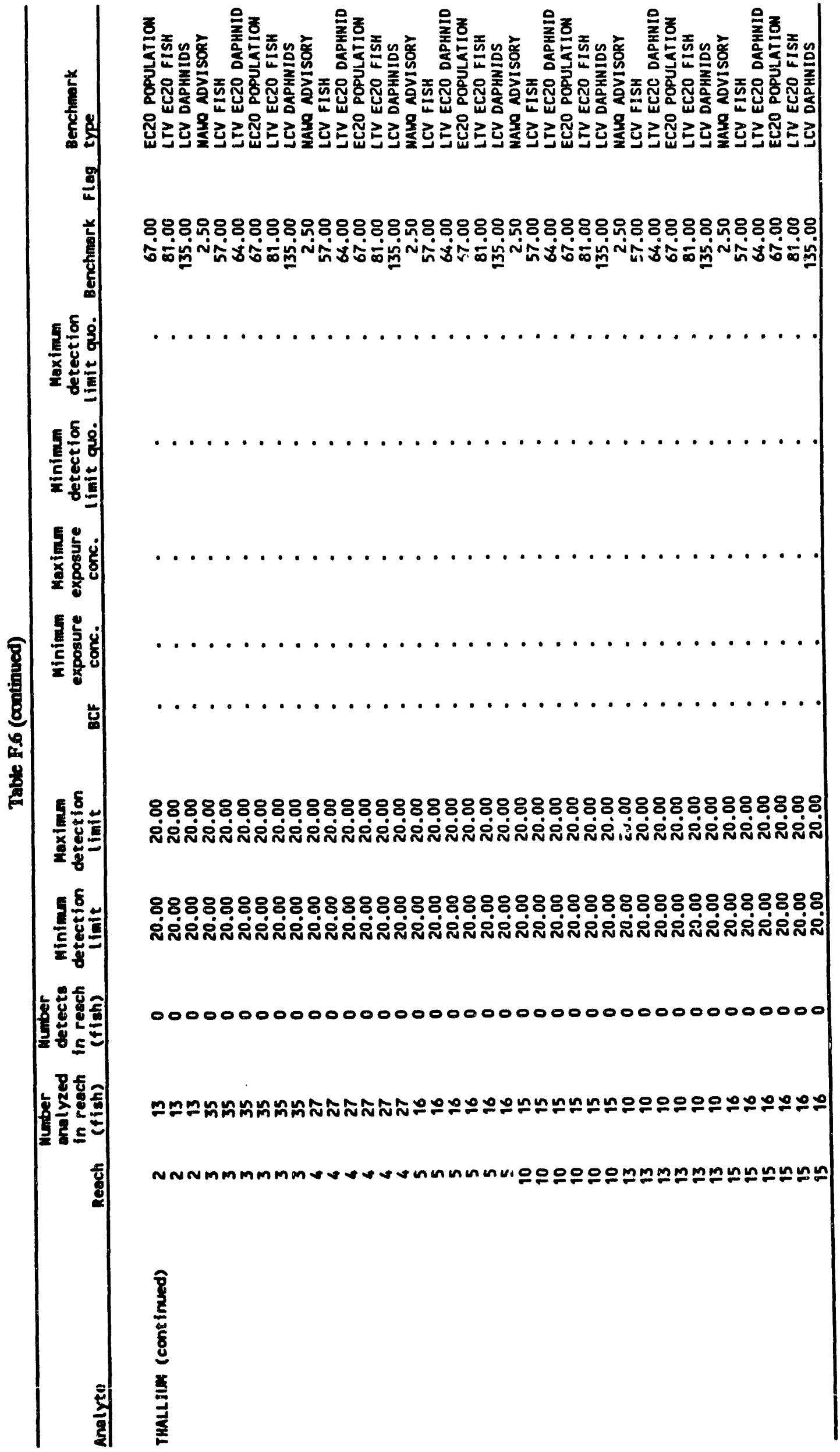




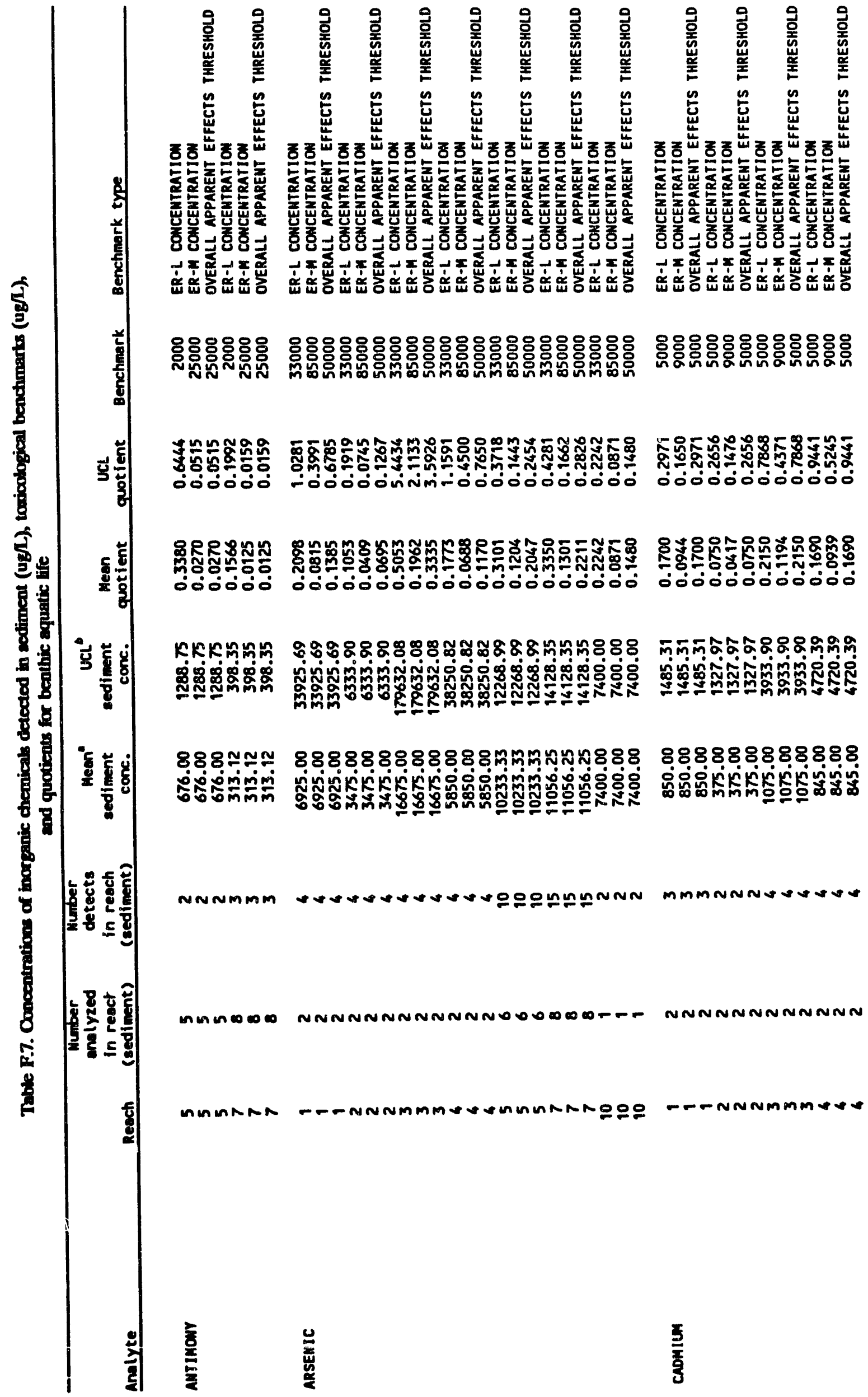


F-87

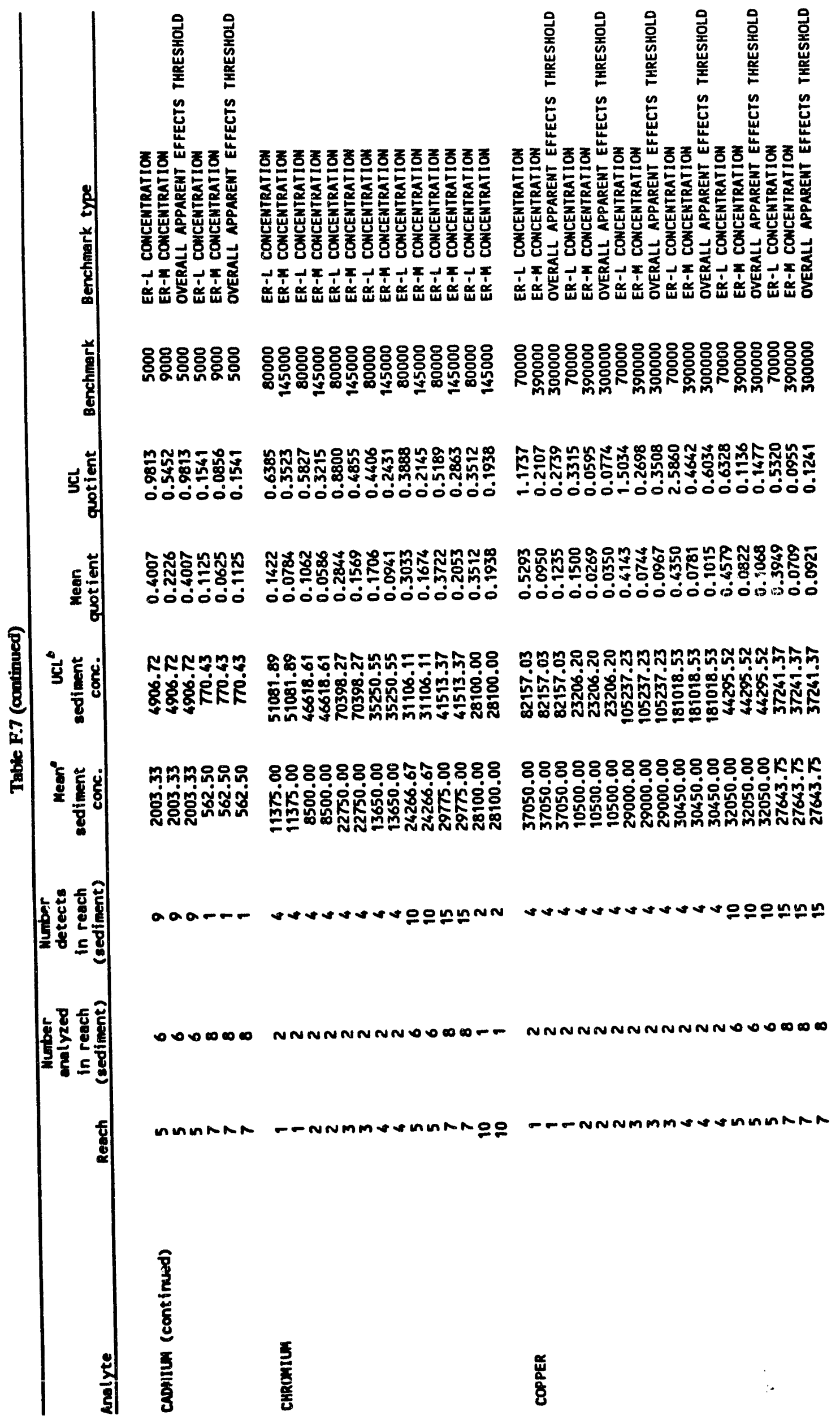




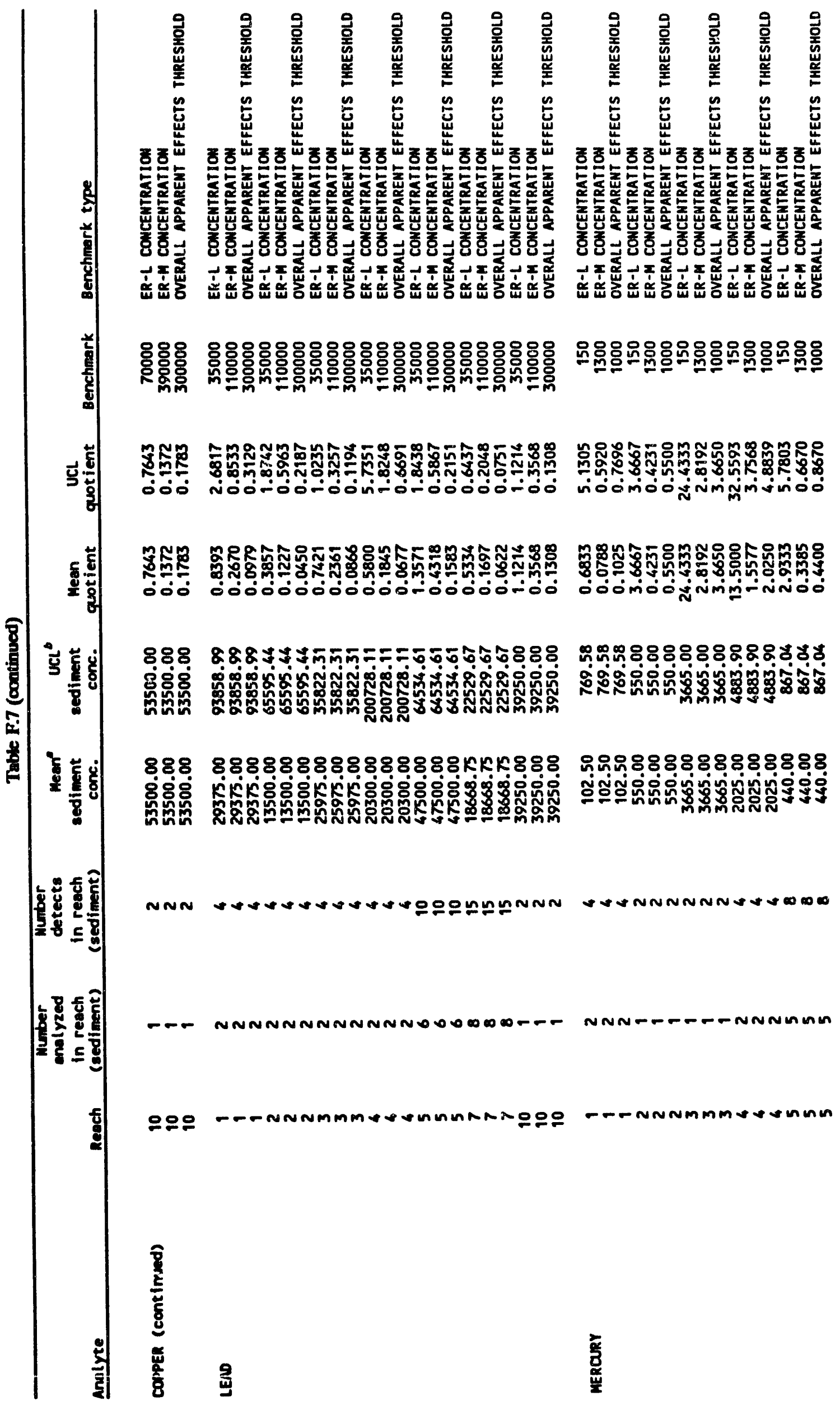


F-89

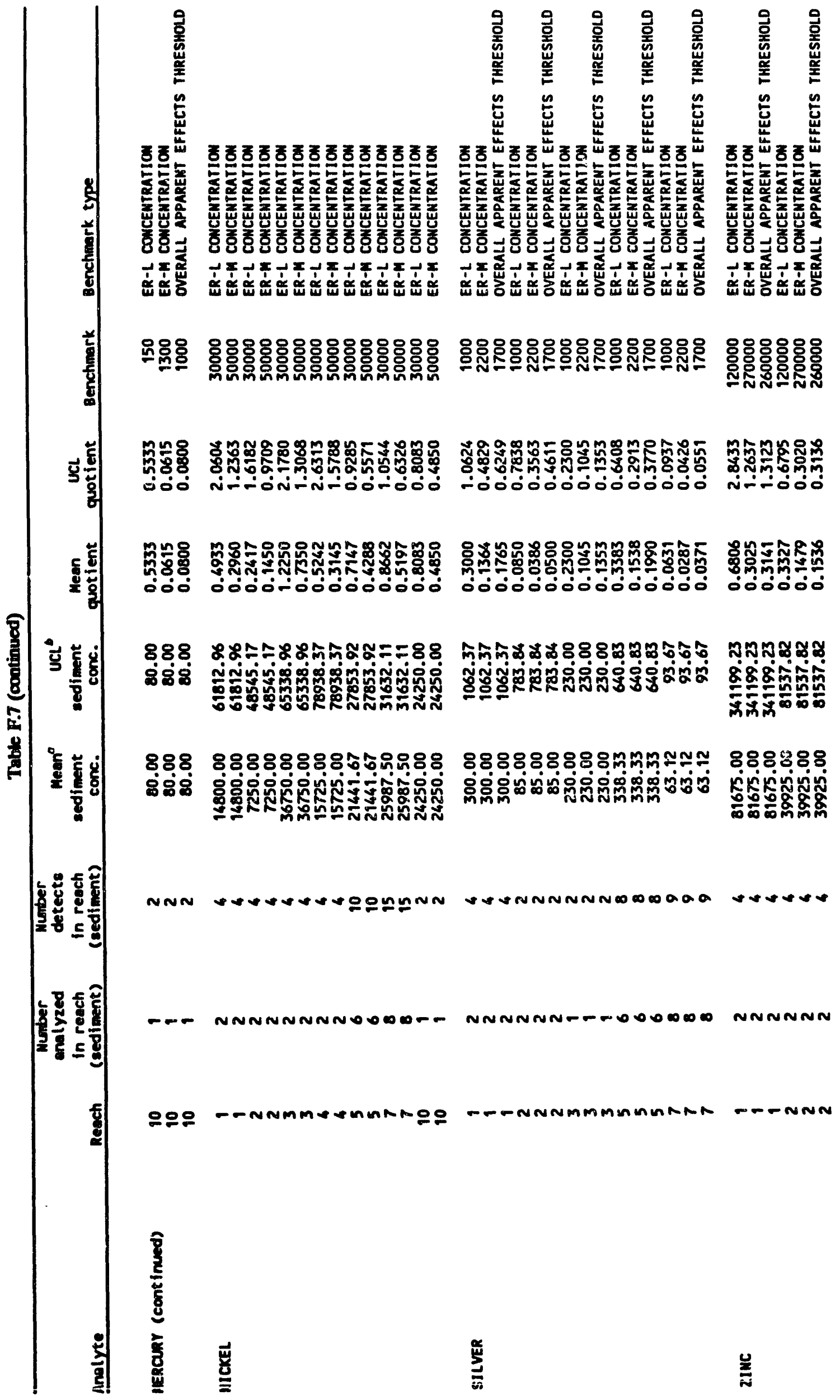




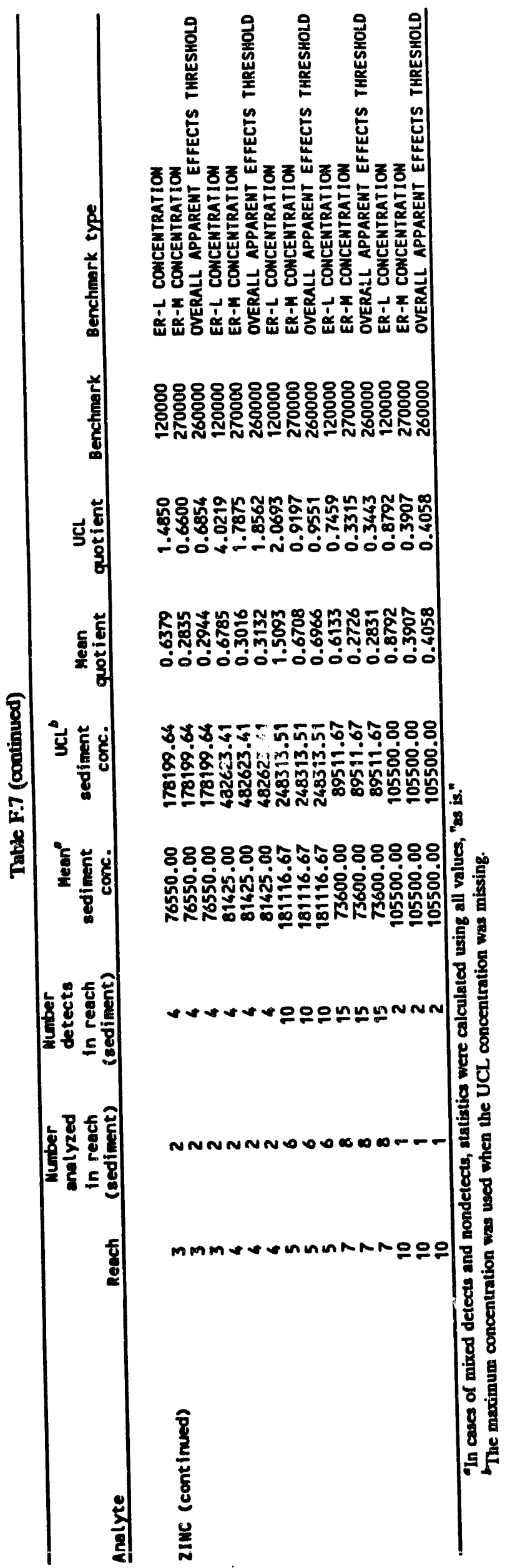




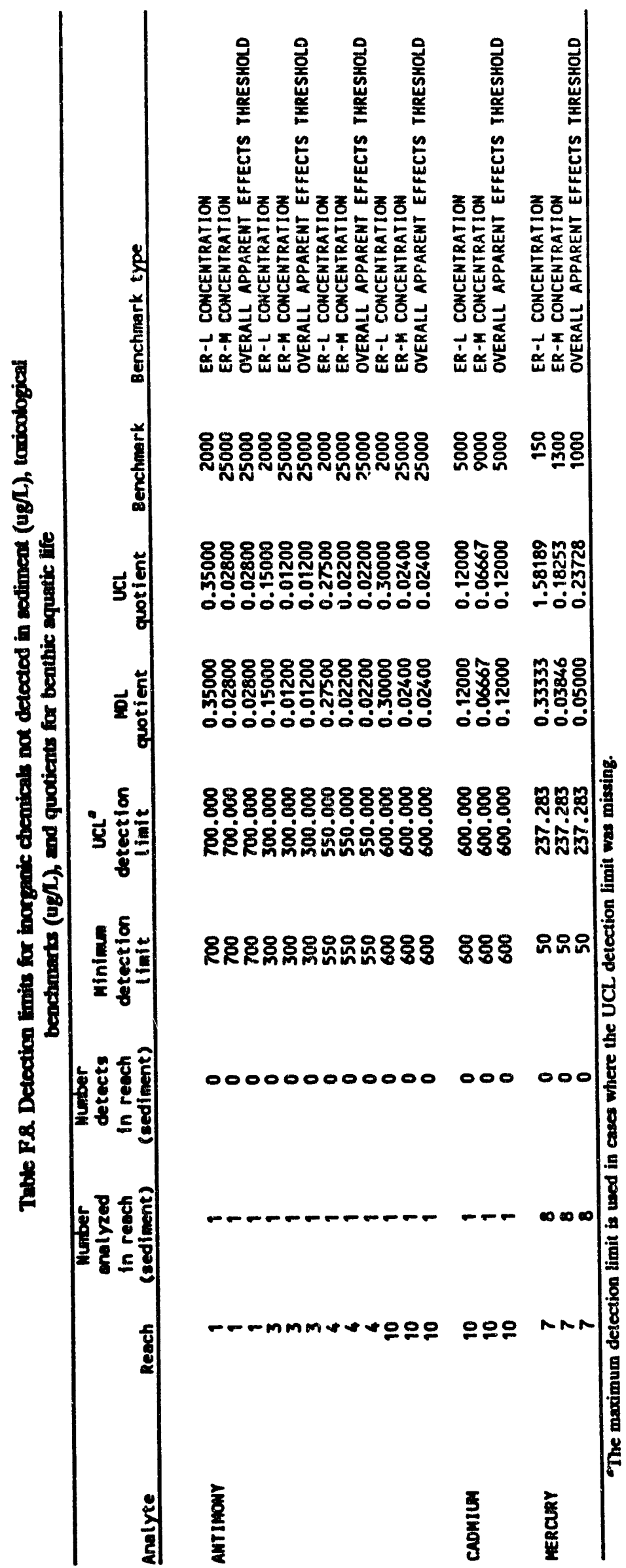




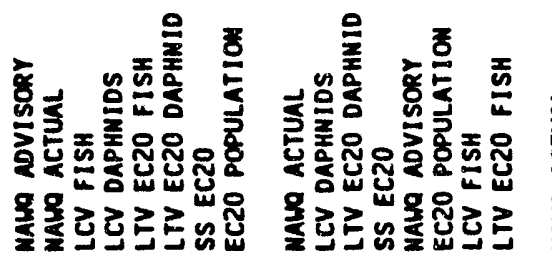

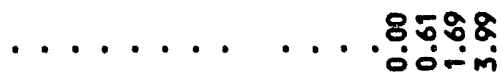

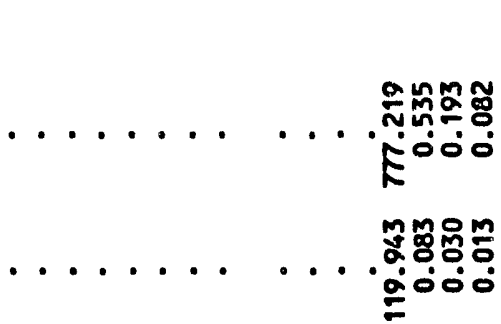

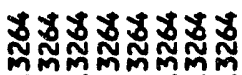
oodoojodo

$\overrightarrow{\mathrm{g}}$

ن

8

马ु

5 हैं

8

๑5

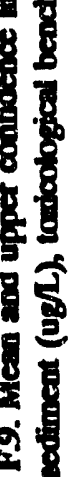

.

ह

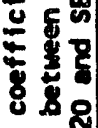

8

8

룽

ह

홍

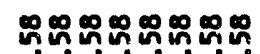

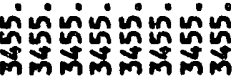

유ํํํํำ

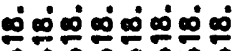

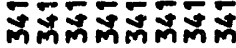

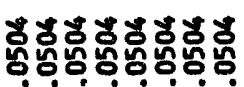

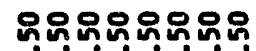
00000000

ํํำํํํํำํํำำ

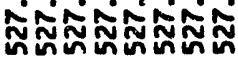

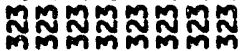

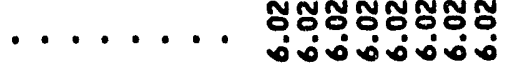

NMNNNNNN

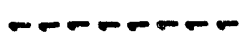

NNNNNNNN

NNNNNNNN

mmmmmmm

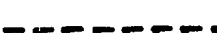

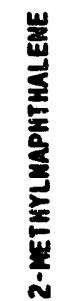

춯중

政

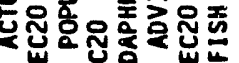

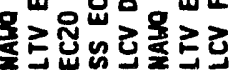

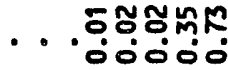

. . ติำ

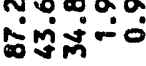

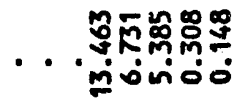

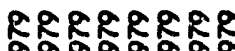
영영영영영 ல0ं0்000

ㅇํํำ $\infty$

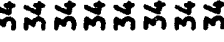

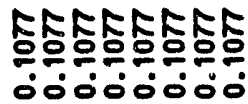

ำำำํำำำำ

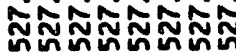

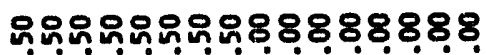

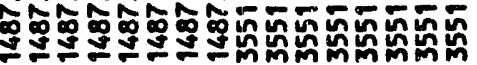

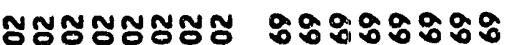

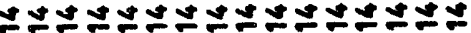

nivinivivivivin

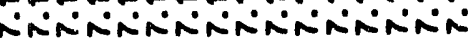

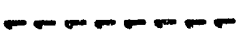

- - - - - MNNNNNNN

NNNNNNNN

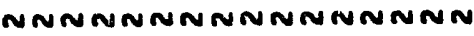

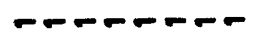

NNNNNNNNMMMMMmMm

$\stackrel{5}{\vdots}$

荌

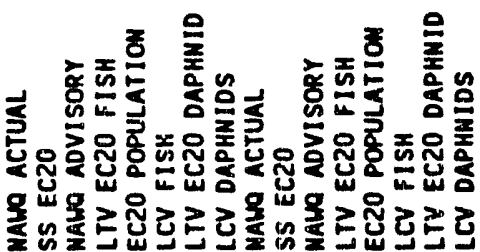

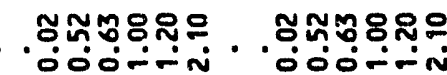

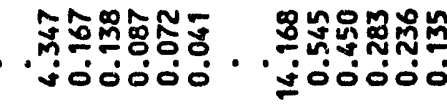

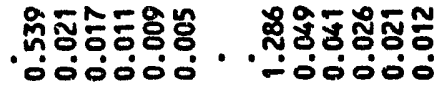

\%ి

வ

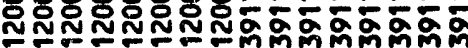

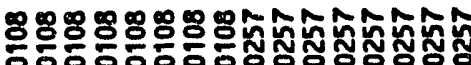

प0ं000000000000 


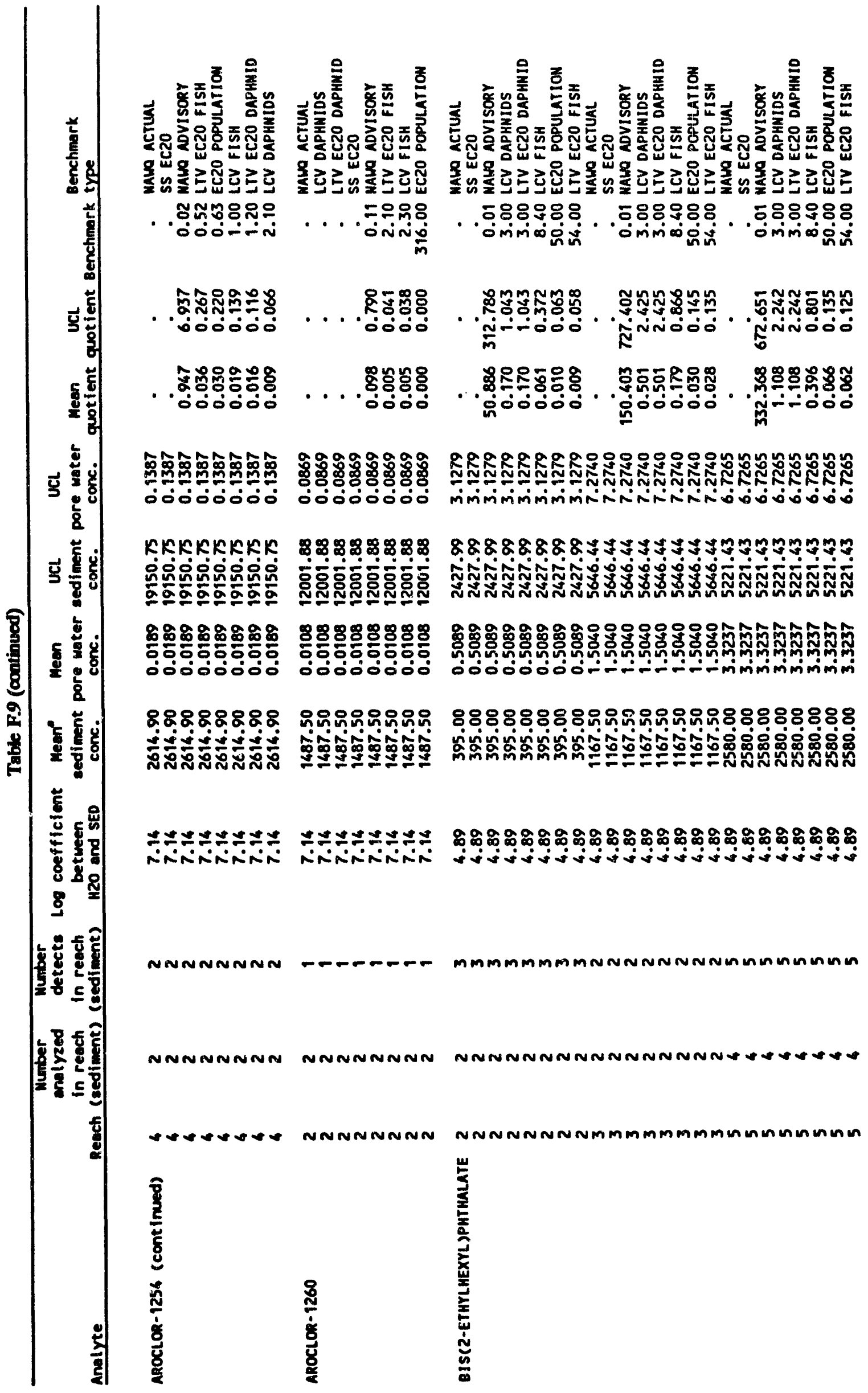




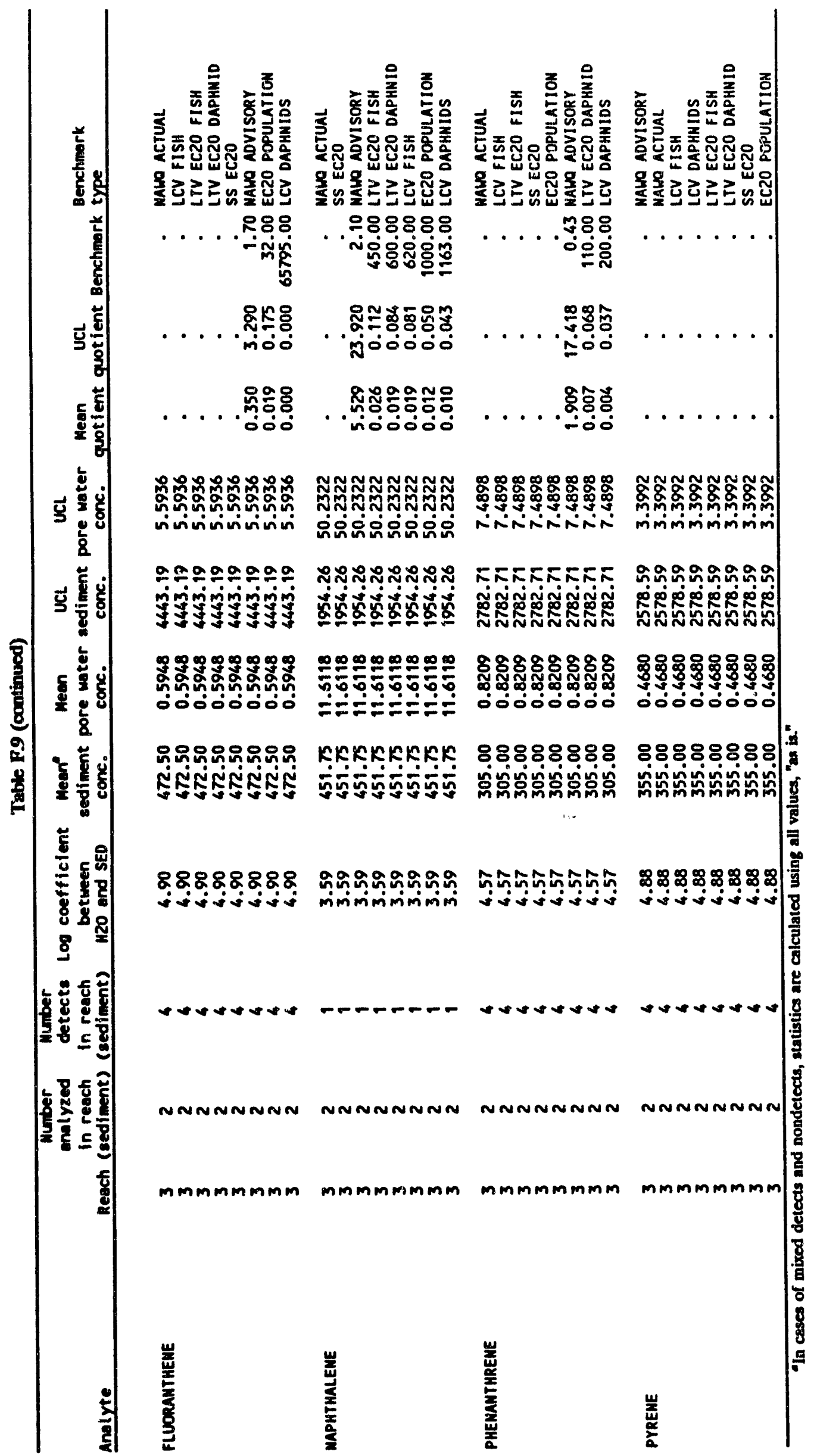


F-95

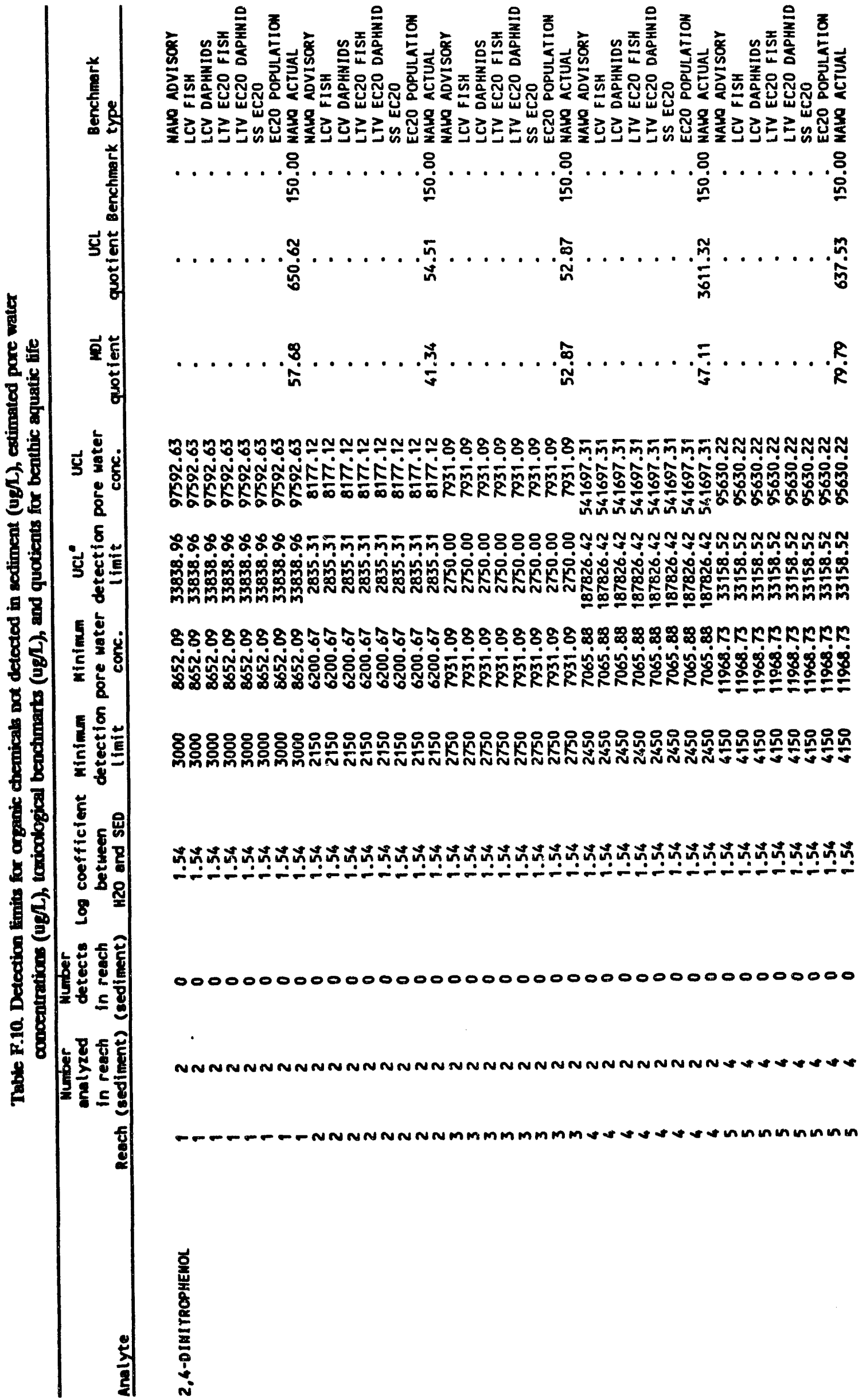




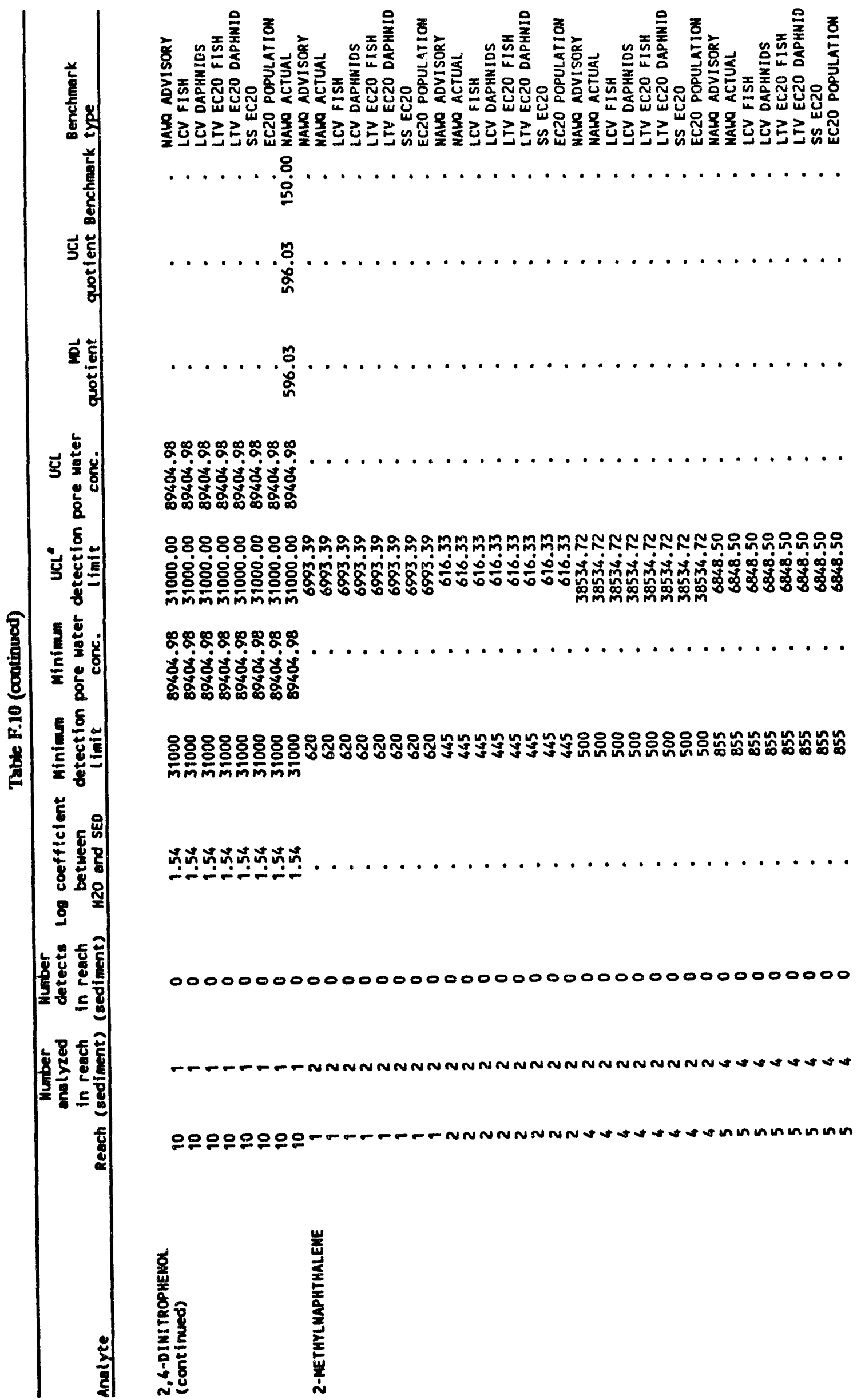




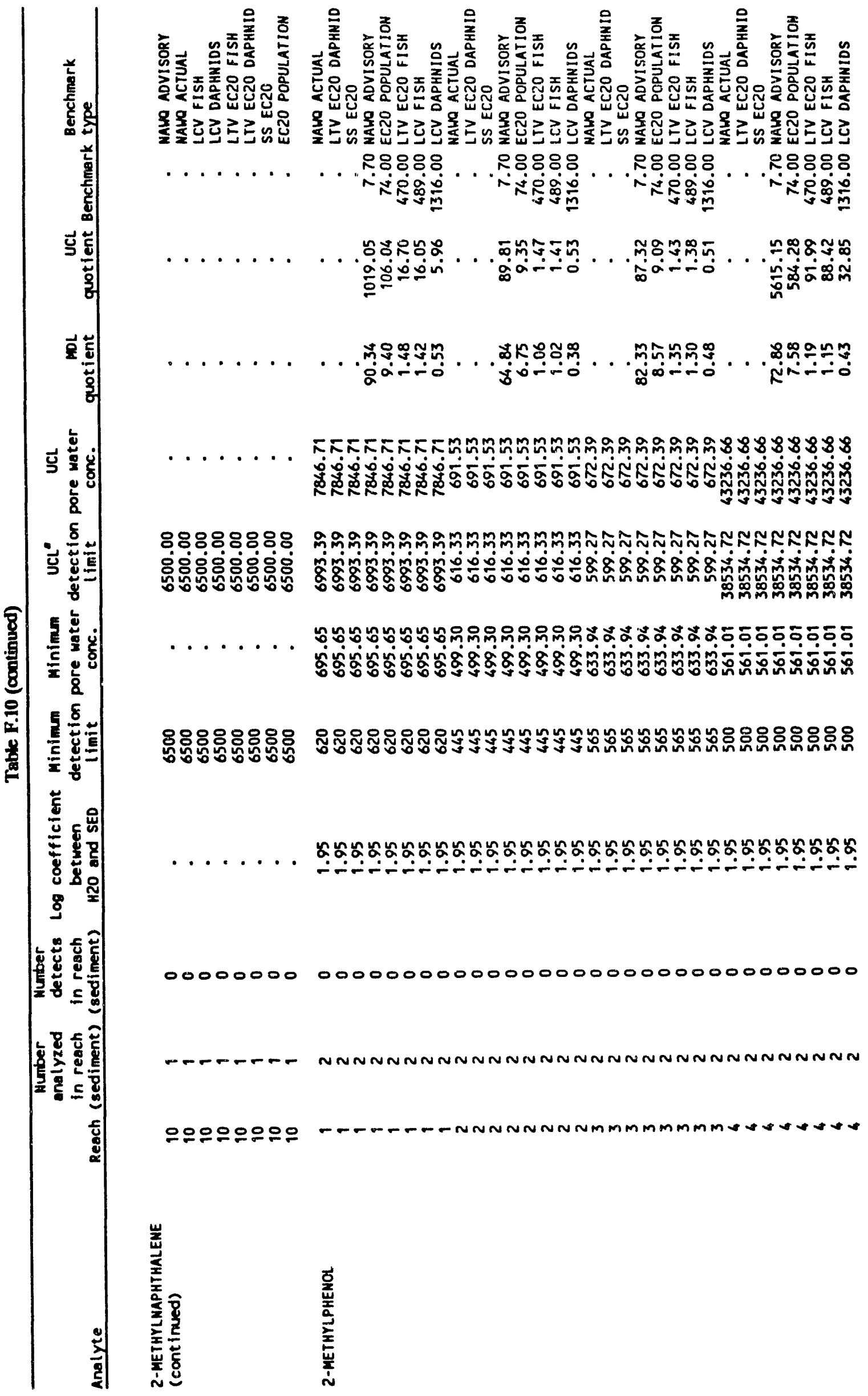


F-98

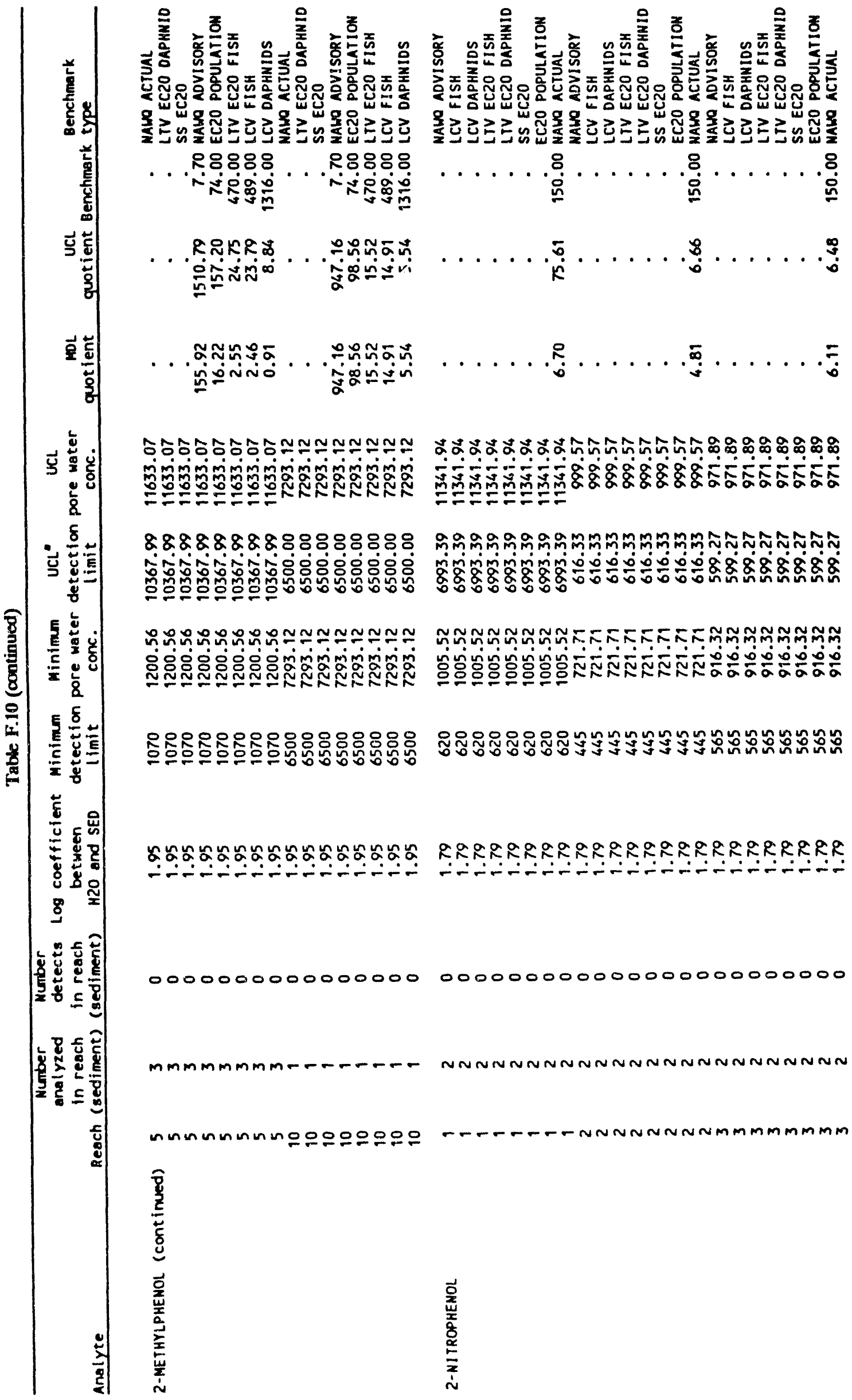


F-99

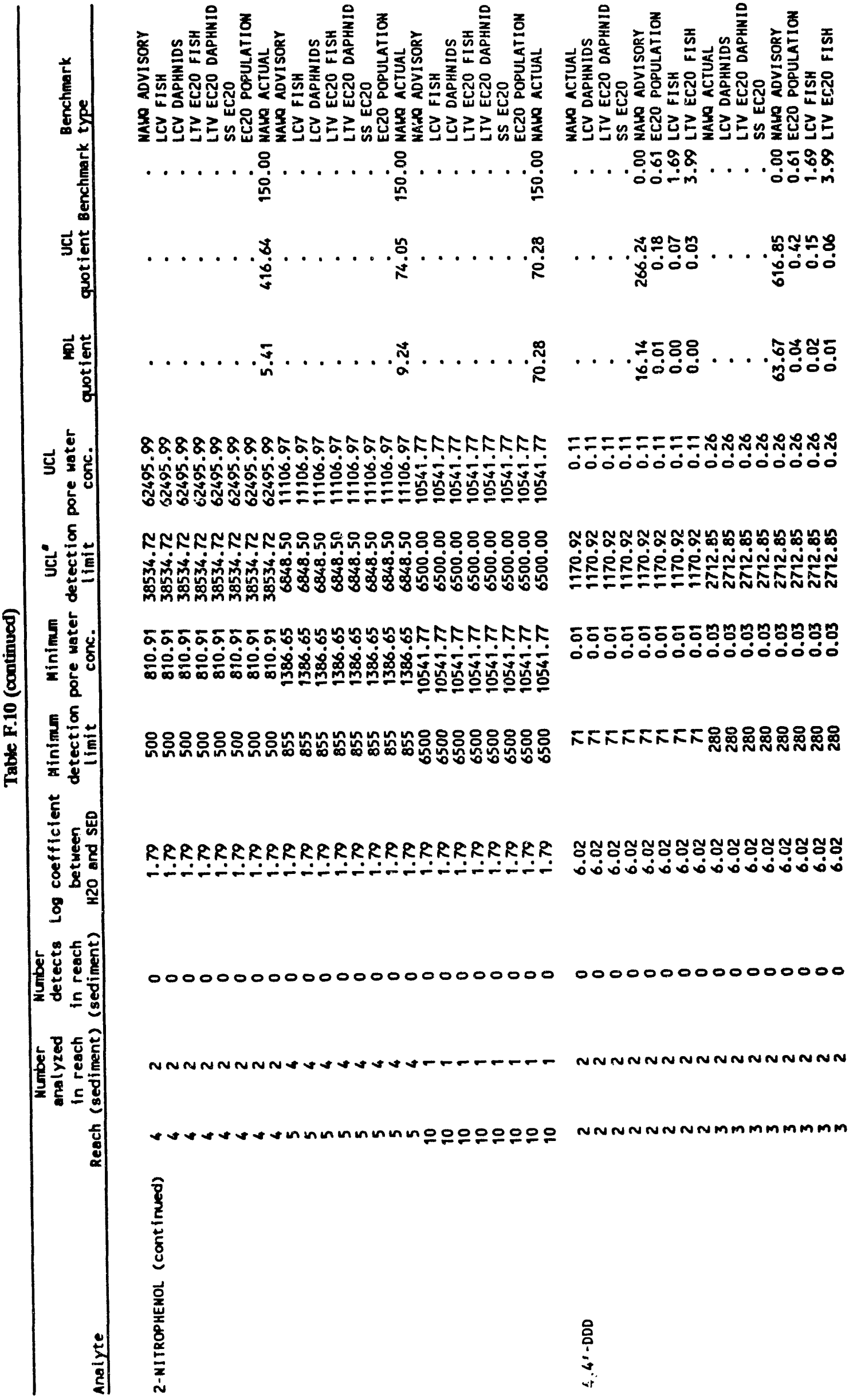


F-100

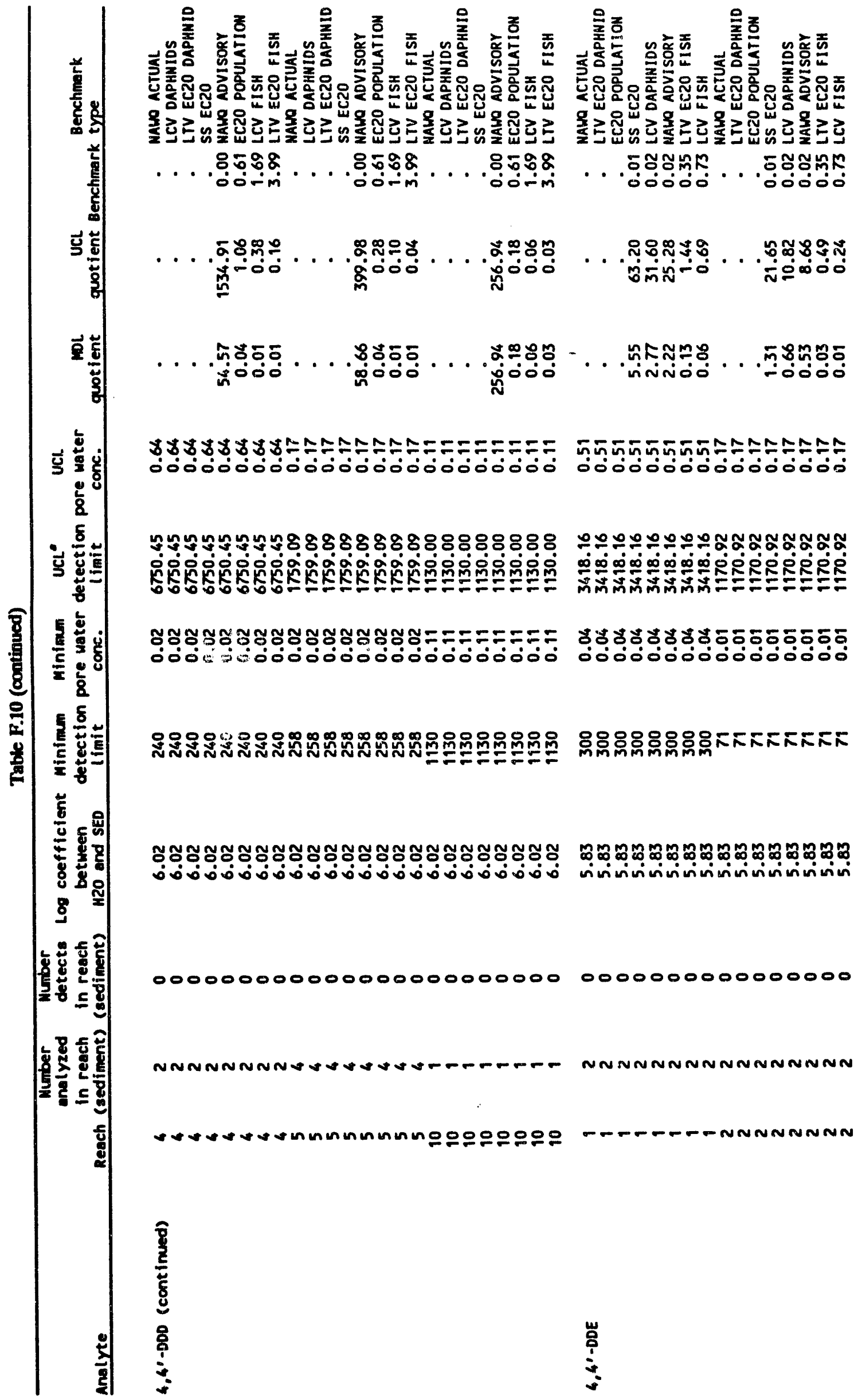




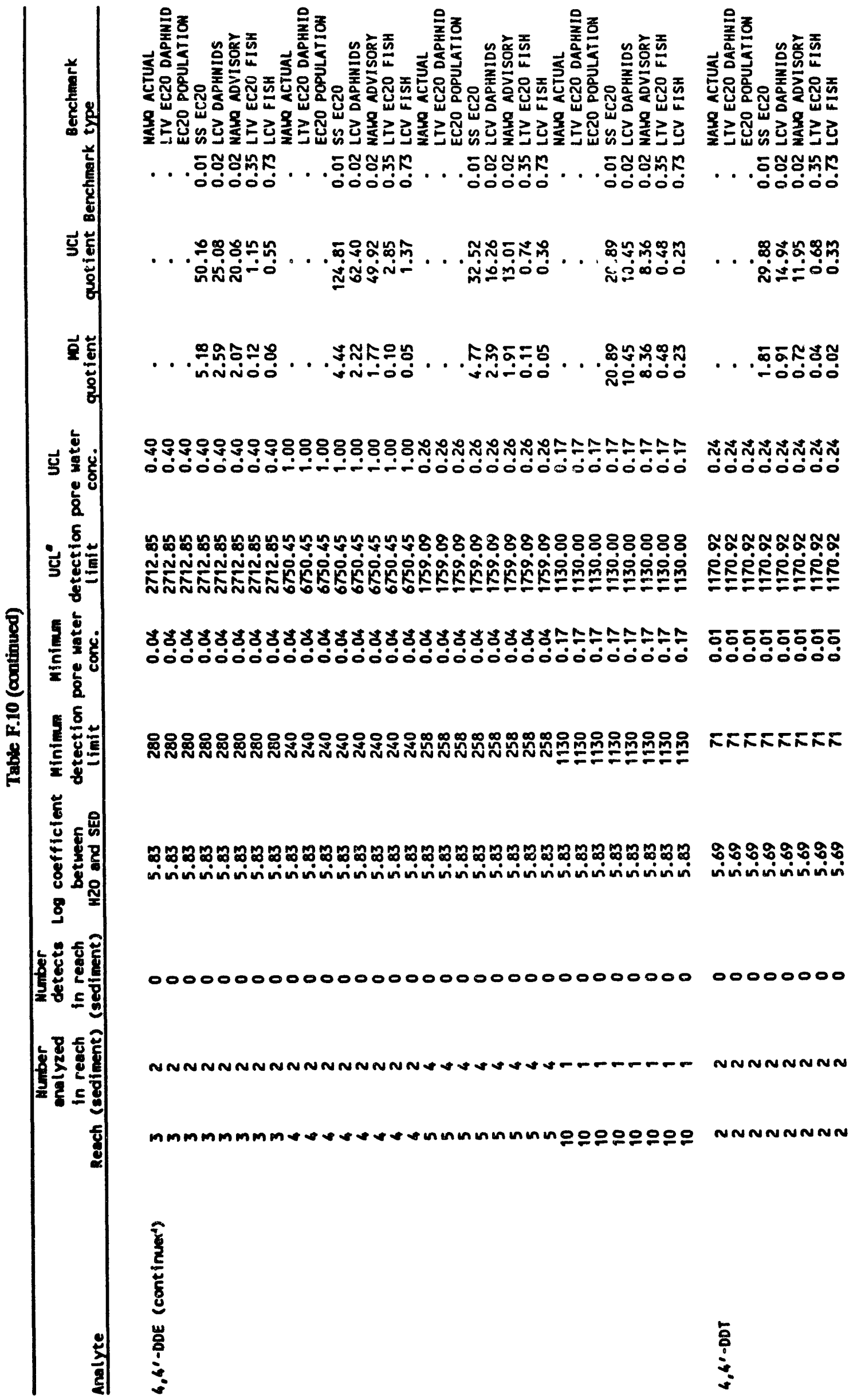




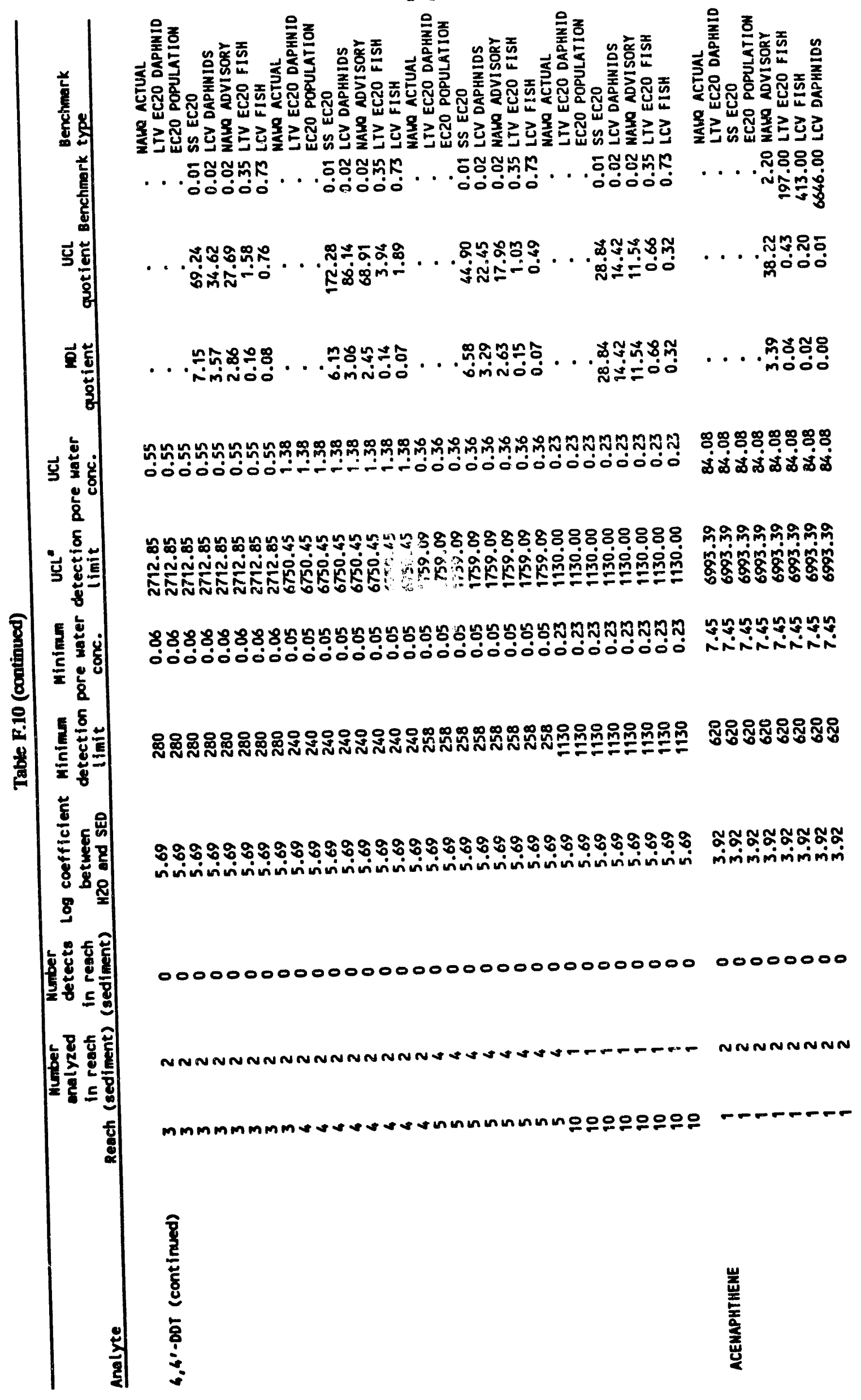


F-103

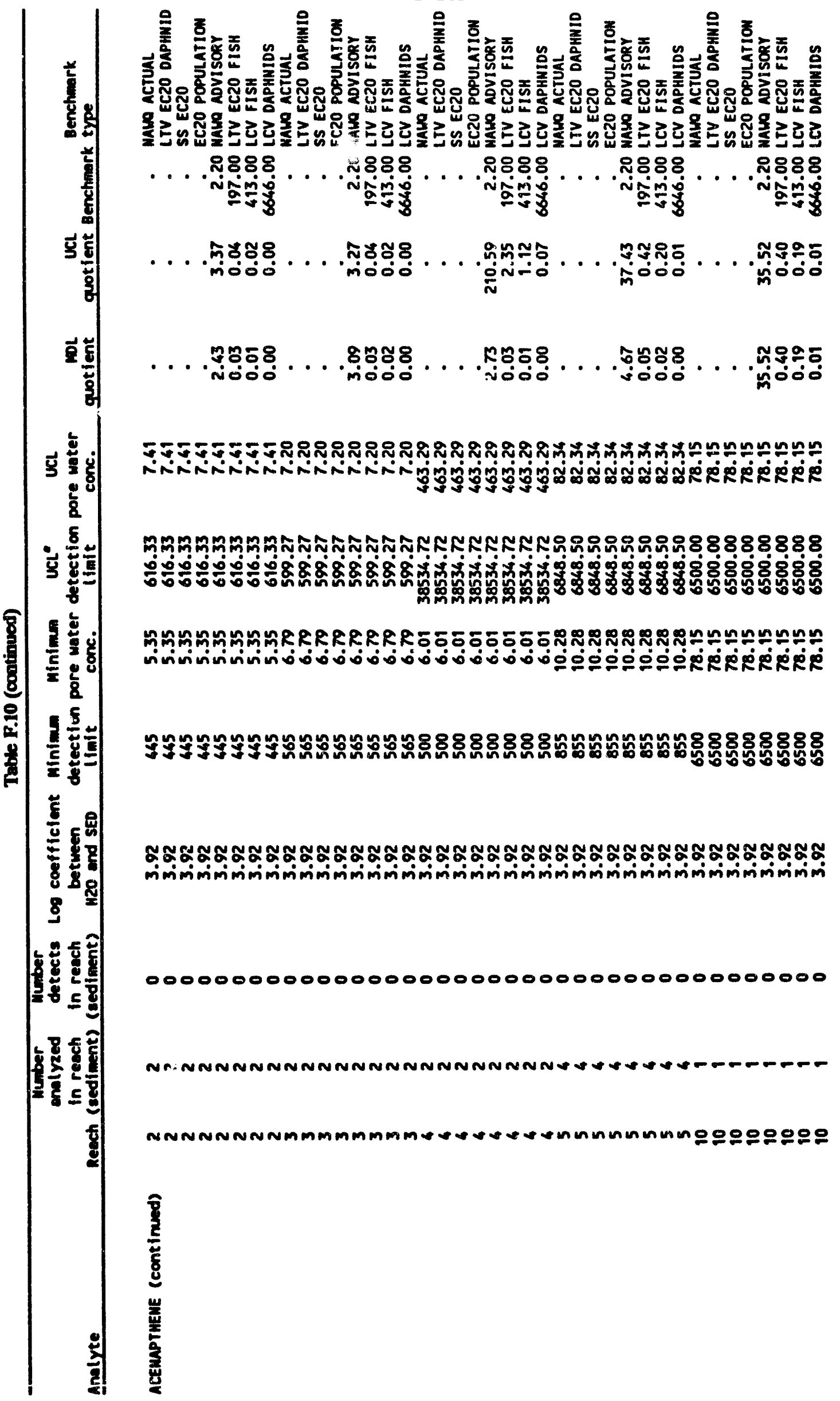




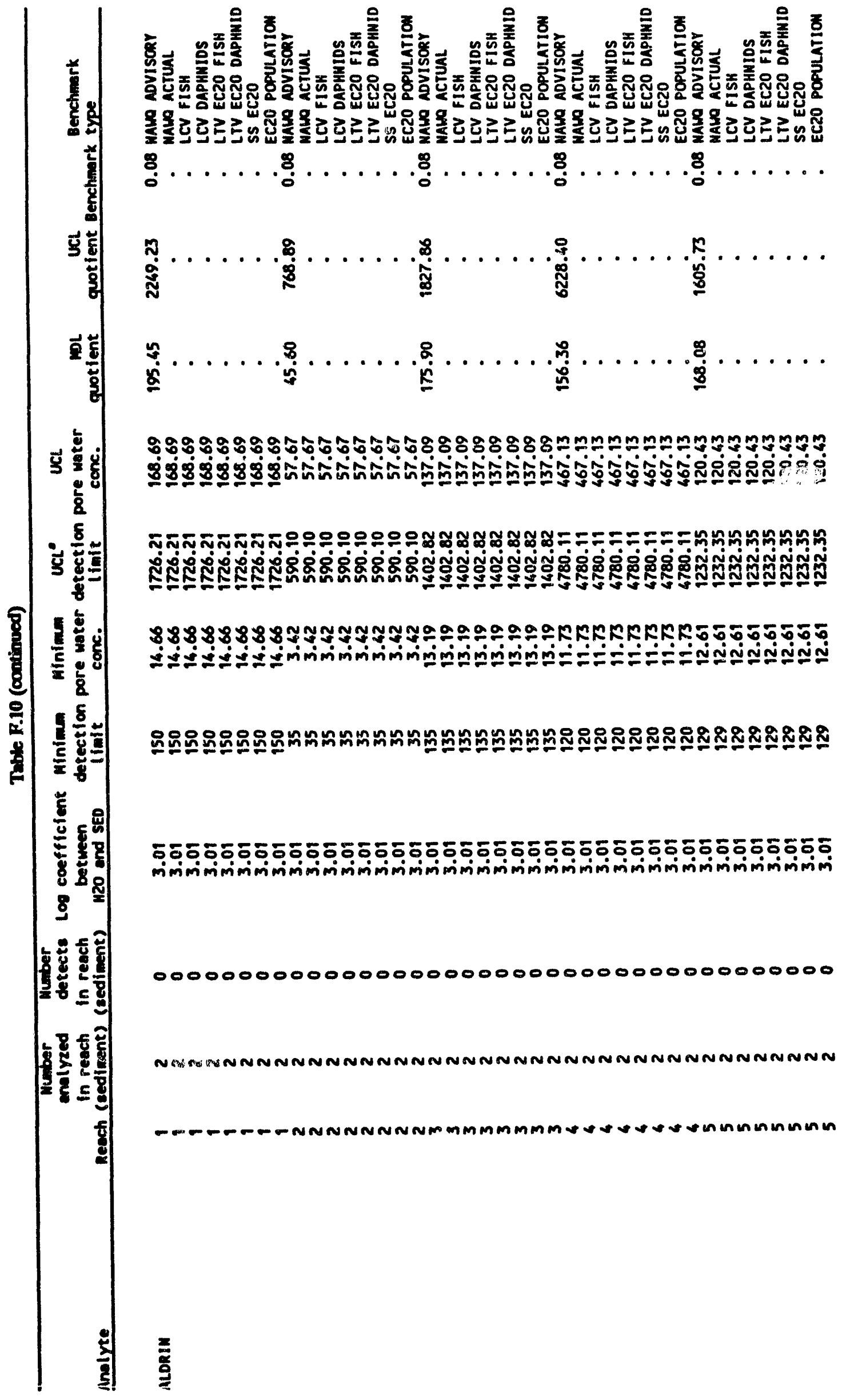




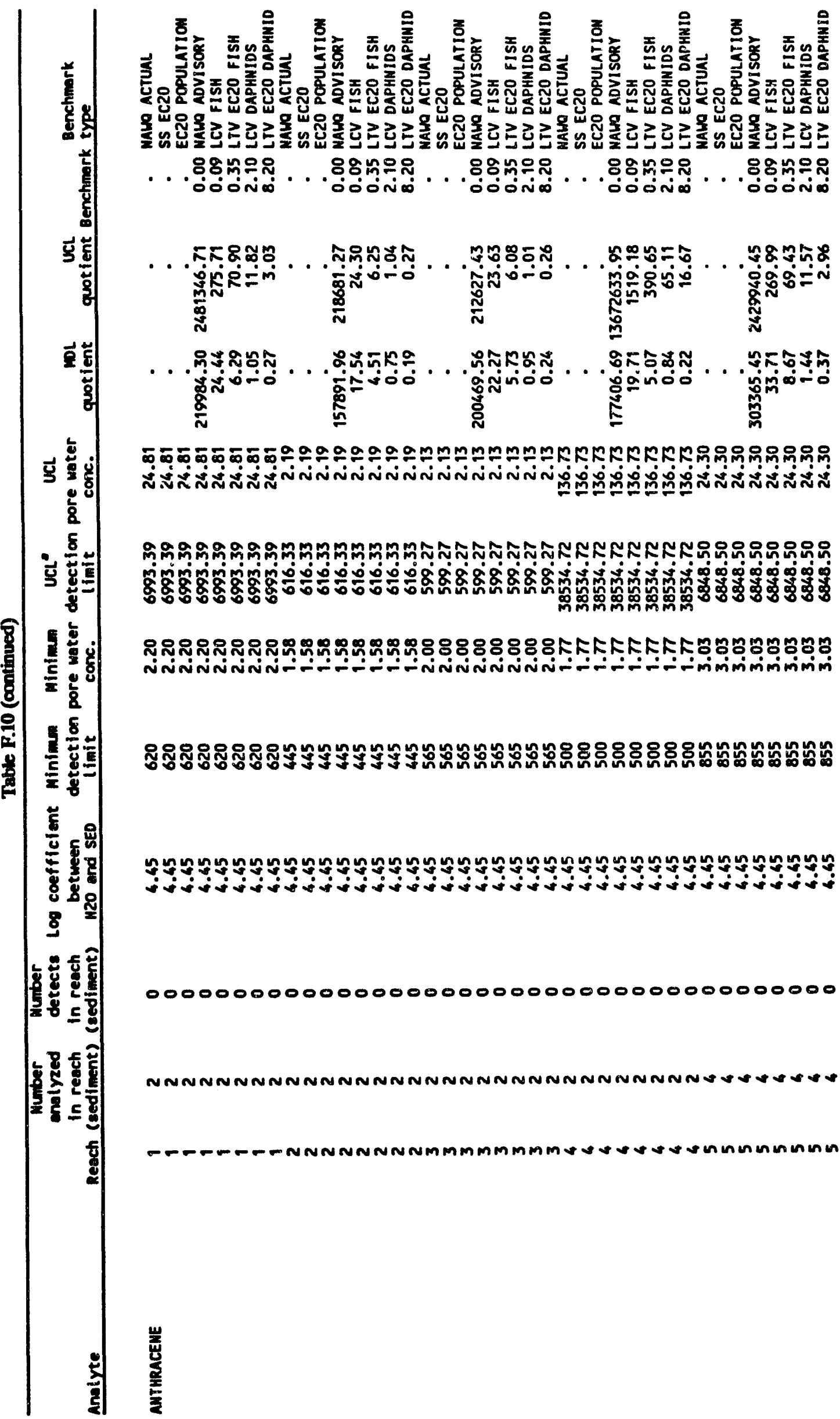


F-106

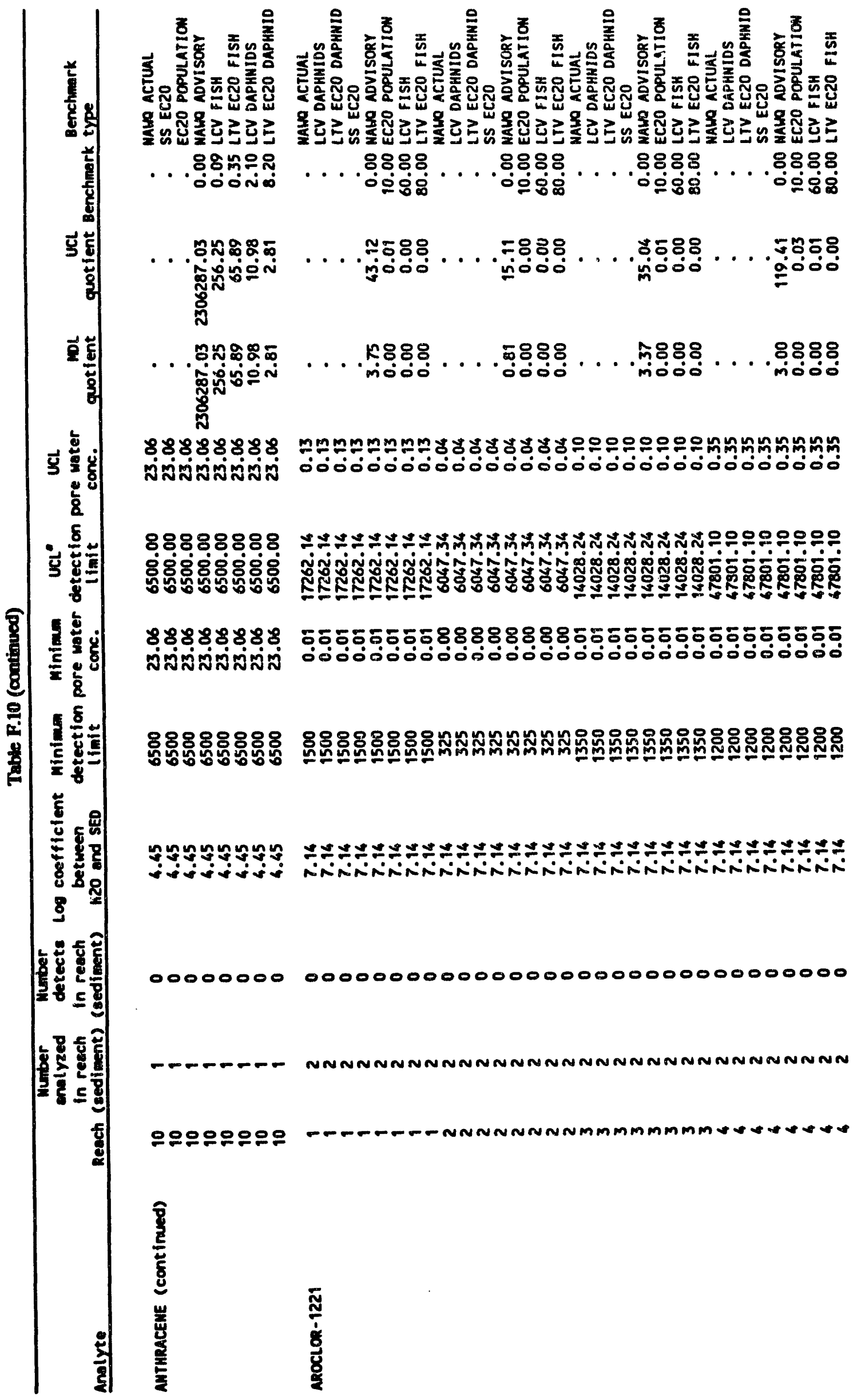




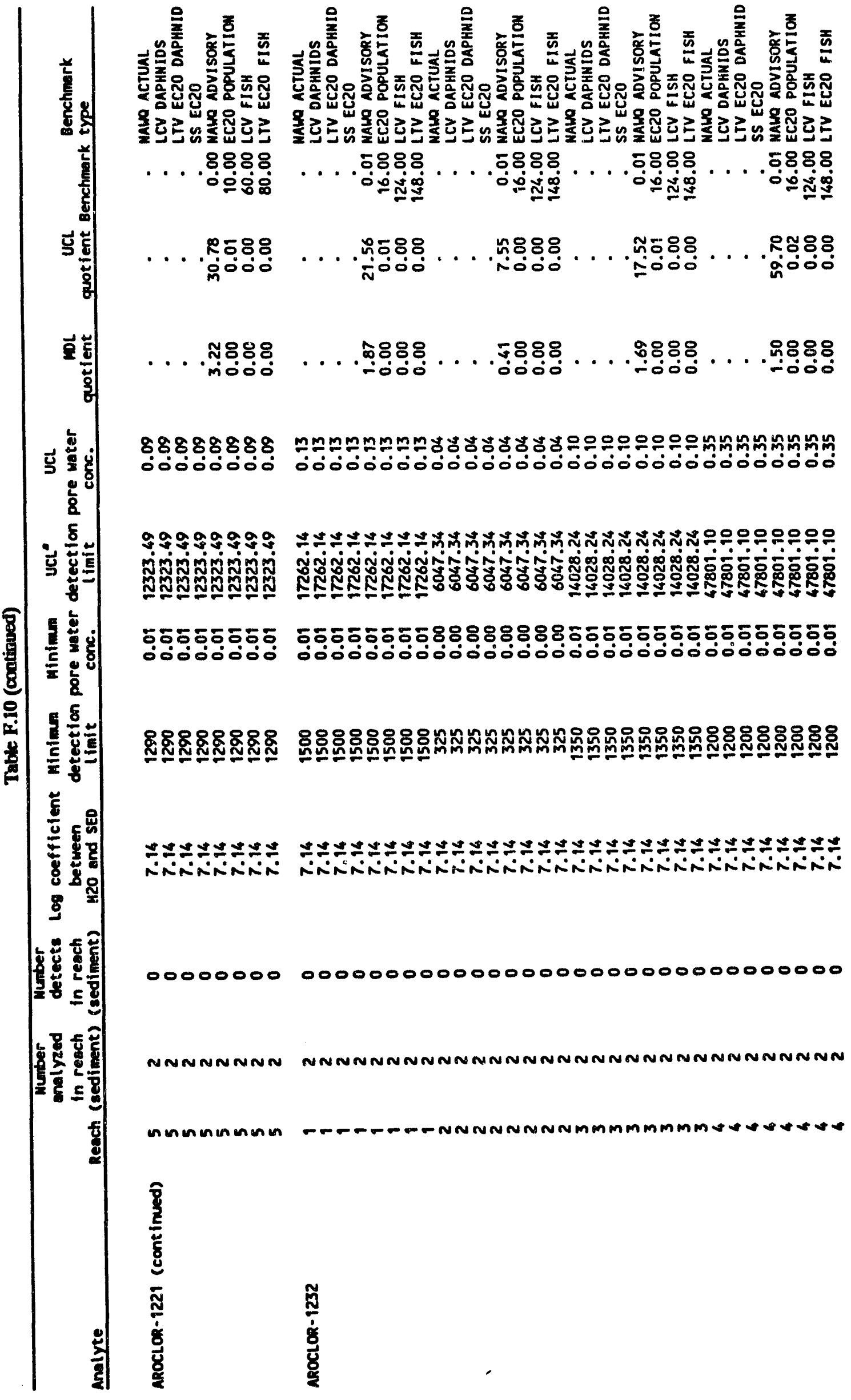


F-108

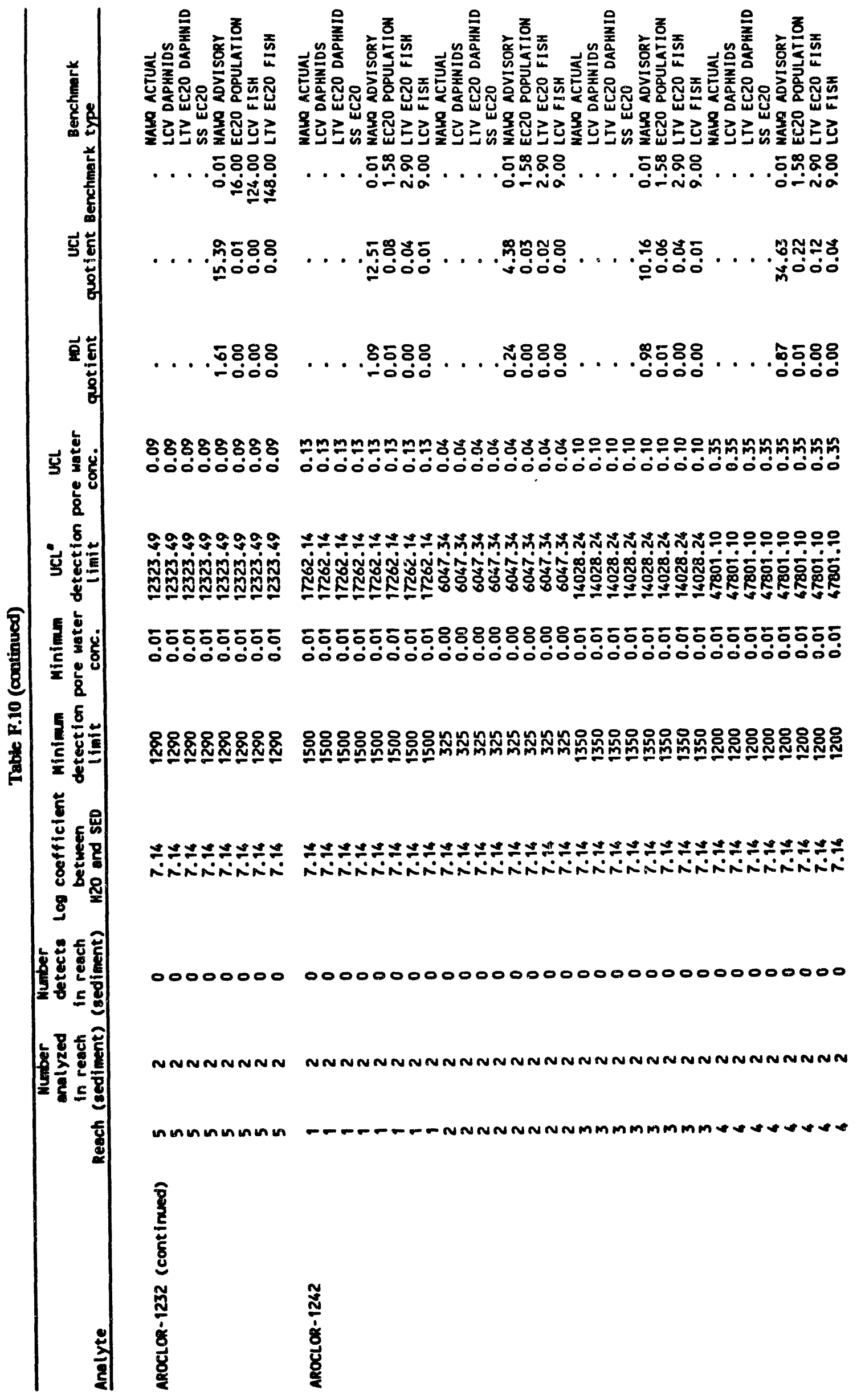


F-109

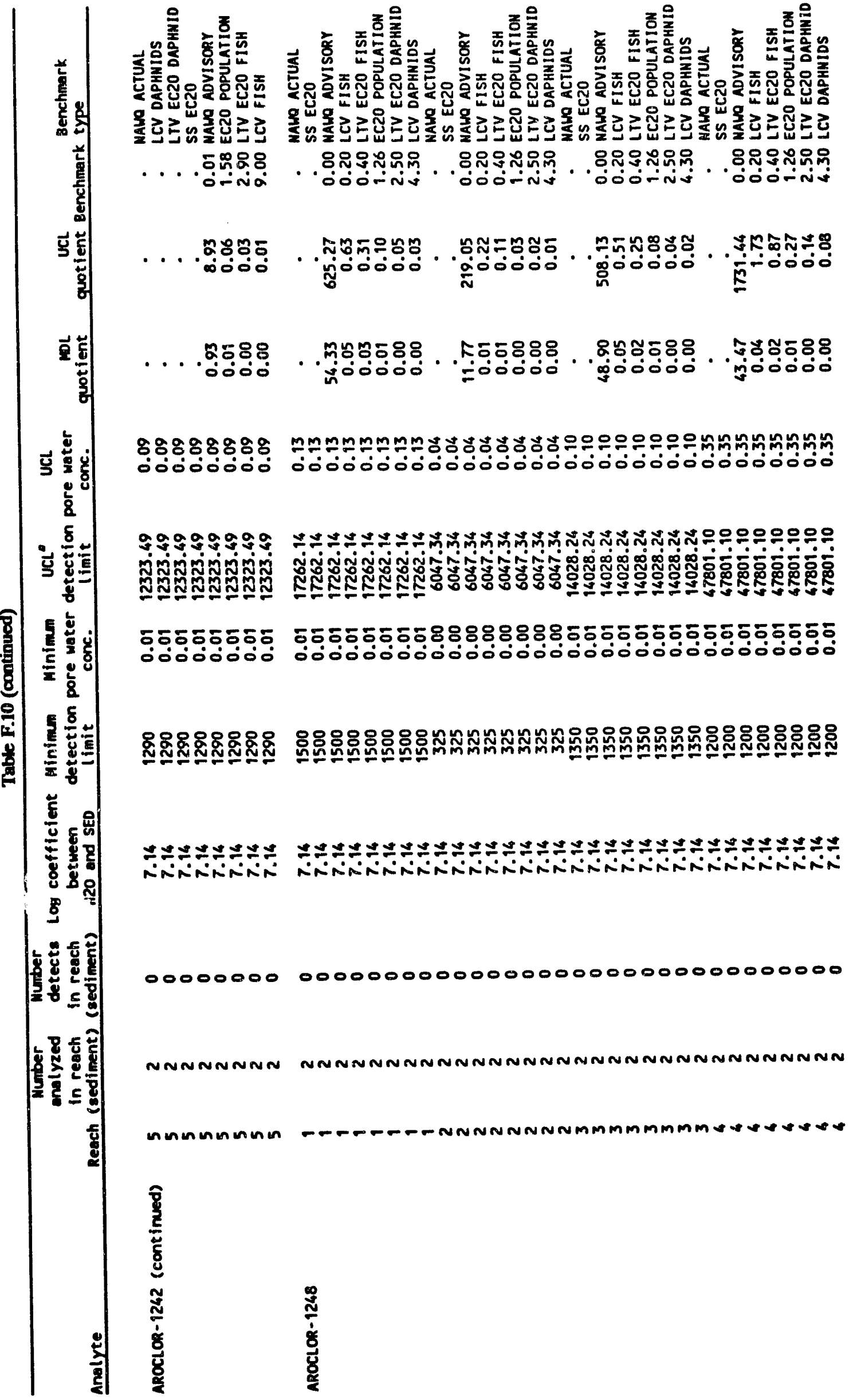


F-110

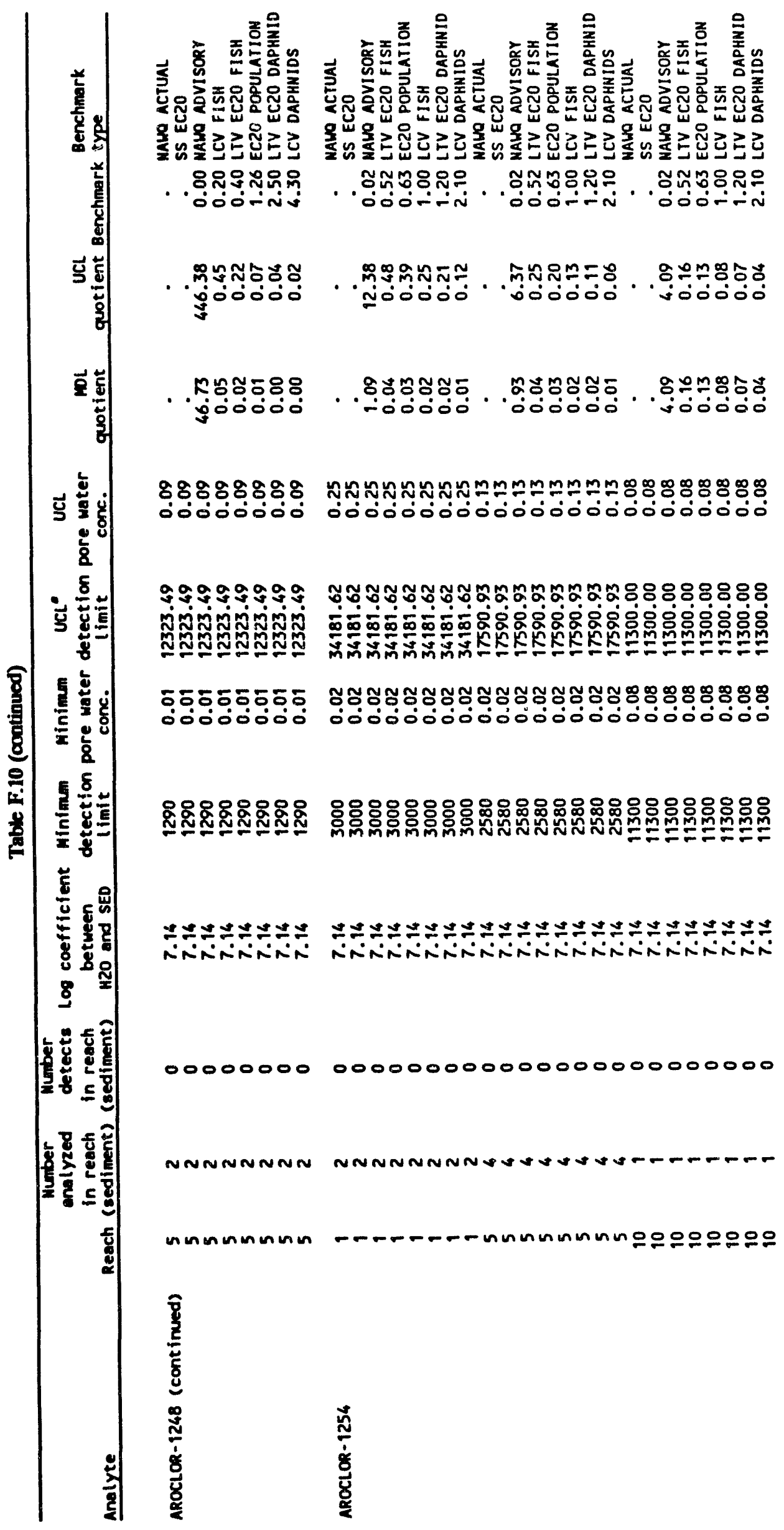


F-111

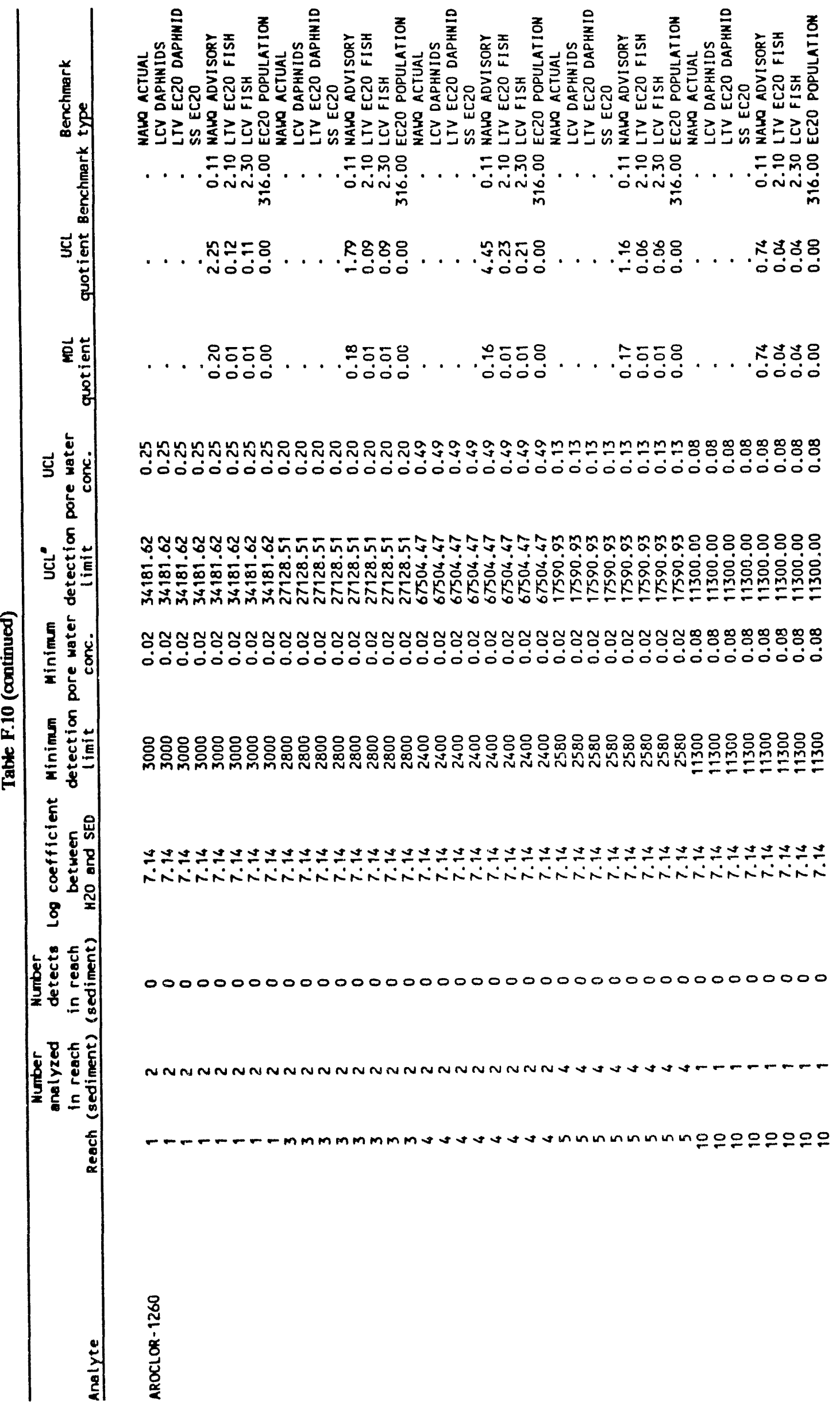


F-112

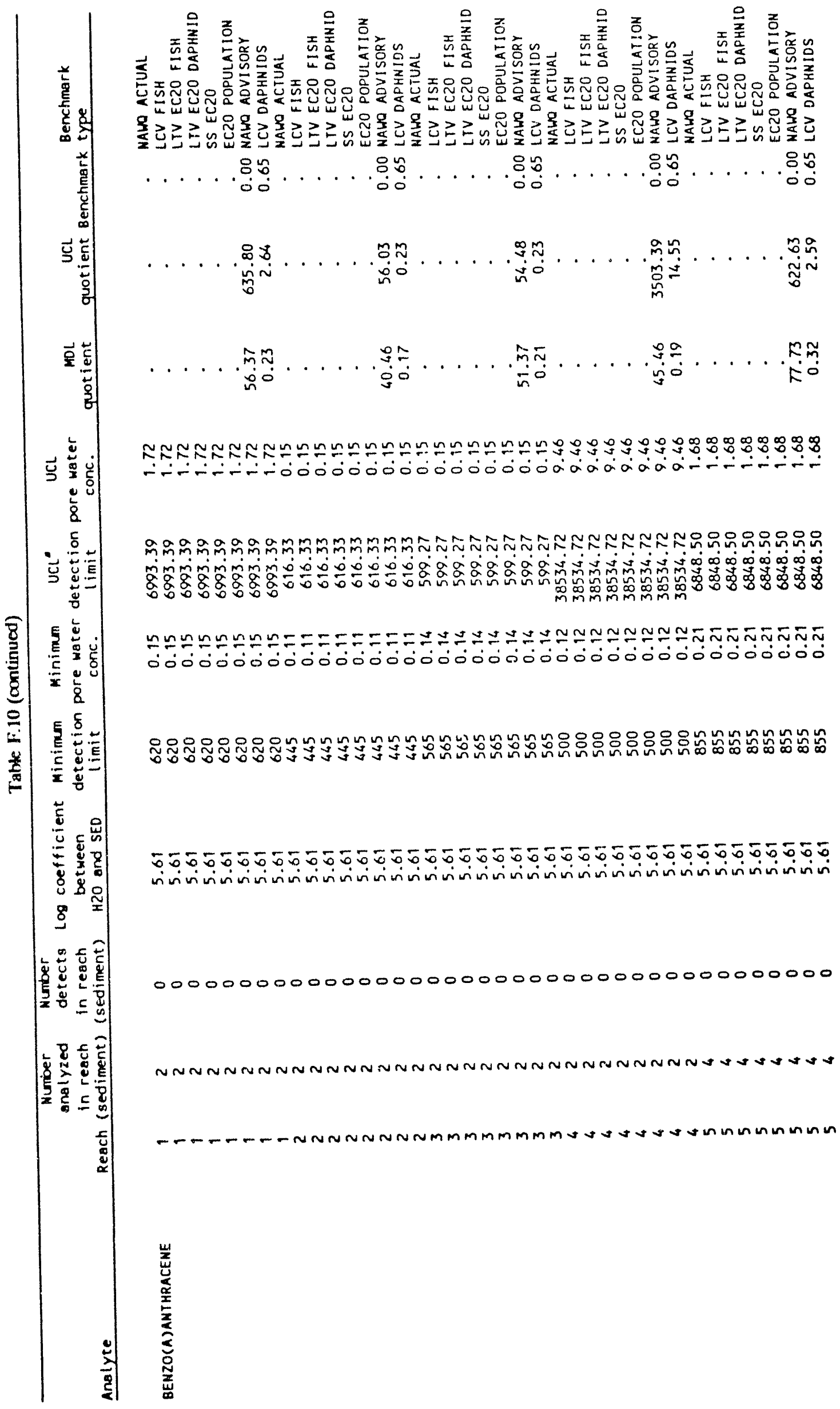


F-113

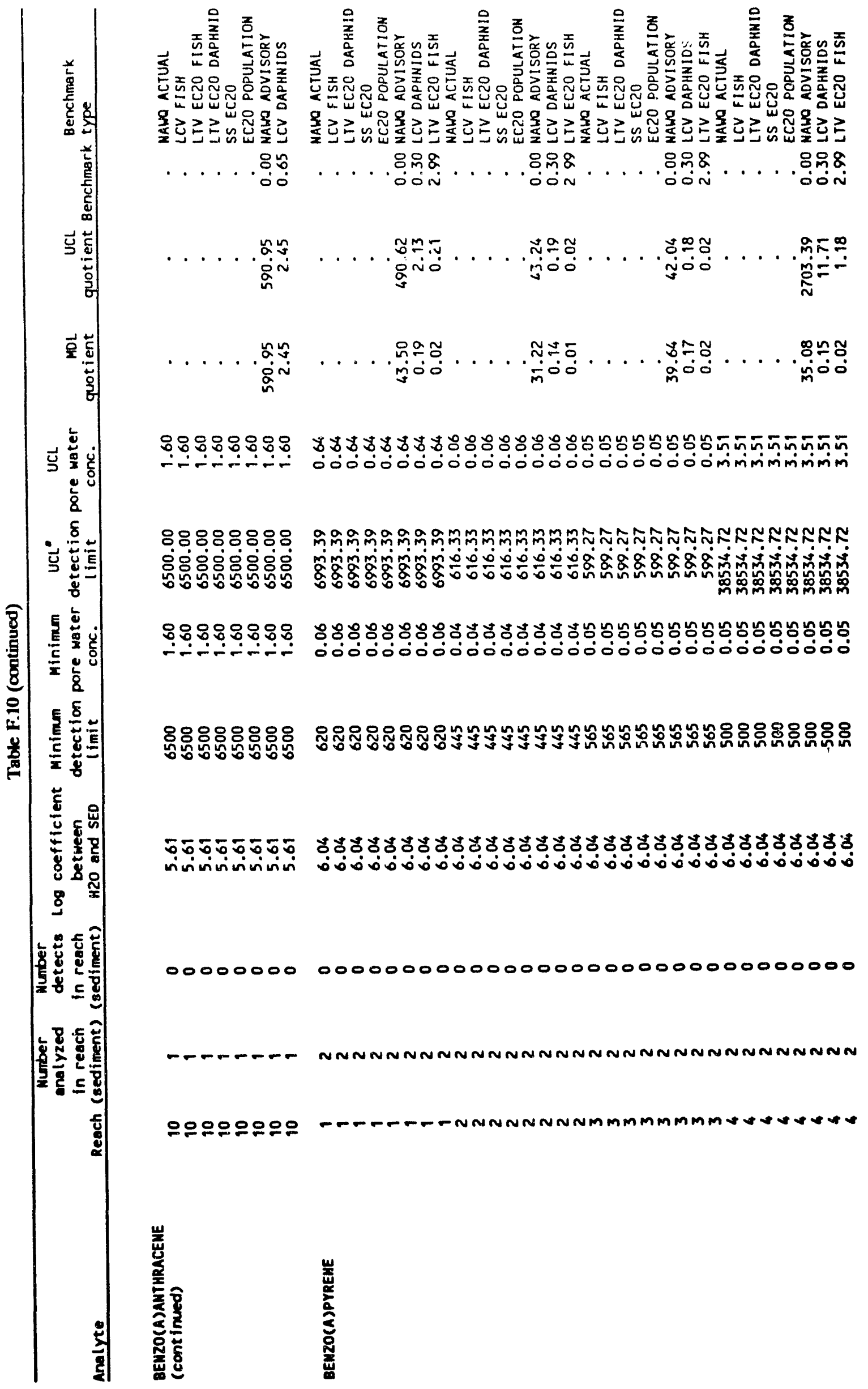


F-114

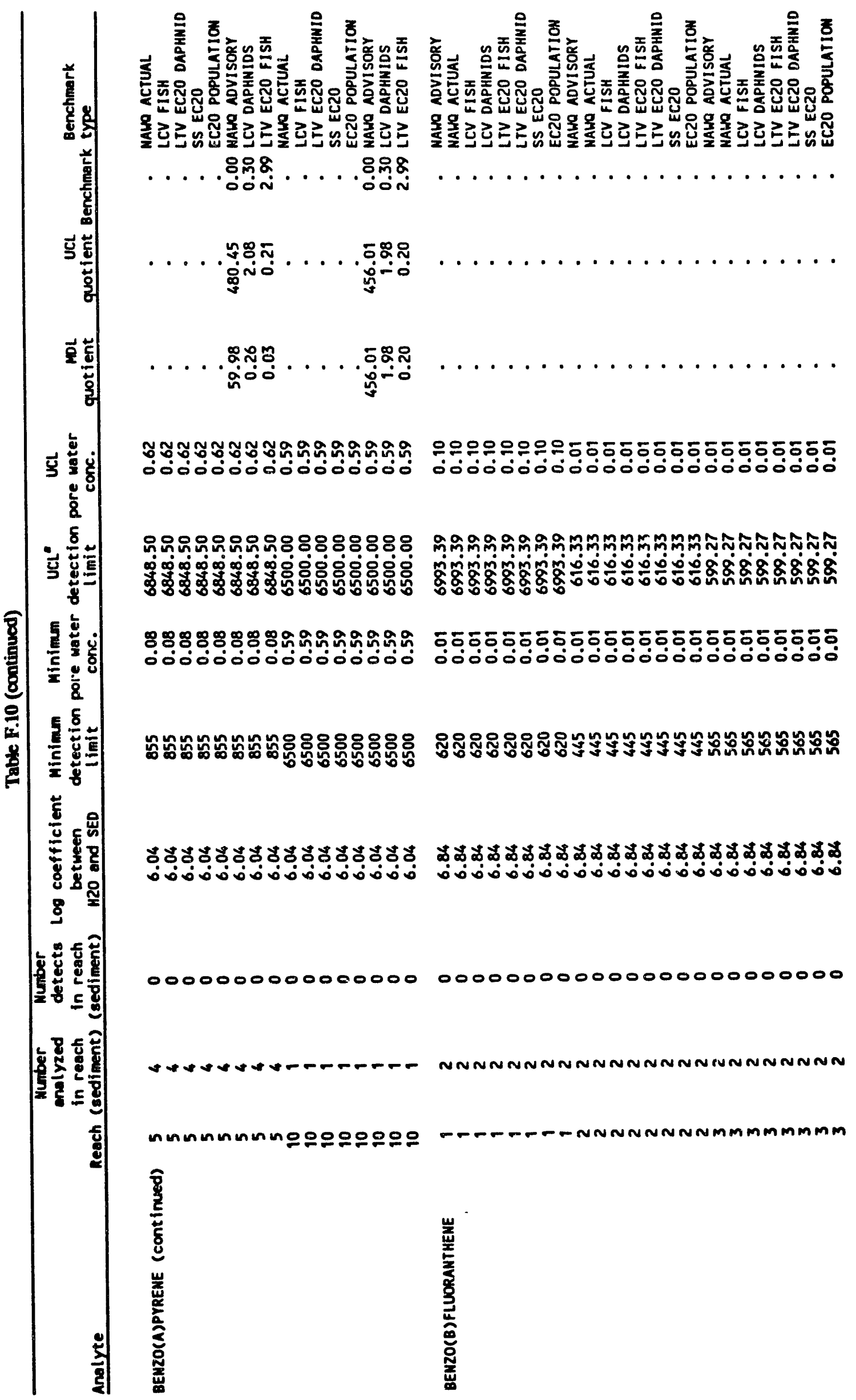




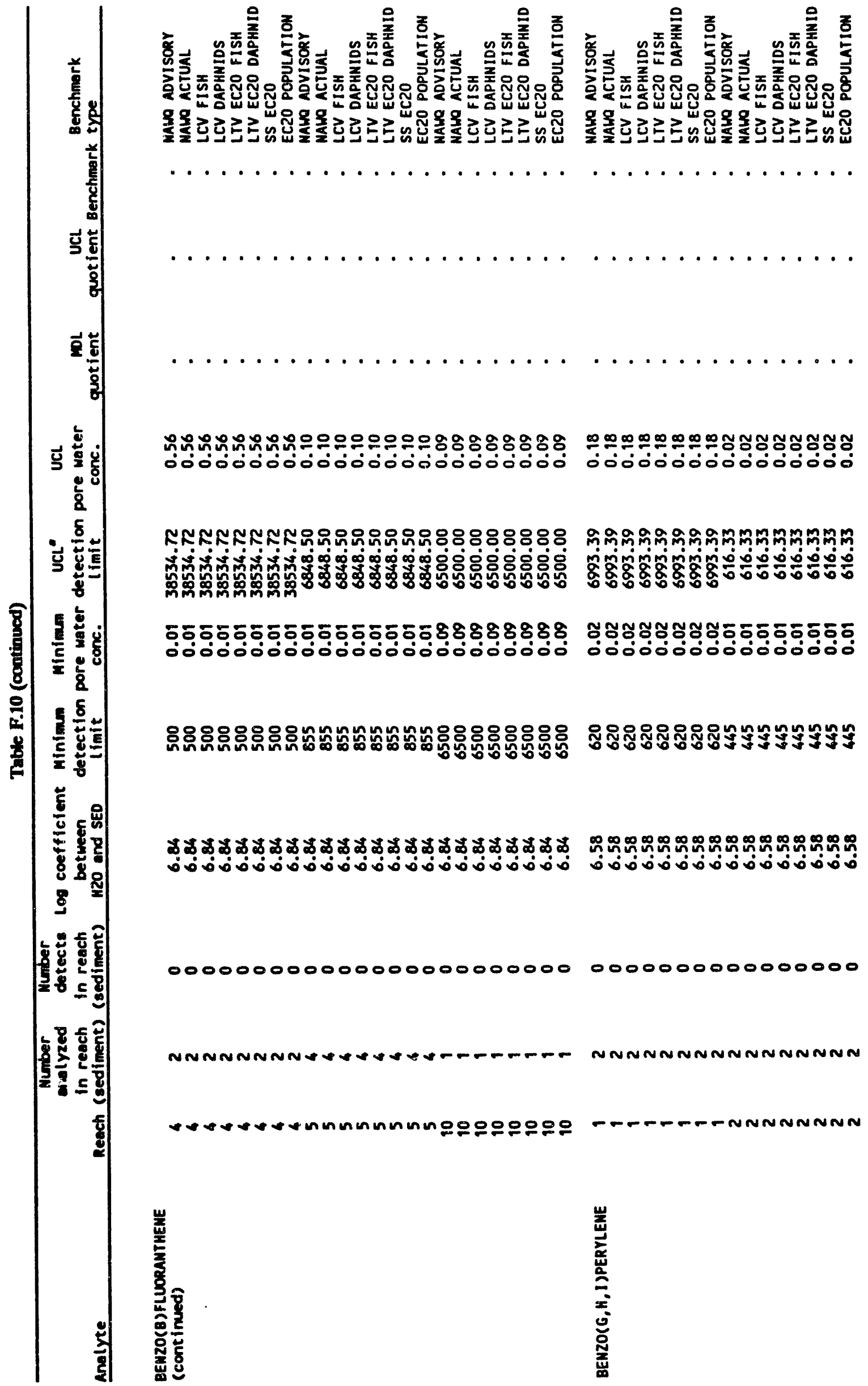




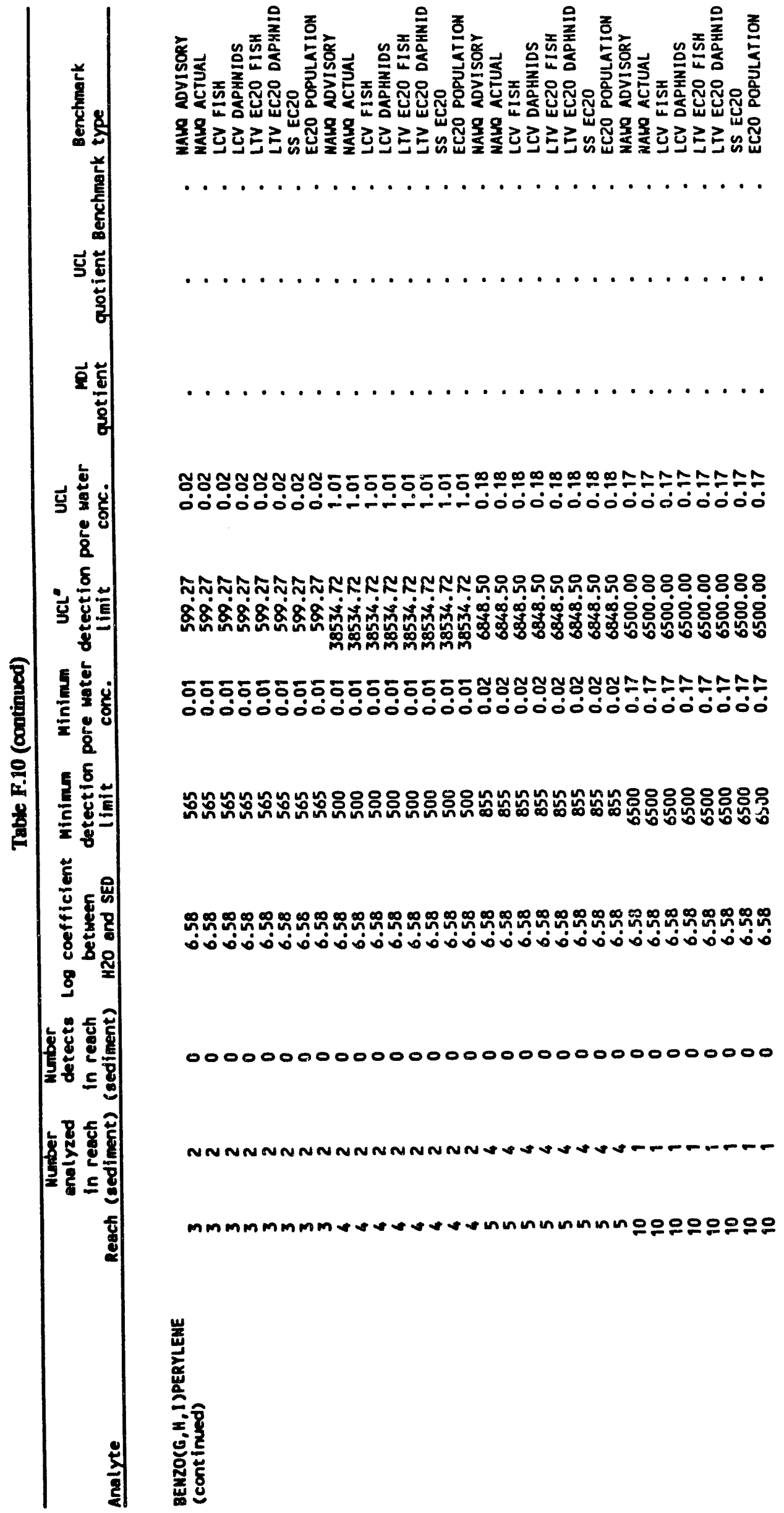




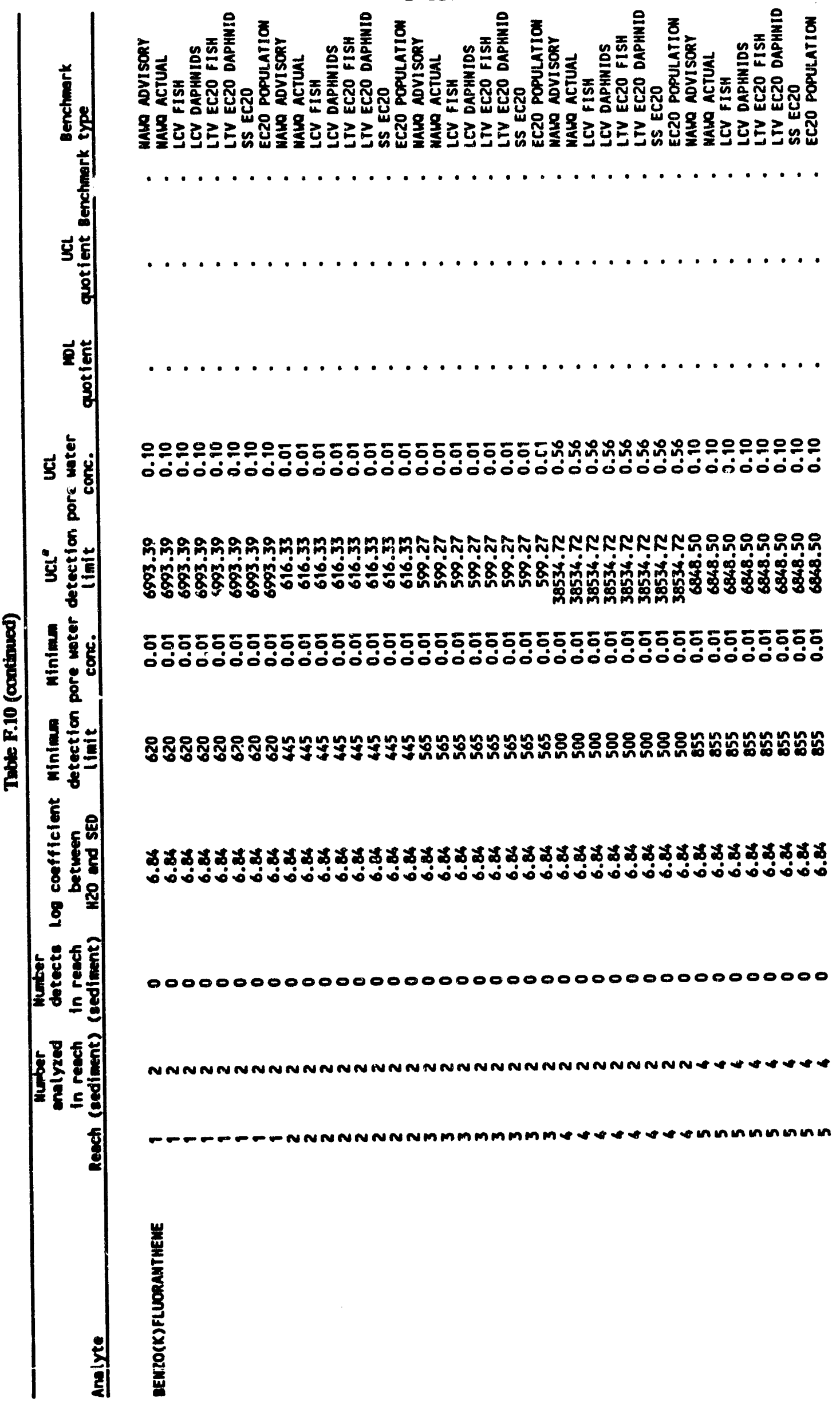


F-118

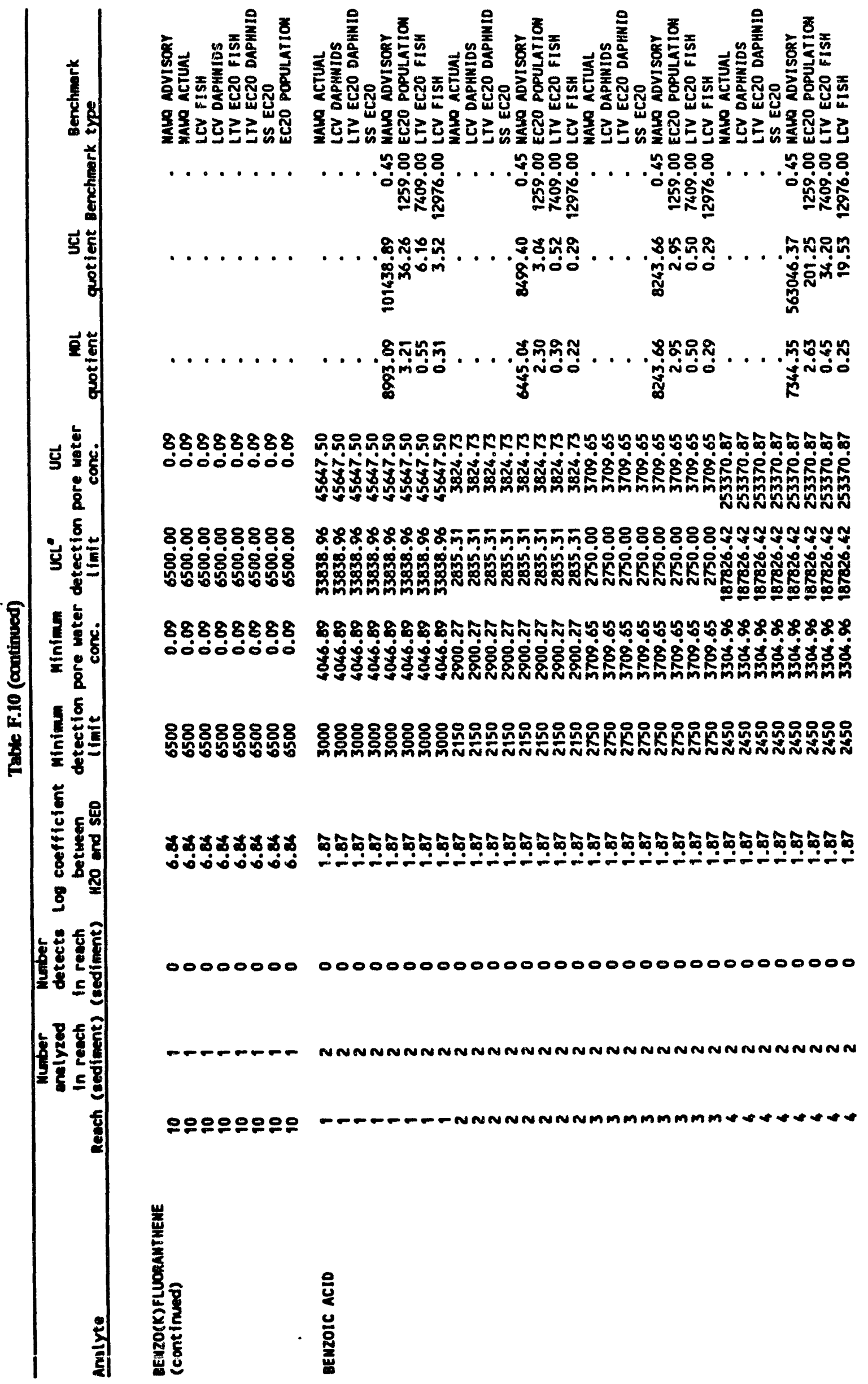


F-119

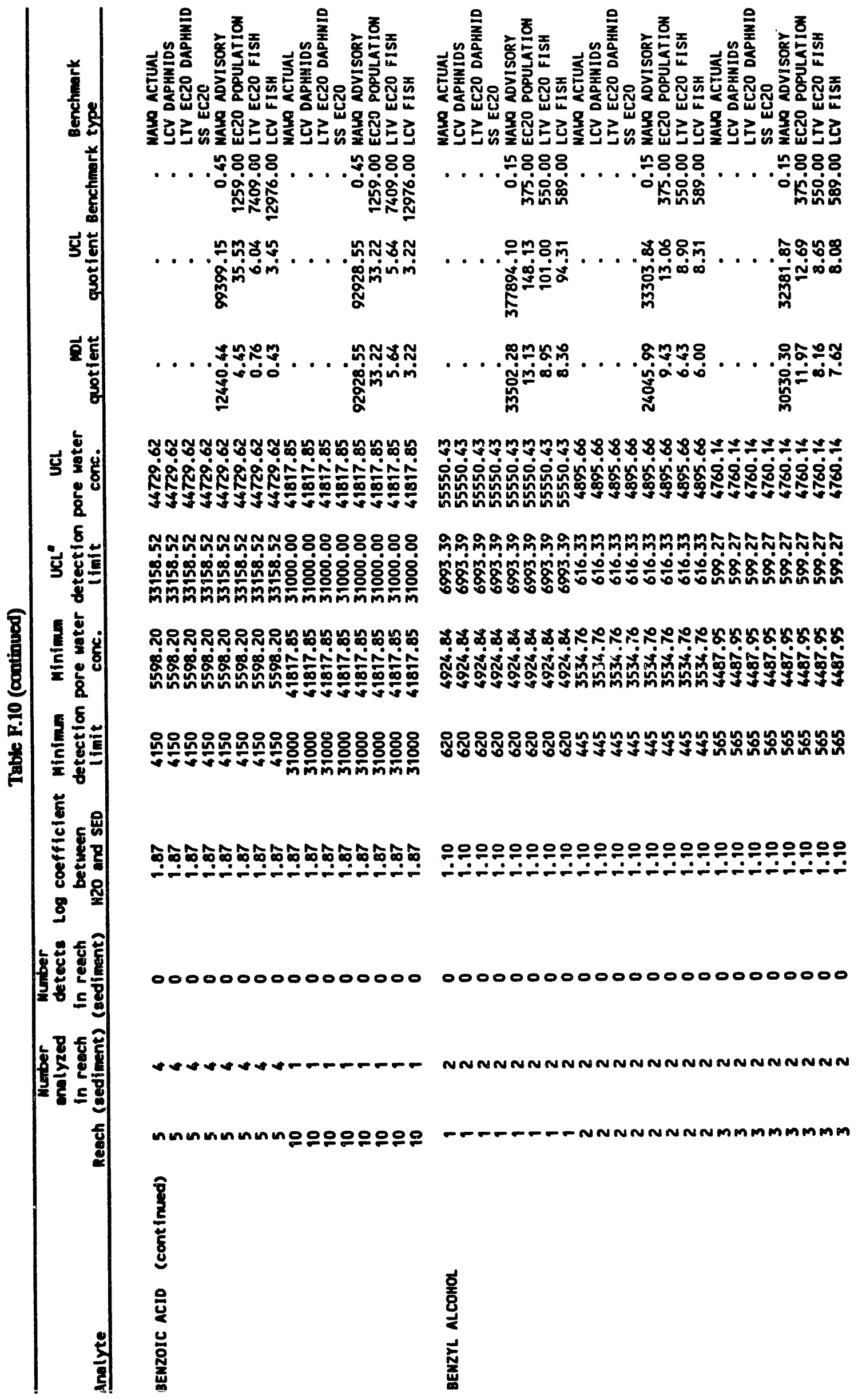


F-120

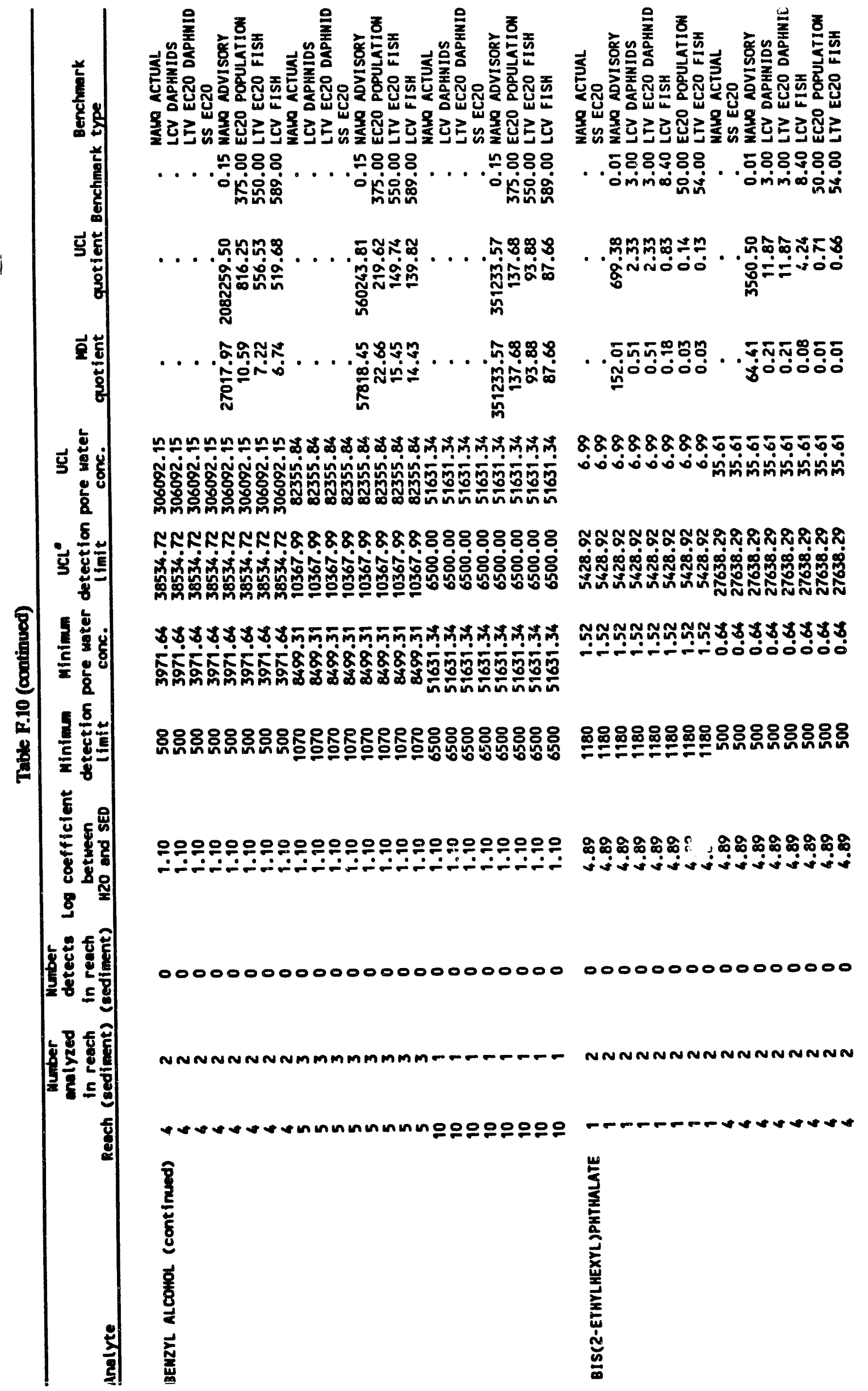




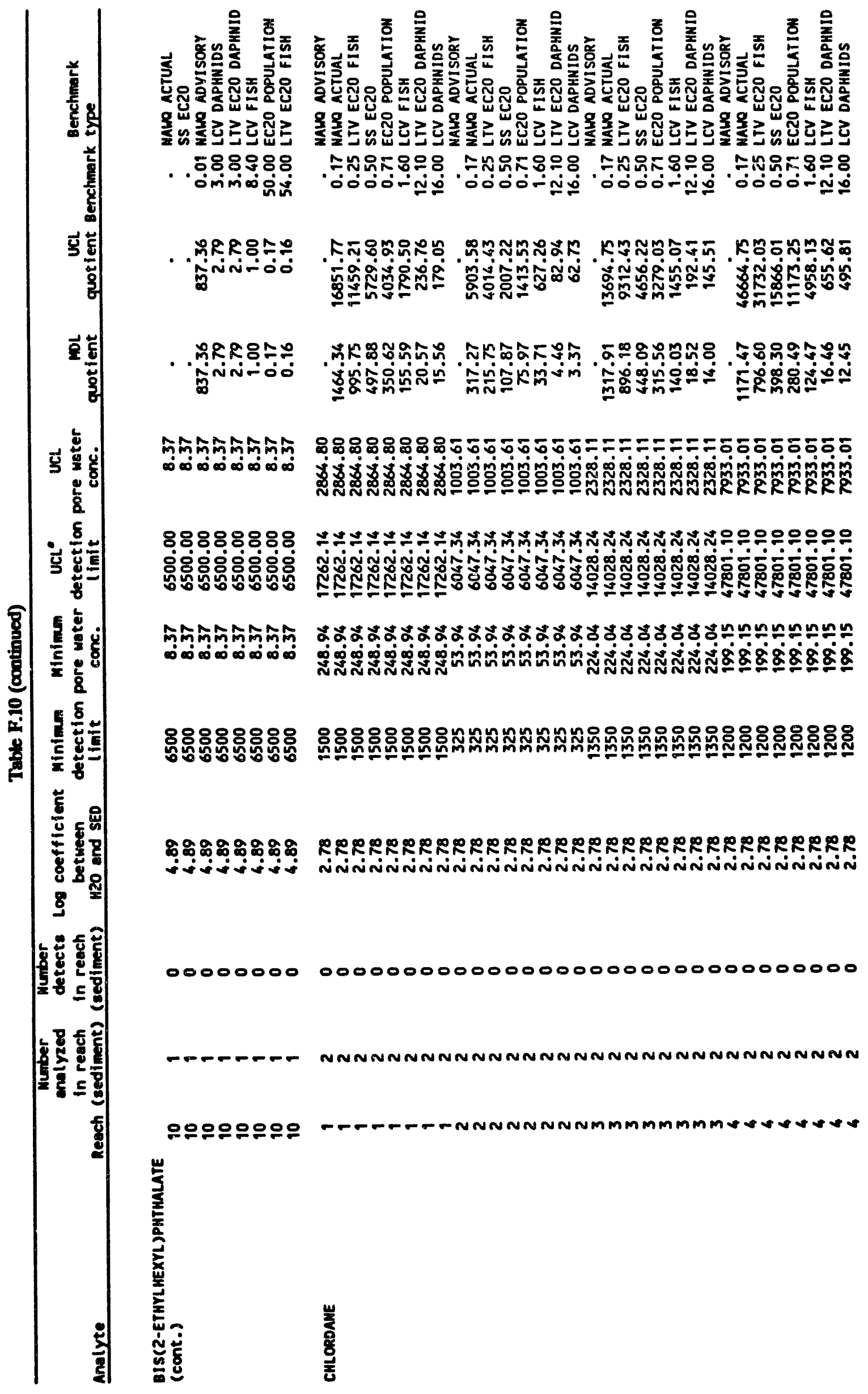




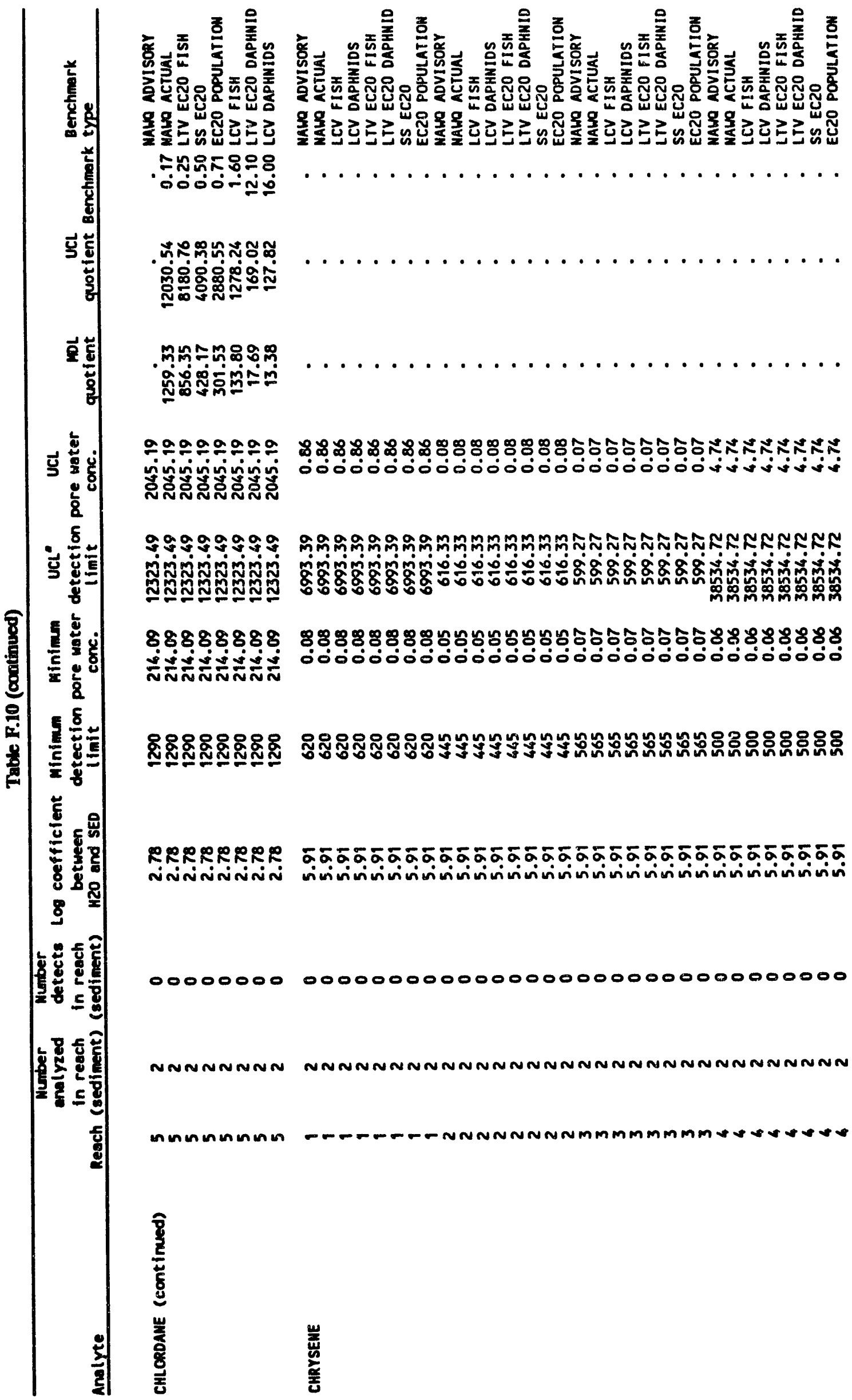


F-123

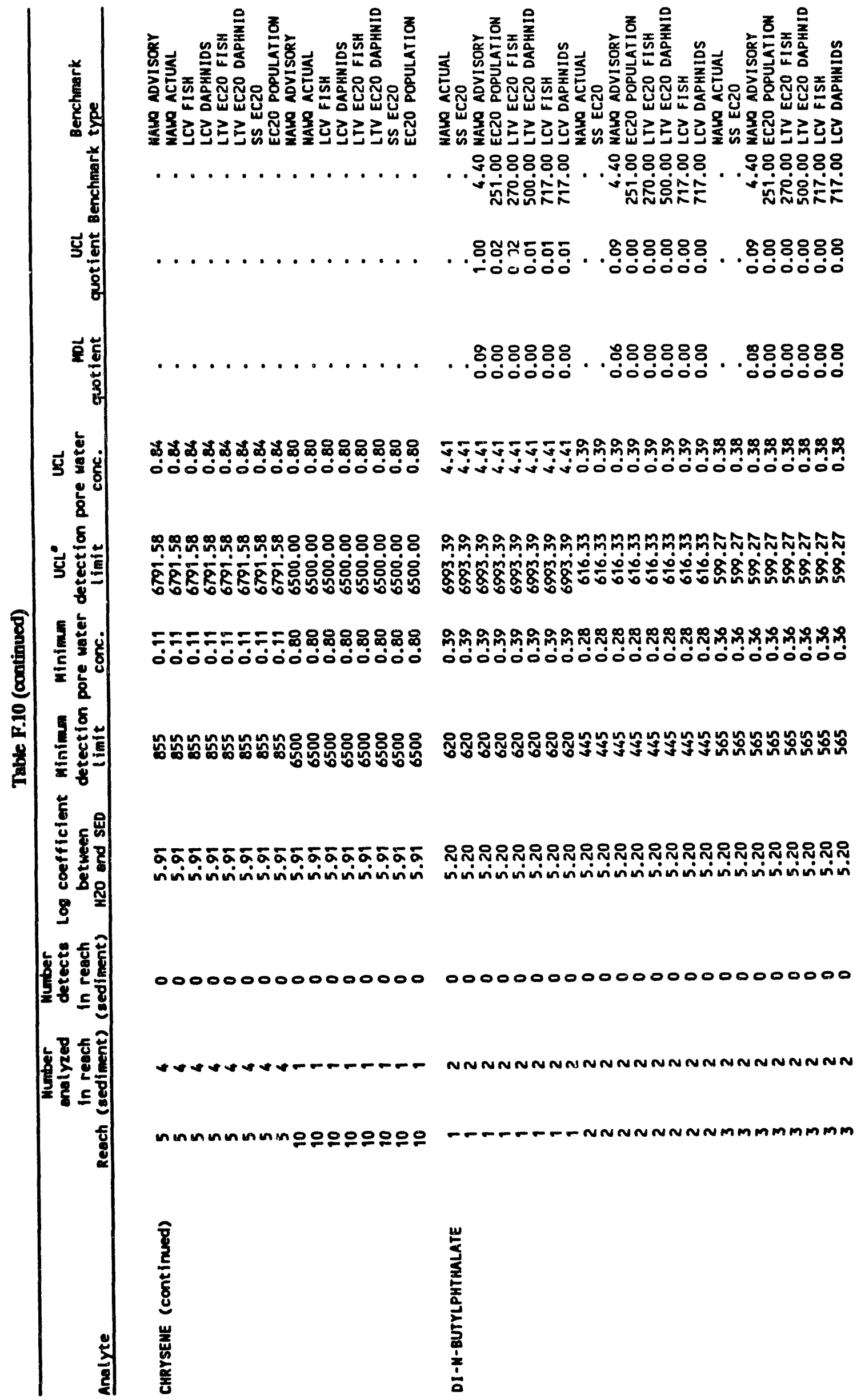


F-124

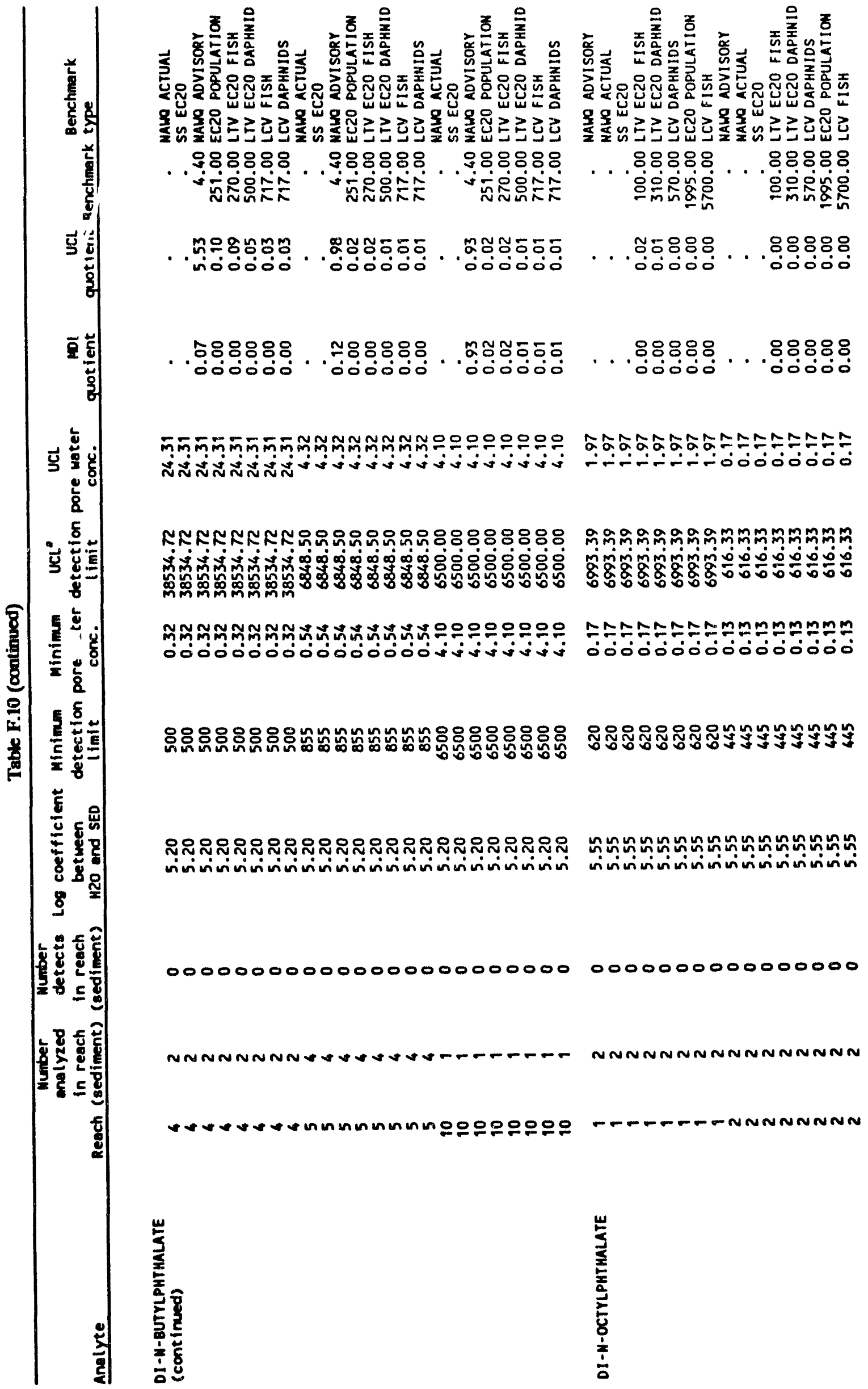




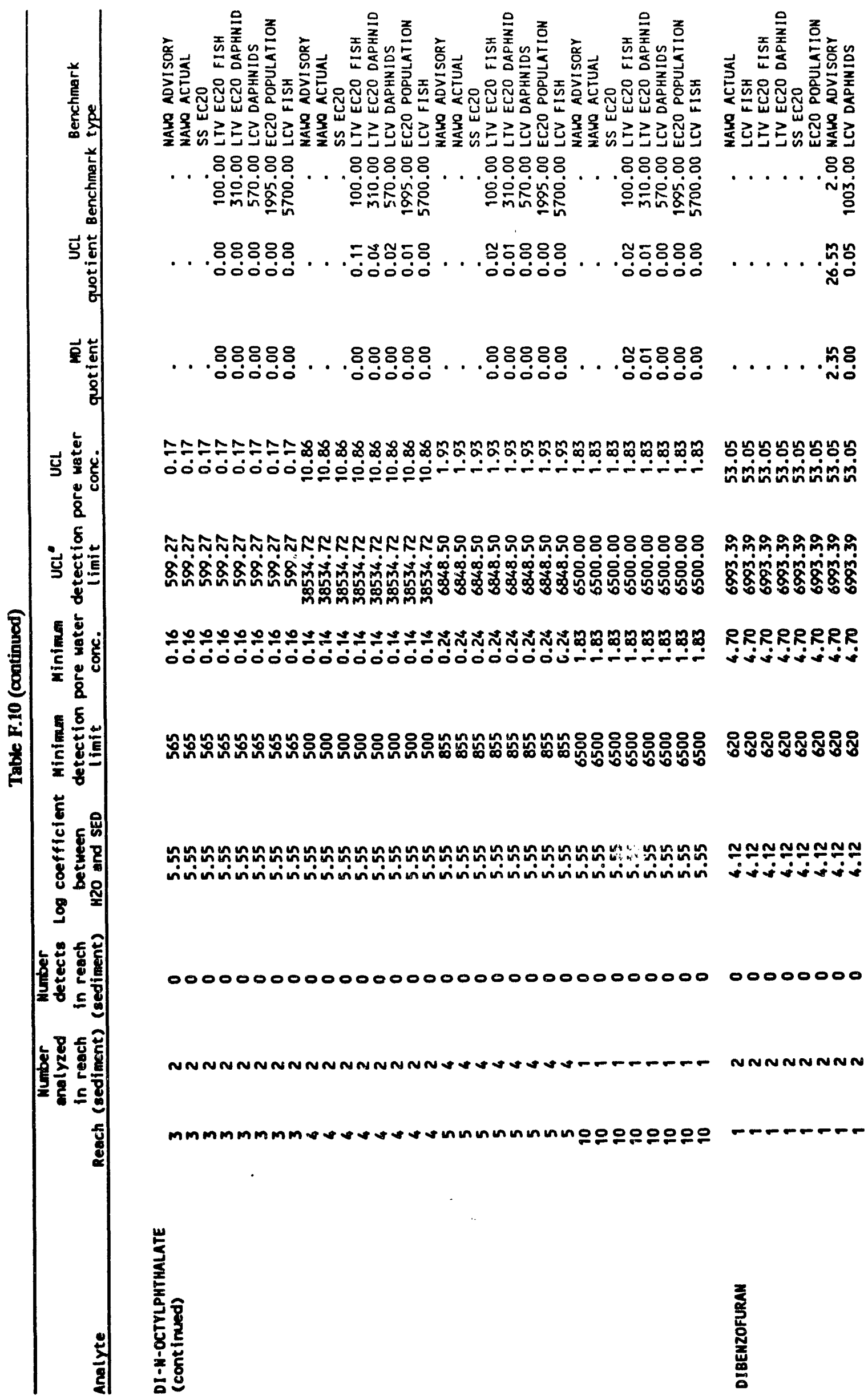


F-126

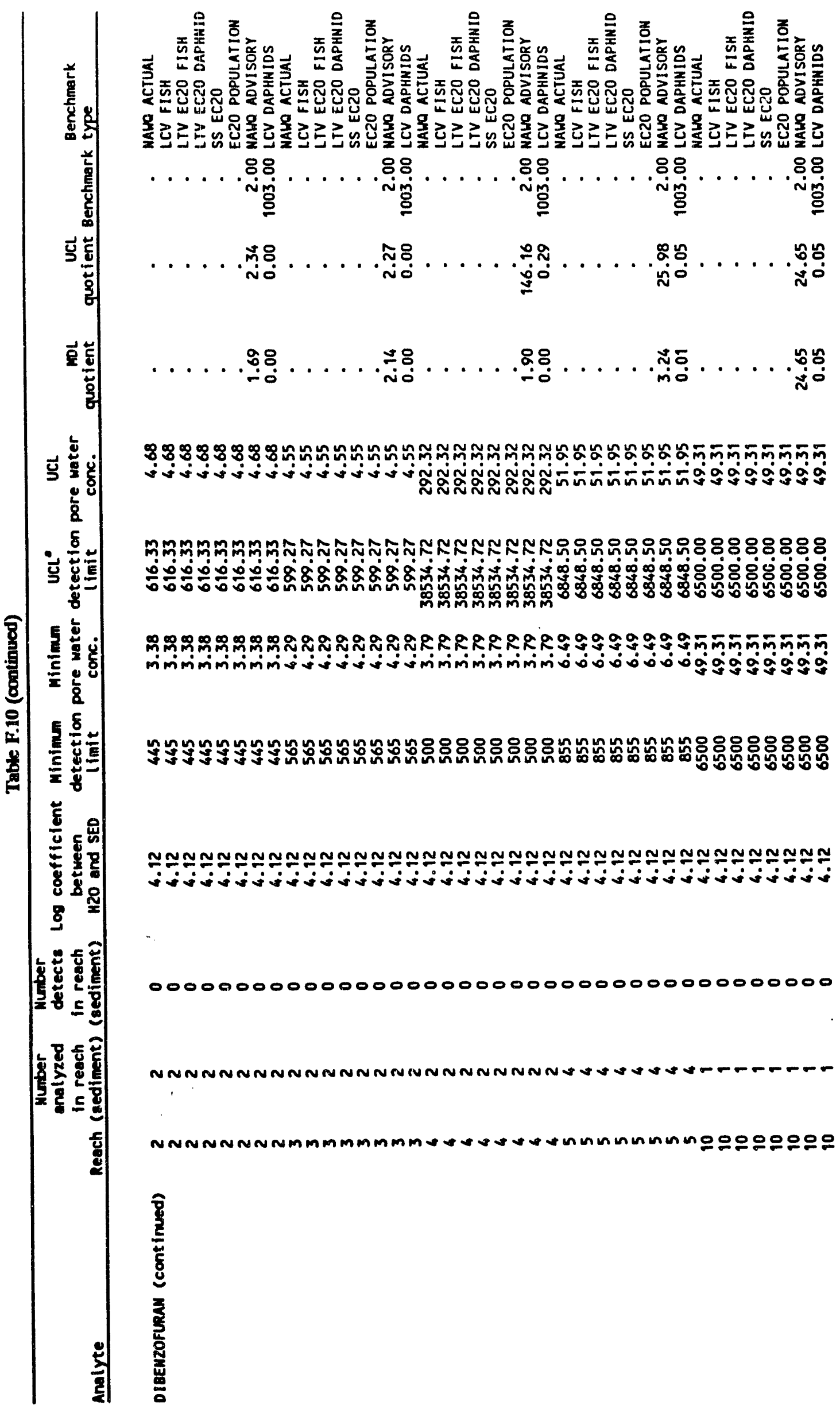




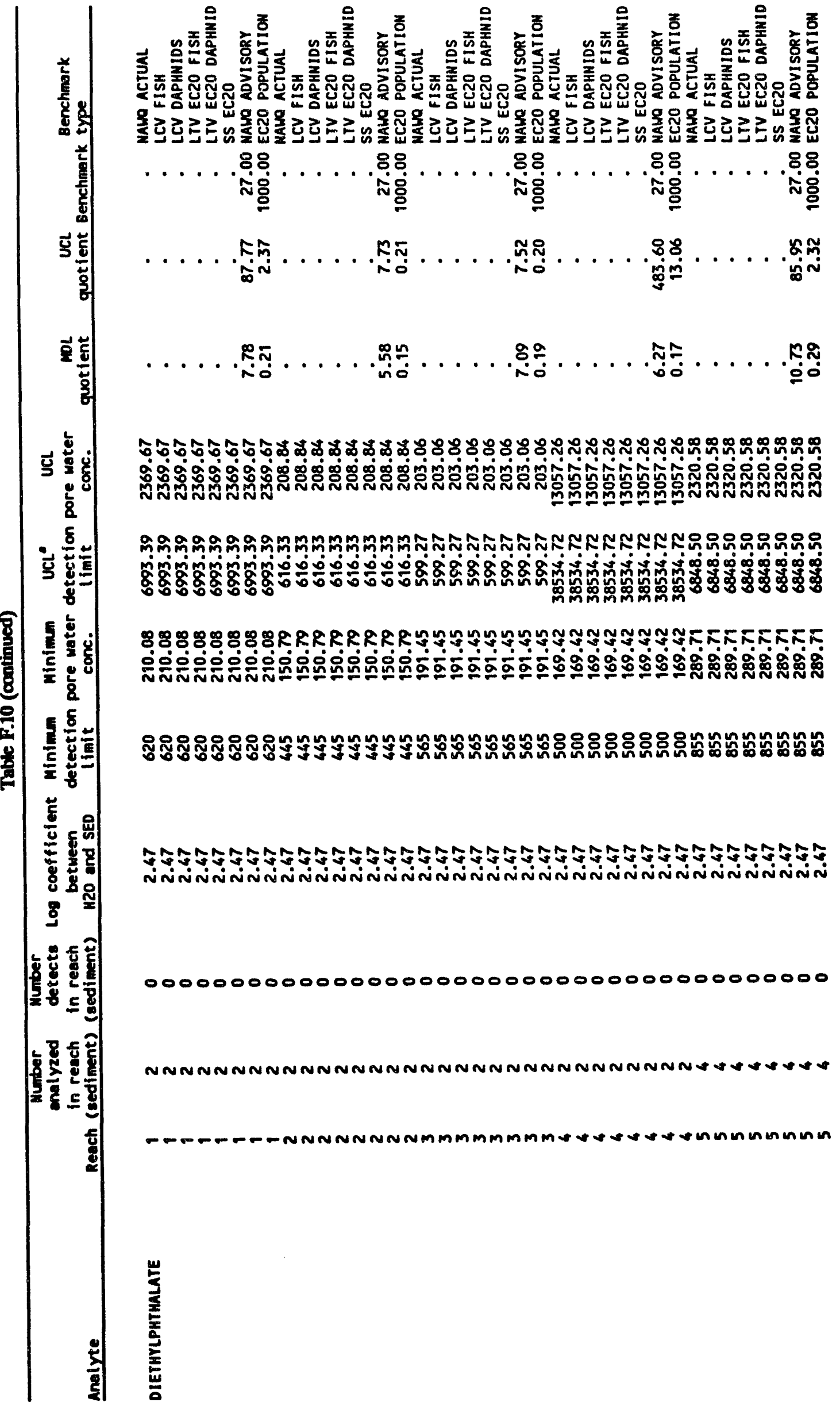


F-128

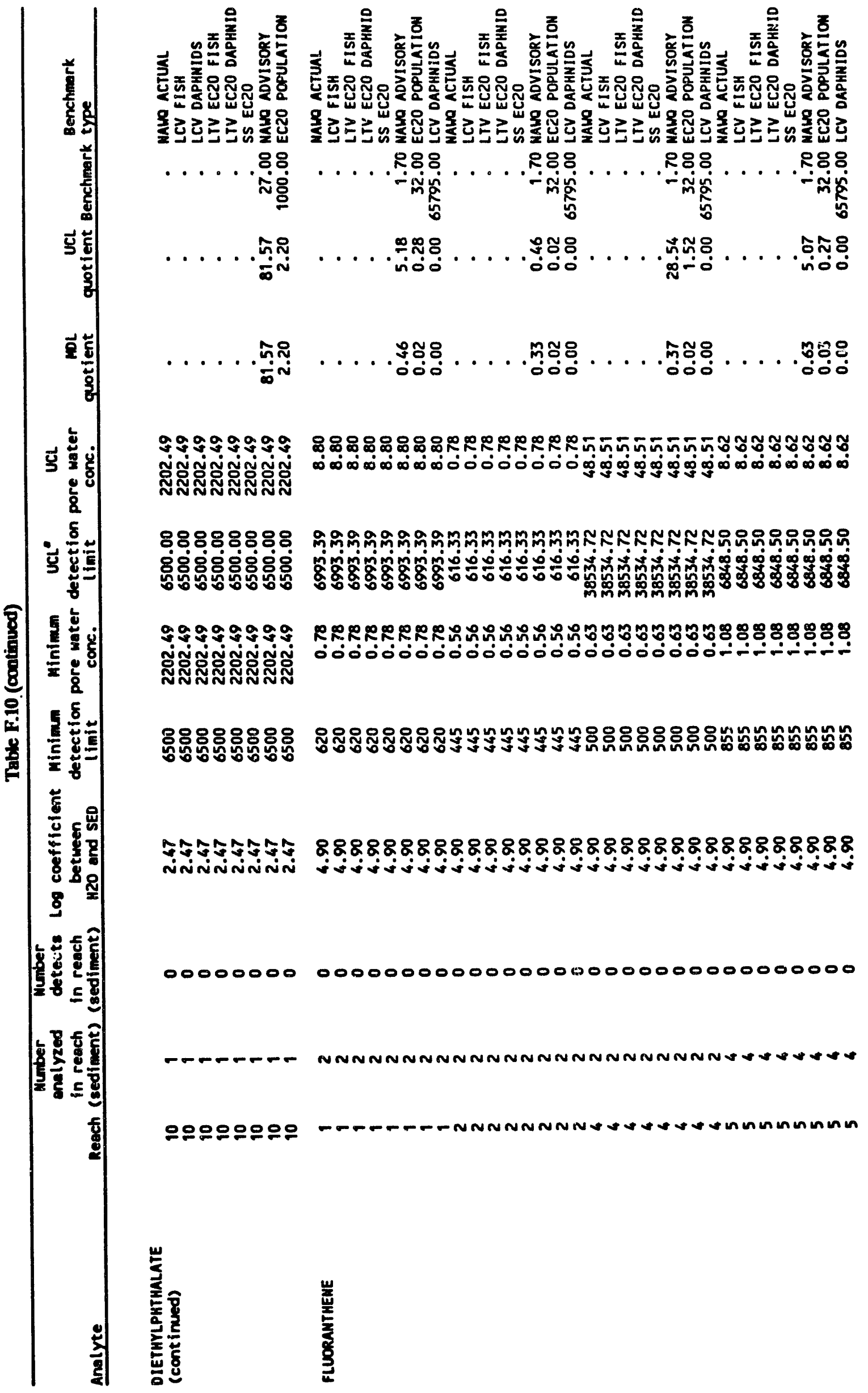


F-129

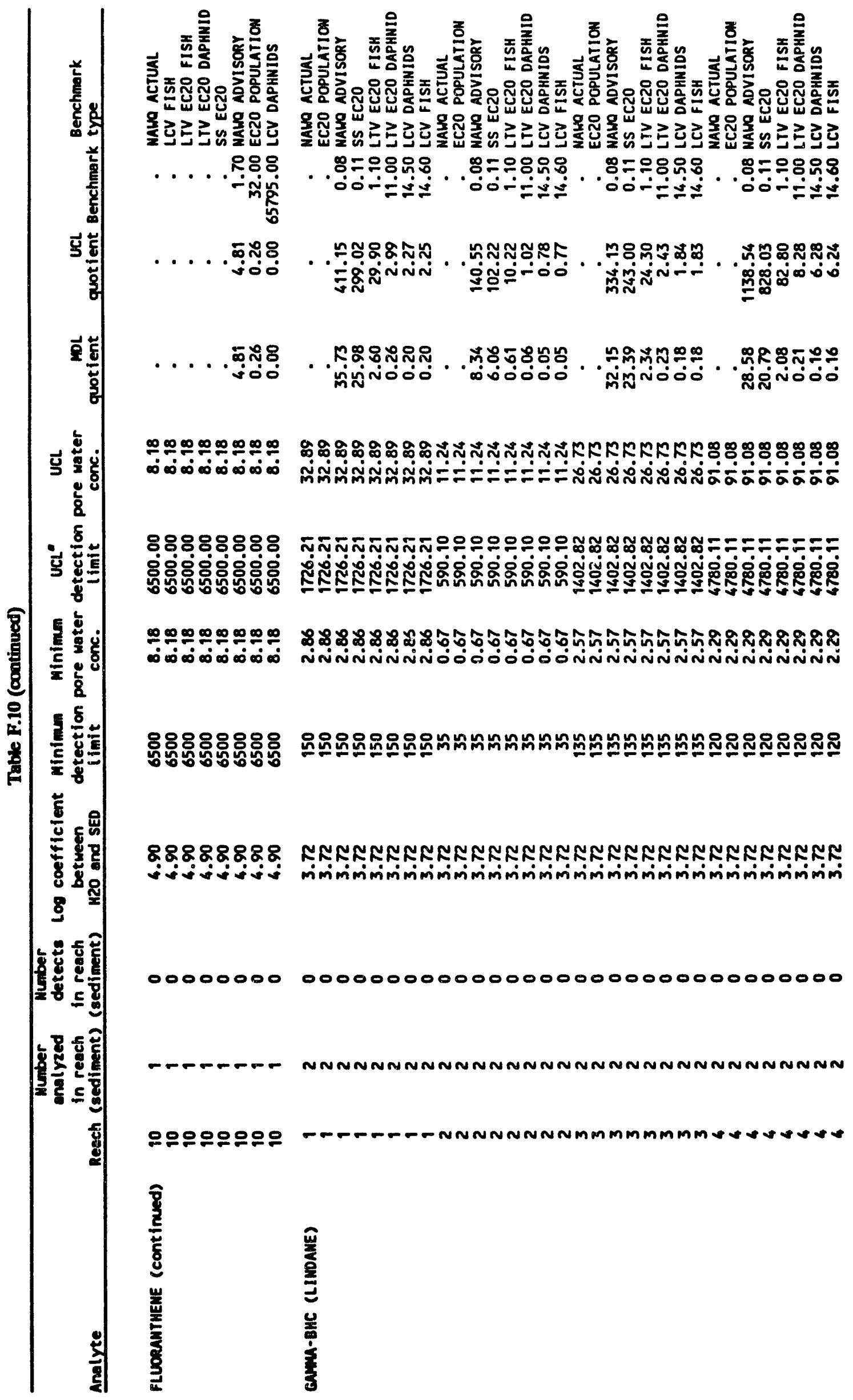


F-130

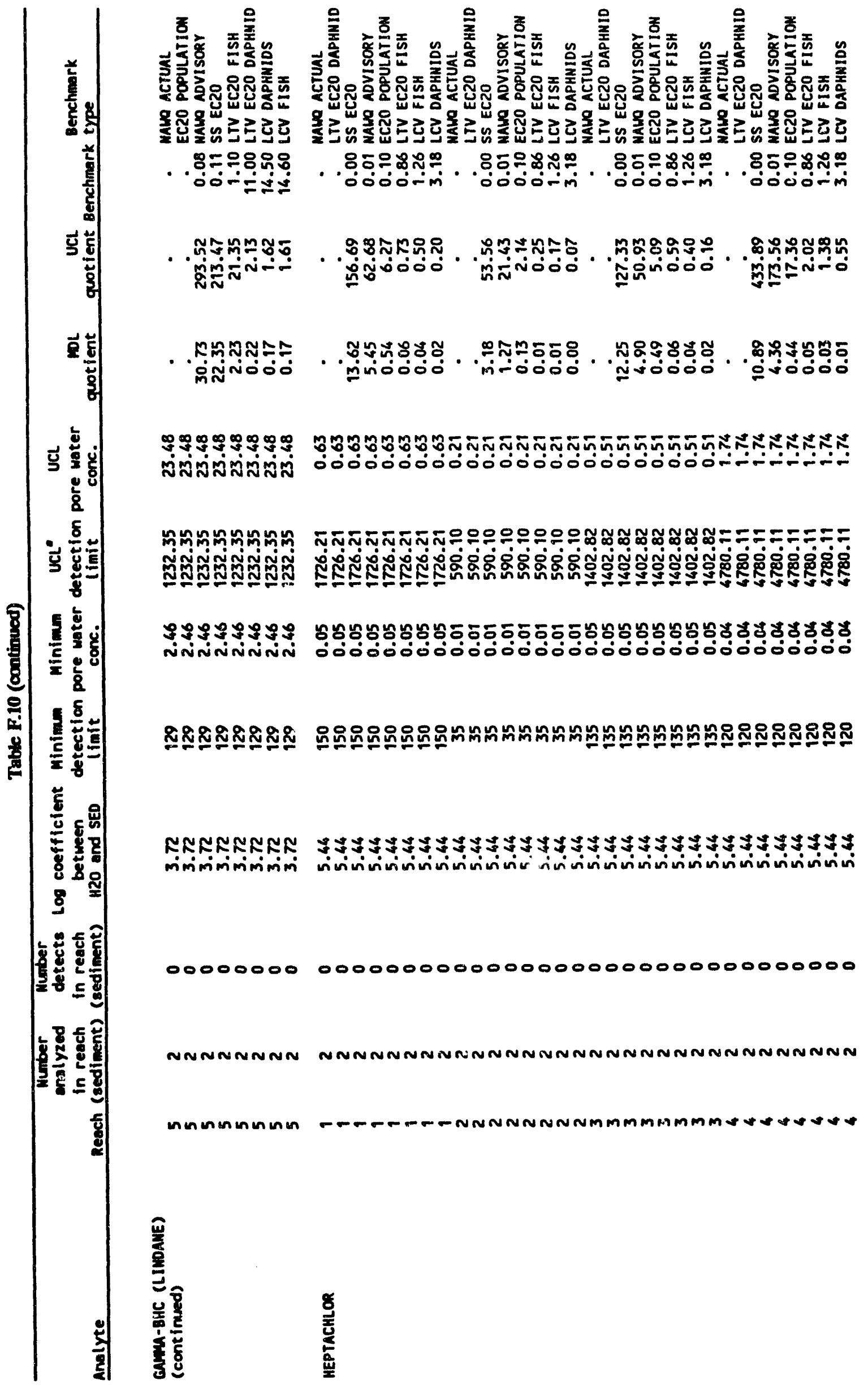




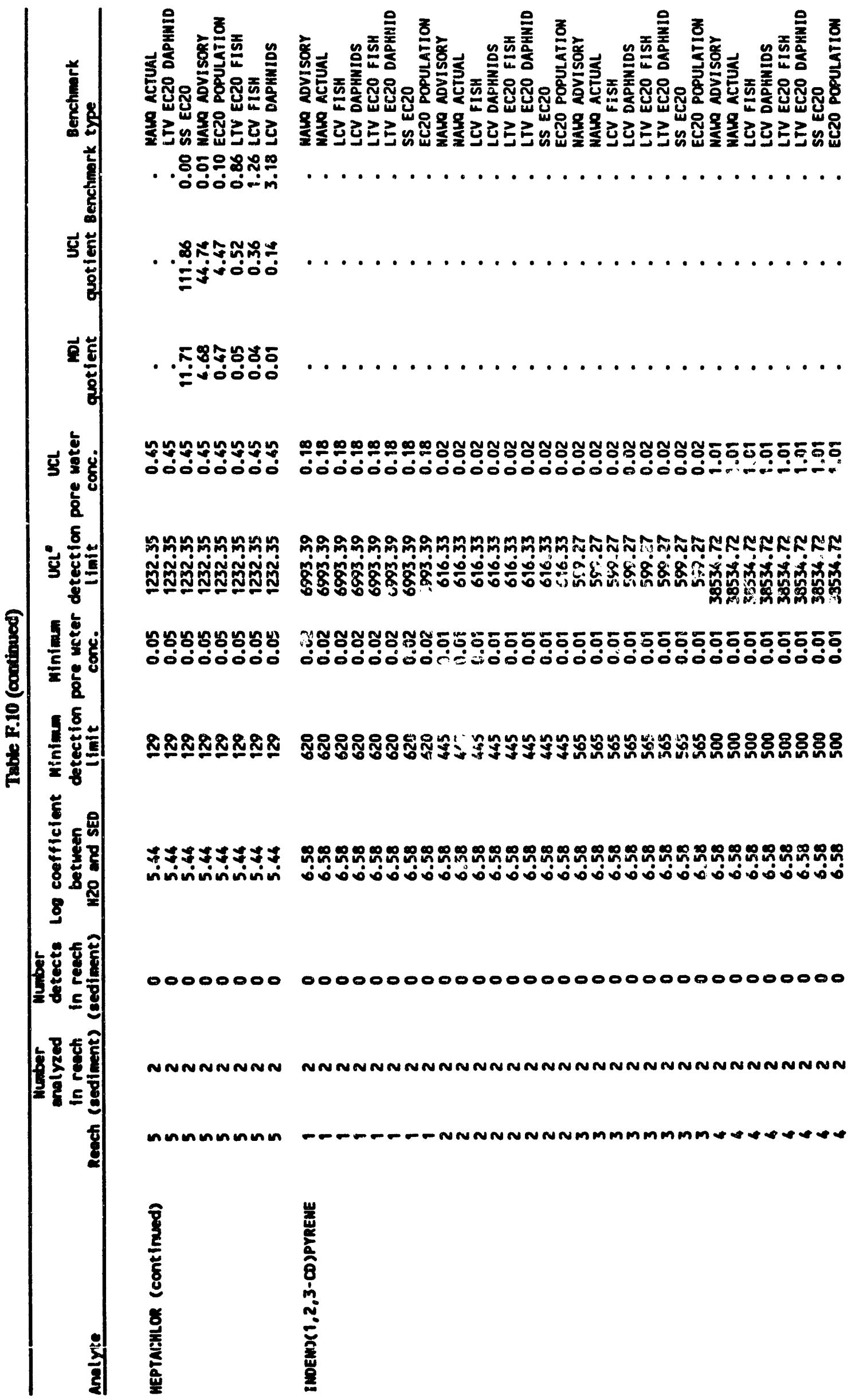


F-132

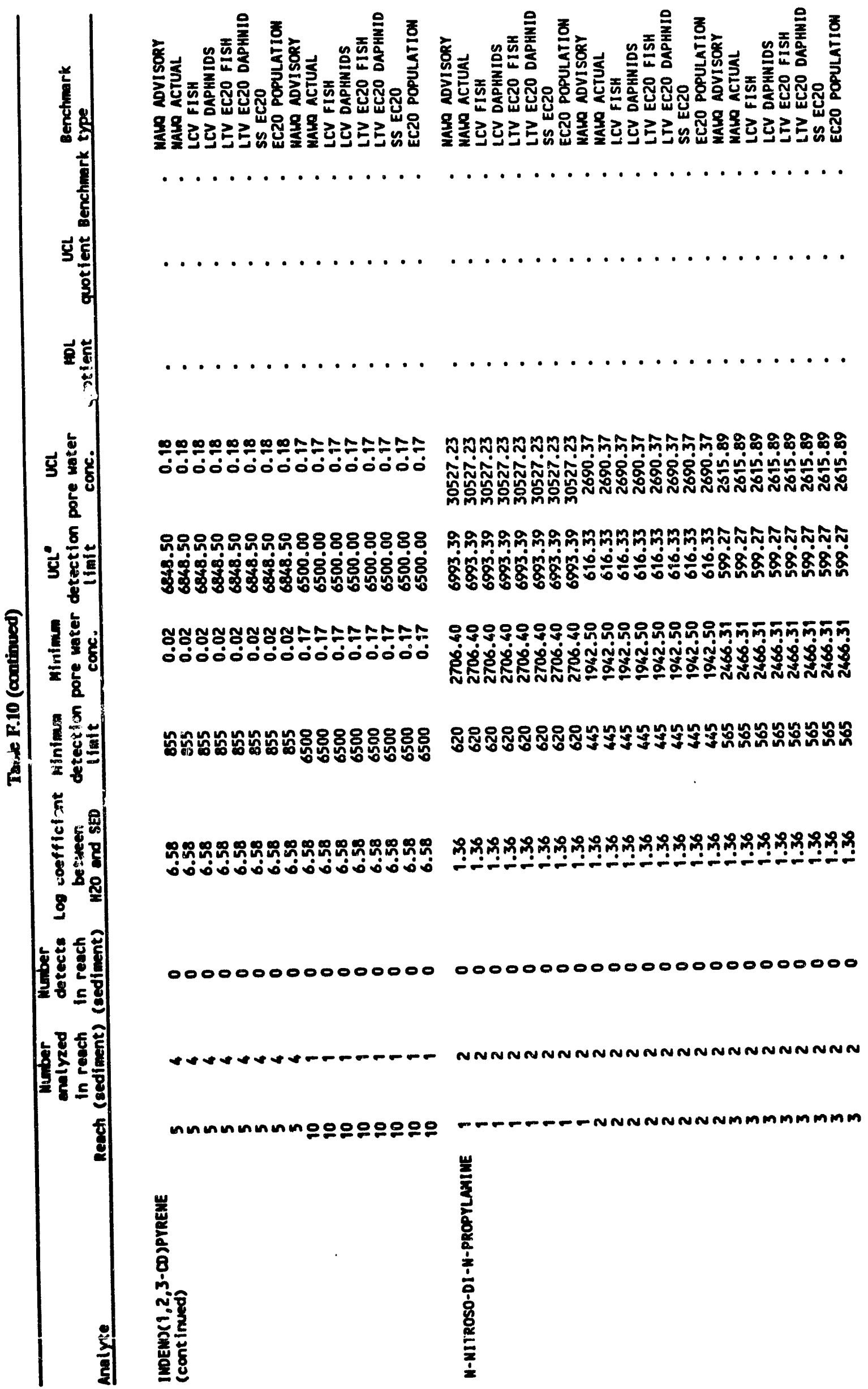


F-133

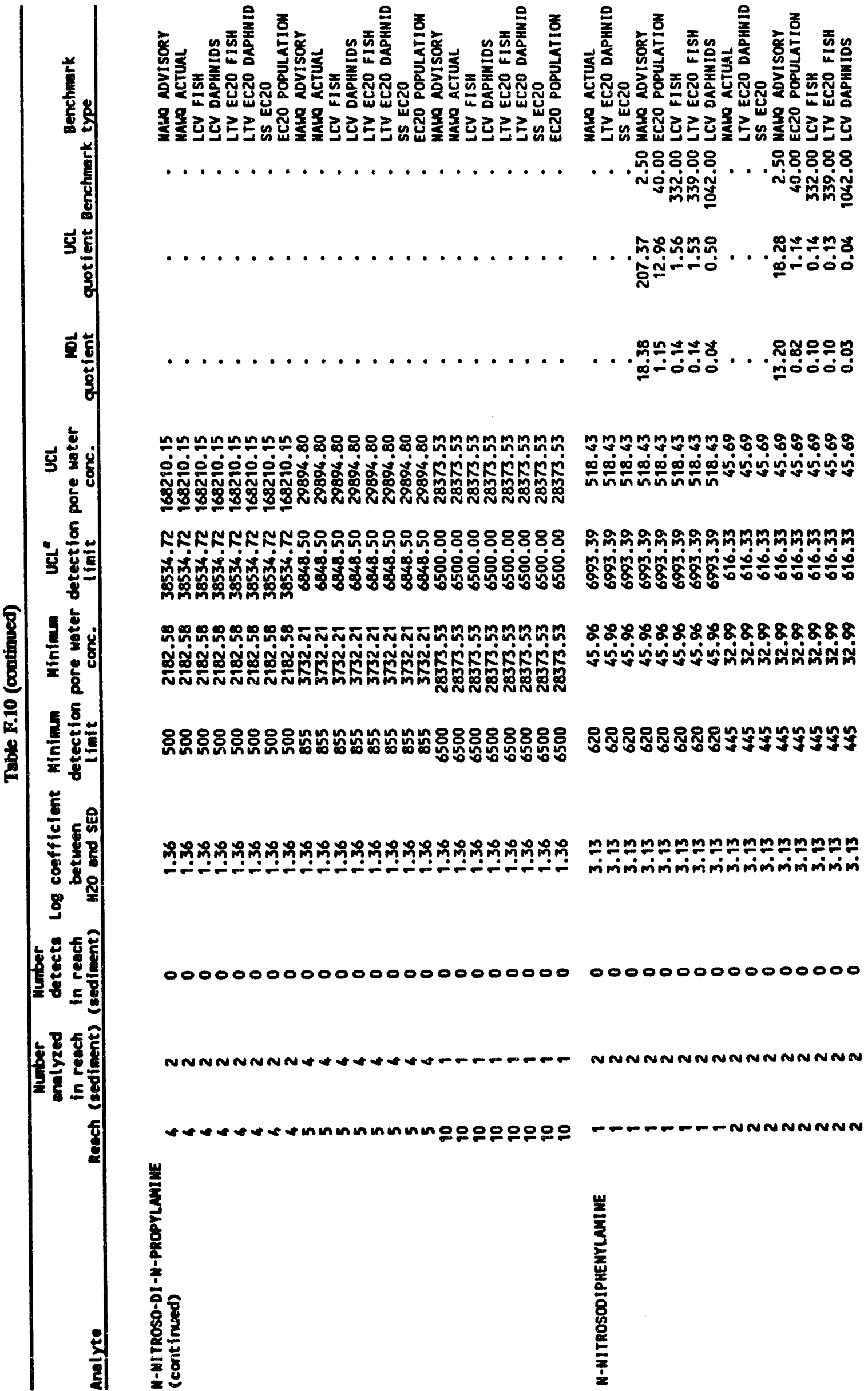


F-134

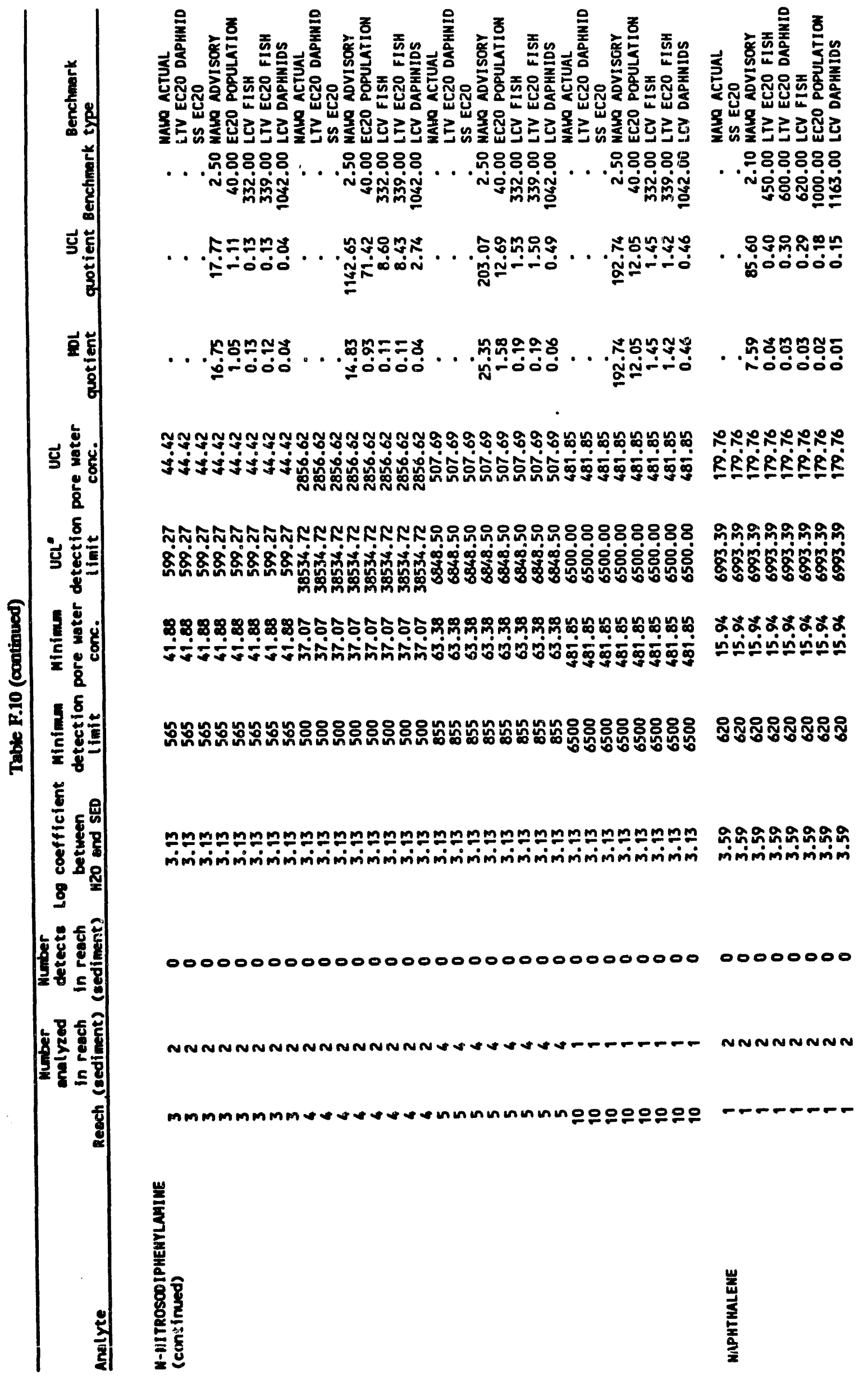




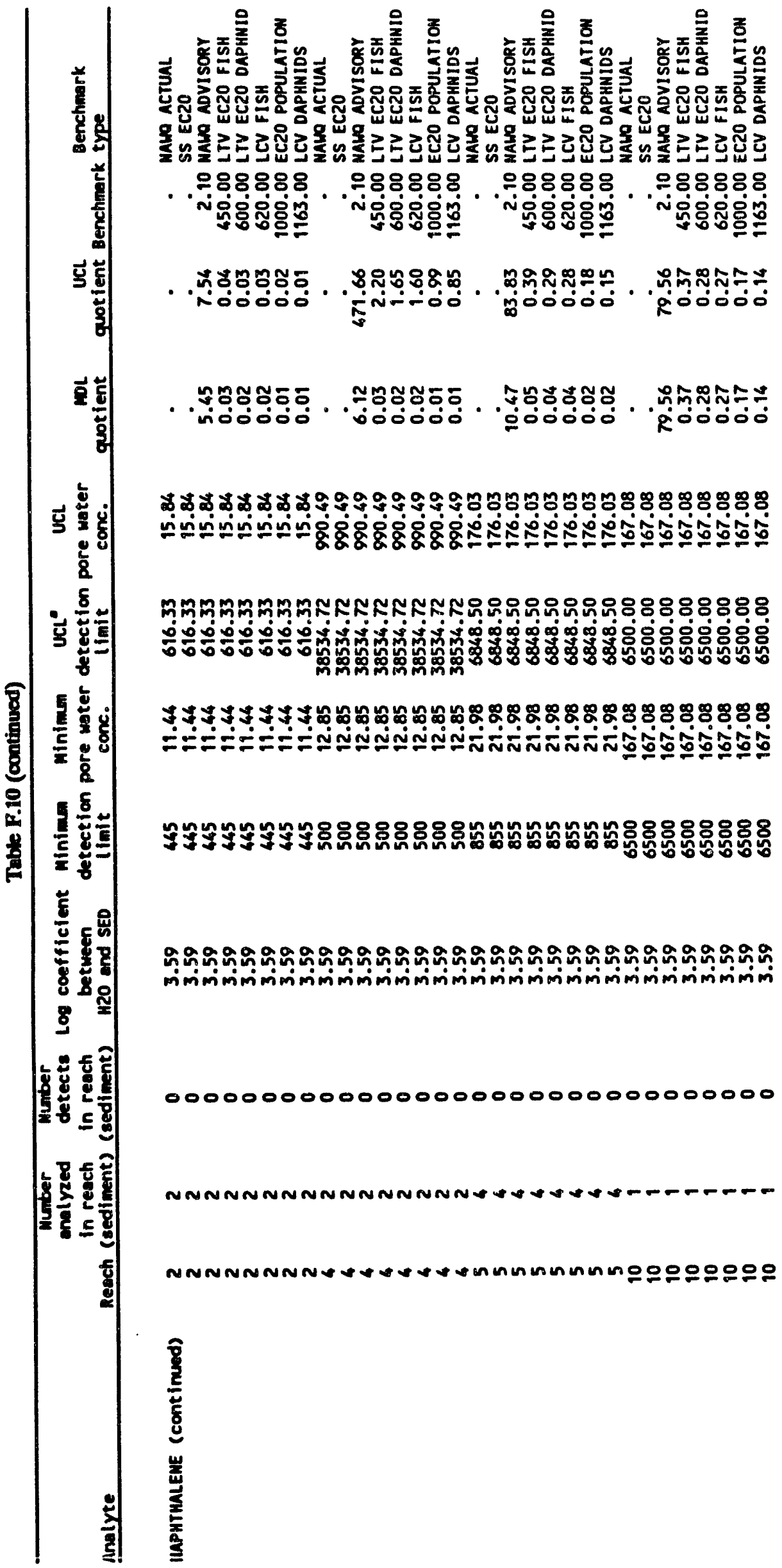




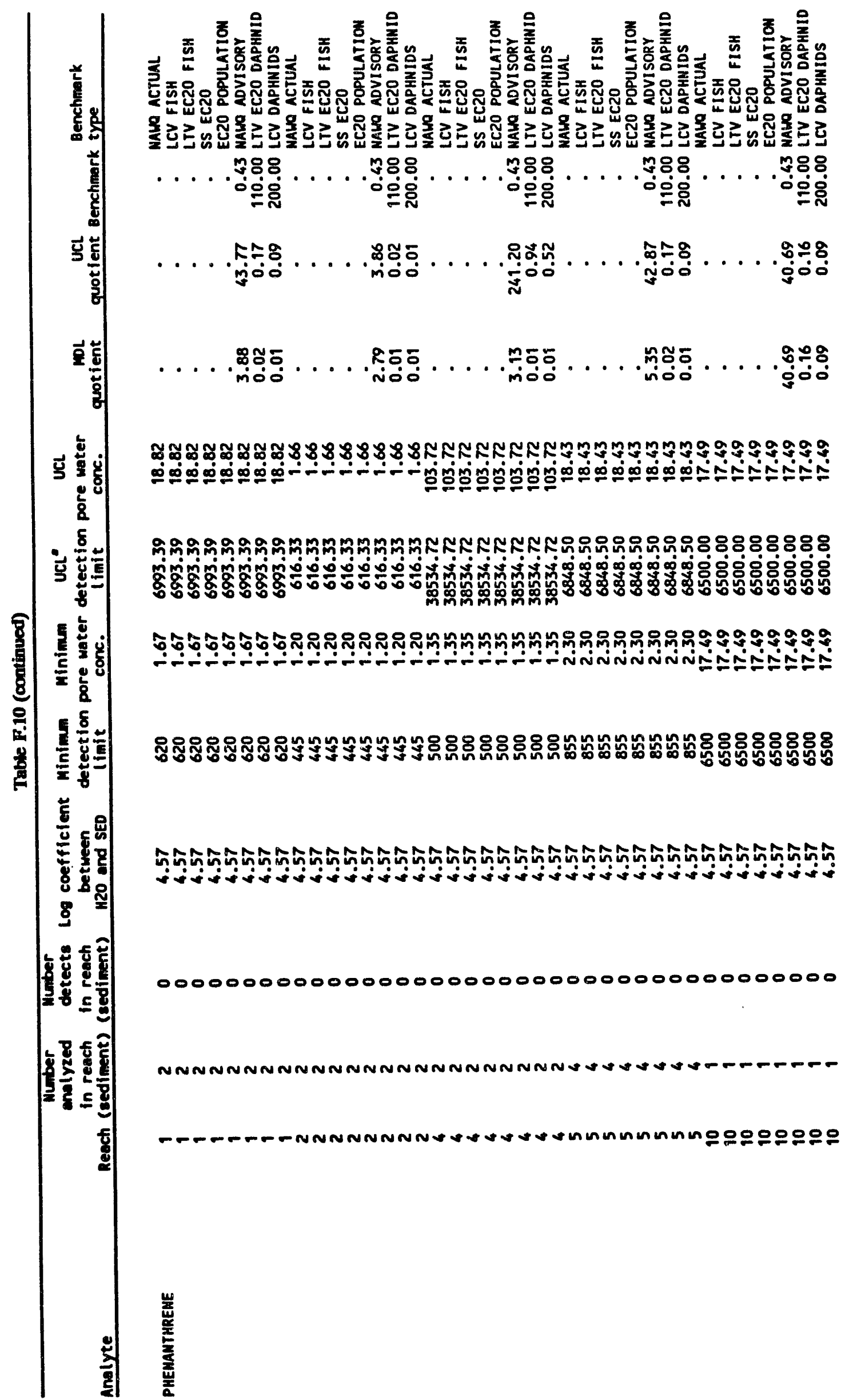




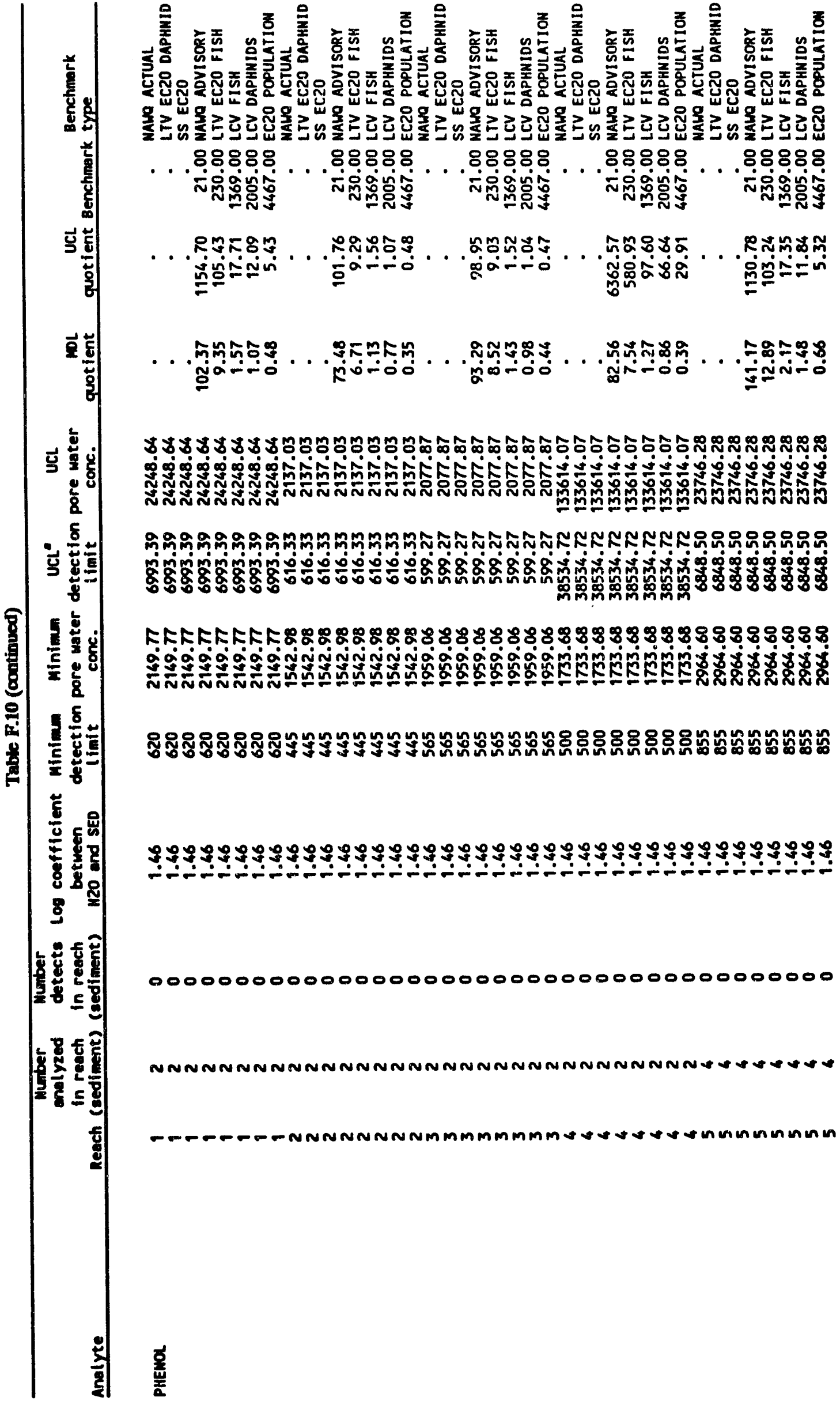




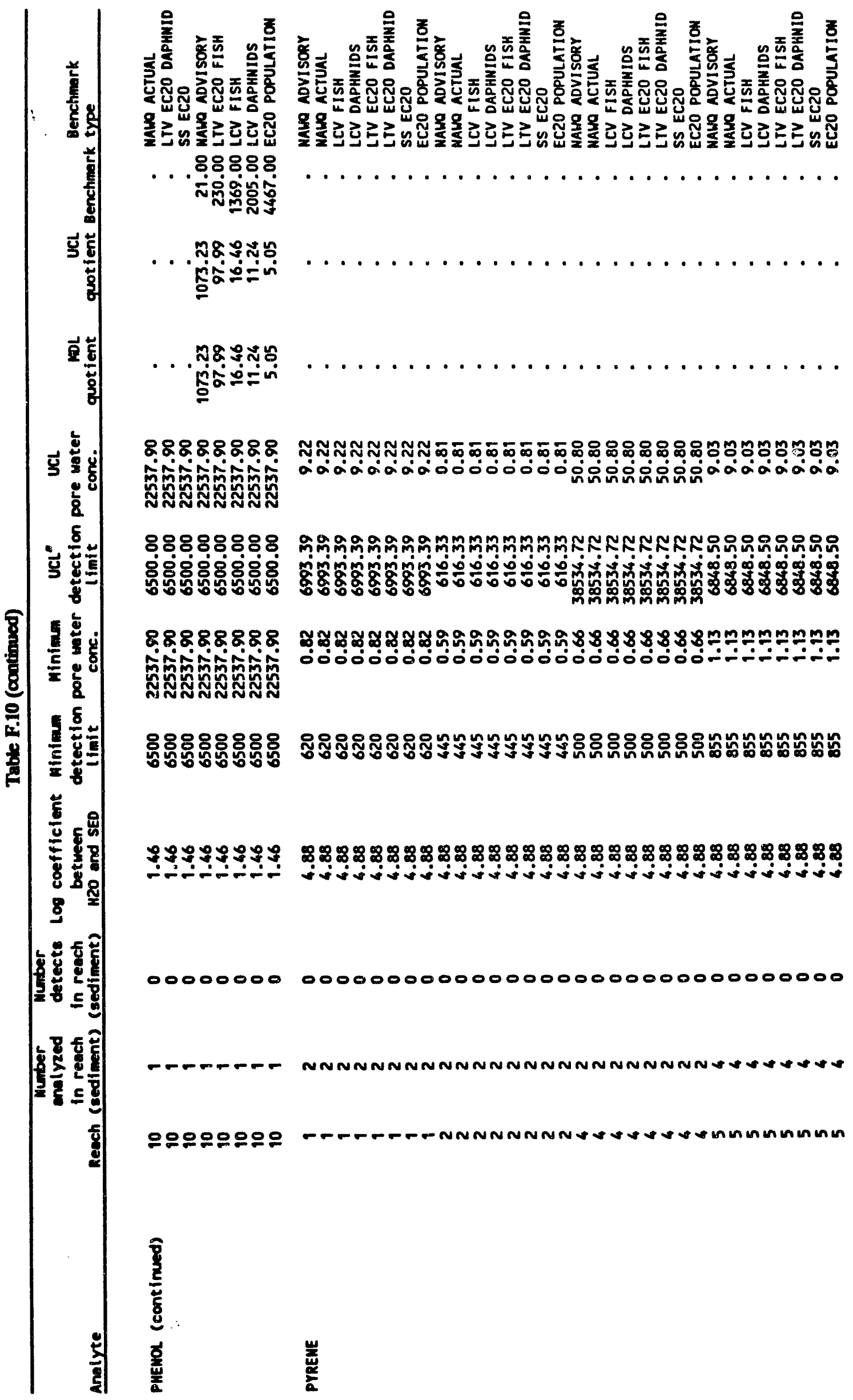




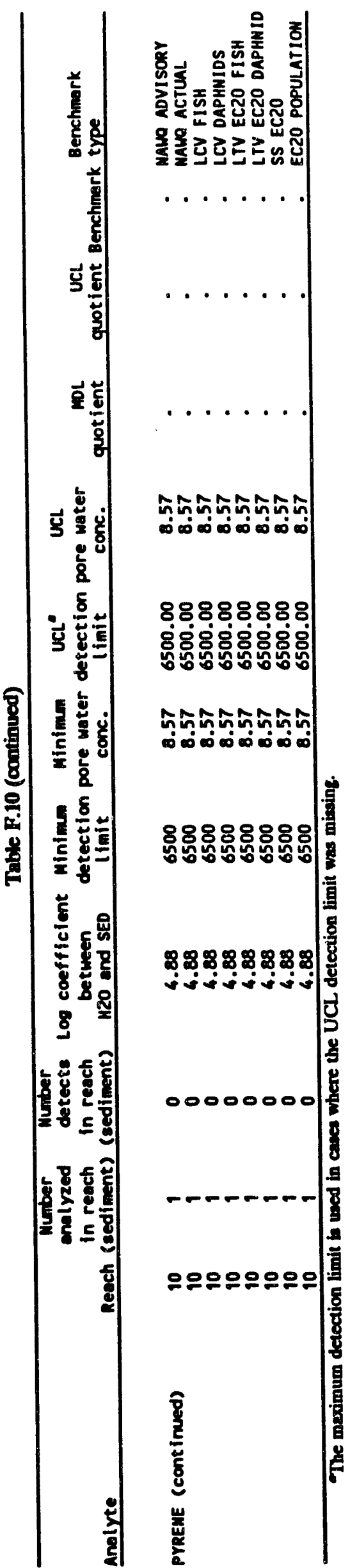


F-140

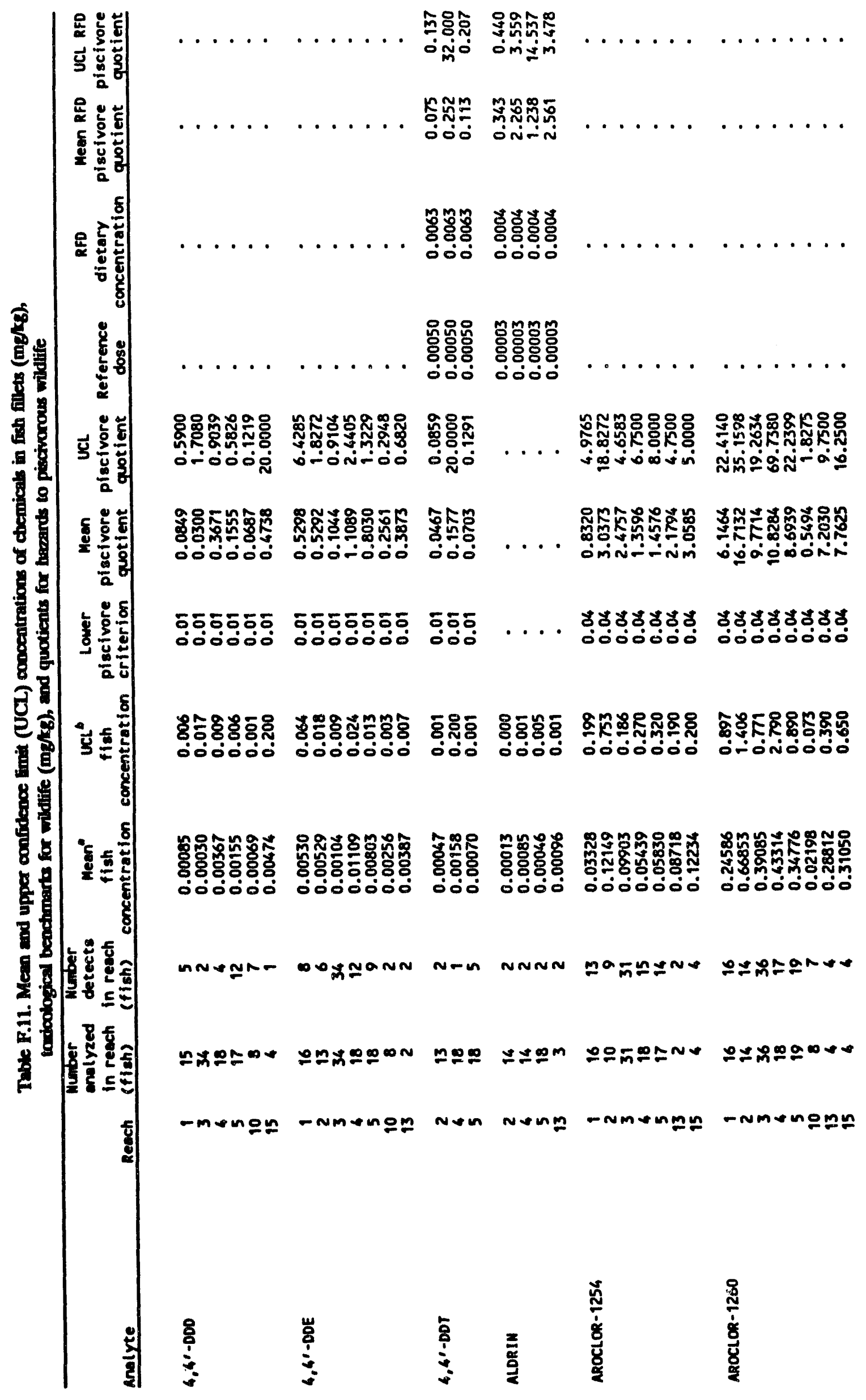




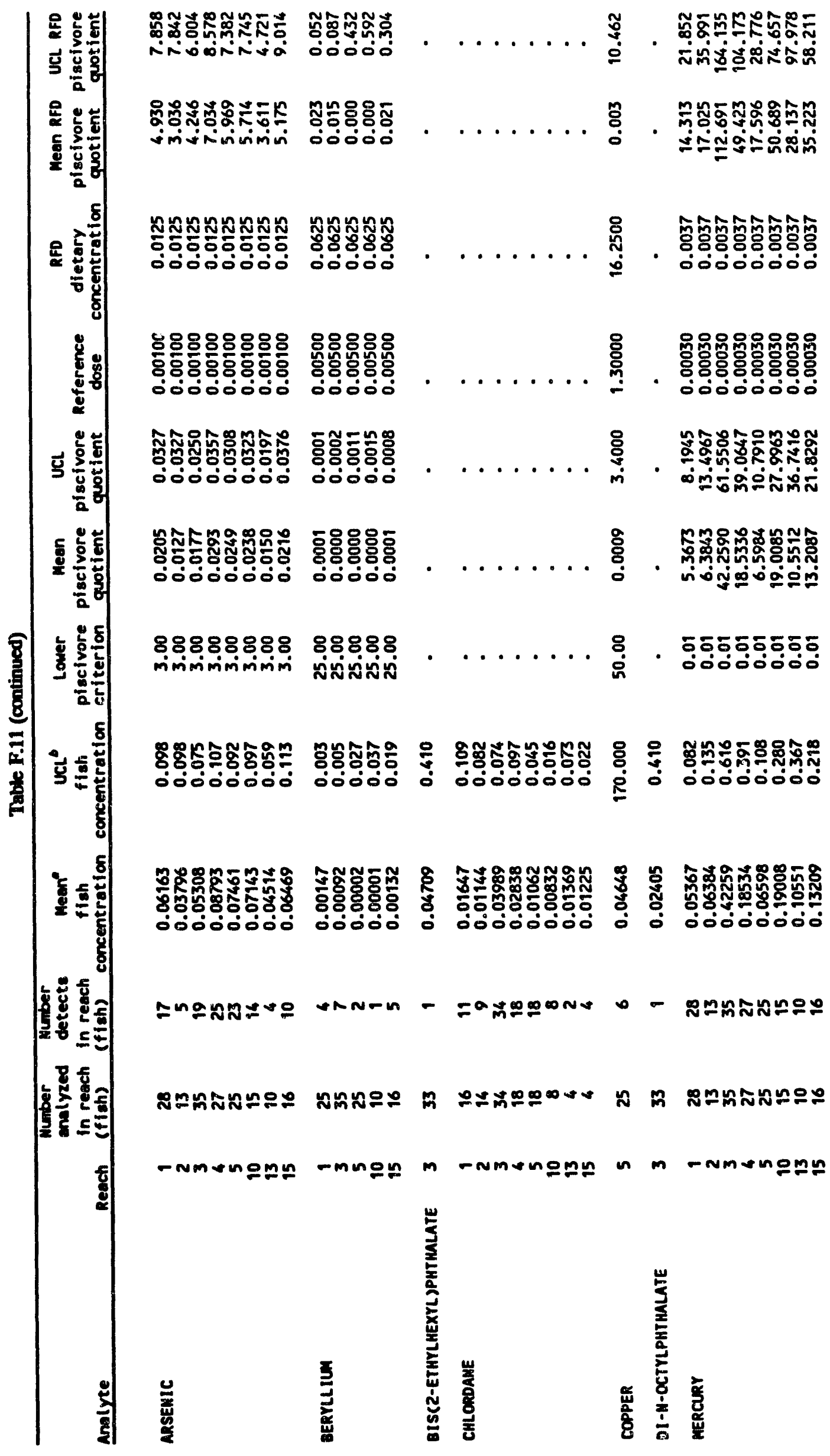


F-142

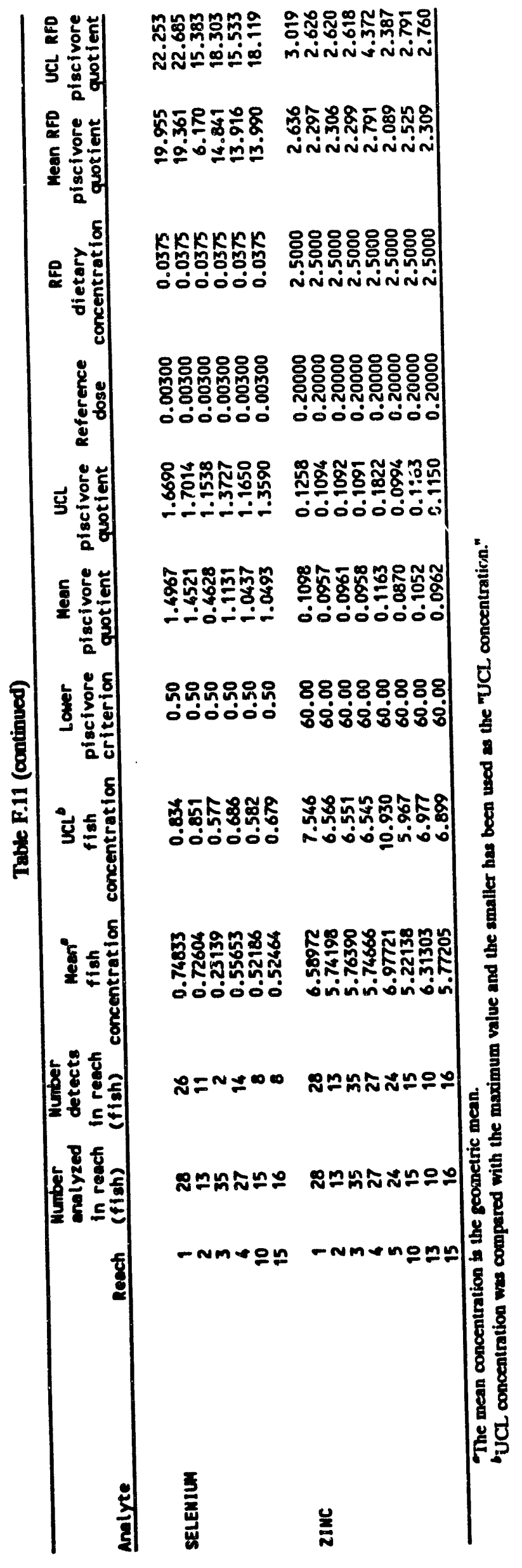




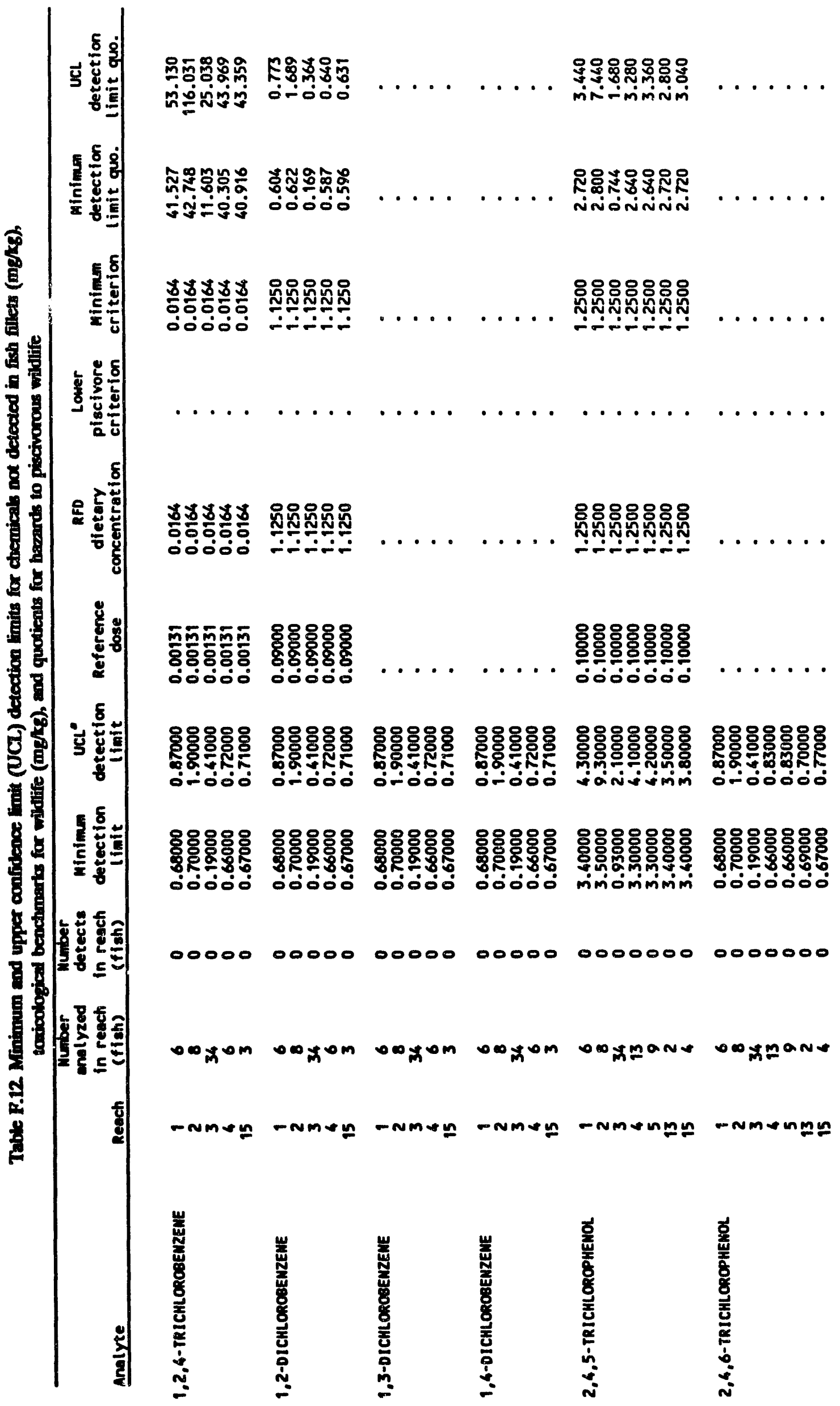




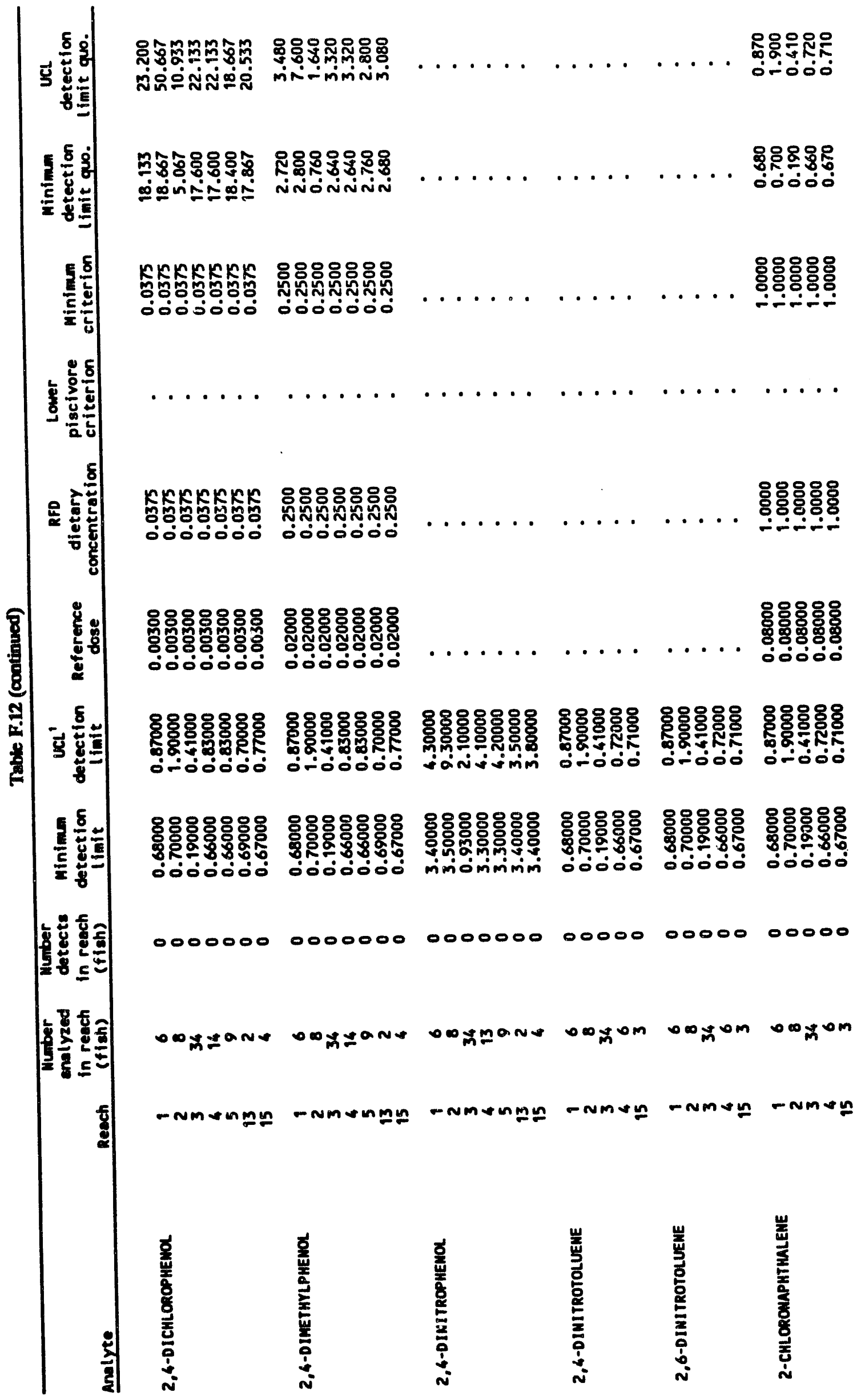




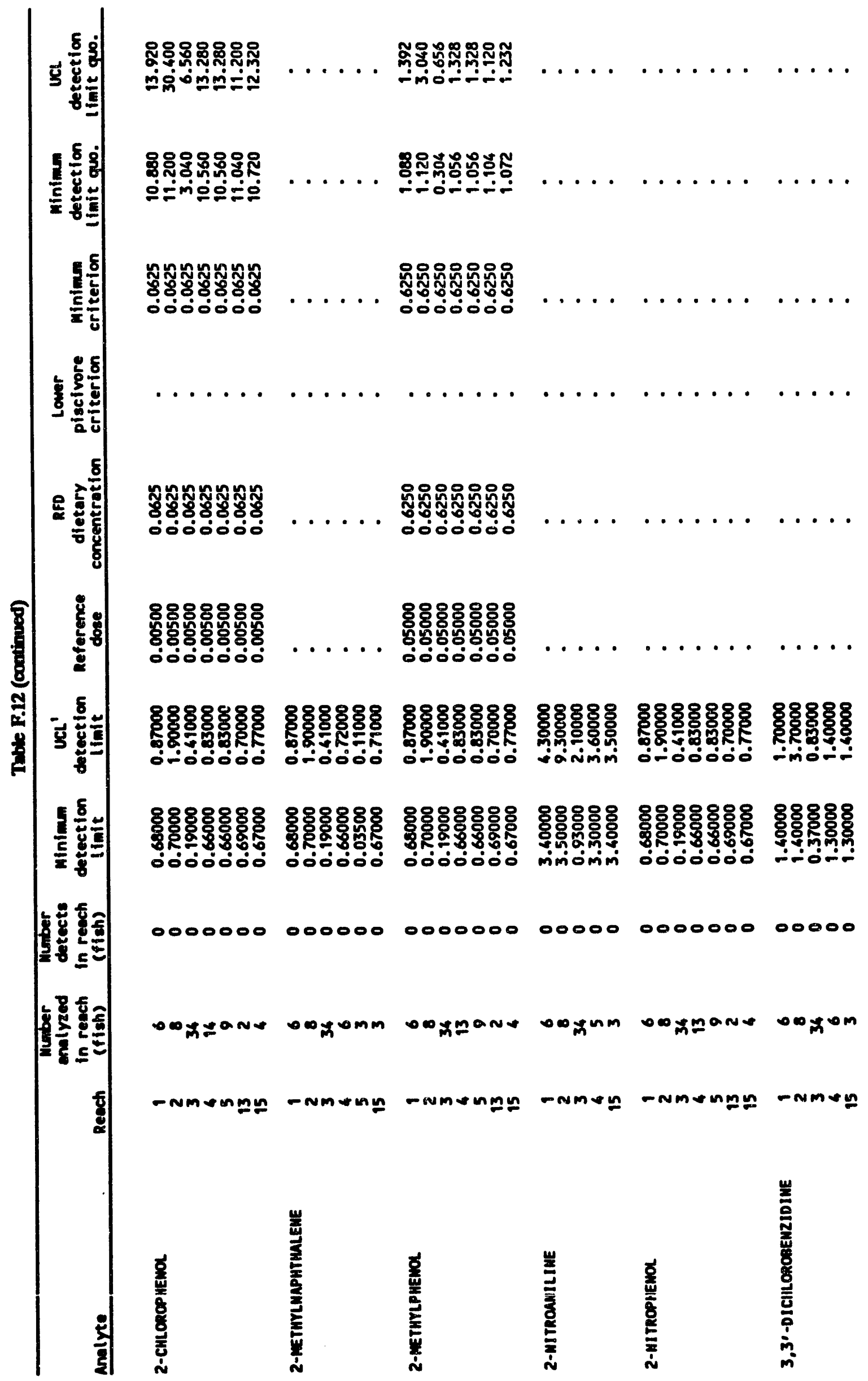




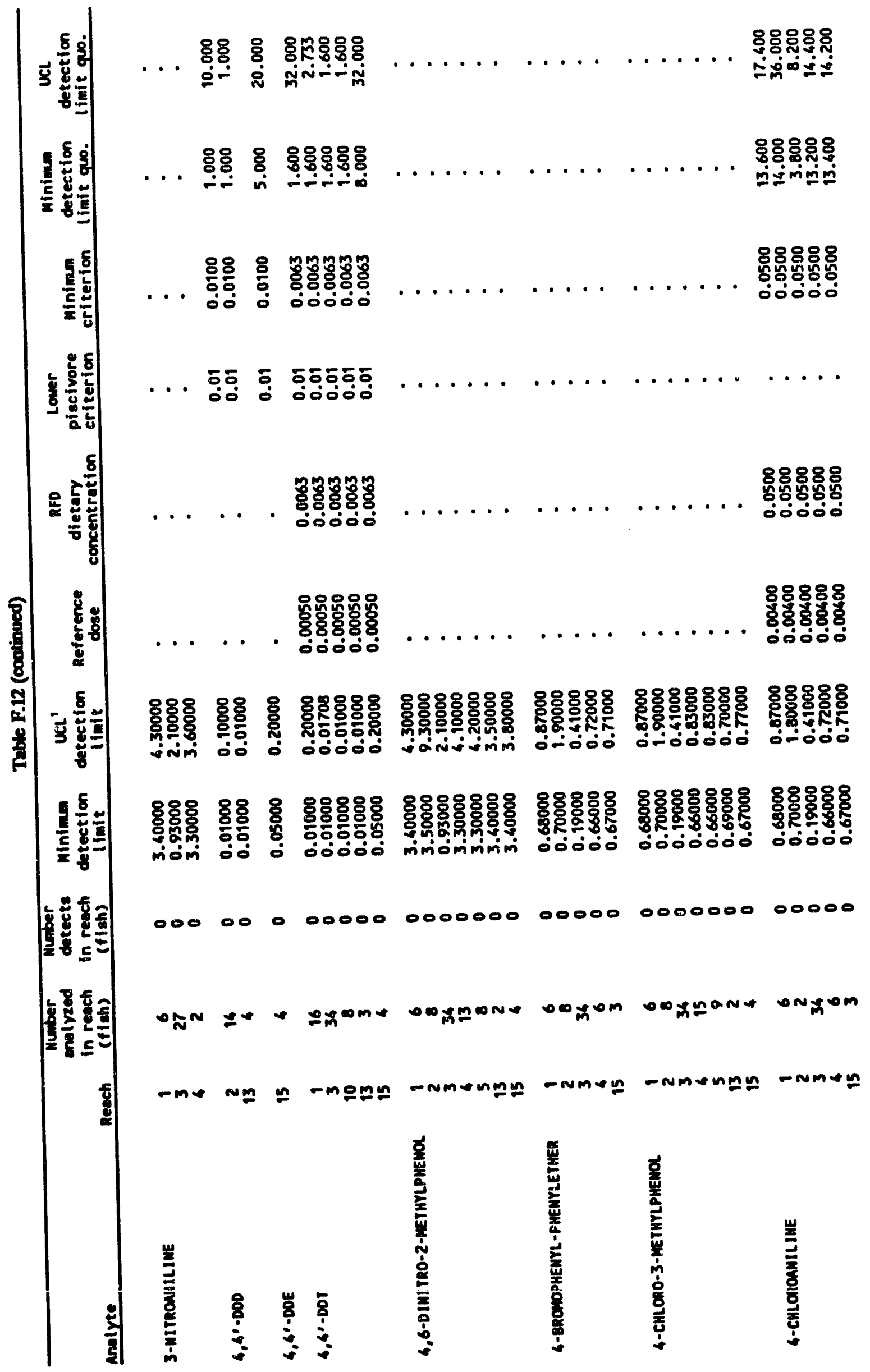




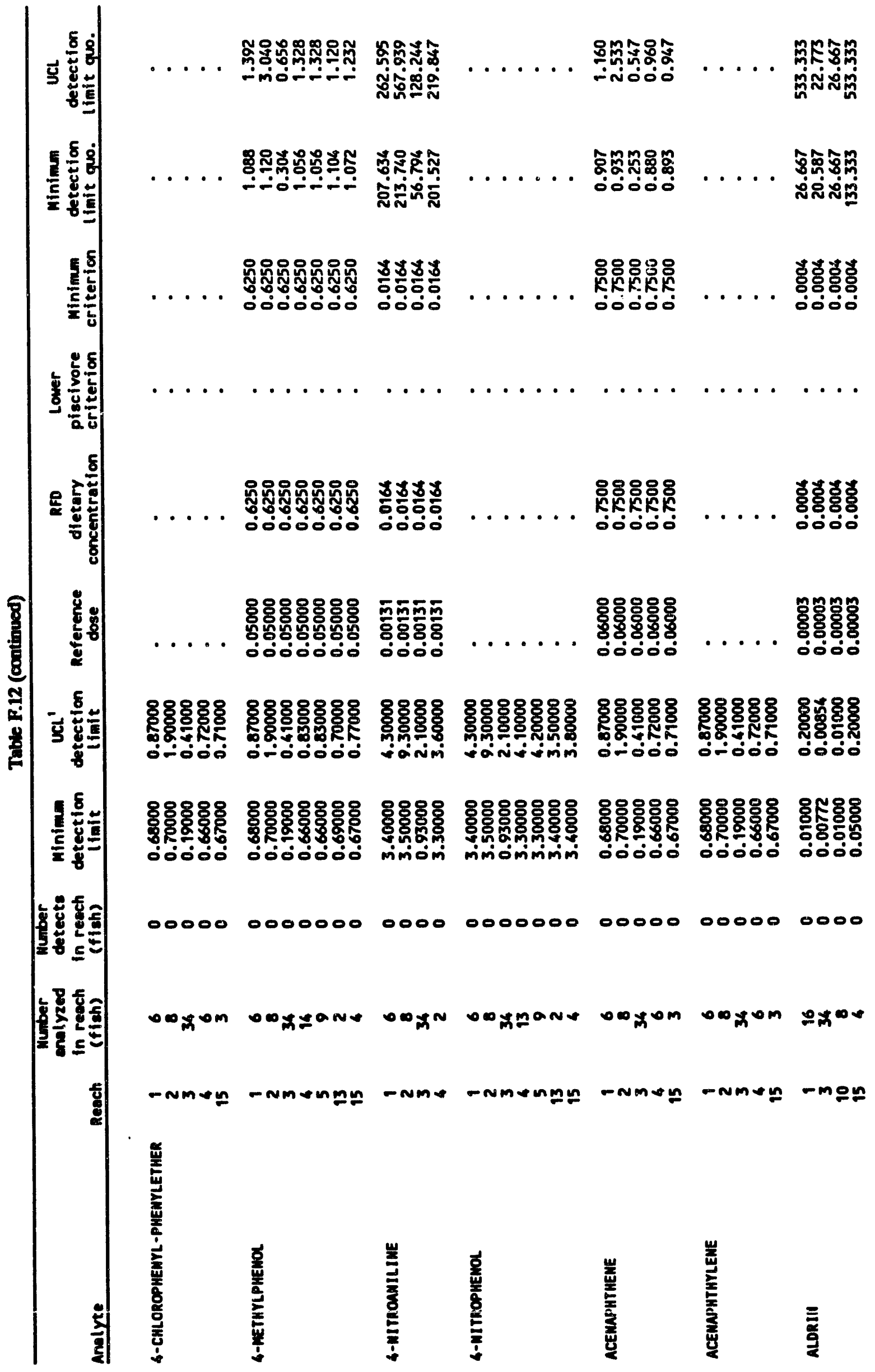




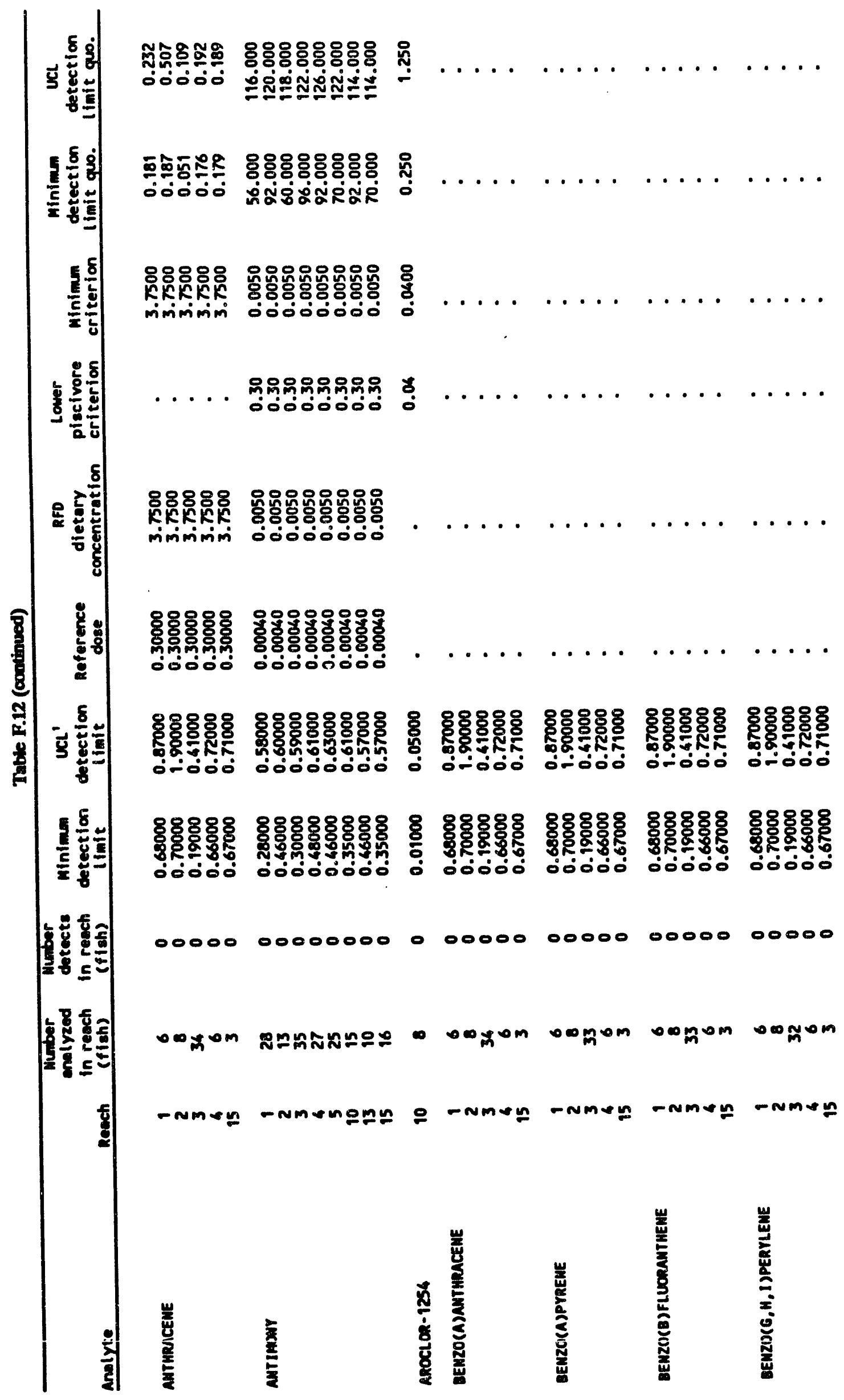




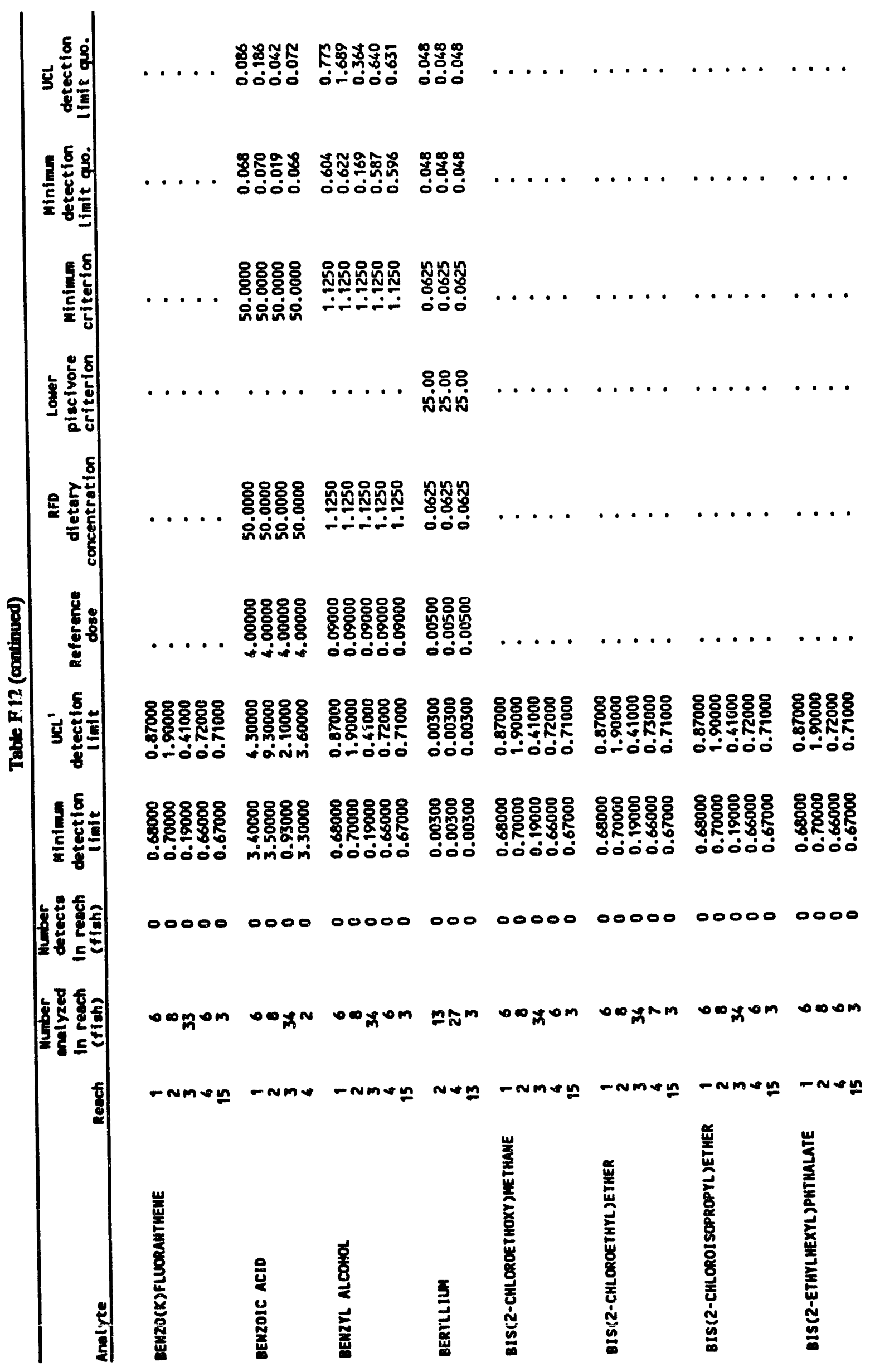




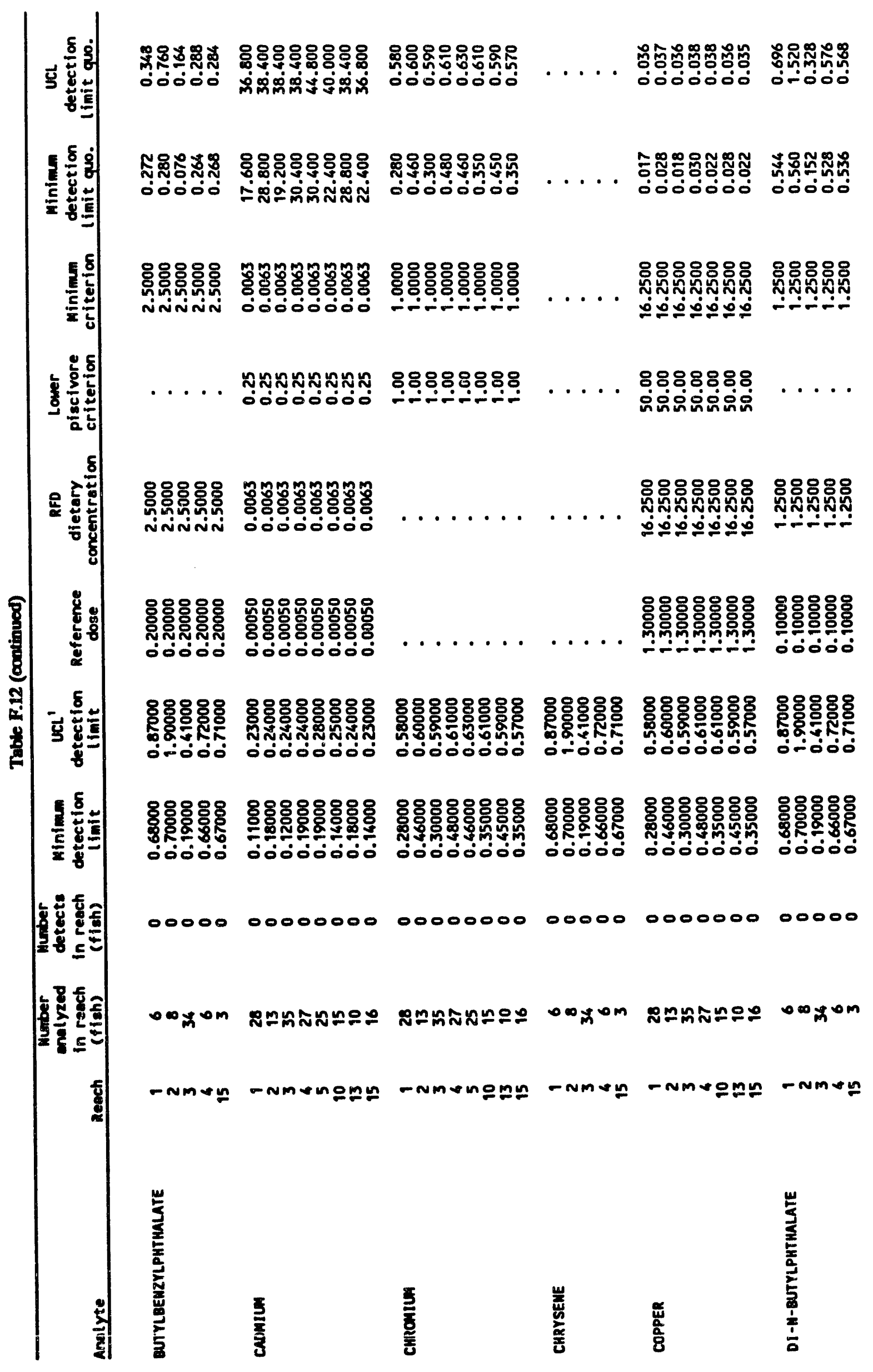


F-151

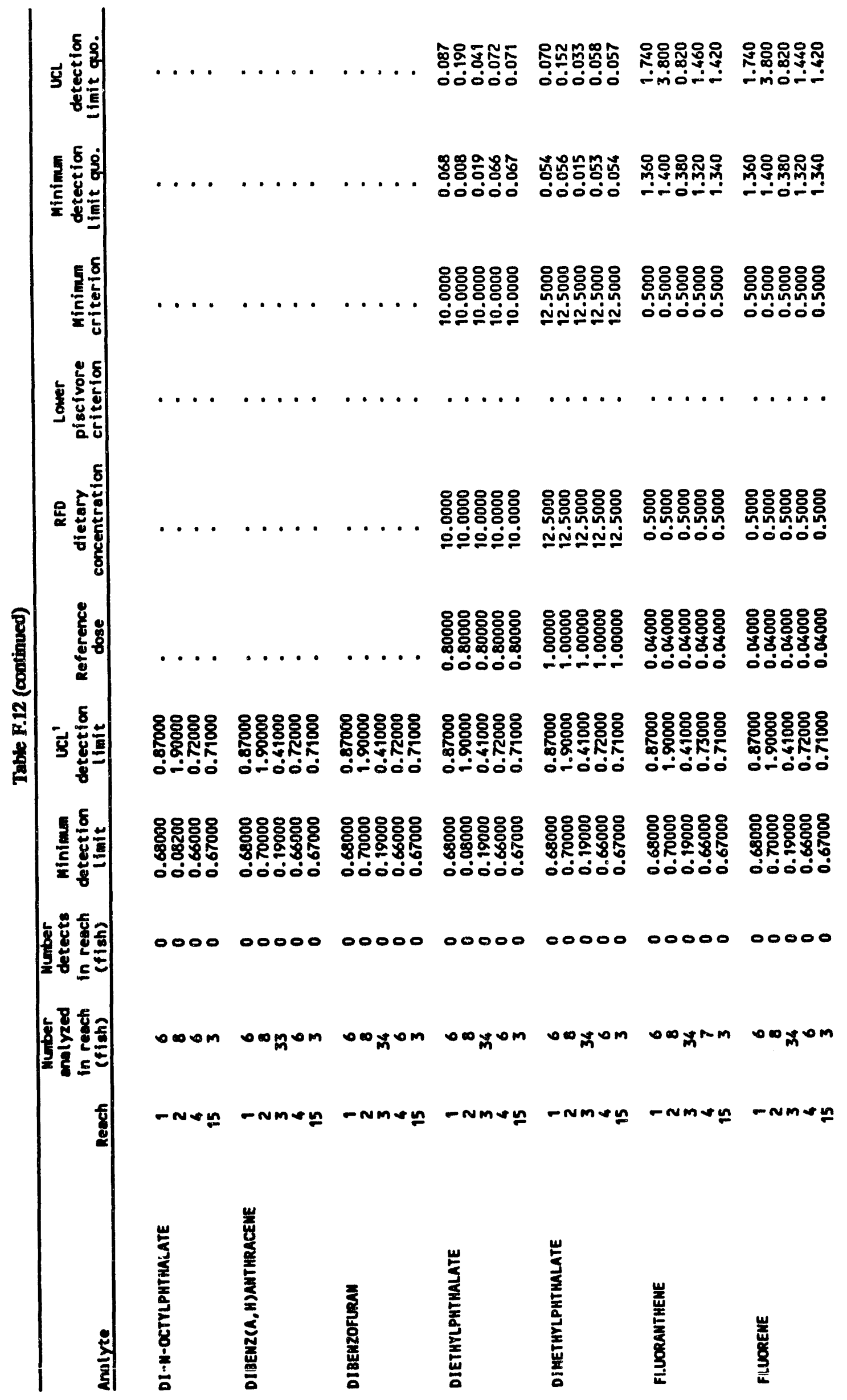




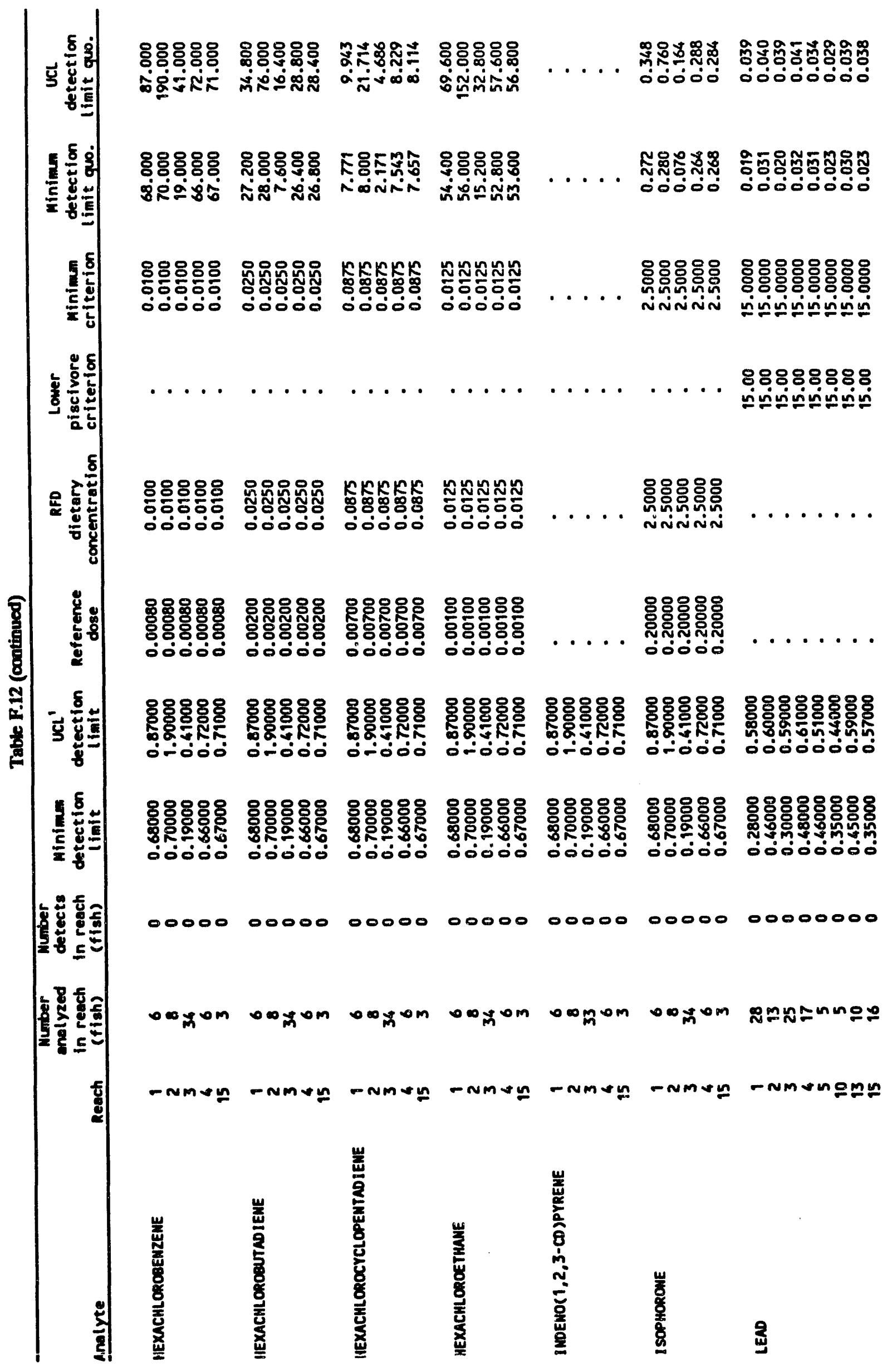




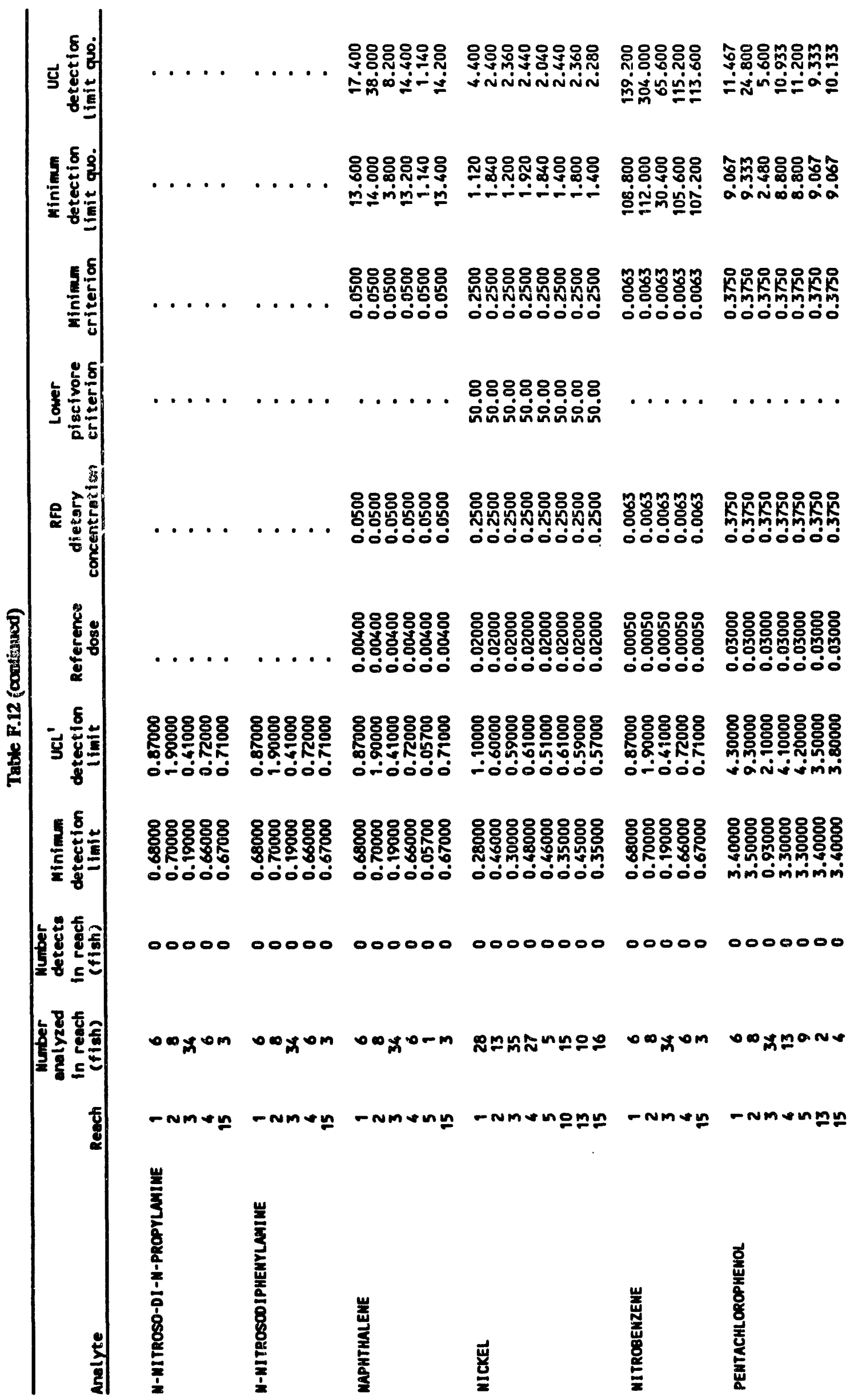


F-154

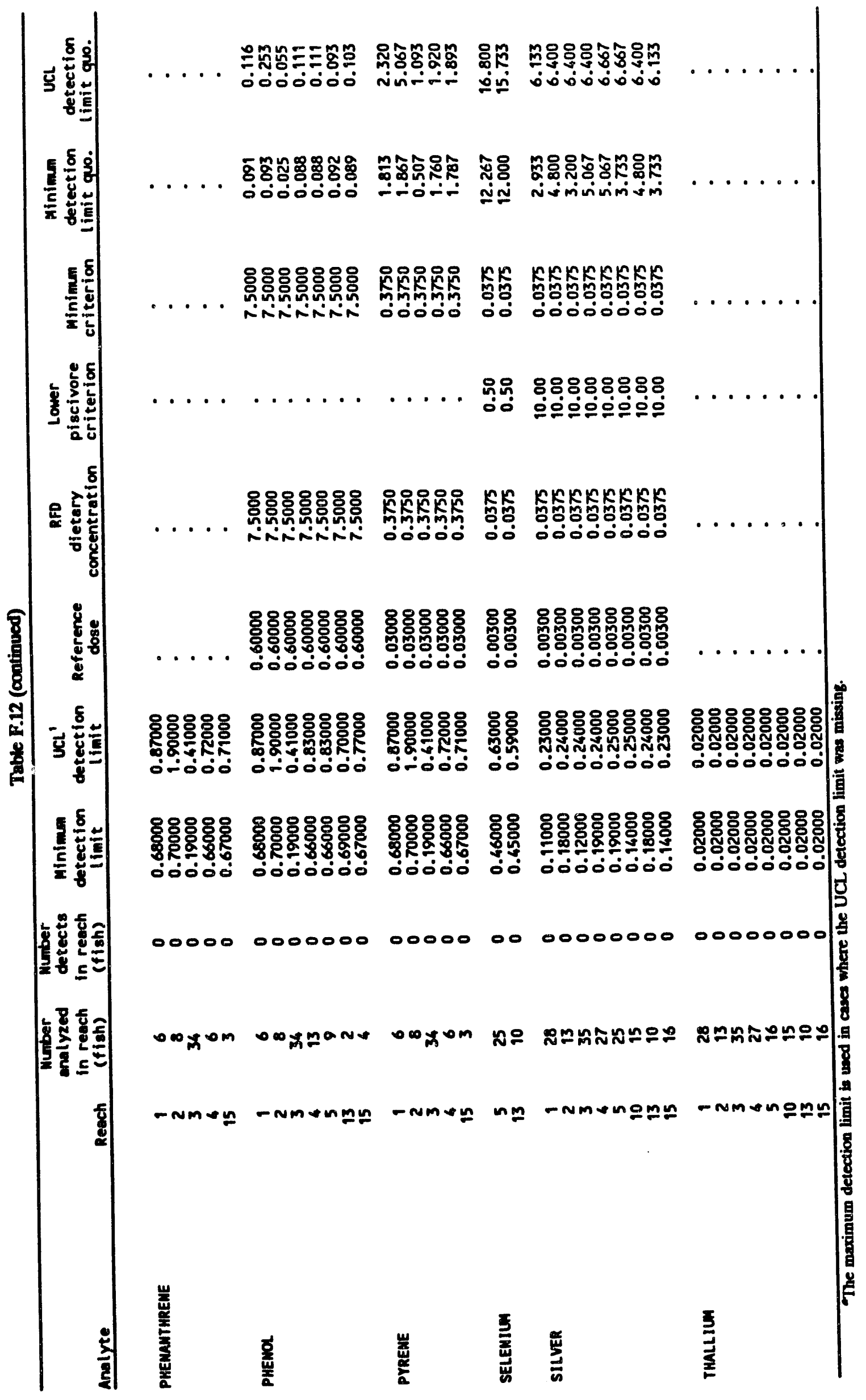


Appendix G

BRADEN BRANCH 
CONTENTS OF APPENDIX G

G.1 STUDY AREA $\ldots \ldots \ldots \ldots \ldots \ldots \ldots \ldots \ldots \ldots \ldots \ldots \ldots \ldots \ldots \ldots \ldots \ldots$

G.2 HISTORICAL BACKGROUND $\ldots \ldots \ldots \ldots \ldots \ldots \ldots \ldots \ldots \ldots \ldots \ldots \ldots$

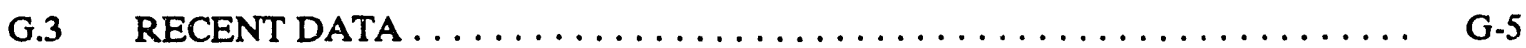

G.4 REFERENCE CONCENTRATIONS $\ldots \ldots \ldots \ldots \ldots \ldots \ldots \ldots \ldots \ldots \ldots \ldots \ldots \ldots$

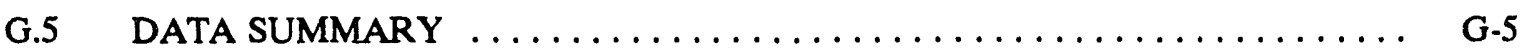

G.6 SUMMARY AND INTERPRETATION $\ldots \ldots \ldots \ldots \ldots \ldots \ldots \ldots \ldots \ldots$ G.12

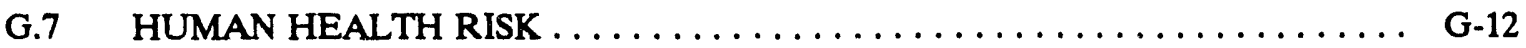

G.8 REFERENCES FOR APPENDIX G $\mathrm{G} \ldots \ldots \ldots \ldots \ldots \ldots \ldots \ldots \ldots \ldots \ldots \ldots \ldots$

\section{TABLES}

G.1 Data listing for CR-ERP Braden Branch sediment grab sample radiological

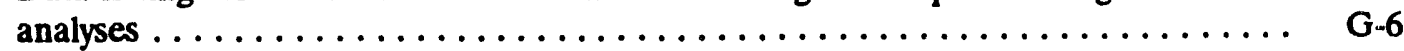

G.2 Summary statistics for Braden Branch sediment core data $\ldots \ldots \ldots \ldots \ldots \ldots$ G-7

G.3 Data listing for CR-ERP Braden Branch sediment core samples radiological analyses $\ldots \ldots \ldots \ldots \ldots \ldots \ldots \ldots \ldots \ldots \ldots \ldots \ldots \ldots \ldots \ldots \ldots \ldots$

G.4 Summary statistics for Braden Branch sediment grab data $\ldots \ldots \ldots \ldots \ldots \ldots$ G-9

G.5 Results of adult nonconservative screening for carcinogens in surface sediment of Braden Branch where at least one measurement was above detection limits

G.6 Results of adult conservative screening for carcinogens in surface sediment of Braden Branch where at least one measurement was above detection limits ......

\section{FIGURES}

G.1 Braden Branch near-shore sample sites $\ldots \ldots \ldots \ldots \ldots \ldots \ldots \ldots \ldots \ldots$ G-4

G.2 Cobalt -60 concentrations at Braden Branch $\ldots \ldots \ldots \ldots \ldots \ldots \ldots \ldots \ldots$ G-10

G.3 Cobalt concentrations in Braden Branch core (no. 18700G) ........... G-11 


\section{BRADEN BRANCH SCREENING-LEVEL RISK ASSESSMENT}

Braden Branch is a known source of ${ }^{60} \mathrm{Co}$ contamination to Melton Hill Reservoir at Clinch River Mile (CRM) 50.5. The source of this contamination was the site of the former American Nuclear Corporation (ANC), which released ${ }^{60} \mathrm{Co}$ into the watershed of Braden Branch. Samples were collected in Braden Branch during Phase 1 of the Clinch River Remedial Investigation to characterize this site. The purpose of this appendix is to summarize the data from sampling of Braden Branch and to present a screening-level assessment of the risk to human health associated with exposure to the contaminated areas.

\section{G.1 STUDY AREA}

Braden Branch Creek is a small stream that enters Melton Hill Reservoir at approximately CRM 50.5 (Fig. G.1). This is several hundred meters upstream and on the opposite shoreline from the Oak Ridge Marina. The creek is separated from Melton Hill Reservoir by a railroad berm. Surface water is exchanged between the two water bodies via a culvert that passes through the berm. Damming caused by the berm creates an embayment on the upstream side, which acts as a settling pond for particles washed from the Braden Branch watershed.

\section{G.2 HISTORICAL BACKGROUND}

In 1968, personnel from ORNL noted abnormally high radioactivity in a water sample from the Braden Branch area of the Clinch River. The source of this radioactivity was traced to the forrmer ANC located on Braden Branch Creek. Under the jurisdiction of the U.S. Atomic Energy Commission (until 1965) and the State of Tennessee (between 1965 and 1970 when ANC closed), ANC used ${ }^{60} \mathrm{Co}$ as a radiation source for medical instruments between 1962 and 1970.

After the contamination was detected in the Clinch River, radiation surveys near the site revealed exposure rates in the $\mathrm{mR} / \mathrm{hr}$ to $\mathrm{R} / \mathrm{hr}$ range. The ANC facility was closed in 1970 , and clean-up efforts commenced. The clean up was restricted to the immediate area around the plant. No effort was made to clean up contamination in the Braden Branch embayment or areas downstream. The Division of Radiological Health of the Tennessee Department of Environment and Conservation (TDEC) obtains results of monthly radiation surveys in the area (approximately 50 acres) and from annual measurements near the building site. Public access to the ANC building and surrounding land is restricted.

Sediment samples were collected from the Braden Branch embayment in 1977 and 1987. In $1977,{ }^{60} \mathrm{Co}$ concentrations in surface sediment within the Braden Branch embayment were as high as $1287 \mathrm{pCi} / \mathrm{g}$ dry wt. The highest concentration found in surface sediment in the embayment during a 1987 survey was $152.0 \mathrm{pCi} / \mathrm{g}$. Explanations for this drop in concentration are (1) radioactive decay; the half-life of ${ }^{60} \mathrm{Co}$ is approximately five years, which means that $1287 \mathrm{pCi} / \mathrm{g}$ dry wt in 1977 would have been reduced to $320 \mathrm{pCi} / \mathrm{g}$ by 1987 , and (2) the redistribution and dilution of contaminated sediment could be responsible for spreading and mixing contaminated sediment within the embayment and into Melton Hill Reservoir. The observation that the highest ${ }^{60} \mathrm{Co}$ concentrations in 1977 were in the upper end of the 
G-4

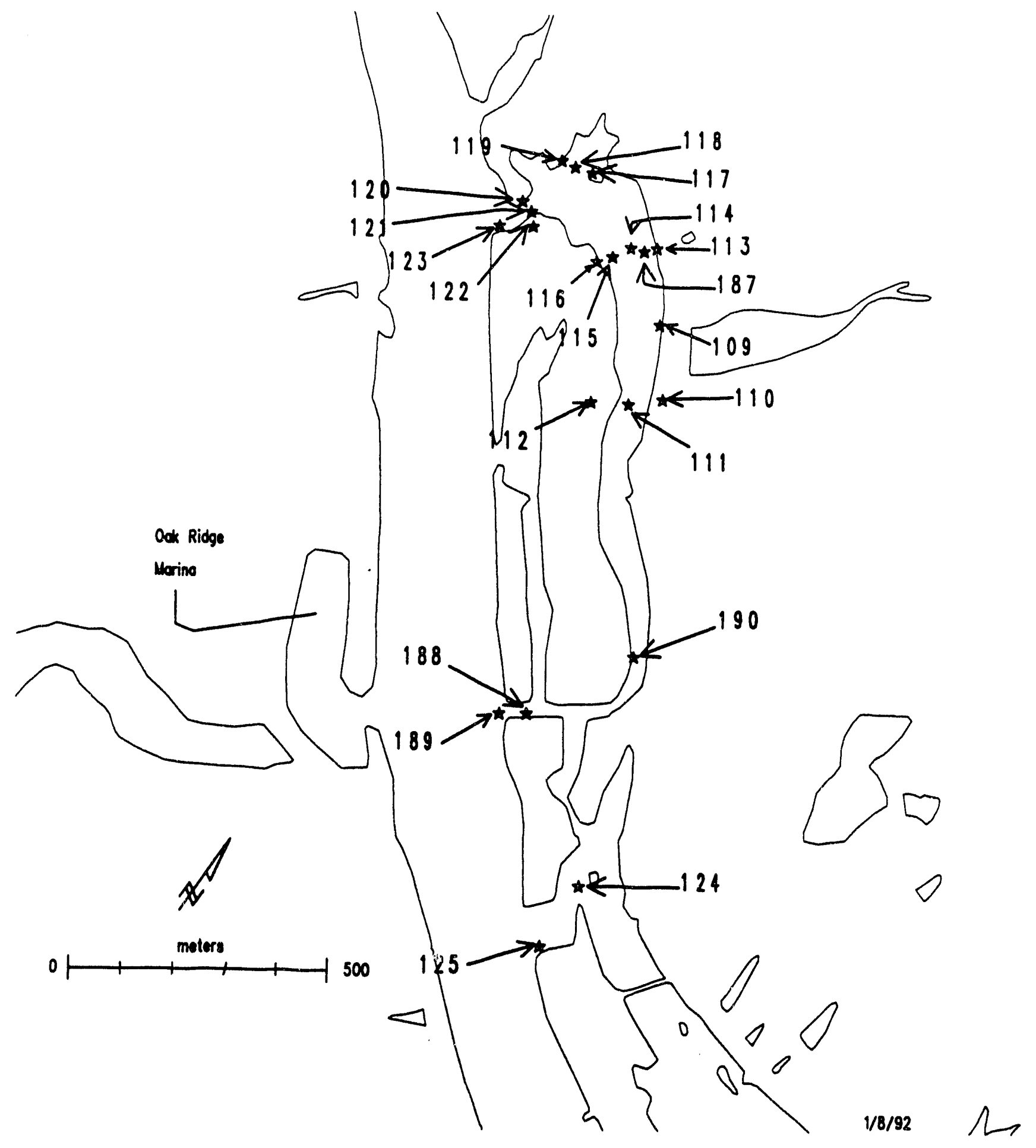

Fig G.1. Braden Branch near-shore sample sitex. 
embayment but in 1987 were in the lower end suggests that there is some redistribution of ${ }^{60} \mathrm{Co}$. Finally, along with redistribution, contaminated sediments may be buried by "cleaner" sediments. There is some historic evidence of this as well. For example, in the 1987 survey of the embayment, a ${ }^{60} \mathrm{Co}$ concentration in the top 6 in. of sediment at one site was $39.9 \mathrm{pCi} / \mathrm{g}$ dry st, while the concentration in the 6-12 in. segment was $383.0 \mathrm{pCi} / \mathrm{g}$ dry wt. However, this pattern is by no means consistent throughout the embayment.

\section{G.3 RECENT DATA}

Sediment sampling was conducted in the immediate vicinity of Braden Branch as Phase 1 of the CRRI. A total of 20 sediment grab samples were taken between July 25 and August 10, 1990 (Table G.1). These samples were taken with a Ponar grab sampler for the purpose of characterizing the radionuclide concentrations in the surface sediment only. A single sediment core was also taken within $300 \mathrm{~m}$ of the confluence of Braden Branch and Melton Hill Reservoir (Table G.2). This core was divided into separate samples by depth intervals (2 $\mathrm{cm}$ to a depth of $48 \mathrm{~cm}$ ) and analyzed to provide a vertical profile of sediment contamination (Table G.3). Sample locations for grab samples (ID nos. 109-125, and 188-190) and for the core sample (ID no. 187) are shown on Fig. G.1.

\section{G.4 REFERENCE CONCENTRATIONS}

Radionuclides are present throughout the world due to natural occurrence and to man-made sources. Sediment samples taken from Norris Reservoir provide reference or "background" concentrations for radionuclides and other contaminants being examined in the CRRI. Norris Reservoir background levels of ${ }^{60} \mathrm{Co}$, which originated from atmospheric testing of nuclear weapons and not from DOE facilities in Oak Ridge, are below minimum detectable activity.

\section{G.5 DATA SUMMARY}

Table G.4 summarizes ${ }^{60} \mathrm{Co}$ surface sediment concentrations from the 20 grab samples and the top $2 \mathrm{~cm}$ of the core sample collected in 1990 . Fig. G.2 shows the ${ }^{60} \mathrm{Co}$ concentration at each of the sample locations. Locations with the highest concentrations (>1.01 pCi/g) are, with the exception of sample no. $190\left({ }^{60} \mathrm{Co}\right.$ concentration $\left.=4.53 \mathrm{pCi} / \mathrm{g}\right)$, within $200 \mathrm{~m}$ of the culvert under the railroad bridge where Braden Branch enters Melton Hill Reservoir.

Figure G.3 shows ${ }^{60} \mathrm{Co}$ concentration by depth in core no. $18700 \mathrm{G}$ and compares these concentrations with those from a core taken from Melton Hill Reservoir at CRM 23.9 (core no. $8200 \mathrm{G})$. The profile for the Braden Branch core indicates that there are two concentration peaks. The first is at a depth of $22 \mathrm{~cm}$ with a concentration of $20.07 \mathrm{pCi} / \mathrm{g}$. The second peak is at $33 \mathrm{~cm}$ with an associated concentration of $39.33 \mathrm{pCi} / \mathrm{g}$. The concentrations from the two downstream cores (near Solway Bridge and Melton Hill Dam) are all less than $1.0 \mathrm{pCi} / \mathrm{g}$ dry wt, and most of the concentrations in these cores are below the detectable limit. The concentrations of ${ }^{60} \mathrm{Co}$ in the Braden Branch core are considerably higher than the minimum detectable levels $(0-0.3 \mathrm{pCi} / \mathrm{g})$ to a depth of $45 \mathrm{~cm}$. 
G-6

言

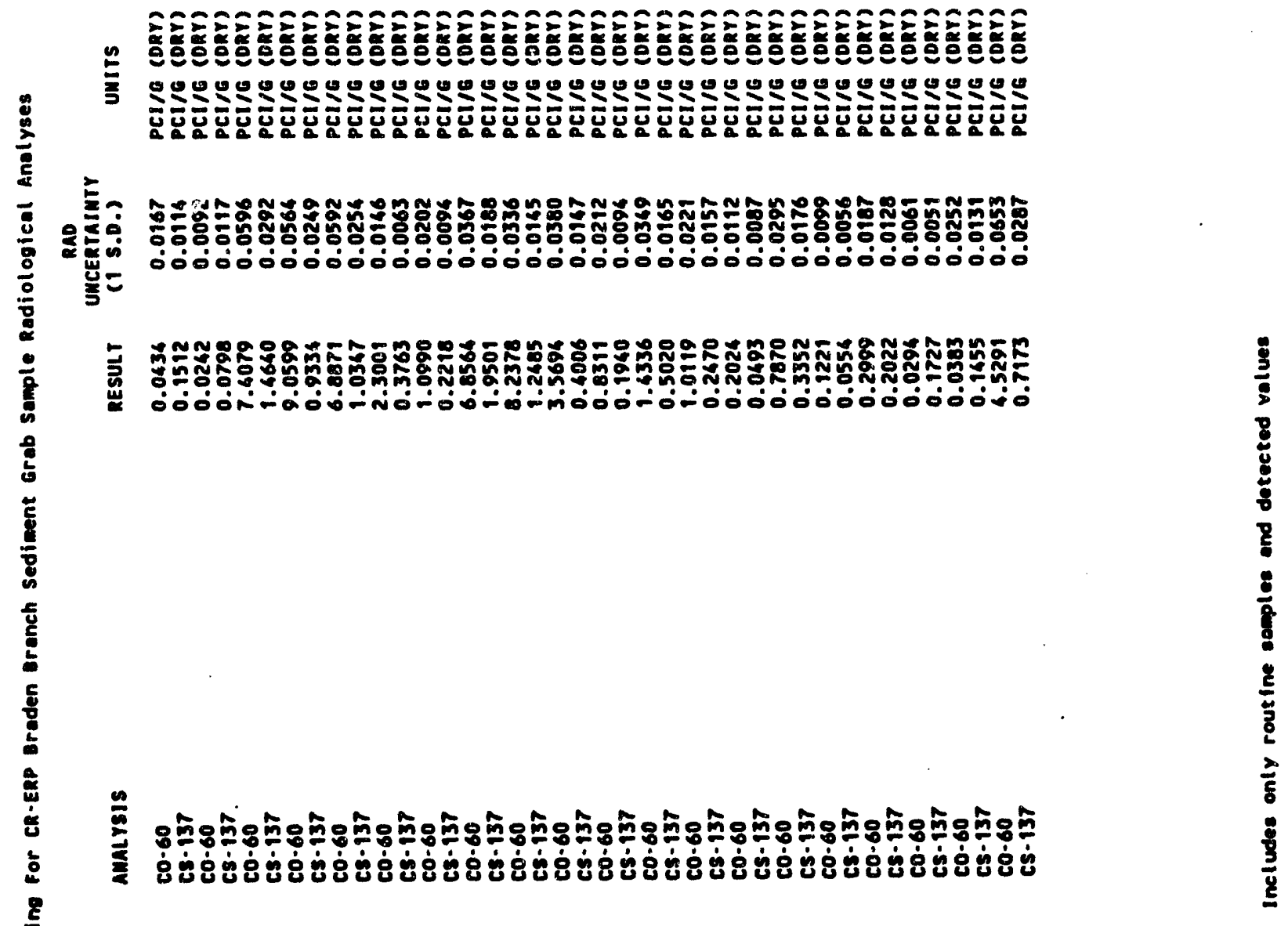

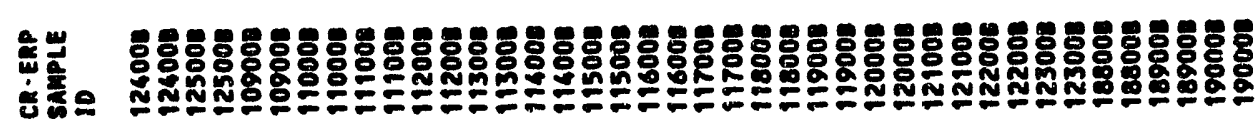

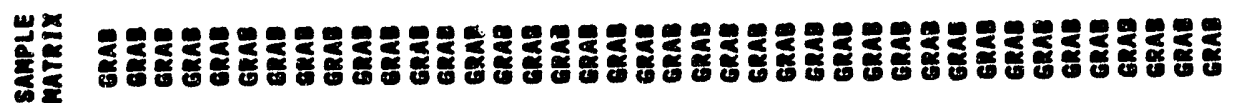

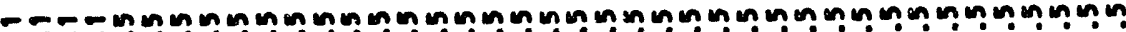

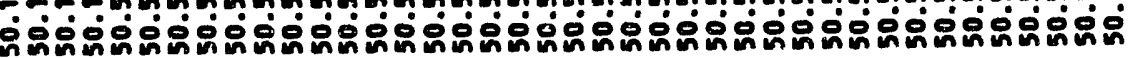
说出

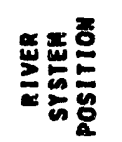




\section{G-7}
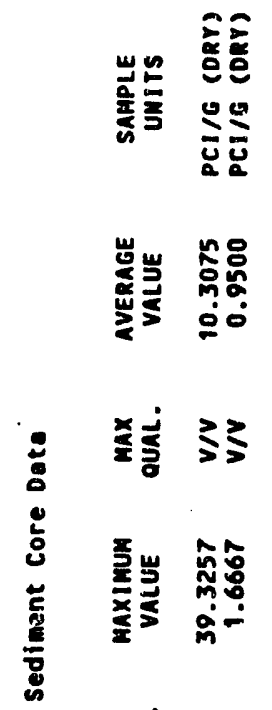

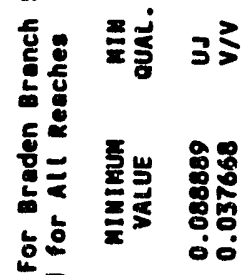

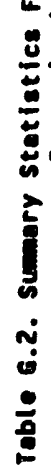

这家

赔高 
G-8

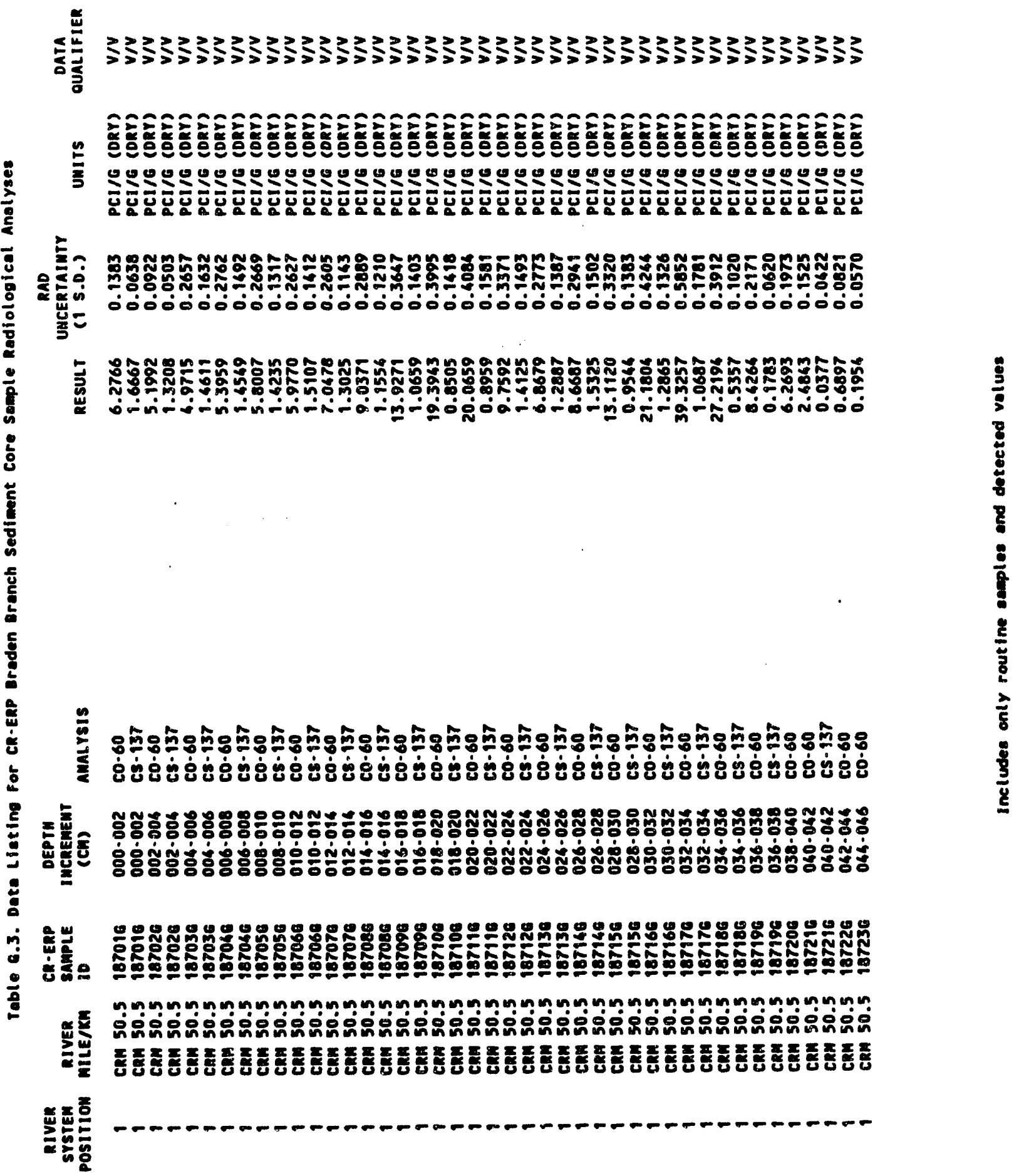


G-9

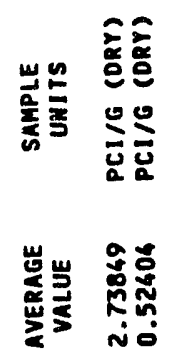

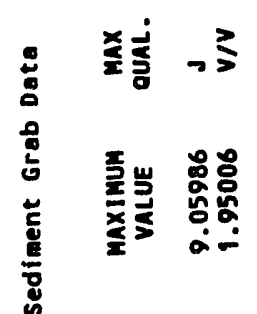

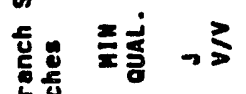

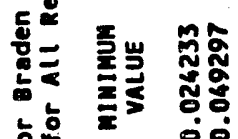

००

递范

s

$\div$

옹

范

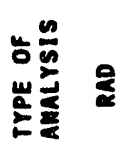




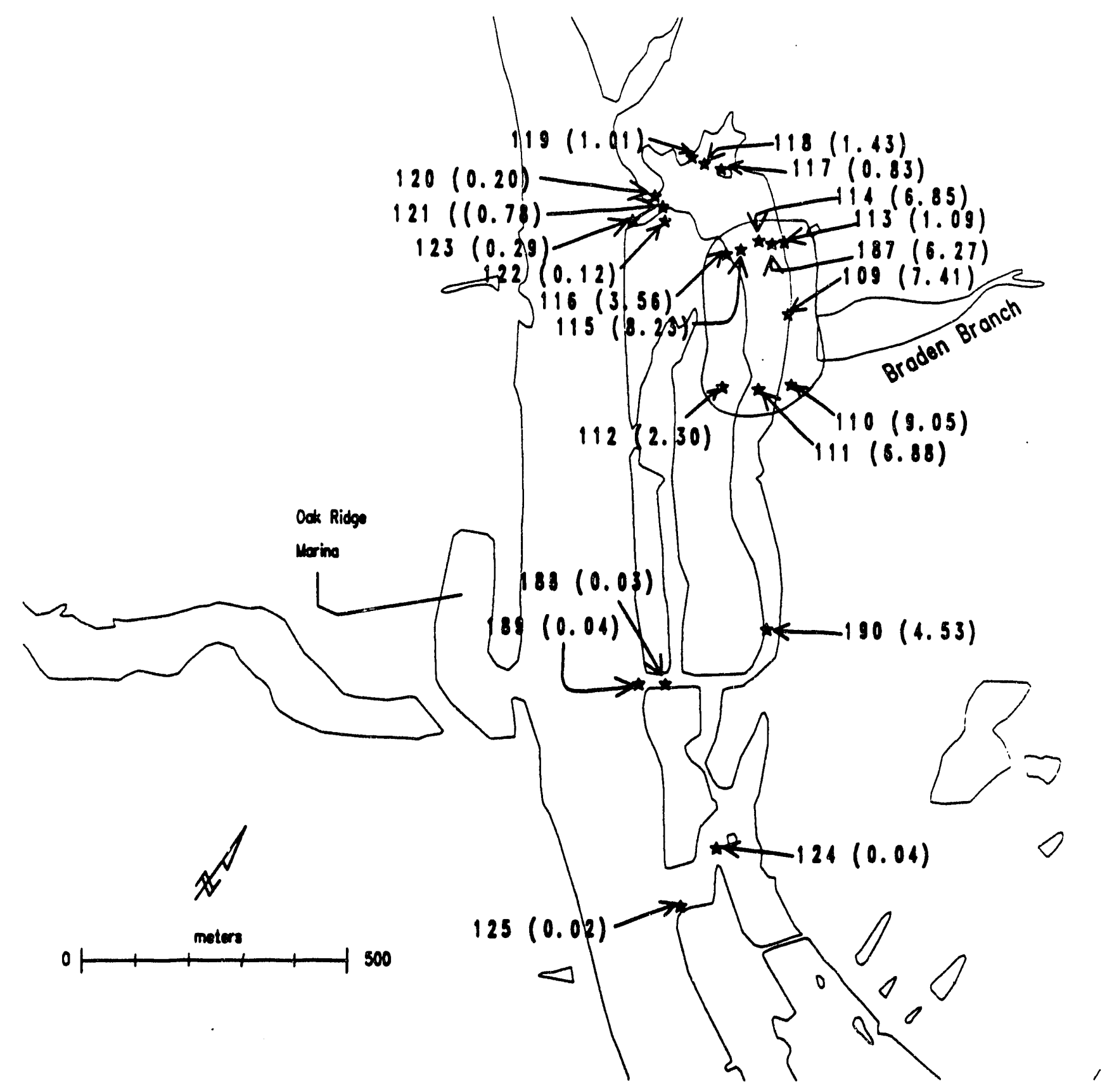

Fig G.2 Cobalt-60 concentrations at Braden Branch. 
G-11

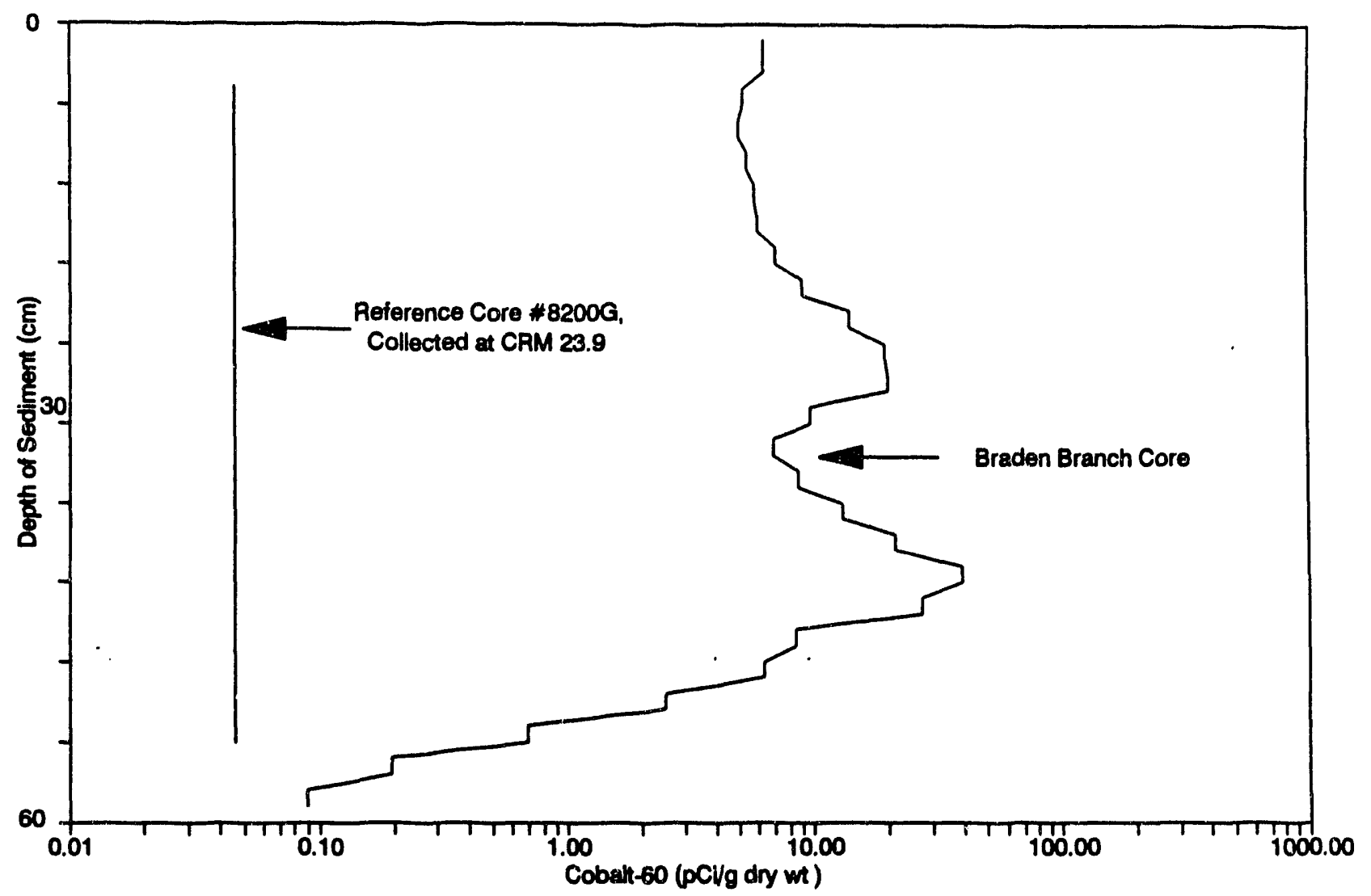

Fig. G.3. Cobalt concentrations in Braden Branch core (no. 18700G). 


\section{G.6 SUMMARY AND INTERPRETATION}

The ${ }^{60} \mathrm{Co}$ sediment concentrations in the Melton Hill Reservoir in the immediate vicinity of the Braden Branch culvert are at least an order of magnitude above the minimum detection levels $(0.3 \mathrm{pCi} / \mathrm{g})$. The highest concentrations are within approximately $200 \mathrm{~m}$ of the culvert under the railroad bridge where Braden Branch flows into Melton Hill Reservoir. The concentration at the sample $1900 \mathrm{G}$ location suggests that contaminant transport has occurred in a southeasterly direction within the small channel. Low concentrations at the channel outlets suggest that downstream transport of ${ }^{60} \mathrm{Co}$ into the main channel of Melton Hill Reservoir may have been minimal in the recent past.

The ${ }^{60} \mathrm{Co}$ concentration profile from the sediment core indicates that there are several peaks in ${ }^{60} \mathrm{Co}$ concentrations that are two orders of magnitude above background levels. While concentrations in downstream cores suggest that downstream movement of contamination has been minimal, the results are inconclusive. The near-background concentrations in these cores could indicate that contaminant dilution has occurred or simply that the cores were not taken where contaminants had deposited.

These results and the results from previous studies indicate that Braden Branch has been a source of ${ }^{60} \mathrm{Co}$ contamination to Melton Hill Reservoir. Furthermore, the elevated concentrations in the surface sediments suggest that Braden Branch may still be contributing measurable amounts of ${ }^{60} \mathrm{Co}$ to the reservoir.

\section{G.7 SCREENING HEALTH RISK ASSESSMENT}

Quantitative accessment of human health risk from exposure to contaminants in the environment is extremely difficult because the data necessary to determine exposure and doses are difficult to obtain. These data include the speed and efficiency of contamination transport along various exposure routes, the magnitude and duration of the exposure, and the relationship between exposure and health risk. Because of the difficulty of acquiring such data, a set of assumptions are typically used to provide screening estimates of lifetime risk of an incremental cancer incidence. The Environmental Protection Agency has developed risk factors for radionuclides and provides guidance in their use to allow the conversion of contaminant concentrations in the environment into estimates of human health risk resulting from various exposure routes (EPA 1991a, b).

Results from screening level risk analysis for 1990 samples, which were collected in Braden Branch embayment, are presented in Table G.5 for nonconservative screening and in Table G.6 for conservative screening. The pathway of most concern is the external exposure pathway. Conservative screening risk due to direct exposure to sediments is $1 \times 10^{-4}$, which indicates it may be of concern. Nonconservative screening risk due to external exposure is $5 \times 10^{-7}$. All screening risk values from ingestion and inhalation pathways are $<1 \times 10^{-7}$ and, therefore, are of little concern.

It should be noted that the sediments in the Braden Branch area are exposed for some part of the year but probably not enough to allow for the $2000 \mathrm{~h} /$ year exposure included in the calculations; therefore, our calculations are conservative and probably are relevant only to the case in which sediments are dredged and used as a source of topsoil. 
G-13

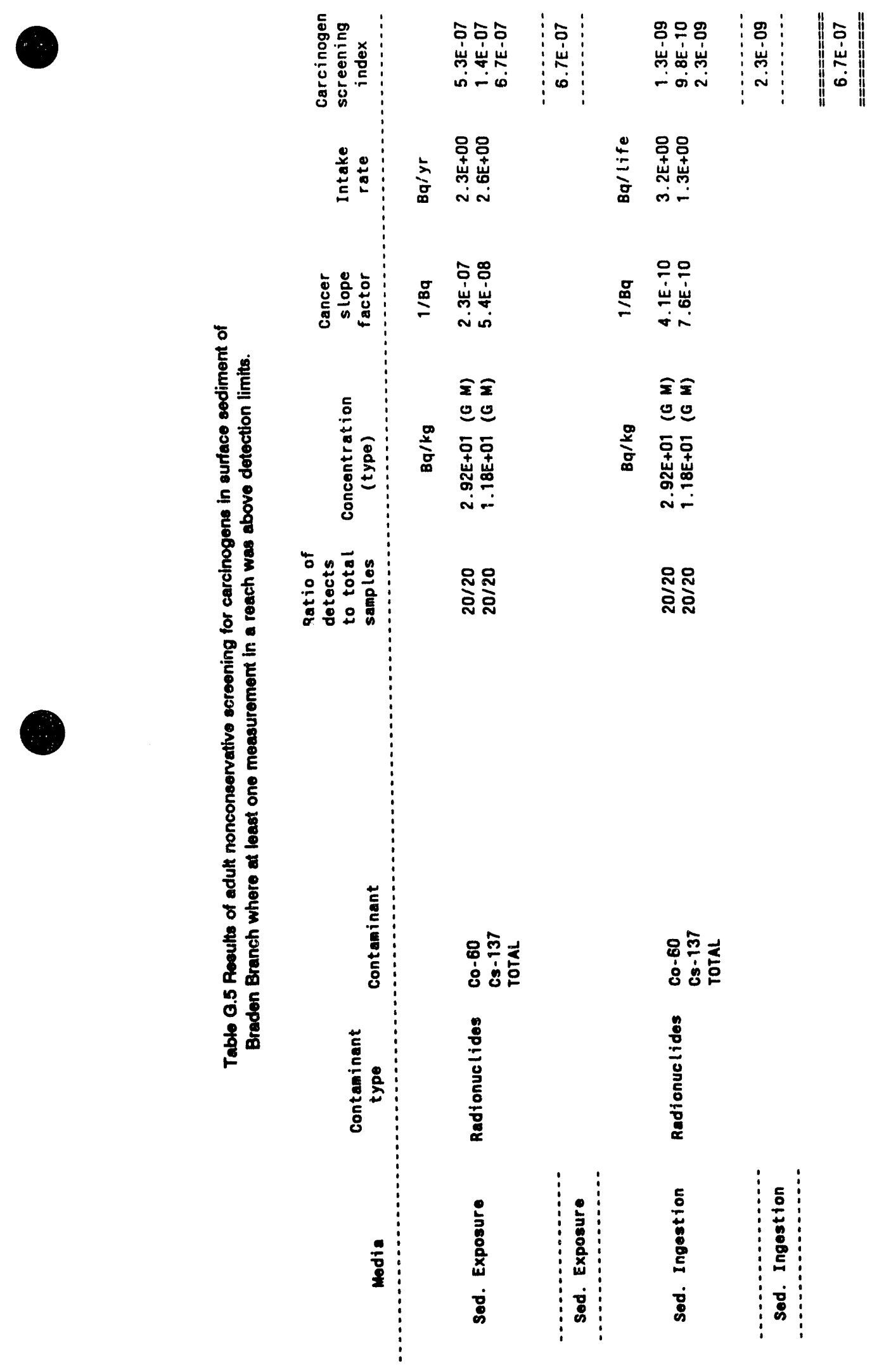


G-14

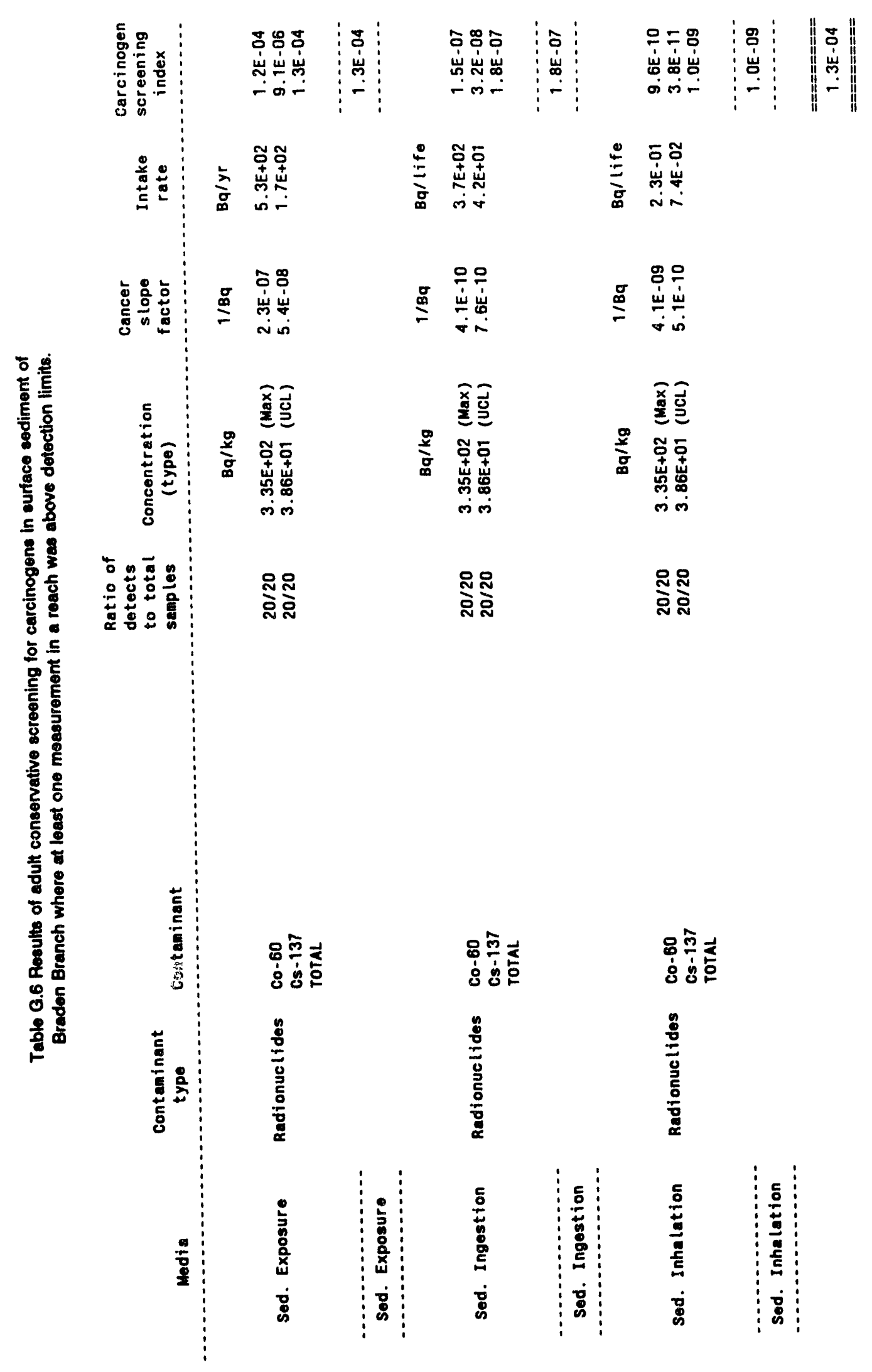


There is virtually no risk from ${ }^{60} \mathrm{Co}$ in deep, undisturbed sediment. Exchange with the water column is minimal, and water acts as an effective shield to gamma radiation. If the sediment is exposed due to draw-down of the water, the potential risk is similar to that of ${ }^{60} \mathrm{Co}$ in exposed sediment. The external exposure is then dominated by the size of the area containing ${ }^{60} \mathrm{Co}$ and the length of time an individual remains in the area of contamination as well as any physical features that act to partially or completely shield an individual from the gamma radiation. 


\section{G.8 REFERENCES FOR APPENDDX G}

Miller, L.F., E.S. Stetar, J.H. Coleman, A. Payne, J. Hoffelt, and D.J. Auslander. 1987. Monitoring of Radionuclide Migration and Exposure Rates From the American Nuclear Corporation Plant Site. In: Proceedings of the 1987 Oak Ridge Model Conference Volume III, Health and Safety. CONF-871075-Vol. 3).

Environmental Protection Agency, 1991a. Health Effects Assessment Summary Tables. Annual FY-1991. OERR 9200.6-303 (91-1).

Environmental Protection Agency, 1991b. OSWER Directive 9285.6-303. March 25, 1991. 
ORNL/ER-155

\section{DISTRIBUTION}

1. S. M. Adams

2. M. L. Ambrose

3. L. D. Bates

4. J. J. Beauchamp

5. D. T. Bell

6. M. S. Bevelhimer

7. B. G. Blaylock

8. C. C. Brandt

9. A. L Brenkert

10. J. B. Cannon

11-15. R. B. Cook

16. W. D. Crumby

17. J. H. Cushman

18. M. F. P. DeLozier

19. C. J. Ford

20. D. E. Fowler

21. M. L. Frank

22. R. H. Gardner

23. C. W. Gehrs

24. M. J. Gentry

25. C. D. Goins

26. J. M. Grebmeier

27. R. S. Halbrook

28. P. J. Halsey

29. R. A. Harris

30. S. G. Hildebrand

31. S. K. Holladay

32. L A. Hook

33. R. N. Hull

34. P. Kanciruk
35. B. L. Kimmel

36. L. A. Kszos

37. I. L. Larsen

38. D. A Levine

39. J. M. Loar

40. R. C. Longman

41. S. E. Madix

42-44. D. M. Matteo

45. C. W. McGinn

46. M. E. Mitchell

47. S. L. Niemela

48-49. P. T. Owen

50. D. E. Reichle

51. K. A. Rose

52. G. E. Rymer

53. F. E. Sharples

54. D. S. Shriner

55. J. L. Skiles

56. S. H. Stow

57. G. W. Suter

58. R. I. Van Hook

59. D. R. Watkins

60. R. K. White

61. L. F. Williams

62. D. C. Wood

63-65. ESD Library

66-70. ER Document Management Center

71. Clinch River ER DMC

72-73. ORNL Laboratory Records

74. ORNL Patent Section

75. Office of Assistant Manager for Energy Research and Development, DOE Oak Ridge Field Office, P.O. Box 2001, Oak Ridge, TN 37831-8600

76. M. Ferre, DOE Oak Ridge Field Office, P.O. Box 2001, Oak Ridge, TN 37831-8541

77. J. F. Franklin, Bloedel Professor of Ecosystem Analysis, College of Forest Resources, University of Washington, Anderson Hall AR-10, Seattle, WA 98195

78-83. C. S. Gist, DOE Oak Ridge Field Office, P.O. Box 2001, Oak Ridge, TN 37831-8541

84. R. C. Harriss, Institute for the Study of Earth, Oceans, and Space, Science and Engineering Research Building, University of New Hampshire, Durham, NH 03824

85. F. O. Hoffman, SENES Oak Ridge, Inc., 677 Emory Valley Road, Suite C, Oak Ridge, TN 37830

86. G. Y. Jordy, Director, Office of Program Analysis, Office of Energy Research, ER-30, G-226, U.S. Department of Energy, Washington, DC 20545

87. K. Murray, Radian Corporation, 120 S. Jefferson Circle, Oak Ridge, TN 37831 
88-89. R. L. Nace, Branch Chief, Nonenrichment Facilities, Oak Ridge Program Division, Office of Eastern Area Programs, Office of Environmental Restoration, EM-423, Trevion 2, U.S. Department of Energy, Washington, DC 20585

90. C. R. Olsen, Environmental Sciences Division, Office of Health and Environmental Research, ER-74, U.S. Department of Energy, Washington, DC 20585

91. R. H. Olsen, Professor, Microbiology and Immunology Department, University of Michigan, Medical Sciences II, \#5605, 1301 East Catherine Street, Ann Arbor, MI 48109-0620

92. A. Patrinos, Director, Environmental Sciences Division, Office of Health and Environmental Research, ER-74, U.S. Department of Energy, Washington, DC 20585

93-94. R. C. Sleeman, DOE Oak Ridge Field Office, P.O. Box 2001, Oak Ridge, TN 37831-8541

95. D. W. Swindle, Radian Corporation, 120 S. Jefferson Circle, Oak Ridge, TN 37831

96-97. H. M. Thron, Chief, Enrichment Facilities, Oak Ridge Program Division, Office of Eastern Area Programs, Office of Environmental Restoration, EM-423, Trevion 2, U.S. Department of Energy, Washington, DC 20585

98. F. J. Wobber, Environmental Sciences Division, Office of Health and Environmental Research, ER-74, U.S. Department of Energy, Washington, DC 20585

99-100. Office of Scientific and Technical Information, P.O. Box 62, Oak Ridge, TN 37831 
